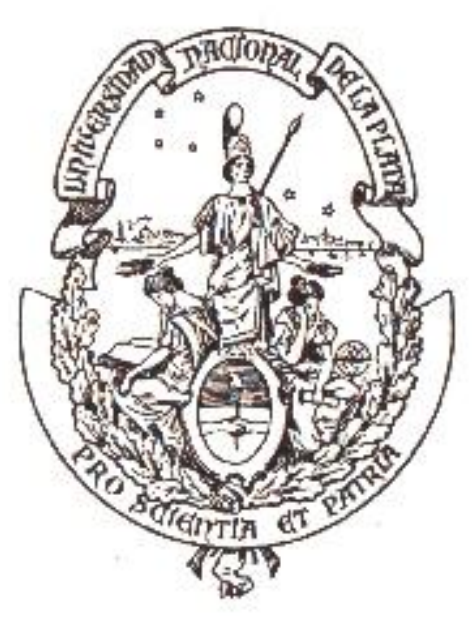

UNIVERSIDAD NACIONAL DE LA PLATA

FACULTAD DE CIENCIAS EXACTAS

DEPARTAMENTO DE QUÍMICA

\title{
ESTUDIO DE LA CALIDAD PANADERA, SENSORIAL Y NUTRICIONAL DE PANES ELABORADOS CON HARINA DE TRIGO FORTIFICADA CON SALES DE CALCIO E INULINA
}

Trabajo de Tesis Doctoral

Bioq. María Victoria Salinas

Directora: Dra. María Cecilia Puppo

Co-Directora: Dra. Patricia Ronayne de Ferrer

2013 
El presente trabajo de Tesis para optar al título de Doctor de la Facultad de Ciencias Exactas de la Universidad Nacional de La Plata fue realizado en el Centro de Investigación y Desarrollo en Criotecnología de Alimentos (CIDCA-UNLP-CONICET) bajo la dirección de la Dra. María Cecilia Puppo y la codirección de la Dra. Patricia Ronayne de Ferrer. 
Dedico mi tesis a mi familia, en especial a mis padres quienes me han dado la vida $y$ apoyado siempre en este arduo camino y al amor de mi vida, Felipe,

por su comprensión y amor infinito. 


\section{Agradecimientos}

A Cecilia Puppo, mi Directora, por haber confiado en mí y darme la oportunidad de hacer el doctorado, por haberme ayudado durante esta etapa y aconsejado no sólo profesionalmente sino personalmente.

A Patricia Ronayne de Ferrer por todo su apoyo y colaboración durante esta etapa, por la excelente disposición a pesar de la distancia.

A los integrantes del grupo de cereales, por su amistad, calidez humana y por todo el aporte previo y la ayuda desinteresada siempre, especialmente a Cristina, Jime y Ana.

A la Universidad Nacional de La Plata, la Facultad de Ciencias Exactas y al Centro de Investigación y Desarrollo en Criotecnología de Alimentos (CIDCA) por haberme dado la posibilidad, brindándome sus instalaciones para realizar el doctorado.

Al Consejo Nacional de Investigaciones Científicas y Técnicas (CONICET) por haberme financiado con las becas Tipo I y Tipo II la realización del doctorado. Y además por el financiamiento (Proyectos de Investigación Plurianuales-PIP) para parte de los insumos empleados en esta tesis.

A la cátedra de Bromatología y Nutrición perteneciente a la Facultad de Farmacia y Bioquímica (FFyB) de la Universidad de Buenos Aires (UBA) por haberme permitido desarrollar parte de mi trabajo en sus laboratorios.

A Evelina Ferrer y Patricia Williams por iniciarme y guiarme en el camino de la investigación cuando era alumna. Por todo los valores y el apoyo que he recibido desde esa etapa hasta ahora.

A Angela Zuleta, Adriana Weisstaub, María Luz P.M de Portela, Julieta Bighnani y demás personal de la FFyB-UBA por todo el aporte sobre la determinación de fibra y la colaboración en los ensayos nutricionales.

A Maria Fernanda Hamet y Analia Abraham por el aporte de técnicas de biología molecular empleadas para la evaluación nutricional del pan in vivo en este trabajo de tesis.

Al Molino Campodónico y su personal, por la donación de la harina utilizada.

A Orafti, por la donación del Synergy1 utilizada como fuente de prebiótico. 
A Molinos Rio de La Plata S.A. por prestarme las instalaciones y los equipos para llevar a cabo los alveogramas y farinogramas.

A los integrantes de la Cátedra de Introducción a la Química/ Química General y Bromatología, que me permitieron ser parte del equipo de trabajo. Especialmente a Bromatología y Nutrición por la paciencia en este periodo final.

A todo el personal del CIDCA, en especial a Javier y Daniel por facilitarme los turnos en el DSC y Claudio los del HPLC; Diana por su ayuda incondicional en búsqueda bibliográfica, Sara por facilitarme las tareas administrativas.

A mis amigas por escucharme y acompañarme en los diferentes ámbitos de la vida, especialmente a Lu, San, Jime y Ana.

A mis compañeritos de box y a los chicos del laboratorio de vegetales, por todos los momentos compartidos.

A mis hermanas, sobrinos, cuñados pero especialmente a mi mamá y a mi papá por todo el sacrificio que hicieron para que yo pueda venir a estudiar y llegar hasta esta instancia, por estar siempre presente.

A mi amorcito Felipe por acompañarme incondicionalmente, por formar parte de mi vida y hacerme ver las cosas desde otro lugar.

A todos los que no nombré pero que han contribuido a que llegue hasta acá.

Muchas gracias. 


\section{Resumen}

Fundamentación del estudio. Según la Encuesta Nacional de Nutrición y Salud de Argentina realizada en los años 2004-2005 en niños y mujeres entre 10 y 49 años (ENNYS, 2007), el calcio resultó uno de los nutrientes más críticos, con un $94,3 \%$ de mujeres que presentaron una ingesta menor a la ingesta diaria recomendada (IDR) (1000 mg/día), independiente de su localización geográfica, situación socioeconómica o edad. En el caso de los niños menores de 2 años el $28 \%$ no cubrían la ingesta adecuada de este mineral, mientras que en el grupo de 2 a 5 años esta cifra llegaba al $45,6 \%$. Esos resultados evidencian que el calcio es uno de los nutrientes más críticos en mujeres y niños. Una dieta con aportes adecuados de calcio podría contribuiría a controlar enfermedades causadas por deficiencia de este elemento como son la osteopenia y la osteoporosis.

Un alimento de consumo masivo por parte de la población es el pan, por lo que la incorporación de calcio a harina de trigo para la obtención de panes nutricionalmente enriquecidos en este mineral resulta un desafío no sólo nutricional, sino también tecnológico. El calcio no sólo debe estar presente en el alimento, también debe ser absorbido por el organismo; una alternativa para aumentar su biodisponibilidad es incorporarlo junto con prebióticos como FOS-Inulina a la formulación.

Objetivos. El objetivo de este trabajo de tesis fue estudiar el efecto del agregado a harina de trigo de tres sales de calcio (carbonato de calcio- $\mathrm{CaCO}_{3}$, citrato de calcio$\mathrm{Ca}_{3} \mathrm{Cl}_{2}$ o lactato de calcio- $\mathrm{CaLA}_{2}$ ) junto con FOS enriquecidos con inulina en las propiedades de hidratación y reológicas de masa y la calidad fisicoquímica, sensorial y nutricional de los panes.

Materiales y Métodos. Se utilizó un diseño compuesto central (DCC), donde los factores fueron Ca y FOS enriquecidos con inulina (In). Se realizó un DCC para cada sal de calcio y un control (sin In ni Ca agregado) fuera del DCC. La formulación básica empleada para la panificación en base a $100 \mathrm{~g}$ de harina fue: $2 \% \mathrm{NaCl}, 3 \%$ levadura, In (entre 0 y 13\%) y sal de calcio (entre 1080 y 2520 ppm Ca) y cantidad de agua farinográfica. El máximo nivel de Ca fue seleccionado teniendo en cuenta la ingesta diaria recomendada de este mineral y los niveles máximos permitidos de $\mathrm{Ca}$ en pan (USDA, 2008), mientras que los niveles de inulina se seleccionaron acorde a la cantidad necesaria para asegurar la biodisponibilidad del Ca. 
Las sales de calcio utilizadas son de diferente naturaleza según el anión que acompaña al calcio. El carbonato de calcio es una sal inorgánica donde la relación catión:anión es 1:1, en cambio el citrato de calcio y lactato de calcio son consideradas sales orgánicas, donde la relación catión:anión es 3:2 y 1:2, respectivamente.

Se evaluaron las propiedades de hidratación (contenido y disponibilidad de agua y movilidad molecular-espectroscopia ${ }^{1} \mathrm{H}-\mathrm{RMN}$ ) y reológicas de la masa (ensayos a grandes deformaciones: farinográficos, análisis de perfil de textura, punción, relajación; y a bajas deformaciones: dinámicos oscilatorios). La microestructura de la masa se analizó por microscopía electrónica de barrido (SEM), contenido de gluten, perfil de gliadinas y gluteninas (SDS-PAGE) y estructura secundaria de proteínas por análisis de la banda Amida I por FTIR. Las propiedades térmicas de masas y dispersiones se estudiaron por medidas de gelatinización de almidón (DSC) y viscosidad (RVA).

Se congelaron porciones de masas a $-18 \stackrel{\circ}{\circ}$ hasta 60 días de almacenamiento y se evaluaron las propiedades reológicas a diferentes tiempos de congelación (1, 7, 30 y 60 días) y sobre las masas una vez descongeladas. Sobre los panes obtenidos a partir de masas frescas y descongeladas se determinó el volumen específico, el color de la corteza, textura de la miga y características del alveolado. Se evaluó el cambio en los atributos texturales de los panes frescos después de 1, 3, 5 y 7 días de almacenamiento a temperatura ambiente. Se estudió el efecto del prebiótico y las sales de calcio sobre la vida útil de los panes a través de ensayos de retrogradación de almidón en masas por DSC y grado de cristalinidad por difracción de rayos $\mathrm{X}$ (DRX).

Los resultados fueron analizados mediante análisis de varianza (ANAVA) y aplicando un modelo de segundo orden se generaron Superficies de Respuesta (SR) para la optimización de algunas variables. En base a estas variables se obtuvieron las formulaciones óptimas de pan, una para cada sal de calcio. Se prepararon dichos panes y se evaluaron por medio de ensayos fisicoquímicos y sensoriales de aceptabilidad. Asimismo, para evaluar el efecto prebiótico en la absorción de calcio, se realizaron ensayos nutricionales in vitro de los panes óptimos e in vivo utilizando las siguientes dietas: Dieta control (DC), dieta + Synergy1 (DS) y dieta + pan (DP). El pan de la dieta DP contenía 2400 ppm de $\mathrm{Ca}$ como $\mathrm{CaCO}_{3}$ y $12 \%$ de Synergy1 (base harina).

\section{Resultados}

Las sales $\mathrm{CaCO}_{3}$ y $\mathrm{Ca}_{3} \mathrm{Cl}_{2}$ sin prebiótico aumentaron el tiempo de desarrollo; en cambio a alto prebiótico las mezclas con $\mathrm{Ca}_{3} \mathrm{Cl}_{2}$ y $\mathrm{CaLA}_{2}$ tardaron más tiempo en desarrollar la masa, independientemente del contenido de la sal. Un alto contenido de 
inulina formó masas menos estables y con mayor aflojamiento en todos los casos.

La inulina, al permitir una menor absorción de agua por parte de la masa, provocó frente a un exceso de agua, una disminución considerable de la tenacidad y extensibilidad alveográfica. Una menor cantidad de agua (farinográfica) en presencia del prebiótico formó masas menos húmedas que necesitaron mayor tiempo para desarrollarse. La inulina restringió la movilidad molecular que en el caso del $\mathrm{Ca}_{3} \mathrm{Cl}_{2}$ y $\mathrm{CaLA}_{2}$ también aumentó con el incremento de sal. $\mathrm{El} \mathrm{CaCO}_{3}$ en presencia de inulina actuó como agente reforzador de la masa, que presentaron menor movilidad molecular, sugiriendo que el prebiótico atrapa e inmoviliza agua dentro de la matriz de gluten, principalmente a alto contenido de Ca (2520 ppm). Asimismo, estas masas de mayor $\mathrm{pH}$ resultaron más homogéneas, duras y elásticas; posiblemente debido a interacciones disulfuro favorecidas a mayor $\mathrm{pH}$.

En general, cuando se usó $\mathrm{CaLA}_{2}$, la masa se formó en menor tiempo y fue más estable que la masa con $\mathrm{Ca}_{3} \mathrm{Cl}_{2}$, resultando en una mayor movilidad molecular. $\mathrm{A}$ mayor nivel de $\mathrm{Ca}_{3} \mathrm{Cl}_{2}$ (2520 ppm Ca) se obtuvo la masa más dura y adhesiva y de menor cohesividad (igual que con $\mathrm{CaCO}_{3}$ ) pero exhibió comportamiento opuesto al $\mathrm{CaLA}_{2}$.

La viscoelasticidad de la masa resultó para $\mathrm{CaCO}_{3}$ y $\mathrm{Ca}_{3} \mathrm{Cl}_{2}$ independiente del nivel de $\mathrm{Ca}$ a diferencia de $\mathrm{CaLA}_{2}$ que varió con la interacción $\mathrm{Ca}^{*} / n$. Un incremento de prebiótico en las sales que estabilizan la red de gluten $\left(\mathrm{CaCO}_{3}\right.$ y $\left.\mathrm{Ca}_{3} \mathrm{Cl}_{2}\right)$ provocó menores valores de $\tan \delta$, asociado a un predominio del comportamiento elástico. $A$ grandes deformaciones la energía almacenada $\left(E_{3}\right)$ resultó mayor con el incremento de prebiótico en masas con $\mathrm{CaCO}_{3}$ y $\mathrm{CaLA}_{2}$ encubriendo el efecto de las sales, a diferencia de $\mathrm{Ca}_{3} \mathrm{Cl}_{2}$.

En general, las masas que formaron mayor cantidad de gluten $\left(\mathrm{CaCO}_{3}\right.$ y $\left.\mathrm{Ca}_{3} \mathrm{Cl}_{2}\right)$, presentaron una matriz más homogénea; en cambio con $\mathrm{CaLA}_{2}$ se obtuvieron masas de estructura de gluten más abierta aunque más duras y elásticas, coincidente con un mayor plegamiento proteico de la que no se logró extraer gran proporción de gliadinas y gluteninas solubles.

El prebiótico, debido a la menor absorción de agua, retrasó e inhibió el proceso de gelatinización (mayores temperaturas y menores entalpías), independientemente de la sal de calcio. A baja inulina (1\%) un aumento de calcio disminuyó la entalpía en masas con $\mathrm{CaCO}_{3}$ pero la aumentó en aquellas con $\mathrm{CaLA}_{2}$.

Con $\mathrm{Ca}_{3} \mathrm{Cl}_{2}$ y $\mathrm{CaLA}$, en presencia de alto prebiótico, se obtuvieron panes de menor volumen específico, de miga más firme con mayor masticabilidad y de menor humedad. Los panes con $\mathrm{CaCO}_{3}$ y $13 \%$ In presentaron menor firmeza y mayor volumen. En general, el prebiótico incrementó la firmeza de las migas con sales 
orgánicas; pero en el caso del $\mathrm{CaCO}_{3}$ y el $\mathrm{Ca}_{3} \mathrm{Cl}_{2}$ un incremento en el nivel de calcio disminuyó la firmeza. Los panes almacenados a $20 \stackrel{\circ}{ } \mathrm{C}$, con $\mathrm{CaLA}_{2}$ e inulina presentaron una velocidad de envejecimiento más rápida que los panes con $\mathrm{CaCO}_{3}$ y $\mathrm{Ca}_{3} \mathrm{Cl}_{2}$, y con una miga más firme.

La formulación del pan óptimo elaborado a partir del DCC con $\mathrm{CaCO}_{3}$ fue $2196 \mathrm{ppm}$ Ca-9,6\% In; con $\mathrm{Ca}_{3} \mathrm{Cl}_{2}$ y CaLA $\mathrm{C}_{2}$ fue de 2400 ppm Ca-7,5\% In y 1326 ppm Ca-4,7\% In, respectivamente. Los panes óptimos obtenidos experimentalmente presentaron parámetros de calidad panadera dentro del intervalo predicho; sensorialmente las mejores puntuaciones en sabor y aceptabilidad global fueron las de los panes con $\mathrm{Ca}_{3} \mathrm{Cl}_{2}$ y $\mathrm{CaLA}$.

Luego del almacenamiento de la masa en estado congelado, se obtuvieron masas más blandas con $\mathrm{CaCO}_{3}$ y $\mathrm{CaLA}_{2}$, mientras que con $\mathrm{Ca}_{3} \mathrm{Cl}_{2}$ se endureció. En presencia del prebiótico las masas se ablandaron aunque presentaron menor adhesividad. No se vio afectado el comportamiento viscoelástico de todas las masas durante el almacenamiento en el periodo de congelación estudiado. En ausencia de prebiótico y con $\mathrm{CaCO}_{3} \circ \mathrm{Ca}_{3} \mathrm{Cl}_{2}$ el volumen específico de panes no se modificó y las migas resultaron menos húmedas y más firmes, independientemente de la sal de calcio.

Los panes óptimos presentaron un menor porcentaje de hidrólisis del almidón, por lo que tendrían un bajo índice glicémico. La dializabilidad de hierro y cinc resultó mayor en los panes elaborados con $\mathrm{Ca}_{3} \mathrm{Cl}_{2}$, por lo que el anión citrato mejoró la disponibilidad de estos minerales.

En el ensayo in vivo se encontró un incremento porcentual de peso de los animales semejante en todos los lotes. El contenido cecal del lote DP resultó más ácido sugiriendo mayor fermentación de la microflora colónica.

La absorción aparente de calcio de DS y DP fue mayor coincidente con una mayor densidad mineral ósea de tibia proximal, mayor número de trabéculas y mayor volumen óseo, lo que se asocia a una mayor fijación de calcio en el hueso.

El recuento de anaerobios viables en materia fecal en medio MRS con cisteína (selectivo para lactobacilos y bifidobacterias) disminuyó con el tiempo (50 días) para DC y aumentó para DS y DP. Asimismo se observaron cambios en el perfil de bandas de ADN (DGGE) entre las distintas muestras para los diferentes días de ensayo. A los 50 días de la experiencia las dietas con FOS/In (DS y DP) presentaron una similitud de $48 \%$ entre sí y diferente al la del lote DC. 
Conclusiones. Los panes resultaron ser un alimento interesante para la fortificación con calcio, los cuales no sólo aportaron calcio, sino también favorecieron la disponibilidad de otros minerales como hierro y cinc, principalmente cuando se utilizó $\mathrm{Ca}_{3} \mathrm{Cl}_{2}$. Los ensayos in vivo, además de reafirmar el efecto del prebiótico sobre la absorción de calcio, nos permitieron inferir que los parámetros de absorción de calcio y el desarrollo de una biota microbiana benéfica no resultaron afectados por el proceso tecnológico de panificación.

El consumo promedio de pan en nuestro país es cercano a los 200 g/día. Si se fortificara la harina con 2400 ppm Ca con 7,5\% In, el pan aportaría alrededor del $24 \%$ de la IA. Por lo tanto, los panes fortificados en presencia de prebiótico son potenciales alimentos funcionales, que además de cubrir deficiencias nutricionales mejorarían la salud de la población. 


\section{INDICE}

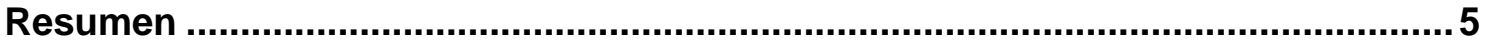

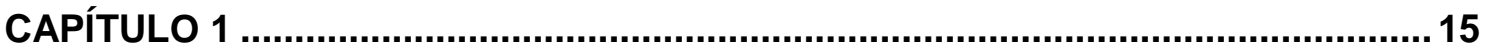

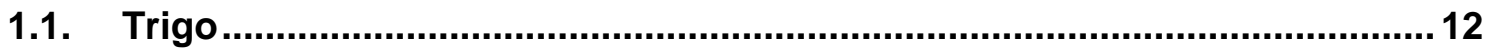

1.1.1. Estructura y composición del grano de trigo .............................................. 13

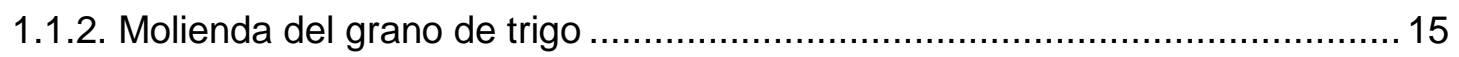

1.2. Composición y tipificación de la harina de trigo ............................................ 16

1.3. Usos de harina de trigo en panificación............................................................. 18

1.4. Componentes de la harina de trigo ............................................................ 19

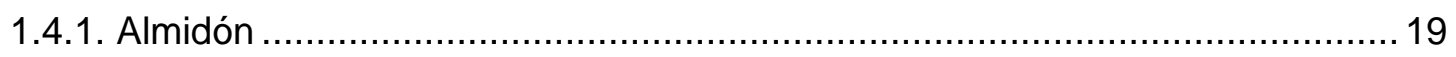

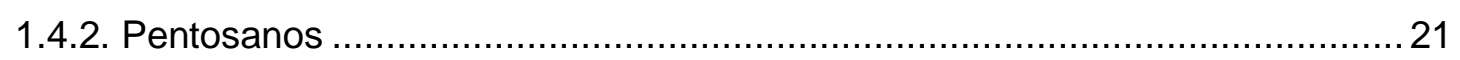

1.4.3. Proteínas ...................................................................................... 23

1.5. Proceso de Panificación.................................................................................... 30

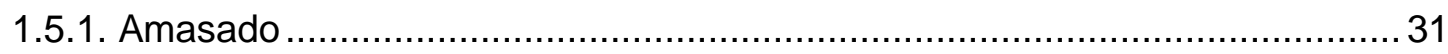

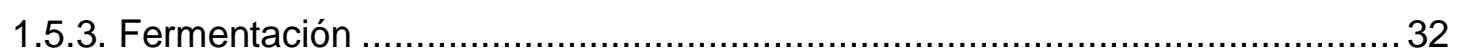

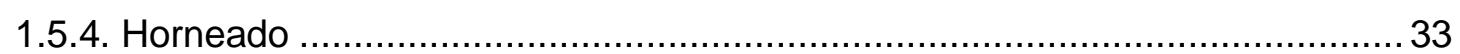

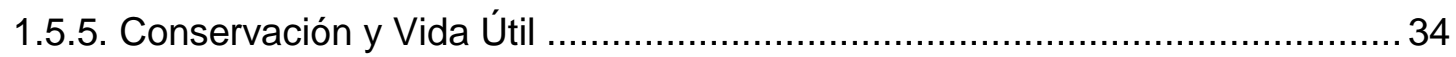

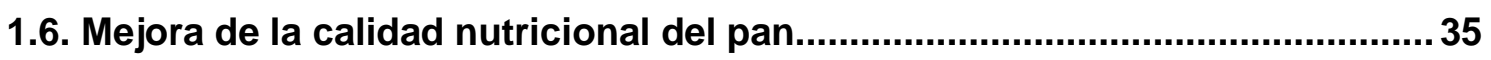

1.6.1. Hierro y zinc. Biodisponibilidad de minerales en alimentos ........................... 40

1.6.2. Calcio. Biodisponibilidad en alimentos............................................................ 40

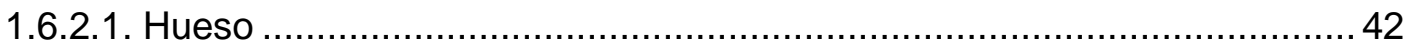

1.6.2.2. Mecanismo de formación, desarrollo y resorción (o remodelación) de

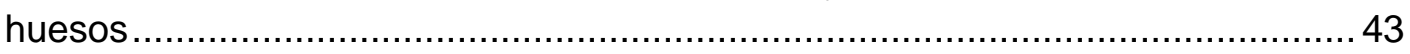

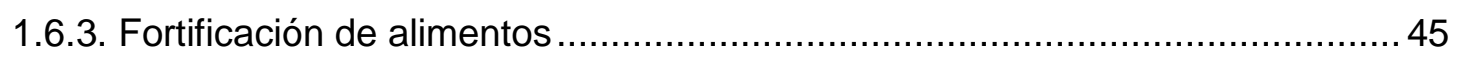

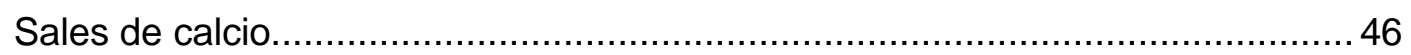

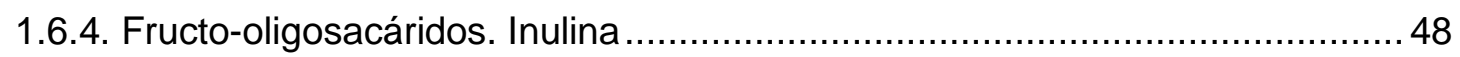

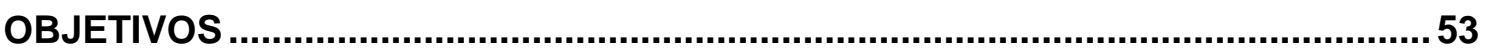

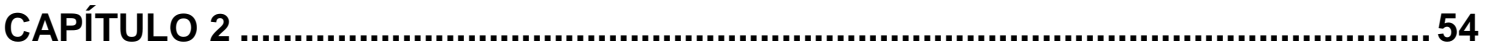

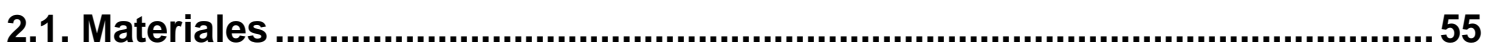

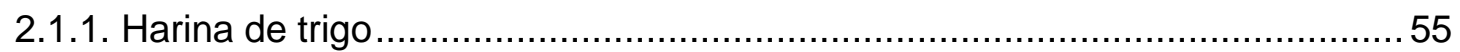

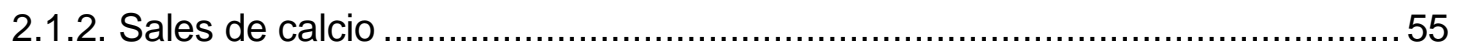

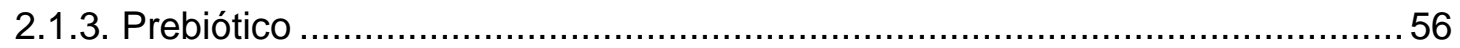

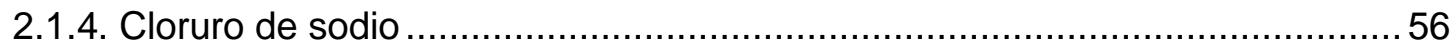

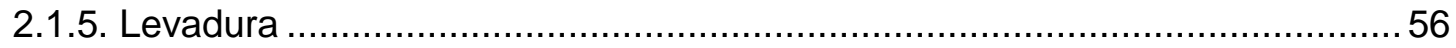

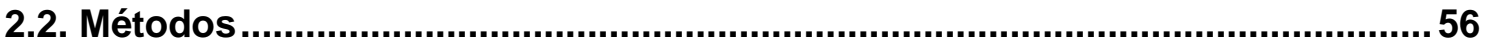

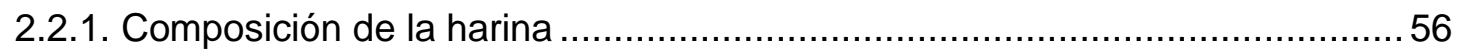




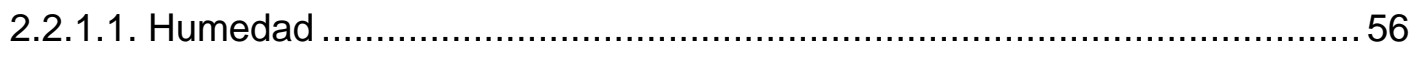

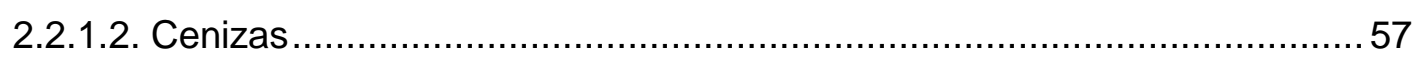

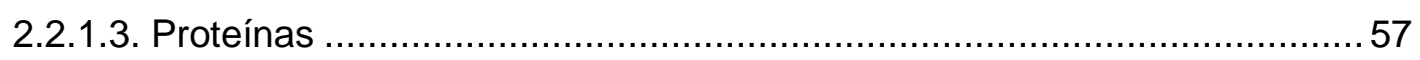

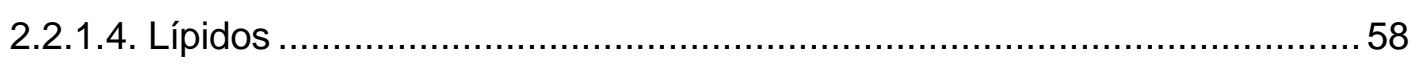

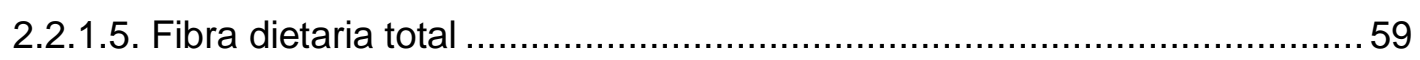

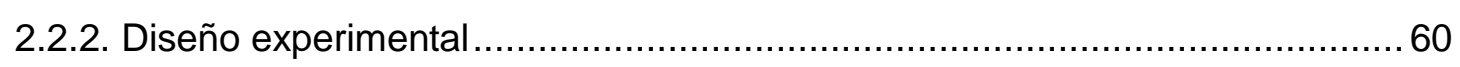

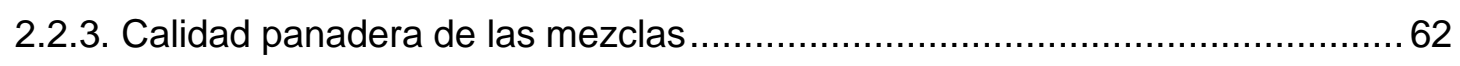

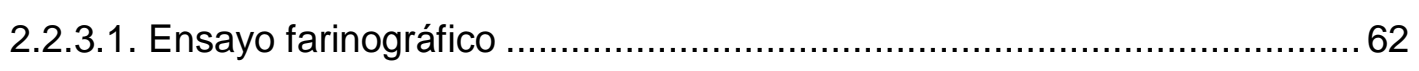

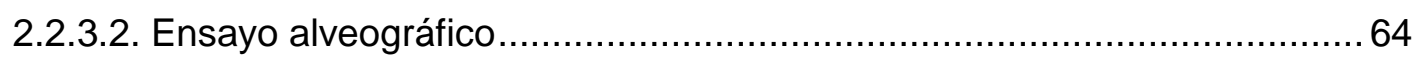

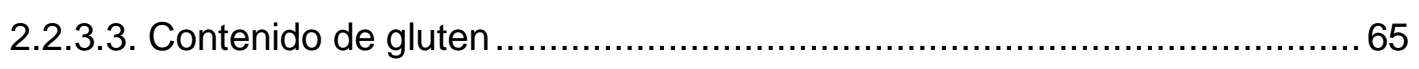

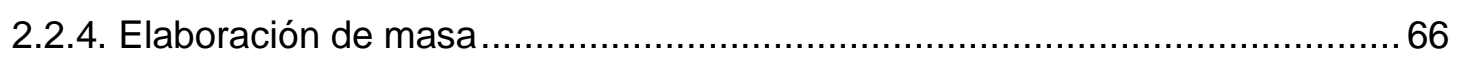

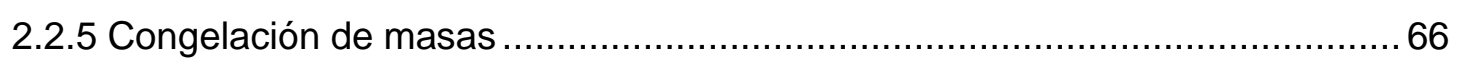

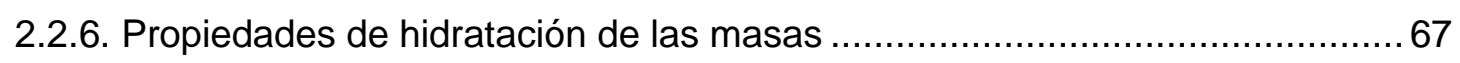

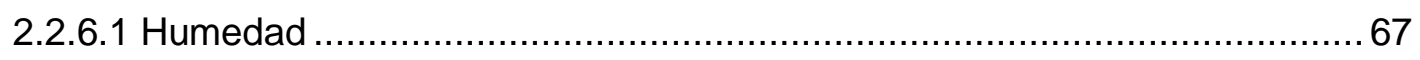

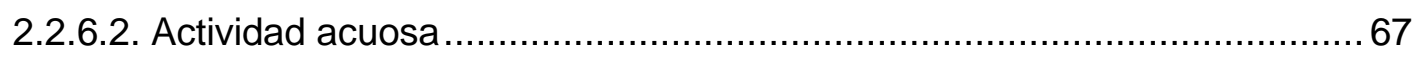

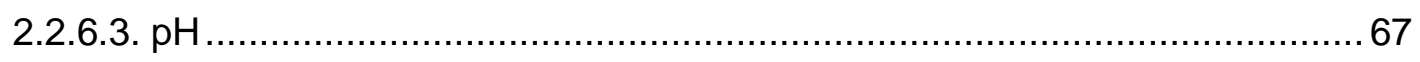

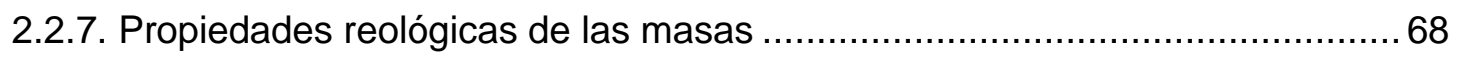

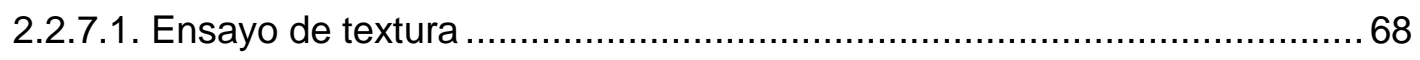

2.2.7.2. Ensayo reológico dinámico sobre las masas....................................... 74

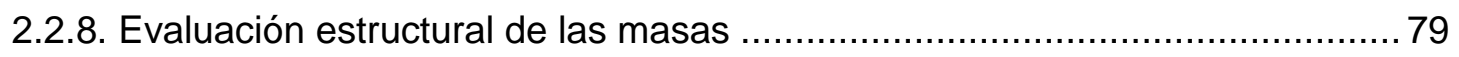

2.2.8.1. Movilidad molecular ...................................................................... 79

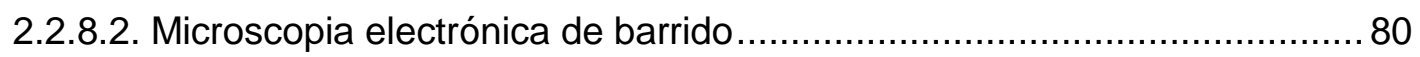

2.2.8.3. Propiedades estructurales de las proteínas ......................................... 81

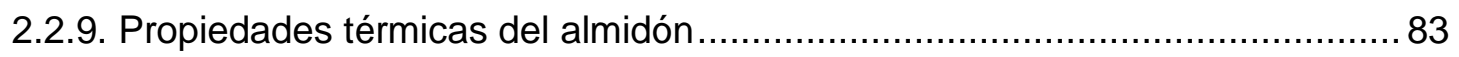

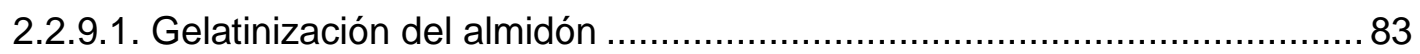

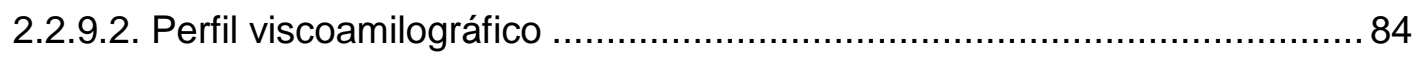

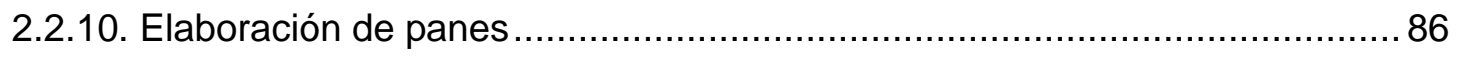

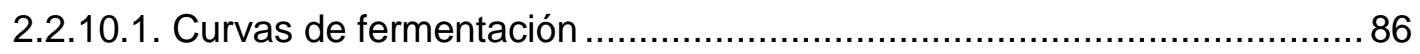

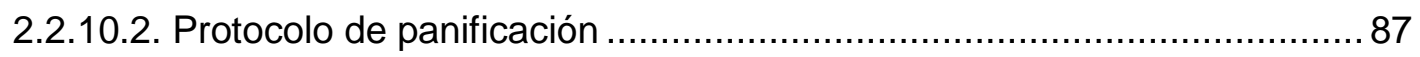

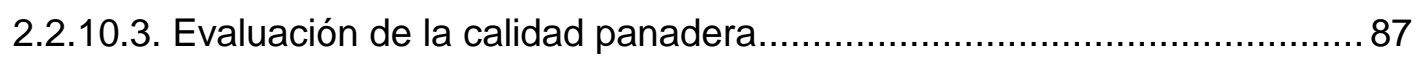

2.2.11. Evaluación de la vida útil de los panes .................................................... 90

2.2.11.1. Análisis de perfil de textura de las migas ......................................... 91

2.3.11.2. Modelado de envejecimiento. Avrami............................................... 91

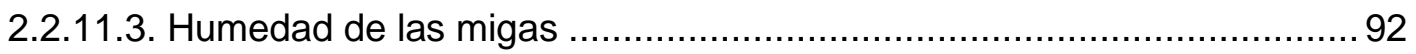

2.2.11.4. Retrogradación del almidón ......................................................... 92

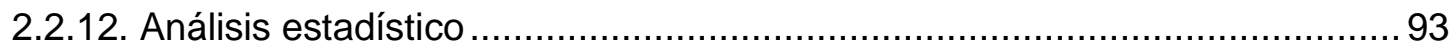


2.2.13. Optimización de la formulación de los panes .............................................93

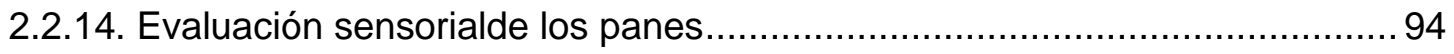

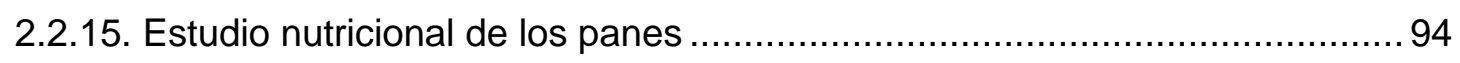

2.2.15.1. Calidad nutricional in vitro .......................................................... 94

2.2.15.2. Calidad nutricional in vivo........................................................... 98

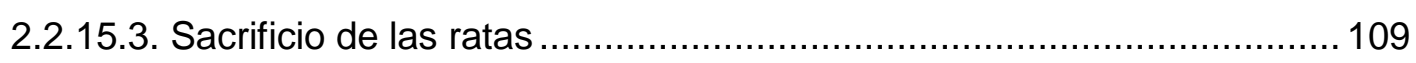

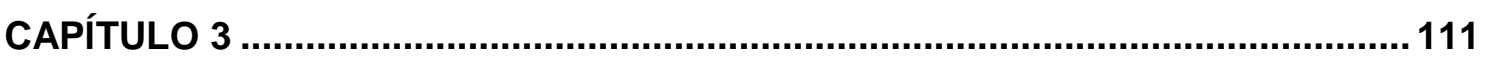

3.1. Caracterización de la harina de trigo.............................................................112

3.2. Efecto de las diferentes sales de calcio y prebiótico sobre las propiedades farinográficas y alveográficas .......................................................................113

3.2.1. Farinogramas y parámetros farinográficos ........................................... 113

3.2.2. Tenacidad y extensibilidad de la masa .................................................. 124

3.3. Efecto de las diferentes sales de calcio y prebiótico sobre las propiedades

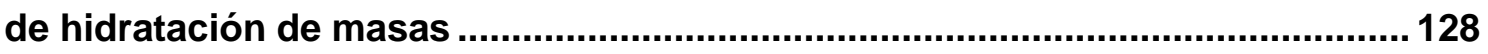

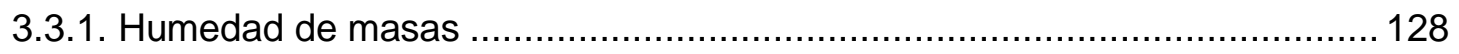

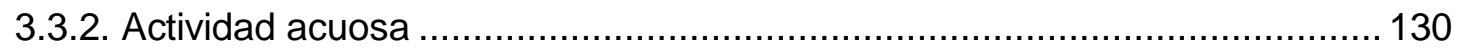

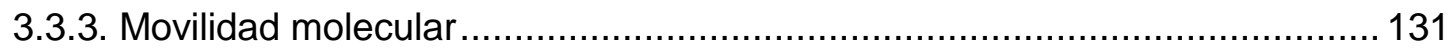

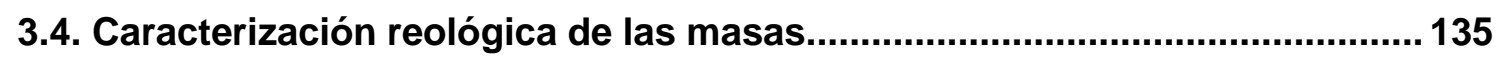

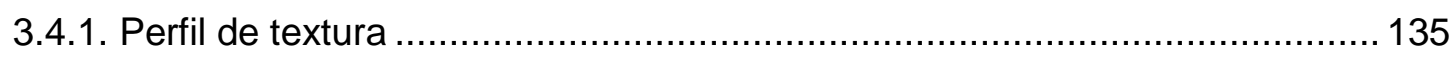

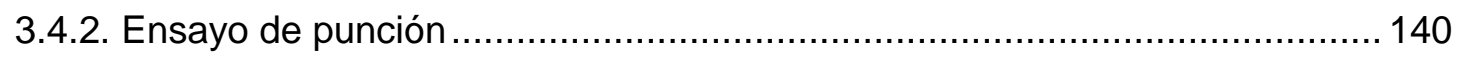

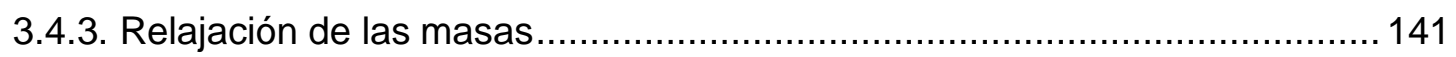

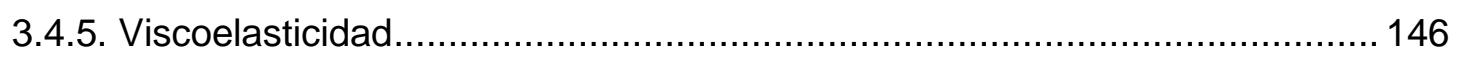

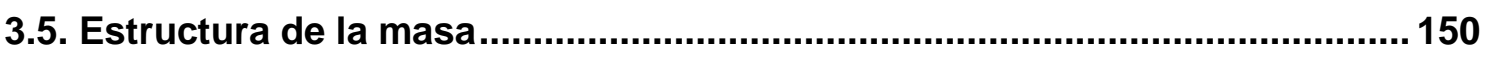

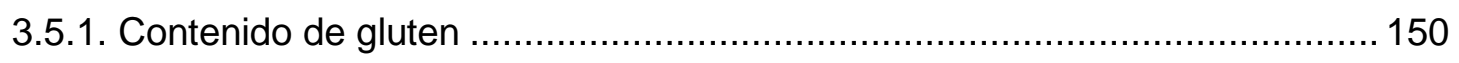

3.5.2. Microestructura de la masa ................................................................ 151

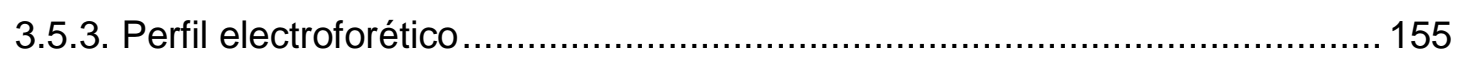

3.5.4. Estructura secundaria de proteínas ......................................................... 156

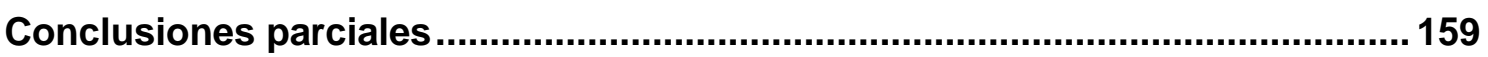

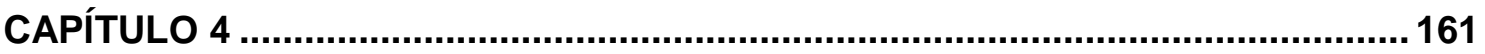

4.1. Composición química de la harina empleada en panificación ....................... 162

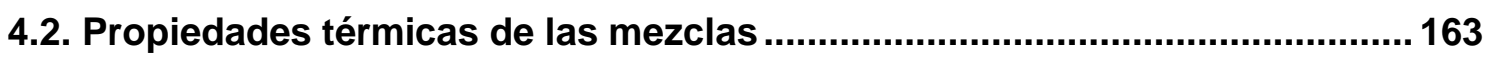

4.2.1. Gelatinización de almidón.................................................................. 163

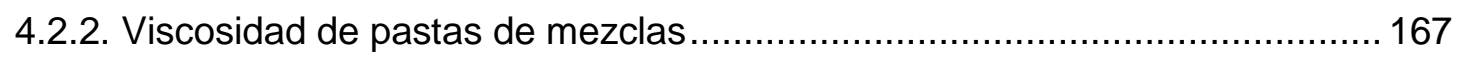

4.3. Capacidad de expansión de la masa durante el proceso de fermentación . 171

4.4. Evaluación de la calidad panadera ................................................................ 173

4.4.1. Volumen especifico ....................................................................... 173 


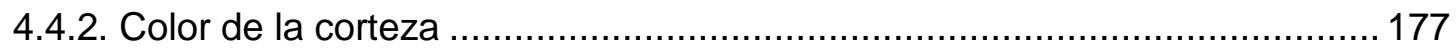

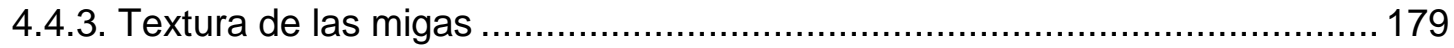

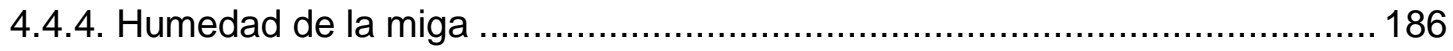

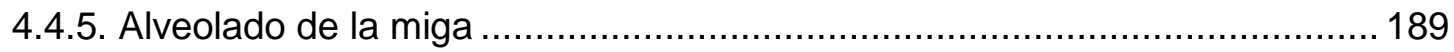

4.5. Estabilidad de los panes frente al almacenamiento ........................................ 191

4.5.1. Firmeza de la miga durante el almacenamiento ........................................ 191

4.5.2. Envejecimiento del pan. Modelo de Avrami ............................................. 197

4.5.3. Humedad de la miga durante el almacenamiento ...................................... 200

4.5.4. Retrogradación del almidón............................................................... 202

Calorimetría diferencial de barrido. DSC .................................................. 203

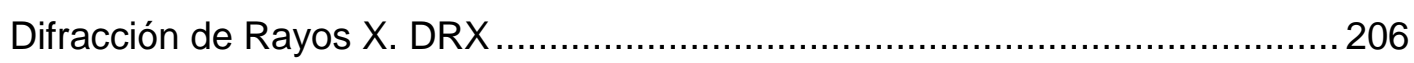

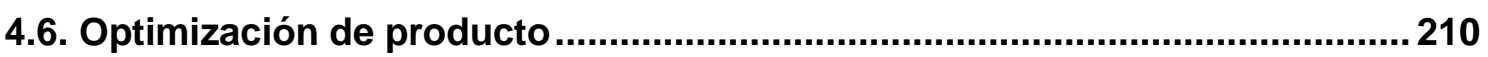

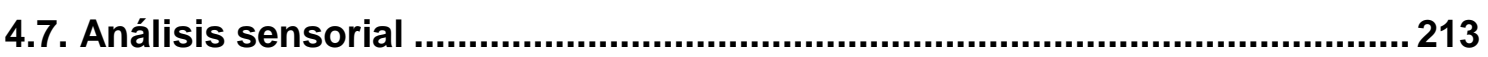

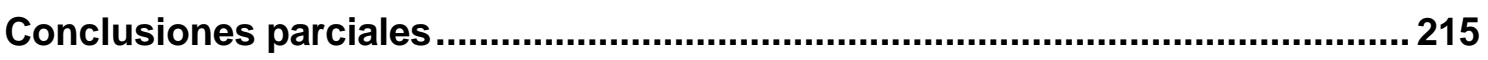

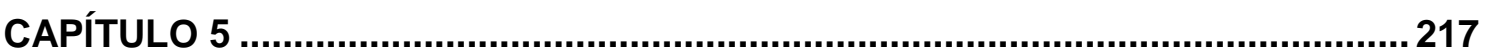

5.1. Evaluación de la calidad de las masas.......................................................219

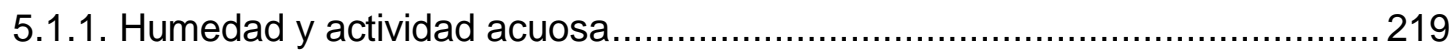

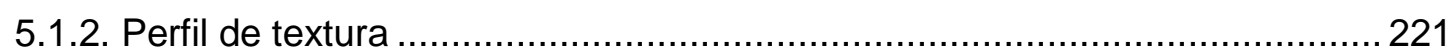

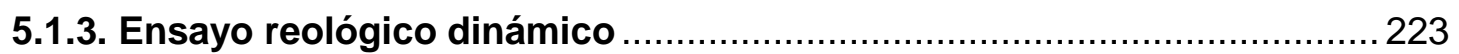

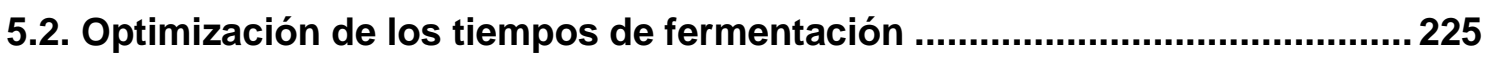

5.3. Evaluación de la calidad panadera .............................................................. 227

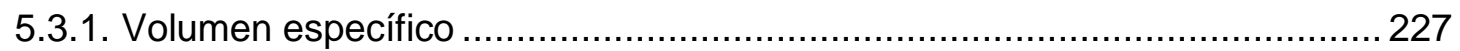

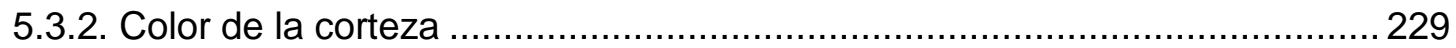

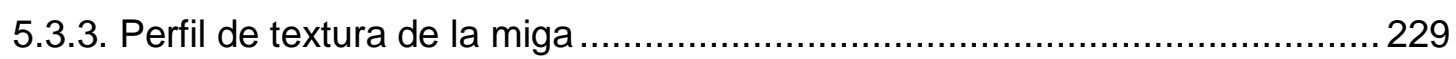

5.3.4. Humedad de la miga ...................................................................... 231

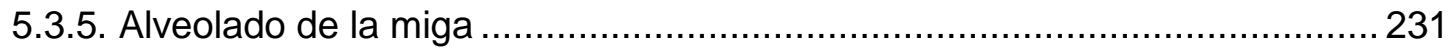

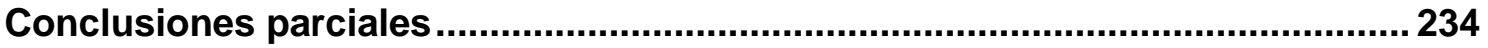

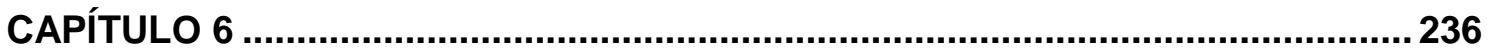

6.1. Estudios nutricionales in vitro realizados sobre los panes...........................237

6.1.1. Determinación de la composición porcentual de los panes..........................237

6.1.2. Digestibilidad in vitro de almidón y estimación del índice glicémico ..............2237

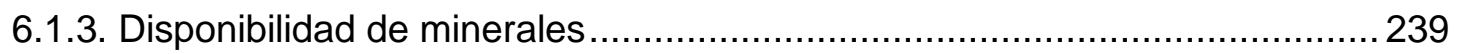

6.2. Ensayo de experimentación sobre modelo animal..........................................240

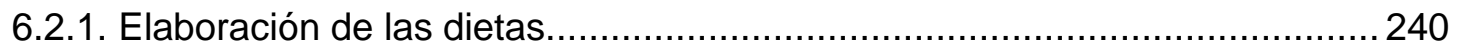

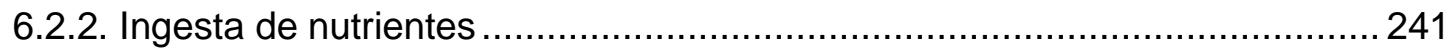

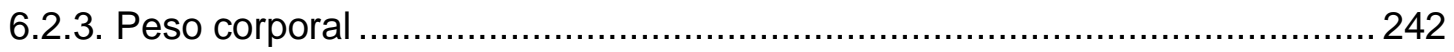


6.2.4. Determinación de la densidad mineral ósea .............................................. 244

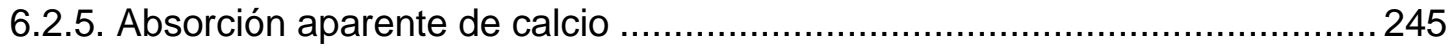

6.2.6. Resultados obtenidos posterior al sacrificio de los animales .......................246

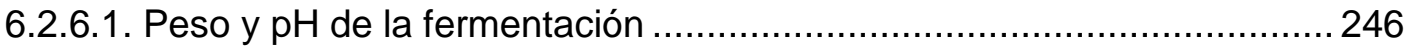

6.2.6.2. Determinación histológica y estimación del volumen óseo .....................247

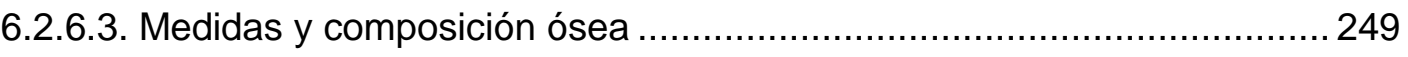

6.2.7. Modificación de la microbiota en heces durante la experiencia ....................250

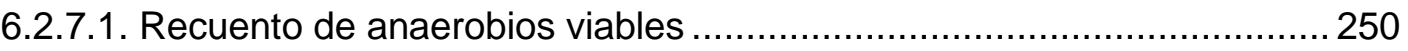

6.2.7.2. Características de las colonias obtenidas en agar MRS ...................... 251

6.2.7.3. Análisis de diversidad microbiológica............................................... 252

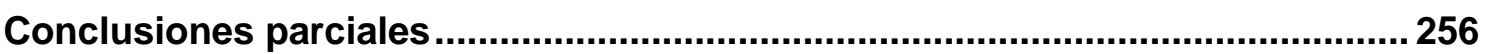

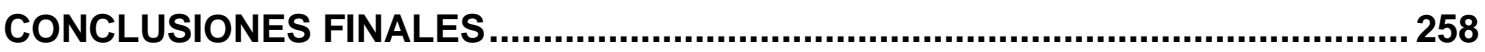

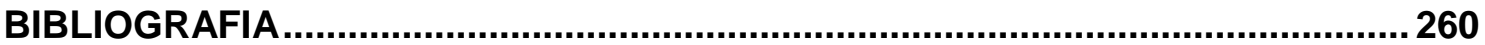


CAPÍTULO 1 
Durante el 2011 la Argentina se encontró entre los 13 principales productores de trigo a nivel mundial, con 16.354.100 toneladas producidas, lo cual situó al trigo como el $4^{\circ}$ producto en el país durante ese año (FAOSTAT, 2013). El Departamento de Agricultura de Estados Unidos (USDA) estimó que en la temporada 2013/14 Argentina cosechará 13 millones de trigo. Argentina, un gran exportador mundial de granos, es el tercer proveedor internacional de maíz y soja y el sexto de trigo (MAG y $P, 2013$ ). En el período enero-noviembre de 2012, el sector molinero nacional molturó un volumen menor de trigo pan que en igual tramo de 2011. Desde el año 2008 el sector ha sometido anualmente a la operación de molienda más de 6 millones de toneladas anuales de este cereal, situación que se ha sostenido en 2012 (Farináceos, 2013).

\subsection{Trigo}

El trigo pertenece a la familia de las gramíneas y al género Triticum. Las especies cultivadas más importantes desde el punto de vista comercial son: Triticum aestivum y Triticum durum.

El trigo se puede clasificar de acuerdo a la dureza del grano en trigos blandos y trigos duros; la dureza es una característica molinera relacionada con la forma en que el endospermo se rompe (Campbell y col., 2007), se trata de una calidad genética (Chang y col., 2006) relacionada con su capacidad molinera y no con su calidad panadera, aunque normalmente a mayor dureza del grano mayor será el contenido proteico y por lo tanto su calidad panadera. La harina se obtiene como producto de la molienda de los granos de trigo. Los granos de trigo más duro ( $T$. durum) tienen mayor facilidad a la molturación, fraccionándose de una forma más o menos regular que dará lugar a harinas con mayor granulometría que serán utilizadas en la elaboración de pastas. En cambio a partir de trigos blandos ( $T$. aestivum) los granos se fraccionan en forma aleatoria irregular produciendo harinas muy finas que se emplearán en productos panificados (Hoseney y Rogers, 1990).

Por otra parte la fuerza del trigo es una cualidad relacionada con sus aptitudes panaderas, es decir la capacidad de una harina para producir pan en piezas de gran volumen con miga de buena textura. Los trigos fuertes suelen poseer un elevado contenido proteico y se obtienen panes de elevada aptitud panadera, en cambio los trigos denominados "flojos" que sólo pueden dar piezas pequeñas con migas de estructura mala suelen tener un contenido proteico bajo, ideales para la fabricación de galletas y pastas (León y Rosell, 2007). 


\subsubsection{Estructura y composición del grano de trigo}

El grano de trigo, desde el punto de vista botánico, es una cariopsis, es decir, un fruto seco indehiscente en el que la pared del ovario (el pericarpio), se encuentra unido con el tegumento exterior de la semilla (testa) por lo que no es posible separarlos (Šramková y col., 2009).

El uso industrial del trigo depende de la estructura del grano. El grano (Figura 1.1) posee una capa de salvado protectora más dura y liviana que el endosperma almidonoso, lo que facilita su separación durante la obtención de harina.

El pericarpio actúa como una cubierta protectora y comprende aproximadamente el $5 \%$ del grano. Posee un $6 \%$ de proteínas, un $2 \%$ de cenizas, un $25 \%$ de celulosa, 0,5\% de lípidos, y $30 \%$ de pentosanos.

Se encuentra conformado por diversas capas: en el exterior, por la epidermis (epicarpio), la hipodermis y restos de células de paredes finas mientras que en el interior, por las células intermedias, las células transversales y las células tubulares.

En la semilla distinguimos tres zonas: el germen o embrión, el endosperma encerrado por la epidermis nucelar y la cubierta de la semilla (Figura 1.1). La cubierta de la semilla y la epidermis nucelar representan el $2,5 \%$ de la semilla de trigo y contienen $15 \%$ de proteínas, $13 \%$ de cenizas y $15 \%$ de pentosanos.

La epidermis nucelar o capa hialina se encuentra fuertemente unida a la cubierta de la semilla y a la capa de aleurona.

- El germen representa aproximadamente el 3\% del grano de trigo y contiene un 30\% de proteínas, $4 \%$ de cenizas, $17 \%$ de azúcares (siendo los mayoritarios sacarosa y rafinosa), 10\% lípidos y contiene gran variedad de enzimas (lipasas, lipooxigenasa, amilasas, proteinasas, etc) y vitaminas de los grupos B (niacina, riboflavina, tiamina) y E (tocoferol). Está formado por el eje embrionario (raíz y tallo rudimentarios) y el cotiledón que funciona como un órgano de digestión, absorción y almacenamiento de nutrientes.

- El endosperma está formado por la capa de aleurona y el endosperma almidonoso. La capa de aleurona rodea por completo al endosperma almidonoso y al germen. Posee gránulos que contienen principalmente proteína. La capa de aleurona contiene aproximadamente el $61 \%$ de los minerales del grano de trigo, el $80 \%$ de la niacina y $60 \%$ de la piridoxina (vitamina $\mathrm{B}_{6}$ ). En la molienda la capa de aleurona se desprende junto con el pericarpio, las envolturas de la semilla y la epidermis nuclear 
constituyendo parte del salvado. El endosperma almidonoso es la fuente de la harina ya que sus células contienen gránulos de almidón embebidos en una matriz proteica. Además, sus células contienen dos tipos de proteínas, unas con función citoplasmática (albúminas y globulinas) y otras de reserva (gliadinas y gluteninas). El endosperma almidonoso presenta una disminución del contenido proteico y de cenizas desde el exterior hacia el centro, siendo posible encontrar una relación 6:1 en el contenido proteico entre diferentes zonas del mismo. El endosperma almidonoso contiene el $72 \%$ de las proteínas del grano de trigo y contiene una proporción importante de las vitaminas riboflavina y ácido pantoténico (Hoseney, 1994a).

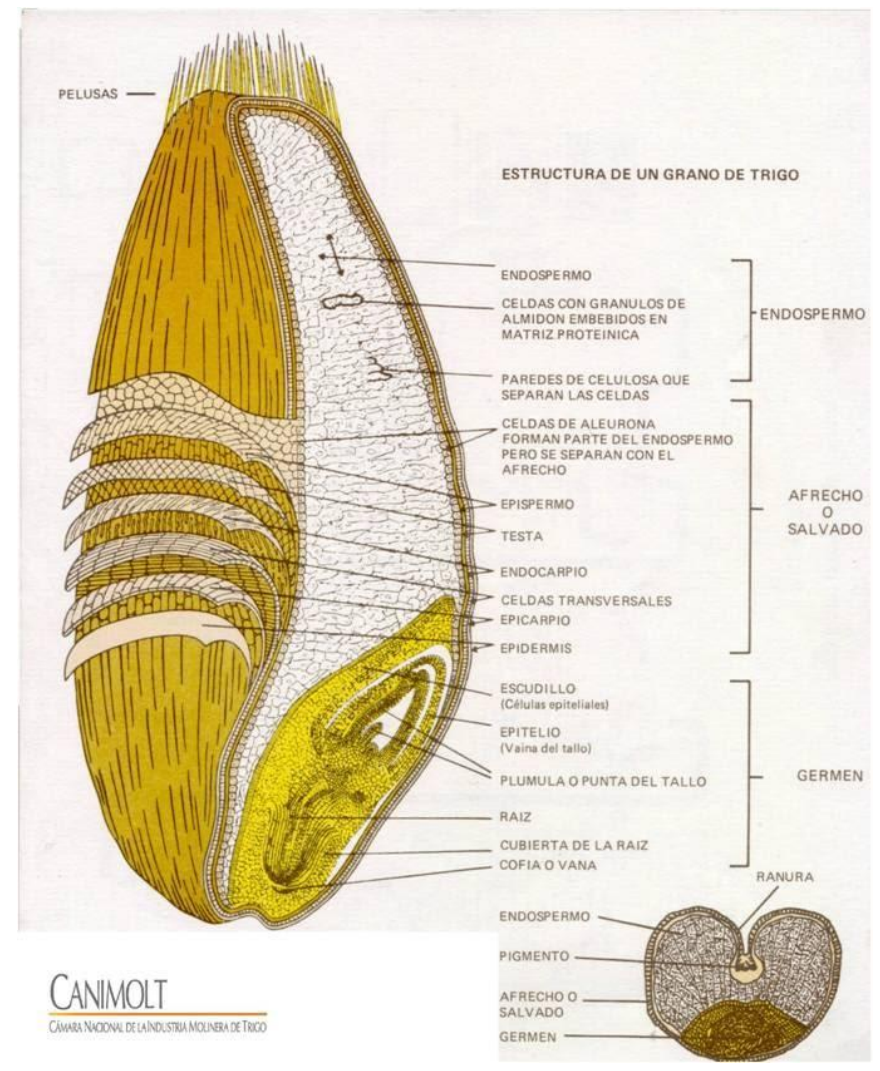

Figura 1.1. Esquema del grano de trigo. Corte longitudinal a través del pliegue (Fuente: http://www.canimolt.org/trigo/estructura-del-grano).

La composición del trigo puede variar según la zona y el año de cosecha. En la Tabla 1.1 se presenta el rango de variación de la composición química de los principales componentes que constituyen el grano de trigo (Matz, 1999). Se puede observar que el grano está formado en su mayor parte por almidón, proteínas y agua. 
Tabla 1.1. Composición química del grano entero de trigo.

\begin{tabular}{cc}
\hline Componente & $\begin{array}{c}\text { Composición porcentual } \\
(\%)\end{array}$ \\
\hline Humedad & $8,0-18,0$ \\
Proteínas & $7,0-18,0$ \\
Lípidos & $1,5-2,0$ \\
Almidón & $60,0-68,0$ \\
Fibra Cruda & $2,0-2,5$ \\
Cenizas & $1,5-2,0$ \\
\hline
\end{tabular}

\subsubsection{Molienda del grano de trigo}

En el proceso de molienda del grano de trigo se separa el endosperma del germen y del salvado obteniéndose la harina.

En la sala de limpieza del molino se reciben los granos de trigo provenientes de los silos y se eliminan impurezas que suelen acompañar al trigo: piedras, paja, arena, polvo, metales, otras semillas, entre otros. En este procedimiento el trigo es fluidizado y pasado a través de un sistema de tamices y de imanes con los que se separan partículas más densas como piedras y metales (Catterall, 1998).

En el proceso de acondicionamiento se adiciona agua al grano de trigo y se deja reposar durante 20 horas para uniformizar la humedad en el grano. Con el acondicionamiento se incrementa la humedad del grano de $14 \%$ a $16 \%$, el pericarpio se vuelve más flexible y laminable, lo cual facilita la separación de las capas de salvado del endosperma y permite obtener fragmentos de mayor tamaño. La eliminación del salvado y el calor generado en el proceso de molienda hacen que la humedad final de la harina obtenida se encuentre cercana al $14 \%$.

Luego de la humidificación se somete a la trituración del trigo en el que se liberan partículas del endosperma con la mínima desintegración posible del salvado (Webb y Owens, 2003). Se emplea un sistema de 4 a 6 pares de rodillos estriados, presentando en cada par uno de los rodillos una velocidad de giro que duplica a la del otro, que rompen y abren el grano extrayéndose el endosperma. Las partículas grandes obtenidas de endosperma corresponden a la sémola. Los productos pasan luego a un 
cernedor oscilatorio que los separa en subfracciones que envía hacia los rodillos de reducción. En esta etapa se obtiene algo de harina que sin pasar por el resto del proceso, se tamiza y separa.

Las muestras así trituradas se someten a purificación por medio del pasaje a través de purificadores, rodillos de molienda y tamices. Los purificadores son tamices que separan las partículas en base a diferencias de tamaño y peso específico por medio de tolvas receptoras cuyo tamaño de poro se incrementa en forma gradual y a través del cual pasa una corriente de aire. Las partículas de endosperma más pesadas permanecen en el tamiz hasta que encuentran un tamaño de poro tal que les permite atravesarlo y caen a la tolva que se encuentra debajo, mientras que las partículas de salvado más livianas son arrastradas por el flujo de aire. La mayor parte del material obtenido en esta etapa pasa hacia el sistema de reducción, mientras que el remanente vuelve al sistema de trituración. Generalmente la purificación del material proveniente de la primera y segunda rotura da lugar a endosperma puro, mientras que la purificación de roturas posteriores da lugar a material con mayor contenido de salvado (Webb y Owens, 2003).

La etapa final de la molienda es la reducción, en ella se obtiene la harina con las características buscadas. Se emplean hasta 12 pares de cilindros de compresión lisos que giran con diferente velocidad para reducir el tamaño de las partículas de harina. De este proceso se obtiene harina de diferente calidad, lográndose la harina de mejor funcionalidad para la panificación a partir de los primeros cilindros. El material obtenido en cada par de cilindros de reducción pasa a través de un cernedor oscilatorio que lo clasifica, la harina se separa y las fracciones restantes, con mayor tamaño de partícula, pasan al cilindro siguiente. La compresión realizada por los cilindros en esta etapa produce la rotura de los gránulos de almidón, lo cual afecta a la absorción de agua de la harina resultante y por ende la calidad final del producto.

\subsection{Composición y tipificación de la harina de trigo}

La composición promedio de la harina de trigo se muestra en la Tabla 1.2. Está compuesta mayoritariamente por almidón, proteínas y agua. 
Tabla 1.2. Composición química de la harina de trigo.

\begin{tabular}{cc}
\hline Componente & $\begin{array}{c}\text { Composición porcentual } \\
(\%)\end{array}$ \\
\hline Almidón & $70-75$ \\
Proteínas & $10,0-12,0$ \\
Lípidos & 2,0 \\
Pentosanos & $2,0-3,0$ \\
Cenizas & 0,5 \\
Humedad & 14 \\
\hline
\end{tabular}

El $73 \%$ de la harina obtenida se utiliza en la fabricación de pan, siendo las harinas de trigo, y en menor grado la de centeno, las únicas que resultan panificables. Esta particularidad de la harina de trigo se debe a las características de las proteínas gliadinas y gluteninas presentes en el grano (Lindsay y Skerritt, 1999; Shewry y col., 2001).

Código Alimentario Argentino (CAA) en su Capítulo IX, artículo 661 (Res 167, 26.1.82) define como "Harina" al producto obtenido de la molienda del endosperma del grano de trigo y tipifica comercialmente a las harinas del siguiente modo: cuatro ceros (0000), tres ceros (000), dos ceros (00), cero (0), medio cero (medio 0), harinilla de primera y harinilla segunda, las cuales se obtienen de la molienda gradual y metódica del endosperma en cantidad de $70-80 \%$ del grano limpio.

En la Tabla 1.3 se muestran las características requeridas para los diferentes tipos de harinas.

La tipificación de las harinas se basa en: 1) el contenido de cenizas determinado a 900- $920^{\circ} \mathrm{C}$ (calculadas sobre residuo seco), 2) la humedad determinada a $130{ }^{\circ} \mathrm{C}$ durante una hora, 3) la absorción farinográfica de agua (cantidad de agua que absorben $100 \mathrm{~g}$ de harina) y 4) el volumen de pan que puede obtenerse a partir de 100 $\mathrm{g}$ de harina. En la determinación de cenizas se admite una tolerancia de hasta un $3 \%$ sobre los valores establecidos para las harinas 000 . Se debe rotular como "harina" o "harina de trigo" con la tipificación correspondiente. 
Tabla 1.3. Tipificación comercial de las harinas según el CAA.

\begin{tabular}{ccccc}
\hline Harina tipo & $\begin{array}{c}\text { Humedad } \\
\mathbf{g} / \mathbf{1 0 0} \mathbf{g} \\
\text { (máx.) }\end{array}$ & $\begin{array}{c}\text { Cenizas } \\
\mathbf{g} / \mathbf{1 0 0} \mathbf{g} \\
\text { (máx.) }\end{array}$ & $\begin{array}{c}\text { Absorción } \\
\mathbf{g} / \mathbf{1 0 0} \mathbf{g}\end{array}$ & $\begin{array}{c}\text { Volumen pan } \\
\mathbf{c m}^{\mathbf{3}} \\
\text { (min.) }\end{array}$ \\
\hline $\mathbf{0 0 0 0}$ & 15,0 & 0,492 & $56-62$ & 550 \\
$\mathbf{0 0 0}$ & 15,0 & 0,650 & $57-63$ & 520 \\
$\mathbf{0 0}$ & 14,7 & 0,678 & $58-65$ & 500 \\
$\mathbf{0}$ & 14,7 & 0,873 & $60-67$ & 475 \\
$\mathbf{1} \mathbf{2} \mathbf{0}$ & 14,5 & 1,350 & - & - \\
\hline
\end{tabular}

\subsection{Usos de harina de trigo en panificación}

Para panificación se emplean más de tres cuartas partes de la harina de trigo consumida internamente, siendo el destino de mayor relevancia las panaderías tradicionales. El procesamiento permite la elaboración de diversos productos como distintos tipos de pan, facturas, productos de repostería y pastelería, vainillas, pizzas, tapas de empanadas, pan dulce, pastas frescas, pastas secas y las masas congeladas (Cuniberti, 2004).

La demanda de la industria del trigo es creciente y sostenida, requiriendo determinadas características en las harinas que luego se traducen en un producto de mejor calidad (García, 2004).

En el país se encuentran funcionando alrededor de 15.000 panaderías utilizando el $70 \%$ de ellas el método sobre tablas con fermentaciones de 8 hasta 16 horas, muy típicas de Argentina. El principal producto es el pan tipo francés, 'baguette', criollo, fugaza, árabe, pan alemán, entre otros. Este sistema de fermentación larga para pan artesanal favorece sensiblemente al sabor del pan, además de requerir un porcentaje muy bajo de levadura. Los trigos deben tener un valor de fuerza panadera alveográfica (W) superior a 250 y gluten entre $28-30 \%$ para ayudar a soportar largas horas fermentando.

El 30\% de la producción de pan se realiza a través del método de panificación directa, con tiempos de fermentación inferiores a 6 horas. Unas 5.000 panaderías producen este tipo de pan, obteniéndose por este método los miñones, galletas, flautas, flautitas y facturas. Las harinas requeridas deben ser de fuerza intermedia, con un W de alrededor de $230-250$ y gluten de aproximadamente $27 \%$. Para este método se 
necesita contar con mejoradores (sustitutos del bromato de potasio) como enzimas, oxidantes, emulsificantes, entre otros; que permitan mantener fermentaciones muy largas (Cuniberti, 2004) y obtener a la vez un pan inocuo y de características organolépticas deseables.

\subsection{Componentes de la harina de trigo}

\subsubsection{Almidón}

El almidón es el polisacárido de reserva del grano de trigo y se encuentra en las células del endosperma empaquetado en forma de gránulos. Está compuesto por dos polímeros de glucosa: amilosa (25\%) y amilopectina (75\%), que representan aproximadamente el 15 y el $50 \%$ de la harina, respectivamente. La amilosa está formada por residuos de glucosa unidos a través de enlaces $\alpha(1 \rightarrow 4)$ (Figura 1.2.a). El grado de polimerización de la amilosa se encuentra entre 500 y 6000 residuos de glucosa y sus cadenas presentan una estructura helicoidal, en la cual los grupos hidroxilo están orientados hacia el exterior, estableciéndose en el interior un ambiente no polar en el cual pueden incluirse moléculas tales como los ácidos grasos. La amilopectina es un polímero altamente ramificado formado por cadenas de residuos de glucosa unidos a través de enlaces $\alpha(1 \rightarrow 4)$ las cuales se unen a través de enlaces $\alpha$ $(1 \rightarrow 6)$, estableciéndose de este modo las ramificaciones (Figura 1.2.b). El grado de polimerización de la amilopectina se encuentra entre $3 \times 10^{5}$ y $3 \times 10^{6}$ residuos de glucosa, sus cadenas se clasifican en A, B, C, en base a la presencia de ramificaciones y extremos reductores y presentan una estructura en clusters.

En la harina de trigo encontramos una distribución bimodal en el tamaño de los gránulos de almidón, los gránulos de menor tamaño son esféricos y con diámetros de hasta $10 \mu \mathrm{m}$ mientras que la población de gránulos de mayor tamaño presenta un tamaño de hasta $20 \mu \mathrm{m}$ y un aspecto lenticular (Karlsson y col., 1983; Moon y Giddings, 1993). Al observarlos con un microscopio de luz polarizada presentan birrefringencia con forma de cruz de Malta, la cual refleja el arreglo radial de las moléculas de almidón en el gránulo alrededor del centro biosintético, el hilium (Jane, 2004). 
a

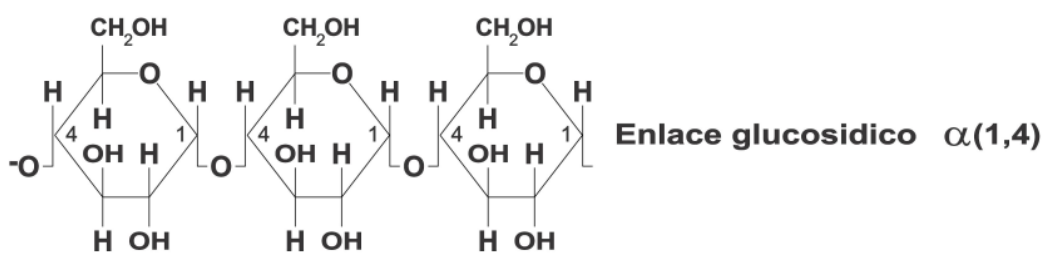

b

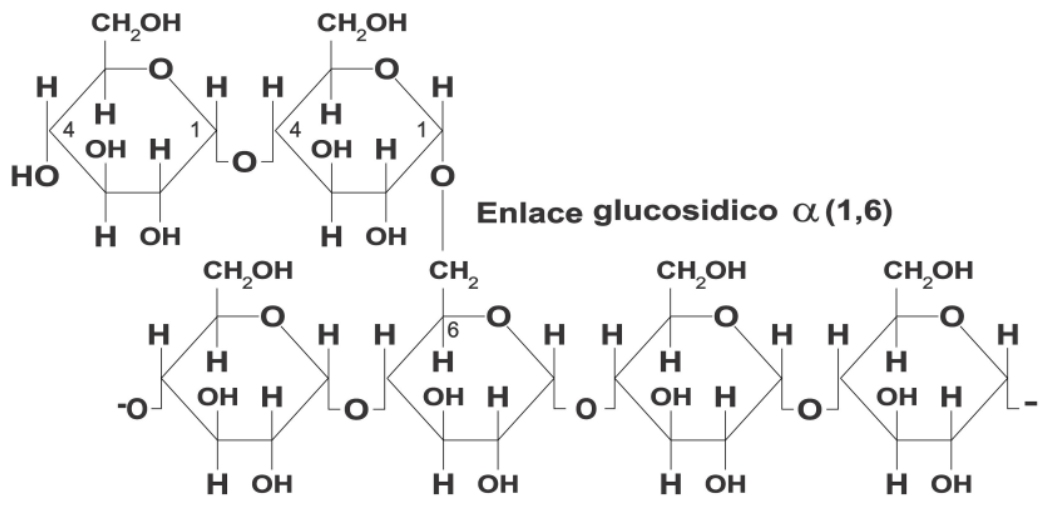

Figura 1.2. Estructuras de: a) amilosa y b) amilopectina.

El gránulo de almidón presenta una estructura semicristalina dado que es posible distinguir zonas amorfas y cristalinas (20-40\%) alternadas. Las zonas amorfas son menos densas y están conformadas principalmente por la amilosa mientras que las zonas cristalinas están formadas principalmente por doble hélices de amilopectina (Figura 1.3.a). Si se prepara una suspensión de almidón en exceso agua a temperatura ambiente los gránulos de almidón pueden absorber parte del agua incrementando su tamaño un 10-30\% (Dengate, 1984). Si esta suspensión se calienta, ocurre un fenómeno irreversible conocido como gelatinización (Figura 1.3.b), en el cual se pierde el orden molecular y el gránulo de almidón pierde la birrefringencia. La gelatinización comienza en las zonas amorfas ya que los enlaces de hidrógenos son más lábiles en estas zonas y permiten la entrada de agua al gránulo por lo que comienza a hidratarse y se hincha. Además, ocurre la disociación de la doble hélice de moléculas de amilopectina, la fusión de las zonas cristalinas y la salida de moléculas de amilosa, lo que ocasiona un incremento de la viscosidad de la suspensión. Para el almidón de trigo la gelatinización determinada por calorimetría diferencial de barrido (DSC), cuando se encuentra en exceso de agua, se presenta como una única endoterma y suele comenzar aproximadamente a los $50{ }^{\circ} \mathrm{C}$ y finalizar cerca de los $80^{\circ} \mathrm{C}$. Mientras que en los sistemas en donde el agua es limitante se observa un aumento del rango de temperatura de gelatinización y un desdoblamiento de la endoterma (Ghiasi y col., 1982). Si se continúa incrementando la temperatura o se realiza un esfuerzo de cizalla la estructura remanente del gránulo sigue dañándose y 
también continúa la salida de amilosa. Al enfriar la pasta así obtenida ocurre la gelación de la amilosa debido a la formación de una estructura de doble hélice entre las moléculas, obteniéndose una matriz de amilosa continua en la cual se encuentran embebidos gránulos de almidón gelatinizados enriquecidos en amilopectina o sus remanentes. La recristalización de la amilosa y la amilopectina se conoce como retrogradación (Figura 1.3.c). El proceso ocurre en el término de horas en el caso de la amilosa y es más lento, de días a semanas para la amilopectina. La retrogradación de la amilopectina ocurre en los gránulos gelatinizados o en los remanentes.
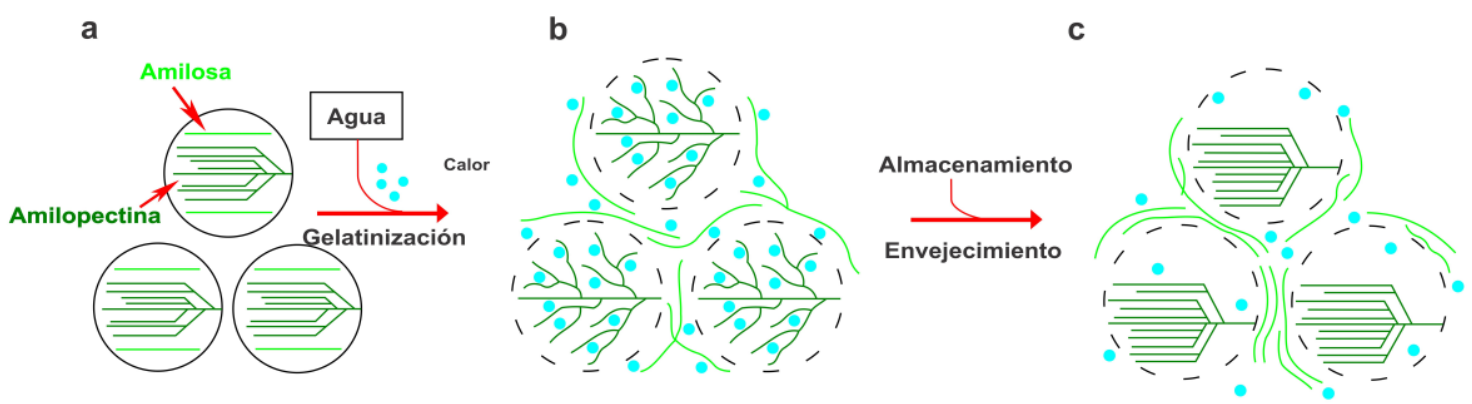

Figura 1.3. Cambios que experimenta el gránulo de almidón en una mezcla almidón-agua durante un calentamiento, enfriamiento y almacenamiento. a) Almidón nativo, b) Gelatinización y gelación, c) Almidón retrogradado.

\subsubsection{Pentosanos}

A todos los polisacáridos no almidonosos presentes en la harina se los denomina en forma genérica como pentosanos (arabinoxilanos y arabinogalactanos), ya que el $80 \%$ de los azúcares que los componen son pentosas: D-xilosa y D-arabinosa. Se los clasifica en base a su solubilidad en agua como pentosanos solubles e insolubles en agua, encontrándose en una relación 25:75 (Meuser y Suckow, 1986).

Los arabinoxilanos (Figura 1.4) son residuos de D-xilosas unidas por enlaces $\beta(1 \rightarrow 4)$ que están sustituidas en el $\mathrm{C}_{3}$ y/o en el $\mathrm{C}_{2}$ por monómeros de L-arabinosa (Perlin, 1951a y b), por lo que la relación arabinosa/xilosa es variable. Pueden tener ácido ferúlico unido al $\mathrm{C}_{5}$ de la L-arabinosa mediante una unión tipo ester (Fausch y col., 1963). La diferencia estructural entre arabinoxilanos solubles en insolubles en agua radica principalmente en el peso molecular (Meuser y Suckow, 1986) y en la relación arabinosa/xilosa (Gruppen y col., 1993).

Los pentosanos, aunque representan sólo el 2-2,5 \% de la harina, absorben de 10-15 veces su peso en agua y forman soluciones muy viscosas o geles por uniones covalentes afectando la distribución de la humedad entre los constituyentes de la 
masa y alterando así la formación del gluten y las propiedades reológicas de la masa y la calidad final del pan (Kim y D’Appolonia, 1977a).

Los arabinoxilanos solubles pueden formar geles por medio de uniones covalentes entre residuos de ácido ferúlico (Vinkx y col., 1991; Figueroa-Espinoza y Rouau, 1998). Ambos tipos poseen una alta capacidad de retención de agua. Se ha determinado que durante la preparación de la masa, un cuarto del agua agregada es retenida por los arabinoxilanos (Atwell, 1998).

El ácido ferúlico de los arabinoxilanos también está involucrado en la formación de complejos proteína-arabinoxilanos a través de enlaces con los residuos de cisteínas y el grupo fenol de la tirosina de las proteínas del gluten (Stauffer, 2007).

Durante el proceso de panificación, los arabinoxilanos insolubles en agua causan un impacto negativo ya que actúan limitando la agregación del gluten debido a impedimentos estéricos (van Oort y col., 1995), absorben una gran cantidad de agua que deja de estar disponible para el desarrollo del gluten y causan la coalescencia de las celdas de gas resultando en una pobre calidad del pan (Courtin y col., 1999, Courtin y Delcour, 2002).

Por el contrario los arabinoxilanos solubles en agua, causan un impacto positivo porque actúan disminuyendo la velocidad de difusión del $\mathrm{CO}_{2}$ en la masa estabilizando las celdas de gas. Además, incrementan la viscosidad de la fase acuosa de la masa aumentando su estabilidad e incluso mejoran el volumen de pan y la firmeza y estructura de la miga (Hoseney, 1984; Gan y col., 1995).

Los arabinoxilanos también tienen efecto sobre el envejecimiento del pan, ya sea por impedimento estérico de las interacciones intermoleculares entre las moléculas de almidón, disminuyendo la retrogradación (Kim y D' Appolonia 1977a, b); o en la redistribución de agua en la masa (Gudmundsson y col., 1991, Eliasson y Larsson 1993, Biliaderis y col., 1995). 


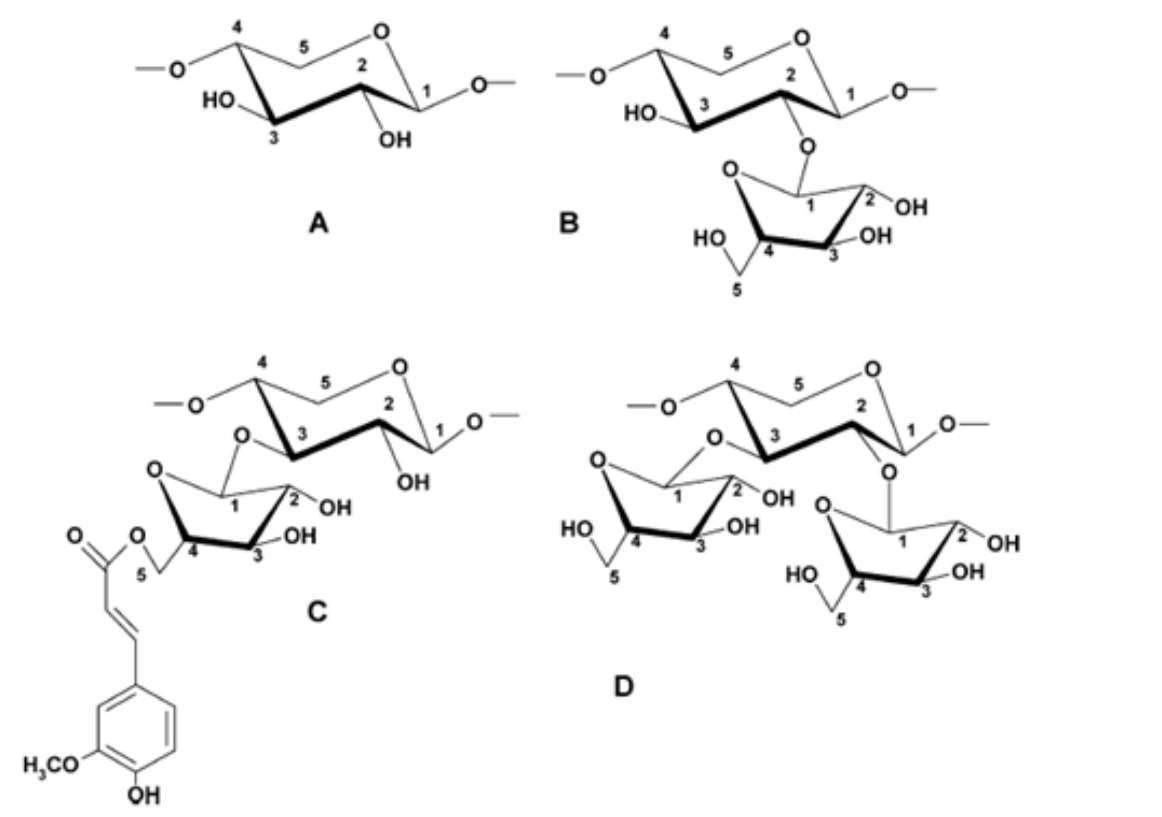

Figura 1.4. Estructura de los arabinoxilanos. A) Residuo de D-Xilosa no sustituida. B) Residuo de D-Xilosa sustituida en el C(O)-2 con un residuo de D-arabinosa. C) Residuo de D-Xilosa sustituida en el C(O)-3 con un residuo de $D$-arabinosa que tiene unido al $C(O)-5$ una molécula de ácido ferúlico. D) Residuo de D-Xilosa sustituida en el C(O)-2 y C(O)-3 con residuos de Darabinosa.

\subsubsection{Proteínas}

Las proteínas de la harina de trigo se clasifican, al igual que para otros cereales, en base a su solubilidad según la secuencia de Osborne (1924) y en base a su funcionalidad: solubles en agua (albúminas), en solución salina diluída (globulinas), en alcohol (prolaminas) y en solución diluida de ácidos o álcalis (glutelinas).

Las prolaminas de trigo se denominan gliadinas y las glutelinas de este cereal se denominan gluteninas. Una fracción importante de proteínas se excluye de las fracciones de Osborne porque no son extraíbles con ninguno de los disolventes utilizados.

Desde el punto de vista de la funcionalidad de las proteínas, se pueden distinguir dos grupos de proteínas de trigo:

- Proteínas no pertenecientes al gluten: Representan entre un 15-20 \% del total de las proteína del trigo (según clasificación de Osborne son las albúminas y globulinas). En su mayor parte son proteínas monoméricas, estructurales o fisiológicamente activas (enzimas). 
- Proteínas de gluten: Son las proteínas de reserva del grano de trigo y constituyen entre el 80 y el $85 \%$ de las proteínas totales. El gluten se designa a la red formada por gluteninas y gliadinas hidratadas durante el amasado.

\section{Proteínas de gluten}

Las gliadinas son un grupo altamente polimórfico de proteínas monoméricas ricas en glutamina y prolina, con un bajo nivel de aminoácidos cargados. Poseen una masa molecular que varía entre los 30 y $80 \mathrm{kDa}$. Bioquímicamente han sido identificados cuatro tipos, de acuerdo a su movilidad cuando son separadas mediante electroforesis ácida (A-PAGE): $\alpha$ - ( 28), $\beta$ - ( 30), Y- (35) y $\omega$-gliadinas (45) (Jones y col., 1959; Woychik y col., 1961). Estudios posteriores mediante cromatografía líquida en fase reversa (RP-HPLC) permitieron la separación de las gliadinas en más de cien componentes y demostraron que las subunidades $\alpha$ - y $\beta$ - se encuentran dentro de un mismo grupo $(\alpha / \beta)$.

Las $\omega$-gliadinas son ricas en glutamina, prolina y fenilalanina, y no contienen residuos de cisteína, por lo que están limitadas para formar interacciones covalentes en la masa

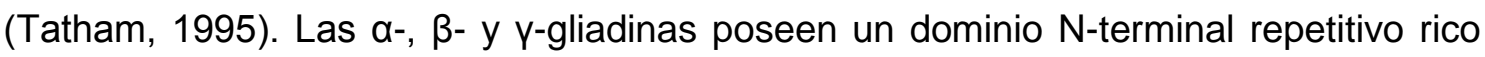
en residuos de glutamina, prolina, fenilalanina y tirosina; y un dominio C-terminal no repetitivo que posee residuos de cisteínas. En general, las $\alpha / \beta$ - gliadinas contienen seis y las $\mathrm{y}$ - gliadinas presentan ocho residuos de cisteínas que forman tres y cuatro enlaces disulfuro intramoleculares respectivamente, por lo que no son capaces de formar nuevos enlaces covalentes y tomar parte en la formación de la red de gluten (Grosch y Wieser, 1999). Sin embargo, estos enlaces disulfuro son importantes para mantener el plegamiento de la estructura que determina la naturaleza de las interacciones no covalentes con la red de gluteninas (Wrigley y col., 1998).

Las $\alpha-, \beta-, y$ y-gliadinas contienen un $30-35 \%$ de su estructura en $\alpha$-hélice. Las $\alpha-$ gliadinas también contienen $10 \%$ de lámina- $\beta$, mientras que las $\omega$-gliadinas no contienen este tipo de estructuras, pero se presentan en la forma giro- $\beta$ (Tatham y col., 1985).

La fracción de gluteninas comprende agregados proteicos que se mantienen unidos por puentes disulfuro y fuerzas no covalentes intermoleculares, y cuya masa molecular varía entre 500.000 y más de 10 millones (Wieser, 2007). Cuando las gluteninas son tratadas con una solución de dodecil sulfato de sodio (SDS) más un agente reductor, como el $\beta$-mercaptoetanol o el ditiotreitol, se obtienen dos grupos de proteínas que se 
diferencian en su masa molecular: las subunidades de baja masa molecular (LMWGS) y las subunidades de alta masa molecular (HMW-GS) (Wieser, 2000).

Payne y Corfield (1979) informaron que, de acuerdo a su movilidad en SDS-PAGE, las gluteninas están formadas por tres grupos de subunidades denominados $\mathrm{A}, \mathrm{B}$ y C. El primer grupo con masa molecular entre 95-136 kDa (HMW-GS); el segundo entre $42-$ 51 , y el último entre $31,5-35,5 \mathrm{kDa}$. Los grupos $\mathrm{B}$ y $\mathrm{C}$ corresponden a las gluteninas de baja masa molecular (LMW-GS). Posteriormente, Jackson y col. (1983) observaron que las LMW-GS pueden dividirse en tres grupos, por lo que adicionó un grupo más al que denominó grupo $\mathrm{D}$.

Las subunidades LMW-GS poseen la habilidad de formar puentes disulfuro que permiten su incorporación dentro de los polímeros de gluteninas. La mayoría de las LMW-GS contienen entre siete y ocho residuos de cisteínas (Grosch y Wieser, 1999; Wieser, 2003), seis residuos están en una posición homóloga a las gliadinas, y por lo tanto pueden formar puentes disulfuro intramoleculares. Los residuos de cisteínas adicionales no son capaces de formar puentes disulfuro intramoleculares, probablemente por impedimento estérico, por lo que pueden formar puentes disulfuro intermoleculares y llevar a la formación de agregados proteicos entre ellas y con las HMW-GS (Pogna y col., 1994). En general, las LMW-GS se relacionan con la resistencia y la extensibilidad de la masa (Metakovskii y col., 1990; Cornish y col., 2001).

De acuerdo a su secuencia de aminoácidos y a su movilidad electroforética las subunidades de HMW-GS se han subdividido en dos tipos: tipo- $x$ (alta masa molecular) y tipo- $y$ (baja masa molecular) (Figura 1.5.a). Estas proteínas difieren en su dominio N-terminal y sus motivos repetitivos (Tatham, 1995). Shewry y col., (2001) presentaron un modelo estructural de HMW-GS, basado en datos espectroscópicos (Figura 1.5.b). Los estudios muestran a las subunidades de gluteninas de alta masa molecular, como moléculas alargadas que poseen una estructura $\beta$-espiral en la región central repetitiva. Mientras que los dominios $\mathrm{N}$ - y C-terminal poseen una estructura similar a las proteínas globulares, presentando $\alpha$-hélices y estructura desordenada. En los dominios terminales se encuentran la mayoría de los residuos de cisteínas que proveen los sitios para la formación de puentes disulfuro intermoleculares. 
a)

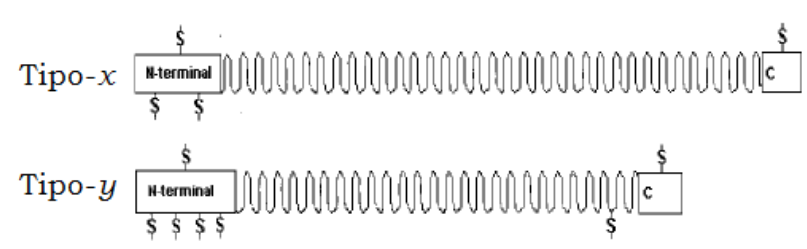

b)

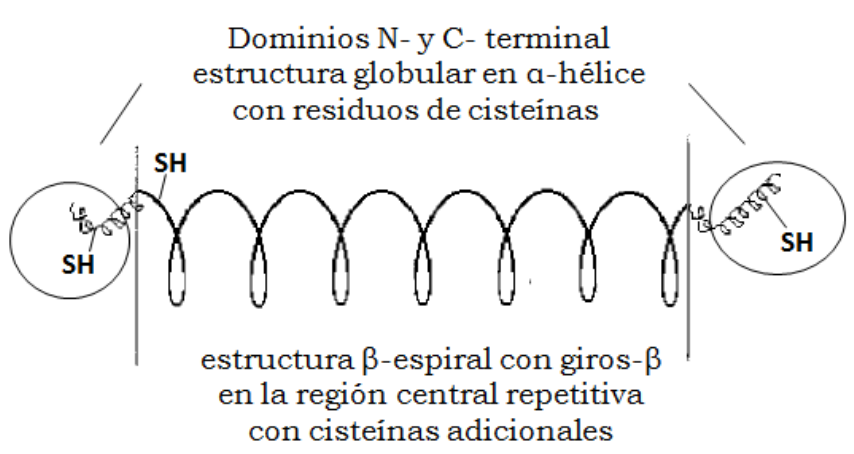

Figura 1.5. Estructura de gluteninas de alta masa molecular (HMW-GS). a) Representación esquemática de HMW-GS tipo $x$ - e $y$ - (Kasarda y col., 1994). b) Modelo estructural de HMWGS (adaptado de Shewry y col., 2001).

A las gluteninas, sobre todo a las HMW-GS, se les asigna la capacidad de conferir a la masa las propiedades viscoelásticas, debido a la repetición de las estructuras tipo giro$\beta$. Parte de las gluteninas poliméricas pueden ser separadas como una capa de gel insoluble en SDS llamado macropolímero de gluteninas (GMP).

\section{Estructura y calidad del gluten}

El gluten es una red compleja de proteínas insolubles, gliadinas y gluteninas, que se obtiene a partir del amasado de la harina de trigo con agua y el posterior lavado de la masa con una solución salina, para eliminar las proteínas solubles (albúminas y globulinas) y el almidón. Como se mencionó anteriormente, una cierta cantidad de albuminas y globulinas puede permanecer luego del lavado, al igual que ciertos polisacáridos no almidonosos como los pentosanos.

Durante la formación de la masa, las interacciones de tipo covalentes y no covalentes entre los polipéptidos más grandes producen una matriz elástica y extensible. Los elementos estructurales responsables de esta propiedad particular son los enlaces disulfuro, interacciones iónicas e hidrofóbicas y secuencias ricas en glicina (Belitz y col., 1986; Ng y col., 1991).

La composición de aminoácidos de las proteínas del gluten muestra que aproximadamente la mitad de los constituyentes son glutamina y prolina, por lo que se 
supone que hay gran cantidad de enlaces puente hidrógeno en el sistema. Otro aporte importante son las interacciones hidrofóbicas, ya que aproximadamente el 35\% de los aminoácidos posee cadenas laterales de naturaleza hidrofóbica (Hoseney, 1994b).

La Figura 1.6 muestra un esquema de la estructura del gluten presentado por Shewry y col. (2001), en el cual las HMW-GS forman la columna vertebral del polímero, y se encuentran unidas entre sí a través de puentes disulfuro intermoleculares ubicados en los extremos. La columna vertebral de HMW-GS sirve de base para que se unan a ella las subunidades de baja masa molecular (LMW-GS) mediante puentes disulfuro en los puntos de ramificación. Las gliadinas, consideradas tradicionalmente por contribuir a la viscosidad del gluten, interactúan principalmente con los polímeros de gluteninas mediante interacciones no covalentes. En el dominio central de las HMW-GS ocurren interacciones puentes de hidrógeno probablemente entre las amidas de los residuos de glutamina. Estas interacciones son muy importantes porque contribuyen a la viscoelasticidad de la masa (Ewart, 1989; Jeffrey y Saenger, 1994; Belton, 1999).

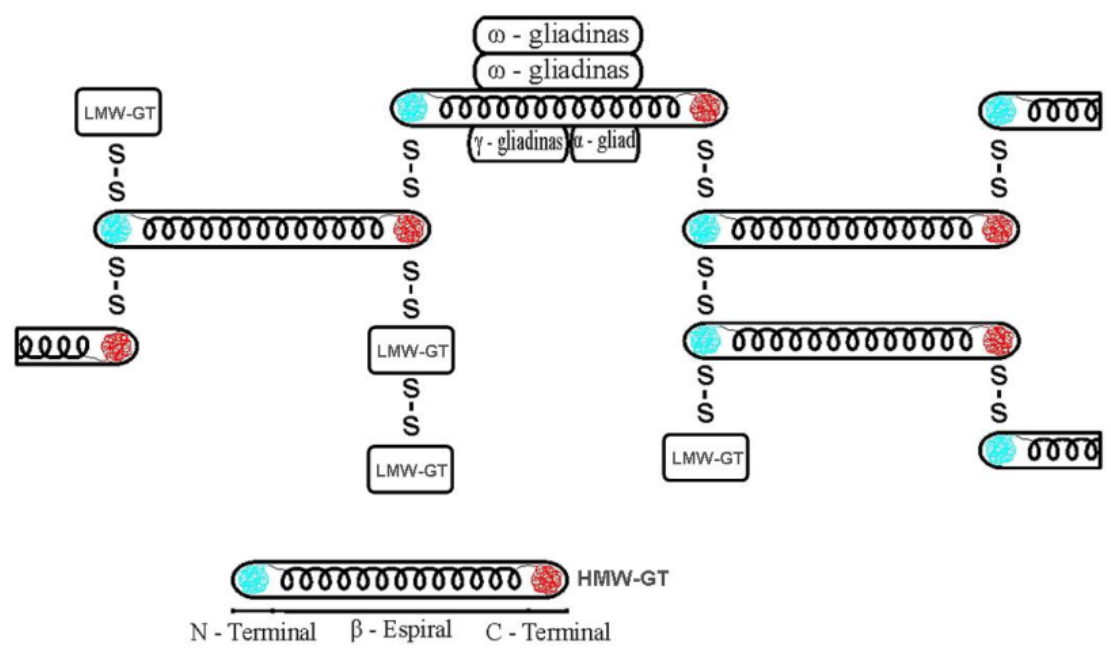

Figura 1.6. Esquema general de la estructura de la red de gluten. HMW: subunidades de gluteninas de alta masa molecular. LMW: subunidades de gluteninas de baja masa molecular. (Adaptado de Shewry y col., 2001). Dibujo: Analia Gómez.

Debido al gran tamaño que poseen, se ha sugerido que los polímeros de gluteninas forman la red continua que provee fuerza y elasticidad a la masa, mientras que los monómeros de gliadinas aportan plasticidad y viscosidad (Belton, 1999).

La elasticidad del gluten ha sido explicada a través de distintas hipótesis. Una de las más aceptadas propone que la elasticidad es una consecuencia de la extensa cantidad de puentes de hidrogeno que unen a las estructuras giros- $\beta$ formando estructuras $\beta$-espirales, que pueden extenderse actuando como resortes (Tatham y 
col., 1985). Otra hipótesis fue propuesta por Ewart (1977) y se centra en la entropía. El autor considera que las moléculas de gluteninas poseen una forma aproximadamente esférica, concatenándose en una estructura de tipo lineal. Bajo una determinada tensión, las moléculas de gluteninas pueden extenderse, reacomodándose en una configuración menos favorable. Una vez que se retira la tensión, las moléculas retornarían a un estado favorable de menor energía.

Belton (1999) describe al gluten como un sistema formado por una estructura de bucles y colas, "loop and train", regiones donde existen interacciones polímerosolvente (loop) y regiones con interacciones polímero-polímero (train). En este modelo las HMW-GS inicialmente presentan una conformación en forma de bucle (loop) que son extendidas durante la extensión del gluten para formar polímeros alineados en los cuales la formación de altas proporciones de estructuras de láminas- $\beta$ se encuentra favorecida. Por esta razón tales polímeros son altamente resistentes a la extensión. El estiramiento de los polímeros produce primero la deformación de los bucles (loops) y posteriormente de las colas (train), a la vez que se disocian interacciones no covalentes (Figura 1.7). Sin embargo, puede producirse la restauración del equilibrio de bucles y colas, lo cual resulta en la relajación de la estructura del polímero. La fuerza de restauración consistirá de un término entrópico asociado con la entropía conformacional de los bucles y con la entalpía de formación de puentes hidrógenos en las colas, la pérdida de entropía resultante de la formación de estos enlaces será compensada, en parte, por el aumento de entropía del agua liberada que se encontraba ligada por enlaces hidrógeno.

a

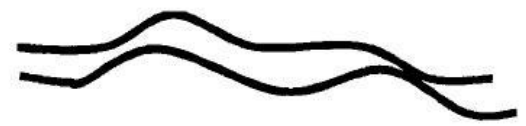

Baja hidratación, desorden, interacciones cercanas

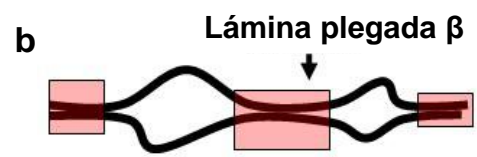

Hidratación intermedia, baja relación bucles/cadenas

C

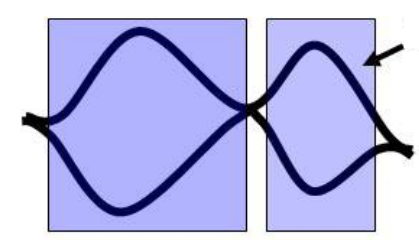

Giros $\beta$

Alta hidratación alta relación bucles/cadenas

Figura 1.7. Deformación de los polímeros causada por la extensión de la red proteica. a) Configuración de equilibrio. b) Pequeña extensión de la red, sólo las regiones de bucles son deformadas. c) Gran extensión de la red, las regiones de bucles son aplastadas y los puentes 
hidrógeno se rompen lo cual permite que las cadenas se deslicen unas sobre otras (Adaptado de Belton, 1999).

Estas proteínas son capaces de absorber gran cantidad de agua y de constituir una red deformable, elástica y extensible que puede retener los gases durante la fermentación y posterior cocción. Durante el amasado se producen interacciones no sólo entre las proteínas y el agua para formar la red de gluten, sino también entre otros componentes de la harina como almidón, polisacáridos no almidonosos (arabinoxilanos, arabinogalactanos) y lípidos (fosfo y glicolípidos) (Carr y col., 1992; Bettge y Morris, 2000; Lee y col., 2001). Estas interacciones permiten obtener una matriz viscoelástica capaz de formar, tras la cocción, el producto con características únicas que conocemos como pan.

Hay dos factores determinantes de la calidad del gluten para panificación: la relación gliadinas/gluteninas y la calidad de las gluteninas. Cada una cumple diferentes roles en la masa; mientras que las gluteninas otorgan resistencia a la deformación y elasticidad, las gliadinas actúan como plastificantes otorgando plasticidad y viscosidad (Belton, 1999 y 2003). Para obtener un pan de buena calidad se necesita un balance adecuado entre viscosidad y tenacidad.

Por otro lado se ha visto que es la fracción correspondiente a las gluteninas la que presenta mayor influencia en la calidad panadera, debido a que variaciones cualitativas y/o cuantitativas en sus subunidades ocasionan cambios en la misma ( $\mathrm{Ng}$ y Bushuk, 1988; Khan y col., 2002). Las variaciones en la composición de las subunidades pueden dar lugar a diferentes interacciones covalentes que son las que determinan la elasticidad de las mismas y a su vez, a diferentes estructuras poliméricas lo cual puede afectar su funcionalidad en el proceso de panificación. El grado de polimerización también es importante dado que según la teoría de polímeros, sólo los que superan un determinado tamaño podrían contribuir a la elasticidad (Singh y MacRitchie, 2001).

Otros componentes minoritarios pero importantes en la harina son los lípidos y las cenizas, entre otros. Los lípidos representan aproximadamente el 2,5\% de la harina; de los cuales el $1 \%$ son apolares y están formados por triglicéridos, diacilglicéridos, ácidos grasos libres y ésteres de colesterol; el 1,5\% restante son lípidos polares y están formados por glicéridos de galactosa $(0,6 \%)$ y fosfolípidos $(0,9 \%)$, los cuales forman complejos de inclusión con la amilosa. 
Las cenizas representan el contenido mineral de la harina. En el grano de trigo se hallan principalmente en las cubiertas externas y en el germen por lo que durante la molienda se reduce considerablemente su contenido en relación a las presentes en el grano. El contenido medio de cenizas de una harina es aproximadamente 0,5\% y esta conformado principalmente por $\mathrm{K}, \mathrm{P}, \mathrm{Mg}, \mathrm{Ca}, \mathrm{Na}, \mathrm{Zn}, \mathrm{Fe}, \mathrm{Mn}, \mathrm{Cu}$, Mo y Co (Czerniejewski y col., 1964).

Altos contenidos de cenizas pueden impartir un color oscuro al producto terminado por lo que se debe tener en cuenta en la elección de la harina (Wheat Marketing Center, 2008).

Existen también otras moléculas que se suelen incorporar a la harina que interaccionan con los diferentes componentes naturales ya presentes y con el agua; y que actúan como aditivos mejoradores de la calidad panadera o como ingredientes para mejorar la calidad nutricional del pan. En este trabajo de tesis esas moléculas son los FOS enriquecidos con inulina y diferentes sales de calcio.

\subsection{Proceso de Panificación}

A través del proceso de panificación se busca obtener un producto esponjoso y apetitoso a partir de la harina de trigo: el pan, el cual es uno de los alimentos procesados más antiguos y más ampliamente consumidos por la humanidad (Dewettinck y col., 2008).

La capacidad de la harina de trigo para formar una masa viscoelástica, determinada como ya mencionamos por las características de las proteínas de gluten, es la que permite la obtención del pan.

Las diferencias principales entre las distintas formas de panificación se encuentran en la mezcla, amasado, incorporación de aire, formación y desarrollo del gluten. La subdivisión de la masa y las etapas del proceso que afectan a las piezas individuales modifican la calidad del producto, aunque dicha calidad se genere durante el desarrollo de la masa. Los cambios deseables resultantes de un desarrollo óptimo de la masa están asociados a la capacidad de la masa de retener burbujas de gas $\left(\mathrm{CO}_{2}\right)$ y permitir, durante las fases de fermentación y horneado, la expansión uniforme de la pieza. Para mejorar la retención de gas es deseable obtener masas extensibles, además la reducción de la resistencia y elasticidad son importantes en la modificación de la estructura de las burbujas durante el proceso (Cauvain, 2002). 


\subsubsection{Amasado}

Durante la etapa de amasado los componentes de la harina de trigo son hidratados y como resultado de la entrega de energía mecánica se produce el desarrollo de la red de gluten, ocurriendo la disrupción de los aglomerados de las proteínas de gluten y transformándose en una red cohesiva y viscoelástica. Durante el amasado la presencia de agua y la realización de un trabajo mecánico permiten la hidratación de gliadinas y gluteninas y se produce el desarrollo de una red viscoelástica, el gluten. La cantidad y calidad del gluten determinan el tiempo necesario de amasado y las propiedades reológicas de la masa. Por otra parte, durante el amasado el almidón absorbe cerca del $40 \%$ del agua (Stauffer, 1998) y actuaría como relleno en la matriz de la masa contribuyendo a aumentar su viscoelasticidad. Se ha propuesto que en la masa el almidón y las proteínas del gluten se encontrarían formando fases diferentes (Tolstoguzov, 1997). En la harina de trigo podemos encontrar hasta un $15 \%$ de gránulos de almidón dañados, los cuales presentan grietas y fisuras producidas durante la molienda. Los gránulos dañados absorben hasta 4 veces más agua que los gránulos intactos y en la etapa de fermentación son más susceptibles a la acción de la enzima $\alpha$-amilasa por lo que modifican las características de la masa en la fermentación (Stauffer, 1998; Howitt y col., 2003; Hajšelová, 2003), ya que a partir de su hidrólisis se forma glucosa que servirá de sustrato para las levaduras. Los lípidos que se encuentran complejados con la amilosa no están disponibles para afectar el procesamiento durante el amasado. Mientras que los que se encuentran libres pueden interaccionar uniéndose al gluten o a la superficie de los gránulos de almidón. Los lípidos polares influyen en el comportamiento del pan en el horneado y en el volumen de pan obtenido ya que aumentan la retención de gas estabilizando los alvéolos de la miga. La mayor estabilidad se debe a la formación de una monocapa lipídica en la interfase gas/líquido de la masa (Sroan y col., 2009).

Los ácidos grasos poliinsaturados pueden ser oxidados por la lipooxigenasa dando lugar a radicales libres e hidroperóxidos que pueden oxidar a carotenoides y proteínas afectando al color de la miga y a las propiedades reológicas (Chung y col., 1978).

Además durante esta etapa se incorporan burbujas de aire. Al final del amasado la masa panaria tiene las características viscoelásticas óptimas para el procesado posterior (Belton, 2003).

La producción de una estructura alveolar definida en el pan depende de la formación y retención de burbujas de gas en la masa, fenómenos que se producen durante la fermentación (Gan y col., 1995). El $\mathrm{CO}_{2}$ presenta alta solubilidad, por lo que queda 
retenido en la fase acuosa y cuando ésta se satura pasa a los alvéolos (Maloney y Foy, 2003). Además, en la masa quedan atrapados durante el amasado $\mathrm{O}_{2}$ y $\mathrm{N}_{2}$. $\mathrm{El} \mathrm{O}_{2}$ se agota rápidamente porque es consumido por las levaduras y el $\mathrm{N}_{2}$ es importante ya que proporciona el núcleo de la burbuja a cuyo interior puede difundir el $\mathrm{CO}_{2}$ cuando abandona la solución. El número y tamaño de las burbujas de gas disponibles en la masa al final del amasado se encuentra influenciado por el método de formación de masa que se emplee y por las condiciones del amasado (Campbell, 2003) y a un adecuado balance entre el flujo viscoso y la fuerza elástica, que depende de las características del gluten.

Una vez que la masa está formada, se lamina para extender la estructura alveolar y reorientar a las proteínas del gluten. Luego hay que someter a la masa a una etapa de reposo que permite que la masa se relaje antes del moldeado; se busca la obtención de una masa a la vez, elástica y moldeable. Además, durante esta etapa se generan sustancias que contribuyen al aroma y sabor de la masa.

Luego del reposo, la masa se divide en piezas, dañando su red de gluten, se las somete a un proceso de boleado para restar el daño producido. A estas etapas suele seguirlas otro tiempo de reposo, durante el cual se continúan modificando las propiedades físicas y químicas de la masa. Luego se arman las piezas adquiriendo la forma del pan.

Existen resultados contradictorios en relación al efecto positivo o no de los arabinoxilanos en panificación. Los pentosanos solubles en agua influyen en la viscoelasticidad de la masa y los insolubles aumentan la consistencia y dureza de la misma, disminuyendo estos últimos el tiempo de desarrollo y aumentando la resistencia a la extensión.

\subsubsection{Fermentación}

El objetivo de la fermentación es permitir que la pieza ya moldeada se relaje y expanda para que se forme una pieza aireada de masa que, cuando se hornee, tenga la forma y el volumen requeridos. En la fermentación, como mencionamos anteriormente, también se producen cambios en la composición de la matriz debido a los productos formados durante la misma como, etanol y $\mathrm{CO}_{2}$, por la acción de las proteasas y amilasas de la harina, y en el caso de que los hubiera, por la acción de los aditivos.

Durante la fermentación la red de gluten sigue experimentando cambios (disminuye su adhesividad y extensibilidad, pero se hace más elástica), y es determinante para la retención del gas formado durante la misma (Hoseney y Rogers, 1990) y en la etapa 
inicial del horneado, lo cual determina el volumen del pan y la estructura de la miga. Los pentosanos aumentarían la estabilidad de los alvéolos por incremento de la viscosidad de la fase acuosa (Hoseney y Rogers, 1990).

\subsubsection{Horneado}

La fase final de la fabricación de pan durante la cual se aplica calor, es el proceso que ocasiona una rápida expansión del gas en la masa, la eliminación de agua, la gelatinización del almidón y la agregación de las proteínas. Estas reacciones, junto a la formación de corteza transforman un trozo de masa en una pieza de pan. La transferencia de calor en una masa menos densa implica que el centro de la pieza puede alcanzar la temperatura requerida $\left(96^{\circ} \mathrm{C}\right)$ en menos tiempo.

Cuando se introducen las piezas en el horno, durante los primeros minutos, antes que mueran las levaduras, se genera la mayor cantidad de $\mathrm{CO}_{2}$ por lo que la masa continua expandiéndose y el gluten debe tener la capacidad de retener el gas que se está produciendo (Maloney y Foy, 2003).

Durante el horneado ocurre la gelatinización del almidón determinando de este modo el volumen alcanzado por el pan y contribuyendo a fijar la estructura alveolar de la miga (Eliasson, 2003). En esta etapa existen varios cambios a la vez en las proteínas: cambia la hidrofobicidad superficial, se produce un intercambio de puentes disulfuro y formación de nuevos enlaces disulfuro (Weegels y col., 1994). Debido a estos cambios, junto con los experimentados por el almidón, se forma la estructura del pan.

Luego del horneado resulta particularmente importante un período de enfriamiento, especialmente cuando el pan se envasa en rebanadas, para que no se rompa al cortarse y evitar el crecimiento de mohos que ocurriría de envasarse la pieza caliente (Pateras, 1998). La pérdida de humedad excesiva debe evitarse porque constituye una pérdida económica además de que acelerará el envejecimiento del pan.

Luego del enfriamiento, en el caso de producción industrial, se procede a envasar el producto. El material más común para realizar el envasado es el polietileno de baja densidad en forma de bolsa. Constituye una buena barrera frente al vapor de agua por lo que se previene la deshidratación, a la vez permite al consumidor ver el producto que está comprando.

De todos modos, y a pesar de la barrera impuesta con el envasado, durante el almacenamiento, el pan experimenta diversos cambios que van en detrimento de su calidad. Durante este período, el almidón es el mayor responsable del endurecimiento del pan debido al fenómeno de retrogradación (Pateras, 1998). El rol del gluten en el 
envejecimiento del pan no es claro aunque se ha encontrado que forma enlaces de hidrógeno con el almidón gelatinizado (Martin y Hoseney, 1991). Algunos autores postulan que durante el envejecimiento del pan los pentosanos tendrían un efecto positivo ya que debido a un efecto estérico interferirían con la asociación intermolecular de la amilosa y la amilopectina (Kim y D’ Appolonia, 1977a y b).

\subsubsection{Conservación y Vida Útil}

El pan fresco posee una corta vida útil, ya que durante el almacenamiento ocurren distintos cambios físicos y químicos conocidos como envejecimiento del pan. La metodología de masas congeladas permite evitar grandes pérdidas económicas causadas por el envejecimiento de los productos panificados y ofrece al consumidor un producto fresco, recién elaborado a toda hora del día (Matuda y col., 2005).

El congelamiento de la masa incluye principalmente el cambio de estado físico (solidificación) del agua; sin embargo, ésta es apenas uno de los componentes de la masa de pan. En la masa de pan puede identificarse una fase líquida (el agua libre) dispersa en una matriz sólida predominantemente amorfa, con eventuales estructuras cristalinas remanentes que provienen de la organización estructural de las moléculas de almidón. También se encuentran dispersas las células de levadura. Ésta es la estructura que será sometida a al proceso de congelación.

En la metodología de masas congeladas, luego de desarrollar la masa y formar las piezas de pan, éstas son congeladas hasta que el centro de las mismas alcanza los $-18{ }^{\circ} \mathrm{C}$. En los puntos de venta, las piezas de masa de pan son descongeladas, fermentadas y horneadas a medida que los productos son consumidos (Giannou y col., 2003). Sin embargo, durante el almacenamiento en estado congelado la calidad de la masa de pan se deteriora gradualmente (Inoue y Bushuk, 1992; Ribotta y col., 2001). Dos factores han sido identificados como posibles razones de la pérdida de calidad observada en los panes obtenidos a partir de masas congeladas: disminución de la producción de $\mathrm{CO}_{2}$ debido a la pérdida de la viabilidad y actividad de las levaduras, y la disminución de la fuerza de la masa.

La congelación de la masa reduce considerablemente la actividad de las levaduras. Diferentes autores mostraron que el congelamiento rápido redujo la capacidad de producción de gas y el número de células viables (Wolt y D'Appolonia 1984a y b; Autio y Sinda, 1992; Inoue y col., 1994).

Si bien gran parte del daño a las células se produce durante el proceso de congelación, las condiciones y el tiempo de almacenamiento en estado congelado afectan también las levaduras. 
El debilitamiento de la masa durante el almacenamiento en estado congelado puede deberse a una pérdida del grado de entrecruzamiento de la red de gluten, causada ya sea por las sustancias reductoras liberadas por las levaduras durante la congelación o por la acción mecánica de los cristales de hielo; o por una redistribución del agua.

La estructura del gluten está sujeta a estrés físico durante la congelación y descongelación. Varriano-Marston y col. (1980) indicaron que la formación de hielo contribuye al debilitamiento de la red de gluten, por lo que parte de la red proteica es escindida por la acción mecánica de los cristales. Además del daño que causa la congelación a la membrana celular de las levaduras, este proceso provoca la liberación de sustancias químicas componentes de las levaduras, particularmente sustancias reductoras, como el glutatión que pueden tener efectos nocivos sobre la estructura del gluten (Ribotta y col., 2003). Estas sustancias reductoras causan la reducción de los puentes disulfuro entre las proteínas del gluten (Belitz y Grosch, 1999). Otros mecanismos propuestos como causantes del debilitamiento de la masa son la redistribución del agua debido a la formación de hielo y la recristalización durante la congelación y el almacenamiento congelado (Inoue y Bushuk, 1991). Durante el proceso de congelación el agua es separada como hielo mientras que el gluten se deshidrata lentamente. Cuando la masa es descongelada y su temperatura supera $0{ }^{\circ} \mathrm{C}$, los cristales de agua funden pero el agua no regresa a su estado y lugar original en la matriz de gluten. La deshidratación del gluten tiene efectos negativos sobre la estructura de la masa y la calidad de los productos horneados (Nicolas y col., 2003). Si bien se sugirieron varias causas para explicar el debilitamiento de la masa, es muy probable que los cambios sean debido a una combinación de todas ellas.

\subsection{Mejora de la calidad nutricional del pan}

Para mejorar la calidad nutricional de los panes se les han agregado diversas fuentes de fibra, complementado la harina de trigo por otras de mayor cantidad y calidad proteica, con salvado como fuente de fibra insoluble y con agregado de diversos minerales como calcio y magnesio. Poco ha sido estudiada la calidad nutricional del pan por el agregado de calcio junto con el de fibra.

Para determinar si un alimento es prioritario, se debe conocer la disponibilidad promedio diaria para el consumo interno "per cápita" de algunos de los alimentos de la canasta familiar, mediante el análisis de las Hojas de Balance de Consumo aparente 
de alimentos, editadas por FAO (FAO, 1996). Si bien hay fluctuaciones en la capacidad de compra, la disponibilidad de alimentos básicos en Argentina ha sufrido pocas modificaciones en las últimas décadas, observándose que el trigo constituye el alimento principal de las dietas nacionales y las carnes en segundo lugar (Tabla 1.4) (FAO, 1996 y 2009).

Tabla 1.4. Consumo aparente promedio diario de los principales alimentos que componen la canasta familiar, en Argentina.

\begin{tabular}{llll}
\hline Período & $1992-1994{ }^{*}$ & $2000 \#$ & $2009 \#$ \\
& g/día/habitante & g/día/habitante & g/día/habitante
\end{tabular}

\begin{tabular}{llll}
\hline Harina de trigo & 302 & 317 & 251 \\
Carne de vaca & 177 & 164 & 148 \\
Carne de cerdo & 16 & 22 & 22 \\
Leche fluida + lácteos & 539 & 606 & 530
\end{tabular}

* FAO, Hojas de Balance de Alimentos, Colección FAO: Estadística número 131, Roma 1996. \# FAO, Hojas de Balance de Alimentos, Colección FAO, Roma 2000 y 2009.

Se consideran alimentos prioritarios aquellos que aportan, en total, hasta $80 \%$ de las Ingestas Diarias Recomendadas (IDR) de los nutrientes críticos (Haytowitz y col., 2002). La transformación de alimentos consumidos a nutrientes se ha realizado mediante el Programa SARA (SARA, 2005), basado en los datos de la Tabla de Composición de Alimentos de ARGENFOODS y la Base de Datos de LATINFOODS, teniendo en cuenta el consumo promedio de los alimentos de la tabla anterior. La comparación de la ingesta media diaria de los nutrientes con las ingestas diarias recomendadas permite calcular la cantidad promedio de nutrientes disponibles para el consumo y el porcentaje de cobertura de las Ingestas Recomendadas para la población adulta (Pita Martin de Portela, 2006). En la Tabla 1.5 puede observarse que los nutrientes probablemente deficitarios son calcio, hierro, zinc y vitamina A; mientras que de los demás habría disponibilidad de alimentos para permitir el consumo de cantidades adecuadas para cubrir las IDR (Valencia y col., 2013).

En el año 2003 se creó en nuestro país una Ley (Decreto № 597 - Poder Ejecutivo Nacional - Ley $\mathrm{N}^{\circ}$ 25.630) que estableció la obligación del enriquecimiento de la harina de trigo comercializada en el territorio nacional con hierro y vitaminas (tiamina, riboflavina, niacina y ácido fólico), por lo cual no se observa deficiencia de dichas vitaminas. 
Tabla 1.5. Ingesta promedio de los nutrientes prioritarios de Argentina y porcentaje de adecuación de las Ingestas Diarias Recomendadas del adulto.

\begin{tabular}{ccc}
\hline Nutrientes & $\begin{array}{c}\text { Ingesta promedio diaria } \\
\text { “per capita” }\end{array}$ & $\begin{array}{c}\text { IDR } \\
(\%)\end{array}$ \\
\hline Calcio & $775 \mathrm{mg}^{*}$ & 78 \\
Hierro & $19 \mathrm{mg} \mathrm{\&}$ & $\begin{array}{c}\text { Variable según } \\
\text { biodisponibilidad }\end{array}$ \\
Zinc & $16,5 \mathrm{mg}$ & $68-82^{\#}$ \\
Vitamina A & $410 \mu \mathrm{g}$ & 100 \\
Tiamina & $3,6 \mathrm{mg} \mathrm{\&}$ & 100 \\
Vitamina C & $69 \mathrm{mg}$ & 100 \\
Riboflavina & $2,2 \mathrm{mg} \mathrm{\&}$ & 100 \\
Niacina & $18 \mathrm{mg}$ & 100 \\
Folatos & $1081 \mu \mathrm{g} \mathrm{\&}$ & 100 \\
Proteínas & $106 \mathrm{~g}$ & 100 \\
Energía & $2544 \mathrm{Kcal}$ &
\end{tabular}

\& Considerando la harina enriquecida con Fe, tiamina, riboflavina, niacina y ácido fólico. \# Según las IDR de FAO para varones y mujeres.

Por otra parte, la Encuesta Nacional de Nutrición y Salud (ENNYS) de Argentina realizada en los años 2004-2005 en niños y mujeres entre 10 y 49 años, proporcionó, por primera vez, información representativa para el total del país, sus provincias y regiones geográficas (ENNYS, 2007). Los resultados evidenciaron que, en el caso de las mujeres, el calcio fue uno de los nutrientes más críticos, con $94,3 \%$ de mujeres que presentaron una ingesta menor a la IDR (de $1000 \mathrm{mg}$ para este grupo), independiente de su localización geográfica, situación socioeconómica o edad. En el caso de los niños menores de 2 años el $28 \%$ no cubrían la ingesta adecuada de este mineral, mientras que en el grupo de 2 a 5 años esta cifra llegaba al 45,6\%. Esos resultados evidencian que el calcio es uno de los nutrientes más críticos en mujeres y niños. Para las embarazadas son varios los nutrientes que por su elevado porcentaje de inadecuación requieren especial atención: hierro, calcio y zinc, entre los principales (Tabla 1.6).

Estos resultados evidencian los nutrientes conflictivos según el grupo poblacional considerado. Una dieta con aportes adecuados de calcio, a través de su incorporación a las harinas, contribuiría a controlar enfermedades causadas por deficiencia de dicho 
elemento como son la osteopenia y la osteoporosis (Berdanier, 1998). Este tipo de enfermedades se producen no sólo por la falta de calcio, sino también por una mala absorción del mismo que puede revertirse por acción de vitamina D (Eitenmiller y Landen, 1999), proteínas y lactosa.

Tabla 1.6. Porcentaje de individuos con ingesta inadecuada de energía, proteínas y nutrientes minerales. Total país (ENNYS, 2007).

\begin{tabular}{ccccc}
\hline & $\begin{array}{c}\text { Niños y niñas } \\
\text { de 6 a 23 } \\
\text { meses }\end{array}$ & $\begin{array}{c}\text { Niños y niñas } \\
\text { de 2 a 5 } \\
\text { años }\end{array}$ & $\begin{array}{c}\text { Mujeres } \\
\text { de 10 a 49 } \\
\text { años }\end{array}$ & Embarazadas \\
\hline Energía & 31,7 & 29,1 & 57,8 & 64,3 \\
Proteínas & 3,3 & 0,90 & 19,0 & 29,1 \\
Hierro & 19,8 & 3,1 & 19,4 & 59,3 \\
Calcio & 28,0 & 45,6 & 94,3 & 88,5 \\
Zinc & 11,6 & 4,2 & 33,5 & 52,1 \\
\hline
\end{tabular}

Solamente tener en cuenta la cantidad de nutrientes a adicionar en un alimento para paliar su deficiencia no indica que vaya a ser utilizado por el organismo. Por ello, es importante tener en cuenta el concepto de biodisponibilidad que informa acerca de "la proporción del nutriente ingerido que puede ser digerido, absorbido y metabolizado o utilizado por el organismo para los fines que le son propios" (Gordon y Peilett, 1992).

Los nutrientes ingeridos no existen aislados en el alimento y están sujetos a interacciones con otros nutrientes o componentes presentes naturalmente en la matriz alimentaria. El proceso digestivo debe permitir su transporte a través de la mucosa intestinal, pero las interacciones de nutrientes con otros compuestos de la dieta pueden modificar los procesos digestivos, inhibiendo o facilitando los procesos de transporte. Los nutrientes absorbidos deben ser capaces de ser transportados hasta los distintos tejidos para ser utilizados por el organismo y para que puedan participar en los procesos metabólicos en los que son necesarios. Además, la utilización depende de las interacciones en el organismo así como del estado de nutrición del individuo lo que implica que la biodisponibilidad representa la integración de una interacción entre la dieta y el individuo que la consume (Miller, 2000). Esas interacciones pueden modificarse durante el procesado y/o almacenamiento del alimento, afectando su digestibilidad, absorción y/o utilización y, por ende, su biodisponibilidad. 
Para evaluar la disponibilidad se pueden utilizar métodos in vitro o in vivo. Los métodos in vivo, pueden utilizar animales de laboratorio o realizarse en humanos. En ambos casos, varían en complejidad y costo, desde los clásicos estudios de balance hasta los más sofisticados con isótopos estables. Sin embargo, dependen del nutriente considerado y no evalúan en todos los casos la totalidad de los factores que determinan la biodisponibilidad (Drago y Valencia, 2008).

Los métodos in vitro pueden referirse a métodos para determinar la absorción o la biodisponibilidad de nutrientes de naturaleza orgánica (como proteínas, vitaminas, aminoácidos) y métodos que, en el caso de minerales, miden la solubilidad, la dializabilidad o la incorporación de micronutrientes en cultivos celulares. Actualmente, uno de los métodos más estudiados se basa en determinar la dializabilidad del elemento en estudio. El método de Miller y col. (1981), modificado por Wolfgor y col. (2002) incluye una digestión enzimática que simula el proceso fisiológico en condiciones controladas de $\mathrm{pH}$, la diálisis en un medio de $\mathrm{pH}$ regulado y la posterior cuantificación de los minerales en el dializado por espectrometría de absorción atómica. La dializabilidad mineral $\left(D_{M}\right)$ se expresa como porcentaje de cada mineral en el dializado en relación a su concentración en el digerido.

\section{Principales factores que condicionan la biodisponibilidad de minerales (FAO/WHO, 2001)}

- Forma química: Ej: hierro: hemínico/no hemínico (Cook y Reddy, 2001).

- Solubilidad: entre los factores que afectan la solubilidad de los minerales se incluyen la valencia, la presencia de otras especies iónicas libres, la presencia de aniones que contienen $\mathrm{O}_{2}$.

- Formación de complejos orgánicos/inorgánicos: dependientes del peso molecular, afinidad, constantes de estabilidad y solubilidad.

- Presencia de compuestos que actúan como ligandos, formando compuestos de coordinación, hidrólisis e hidratación. Pueden ser inhibidores: forman complejos insolubles, no absorbidos por su baja solubilidad y/o elevada constante de estabilidad (fitatos, polifenoles, entre otros) o potenciadores: forman complejos solubles, absorbibles por formar complejos que por su solubilidad y constante de afinidad permiten su transferencia a los receptores de la mucosa intestinal (entre los cuales se encuentran ácidos orgánicos y prebióticos).

- Actividad redox de otros componentes del alimento

- Interacción mineral-mineral (Reddy y Cook, 1997) 


\subsubsection{Hierro y zinc. Biodisponibilidad de minerales en alimentos}

La deficiencia de hierro ocupa el tercer lugar entre las nutricionales y se estima que afecta al 30\% de la población mundial (Trumbo y col., 2001); su incidencia es mayor en los países en vías de desarrollo, siendo los grupos más vulnerables los menores de 2 años, embarazadas, adolescentes y mujeres en edad fértil. En América Latina constituye, en general, la segunda carencia nutricional y la prevalencia puede alcanzar en ciertas poblaciones infantiles más de $80 \%$ (FAO, 2001). Su principal causa es la baja ingesta y/o biodisponibilidad de hierro de la dieta, asociada a la presencia de parasitosis intestinales, malnutrición proteico-calórica o aumento de las necesidades. La presencia en la dieta de componentes que afectan de modo variable la absorción del hierro hace que la ingesta no se correlacione con la biodisponibilidad y utilización, pudiendo existir anemia ferropénica pese a ingestas de hierro aparentemente adecuadas. Existen algoritmos para calcular la absorción y biodisponibilidad de hierro en función de la composición de la dieta, teniendo en cuenta la presencia de factores inhibidores (fitato, calcio, polifenoles, proteínas de soja y huevo), potenciadores (ácido ascórbico, aporte de carnes y Fe hemínico) y estado nutricional (en función de los niveles de ferritina sérica) (Hallberg y Hulthén, 2000).

Una de las estrategias propuestas para combatir las deficiencias de micronutrientes consiste en la fortificación/enriquecimiento de alimentos y/o administración de suplementos dietarios o hierro farmacológico. En esos casos es necesario elegir la fuente más adecuada del nutriente a utilizar, y, en el caso de alimentos, la formulación y los procesados que optimicen su biodisponibilidad potencial.

La biodisponibilidad del Zn depende de factores exógenos y endógenos. Dentro de los exógenos o dietarios la cantidad de Zn en la dieta, las proteínas, el calcio y el ácido fítico condicionan la cantidad de $\mathrm{Zn}$ absorbido. Este mineral es utilizado como cofactor de numerosas enzimas relacionadas con la utilización de la energía, la síntesis de proteínas y la protección oxidativa. Además juega un rol fundamental en la estabilización de ciertas macromoléculas y membranas celulares, regula la transcripción uniéndose a proteínas nucleares (dedos de zinc).

\subsubsection{Calcio. Biodisponibilidad en alimentos}

El organismo humano adulto contiene entre 850 y $1500 \mathrm{~g}$ de este mineral, que representan alrededor del 1,7\% del peso corporal. El $99 \%$ se encuentra localizado en 
el tejido óseo, formando junto con el fósforo un fosfato complejo, la hidroxiapatita $\left[\mathrm{Ca}_{10}\left(\mathrm{PO}_{4}\right)_{6}(\mathrm{OH})_{2}\right]$, depositada sobre una matriz proteica proporcionándole al esqueleto la fortaleza necesaria para que ejerza su función de órgano de sostén y el 1\% restante de este mineral se encuentra en fluidos y tejidos regulando distintas funciones fisiológicas como la contractilidad muscular, automatismo cardiaco y coagulación sanguínea entre otras.

Desde el nacimiento existe junto con el incremento de peso, un incremento del contenido de calcio corporal que permite alcanzar el valor máximo de masa ósea en la tercera década (humanos). Luego se mantiene con pocos cambios, hasta que alrededor de los 50 años comienza a declinar, con una mayor pendiente en la mujer que en el hombre. El pico de máxima densidad mineral ósea (DMO) depende de la ingesta de calcio durante la etapa de crecimiento y condiciona la pérdida posterior con el consiguiente deterioro de su resistencia y aumento del riesgo de fracturas (osteoporosis).

El calcio ingerido en los alimentos es ionizado en el medio ácido del estómago y en el intestino interacciona con las secreciones digestivas y con los demás componentes de la dieta, formando complejos con constantes de estabilidad y solubilidad dependientes del $\mathrm{pH}$ intestinal, que condicionan la absorción. Los factores que favorecen la solubilidad y la absorción son alguna proteínas, aminoácidos y péptidos, el ácido cítrico, la lactosa y algunos otros compuestos que forman complejos solubles o modifican el pH intestinal. La relación calcio/fósforo juega un papel muy importante en la absorción del calcio ya que el exceso de fósforo forma fosfatos de calcio de baja solubilidad. Los factores que disminuyen la absorción del calcio por formación de complejos insolubles son oxalato (Heaney y Weaver, 1989), fitato, ácidos grasos de cadena larga, fluoruro, fosfato, componentes de la fibra y cationes bivalentes que interaccionan por un mecanismo competitivo. El calcio que se mantiene soluble en todo el intestino delgado es absorbido por diversos mecanismos y es incorporado al tejido óseo conjuntamente con el fósforo formando la hidroxiapatita (Heaney y Recker, 1985; Bronner y Pansu D, 1999; Pita Martin de Portela, 2003).

Por todos estos motivos, la evaluación de la biodisponibilidad del calcio no es fácil y se asume que la absorción es sinónimo de biodisponibilidad (Gordon y Peilett, 1992). Existen trabajos que determinan la absorción en ratas y otros que aplican la dializabilidad "in vitro", proporcionando resultados que se pueden considerar aproximados para extrapolarlos al humano.

La absorción de Ca en una dieta mixta, aplicando el método de balance, se considera que oscila entre $30-40 \%$ en el adulto; aunque puede ser mayor en niños y adolescentes (Ross y col., 2010). 


\subsubsection{Hueso}

El hueso está compuesto por matriz orgánica (colágeno), matriz inorgánica (agua e hidroxiapatita) y células (osteoblastos, osteocitos y osteoclastos). Los huesos se pueden clasificar en largos, cortos y planos según la/las dimensiones que predomine.

Desde el punto de vista macroscópico, el tejido óseo se organiza en los huesos de dos formas diferentes. El tejido óseo esponjoso, sustancia esponjosa o hueso trabecular está compuesto por finos listones $u$ hojas, las trabéculas que se entrecruzan en distintas direcciones y forman un reticulado esponjoso cuyos espacios huecos intercomunicantes están ocupados por la médula ósea. Por el contrario, el tejido óseo compacto, sustancia compacta o hueso cortical forma, a simple vista, una masa compacta sin espacios visibles. Casi todos los huesos se componen de tejido óseo cortical y trabecular, aunque en cantidad y distribución muy variables de ambos tipos. Los huesos largos (por ej. tibia) se dividen en tres partes: epífisis, diáfisis y metáfisis (Figura 1.8). En éstos la diáfisis se compone de tejido óseo compacto que, al igual que un tubo de paredes gruesas rodea el espacio medular. Por el contrario, los extremos de los huesos largos o epífisis se componen casi con exclusividad de tejido óseo esponjoso, que sólo en la parte más externa se transforma en una fina capa de tejido óseo compacto. Las superficies articulares están aquí recubiertas por una capa de cartílago hialino, el cartílago articular. El espacio medular de la diáfisis se comunica con los espacios de la sustancia esponjosa de las epífisis. Durante el período de crecimiento la diáfisis está separada de cada epífisis por un disco de cartílago, el disco epifisario, donde se produce el crecimiento longitudinal del hueso. Además de las superficies articulares recubiertas por cartílago, los huesos están rodeados por una capa de tejido conectivo denso, el periostio. Una delgada capa interior de tejido conectivo rico en células, el endostio, recubre el espacio medular y los espacios de la sustancia esponjosa. (Ross y Pawlina, 2007). 


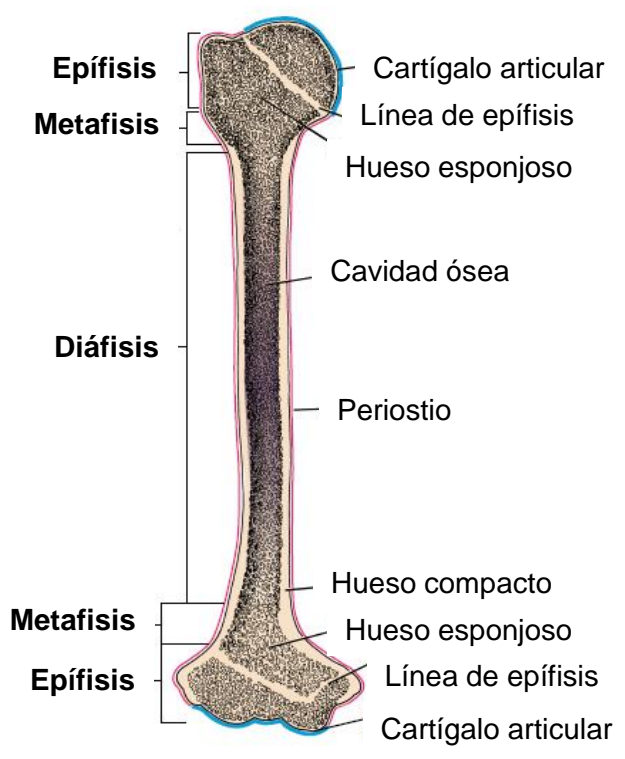

Figura 1.8. Estructura típica de hueso largo. (Adaptado de Ross y Pawlina, 2007).

El calcio del hueso está en equilibrio dinámico con el plasmático, mediante un proceso continuo de formación y resorción ósea. La masa ósea está determinada por factores genéticos, hormonales, nutricionales y por la actividad física.

\subsubsection{Mecanismo de formación, desarrollo y resorción (o remodelación) de huesos}

\section{Formación}

La formación de hueso (Figura 1.9) durante la etapa fetal del desarrollo se produce por dos procesos: a) osificación intramembranosa, principalmente en los huesos planos, que consiste en el desarrollo del centro de osificación, calcificación, formación de trabéculas y desarrollo de periostio; b) osificación endocondral, que ocurre principalmente en huesos largos y comprende el desarrollo del modelo de cartílago, crecimiento del mismo, desarrollo del centro de osificación primario (desarrollo fetal, comienza la calcificación del cartílago y se forma la diáfisis), desarrollo del centro de osificación secundaria (luego del nacimiento, se forma la epífisis). La diáfisis y la epífisis de un hueso largo están separadas por una zona de crecimiento del cartílago. Cuando el niño alcanza la madurez esquelética, todo el cartílago se sustituye por hueso y se produce la fusión de la diáfisis y la epífisis y luego tiene lugar la formación de cartílago articular y la placa epifisaria. En una etapa posterior la epífisis cartilaginosa, luego de la calcificación y la deposición ósea, se convierte en hueso. 


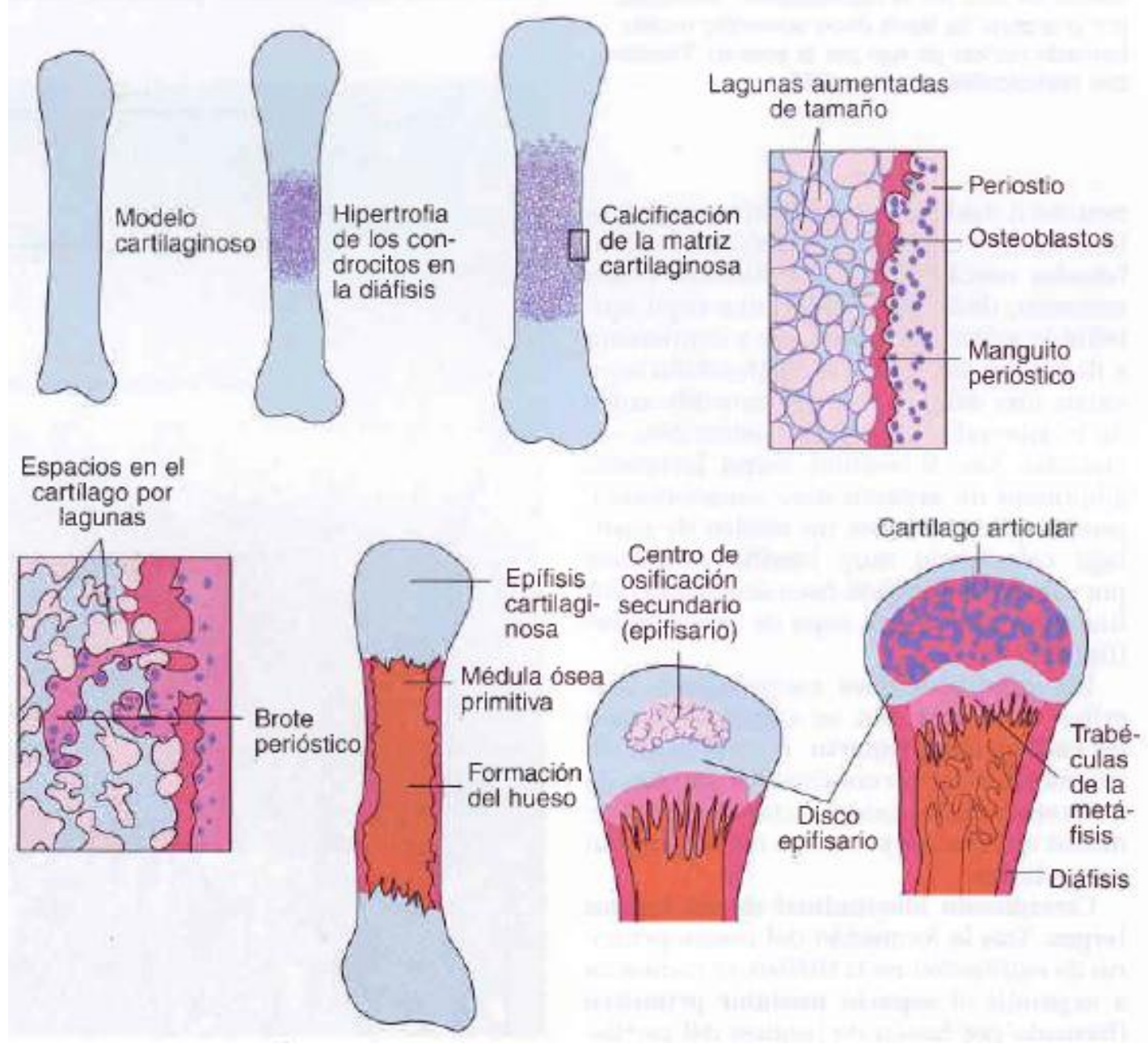

Figura 1.9. Osificación endocondral de hueso largo. (Adaptado de Geneser, 2004).

\section{Remodelación}

Remodelación o el recambio óseo es el proceso de resorción seguido por el reemplazo de hueso con poco cambio en la forma y se produce durante toda la vida de una persona. Los osteoblastos y osteoclastos, acoplados entre sí a través de la señalización celular paracrina, se conocen como unidad de remodelación ósea. Aproximadamente el $10 \%$ de la masa del esqueleto de un adulto se remodela cada año. El objetivo de la remodelación es la de regular la homeostasis del calcio, y también para dar forma y esculpir el esqueleto durante el crecimiento (Geneser, 2004).

\section{Volumen óseo}

El volumen óseo se determina por las tasas de formación de hueso y la resorción ósea. Resulta del equilibrio entre la formación y la remodelación, cuando la primera predomina sobre la segunda se produce un incremento del volumen óseo. La 
formación de hueso depende de varios factores de crecimiento producidos por las células óseas, para el almacenamiento en la matriz extracelular ósea. Estos factores de crecimiento de la matriz ósea, causantes de la proliferación de precursores de osteoblastos, actúan como potenciales determinantes de la formación de hueso local (Geneser, 2004).

Debido a que en nuestro país la deficiencia de calcio es crítica en gran parte de la población se fortificará con calcio la harina para la obtención de panes nutricionalmente enriquecidos en este mineral.

\subsubsection{Fortificación de alimentos}

La fortificación de alimentos requiere el cumplimiento de requisitos mínimos para que su implementación logre las metas nutricionales deseadas. Los criterios generales enunciados por el Food and Nutrition Board de la National Academy of Sciences (Trumbo y col., 2001) para llevar a cabo la fortificación/enriquecimiento de alimentos son:

- Comprobación de que la ingesta de un nutriente está por debajo del nivel deseable en las dietas de un número significativo de personas.

- El alimento a fortificar, elegido como vehículo, debe ser consumido en cantidades que aseguren un aporte significativo y constante en las dietas de las poblaciones que presentan una ingesta insuficiente del nutriente en cuestión.

- La fortificación no debe crear desequilibrio de nutrientes esenciales.

- Los nutrientes agregados deben ser fisiológicamente disponibles en el alimento fortificado.

- El alimento fortificado debe ser estable en condiciones de almacenamiento y uso normales.

- Existencia de seguridad razonable de que no ocurra ingesta excesiva o efectos adversos.

Se debe tener en cuenta que la formulación y el procesado pueden influir en forma positiva en la biodisponibilidad de los minerales (Hotz y Gibson, 2007). Una formulación adecuada puede incrementar los nutrientes biodisponibles a través no sólo de la fortificación, sino también de la incorporación de potenciadores de absorción, la 
eliminación de inhibidores y la prevención de interacciones negativas (Drago y Valencia, 2008).

\section{Sales de calcio}

Durante la molienda de trigo, se pierde una alta proporción de minerales, localizados principalmente en las capas más externas de aleurona, resultando en una reducción en el valor nutricional de la harina. Los nutrientes removidos durante la molienda (tiamina, niacina, hierro, entre otros) pueden ser reincorporados a todos los tipos de harinas, sin que dicha adición resulte nociva para la salud humana. Esta pérdida de minerales puede ser compensada mediante la fortificación de la harina en forma directa con sales minerales que contengan diferentes iones (calcio, magnesio, hierro) (Rosell, 2003). Teniendo en cuenta esta tendencia al consumo de alimentos más naturales y nutritivos, se puede profundizar aún más el estudio del beneficio del agregado de ingredientes nutricionales a las harinas, como minerales y fibra.

Dado que el contenido de calcio intrínseco de las harinas blancas, y por ende, de los panes elaborados con ellas, es muy bajo, el aporte a la dieta global en nuestro país es ínfimo. En varios países europeos y americanos las harinas se enriquecen con calcio, con niveles que oscilan entre 1100 y 2500 ppm, siendo esta adición obligatoria en algunos casos y optativa en otros. Se estima que en tales condiciones, según el nivel de adición y el consumo de panificados, estos productos podrían aportar entre el 10 y el $30 \%$ de las ingestas diarias recomendadas. Los panes fortificados con calcio resultan de esta forma, una alternativa interesante para proveer este mineral a la población.

Las tres sales de calcio utilizadas en este trabajo de tesis integran la lista positiva de ingredientes alimentarios cumpliendo con las exigencias establecidas por las normas locales (CAA, 2013) y responden a las exigencias de pureza establecidas por el codex alimentarius (FAO/OMS, 2013) y por el código de sustancias químicas para alimentos (FCC; Food Chemical Codex).

\section{Carbonato de calcio}

El carbonato de calcio es una sal de calcio inorgánica cuya fórmula química es $\mathrm{CaCO}_{3}$, la masa molecular relativa es 100,1 . Es un polvo blanco, fino, microcristalino, inodoro, insípido y estable al aire. Aporta un 40\% de calcio.Su numeración es E-170(i) según el INS (International Numbering System, Codex Alimentarius FAO/OMS). 


\section{Citrato de calcio}

El citrato tricalcico es una sal orgánica cuya fórmula químicas $\mathrm{Ca}_{3}\left(\mathrm{C}_{6} \mathrm{H}_{5} \mathrm{O}_{7}\right)_{2} \cdot 4 \mathrm{H}_{2} \mathrm{O}$, y su estructura química se muestra en la Figura 1.10. La masa molecular relativa es 570,5. Es un polvo blanco, fino e inodoro. Aporta un $21 \%$ de calcio. Su numeración es E-333 (iii) según el INS (International Numbering System, Codex Alimentarius FAO/OMS). Esta sal de calcio posee diversas funciones como secuestrante y acidulante. Se debe emplear con precaución ya que puede provocar efector adversos como urticaria. En grandes cantidades puede causar pequeñas ulceras en la membrana mucosa de la boca y puede erosionar los dientes.<smiles>C=C([O-])C(O)(CC(=O)[O-])CC(=O)[O-]</smiles><smiles>O=C([O-])CC(O)(CC(=O)[O-])C(=O)[O-]</smiles>

Figura 1.10. Estructura química del citrato de calcio.

\section{Lactato de calcio}

El lactato de calcio es una sal orgánica cuya fórmula química es $\mathrm{Ca}\left(\mathrm{C}_{3} \mathrm{H}_{5} \mathrm{O}_{3}\right)_{2} . \mathrm{XH}_{2} \mathrm{O}$; se muestra en la Figura 1.11 la estructura química de esta sal. La masa molecular relativa es 218,22 (anhidra). Es un polvo cristalino o granuloso de color blanco o crema; casi sin olor, conteniendo 5 moléculas de agua de cristalización. Aporta un 18\% de calcio. Su numeración es E-327 según el INS (International Numbering System, Codex Alimentarius FAO/OMS). Su uso es inofensivo.<smiles>CC(O)C(=O)[O-]</smiles>

Figura 1.11. Estructura química del lactato de calcio. 
No sólo es importante la cantidad de calcio a utilizar sino también la disponibilidad; para aumentar este parámetro se le agregará prebiótico. Ambos contribuyen a que el pan sea un alimento funcional, a través de un mayor aporte de calcio y de fibra prebiótica. El CAA ha incorporado la definición de prebiótico en el art. 1390. A los fines de determinar si el pan es un alimento funcional el producto debería cumplir con las especificaciones dispuestas por el Ministerio de salud según la Disp. 2873 (21.05.2012).

\subsubsection{Fructo-oligosacáridos. Inulina}

Los hidratos de carbono (disacáridos, oligosacáridos y polisacáridos), nutrientes mayoritarios de la dieta, presentan una biodisponibilidad que depende de la posibilidad de ser absorbidos en el intestino delgado. Según sean o no hidrolizados en el tracto gastrointestinal, se clasifican en disponibles y no disponibles. Los disponibles (azúcares simples y almidón), que se caracterizan por tener uniones a entre sus monómeros, mientras que los no degradables (oligosacáridos y polisacáridos no almidón) constituyen la fracción indigerible, con uniones $\beta$, no hidrolizables, también llamada fibra dietaria. Estos compuestos no degradables, presentes en las estructuras vegetales, llegan intactos al intestino grueso, donde pueden ser sustratos de las enzimas bacterianas de la flora intestinal, provocando diferentes efectos fisiológicos en el huésped: sobre el funcionamiento intestinal, la colesterolemia, glucemia e insulinemia (Roberfroid, 1993).

Es creciente el interés de numerosos estudios que establecen la relación entre flora intestinal y salud. La posibilidad de modificar la microflora intestinal mediante algún componente de la dieta ha atraído la atención tanto de tecnólogos, industriales y científicos como por parte de los consumidores, porque de este efecto derivan efectos fisiológicos de importante repercusión en la salud humana. Esta capacidad de modificar la flora se conoce como efecto prebiótico y los prebióticos se definen como "ingredientes no digeribles de los alimentos que afectan beneficiosamente al huésped por una estimulación selectiva del crecimiento y/o actividad de una o un limitado grupo de bacterias en el colon" (Gibson y Roberfroid, 1995). Para que un componente sea incluido en la categoría de prebiótico se deberán cumplir dos criterios: 1) escapar de la digestión por las enzimas endógenas del tracto digestivo humano (componente resistente); 2) ser fermentado selectivamente por las bacterias sacarolíticas de la microflora colónica (Bifidobacterias y Lactobacillus). Estas bacterias intestinales 
metabolizan en forma rápida estos oligosacáridos y polisacáridos, produciendo ácidos grasos de cadena corta (butírico, acético y propiónico) que bajan el pH en el lumen del intestino grueso. Las Bifidobacterias y Lactobacillus son resistentes al medio ácido mientras que las bacterias perjudiciales, como el Clostridium, son sensibles a las condiciones ácidas.

Dentro de los hidratos de carbono no disponibles, es importante señalar a los fructanos, como la inulina, polisacárido de reserva presente en diversos vegetales y también obtenidos industrialmente a partir de fuentes naturales, como la raíz de achicoria, o sintéticamente a partir de sacarosa. Existen estudios que muestran evidencia promisoria de que la inulina y fructo-oligosacaridos (FOS) aumentan la absorción de calcio, magnesio y hierro en humanos (Coudray y col., 1997 y 2003). Además la inulina tiene una larga historia de uso por los diabéticos, y de hecho, se ha informado que beneficia a los diabéticos en altas dosis (40-100mg/día) (Niness, 1999). El ácido butírico formado, tiene un efecto protector de la mucosa colónica, aumentando la proliferación de células normales y produciendo mayor secreción de mucina, una barrera que puede proteger a las células epiteliales del ataque de compuestos reactivos (Pool-Zobel y col., 2002).

La inulina es un carbohidrato de reserva energética presente en más de 36.000 especies de plantas (Flickinger y col., 2003). Entre las especies de plantas que producen fructanos se identifican las del grupo Liliaceae (ajo, cebolla, espárrago) y Compositae (achicoria, pataca o tupinambo y yacon). Son pocas las especies apropiadas para obtener este carbohidrato a nivel industrial, siendo la más común Cichorium intybus (achicoria).

Químicamente, está constituida por moléculas de fructosa unidas por enlaces $\beta-(2 \rightarrow 1)$ fructosil-fructosa, siendo el término "fructanos" usado para denominar este tipo de compuestos (Watherhouse y Chatterton, 1993; Roberfroid, 2005a). En la inulina las cadenas de fructosa tienen la particularidad de terminar en una unidad de glucosa unida por un enlace $\alpha(1 \rightarrow 2)$ (Flamm y col., 2001) (Figura 1.12), aunque también pueden terminar con una fructosa (Roberfroid, 1999). 


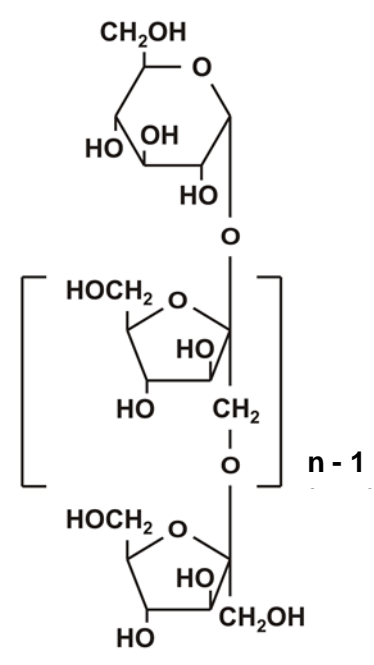

Figura 1.12. Estructura química de la inulina con una molécula terminal de glucosa ( $\alpha$-Dglucopiranosil).

Los fructanos más ampliamente estudiados y de mayor uso a nivel industrial son la inulina, la oligofructosa y los FOS (Biedrzycka y Bielecka, 2004). Se caracterizan por sus enlaces de tipo $\beta(2 \rightarrow 1)$ entre las unidades de fructosa, con un grado de polimerización que varía entre 2 y 60 unidades (Biedrzycka y Bielecka, 2004), y se les considera carbohidratos de cadena corta o de bajo nivel de polimerización (Englyst y Hudson, 1996; Roberfroid, 2000 y 2005b).

Tanto la inulina, como la oligofructosa y los FOS presentan una estructura polimérica predominantemente lineal. Las diferencias radican en el grado de polimerización, siendo la inulina el compuesto con el mayor rango y promedio. En la Tabla 1.7 se presenta una comparación entre los tres compuestos fructanos. Las diferencias estructurales entre ellos condicionan sus características físicas y químicas, y las propiedades que determinan su uso como ingrediente.

Tabla 1.7. Comparación del grado de polimerización de los diferentes fructanos.

\begin{tabular}{cccc}
\hline Origen & Inulina & Oligofructosa & FOS \\
\hline Rango GP & $2-60$ & $2-9$ & $2-4$ \\
GP $_{\text {prom }}$ & $10-12$ & $3-7$ & $3-7$ \\
\hline
\end{tabular}

GP: grado de polimerización 
Los FOS y la oligofructosa son muy similares, pero con diferencias estructurales asociadas a sus diferentes orígenes (hidrólisis enzimática de inulina para la oligofructosa y transfructosilación de sacarosa para los FOS).

Los fructanos por su configuración química no pueden ser hidrolizados por las enzimas digestivas del hombre, por lo que permanecen intactos en su recorrido por la parte superior del tracto gastrointestinal, pero son hidrolizados y fermentados en su totalidad por las bacterias (Bifidobacterias y Lactobacillus) de la parte inferior del tracto gastrointestinal (intestino grueso, colon). De esta manera, este tipo de compuestos se comportan como fibra dietética (Gibson y Roberfroid, 1995; Flamm y col., 2001; Slavin, 2003). El Codex Alimentarius definió la fibra dietética como el material que precipita en solución de etanol, de acuerdo con los métodos clásicos de análisis (Prosky y Hoebregs, 1999). Pero estos métodos no cuantifican aquellos compuestos que cumplen con las definiciones más recientes de fibra dietética, ya que éstos no precipitan en medio acuoso de etanol.

El Synergy1® (Beneo-Orafti, Bélgica) es una combinación de oligofructosa e inulina en una proporción de 70:30 en peso. Es un polvo blanco, con olor y sabor dulce, aportado por el FOS. Como son moléculas relativamente pequeñas (peso molecular aproximado de 6.000), en comparación con otros compuestos convencionalmente aceptados como fibra dietética (peso molecular entre 10.000 - 50.000), no precipitan completamente en solución de etanol, pues son solubles o parcialmente solubles en dicho solvente.

El uso de FOS enriquecidos con inulina aporta beneficios a la salud: a) provocan la disminución de los niveles lipídicos y glucosa en sangre y la acción laxante; b) poseen la capacidad de la inulina de modular la flora intestinal (Roberfroid, 1993; Gibson y col., 1995; Rastall y col., 2000).

Los prebióticos, como la inulina y la oligofructosa, están ganando atención debido a que mejoran la absorción de minerales de la dieta, el contenido mineral óseo (CMO) y la estructura del hueso (Harrington y col., 2001; Scholz-Ahrens y Schrezenmeir, 2007).

Se han descripto distintos mecanismos del incremento de la absorción de minerales mediados por FOS. Al descender el pH, el mineral es más soluble en el lumen del intestino y de esta forma es más fácilmente absorbido por las células de la mucosa intestinal (Ohta y col., 1995). Se producen modificaciones en la arquitectura de la mucosa intestinal (ensayos con ratas) que surgen como consecuencia el aumento del número de células y el número de las criptas; estas modificaciones podrían contribuir 
a un aumento en la superficie de absorción para la absorción del mineral (Kleessen y col., 2003).

Younes y col. (2001) estudiaron el efecto de la inulina y almidón resistente en la fermentación del intestino de ratas reportando un incremento en la absorción y balance de $\mathrm{Ca}$ y $\mathrm{Mg}$, sin alterar la concentración en plasma de ambos minerales. La inulina agregada a la dieta aumenta la retención de calcio en el cuerpo entero (Raschka y Daniel, 2005) y afecta positivamente la mineralización de los huesos (Zafar y col., 2004; Bosscher y col., 2006).

En los últimos años se han realizado algunos estudios relacionados con la incorporación de minerales (Ranhotra y col., 1997, 2000) y prebióticos (Praznik y col., 2002, Wang y col., 2002, O’ Brien y col., 2003) a harinas de cereales para panificación, pero queda mucho aún por dilucidar acerca de la relación existente entre la calidad panadera (volumen, relación de forma) de las piezas, la aceptabilidad sensorial por parte de los consumidores y la biodisponibilidad de los nutrientes agregados. Se han descrito ya mecanismos mediante los cuales la inulina y la oligofructosa influyen en la absorción del calcio (Scholz-Ahrens y col., 2002; Weaver, 2005), pero no con matrices panarias.

En algunos países desarrollados en los que se considera que la ingesta de calcio de la población es adecuada, se ha cuestionado la fortificación de la harina con calcio debido al efecto negativo que puede tener sobre la absorción de otros minerales como el hierro y el zinc. Por ello, resulta de gran interés indagar sobre las interacciones entre minerales, a distintos niveles de fortificación con calcio en productos panificados. 


\section{OBJETIVOS}

\section{Objetivos Generales}

- Realizar un estudio integral de la calidad de panes elaborados con harina de trigo fortificada con calcio e inulina como fibra prebiótica.

- Generar los conocimientos básicos que contribuyan al desarrollo industrial de panes funcionales.

\section{Objetivos Específicos}

- Evaluación del efecto de las diferentes sales de calcio y FOS enriquecido con inulina, en diferentes niveles, sobre las propiedades de hidratación de las mezclas con harina de trigo. Caracterización reológica y estructural de las masas.

- Estudio de las propiedades térmicas de las masas y su efecto en la calidad de los diferentes panes.

- Análisis de la vida útil de los panes por evaluación de la retrogradación del almidón.

- Optimización de los factores (sal de calcio y FOS enriquecido con inulina) para la obtención de panes óptimos de calidad aceptable.

- Estudio del efecto de la congelación en las propiedades de hidratación y reológicas de la masa, y en la calidad panadera de panes obtenidos a partir de la misma.

- Evaluación nutricional in vitro (dializabilidad) e in vivo (biodisponibilidad) del pan fortificado con calcio y FOS enriquecido con inulina. 


\section{CAPÍTULO 2}




\subsection{Materiales}

\subsubsection{Harina de trigo}

Las harinas de trigo (Triticum spp) empleadas en esta tesis fueron tipificadas como tipo 0000 (Código Alimentario Argentino, CAA) y obtenidas durante las cosechas 2009 y 2010, fueron donadas por Molino Campodónico Ltda. (La Plata, Argentina). Esta harina de trigo fue enriquecida según Ley 25.630 (Decreto Reglamentario № 597/2003 sobre Prevención de las anemias y malformaciones del tubo neural sancionada el 31/07/2002 y promulgada el 22/08/2002); adicionándole sulfato ferroso, niacina, ácido fólico y vitaminas $B_{1}$ y $B_{2}$.

Los parámetros alveográficos de la harina empleada para la realización de las masas (cosecha 2009), proporcionados por el Molino, fueron: $P=113 \mathrm{~mm}$ de $\mathrm{H}_{2} \mathrm{O}, \mathrm{L}=62$ $\mathrm{mm}, \mathrm{W}=279.10^{-4} \mathrm{~J}$ y los parámetros de la harina utilizada en los ensayos de panificación (cosecha 2010) fueron: $\mathrm{P}=132 \mathrm{~mm}$ de $\mathrm{H}_{2} \mathrm{O}, \mathrm{L}=47 \mathrm{~mm}, \mathrm{~W}=264.10^{-4} \mathrm{~J}$.

Durante el período de duración del trabajo de tesis, la harina fue fraccionada en recipientes plásticos con cierre hermético $(5 \mathrm{~kg})$ y conservada en cámara a $-18^{\circ} \mathrm{C}$.

\subsubsection{Sales de calcio}

\section{Carbonato de calcio}

El carbonato de calcio $\left[\mathrm{CaCO}_{3}\right.$ ] empleado, denominado $\mathrm{CaCO}_{3}$ de aquí en adelante, fue marca Anedra S.A (Argentina) con una pureza del 99\%.

\section{Citrato de calcio}

El citrato de calcio $\left[\mathrm{Ca}_{3}\left(\mathrm{C}_{6} \mathrm{H}_{5} \mathrm{O}_{7}\right)_{2} \cdot 4 \mathrm{H}_{2} \mathrm{O}\right.$ ] empleado, denominado $\mathrm{Ca}_{3} \mathrm{Cl}_{2}$ de aquí en adelante, fue marca Fluka S.A. (Argentina) con un $99,5 \%$ de pureza.

\section{Lactato de calcio}

El lactato de calcio $\left[\mathrm{Ca}\left(\mathrm{C}_{3} \mathrm{H}_{5} \mathrm{O}_{3}\right)_{2}\right]$ empleado, denominado $\mathrm{CaLA} \mathrm{A}_{2}$ de aquí en adelante, fue marca Sigma-Aldrich (Argentina) con una pureza del 98,1\%. 


\subsubsection{Prebiótico}

Se utilizó como prebiótico una mezcla de fructo-oligosacáridos (FOS) enriquecidos con inulina (In) en una proporción FOS:In de 70:30 (Synergy1®) donada por BENEO Orafti (Bélgica).

\subsubsection{Cloruro de sodio}

Se empleó cloruro de sodio marca CELUSAL, FINA corrediza (Argentina).

\subsubsection{Levadura}

La levadura utilizada en la elaboración de las masas empleadas para la optimización de los tiempos de fermentación y para la realización de los panes fue levadura fresca prensada marca CALSA S.A (Argentina).

\subsection{Métodos}

\subsubsection{Composición de la harina}

Se determinaron el contenido de humedad, proteínas, lípidos, fibra dietaria total, ceniza de ambas harinas según se describen a continuación. El contenido de hidratos de carbono se calculó por diferencia.

\subsubsection{Humedad}

La determinación de humedad se realizó a través del método indirecto. Se basa en la pérdida de peso de la muestra por evaporación del agua. Se realizó según método AACC 44-19 (2000), en el cual la muestra $(3 \pm 0,001) \mathrm{g}$ se seca en estufa (San Jor, Argentina) durante dos horas a $135^{\circ} \mathrm{C}$. El porcentaje de humedad se calculó por diferencia de peso medido antes y después del calentamiento de la muestra. El ensayo se realizó por triplicado.

El porcentaje de agua se calculó utilizando la ecuación 2.1 (Ec. 2.1) 


$$
H(\%)=\frac{\left(m_{1}-m_{2}\right)}{\left(m_{1}-m_{0}\right)} * 100
$$

donde:

$$
\begin{aligned}
& \mathrm{m}_{0}=\text { masa de capsula de Petri vacía }(\mathrm{g}) \\
& \mathrm{m}_{1}=\text { masa de capsula de Petri con la muestra húmeda }(\mathrm{g}) \\
& \mathrm{m}_{2}=\text { masa de capsula de Petri con sólidos luego del secado }(\mathrm{g})
\end{aligned}
$$

\subsubsection{Cenizas}

Se determinó el contenido de cenizas empleando método directo según AACC 08-01 (2000) basado en la oxidación completa de la materia orgánica, quedando las cenizas en el residuo. Se pesaron $(5 \pm 0,0001) \mathrm{g}$ de harina en cápsula de porcelana previamente calcinada y pesada. Se carbonizaron con mechero en triangulo de pipa y luego se calcinaron a $550{ }^{\circ} \mathrm{C}$ hasta obtención de residuo blanquecino y peso constante. La determinación se realizó por triplicado.

El calculó el contenido de cenizas utilizando la ecuación 2.2

$$
C(\%)=\frac{\left(m_{1}-m_{0}\right)}{m} * 100
$$

donde:

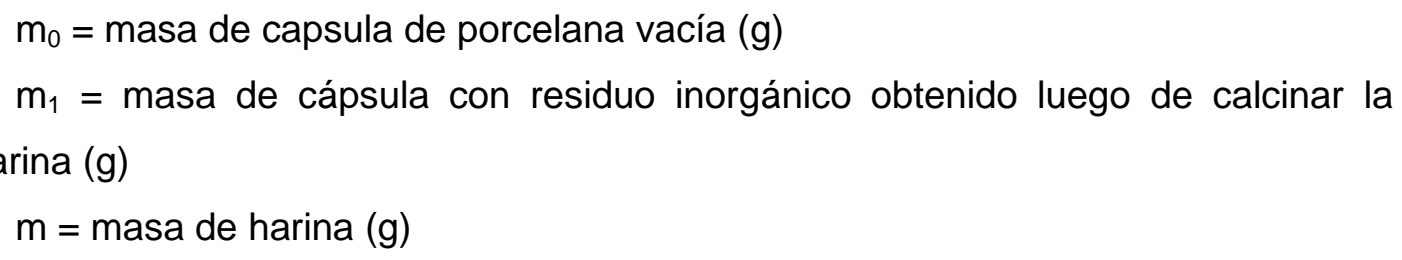

\subsubsection{Proteínas}

La determinación del contenido de proteínas se realizó por el método de Kjeldahl. En este método se determina el contenido de nitrógeno total. La digestión de la materia orgánica se realiza con $\mathrm{H}_{2} \mathrm{SO}_{4}$ concentrado p.a., en presencia de la mezcla catalizadora $\mathrm{K}_{2} \mathrm{SO}_{4}$ anhidro p.a. y $\mathrm{Cu}_{2} \mathrm{SO}_{4} \cdot 5 \mathrm{H}_{2} \mathrm{O}$ en relación 10:1 en un digestor (BÜCHI K-435, Suiza). Una vez finalizada esta etapa se procede a la liberación del 
amonio formado como amoniaco, empleando $\mathrm{NaOH} 32 \% \mathrm{p} / \mathrm{v}$ en un equipo semiautomático (BÜCHI K-350, Suiza), que se destila sobre $50 \mathrm{ml}$ de $\mathrm{H}_{3} \mathrm{BO}_{3} 4 \% \mathrm{p} / \mathrm{v}$ en presencia de indicador de Mortimer. Se valoró directamente el borato de amonio formado utilizando $\mathrm{HCl}$ 0,1032 N. Se realizó un blanco para evaluar la posible presencia de compuestos nitrogenados en los reactivos empleados.

El porcentaje de nitrógeno se calculó empleando la ecuación 2.3:

$$
N(\%)=\frac{\left(V_{m}-V_{b}\right)}{m} * N_{H C l}{ }^{*} P_{\text {meq }} * 100
$$

donde:

$$
\begin{aligned}
& \mathrm{V}_{\mathrm{m}}=\text { volumen de } \mathrm{HCl} \text { gastados en la titulación de la muestra }(\mathrm{ml}) \\
& \mathrm{V}_{\mathrm{b}}=\text { volumen de } \mathrm{HCl} \text { gastados en la titulación del blanco }(\mathrm{ml}) \\
& \mathrm{N}_{\mathrm{HCl}}=\text { normalidad del } \mathrm{HCl} \\
& \mathrm{P}_{\text {meq }}=\text { peso mili equivalente del nitrógeno }(\mathrm{g} / \mathrm{meq}) \\
& \mathrm{m}=\text { masa de la muestra }(\mathrm{g})
\end{aligned}
$$

Para estimar el contenido de proteínas se multiplicó el porcentaje de nitrógeno por el factor de conversión $f=5,71 \mathrm{~g}$ proteína/g nitrógeno, usualmente empleado para harina de trigo. Las determinaciones se realizaron por triplicado.

\subsubsection{Lípidos}

La determinación de lípidos se realizó por extracción semi-continua empleando una mezcla de solventes orgánicos para su extracción utilizando una modificación de la técnica AACC 30-25.01 (2000) en la cual se emplea el equipo de Soxhlet. Los lípidos de la harina fueron extraídos con mezcla de éter de petróleo (fracción 30-60) y éter dietílico en relación 1:1 llevándose a cabo unas siete sifonadas para lograr una extracción completa. Una vez finalizada la extracción se obtuvo gravimétricamente el extracto etéreo luego de evaporar el solvente. Las determinaciones se realizaron por triplicado.

El porcentaje de lípidos se calculó empleando la ecuación 2.4:

$$
L(\%)=\frac{\left(m_{1}-m_{0}\right)}{m} * 100
$$


donde:

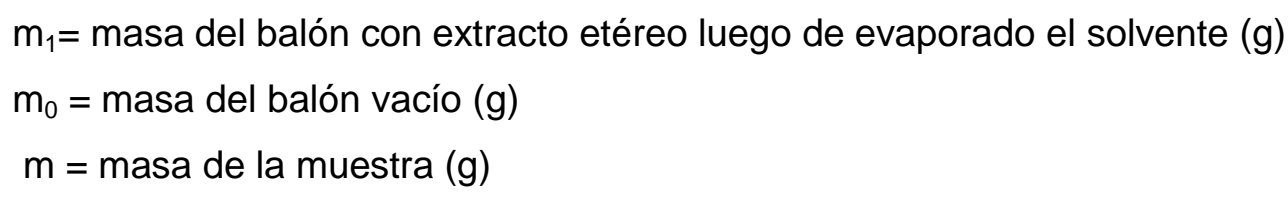

\subsubsection{Fibra dietaria total}

Se determinó el contenido de fibra dietaria total (FDT) de las harinas según AACC 3205 (2000), empleándose el método enzimo-gravimétrico. A la muestra $(1 \pm 0,001) \mathrm{g}$ de harina) se le adicionó buffer fosfato $\mathrm{pH}=6$, luego fue tratada con $\alpha$-amilasa termoestable a $100^{\circ} \mathrm{C}$ y digerida por vía enzimática con proteasa y amiloglucosidasa para eliminar las proteínas y el resto de almidón. Posteriormente, se precipitó la fibra dietaria (FD) por adición de etanol 95\% v/v y se reposó durante 1 hora. Transcurrido ese tiempo la FD fue filtrada y lavada en pasos sucesivos con etanol $78 \%$, etanol $95 \%$ y acetona pura, posteriormente fue secada $\left(105^{\circ} \mathrm{C}\right)$ y pesada. A uno de los residuos de FD se le determinó el contenido de cenizas incinerando la muestra a $550{ }^{\circ} \mathrm{C}$, y al otro se le determinó contenido de proteínas por el método de Kjeldahl.

La FDT (Ec. 2.8) se determinó como el peso de la fibra dietaria filtrada al que se le descontó el contenido de proteínas (Ec. 2.6) y cenizas (Ec. 2.7)

$$
\begin{gathered}
\operatorname{FD}(\%)=\frac{\left(m_{1}-m_{0}\right)}{m} * 100 \\
P(\%)=\frac{V_{m}{ }^{*} N_{H C l}{ }^{*} P_{m e q} * f}{\left(m_{1}-m_{0}\right)} * 100 \\
C(\%)=\frac{\left(m_{2}-m_{1}\right)}{\left(m_{1}-m_{0}\right)} * 100 \\
\text { FDT }(\%)=F D(\%)-[P(\%)+C(\%)]
\end{gathered}
$$

donde:

$$
\begin{aligned}
& \mathrm{m}_{1}=\text { masa del filtro junto con el residuo de fibra dietaria }(\mathrm{g}) \\
& \mathrm{m}_{0}=\text { masa del filtro con celite }(\mathrm{g}) \\
& \mathrm{m}=\text { masa de la harina }(\mathrm{g})
\end{aligned}
$$


$\mathrm{m}_{2}=$ masa del filtro con celite junto a las cenizas $(\mathrm{g})$

$\mathrm{V}_{\mathrm{m}}=$ volumen de $\mathrm{HCl}$ gastados en la titulación de la muestra $(\mathrm{ml})$

$\mathrm{N}_{\mathrm{HCl}}=$ normalidad del $\mathrm{HCl}$

$P_{\text {meq }}=$ peso miliequivalente del nitrógeno $(\mathrm{g} / \mathrm{meq})$

$f=$ factor de conversión de Kjeldahl

\subsubsection{Diseño experimental}

Con el objetivo de evaluar la posible interacción de la sal de calcio empleada y la inulina sobre la masa, así como también para optimizar la formulación sobre diferentes variables de calidad del pan se utilizó un diseño compuesto central (DCC).

El diseño compuesto central es un diseño experimental que consta de: a) una parte factorial, diseño $2^{k}$, donde $k$ indica la cantidad de factores codificados como \pm 1 ; b) una parte axial: dos puntos axiales en los ejes correspondientes a cada uno de los factores, situados a una distancia a del centro del diseño y c) replicado del punto central para estimar la suma de los cuadrados del error, formando una estrella (Figura 2.1). Si la distancia desde el centro del diseño a un punto factorial es de \pm 1 unidad para cada factor, la distancia desde el centro del espacio de diseño a un punto neutro es $\pm \alpha$ con $|\alpha|>1$.

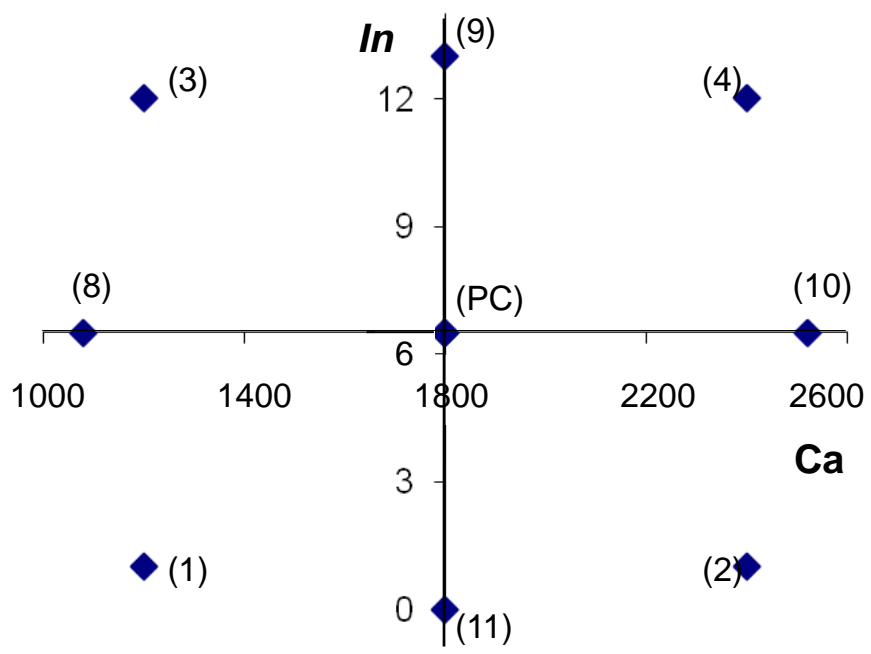

Figura 2.1. Diseño compuesto central empleado. Ca: ppm de calcio. In: $\%$ p/p inulina. PC: punto central.

En esta tesis se realizó un diseño compuesto central (Tabla 2.1) bifactorial. Los factores utilizados fueron: calcio $\left(X_{1}\right)$ y Synergy1 como fuente de inulina $\left(X_{2}\right)$. Se 
analizaron cinco niveles de cada factor y triplicado del punto central (PC) del diseño, dando lugar a 11 combinaciones. Se realizaron 3 diseños diferentes, uno para cada sal de calcio y se incluyó un control fuera de los diferentes DCC, sin inulina ni calcio agregado. El máximo nivel de Ca fue seleccionado de acuerdo a los niveles máximos permitidos de $\mathrm{Ca}$ a ser incorporados en el pan, en respuesta a la ingesta diaria recomendada de este mineral (USDA, 2008). Los niveles de inulina fueron seleccionados de acuerdo a la cantidad necesaria para asegurar la biodisponibilidad del Ca. Los niveles de calcio (ppm: miligramos de calcio/kg de harina) e inulina (\%: $\mathrm{g}$ In/100 g harina) seleccionados para el diseño experimental se muestran en la Tabla 2.1. Todas las muestras tuvieron además $2 \%$ de cloruro de sodio.

Tabla 2.1. Valores codificados y decodificados del DCC

\begin{tabular}{ccccc}
\hline & \multicolumn{2}{c}{ Codificados } & \multicolumn{2}{c}{ Decodificados } \\
\cline { 2 - 5 } Formulación & $\mathbf{X}_{\mathbf{1}}$ & $\mathbf{X}_{\mathbf{2}}$ & $\begin{array}{c}\text { Calcio } \\
\text { (ppm) }\end{array}$ & $\begin{array}{c}\text { Inulina } \\
(\%)\end{array}$ \\
\hline $\mathbf{1}$ & -1 & -1 & 1200 & 1 \\
$\mathbf{2}$ & 1 & -1 & 2400 & 1 \\
$\mathbf{3}$ & -1 & 1 & 1200 & 12 \\
$\mathbf{4}$ & 1 & 1 & 2400 & 12 \\
$\mathbf{5 ( P C )}$ & 0 & 0 & 1800 & 6,5 \\
$\mathbf{6}$ (PC) & 0 & 0 & 1800 & 6,5 \\
$\mathbf{7}$ (PC) & 0 & 0 & 1800 & 6,5 \\
$\mathbf{8}$ & $-1,2$ & 0 & 1080 & 6,5 \\
$\mathbf{9}$ & 0 & $+1,2$ & 1800 & 13 \\
$\mathbf{1 0}$ & $+1,2$ & 0 & 2520 & 6,5 \\
$\mathbf{1 1}$ & 0 & $-1,2$ & 1800 & 0 \\
\hline $\mathbf{C}$ & - & - & 0 & 0 \\
\hline
\end{tabular}

PC: punto central. C: control

Durante toda la tesis se codificarán las diferentes formulaciones empleando las dos primeras letras del nombre del anión con mayúscula seguido del número de la formulación. Ej. CA4: carbonato de calcio, formulación 4.

La metodología de superficie de respuesta (MSR), propuesta por Box y Wilson (1951), es un conjunto de técnicas matemáticas y estadísticas útiles para modelar y analizar problemas en los cuales una respuesta de interés es influida por varias variables, y el 
objetivo es optimizar esta respuesta (Montgomery, 1997; Khuri y Cornell, 1996). Diseños factoriales completos son la mejor estrategia para estudiar simultáneamente el efecto de varios factores sobre la respuesta de la muestra y para estimar la interacción entre ellos e incluso los efectos de segundo grado.

Se empleó el programa Statgraphics plus para Windows 5.1 para ajustar un modelo de segundo orden y generar el gráfico de superficie de respuesta. El modelo propuesto (Montgomery, 1997; Khuri y Cornell, 1996) para cada respuesta viene dado por la ecuación 2.9 (Ec. 2.9)

$$
\mathrm{Y}=b_{0}+b_{1} \mathrm{X}_{1}+b_{2} \mathrm{X}_{2}+b_{11} \mathrm{X}_{1}^{2}+b_{22} \mathrm{X}_{2}^{2}+b_{12} \mathrm{X}_{1} \mathrm{X}_{2}
$$

donde:

$$
\begin{aligned}
& Y: \text { variable respuesta estudiada } \\
& b_{0}: \text { valor de la respuesta ajustada en el punto central del diseño. } \\
& b_{1}, b_{2}: \text { términos de regresión lineal } \\
& b_{11}, b_{22}: \text { términos de regresión cuadrática } \\
& b_{12}: \text { términos de regresión correspondiente a la interacción } \\
& \mathrm{X}_{1} \text { : variable independiente codificada calcio } \\
& \mathrm{X}_{2} \text { : variable independiente codificada inulina }
\end{aligned}
$$

Las adecuaciones de modelo fueron verificadas a través de un análisis de varianza (prueba de F) y los valores de coeficiente de determinación $\left(R^{2}\right)$. También se calculó el error estándar de la estimación $\left(\mathrm{S}_{\mathrm{Cal}}\right)$ que mide la variabilidad o dispersión de los valores observados alrededor de la superficie de respuesta generada. Este error se calcula con la finalidad de medir la confiabilidad de la ecuación de la estimación. O sea que si $\mathrm{S}_{\mathrm{Cal}}$ es cero todos los datos experimentales están concentrados alrededor de la superficie obtenida por el modelo de regresión aplicado.

\subsubsection{Calidad panadera de las mezclas}

\subsubsection{Ensayo farinográfico}

Para determinar el comportamiento de las mezclas de harina durante el amasado se realizó un ensayo Farinográfico empleando un Farinografo de Brabender -300 g- 
(Brabender, Duigsburg, Alemania) según método 54-21, AACC (2000). Este equipo mide la fuerza realizada por las paletas durante el mezclado a velocidad constante y la absorción de agua necesaria para alcanzar la consistencia deseada. Esta técnica fue utilizada, no sólo para obtener los farinogramas de la harina, sino también los de la harina fortificada con minerales y prebiótico en las proporciones mencionadas en la Tabla 2.1.

Para este fin, se amasaron $300 \mathrm{~g}$ de muestra y una determinada cantidad de agua (necesaria hasta alcanzar la consistencia deseada) a velocidad constante registrando la resistencia que opone la masa al trabajo mecánico continuo en función del tiempo. El ensayo se realizó por duplicado.

A partir del diagrama de consistencia - Unidades Brabender (UB)- en función del tiempo (Figura 2.2), se obtuvieron los siguientes parámetros:

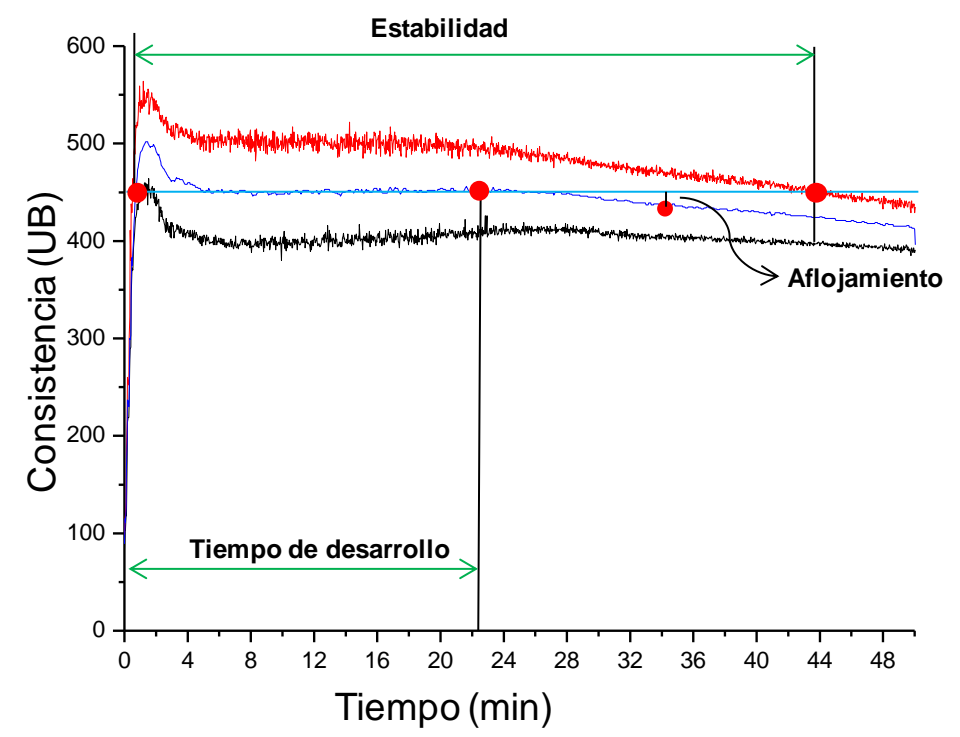

Figura 2.2. Farinograma obtenido experimentalmente.

- Absorción de agua (Ab): cantidad de agua destilada necesaria para que la masa alcance una consistencia determinada (500 UB). Se expresa como mililitros de agua cada 100 gramos de sólidos.

- Tiempo de desarrollo $\left(t_{d}\right)$ : tiempo que transcurre desde el comienzo del agregado de agua hasta la consistencia máxima (segundo pico). Se expresa en minutos.

- Estabilidad (Es): tiempo durante el cual la masa mantiene la máxima consistencia, desde el punto en que la parte superior de la curva impacta por primera vez la línea de 500 UB y el punto en que la deja. Se expresa en minutos.

- Aflojamiento (Af): mide la caída de la masa en UB, representa la diferencia entre 
la máxima consistencia y la que se obtiene 12 minutos después.

La mezcla con 2400 ppm de lactato de calcio $\left(\mathrm{CaLA}_{2}\right)$ y $12 \%$ de inulina (In) presentó un farinograma muy particular, por lo que fue seleccionada para observar mediante microscopía la microestructura en las diferentes etapas de mezclado. Los ingredientes sólidos junto con el agua (según $\mathrm{Ab}$ ) fueron mezclados en una amasadora planetaria comercial de pequeña capacidad (Kenwood Major, Italia) a $90 \mathrm{rpm}$. Se tomaron piezas cilíndricas de masa (4 mm de diámetro x $5 \mathrm{~mm}$ de alto) a diferentes tiempos $(8,16,29$, 45 y $100 \mathrm{~min})$ y se fijaron en solución de glutaraldehído $(2,5 \% \mathrm{v} / \mathrm{v})$ para analizarlas por microscopia electrónica de barrido (Scanning Electron Microscopy, SEM) como se describirá en la sección 2.2.8.2.

\subsubsection{Ensayo alveográfico}

Para evaluar las propiedades mecánicas de las masas obtenidas de las mezclas de harina de trigo y los nutrientes se utilizó el alveógrafo de Chopin (Villeneuve-laGarenne Cedex, Francia) empleando el método AACC 54-30 A (2000). El disco de masa es inflado con aire presurizado, simulando la deformación que esta sufre como consecuencia de los gases que se generan durante la fermentación y el horneado. El ensayo fue modificado, agregando igual cantidad de solución de cloruro de sodio $(2,5 \% \mathrm{p} / \mathrm{v})$ a todas las mezclas según la humedad de la harina. Se analizaron 5 discos de masas por cada formulación. Se midió la presión en el interior de la burbuja hasta la ruptura de la masa.

Se registró la fuerza necesaria para inflar y hacer estallar el globo de masa en función de la distancia. A partir del diagrama obtenido (Figura 2.3) se determinaron los siguientes parámetros:

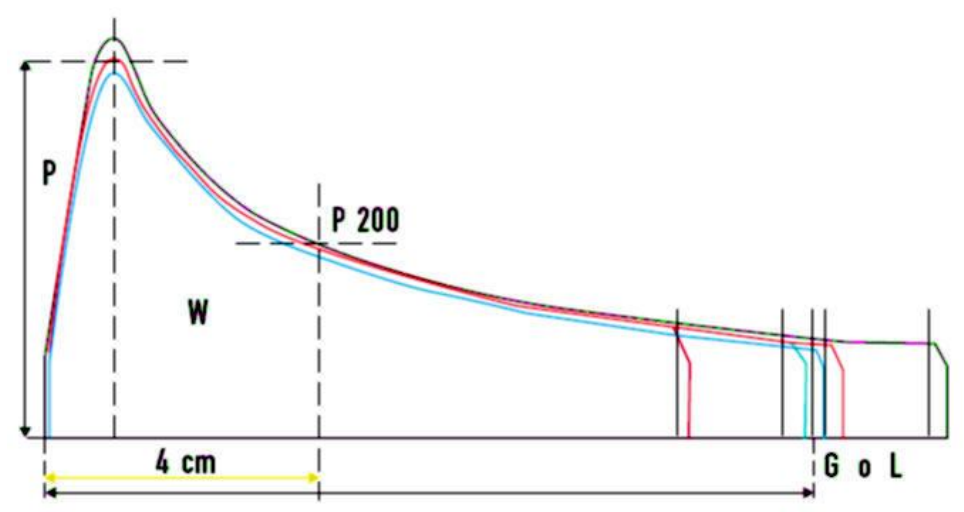

Figura 2.3. Alveograma obtenido de http://www.concereal.es/alveografo 
- Sobrepresión máxima o tenacidad (P): representa el valor de la presión máxima, relacionado con la resistencia de la masa a la deformación, cuanto mayor es la resistencia a la deformación mayor tenacidad. Se expresa en milímetros.

- Abscisa media a la ruptura o extensibilidad (L): representa la extensibilidad de la masa antes de la ruptura. Se expresa en milímetros.

- Relación P/L: balance entre la tenacidad y la extensibilidad de la masa.

- Trabajo de deformación (W): área bajo la curva del alveograma que representa la fuerza panadera. Se expresa en decimas de milijoule $\left(10^{-4} \mathrm{Joule}\right)$.

\subsubsection{Contenido de gluten}

Se determinó el contenido de gluten de las diferentes formulaciones de acuerdo al método AACC 38-12 (2000) modificado. La modificación consistió en formar la masa en una amasadora planetaria y emplear este equipo para el lavado de la masa. Esta modificación surge como consecuencia de que los tiempos necesarios para la formación de la masa obtenidos a través del farinograma son mayores al tiempo máximo que se permite amasar en el Glutomatic 2200 (Perten Instruments, Suecia). La cantidad de masa equivalente a colocar $10 \mathrm{~g}$ de harina se amasó durante 1 minuto y se lavó durante 5 minutos empleando malla metálica de $80 \mu \mathrm{m}$ de poro. El gluten obtenido se centrifugó empleando una centrifuga 2015 (Perten Instruments, Suecia) a 6000 rpm durante $1 \mathrm{~min}$. Se registró el peso del gluten húmedo total $\left(\mathrm{m}_{1}\right)$. Se calculó la cantidad de gluten húmedo $(\mathrm{GH})$ cada $100 \mathrm{~g}$ de harina, referido a una harina de $14 \%$ de humedad. Finalmente, el gluten se secó en condiciones estandarizadas a $150 \stackrel{\circ}{ } \mathrm{C}$ durante 5 minutos en el Glutork (Perten Instruments, Suecia) y se pesó luego de alcanzar temperatura ambiente. Se calculó el porcentaje de gluten seco (GS).

$$
\begin{aligned}
& G H(\%)=\frac{m_{1}}{m} * 100 * \frac{(100-14)}{(100-H)} \\
& G S(\%)=\frac{m_{2}}{m} * 100 * \frac{(100-14)}{(100-H)}
\end{aligned}
$$

donde:

$$
\begin{aligned}
& \mathrm{m}_{1}=\text { masa de gluten húmedo }(\mathrm{g}) \\
& \mathrm{m}_{2}=\text { masa del gluten seco }(\mathrm{g})
\end{aligned}
$$




$$
\begin{aligned}
& \mathrm{m}=\text { cantidad de masa pesada }(\mathrm{g}) \\
& \mathrm{H}=\text { humedad de la harina }(\%)
\end{aligned}
$$

\subsubsection{Elaboración de masa}

La formulación empleada en la elaboración de las masas consistió en harina de trigo, $\mathrm{NaCl}$ ( $2 \%$ base harina), sal de calcio e inulina según el diseño descripto en la sección 2.2.2 y agua destilada fría según la absorción farinográfica. Primero se mezclaron los ingredientes sólidos durante un minuto en una amasadora planetaria (Kenwood Major, Italia), luego se agregó el agua y se amasó durante el tiempo de desarrollo. El primer minuto se amasó a 50 rpm y el resto del tiempo a 90 rpm hasta completar el tiempo de desarrollo. La masa obtenida se la laminó (4 pasadas) en una laminadora manual con un espesor de $0,5 \mathrm{~cm}$ con el objeto de alinear los filamentos de gluten para así aumentar la fuerza de la masa. Una vez laminada, se la dejó reposar a temperatura ambiente durante 15 minutos tapada con film para evitar la deshidratación superficial. Una vez terminado el periodo de reposo, se estiró (1 cm de espesor) y se cortaron piezas de $3 \mathrm{~cm}$ con sacabocado cilíndrico para emplearlas en estudios posteriores.

\subsubsection{Congelación de masas}

Se realizaron ensayos de congelación de las masas de algunos niveles con el fin de evaluar los cambios que pueden ocurrir durante el congelado a $-18^{\circ} \mathrm{C}$. Se estudiaron las masas C, la 4 y la 11 de la Tabla 2.1 de los 3 diseños. Diferentes fracciones de masas, envueltas individualmente en film y colocadas en bolsa tipo ziploc fueron almacenadas en el freezer durante $1,7,30$ y 60 días. Una vez finalizado el almacenamiento se colocaron las porciones de masa sobre una bandeja en la fermentadora (Brito Hnos, Argentina) a $30 \stackrel{\circ}{\circ} 70 \% \mathrm{HR}$ (HR, humedad relativa) durante dos horas, tiempo en el que se logra completar el proceso de descongelación. Una vez alcanzado este tiempo se procedió a su análisis de igual forma que para las masas sin congelar.

A las masas congeladas sólo se les analizó el contenido de humedad, actividad acuosa, perfil de textura y ensayo reológico dinámico. 


\subsubsection{Propiedades de hidratación de las masas}

Se determinó a las masas la humedad, relacionada con la cantidad de agua en la muestra y la actividad acuosa, relacionada con la disponibilidad de agua. También se midió el $\mathrm{pH}$ de las masas vinculado con la concentración de protones del medio, el cual podría ser modificado dependiendo el tipo de sal de calcio utilizada.

\subsubsection{Humedad}

Se determinó el contenido de agua según se describió en la sección 2.2.1.1. La porción de masa fue estirada sobre la superficie de la placa de Petri formando una fina lámina con el fin de lograr una mayor superficie de evaporación.

\subsubsection{Actividad acuosa}

La actividad acuosa $\left(a_{w}\right)$, definida como el cociente entre la presión parcial del vapor de agua en equilibrio con el alimento y la presión del vapor de agua pura a una determinada temperatura, se analizó a $25^{\circ} \mathrm{C}$. Para su determinación se utilizó el equipo Meter AquaLab series 3 (Decagon Devices, Inc., Washington, Estados Unidos). Este instrumento mide la actividad acuosa basándose en la técnica del punto de rocío. Este ensayo se realizó por duplicado. Se empleó una solución de sulfato de potasio saturada como estándar de calibración.

\subsubsection{3. $\mathrm{pH}$}

Calaveras (2004) define el pH como el estado de la masa caracterizado por tener más iones hidrógenos, es decir más ácida. Se mide en $\left[\mathrm{H}^{+}\right]$. Se determinó el pH de las masas en ausencia de levadura, empleando un pHmetro (SevenMulti, Mettler Toledo, Estados Unidos) con un electrodo de punta especialmente diseñado para sólidos, el cual se introdujo $(2 \mathrm{~cm})$ dentro de la masa a $25^{\circ} \mathrm{C}$ en forma similar a lo descripto por Miller y col. (1994). Para una buena lectura es importante un buen contacto entre la masa y el electrodo.

Es importante conocer el $\mathrm{pH}$ de la masa debido a que valores entre 4 y 5,5 las levaduras tienen la máxima formación de gas. Esta determinación se realizó por 
duplicado sólo en masa fresca.

\subsubsection{Propiedades reológicas de las masas}

Se realizaron diferentes ensayos para estudiar el comportamiento reológico de las masas.

\subsubsection{Ensayo de textura}

Se empleó un texturómetro (TA.XT2i, Stable Micro System, Surrey, Reino Unido) utilizando el programa Texture Expert para Windows (v.1.2) para estudiar el comportamiento reológico de las masas aplicando grandes deformaciones.

\subsection{Análisis de perfil de textura}

Se realizó un análisis de perfil de textura (Texture Profile Analysis, TPA), que consiste en un ensayo de doble compresión con un tiempo de espera entre ellos (Bourne, 2002), sobre discos de masa obtenidos a partir de masas frescas y congeladas. Al disco de masa, colocado en un plato inferior que posee círculos concéntricos ranurados para reducir el deslizamiento, se lo sometió a un ciclo de doble compresión empleando una deformación del $40 \%$ de la altura original con una sonda de aluminio SMSP/75 (de 7,5 cm de diámetro) y una celda de $25 \mathrm{~kg}$. Se esperó $5 \mathrm{~s}$ entre ambos ciclos. La velocidad del ensayo fue de $0,5 \mathrm{~mm} / \mathrm{s}$. Se ensayaron 15 discos por cada formulación. Se registró la fuerza, expresada en newton, en función del tiempo, expresado en segundos obteniéndose un gráfico como el de la Figura 2.4, del cual se obtuvieron los siguientes parámetros (Bourne, 1978; Bourne, 2002; Steffe, 1996):

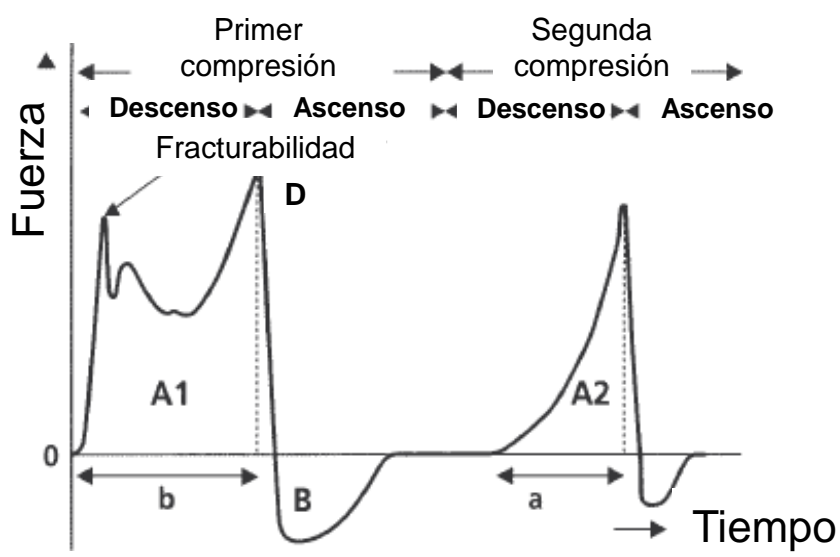

Figura 2.4. Curva generalizada obtenida a través de un análisis de perfil de textura (Adaptado de Bourne, 2002). 
- Dureza (D): fuerza máxima del primer ciclo de compresión. Se expresa en unidades de fuerza $(\mathrm{N})$.

- Consistencia (Cons): suma de las áreas positivas del primer $\left(A_{1}\right)$ y segundo $\left(A_{2}\right)$ ciclos. Posee unidades de N*s.

- Cohesividad (Coh): Es el cociente entre el área de la segunda compresión $\left(A_{2}\right)$ y el área de la primera compresión $\left(A_{1}\right)$. Representa la fuerza con la que están unidas las partículas en la masa, límite hasta el cual se puede deformar antes de romperse (Szczesniak, 2002). Es un parámetro adimensional.

- Adhesividad (Adh): área del pico negativo después del primer ciclo de compresión (B), representa el trabajo necesario para despegar el émbolo de la superficie del alimento. Se mide en $\mathrm{N}^{*} \mathrm{~s}$.

- Elasticidad (Elast): altura que recupera el alimento durante el tiempo transcurrido entre el primer ciclo y el segundo y es la relación entre las distancias a y $b(a / b)$. Es un parámetro adimensional.

- Gomosidad (Gomos): producto de la dureza por la cohesividad. Se expresa en N.

\subsection{Ensayo de punción}

En este ensayo se mide la fuerza requerida para introducir un punzón o sonda de metal sobre un alimento o matriz a una profundidad constante (Bourne, 2002).

Los discos obtenidos a partir de masas frescas, fueron sometidos a un ensayo de punción de $40 \%$ de la altura original con una sonda SMSP/3 (3 mm diámetro) de punta plana y una celda de $25 \mathrm{~kg}$. La velocidad del ensayo fue de $1 \mathrm{~mm} / \mathrm{s}$. Se ensayaron 5 discos por cada formulación, a cada uno se le aplicó dos ensayos de punción. Se registró la fuerza en función del tiempo, obteniéndose un gráfico como el de la Figura 2.5, del cual se obtuvieron los siguientes parámetros: 


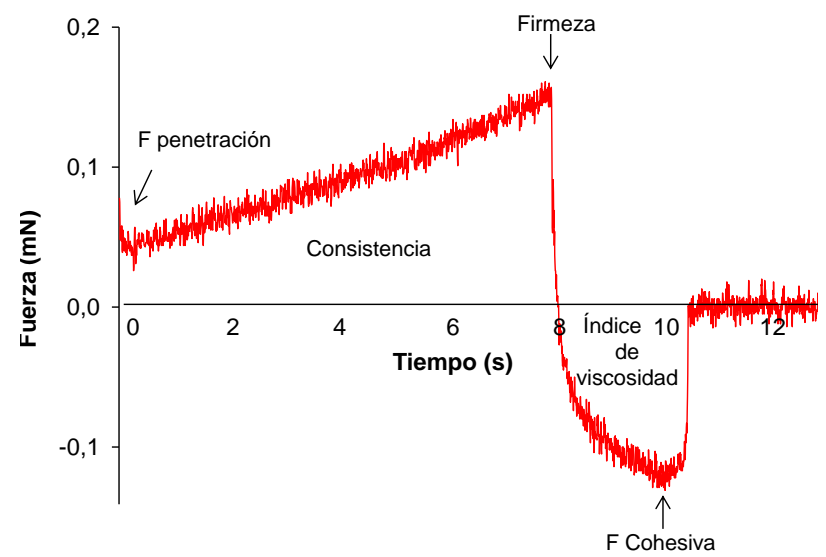

Figura 2.5. Grafica de punción obtenida a partir de una masa.

- $\quad$ Fuerza de penetración $\left(F_{p}\right)$ : fuerza requerida por la sonda para penetrar en la masa. Se expresa en milinewton $(\mathrm{mN})$.

- $\quad$ Firmeza (F): fuerza máxima ejercida al finalizar la penetración, antes que la sonda retorne a su posición original. Se expresa en $\mathrm{N}$.

- $\quad$ Consistencia: área positiva bajo la curva. Se expresa en $\mathrm{N}^{*} \mathrm{~s}$.

- Índice de viscosidad (IV): área negativa de la curva. También denominado trabajo de cohesión. Se expresa en unidades de $N^{*} s$.

- $\quad$ Fuerza cohesiva: máxima fuerza negativa, tomada como una indicación de la cohesividad de la muestra. Se expresa en N.

\subsection{Ensayo de relajación}

El ensayo de relajación consiste en deformar el material aplicando una compresión a deformación constante (Figura 2.6.A) y registrándose la fuerza que opone el material para mantener dicha deformación en función del tiempo.

Cuando el ensayo de relajación se aplica sobre diversos materiales, se observan diferentes comportamientos (Figura 2.6.B): si el material es sólido (elástico ideal) no experimenta relajación (Figura 2.6.B.a). Si el material posee comportamiento viscoso ideal (liquido), se relaja instantáneamente (Figura 2.6.B.b). Los materiales viscoelásticos poseen un comportamiento intermedio entre ambos, se relajan en forma gradual y el valor de esfuerzo final $\left(\sigma_{e}\right)$ dependerá de qué tipo de comportamiento predomine. Si predomina el comportamiento sólido sobre el líquido se alcanzará un valor de equilibrio positivo (Figura 2.6.B.C); en el caso que predomine el comportamiento fluido sobre el sólido el esfuerzo final será cero (Figura 2.7.B.d) 
(Steffe, 1996).

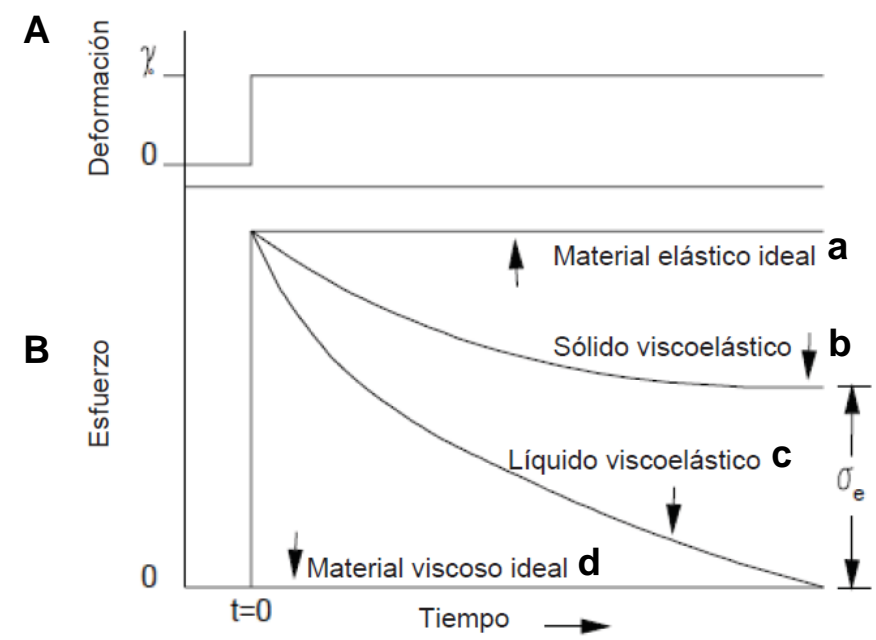

Figura 2.6.A) Deformación en función del tiempo. B) Curvas de relajación de diferentes materiales. $\gamma_{0}$ : deformación aplicada. $\sigma_{\mathrm{e}}$ : valor de esfuerzo alcanzado en el equilibrio (Adaptado de Steffe, 1996).

El comportamiento viscoelástico de los materiales viscoelásticos se representa mediante diferentes modelos. El comportamiento de fluido ideal obedece la Ley de Newton (Ec. 2.12), con un pistón trabajando en un cilindro, mientras que el del sólido ideal está representado por un resorte y obedece la Ley de Hooke (Ec. 2.13). El pistón representa la disipación de energía en forma de calor mientras que el resorte representa la energía almacenada en el material.

$$
\sigma=\eta * \ddot{\gamma}
$$

donde:

$\sigma:$ esfuerzo de corte $(\mathrm{kPa})$

$\eta$ : Coeficiente de viscosidad dinámica ( $\left.\mathrm{Pa}^{*} \mathrm{~s}\right)$

$\dot{\gamma}$ : gradiente de velocidad $\left(\mathrm{s}^{-1}\right)$

$$
\sigma=E \gamma
$$

donde:

$$
\text { б: esfuerzo }(\mathrm{kPa})
$$


E: modulo elástico $(\mathrm{kPa})$

$\gamma$ : deformación relativa (-)

Se considera que el material viscoelástico internamente trabaja con diferente combinación de resortes y pistones. Los modelos más sencillos son dos, el modelo de Maxwell con el resorte y el pistón en serie (Figura 2.7.a) y el modelo de Kelvin-Voigt con el resorte y el pistón conectados en paralelo (Figura 2.7.b).
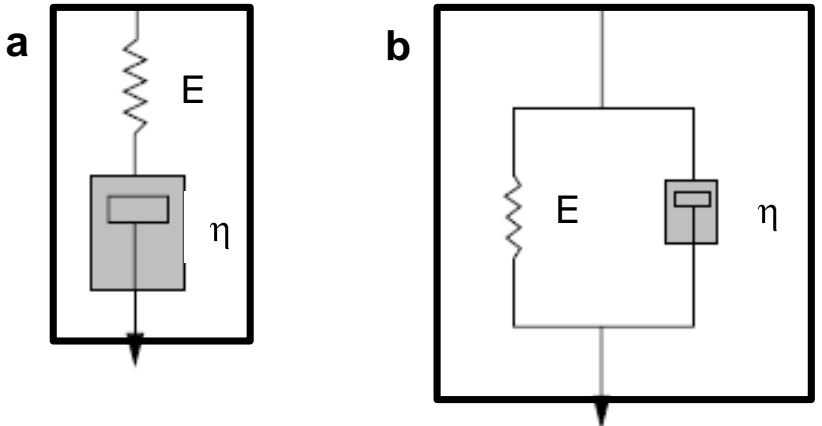

Figura 2.7. a) Modelo de Maxwell. b) Modelo de Kelvin-Voigt.

El modelo de Maxwell es el que frecuentemente se ha utilizado para interpretar los datos de las curvas obtenidas en los ensayos de relajación de fluidos viscoelásticos. Como los elementos están en serie, puede suponerse que la deformación total del material es igual a la suma de las dos deformaciones (Ec. 2.14)

$$
\gamma=\gamma \text { resorte }+\gamma \text { pistón }
$$

Diferenciando la Ec 2.14 respecto del tiempo y usando las definiciones provenientes de las ecuaciones 2.12 y 2.13 puede obtenerse la ecuación general del modelo de Maxwell (Ec. 2.15)

$$
d \gamma / d t=1 / E(d \sigma / d t)+\sigma / \eta
$$

Reordenando la ecuación 2.15 obtenemos la siguiente expresión:

$$
\sigma+(\eta / E)(d \sigma / d t)=\eta
$$

ó

$$
\sigma+T_{\text {rel }}(d \sigma / d t)=\eta
$$


donde:

$T_{\text {rel }}$ es el tiempo de relajación definido como la relación entre el componente viscoso y el componente elástico $(\eta / E)$.

Como el ensayo de relajación consiste en aplicar una deformación constante en el tiempo, $\gamma_{0}$, entonces $\dot{\gamma}=\mathrm{d} \gamma / \mathrm{dt}=0$, la Ec 2.17 queda de la siguiente forma:

$$
\sigma+T_{\text {rel }}(d \sigma / d t)=0
$$

derivando la ecuación 2.18 respecto del tiempo, obtenemos:

$$
\sigma(t)=\sigma_{0 .} \exp \left(-t / T_{\text {rel }}\right)
$$

donde $\sigma_{0}$ es el esfuerzo al inicio de la deformación, la cual va ir decayendo exponencialmente en función del tiempo.

El modelo de Maxwell no considera el esfuerzo en el equilibrio. Por esta razón, el comportamiento viscoelástico en los alimentos puede ser mejor descripto empleando el modelo generalizado de Maxwell (Hassan y col., 2005; Lima y Singh, 2001, Rodriguez-Sandoval y col., 2009), que consiste en varios elementos de Maxwell y un resorte, conectados en paralelo. El resorte contempla el término del esfuerzo del equilibro. El modelo que mejor ajusta en las masas contiene dos elementos de Maxwell asociado a un resorte (Figura 2.8).

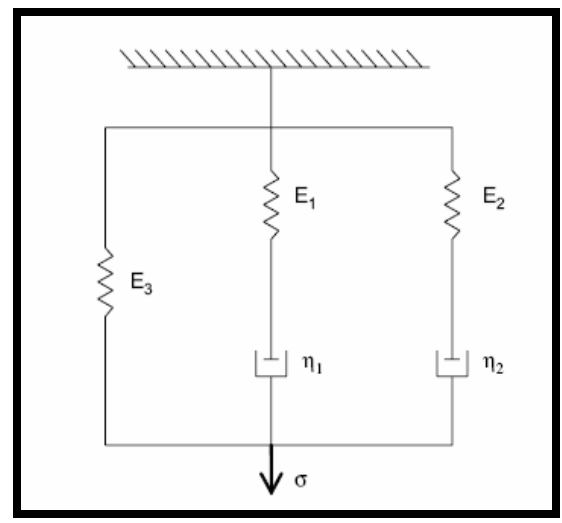

Figura 2.8. Modelo de Maxwell generalizado aplicado a las masas.

La ecuación obtenida del modelo de Maxwell generalizado (Ec. 2.20) es la siguiente: 


$$
\sigma(t)=\sigma_{1}{ }^{*} \exp \left(-t / T_{1}\right)+\sigma_{2}{ }^{*} \exp \left(-t / T_{2}\right)+\sigma_{3}
$$

Donde $\sigma(\mathrm{t})$ representa el esfuerzo medido durante el ensayo de relajación, t representa el tiempo. El tiempo de relajación $\left(\mathrm{T}_{\mathrm{i}}\right)$ está definido como la relación entre la viscosidad y el módulo elástico $\left(T_{i}=\eta_{i} / E_{i}\right)$.

El módulo elástico $\left(E_{i}\right)$ es definido como la relación entre el esfuerzo y la constante de deformación $\left(E_{i}=\sigma_{i} / \varepsilon_{0}\right)$. Donde $\varepsilon_{0}$ es una tensión constante calculada como el cociente de la deformación a la altura inicial de la muestra.

Los discos de masa se sometieron a una compresión de $40 \%$ a $0,5 \mathrm{~mm} / \mathrm{s}$ durante 20 minutos empleando el texturómetro. El ensayo se realizó a $25^{\circ} \mathrm{C}$. Se registró la fuerza en función del tiempo. Para evitar la desecación de las muestras los bordes fueron cubiertos con vaselina semisólida. El ensayo se realizó por triplicado para cada formulación. Se ajustó la curva de esfuerzo en función del tiempo utilizando el modelo de Maxwell generalizado (Ec. 2.20) usando OriginPro8 (OriginLab Corporation, MA, Estados Unidos) considerando dos elementos de Maxwell la ecuación 2.20 quedaría según la ecuación 2.21 de la siguiente forma:

$$
\sigma(t)=E_{3}{ }^{*} \gamma_{0}+A_{1}{ }^{*} \exp \left(-t / T_{1}\right)+A_{2}{ }^{*} \exp \left(-t / T_{2}\right)
$$

donde:

$A_{i}$ : factores pre-exponenciales.

$\mathrm{T}_{\mathrm{i}}$ : son los tiempos de relajación, definidos como la relación entre el componente viscoso y elástico $\left(\eta_{i} / E_{i}\right)$.

\subsubsection{Ensayo reológico dinámico sobre las masas}

Los ensayos reológicos dinámicos son ampliamente utilizados para estudiar el comportamiento viscoelástico en los alimentos. Los resultados obtenidos a partir de estos test son muy sensibles a la composición química y estructura física del material estudiado (Steffe, 1996).

La muestra se coloca entre un sistema de platos paralelos rugosos a temperatura controlada, donde el plato inferior se encuentra fijo y el superior oscila horizontalmente a una frecuencia fija $(\omega)$ entonces la deformación oscilatoria del material en función del 
tiempo está dada por la ecuación 2.22:

$$
\gamma=\gamma_{0} \operatorname{sen}(\omega t)
$$

donde:

$$
\begin{aligned}
& \gamma=\text { deformación del material }(-) \\
& \gamma_{0}=\text { amplitud de deformación }(-) \\
& \omega=\text { velocidad angular }(\mathrm{rad} / \mathrm{s} \text { o Hertz }(\mathrm{Hz})) \\
& \mathrm{t}=\text { tiempo }(\mathrm{s})
\end{aligned}
$$

El gradiente de deformación periódico se puede evaluar derivando la ecuación 2.22:

$$
\delta \gamma / \delta t=\gamma_{0}{ }^{*} \omega{ }^{*} \cos (\omega t)
$$

Si la amplitud de deformación que se aplica es pequeña, de forma que nos encontramos en el rango de viscoelasticidad lineal, el esfuerzo producido está dado por la ecuación 2.24:

$$
\sigma=\sigma_{0}^{*} \operatorname{sen}(\omega t+\delta)
$$

donde:

$$
\begin{aligned}
& \sigma=\text { esfuerzo }(\mathrm{kPa}) \\
& \sigma_{0}=\text { amplitud del esfuerzo }(\mathrm{kPa}) \\
& \delta=\text { ángulo de desfasaje que separa al esfuerzo de la deformación }\left(^{\circ}\right) \\
& \mathrm{t}=\text { tiempo }(\mathrm{s})
\end{aligned}
$$

Para un material perfectamente elástico, la onda de deformación se encontrará en fase con el esfuerzo $(\sigma)$ aplicado. Por lo tanto para un sólido ideal el ángulo de desfasaje (ठ) entre el esfuerzo aplicado y la deformación será de $0^{\circ}$. Si en cambio se realiza para un material viscoso ideal, la onda que representa la deformación oscilatoria se encuentra exactamente fuera de fase $\left(\delta=90^{\circ}\right)$ con respecto a la correspondiente al esfuerzo (Steffe, 1996).

Los materiales viscoelásticos presentan un comportamiento intermedio entre el correspondiente al viscoso ideal y al elástico ideal, por lo tanto las funciones 
trigonométricas que representan la deformación y el esfuerzo presentan ángulos de desfasaje entre 0 y $90^{\circ}$ (Figura 2.9).

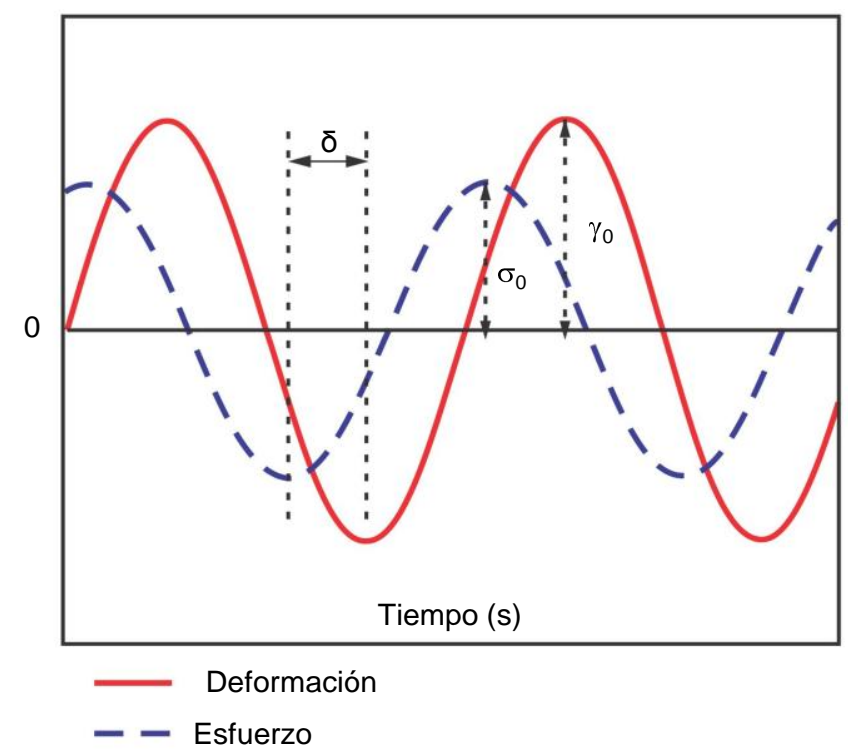

Figura 2.9. Comportamiento mostrado por un material viscoelástico.

La ecuación 2.24 también puede escribirse como:

$$
\begin{aligned}
& \sigma=G^{\prime} \gamma+\left(G^{\prime \prime} / \omega\right) \\
& G^{\prime}=\left(\sigma_{0} / \gamma_{0}\right) \cos \delta
\end{aligned}
$$

y

$$
G^{\prime \prime}=\left(\sigma_{0} / \gamma_{0}\right) \operatorname{sen} \delta
$$

donde:

G' = módulo de almacenamiento o módulo elástico (Ec. 2.26) relacionado con la respuesta del material como un sólido. Se expresa en kilopascales (kPa).

G"= módulo de pérdida o viscoso (Ec. 2.27) relacionado con la respuesta del material como un fluido. Se expresa en $\mathrm{kPa}$.

Otras funciones que describen el comportamiento viscoelástico de la muestra y su dependencia con la frecuencia son el módulo complejo (Ec. 2.28) y la tangente del ángulo de desfasaje (Ec. 2.29). 


$$
\begin{aligned}
& G^{*}=\sigma_{0} / \gamma_{0}=\left[\left(G^{\prime}\right)^{2}+\left(G^{\prime \prime}\right)^{2}\right]^{1 / 2} \\
& \tan \delta=G^{\prime \prime} / G^{\prime}
\end{aligned}
$$

La tan $\delta$ se vincula con la relación entre la energía perdida por la muestra por ciclo respecto a la energía almacenada por ciclo (Steffe, 1996).

Se empleó un reómetro oscilatorio de esfuerzo controlado (RS600, Haake Alemania) utilizando el programa RheoWin data Manager 3.30. Para los diferentes ensayos se utilizó un sensor de platos rugosos paralelos, el plato superior móvil (PP35/S) de 35 $\mathrm{mm}$ de diámetro y el plato inferior fijo (D35/S). Se trabajó a temperatura controlada $\left(25^{\circ} \mathrm{C}\right)$. El espacio entre los platos fue de $1,5 \mathrm{~mm}$. Se colocó el disco de masa sobre el plato inferior y se lo comprimió hasta alcanzar la distancia entre platos adecuada, se cortó el excedente de masa y luego se la recubrió con vaselina semisólida para evitar la deshidratación superficial durante el ensayo. Se esperó el tiempo necesario para que se relaje la masa (15 minutos) antes de comenzar con los diferentes ensayos.

\section{Barrido de deformación}

Se realizó un barrido de deformación a una frecuencia de $1 \mathrm{~Hz}$ entre 0,5 y 200 Pa para determinar el máximo de deformación $\left(\gamma_{0}\right)$ para la muestra en el rango de viscoelasticidad lineal. Se define como rango de viscoelasticidad lineal de un material a aquel en el cual las propiedades del mismo no dependen de la magnitud del esfuerzo aplicado, de la deformación realizada o de la velocidad de aplicación de la deformación. El ensayo se realizó por triplicado. Se registró el módulo complejo G* en función del esfuerzo obteniéndose un gráfico como el de la Figura 2.10. 


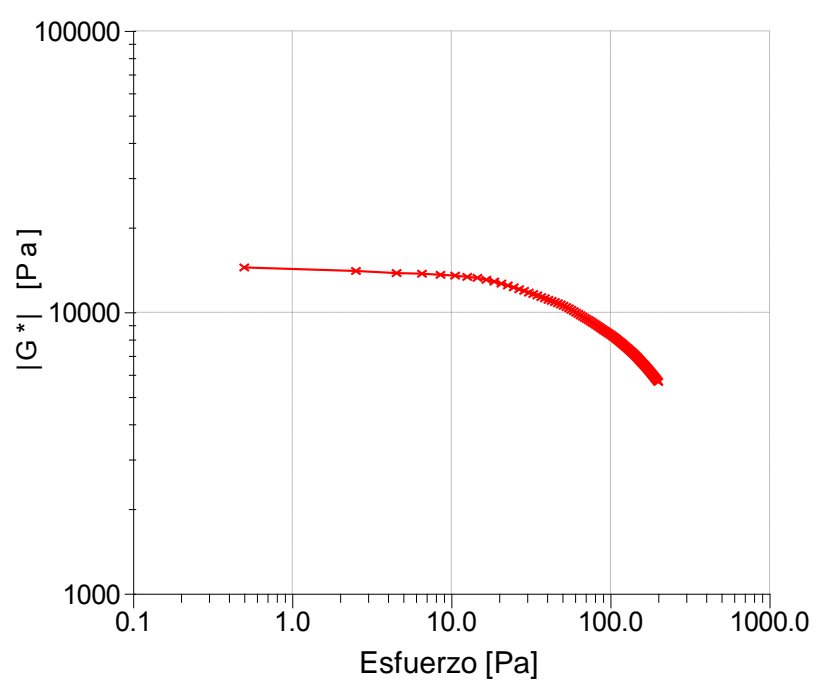

Figura 2.10. Curva de deformación obtenida experimentalmente.

El rango de viscoelasticidad lineal alcanza hasta aproximadamente los $10 \mathrm{~Pa}$.

\section{Barrido de frecuencia}

Se realizó un barrido de frecuencia entre $0,005 \mathrm{~Hz}$ y $100 \mathrm{~Hz}$ (Figura 2.11) a deformación constante dentro de un rango viscoelástico lineal $(\tau=5 \mathrm{~Pa})$. Se obtuvo el módulo elástico o de almacenamiento (G'), el módulo viscoso o de pérdida (G") y la tangente del ángulo de desfasaje tan $\delta=$ G"/G' en función de la frecuencia.

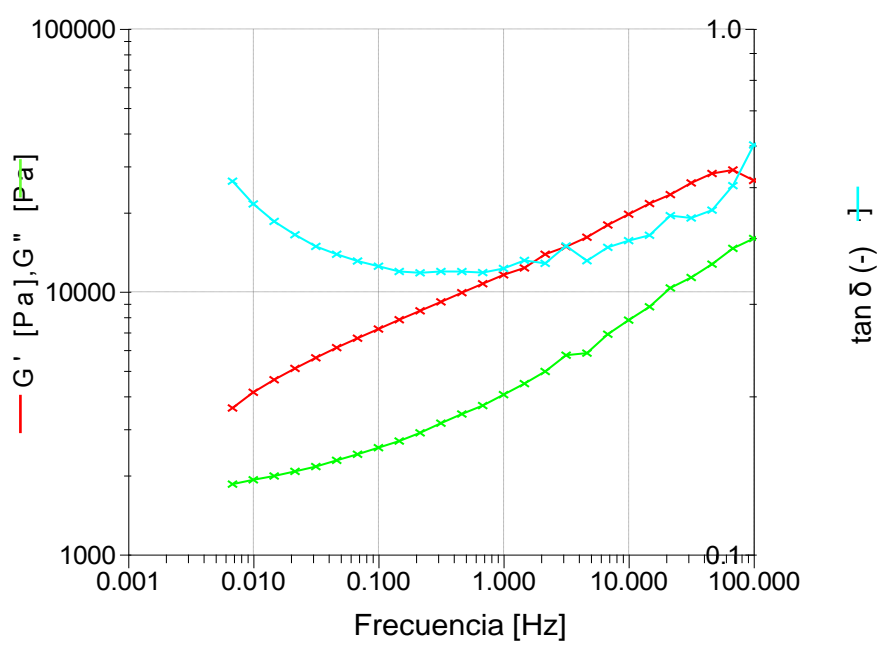

Figura 2.11. Barrido de frecuencia experimental. 


\subsubsection{Evaluación estructural de las masas}

Se realizaron diferentes ensayos para evidenciar la posible interacción entre los diferentes componentes de la masa, y poder dilucidar alguna conclusión respecto a la estructura de la misma. Se emplearon las técnicas de Resonancia Magnética Nuclear (RMN) para estudiar la movilidad molecular, microscopia electrónica de barrido (SEM) para visualizar la masa a nivel molecular. El posible efecto de las diferentes sales de calcio y del prebiótico sobre las proteínas que conforman la red de gluten se estudió por espectroscopia infrarroja en la que se analizó la estructura secundaria de las proteínas de gluten y mediante análisis de gliadinas y gluteninas por electroforesis (SDS-PAGE).

\subsubsection{Movilidad molecular}

La movilidad molecular de las diferentes masas se analizó mediante ensayos de relajación empleando un equipo de baja resolución Brücker Minispec (Brücker, Estados Unidos). Una porción de masa fue introducida en el tubo de vidrio de $1 \mathrm{~cm}$ de diámetro, hasta alcanzar los $3 \mathrm{~cm}$ de altura y los tubos fueron cerrados para evitar la deshidratación de la masa. Los núcleos son excitados por unos pocos milisegundos y cuando el pulso se detiene, vuelven al estado fundamental emitiendo una señal. En la curva de relajación obtenida se registra la intensidad de señal del protón $\left({ }^{1} \mathrm{H}\right)$ en función del tiempo registrándose un decaimiento exponencial de la señal. Se midió la intensidad de señal en el tiempo usando una secuencia de pulso de Carr-PurcelMeiboon-Gill con un tiempo entre pulsos de $200 \mu \mathrm{s}$. El empleo de secuencia de pulsos es necesario cuando se miden tiempos de relajación del orden de los milisegundos. El decaimiento de la Intensidad de señal en el tiempo (Figura 2.12) se modeló con una ecuación exponencial (Ec. 2.30), obteniéndose los tiempos de relajación spin-spin $(\lambda)$ de los núcleos de hidrógeno presentes en la masa. Esta medida fue realizada por cuadruplicado a temperatura ambiente $\left(20^{\circ} \mathrm{C}\right)$. 


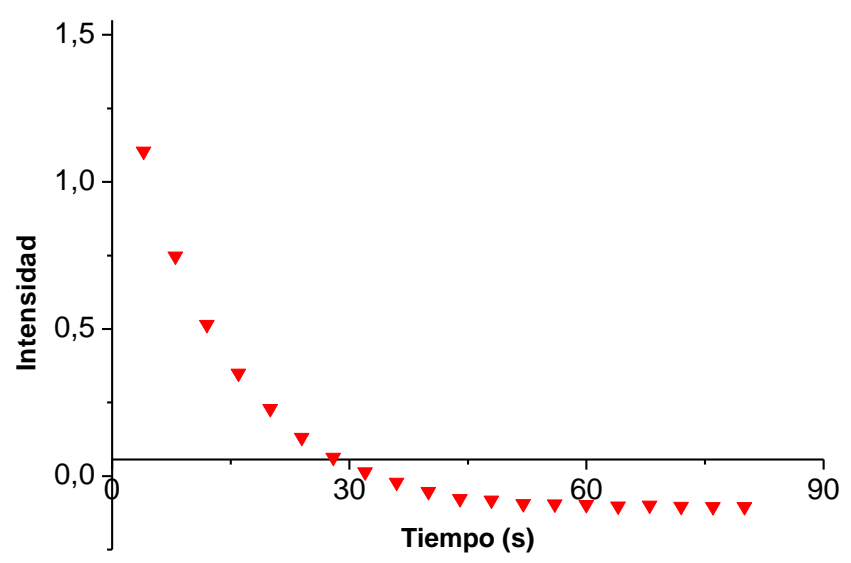

Figura 2.12. Grafico típico de intensidad de señal en función del tiempo del ensayo de relajación de masa.

La señal de eco de espín en $t=0$ es proporcional al número de núcleos de hidrógeno de cada especie. En el presente trabajo, las curvas de decaimiento se ajustaron utilizando la Ec. 2.30 mediante el programa OriginPro 8 (Estados Unidos).

$$
I=A * \exp (-t / \lambda)
$$

donde:

I = Intensidad de señal

$A=$ factor pre-exponencial. Representa la intensidad de señal de los protones a tiempo cero.

$\lambda=$ tiempo de relajación spin-spin $(\lambda)$ de los núcleos de hidrógeno. Se expresa en milésimas de segundo ( $\mathrm{ms})$.

$$
\mathrm{t}=\text { tiempo }(\mathrm{ms}) \text {. }
$$

\subsubsection{Microscopia electrónica de barrido}

Para la visualización de la microestructura de la masa se empleó la técnica de microscopia electrónica de barrido (SEM).

Se sumergieron piezas cilíndricas de masas de $4 \mathrm{~mm}$ de diámetro y $5 \mathrm{~mm}$ de alto en glutaraldehído 2,5\% v/v para su óptima conservación. Luego se lavaron dos veces con buffer fosfato $0,5 \mathrm{M}$ antes de su deshidratación. La deshidratación se llevó a cabo mediante una seria graduada de acetona: $25 \%, 50 \%, 75 \%$, y tres veces con acetona $100 \%$. 
El secado de las muestras se realizó en el punto crítico con $\mathrm{CO}_{2}$ (Bray, 2000). Las muestras se cubrieron con oro en un recubridor sputter (Pelco, Redding, Estados Unidos) y fueron observadas a $5 \mathrm{Kv}$ en un JEOL JSM 35 CF Microscopio Electrónico de Barrido (Tokio, Japón).

\subsubsection{Propiedades estructurales de las proteínas}

\subsection{Perfil de gliadinas y gluteninas}

Los cambios en el perfil electroforético de las proteínas que forman el gluten, gliadinas y gluteninas, como consecuencia de su posible interacción con la inulina y las sales agregadas se analizaron por SDS-PAGE.

\section{Extracción secuencial de las fracciones proteicas}

Las distintas fracciones proteicas fueron extraídas a partir de las diferentes masas liofilizadas y de las harinas empleando extracciones consecutivas con diferentes solventes según la secuencia de Osborne modificada. Para la extracción de albúminas se empleó agua destilada, para las globulinas un buffer Tris- $\mathrm{HCl} 50 \mathrm{mM}(\mathrm{pH}$ 7,8) conteniendo $\mathrm{KCl} 100 \mathrm{mM}$ y EDTA $5 \mathrm{mM}$; las gliadinas se extrajeron con 1-propanol $(50 \% \mathrm{p} / \mathrm{v})$ y finalmente se utilizó una solución de ácido acético $0,1 \mathrm{M}$ para extraer las gluteninas.

Se pesaron $3 \mathrm{~g}$ de masa liofilizada o harina, se le agregó $15 \mathrm{ml}$ del solvente de extracción, se agitó durante 30 minutos a temperatura ambiente. Una vez cumplido este periodo las suspensiones fueron centrifugadas (centrífuga Avanti J-25- Beckman Coulter, California, Estados Unidos) a $12096 \mathrm{~g}$ durante 15 min a $4{ }^{\circ} \mathrm{C}$. Se separó el sobrenadante del precipitado y a éste último se le agregaron nuevamente $15 \mathrm{ml}$ del solvente de extracción. Se agitó 15 minutos y se centrifugó en las mismas condiciones detalladas anteriormente. Sobre el precipitado obtenido se agregó el segundo solvente de extracción y se procedió igual que con el primer solvente. Y así sucesivamente con el resto de los solventes. Sólo las proteínas provenientes de la primera extracción con 1-propanol y ácido acético se liofilizaron para realizar la electroforesis.

\section{Reactivos utilizados}

Buffer de electrodo o de corrida 5X: Tris base 0,125 M con glicina 0,96 M y SDS $0,5 \%, \mathrm{pH}=8,3$. 
Buffer separador $4 \mathrm{X}$ : Tris base 1,5 M, SDS 0,4\%, pH 8,8

$\checkmark$ Solución de Acrilamida/Bis acrilamida 30,8\%

$\checkmark$ TEMED (N, N, $\mathrm{N}^{\prime}, \mathrm{N}^{\prime}$, -tetrametiletilendiamina) $0,4 \%$

$\checkmark$ Persulfato de amonio $10 \%$

$\checkmark$ Buffer de muestra 4X: Tris base 0,37 M, glicerol 25\% p/v, SDS 4,0\% p/v y azul de bromofenol $0,1 \% \mathrm{p} / \mathrm{v}$

$\checkmark$ Buffer stacking 4X: Tris base 0,5 M, SDS 0,4\%, pH 6,8 buffer apilador

$\checkmark$ El colorante fue preparado disolviendo 1,92 g de Coomasie Blue R- 250 en $400 \mathrm{ml}$ de alcohol metílico, $440 \mathrm{ml}$ de agua destilada y $160 \mathrm{ml}$ de ácido acético.

$\checkmark$ El decolorante utilizado tuvo la siguiente composición: $650 \mathrm{ml}$ de agua, $100 \mathrm{ml}$ de ácido acético y $250 \mathrm{ml}$ de etanol.

$\checkmark$ Patrones de baja masa Molecular: fosforilasa b (97 kDa), albúmina (66 kDa), ovoalbúmina (45 kDa), anhidrasa carbónica (30 kDa), inhibidor de tripsina (20,1 kDa) y a- lactoalbúmina $(14,4 \mathrm{kDa})$ (GE Healthcare, Inglaterra), los que se prepararon disolviéndolos en $200 \mu \mathrm{l}$ de buffer de muestra con $\beta$-mercaptoetanol. (Pharmacia, Biotech, Estados Unidos).

\section{Protocolo}

Las electroforesis se llevaron a cabo en mini placas utilizando el equipo Mini-Protean III (BIO-RAD, Inglaterra). Se utilizaron geles de $1 \mathrm{~mm}$ de espesor con 10 calles cada uno, en los cuales el gel separador tuvo una concentración de acrilamida/bisacrialmida del $12 \%$ y el gel apilador o concentrador del $4 \%$. Las fracciones proteicas liofilizadas fueron resuspendidas en el buffer de muestra (dos horas a $60^{\circ} \mathrm{C}$ ). El volumen de muestra sembrado por calle fue de 15 - $20 \mu \mathrm{l}$ mientras que el volumen sembrado para el patrón fue de $4 \mu \mathrm{l}$. Las corridas se realizaron a corriente constante $(30 \mathrm{~mA} / \mathrm{gel})$ durante el tiempo necesario. Luego los geles se fijaron y tiñeron con solución de Coomassie Blue R-250 y posteriormente se decoloraron. También se les realizó tinción con plata para obtener una mayor resolución.

Los geles fueron fotografiados empleando una cámara fotográfica Nikon 3000 y se realizó el análisis de las masas moleculares de las bandas con el empleo del programa Sigma Gel versión 1.0 (Jandel Scientific, Estados Unidos).

\subsection{Estructura secundaria de proteínas de gluten}

El efecto de las sales de calcio y la inulina sobre los cambios en la estructura secundaria de las proteínas de gluten se analizó por espectroscopia infrarrojo. Las 
masas fueron preparadas según se describió en la sección 2.2.4 y fueron congeladas a $-80 \stackrel{\circ}{ } \mathrm{C}$, liofilizadas y molidas. Los espectros infrarrojo de las distintas muestras sólidas fueron medidos en un espectrofotómetro FTIR Brüker (Alemania) IFS 66. Para la cuantización de las muestras, los espectros fueron determinados por triplicado manteniendo la proporción de 49,54\% de muestra en relación a $\mathrm{KBr}$. La resolución espectral fue de $\pm 6 \mathrm{~cm}^{-1}$ y se realizaron 1000 scans de barrido. La determinación de la estructura secundaria de la proteína se llevó a cabo sobre la base del procedimiento descrito por Byler y Susi (1986) analizando la región entre $1580-1780 \mathrm{~cm}^{-1}$ con la finalidad de analizar la banda amida I. Las frecuencias, el número de picos, el ancho de los mismos a utilizar en el procedimiento de ajuste interactivo se obtuvieron analizando la segunda derivada. Las áreas de las bandas fueron calculadas por integración de la banda de Amida I. El procedimiento de ajuste de la curva se llevó a cabo asumiendo una mezcla inicial de funciones Lorentzianas y Gaussianas (FWHH de 13 a $18 \mathrm{~cm}^{-1}$ ) con un factor de resolución máximo. Correcciones de la línea de base, procedimiento de normalización, derivación, ajuste de curvas y cálculo del área se llevaron a cabo por medio de los programas Grams/32 (Galactic Industries Corporation) y OPUS.

\subsubsection{Propiedades térmicas del almidón}

Para evaluar las diferentes transiciones térmicas que involucran al almidón, vinculadas al proceso de panificación y almacenamiento del pan, se utilizó la calorimetría diferencial de barrido (Differential Scanning Calorimetry, DSC) en masas. Para determinar las propiedades de viscosidad durante la cocción y enfriamiento de suspensiones de harina con $\mathrm{NaCl}$, sal de calcio y prebiótico se empleó un analizador de viscosidad rápido (Rapid Visco Analyser, RVA).

Las mezclas estudiadas por ambas técnicas fueron las siguientes: C $(0 \mathrm{ppm} \mathrm{Ca}, 0 \%$ In); CA1, Cl1 o LA1 (1200 ppm Ca, 1\% In); CA2, Cl2 o LA2 (2400 ppm Ca, 1\% In); CA3, CI3 o LA3 (1200 ppm Ca, 12\% In) y CA4, Cl4 o LA4 (2400 ppm Ca, 12\% In). Además las masas CA11, Cl11 y LA11 (1800 ppm Ca- 0\% In) se estudiaron por DSC

\subsubsection{Gelatinización del almidón}

Para estudiar el efecto de las diferentes sales de calcio y prebiótico en los procesos de gelatinización y retrogradación del almidón en masas frescas, se pesaron alrededor de 
10 miligramos de masa en cápsulas de aluminio las cuales fueron selladas herméticamente y sujetas a un ciclo de calentamiento desde $5^{\circ} \mathrm{C}$ hasta $140{ }^{\circ} \mathrm{C}$ a una velocidad de $10^{\circ} \mathrm{C} / \mathrm{min}$ en un calorímetro diferencial de barrido (Q100 TA Instruments, Estados Unidos). Como referencia se empleó una capsula vacía. La calibración del equipo se llevó a cabo empleando indio, ácido láurico y ácido esteárico como patrones de calibración. La gelatinización del almidón en las masas es evidenciada en el termograma por dos picos (Figura 2.13). Los picos I y II corresponden a la gelatinización y el III a la disociación del complejo amilosa-lípido. Por medio del software TA Instruments Universal Analysis 2000 (Versión 4.2E, Estados Unidos) se calcularon los siguientes parámetros: la temperatura de inicio $\left(T_{\text {ons }}\right)$, las de pico $\left(T_{p l} y\right.$ $\mathrm{T}_{\text {pll }}$ ) y la de finalización ( $\left.\mathrm{T}_{\text {off }}\right)$ y la variación de entalpía $\left(\Delta \mathrm{H}_{\mathrm{g}}\right)$ asociada a la gelatinización. El ensayo se realizó por duplicado.

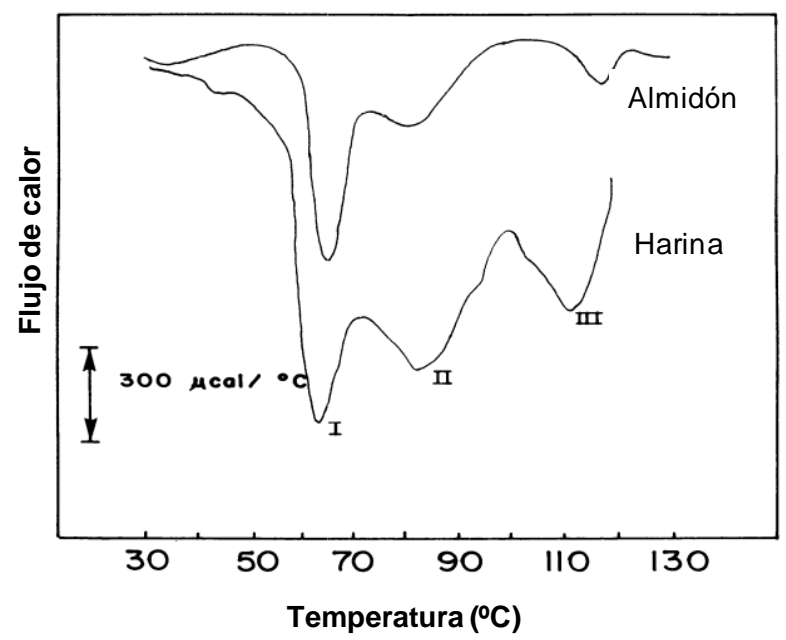

Figura 2.13. Termogramas obtenidos por DSC. Adaptado de Ghiasi y col. (1982).

\subsubsection{Perfil viscoamilográfico}

Para evaluar el comportamiento de las diferentes suspensiones ante un ciclo de calentamiento/enfriamiento se empleó un viscoamilografo rápido (Serie 4, Newport Scientific Pty.LTD., Warriewood, Australia). El ensayo se realizó por triplicado de acuerdo al método AACC 76-21 (2000), en el cual a $3,50 \mathrm{~g}$ de sólidos (14\% de humedad) se agregan $(25,0 \pm 0,1) \mathrm{ml}$ de agua destilada y se coloca en el RVA. Se agita la suspensión vigorosamente $(960 \mathrm{rpm})$ durante $10 \mathrm{~s}$ con el fin de homogeneizar y luego a $160 \mathrm{rpm}$ hasta finalizar el ensayo. La suspensión es calentada a $50{ }^{\circ} \mathrm{C}$ durante 1 min y luego hasta $95^{\circ} \mathrm{C}$ a una velocidad de $12,16{ }^{\circ} \mathrm{C} / \mathrm{min}$. Se mantiene a $95^{\circ} \mathrm{C}$ durante $2,5 \mathrm{~min}$. Finalizado este tiempo, comienza a disminuir la temperatura a $50^{\circ} \mathrm{C}$ en $3,8 \mathrm{~min}$ manteniéndose a esta temperatura durante $1 \mathrm{~min}$. En la Figura 2.14 
se muestra un perfil de viscosidad típico y los diferentes parámetros obtenidos empleando el programa Thermocline para Windows (versión 2.4, Australia).

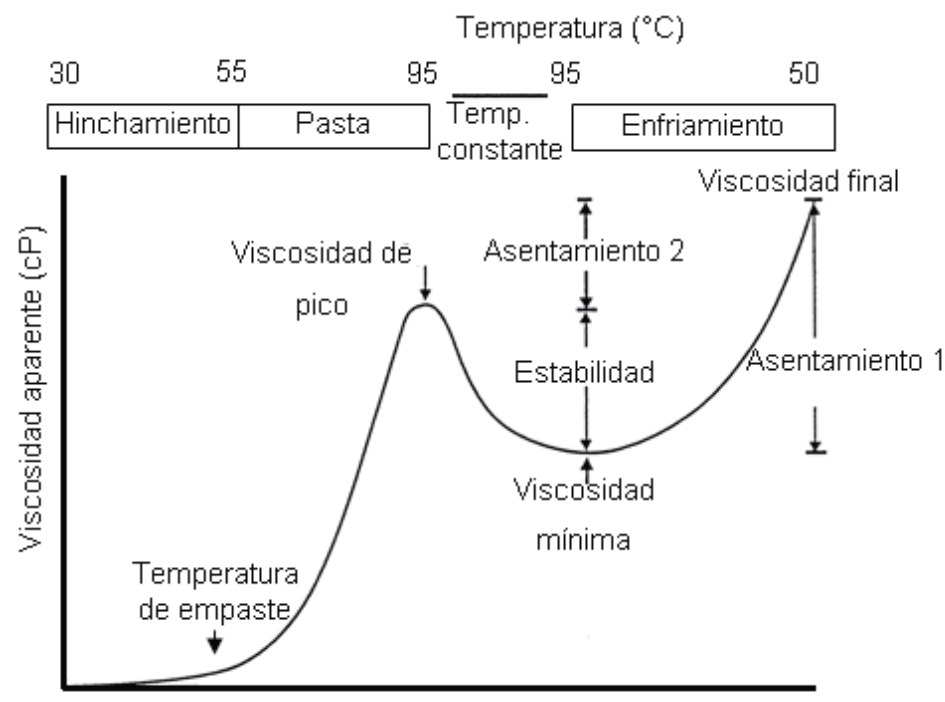

Figura 2.14. Perfil viscoamilográfico típico de almidón de trigo y parámetros calculados a partir del mismo. Adaptado de Dengate, 1984.

Se obtuvieron los siguientes parámetros:

- Temperatura de empaste $\left(T_{e}\right)$ : temperatura a la cual comienza el aumento de viscosidad.

- Tiempo de empaste $\left(t_{p}\right)$ : tiempo al cual comienza el aumento de la viscosidad.

- Viscosidad de pico (VP): máxima viscosidad obtenida durante el calentamiento hasta $95^{\circ} \mathrm{C}$, relacionada con la capacidad de la muestra para ligar agua.

- Viscosidad mínima (VM): viscosidad de la pasta caliente, medida durante el mantenimiento de la temperatura en $95^{\circ} \mathrm{C}$, y cuyo valor depende de la habilidad de la muestra para resistir el calentamiento y el esfuerzo de cizalla.

- Viscosidad final (VF): relacionada con la habilidad de la muestra para formar una pasta viscosa o gel después de la cocción y el enfriamiento.

- Estabilidad (BD; breakdown): diferencia entre VP y VM, relacionada con la habilidad de la suspensión para resistir el calentamiento y el esfuerzo de cizalla.

- Asentamiento 1 (SB-1, setback 1): diferencia entre VF y VM.

- Asentamiento 2 (SB-2, setback 2): diferencia entre VF y VP. Al enfriar la muestra ocurre una asociación de las moléculas de almidón formándose un gel por lo que esta zona de la curva se relaciona con la tendencia a retrogradar de la pasta. 


\subsubsection{Elaboración de panes}

\subsubsection{Curvas de fermentación}

Se realizaron las curvas de fermentación para evaluar el comportamiento de las masas frente al leudado y determinar el tiempo óptimo de fermentación de las masas frescas y congeladas previo al ensayo de panificación. Las masas para este ensayo se prepararon de igual modo al descripto en inciso 2.2.4, pero con el agregado de levadura (3\% b.h.). Una vez formada la masa, se dejó reposar por $10 \mathrm{~min}$, se laminó (4 pasadas) y se dejó descansar otros $10 \mathrm{~min}$. Una vez finalizado ese tiempo, se colocaron piezas esféricas de $50 \mathrm{~g}$ en una probeta de $500 \mathrm{ml}$ ( $5 \mathrm{~cm}$ de diámetro) provista de un émbolo móvil, las cuales se colocaron en una fermentadora a $30{ }^{\circ} \mathrm{C}$. Se midió el incremento del volumen en función del tiempo, inicialmente cada 10 min y luego cada 30 min durante 4 hs obteniéndose una gráfica como se muestra en la Figura 2.15. Las curvas se ajustaron con el programa Sigmaplot 10.0 empleando el modelo de Chapman de 3 parámetros (Ec. 2.31). El tiempo requerido para alcanzar 3/4 del incremento máximo se definió como el tiempo de fermentación, debido a que durante el inicio del horneado continúa leudando la masa hasta que se fija la estructura y hasta producirse la muerte de las levaduras. Las curvas se realizaron por duplicado.

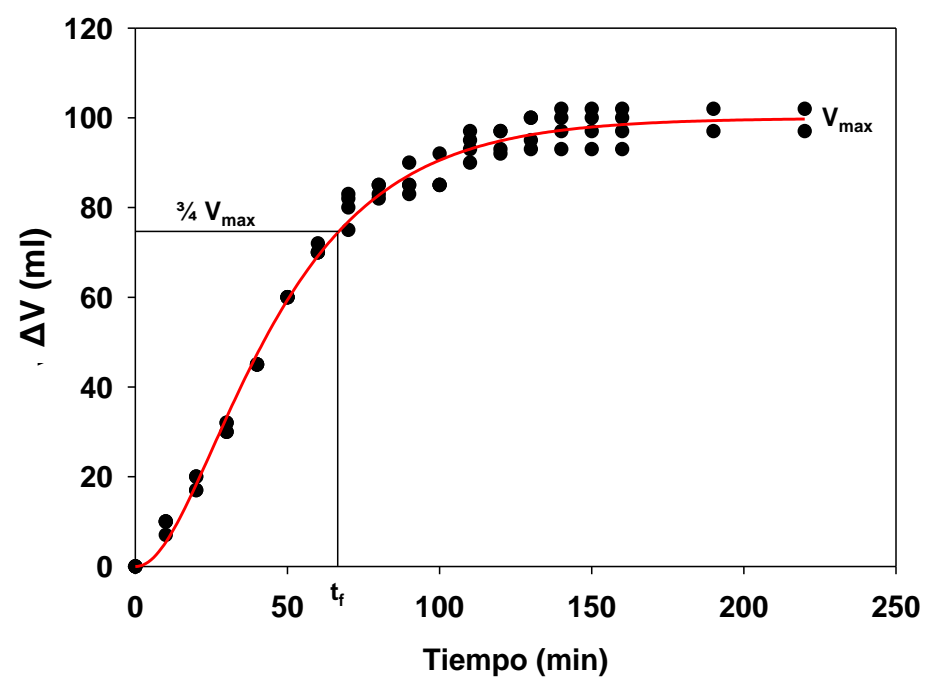

Figura 2.15. Curva de fermentación obtenida experimentalmente.

$$
\Delta \mathrm{V}=\mathrm{V}_{\max }{ }^{*}\left[1-\exp \left(-\mathrm{b}^{*} \mathrm{t}\right)\right]^{\mathrm{c}}
$$


donde:

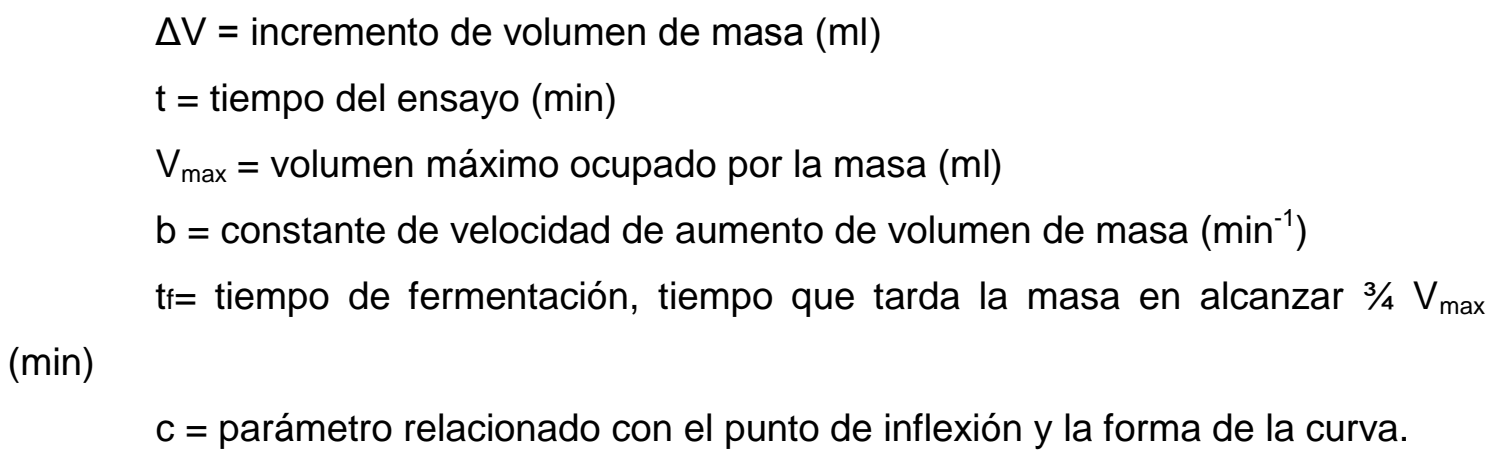

\subsubsection{Protocolo de panificación}

La masa para la obtención de los panes se preparó según lo descripto en la sección 2.2.10.1. Una vez obtenida la masa, se cortaron y bollaron piezas de $90 \mathrm{~g}$, se dejaron descansar 10 min y se armaron las piezas tipo pan francés en una armadora de pan (MPZ, Argentina).

Las piezas de masa congelada (C, CA4, CA11, Cl4, Cl11, LA4 y LA11) se descongelaron 2 hs en cámara de fermentación (Brito Hnos, Argentina) a $30{ }^{\circ} \mathrm{C}$ envueltas en film. Todas las masas (frescas y congeladas/descongeladas) se fermentaron en cámara de fermentación a $30 \stackrel{\circ}{\circ}$ según tiempo de fermentación obtenido de la curva de fermentación que se describió en la sección anterior (Sección 2.2.10.1). La cocción se realizó durante $26 \min$ a $210^{\circ} \mathrm{C}$ en un horno eléctrico de convección (Ariston, Argentina). Una vez finalizado el horneado, se dejaron los panes a temperatura ambiente y una vez alcanzada esta temperatura se procedió a evaluar la calidad del producto obtenido a partir de las distintas formulaciones. Los ensayos fueron realizados por duplicados.

\subsubsection{Evaluación de la calidad panadera}

La evaluación de la calidad panadera de todos los panes obtenidos en el trabajo experimental se realizó a través diferentes ensayos: volumen específico de la pieza, color de corteza, textura, humedad y alveolado de la miga.

\subsection{Volumen especifico de los panes}

Se determinó el volumen de 5 panes de cada formulación por desplazamiento de 
semillas de colza en un volumenómetro. Se mide el volumen inicial que ocupan las semillas inicialmente y luego se agrega un pan de masa conocida y se lee el nuevo volumen alcanzado. El desplazamiento que presentan las semillas es directamente proporcional al volumen del pan. El volumen específico se calculó como el cociente entre el volumen y la masa de la pieza de pan.

\subsection{Color de la corteza}

La apariencia es clave en un producto para que sea del agrado de los consumidores. La forma y el color son parámetros básicos, siendo éste último el más importante a considerar.

El aspecto visual de los alimentos lo conforman la transparencia y la opacidad, relacionadas con la cantidad de luz que el material deja pasar a través de él o bien que se refleja en él. Existen diversos sistemas para la medición de color. Los más comunes son: sistema CIELAB, propuesto en 1971 por CIE (CIE, Comission Internationale de I’Éclairage), el cual define un espacio en coordenadas rectangulares $\left(L^{*}, a^{*}, b^{*}\right)$ junto con otro en coordenadas cilíndricas $\left(L^{*}, H^{*}, C^{*}\right)$; y el sistema Hunter el cual es el más utilizado en los alimentos. Este último define un espacio cartesiano en que $L$ es la claridad o luminosidad, va desde 0 (negro) a 100 (blanco). El parámetro a define a los componentes rojo - verde, rojo para valores positivos y verde para negativos. El parámetro $b$ define la componente amarillo - azul, amarrillo para valores positivos y azul para negativos (Figura 2.16).

Se realizaron 40 medidas de color por panificación en ocho panes, y cinco campos por pan con un colorímetro de superficie Chroma Meter CR 400 Konica Minolta (Japón).

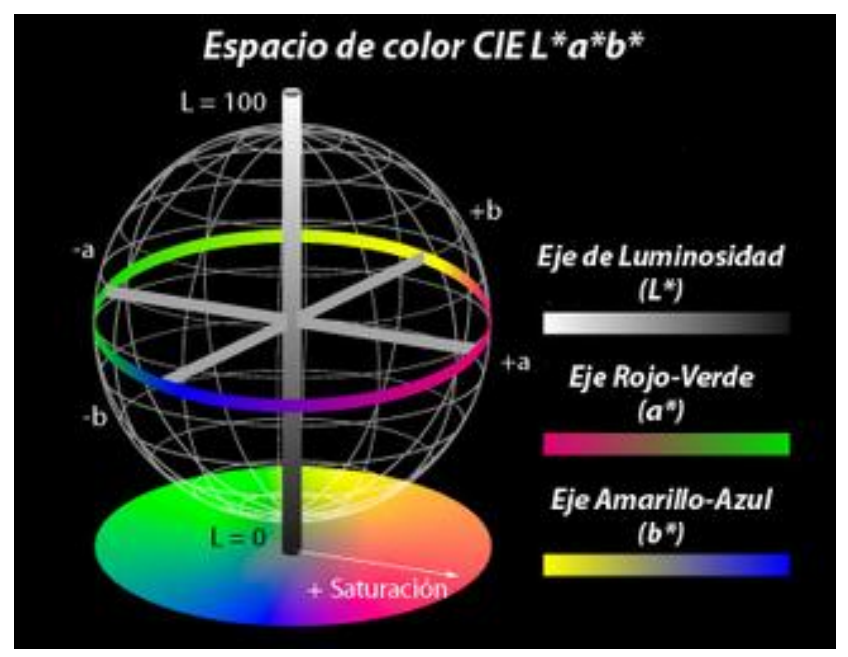

Figura 2.16. Espacio de color Hunter L, a, b. 
Se calculó el índice de pardeamiento (IP) según se muestra en la Ecuación 2.32, que es una medida de la pureza del color marrón (Buera y col., 1985). Este parámetro ha demostrado presentar una correlación lineal con la concentración de pigmento marrón por lo que ha resultado de utilidad para la evaluación de los cambios de color en alimentos que experimentan reacciones de pardeamiento enzimático y no enzimático. En particular, en panificación ha permitido observar variaciones en el color del pan debido a modificaciones en la formulaciones empleadas (Shittu y col. 2007 y 2008; Komlenić y col., 2010).

donde:

$$
x=\frac{a+1,75 L}{5,645 L+a-3,012 b}
$$

$$
\mathrm{IP}=\frac{100(\mathrm{x}-0,31)}{0,172}
$$

a: posición entre verde y rojo

b: posición entre azul y amarillo

L: luminosidad

\subsection{Firmeza de la miga}

Para analizar la firmeza de la miga se realizó un análisis de perfil de textura (TPA) de la miga: Se ensayaron 4 panes por panificación donde se cortaron 2 rodajas por cada pan de $2 \mathrm{~cm}$ de espesor las cuales fueron sometidas a dos ciclos de compresión hasta un $40 \%$ de su altura original. La velocidad de ensayo fue de $0,5 \mathrm{~mm} / \mathrm{s}$. Se empleó un texturómetro TA.XT2i (Stable Micro Systems, Surrey, Reino Unido) con una celda de $25 \mathrm{~kg}$. Se determinaron los parámetros dureza, consistencia, cohesividad, elasticidad, cohesividad explicados en 2.2.7.1.1. También se calculó la masticabilidad (Mast) como el producto de la gomosidad por la elasticidad.

\subsection{Humedad de la miga}

Se determinó humedad de las migas desgranadas según se describió en la sección 2.2.1.1 para la harina de trigo. 


\subsection{Alveolado de la miga}

El alveolado de la miga se determinó mediante el análisis digital de imágenes escaneadas de las rodajas de pan. Se escanearon 8 rodajas de pan por cada formulación empleando un escáner HP 4070; el tamaño de las imágenes obtenidas fue de $10 \mathrm{~cm}$ por $10 \mathrm{~cm}$ y la resolución $350 \mathrm{dpi}$ (Figura 2.17.a). Para el análisis de las imágenes se empleó el programa ImageJ 1.37v (Estados Unidos). Para transformar los pixeles en $\mathrm{cm}$ se calibró escaneando una regla en las mismas condiciones que las rodajas y se obtuvo que 138 pixeles $=1 \mathrm{~cm}$. Sobre la región central de cada miga se seleccionó manualmente una imagen cuadrada de $3,17 \mathrm{~cm}$ de lado (Figura 2.17.b). Esta imagen cuadrada en color se convirtió a imagen 8-bit en escalas de grises (Figura 2.17.c) y luego fue binarizada empleando el algoritmo Isodata y un valor umbral de 209 , de modo que los niveles de grises menores al umbral se convirtieron en negro y los mayores en blanco (Figura 2.17.d). Los alveolos representan los puntos negros. Se consideró como umbral alveolar $0,005 \mathrm{~cm}^{2}$, valores por debajo de ese umbral no se cuentan como alveolos, sino como imperfecciones de la imagen.

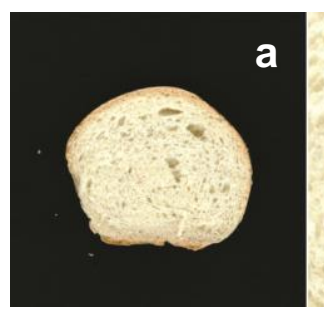

b

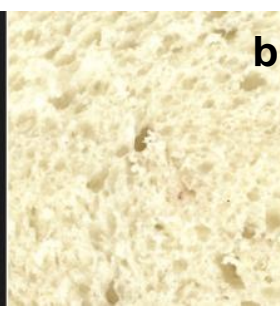

b.

Figura 2.17. Secuencia realizada en el análisis de imágenes de las migas

Se determinaron los siguientes parámetros:

- Número total de alveolos (N): Números total de alveolos por unidad de área $\left(\mathrm{cm}^{-2}\right)$

- Area media de los alveolos (AM): Calculada como el área ocupada por los alveolos respecto a la cantidad de alveolos. Se expresa en $\mathrm{cm}^{2}$.

- Fracción de aire (AT): es el porcentaje del área total que corresponde al área ocupada por los alveolos. Se calcula como el área ocupada por los alveolos respecto al área total de la imagen seleccionada.

\subsubsection{Evaluación de la vida útil de los panes}

Los panes se envolvieron individualmente en film y se envasaron en bolsas de 
polietileno y almacenaron durante 1 y 3 días y algunos niveles durante 5 y 7 días a (20 $\pm 0,1){ }^{\circ} \mathrm{C}$. El envejecimiento del pan se analizó a través de medidas de humedad y perfil de textura de miga y el proceso de retrogradación del almidón por calorimetría diferencial de barrido y difractometría de rayos $X$.

\subsubsection{Análisis de perfil de textura de las migas}

Se procedió según se explicó en la sección 2.2.10.3.3.

\subsubsection{Modelado de envejecimiento. Avrami}

El proceso de panificación es uno de los factores más importantes que determinan las características del pan y la cinética de endurecimiento del mismo. Se aplico la ecuación de Avrami modificada, para estudiar la cinética de envejecimiento del pan, a la firmeza de la miga en función del tiempo de almacenamiento. Esta ecuación fue derivada para la cristalización en una matriz sólida restringida, y considera que la fracción de cristalización que está por ocurrir es una función exponencial decreciente respecto al tiempo. Este modelo ha sido ampliamente utilizado para la descripción de medidas de envejecimiento y caracterización de firmeza de la miga con limitaciones en el análisis matemático. En la mayoría de los trabajos, se ha utilizado una regresión nolineal para modelar y obtener uno o más parámetros de envejecimiento de pan (Kim y col., 1977c; Russell, 1983).

La aplicación de este modelo en la firmeza del pan se basa en la retrogradación del almidón, y en este contexto los parámetros matemáticos de la ecuación de Avrami (Ec. 2.34) involucran un significado físico:

$$
\theta(t)=\left(T_{\infty}-T_{t}\right) /\left(T_{\infty}-T_{0}\right)=\exp \left(-k \cdot t^{n}\right)
$$

donde:

$\theta$ : Fracción de recristalización que ocurrirá en el tiempo.

$T_{0}, T_{t}$ y $T_{\infty}$ : Firmeza inicial, en el tiempo t y en un tiempo infinito,

$\mathrm{k}$ : constante de velocidad (por lo general $1 / \mathrm{k}=$ constante de tiempo para comparar la tasa de endurecimiento del pan, depende de la velocidad de crecimiento de los cristales y de la nucleación). Posee unidades: días ${ }^{-1}$.

$\mathrm{n}$ : es el exponente de Avrami, que es una característica relacionada con la 
forma en que se produce la nucleación de pequeños cristales y su posterior crecimiento.

Se almacenaron los panes control y las formulaciones 1, 2, 3 y 4 de los distintos diseños obtenidos como se describió en la sección 2.2.10.2 y se almacenaron durante 7 días. Los días 1, 3, 5 y 7 se determinaron la firmeza de la miga (sección 2.2.10.3.3)

\subsubsection{Humedad de las migas}

Se procedió según se explicó en la sección 2.2.10.3.4.

\subsubsection{Retrogradación del almidón}

La retrogradación de la amilosa y amilopectina, componentes principales del almidón responsable del incremento en la dureza, se analizó mediante las siguientes técnicas:

\subsection{Calorimetría Diferencial de Barrido. DSC}

Se procedió a la gelatinización del almidón de las masas frescas según se explico en la sección 2.2.9.1, pero calentando hasta $105^{\circ} \mathrm{C}$, temperatura que alcanza la miga en el centro del pan con el fin de simular el horneado. Luego se almacenaron las diferentes capsulas en cámara de $(20 \pm 0,1)^{\circ} \mathrm{C}$ durante 3,5 y 7 días. Una vez alcanzado el tiempo de almacenamiento se repitió el calentamiento en el calorímetro diferencial de barrido y se determinaron los mismos parámetros obtenidos durante la gelatinización. Sólo se observa la retrogradación de la amilopectina, ya que la amilosa retrogradada es estable a la temperatura estudiada y no puede cuantificarse por esta técnica.

Para evaluar el proceso de retrogradación puede calcularse también el índice de retrogradación (IR) (León y col., 1997; Bárcenas y Rosell, 2005) que se define como el cociente entre la entalpía de retrogradación y la entalpía de gelatinización (Ec. 2.35).

$$
\operatorname{IR}(\%)=\frac{\Delta \mathrm{Hr}}{\Delta \mathrm{Hg}}{ }^{*} 100
$$

donde: 
$\Delta \mathrm{H}_{\mathrm{r}}$ : variación de entalpia de masa gelatinizada, luego del almacenamiento.

$\Delta \mathrm{H}_{\mathrm{g}}$ : variación de entalpia de masa durante la gelatinización.

\subsection{Difracción de Rayos X. DRX}

Se congelaron a $-80^{\circ} \mathrm{C}$ y se liofilizaron migas de pan previamente almacenados a 0 y 5 días. Las migas liofilizadas se molieron y se comprimieron durante 5 min en el recipiente de muestra del equipo con un émbolo de $1000 \mathrm{~g}$. Las muestras se cubrieron con un film de kapton y se analizaron en un difractómetro X'Pert Pro (PANalytical, Holanda) de polvo equipado con un programa de análisis de datos con monocromador de grafito cristalino. El equipo consta con un generador de rayos $X$ equipado con un tubo de cobre que opera a una tensión de $40 \mathrm{kV}$ y a una corriente de $40 \mathrm{~mA}$. La muestra es irradiada con una radiación monocromática $\mathrm{Cu} \mathrm{k}_{\alpha}$ a una longitud de onda de $0,154 \mathrm{~nm}$. Se realizó un barrido rutinario equivalente a $1 \% / \mathrm{min}$ (un paso de $0,02^{\circ} 2 \theta$ y 1 segundo de conteo por paso) en un rango $2 \theta$ de 4-40 grados.

Las áreas cristalinas y la fracción amorfa se cuantificaron por ajuste de los patrones de difracción. El grado de cristalinidad se determinó mediante el cociente entre el área total de la fracción cristalina y el área total del espectro correspondiente a las fracciones cristalina y amorfa.

\subsubsection{Análisis estadístico}

Se realizó un análisis de varianza monofactorial de los pseudoreplicados de los diferentes parámetros estudiados cuyo factor fue la formulación en un mismo DCC estudiado.

En los ensayos de congelación y almacenamiento se compararon las medias a través de un análisis de varianza monofactorial, el factor fue la formulación y el tiempo, respectivamente.

\subsubsection{Optimización de la formulación de los panes}

Los niveles óptimos de los ingredientes utilizados, sal de calcio e inulina, fueron determinados mediante la superposición de las superficies de contorno de alguna de las variables estudiadas sobre el pan (Capanzana y Buckle, 1997; Vatsala y col., 
2001).

Las formulaciones óptimas fueron seleccionadas de acuerdo al mayor valor de deseabilidad y utilizadas para calcular los valores predichos de variables de respuesta mediante las ecuaciones de predicción derivadas por RSM. Se verificó experimentalmente la formulación óptima de los panes predicha a partir de cada diseño y los resultados se compararon estadísticamente a los valores predichos del modelo matemático.

\subsubsection{Evaluación sensorial de los panes}

Se realizó un análisis sensorial de los panes óptimos con un panel no entrenado de aproximadamente 45 personas empleando una escala hedónica de 9 puntos para evaluar la magnitud de la diferencia entre los parámetros evaluados para las diferentes muestras. Los atributos evaluados fueron: sabor, textura, apariencia y aceptabilidad global.

\subsubsection{Estudio nutricional de los panes}

La calidad nutricional de algunos de los panes del diseño experimental se estudió a través de ensayos in vitro e in vivo. Los ensayos in vitro se realizaron sobre panes de mejor calidad tecnológica cuya fórmula resultó de la optimización a través de la metodología de superficie de respuesta. La formulación CA4 fue la que se utilizó para los ensayos in vivo.

\subsubsection{Calidad nutricional in vitro}

Se determinó la composición porcentual de los panes óptimos y del pan secado y molido que se emplearon para la realización de la dieta de los ensayos in vivo. Sobre los panes óptimos se determinó además de la composición porcentual, la digestibilidad de almidón y la disponibilidad de hierro y calcio.

\subsection{Composición porcentual}

Se determinó el contenido de cenizas, proteínas, humedad y fibra dietaria total según lo descripto en la sección 2.2.1. Y el contenido de lípidos se determinó empleando el método de ratzlaff según método 30-10-01 (AACC, 2000). 


\section{Determinación del porcentaje de Inulina-FOS del pan seco y molido (CA4)}

Una suspensión de pan al 10\% p/v en agua destilada se la coloca en un baño de agua a $85{ }^{\circ} \mathrm{C}$ con agitación constante durante $30 \mathrm{~min}$. La inulina y FOS se solubilizan en agua. Concluido el tiempo se filtra una porción de la solución acuosa, colocando el filtrado en un tubo eppendorf listo para ser inyectado en el cromatógrafo. Se utilizó la técnica de HPLC (High Performance Liquid Chromatography) empleando una columna de intercambio iónico y un detector de índice de refracción. Flujo =0,7 $\mathrm{ml} / \mathrm{min}$. Se utilizó una suspensión de Synergy1 como patrón. Se obtuvo el tiempo de retención del pico y las áreas de pico a partir de las cuales se calculó el porcentaje de prebiótico como:

$$
\% \text { syn }=\frac{A_{\text {pan }}}{A_{\text {patrón }}} * 10
$$

donde:
$A_{\text {pan }}$ : Área del pico obtenida a partir de la solución acuosa de pan
A patrón: Área del pico obtenida a partir de la solución acuosa de patrón
10: factor de dilución.

\subsection{Digestibilidad de almidón}

Para medir la digestión del almidón se utilizó el método in vitro reportado por Holm y col. (1985). Se determinó la tasa de hidrólisis in vitro del almidón de un alimento tal como se ingiere como una medida de la digestibilidad del almidón. El polisacárido es hidrolizado con $\alpha$-amilasa, se reduce a azúcares los cuales son expresados como equivalentes de maltosa determinados espectrofotométricamente.

\section{Reactivos utilizados}

$\checkmark$ Buffer fosfato: se disuelven en $700 \mathrm{ml}$ de agua $3,03 \mathrm{~g} \mathrm{KH}_{2} \mathrm{PO}_{4}, 3,96 \mathrm{~g}$ $\mathrm{Na}_{2} \mathrm{HPO}_{4} \cdot 2 \mathrm{H}_{2} \mathrm{O}$ y $0,40 \mathrm{~g} \mathrm{NaCl}$. Se lleva a $\mathrm{pH}$ 6,9 y a 1 litro en matraz aforado.

$\checkmark$ Reactivo de 3,5 dinitrosalicílico (DNS): se disuelve en cierta cantidad de agua destilada 10,0 $\mathrm{g}$ de ácido 2,3 dinitrosalicílico, $300 \mathrm{~g}$ tartrato de sodio y potasio tetrahidratado y $16 \mathrm{~g}$ de $\mathrm{NaOH}$. Se lleva a 1 litro. 
a-amilasa Tipo IA $1200 \mathrm{U} / \mathrm{mg}$ (Sigma): Diluir $56 \mu \mathrm{l}$ de enzima con $16 \mathrm{ml}$ de buffer fosfato (preparados dentro de los 30 minutos previos al comienzo de la hidrólisis).

$\checkmark$ maltosa anhidra: solución patrón $0,2 \mathrm{mg} / \mathrm{ml}$ en agua destilada.

\section{Protocolo}

En este ensayo a $500 \mathrm{mg}$ de almidón o su equivalente se le añaden $50 \mathrm{ml}$ de buffer fosfato y se incuba a $37^{\circ} \mathrm{C}$ con agitación constante. En nuestro caso el equivalente resultó ser la miga de los tres panes óptimos y del pan control, considerando el contenido de hidratos de carbono totales como almidón. Antes de adicionar la enzima, se tomaron dos alícuota de $0,2 \mathrm{ml}$ cada una para marcar como tiempo cero. Posteriormente se adicionó la enzima $\alpha$-amilasa y a los 5, 15, 30 y 60 min se tomaron alícuotas de 0,2 ml, los cuales se colocaron en tubos de ensayo conteniendo 0,8 $\mathrm{ml}$ de agua destilada. Los tubos fueron calentados en un baño de agua en ebullición por 10 min. Una vez frio, se les agregó $1 \mathrm{ml}$ de reactivo de DNS en todos los tubos y se colocaron en baño maría nuevamente durante 10 minutos para favorecer la reacción de los azúcares reductores (principalmente lactosa) con el DNS. Luego se añadieron $15 \mathrm{ml}$ de agua destilada realizando una buena homogenización de la mezcla. Se leyeron las absorbancias a $530 \mathrm{~nm}$ en paralelo con una curva estándar de maltosa (0 $2 \mathrm{mg}$ maltosa/ $2 \mathrm{ml}$ ). Finalmente se calculó la tasa de hidrólisis como los $\mathrm{mg}$ de maltosa/g almidón liberada durante la hidrólisis. La masa de almidón se calculó teniendo en cuenta la cantidad de harina de cada formulación

\subsection{Disponibilidad de hierro, calcio y cinc}

Se analizó la dializabilidad de estos minerales, como un indicador de la biodisponibilidad potencial por medio del método in vitro de Miller y col. (1981), modificado por Wolfgor y col. (2002). El procedimiento involucra una digestión enzimática en condiciones que simulan las fisiológicas.

\section{Reactivos utilizados}

$\checkmark$ Solución a -amilasa (SIGMA): $6 \mathrm{~g}$ de amilasa/100 $\mathrm{ml}$ de agua.

$\checkmark \mathrm{HCl} 6 \mathrm{~N}$ valorado

$\checkmark$ Solución de pepsina (SIGMA): $16 \mathrm{~g}$ de pepsina/100 $\mathrm{ml}$ de $\mathrm{HCl} 0,1 \mathrm{~N}$.

$\checkmark$ PIPES (SIGMA P-3768): Concentración calculada en base a los meq totales calculados. 
Solución de bilis-pancreatina: $2,5 \mathrm{~g}$ bilis y $0,4 \mathrm{~g}$ de pancreatina en $100 \mathrm{ml}$ de $\mathrm{NaHCO}_{3} 0,1 \mathrm{~N}$.

\section{Protocolo}

A $15 \mathrm{~g}$ de pan molido en una procesadora se le adicionó $7 \mathrm{ml}$ de una solución acuosa al $3 \%$ de a-amilasa y $45 \mathrm{ml}$ de agua destilada. Se incubó durante $30 \mathrm{~min}$ a $37^{\circ} \mathrm{C}$ con agitación.

Se ajustó el pH en 2 con solución valorada de $\mathrm{HCl} 6 \mathrm{~N}$ y se agregaron 1,6 $\mathrm{ml}$ de pepsina- $\mathrm{HCl}$, incubándose la mezcla a $37^{\circ} \mathrm{C}$ durante 2 hs, con agitación (digestión estomacal).

Dos alícuotas de $15 \mathrm{~g}$ del digerido se colocaron en frascos limpios con bolsas de diálisis (Spectrapore Molecular Weight cut-off 6000-8000) conteniendo 18,75 ml de buffer PIPES 0,15 M y pH variable. El pH del buffer a utilizar se establece luego de hacer ensayos previos en base a la matriz alimentaria en estudio, para obtener un $\mathrm{pH}$ final uniforme de 6,5 $\pm 0,2$, al final de la segunda incubación a $37 \stackrel{\circ}{ } \mathrm{C}$.

Después de una hora de incubación, cuando el pH alcanzó un valor mínimo de 4,5 se agregaron $3,75 \mathrm{ml}$ de una mezcla de bilis-pancreatina prosiguiéndose la incubación durante dos horas a $37^{\circ} \mathrm{C}$ (digestión intestinal).

Las bolsas de diálisis fueron removidas y enjuagadas con agua ultra pura y los dializados se transfirieron a tubos tarados y se pesaron. Se procedió a la mineralización de los dializados con mezcla $\mathrm{HNO}_{3}$ y $\mathrm{HClO}_{4}$ en partes iguales a $140 \stackrel{\circ}{ } \mathrm{C}$ durante 2 hs. Se determinó el contenido total de minerales por espectroscopia de absorción atómica y se calculó la dializabilidad mineral porcentual $\left(D_{M}\right)$ según la ecuación 2.37 como:

$$
D_{M}=\frac{m_{d}}{m_{D}} * 100
$$

donde:

$m_{d}$ : masa del mineral $M$ en el dializado. Expresada en miligramos ( $\mathrm{mg}$ ). $\mathrm{m}_{\mathrm{D}}$ : masa del mineral $\mathrm{M}$ total en la muestra digerida. Expresada en $\mathrm{mg}$. 


\section{Determinación de calcio, hierro y cinc.}

El contenido de calcio, hierro y cinc en las muestras se determinaron (previa mineralización por vía húmeda con mezcla nitro-perclórica) utilizando un espectrofotómetro de absorción atómica (Perkin Elmer AAnalyst 400, Estados Unidos), con llama de aire-acetileno, slit de $0,5 \mathrm{~mm}$ y longitud de onda de $422,7 \mathrm{~nm}$ para el calcio, de $248,3 \mathrm{~nm}$ para hierro y de $213,9 \mathrm{~nm}$ para el cinc. Se agregó cloruro de lantano, 6500 ppm en la solución de lectura, para evitar interferencias de fósforo en la determinación del calcio (AOAC, 2000). El material de referencia NIST 8435 RM (leche entera en polvo) también fue sometido a un tratamiento idéntico para verificar la exactitud de los procedimientos analíticos.

\subsubsection{Calidad nutricional in vivo}

Se hizo un estudio in vivo empleando ratas machos Wistar que se dividieron en tres lotes, administrándose a cada uno durante 60 días, una dieta diferente. Las dietas fueron: Dieta control (DC), dieta + Synergy1 (DS) y dieta + pan (DP). El pan seleccionado para la realización del ensayo in vivo fue el que contenía 2400 ppm de $\mathrm{Ca}$, como $\mathrm{CaCO}_{3}$ y $12 \%$ de Synergy1 (base harina) (formulación CA4) debido a que era la formulación que presentaba mejor calidad panadera al momento de realizar el experimento. Se preparó una gran cantidad de pan, con varias panificaciones que fue congelado hasta el momento de ser utilizado; en ese momento se descongeló, se cortó en rodajas de $1 \mathrm{~cm}$ de espesor que se colocaron en una bandeja metálica y se secaron en estufa a convección forzada a $40{ }^{\circ} \mathrm{C}$, durante $20 \mathrm{~min}$ (10 min de cada lado). Una vez frio se molió para ser empleado como ingrediente en la dieta animal.

Durante la experiencia se evalúo la ingesta de nutrientes, el incremento de peso de los animales y la densidad mineral ósea (DMO). Se calculó la absorción aparente de calcio. En forma complementaria, con el objetivo de determinar si las dietas producen una modificación de la microbiota intestinal de los animales, se realizó recuento de bacterias viables y se estudió la huella genética de la microbiota intestinal mediante amplificación por reacción en cadena de la polimerasa (PCR, polymerase chain reaction) y detección de los productos por electroforesis en gel con gradiente desnaturalizante (DGGE, Denaturing Gradient Gel Electrophoresis). Una vez sacrificados los animales se les removió el ciego, el fémur y la tibia para evaluar la consecuencia de las diferentes dietas. 


\subsection{Diseño experimental}

Se utilizaron tres lotes de 8 animales cada uno a los que se les suministro las dietas control (DC), dieta con Synergy1 (DS) y dieta con pan (DP) durante 60 días. En la Figura 2.18 se muestra un esquema del diseño experimental usado y la cronología de los ensayos realizados durante la experiencia antes del sacrificio de los animales.

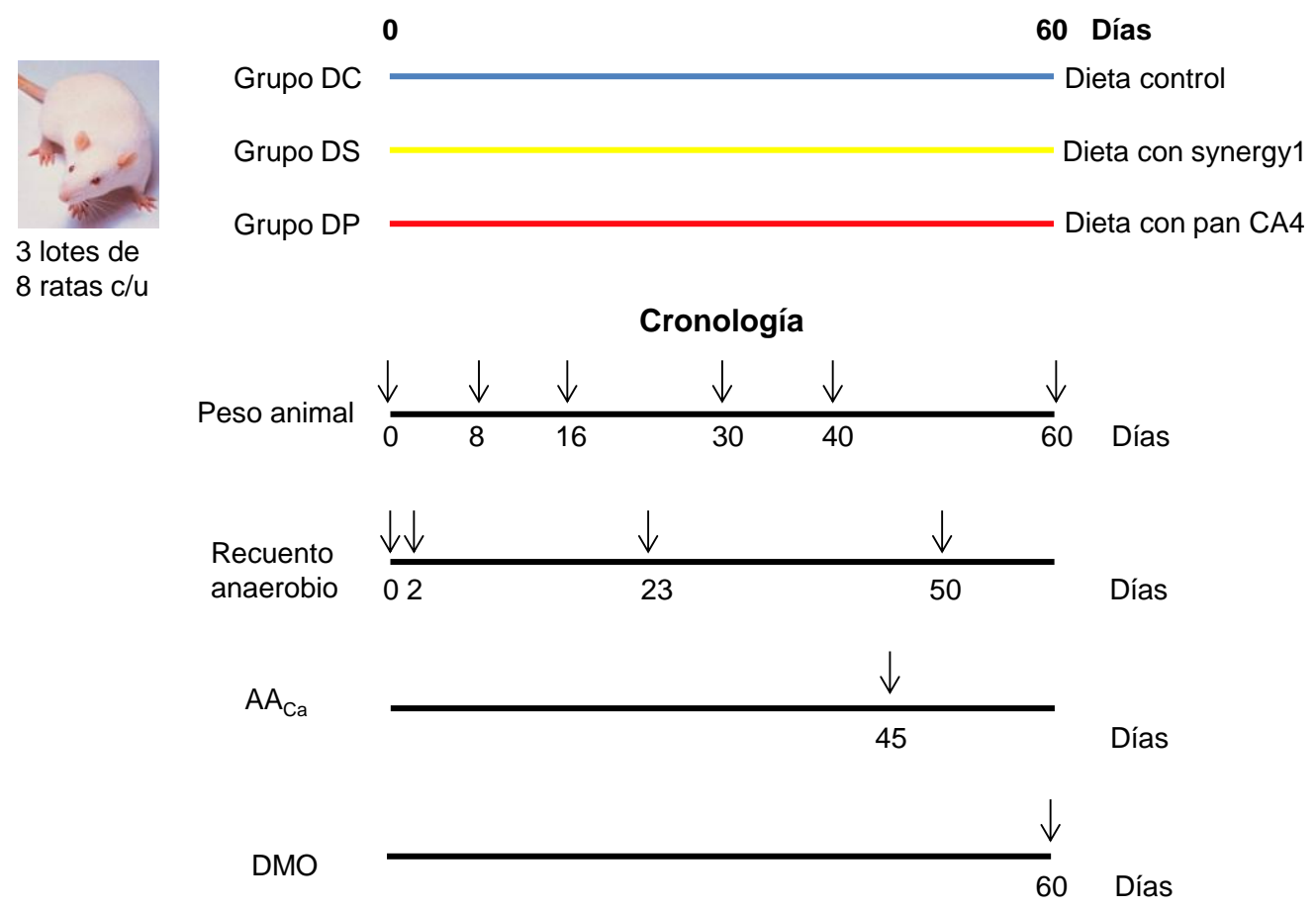

Figura 2.18. Esquema del diseño experimental utilizado.

\subsection{Animales}

Se trabajó con ratas Wistar machos obtenidas por parto normal luego de 21 días de gestación $(n=24)$, las madres pertenecientes al bioterio de la Cátedra de Bromatología y Nutrición de la Facultad de Farmacia y Bioquímica de la Universidad de Buenos Aires fueron alimentadas con dieta stock para roedores a libre demanda. La madre y su progenie (6 a 8 por madre) se trasladaron a jaulas plásticas hasta el destete (alrededor de 21 días de edad). Finalizado el destete, se pesaron y se distribuyeron al azar en tres grupos de 8 ratas cada uno de manera que el peso promedio inicial de cada grupo no presentara diferencias estadísticamente significativas entre sí.

Durante toda la experiencia, se mantuvieron los animales en jaulas galvanizadas individuales, con piso de malla, para controlar las condiciones de higiene y evitar la 
coprofagia. Se respetaron los ciclos luz-oscuridad de 12 horas (8-20 hs: ciclo luz), la temperatura ambiente $(21 \pm 1) \stackrel{\circ}{\circ}$ y la humedad relativa $(60 \pm 10) \%$, para no alterar el ritmo de alimentación. En todo momento se controló el agua para beber (dispuesta a libre demanda). Se siguieron las normas de la guía para el cuidado y uso de animales de experimentación de acuerdo al National Institute of Health (NIH) aprobado por el Comité de Ética, Guía para el Cuidado y Uso de Animales de Laboratorio de la Facultad de Farmacia y Bioquímica de la Universidad de Buenos Aires.

\subsection{Dietas}

Las dietas fueron confeccionadas de acuerdo al documento elaborado por el American Institute of Nutrition Rodent Diets (Revers, 1993), los ingredientes empleados en la elaboración de las tres dietas utilizadas en este ensayo se muestran en la Tabla 2.2. Se adicionó un $10 \%$ p/p In en la dieta proveniente del pan CA4 molido (DP) o de la In directamente (DS). En la dieta control se utilizó celulosa como fuente de fibra (5\%). La proteína agregada fue caseinato de potasio (Nestle Argentina S.A., contiene un 85\% de proteínas y 0,095\% Ca), los lípidos (aceite de maíz comercial). La mezcla de minerales y vitaminas de acuerdo a AIN 93 M-MX y VX, respectivamente. La dextrina fue adicionada como carbohidrato hasta completar el kilo de dieta.

Como la dieta DP contenía pan, que aporta proteínas, se agregó menos caseína que en las otras dos dietas a fin de obtener la misma cantidad de proteínas en las tres. Lo mismo ocurrió con las sales minerales y los lípidos.

Tabla 2.2. Ingrediente empleado por $\mathrm{kg}$ de dieta.

\begin{tabular}{cccc}
\hline & DC & DS & DP \\
\hline Caseinato de K (g) & 200 & 200 & 116 \\
Sales minerales (g) & 35 & 35 & 16,2 \\
Mezcla vitamínica (g) & 10 & 10 & 10 \\
L-Cistina (g) & 3 & 3 & 3 \\
Solución de Vit A (ml) & 1 & 1 & 1 \\
Aceite (g) & 69 & 69 & 41,2 \\
Colina (m) & 7,1 & 7,1 & 7,1 \\
Synergy1 & ----- & 100 & ---- \\
Pan & ----- & ---- & 763,4 \\
Fibra (celulosa) & 50 & ---- & ---- \\
Dextrina (g) & 624,9 & 574,9 & 42,1 \\
\hline
\end{tabular}




\section{Análisis de composición de la dieta}

Se realizaron los análisis de composición de las dietas según se describió en la sección 2.2.15.1.1 para confirmar que fueran isocalóricas. Se determinó también el contenido de calcio a partir de las cenizas.

\section{Determinación de calcio}

Las cenizas obtenidas luego de la mineralización por vía seca en mufla a $550 \stackrel{\circ}{\mathrm{C}}$ se disolvieron en ácido clorhídrico concentrado p.a. y se llevaron a volumen adecuado con agua destilada. Se determinó el contenido de Ca según se describió en la sección 2.2.15.1.3.

\subsection{Consumo de dieta}

El consumo cada dos o tres días se calculó por la diferencia de peso del comedero con una balanza electrónica Mettler PC 4400 (precisión $\pm 0,1$ ) g y en base al consumo se calculó la ingesta diaria ( $\mathrm{g} /$ día) e ingesta total durante toda la experiencia.

\subsection{Peso corporal}

Se efectuó el registro de peso de cada cría al inicio de la experiencia, durante y al finalizar la misma, utilizando balanza analítica OHASUS Explorer (precisión $\pm 0,01$ ) g.

\subsection{Densidad mineral ósea}

Se determinó la densidad mineral ósea (DMO) de los animales anestesiados previamente $(0,1 \mathrm{mg}$ de clorhidrato de ketamina $+0,1 \mathrm{mg}$ de maleato de acetopromazinc, ambos cada $100 \mathrm{~g}$ de peso corporal) hacia el final del ensayo y previo al sacrificio. La DMO del esqueleto axial y apendicular se midió en un densitómetro DPX (DPX Alpha 8034, Lunar Radiation Corporatioon, Madison, WI, Estados Unidos) con un programa especial para pequeños animales. Se realizó una densitometría total (cuerpo entero), de columna, fémur y tibia proximal. El equipo estima el contenido mineral óseo (CMO), expresado en gramos, pero como no todos los animales pesan lo mismo, se relativiza este parámetro expresándolo en miligramos por kilogramo de peso corporal. También determina el área de todo el cuerpo de la rata, de la columna, 
del fémur y tibia proximal, expresada en $\mathrm{cm}^{2}$ y por último calcula la densidad mineral ósea (DMO) definida como CMO/Área, que se expresa en $\mathrm{mg} / \mathrm{cm}^{2}$.

La precisión fue evaluada midiendo a la misma rata cinco veces con reposicionamiento entre mediciones sobre el mismo animal. El coeficiente de variación (CV) fue de 0,9\% para la DMO de esqueleto total y 3,0\% para el CMO.

El análisis de las diferentes sub-áreas se llevó a cabo sobre la imagen del animal en la pantalla utilizando herramientas ROI (Region Of Interest) para cada segmento. El CV de $\mathrm{CMO}$ fue de 2,2\% para el fémur. Para minimizar las variaciones del observador, todos los análisis fueron realizados por el mismo técnico.

\subsection{Absorción aparente de calcio}

Durante la última quincena se midió el consumo de alimento durante tres días, recogiendo simultáneamente las heces para calcular el porcentaje de absorción de Ca. Se calcinaron y mineralizaron las heces y las dietas hasta la obtención de cenizas blanquecinas y se continúo con la determinación de calcio según se describió en la sección 2.2.15.1.3. Se calculó la absorción aparente de calcio $\left(A_{\mathrm{Ca}}\right)$ según la ecuación 2.38:

$$
A_{C a}(\%)=\frac{(I-F)}{I} * 100
$$

donde:

I: Calcio ingerido en la dieta. Expresado en mg

F: Calcio excretado en materia fecal. Expresado en mg

\subsection{Microbiota de homogenatos fecales}

Se tomaron muestras de materia fecal de las ratas de todos los lotes durante los días $0,2,9,16,23,30,50$ y 60 de la experiencia en tubos estériles. Se las dividió en dos fracciones. A una fracción se le realizó un recuento de anaerobios viables y otra fracción fue congelada a $-80 \stackrel{\circ}{ } \mathrm{C}$ hasta su posterior análisis por DGGE (Denaturing Gradient Gel Electrophoresis) 


\section{Recuento de anaerobios viables}

Se realizó un recuento de microorganismos viables dirigido a las poblaciones de bifidobacterias y lactobacilos. Para ello se tomaron muestras de materia fecal de ratas pertenecientes a los diferentes lotes y se les realizó un recuento por siembra en superficie en agar MRS (De Man y col., 1960) con cisteína (0,05\% p/v).

\section{Medios de cultivo utilizados}

$\checkmark$ Buffer PBS: $\mathrm{KH}_{2} \mathrm{PO}_{4}(0,144 \mathrm{~g} / \mathrm{l}), \mathrm{NaCl}(9,0 \mathrm{~g} / \mathrm{l}), \mathrm{Na}_{2} \mathrm{HPO}_{4}(0,795 \mathrm{~g} / \mathrm{l}), \mathrm{H}_{2} \mathrm{O}$ (c.s.p. $\left.1 \mathrm{l}\right)$

$\checkmark$ Caldo MRS: Se utilizó caldo MRS Difco (Difco Laboratories, Detroit, MI, Estados Unidos) con la siguiente composición: Peptona universal (10 g/l), Extracto de carne (5 $\mathrm{g} / \mathrm{l})$, Extracto de levadura (5 g/l), D(+) glucosa (20 g/l), $\mathrm{K}_{2} \mathrm{HPO}_{4}(2 \mathrm{~g} / \mathrm{l})$, Tween 80 (1 g/l), Citrato ácido de amonio (2 g/l), Acetato de sodio (5 g/l), $\mathrm{MgSO}_{4}(0,1 \mathrm{~g} / \mathrm{l}), \mathrm{MnSO}_{4}(0,05$ g/l). pH final: 6,5.

$\checkmark$ Agar MRS: Caldo MRS junto a 0,05\% p/v cisteína (Cys) y agar (15 g/l).

\section{Protocolo}

Se introdujo una cantidad conocida de materia fecal dentro de un tubo estéril que contenía $1 \mathrm{ml}$ de buffer PBS y se procedió a disgregarlo en esterilidad. Posteriormente se realizaron diluciones seriadas de dicha muestra homogeneizada en buffer PBS estéril y se sembró $0,1 \mathrm{ml}$ de la muestra en agar MRS con Cys por duplicado. Las muestras se incubaron en anaerobiosis a $37^{\circ} \mathrm{C}$ durante 48 hs. Finalmente, se contó el número de colonias y el resultado se expresó en unidades formadora de colonias por gramo de materia fecal -MF- (ufc/g MF). Se tomaron fotos de las diferentes colonias obtenidas utilizando una lupa (LEICA, Alemania).

\section{Coloración de gram}

Se les realizó la coloración de Gram y seguidamente se hizo la observación microscópica de los preparados.

\section{Soluciones de trabajo}

Cristal violeta: $10 \mathrm{~g} / \mathrm{l}$ en agua destilada. 
Safranina (solución madre): $25 \mathrm{~g} / \mathrm{l}$ de etanol. Se realiza una dilución 1/10 en agua destilada para realizar la coloración.

Lugol: $10 \mathrm{~g} \mathrm{I}_{2}+20 \mathrm{~g} \mathrm{KI}$ en 1 I de agua destilada.

$\checkmark$ Decolorante: etanol: acetona en relación 4:1.

$\checkmark$ Las soluciones deben ser filtradas antes de ser utilizadas.

\section{Protocolo}

La coloración se llevó a cabo a partir de cultivos frescos de los microorganismos. Se fijó las muestras a la llama y posteriormente se aplicaron las soluciones y se realizaron los sucesivos lavados siguiendo el esquema que se detalla en la Tabla 2.3:

Tabla 2.3. Esquema realizado en la coloración de gram

\begin{tabular}{cc}
\hline Solución & Tiempo \\
\hline Cristal violeta & $2 \mathrm{~min}$ \\
Lugol & $30 \mathrm{~s}$ \\
Lugol & $30 \mathrm{~s}$ \\
\hline \multicolumn{2}{c}{ Lavar con agua } \\
\hline Decolorante & $10 \mathrm{~s}$ \\
\hline \multicolumn{2}{c}{ Lavar con agua } \\
\hline \multicolumn{2}{c}{ Safranina } \\
\hline
\end{tabular}

\section{Análisis de diversidad microbiológica}

Se realizó un análisis de diversidad microbiológica empleando la técnica DGGE. Se extrajo ADN (Ácido desoxirribonucleico) de algunas de las muestras de materia fecal congeladas a $-80^{\circ} \mathrm{C}$. Se estudió la huella genética de la microbiota intestinal mediante amplificación de regiones variables de ARNr 16S por PCR (Reacción de polimerasa en cadena), se realizó una electroforesis en gel de agarosa para confirmar si la amplificación fue óptima y finalmente se realizó la electroforesis en gradiente desnaturalizante.

\section{Obtención de ADN a partir del contenido fecal}

Una porción de materia fecal (500 mg) fue colocada en $1 \mathrm{ml}$ de buffer PBS. A partir de dicha suspensión se procedió a la extracción de ADN genómico utilizando un kit 
comercial específico para este tipo de muestra (AccuPrepStool ADN Extraction kit, BIONEER, Corea) (Gueimonde y col., 2004). Para ello se siguieron las instrucciones descriptas por el proveedor. El ADN obtenido se almacenó hasta su uso en tubos eppendorf libres de $\mathrm{ADN}$ a $-18^{\circ} \mathrm{C}$.

\section{Amplificación del ADNr 16S}

Se amplificó la región V3 del gen que codifica para el ARNr 16S, utilizando los oligonucleótidos sintéticos 518R/341F-GC (Invitrogen, Estados Unidos) de 193 pares de bases, pb. Para el análisis de la diversidad microbiana en materia fecal se utilizaron los siguientes iniciadores (primers) de regiones conservadas de la región V3 del 16S rDNA.

Las secuencias 5' => 3' de ambos primers fueron:

\section{R: ATT ACC GCG GCT GG}

341F-GC: CGC CCG CCG CGC GCG GCG GGC GGG GCG GGG GCA CGG G

Para la amplificación se procedió a preparar una mezcla inicial de reacción (premix) que consta de los siguientes reactivos necesarios para la amplificación (Tabla 2.4)

Tabla 2.4. Volumenes empleados para la preparación de premix.

\begin{tabular}{cc}
\hline & $\mathbf{V}(\boldsymbol{\mu l})$ \\
\hline Buffer Taq 10X (Inbio-Highway, Tandil) & 5 \\
$\mathbf{M g C l}_{2}$ (Inbio-Highway, Tandil) & 5 \\
dNTP (Inbio-Highway, Tandil) & 5 \\
Oligonucleótidos sintéticos (Invitrogen, Estados Unidos) & $2,5(\mathrm{c} / \mathrm{u})$ \\
Taq polimerasa (Inbio -Highway, Tandil) & 0,5 \\
Agua miliQ & 26,42 \\
\hline
\end{tabular}

Los volúmenes varían según el número de muestras y el volumen final deseado. Tanto para la preparación del material como para la manipulación se utilizaron guantes con el objetivo de proteger a la muestra de enzimas que degradan el ADN o de la contaminación con material extraño. 
La mezcla de reacción se mantuvo en baño de hielo para conservar la actividad de la enzima polimerasa. Luego se fraccionó en tubos eppendorf y se adicionó a cada uno de ellos el ADN molde que se deseaba amplificar. La cantidad de ADN molde utilizado fue de $3 \mu$ de ADN molde.

La amplificación se llevó a cabo en un termociclador (MyCyclerThermalCycler, BioRad, Hercules, CA, USA) programado previamente con las temperaturas adecuadas a cada par de oligonucleótido. El programa utilizado para los oligonucleótidos ensayados se detalla en la Tabla 2.5

Tabla 2.5. Condiciones de a amplificación de la región V3 del ADNr 16S.

\begin{tabular}{cccc}
\hline \multicolumn{5}{c}{ Oligonucleótido sintético 518R/341F-GC } \\
\hline Temperatura $\left({ }^{\circ} \mathbf{C}\right)$ & Tiempo & $\mathbf{N}^{\circ}$ de ciclos & Descripción \\
\hline 94 & $5 \mathrm{~min}$ & 1 & Desnaturalización Inicial \\
94 & $30 \mathrm{~s}$ & & Desnaturalización \\
60 & $60 \mathrm{~s}$ & 30 & Annealing \\
72 & $30 \mathrm{~s}$ & & Extensión \\
72 & $5 \mathrm{~min}$ & 1 & Extensión final \\
\hline
\end{tabular}

Los amplicones obtenidos se almacenaron a $4^{\circ} \mathrm{C}$ hasta su utilización.

\section{Electroforesis en gel de agarosa}

Para constatar que los amplicones obtenidos tuviesen el tamaño esperado (193 bp) los mismos fueron separados en un gel de agarosa ( $1 \% \mathrm{p} / \mathrm{v}$ en buffer TAE) mediante electroforesis junto a un patrón de peso molecular de concentración y tamaño conocidos.

Se utilizó un equipo de electroforesis. Para la preparación del gel se pesaron $1 \mathrm{~g}$ de agarosa en frasco de vidrio y se le adicionaron $100 \mathrm{ml}$ de buffer TAE (previamente preparado utilizando material volumétrico y empleando agua MilliQ) y $10 \mu$ de bromuro de etidio (concentración). La solución resultante se calentó en microondas hasta disolución completa y luego se volcó sobre el soporte de electroforesis. Una vez solidificado se procedió a la siembra de las muestras. Para la preparación de las muestras se combinaron $25 \mu$ de cada producto PCR con $5 \mu$ de buffer de corrida (6X). Una vez completa la corrida, el gel fue revelado mediante observación en un 
transiluminador.

La verificación se realizó comparando en el gel las distancias recorridas por la muestra y el patrón.

Electroforesis en gel de acrilamida con gradiente desnaturalizante (Denaturing Gradient Gel Electrophoresis, DGGE)

Los amplicones evaluados mediante DGGE fueron los obtenidos por amplificación de un ADN molde con oligonucleótidos ricos en GC.

\section{Reactivos}

Solución de Acrilamida-Bisacrilamida 40\%: Acrilamida (38,93 g), Bisacrilamida (1,07 g), $\mathrm{H}_{2} \mathrm{O}$ bidestilada (c.s.p $100 \mathrm{ml}$ ). Filtrada a través de un filtro de 0,45 $\mu \mathrm{m}$ y conservada a $4{ }^{\circ} \mathrm{C}$.

Buffer de muestra: 0,25 $\mathrm{ml}$ de Azul de bromofenol (2\%), 0,25 $\mathrm{ml}$ de Xileno cianol (2\%), $7 \mathrm{ml}$ de Glicerol (100\%) y 2,50 ml de agua destilada.

Solución de teñido: $30 \mu \mathrm{l}$ de Sybr Gold (Invitrogen) y $300 \mu \mathrm{l}$ de Buffer TAE. Preparada en el momento de ser utilizada y conservada al reparo de la luz.

Gel apilador: $5 \mathrm{ml}$ de acrilamida/bisacrilamida (40\%), $5 \mu$ I TEMED y $5 \mu \mathrm{l}$ de persulfato de amonio (10\%).

Gel separador: $8 \%$ de acrilamida. Se prepara a partir de una solución de acrilamida/bisacrilamida (40\%).

Para preparar la solución de agente desnaturalizante $(80 \%)$ se le agrega urea y formamida de acuerdo al protocolo que se detalla en la Tabla 2.6:

Tabla 2.6. Composición de las soluciones 0 y $80 \%$ desnaturalizantes.

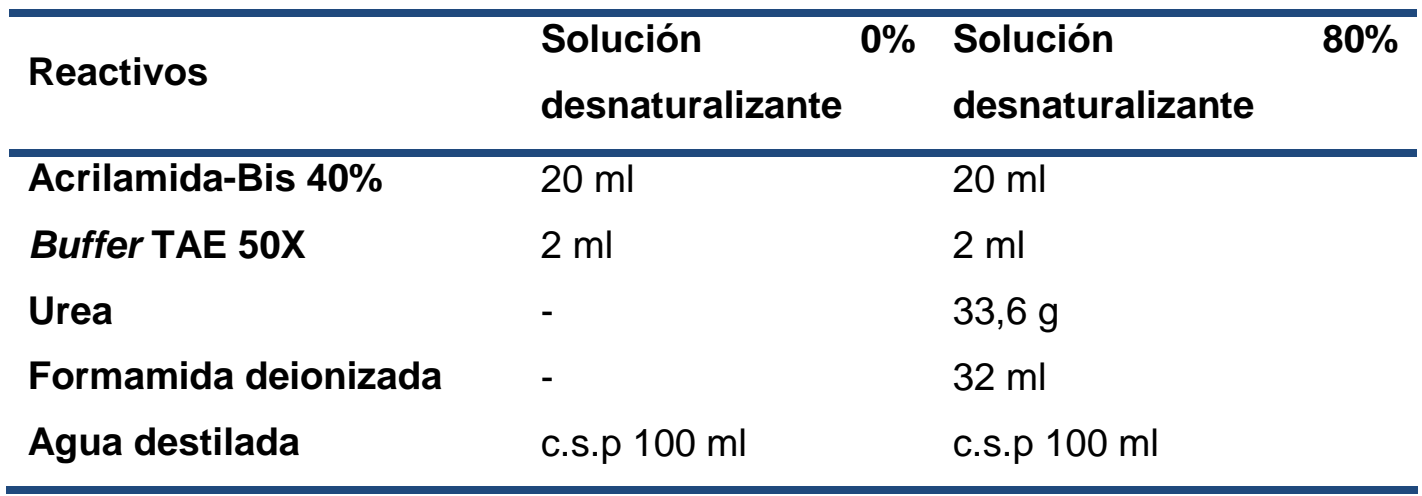




\section{Protocolo}

Se realizó una concentración en gradiente 40\%-60\% combinando las soluciones desnaturalizante $0 \%$ y $80 \%$ desnaturalizante (urea/formamida). Este gradiente fue el que mejor resolución presentó cuando se estudiaron diferentes cepas de bifidobacterias y lactobacilos (Hamet, 2012). Para preparar la concentración 40\% se mezcló $5,75 \mathrm{ml}(0 \%)$ y $5,75 \mathrm{ml}(80 \%)$ y para la $60 \% 2,87 \mathrm{ml}(0 \%)$ y $8,63 \mathrm{ml}(80 \%)$. Una vez combinadas ambas soluciones, e inmediatamente antes de comenzar a formar el gradiente, se les adicionó $4,4 \mu \mathrm{l}$ de Temed y $44 \mu \mathrm{l}$ de persulfato de amonio $10 \%$ y se agitó. Luego se procedió a la formación de los geles en gradiente. El gradiente desnaturalizante se formó utilizando un sistema de vasos comunicantes y bomba de vacío. Los vasos comunicantes se colocaron sobre un agitador magnético y se introdujo un buzo magnético en el vaso más cercano al orificio de salida que contendría la solución de mayor concentración de agente desnaturalizante. El equipo consta de dos soportes con una capacidad de cuatro geles (2 por soporte) por corrida. Una vez armados se introdujeron dentro de la cuba previamente cargada con buffer TAE y precalentada a $60^{\circ} \mathrm{C}$. Se encendió el sistema de recirculación de líquido del equipo y se procedió a la siembra de las muestras.

Previo a la siembra las muestras fueron combinadas con un volumen de buffer muestra (25 $\mu \mathrm{l}$ de muestra $+5 \mu$ de buffer muestra) y luego sembradas con jeringa Hamilton.

El equipo se conectó a una fuente a $100 \mathrm{~V}$ de modo que la corriente que pasara por cada gel fuera de aproximadamente de $35 \mathrm{~mA}$. Las corridas electroforéticas fueron de 16 horas a $60^{\circ} \mathrm{C}$. Se utilizó un equipo DGGE-2401 C.B.S (C.B.S. Scientific Co., Del Mar, CA, Estados Unidos) con geles de $15 \times 20 \times 0,75 \mathrm{~cm}$ de tamaño. Una vez finalizada la corrida electroforética, los geles fueron incubados en la solución de teñido (Sybr Gold, Invitrogen, USA) en oscuridad durante 30 minutos. Las bandas se observaron con luz UV en un transiluminador.

\section{Análisis del gel, comparación de bandas}

El análisis de los perfiles obtenidos por estas técnicas puede ser realizado visualmente o numéricamente. La interpretación visual de los perfiles solo se puede llevar a cabo cuando se comparan perfiles de baja complejidad. En aquellas muestras donde el número de bandas de los perfiles aumenta o bien cuando se deben comparar un alto número de perfiles, se utilizan métodos numéricos. Con este objetivo se procede a 
digitalizar las imágenes de los geles y procesarlos con el programa Gelcompar. Este programa realiza el análisis numérico de los patrones de bandas y además incluye herramientas estadísticas para la interpretación de los datos.

Idealmente la posición de cada banda en el perfil de una muestra es representativa de una especie. Sin embargo, en la práctica, el efecto observado en ciertas taxa cuando se utilizan oligonucleótidos para los genes del ARNr 16S, puede llevar a una sobreestimación del número de especies predominantes en las muestras analizadas debido a la presencia de operones múltiples.

\subsubsection{Sacrificio de las ratas}

Una vez alcanzado el tiempo final del experimento, 60 días, los animales fueron sacrificados bajo anestesia $(0,1 \mathrm{mg}$ de clorhidrato de ketamina/100 $\mathrm{g}$ de peso corporal $+0,1 \mathrm{mg}$ de maleato de acetopromazinc/100 $\mathrm{g}$ de peso corporal). Se extrajeron muestras de sangre bajo punción cardiaca, el fémur y tibia derechos, así como también el ciego para su posterior análisis.

\subsection{Peso y pH del ciego}

Para evaluar el efecto de las diferentes dietas sobre la fermentación colónica se pesó el ciego en una balanza analítica y se determinó el pH del contenido cecal.

\subsection{Volumen óseo}

La tibia derecha fue resecada y fijada por inmersión en formol tamponado durante 48 horas, descalcificada en una solución 10\% de EDTA (ácido etilendiaminotetraacético) durante 25 días a $\mathrm{pH}=7$ y luego la tibia descalcificada es embebida en parafina. Se obtuvo una sección longitudinal de 8 a $10 \mu \mathrm{m}$ de espesor del hueso subcondral a nivel del tercio medio, incluyendo el tejido esponjoso primario y secundario. Esta se colorea con hematoxilina-eosina y se obtiene una microfotografía (Axioskop, Carl Zeiss, Estados Unidos) con la que se determina el porcentaje de volumen óseo en el área central metafisiana del hueso que aparece en la imagen digitalizada (Parfitt y col., 1987). 


\subsection{Composición ósea}

Se analizaron los fémures derechos, libres de tejido muscular. Se secaron durante 72 hs en estufa a $100{ }^{\circ} \mathrm{C}$. Se extrajo el tejido graso sumergiéndolos durante 15 días en una mezcla de cloroformo: metanol (3:1), que se cambió cada 3 días. Posteriormente se secaron en estufa durante 48 hs a $100{ }^{\circ} \mathrm{C}$, realizando sobre la muestra desengrasada y seca las siguientes determinaciones:

Longitud del hueso. Se determinó con calibre Vernier, con una aproximación de 1:20.

Peso del hueso. Se pesó con una balanza analítica Mettler con precisión $\pm 0,1 \mathrm{mg}$.

Contenido de calcio. Los huesos se calcinaron mediante mineralización por vía seca en mufla a $550 \stackrel{\circ}{\mathrm{C}}$ hasta la obtención de cenizas blanquecinas y se procedió a la determinación de calcio según se explicó en la sección 2.2.15.2.3.

Contenido de fósforo. Se determinó por el método colorimétrico de Gomori (1942).

Materia orgánica no lipídica. Se determinó por diferencia entre el valor del peso del hueso desengrasado y el peso del hueso. Se calculó la relación de cenizas respecto a la materia orgánica no lipídica. 
CAPÍTULO 3 


\subsection{Caracterización de la harina de trigo}

Resulta importante el conocimiento de los componentes del material de partida usado como base en la elaboración y caracterización físico-química de las masas y panes nutricionales. En la Tabla 3.1 se observa la composición porcentual de la harina de trigo utilizada en la elaboración de masas en este trabajo de tesis.

Tabla 3.1. Composición de la harina.

\begin{tabular}{cc}
\hline Componente & $\begin{array}{c}\text { Composición porcentual } \\
\text { (\%) }\end{array}$ \\
\hline Proteínas (P) & $9,75 \pm 0,41$ \\
Lípidos (L) & $1,12 \pm 0,08$ \\
Humedad (H) & $12,65 \pm 0,16$ \\
Fibra dietaria total (FDT) & $2,85 \pm 0,27$ \\
Cenizas (C) & $0,361 \pm 0,001$ \\
Hidratos de carbono (HC) & 73,27 \\
\hline
\end{tabular}

Media \pm desviación estándar.

El contenido de hidratos de carbono fue calculado por diferencia (100 - P - L - H - FDT - C). Esta harina, de acuerdo al porcentaje de ceniza, puede tipificarse como 0000, debido a que el porcentaje de ceniza es menor a 0,492\% (CAA, 2013). El porcentaje de humedad es adecuado para esta harina. Conocer el contenido de proteínas, es un parámetro de calidad de harina importante debido a que se relaciona con la absorción de agua, la fuerza del gluten, el tiempo de amasado y estabilidad de la masa. Influye además sobre los atributos de calidad del producto terminado (Wheat Marketing Center, 2004). Las proteínas de la harina pueden variar su porcentaje entre el $10 \%$ las más débiles hasta el 12\% las de mayor fuerza (De la Vega, 2009), por lo que esta harina tiene un contenido de proteína cerca del límite inferior. De todos modos, no sólo es importante la cantidad, sino la calidad de las proteínas, es decir, el balance y la naturaleza en gliadinas y gluteninas que definen la calidad del gluten, entre otros parámetros (Gianibelli y col., 1994 y 2001).

En la Tabla 3.2 se presentan los parámetros farinográficos, los alveográficos y el contenido porcentual de gluten húmedo $(\mathrm{GH})$, gluten seco (GS) y la relación gluten húmedo/gluten seco correspondientes a la harina empleada para la elaboración de las masas. 
Tabla 3.2. Parámetros farinográficos, alveográficos y contenido de gluten de la harina.

\begin{tabular}{cccc}
\hline \multicolumn{4}{c}{ Parámetros farinográficos } \\
\hline $\mathbf{A b}(\%)$ & $\mathbf{t}_{\mathrm{d}}(\mathbf{m i n})$ & Es (min) & Af (UB) \\
56,4 & 12 & 36,5 & 10 \\
\hline \multicolumn{4}{c}{ Parámetros alveográficos } \\
\hline $\mathbf{P}(\mathbf{m m})$ & $\mathbf{L}(\mathbf{m m})$ & $\mathbf{P} / \mathbf{L}(-)$ & $\mathbf{W}^{*} \mathbf{1 0}^{-4}(\mathbf{J})$ \\
108 & 74 & 1,46 & 188 \\
\hline GH (\%) & Contenido de gluten & GH/GS (-) \\
29,3 & GS (\%) & 3,21 \\
\hline
\end{tabular}

Además del contenido de humedad y cenizas adecuadas para tipificar la harina, el CAA, señala que si la absorción farinográfica está entre 56 y 62 g agua/100g harina, se tipifica como harina 0000 . Es una harina de calidad óptima ya que el aflojamiento es menor a 30 UB y posee una estabilidad mayor a 10 minutos. El valor del trabajo de deformación (W) está entre 180 y 200, por lo cual es considerada una harina fuerte apta para productos de horno fermentados (panificados, en nuestro caso). La relación $\mathrm{P} / \mathrm{L}$ es aproximadamente 1 por lo que esta harina resulta apta para la elaboración de panificados.

La relación GH/GS resultó cercana a la óptima que es 3 , y da idea de la capacidad de retención de agua del gluten, también está asociada a la calidad panadera de la harina.

\subsection{Efecto de las diferentes sales de calcio y prebiótico sobre las propiedades farinográficas y alveográficas}

\subsubsection{Farinogramas y parámetros farinográficos}

La Figura 3.1 muestra los farinogramas correspondientes a las mezclas codificadas como C, CA1, Cl1, LA1, CA2, Cl2, LA2 y LA4 del diseño experimental. 

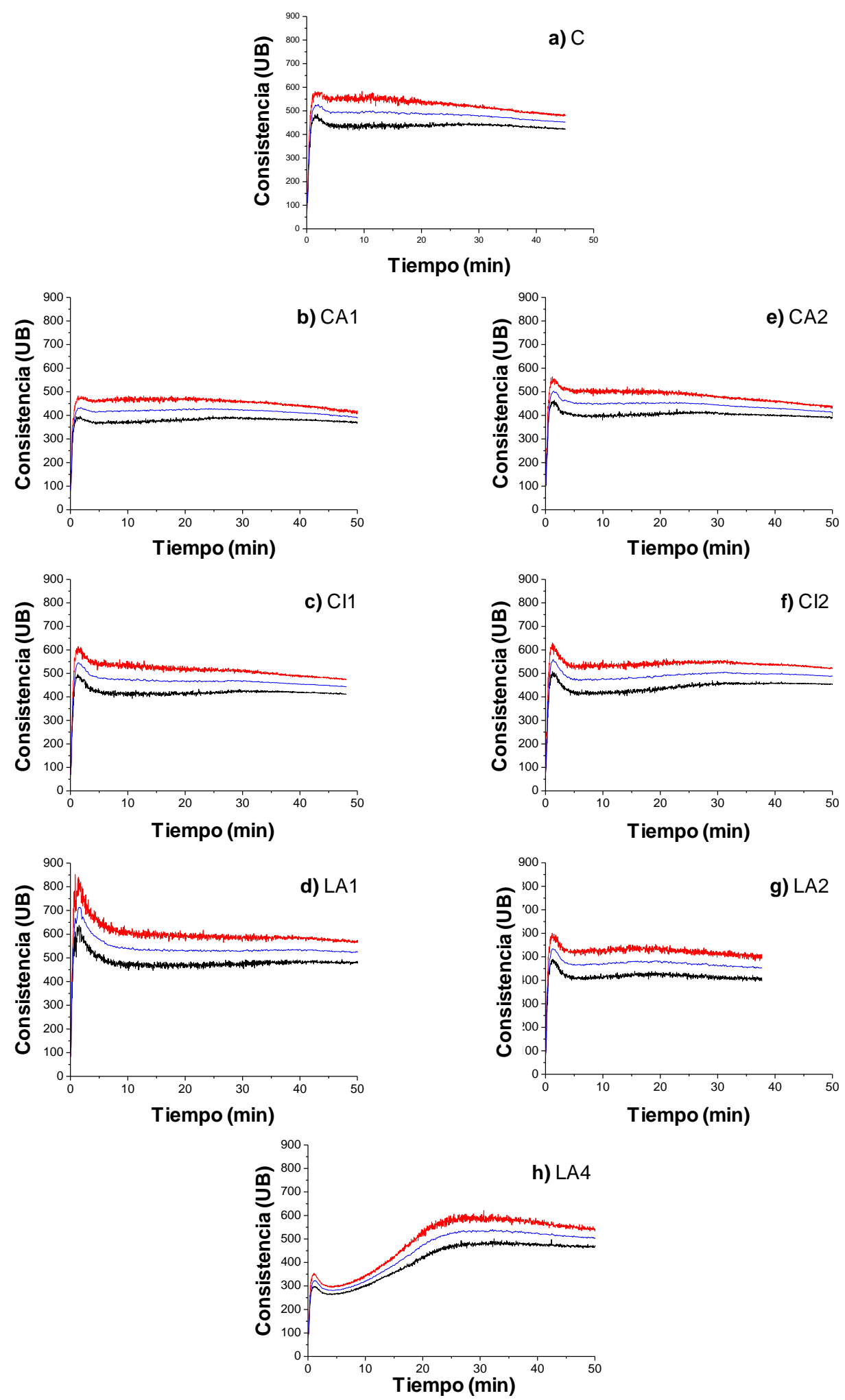

Figura 3.1. Farinogramas de algunas de las mezclas del diseño: a) Control (C); b, c, d) 1200 ppm Ca, 1\% In (CA1, Cl1, LA1); e, f, g) 2400 ppm Ca, 1\% In (CA2, Cl2, LA2); h) 2400 ppm Ca, $12 \% \ln ($ LA4). 
El Farinograma de la muestra control (C) (Figura 3.1.a) presentó dos picos, uno a corto tiempo (2 min) correspondiente a la hidratación de los componentes de la harina en presencia de sal, y un segundo pico (12 min) perteneciente a la óptima consistencia de la masa formada. Las diferentes sales de calcio e inulina utilizadas durante es trabajo de tesis modificaron en cierto grado este perfil farinográfico.

Para el caso de las mezclas elaboradas con 1\% In y 1200 ppm Ca (CA1, Cl1, LA1), la forma del farinograma dependió del tipo de sal. El farinograma obtenido a partir de la mezcla CA1 (Figura 3.1.b) fue similar al de la mezcla C. En cambio, cuando se utilizaron sales de calcio orgánicas se observaron diferencias en la forma del primer pico. Este pico fue más pronunciado para la mezcla LA1 (Figura 3.1.d) que para Cl1 (Figura 3.1.c), debido probablemente a la distinta interacción de cada anión con el agua, ya que la cantidad del catión fue la misma en ambos casos. La capacidad de ciertos iones, principalmente de los aniones, de alterar la estructura del agua y por consiguiente la interacción entre las proteínas, es bien conocido. Kinsella y Lee Hale (1984) estudiaron cómo la hidratación de los diferentes aniones afecta las interacciones hidrofóbicas de las proteínas, contribuyendo a la consistencia de la masa. Estos autores encontraron que el anión fluoruro $\left(\mathrm{F}^{-}\right)$potencia los enlaces de hidrogeno en la estructura del agua y por lo tanto, refuerza los efectos hidrofóbicos sobre las proteínas, reduciendo ligeramente la consistencia de la masa luego del primer pico, aunque se desarrolla una red de gluten normal con estabilidad prolongada. También encontraron que el anión tiocianato $\left(\mathrm{SCN}^{-}\right)$, ion caotrópico, altera la estructura normal de agua perturbando los enlaces de hidrógeno; como consecuencia de esta perturbación provoca una reducción de las interacciones hidrofóbicas entre las proteínas, favoreciendo un primer pico de pronunciada consistencia, pero con un deterioro acelerado de la red del gluten. En nuestro caso, los farinogramas de las mezclas con anión citrato mostraron un comportamiento similar al de las muestras con fluoruro estudiadas por Kinsella y Lee Hale (1984), y como el Fen la Serie de Hofmeister se encuentra entre los aniones estabilizadores (Schwierz y col., 2010), asumimos que el citrato también es un ión estabilizador. Iones estructurantes del agua (citrato $>$ acetato $>\mathrm{Mg}^{+2}$ ) mejoran la coordinación tetraédrica de los enlaces de hidrógeno en la estructura del agua; e iones que disturban la estructura del agua, como el $\mathrm{K}^{+}$, interrumpen la coordinación tetraédrica del agua (Calligaris y Nicoli, 2006). El farinograma de las mezclas de harina de trigo en presencia de ion tiocianato fue presentado por Kinsella y Lee Hale (1984), siendo similar al farinograma que obtuvimos en presencia de lactato. Por lo tanto, se supone que el ión lactato tiene el mismo efecto desestabilizador que el $\mathrm{SCN}^{-}$, encontrándose este anión en la posición final de la Serie de Hofmeister, equivalente a los iones más 
desestabilizadores (Schwierz y col., 2010).

A continuación se sugiere la siguiente Serie de Hofmeister ampliada para una mejor comprensión de la discusión de los aniones que forman parte de las sales de calcio utilizadas para la fortificación de la harina de trigo: citrato > carbonato > lactato.

Un incremento en el nivel de calcio (2400 ppm) sin incrementar el contenido de inulina no modificó el farinograma, independientemente del tipo de sal de calcio utilizada (Figuras 3.1.e, 3.1.f y 3.1.g). Las mezclas $\mathrm{Cl} 2$ y LA2 presentaron similar farinograma (Figuras 3.1.f y 3.1.g) aunque el segundo pico de la mezcla LA2 alcanzó en un menor tiempo la consistencia de 500 UB.

En presencia de todos los tipos de sales, orgánicas $\left(\mathrm{CaLA}_{2}\right.$ y $\left.\mathrm{Ca}_{3} \mathrm{Cl}_{2}\right)$ e inorgánica $\left(\mathrm{CaCO}_{3}\right)$, un incremento en el contenido de $\mathrm{FOS}$ enriquecido con inulina (12\%) provocó un cambio sustancial en la consistencia del segundo pico del farinograma. En la Figura 3.1.h sólo se muestra el farinograma de la mezcla LA4. Se observó un segundo pico excesivamente pronunciado (centrado en 500 UB), en comparación con el primero. Los cambios observados en el farinograma podrían estar relacionados con el tipo de estructura del gluten que se forma durante el amasado en presencia de In sugiriendo una predominancia del efecto del prebiótico sobre el efecto de la sal de calcio en el desarrollo de la masa (Salinas y col., 2012; Salinas y Puppo, 2013a).

La mezcla control, $\mathrm{C}$, presentó una absorción farinográfica $(\mathrm{Ab})$ mayor a la de todas las mezclas, siendo su valor $56,4 \%$. Para algunas de las variables estudiadas en este trabajo de tesis se ajustó la ecuación cuadrática (Ec. 2.9) descripta en la sección 2.2.2 cuyos términos son significativos cuando el valor de $p$ fue menor a 0,05. Empleando estas ecuaciones se predijo el comportamiento de la respuesta que se representó en una superficie de respuesta. La Figura 3.2 muestra los tres gráficos de superficies de respuestas generadas luego de aplicar el modelo cuadrático para la $\mathrm{Ab}$, donde cada superficie generada corresponde al diseño experimental de una de las sales de calcio estudiada. Sobre las superficies se graficaron los valores promedios obtenidos. En la Tabla 3.3 se muestran los coeficientes de regresión a partir de los cuales se generó la superficie de respuesta, los coeficientes de determinación y el error estándar de la estimación. La $\mathrm{Ab}$ de la mezcla con $\mathrm{CaCO}_{3}$ e In, varió proporcionalmente con $\operatorname{In}^{2}$ e inversamente con In, independientemente de la cantidad de sal inorgánica agregada (Figura 3.2.a, Tabla 3.3). La Ab de las mezclas con sales de calcio orgánicas también resultó independiente del contenido de sal pero variaron significativamente sólo con $/ n^{2}$ (Figuras 3.2.b y 3.2.c, Tabla 3.3). Un decrecimiento en Ab al incrementar el contenido de inulina fue reportado por diversos autores (Wang y col., 2002; O'Brien y col., 2003; Peressini y Sensidoni, 2009). Este comportamiento está relacionado con la alta 
capacidad de retención de agua de esta molécula (De Gennaro y col., 2000). Sin embargo no se había estudiado hasta el momento el efecto combinado de masas con inulina en presencia de sales de calcio.

a

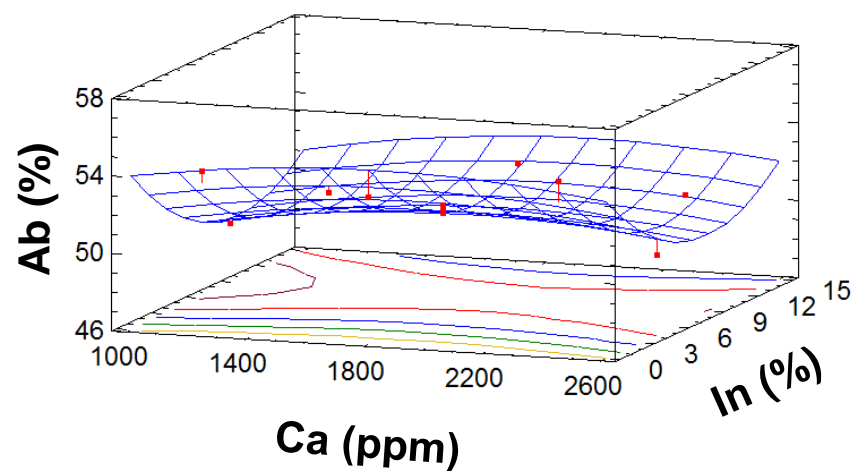

b

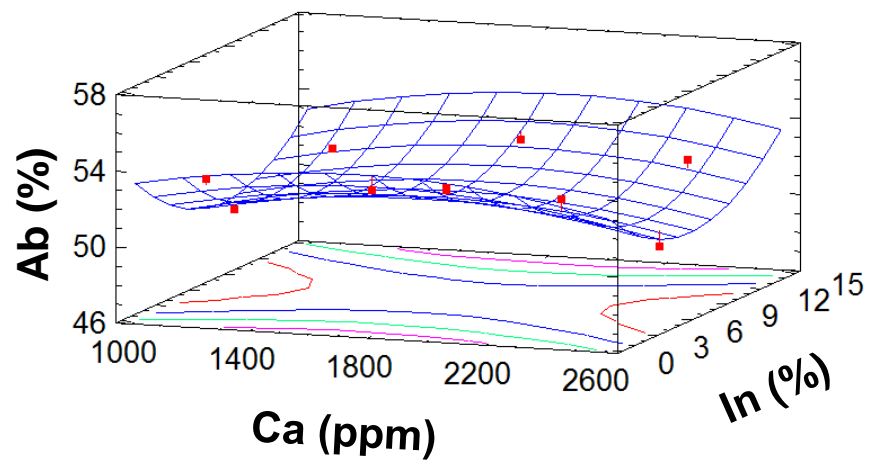

C

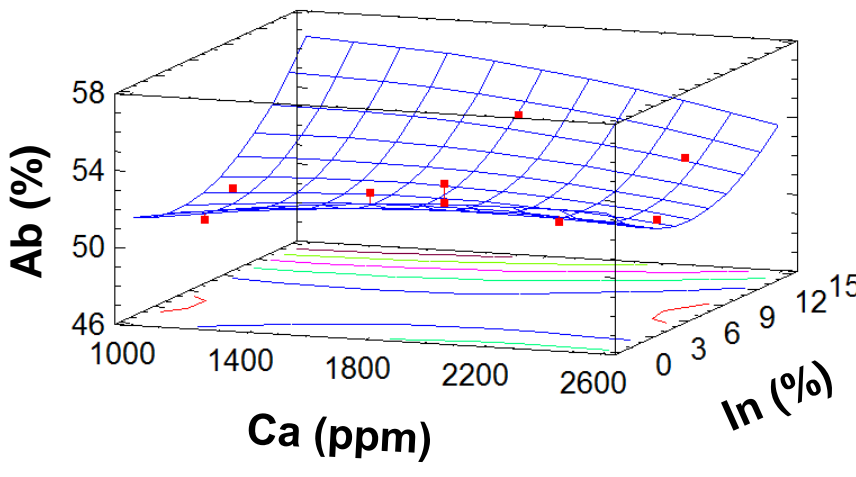

$\mathrm{Ab}(\%)$

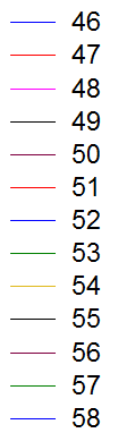

$\mathrm{Ab}(\%)$

$-46$

$-47$

- 48

$-49$

- 50

- 51

- 52

- 53

- 54

$\begin{array}{r}55 \\ -56 \\ \hline\end{array}$

- 57

- 58

Ab (\%)

- 46

- 47

$-48$

$-49$

- 50

- 51

- 52

- 53

- 54

$-55$

56
57

57
-58

Figura 3.2. Gráfico de superficie de respuesta de la variable absorción de agua de las mezclas: a) $\mathrm{CaCO}_{3}$, b) $\mathrm{Ca}_{3} \mathrm{Cl}_{2}$, c) $\mathrm{CaLA}_{2}$. Los puntos sobre la RSM representan las medias de los valores experimentales obtenidos. Debajo de la misma se visualiza la superficie de contorno. 
Tabla 3.3. Análisis de varianza y coeficientes de regresión del modelo polinomio de segundo orden obtenido para la variable absorción de agua $(A b)$.

\begin{tabular}{|c|c|c|c|c|c|c|}
\hline \multirow{3}{*}{$\begin{array}{l}\text { Términos } \\
\text { de } \\
\text { regresión }\end{array}$} & \multicolumn{2}{|c|}{$\mathrm{CaCO}_{3}$} & \multicolumn{2}{|c|}{$\mathrm{Ca}_{3} \mathrm{Cl}_{2}$} & \multicolumn{2}{|c|}{$\mathrm{CaLA}_{2}$} \\
\hline & \multicolumn{2}{|c|}{$A b(\%)$} & \multicolumn{2}{|c|}{$A b(\%)$} & \multicolumn{2}{|c|}{$A b(\%)$} \\
\hline & b & $p$-valor & b & $p$-valor & B & $p$-valor \\
\hline Constante $\left(b_{0}\right)$ & 51,0 & & 51,6 & & 51,8 & \\
\hline $\mathrm{Ca}$ & 0,18 & 0,66 & $-0,01$ & 0,97 & $-0,01$ & 0,97 \\
\hline $\ln$ & $-1,45$ & 0,01 & $-0,49$ & 0,21 & 0,42 & 0,08 \\
\hline $\mathrm{Ca}^{2}$ & $-0,53$ & 0,35 & $-0,75$ & 0,19 & $-0,55$ & 0,11 \\
\hline $\ln ^{2}$ & 1,59 & 0,03 & 1,56 & 0,03 & 1,25 & 0,01 \\
\hline $\mathrm{Ca}^{*} \ln$ & 0,1 & 0,85 & 0,11 & 0,81 & $-0,42$ & 0,16 \\
\hline $\mathrm{R}^{2}$ & & 0,837 & & 0,82 & & 0,907 \\
\hline $\mathrm{S}_{\mathrm{Cal}}$ & & 1,01 & & 0,864 & & 0,489 \\
\hline
\end{tabular}

Se encontraron diferencias significativas cuando $p$-valor $<0,05$.

El tiempo de desarrollo $\left(t_{d}\right)$ obtenido a partir de los farinogramas puede observarse en la Figura 3.3.

En ausencia de $I n$, el agregado de $\mathrm{CaCO}_{3}$ provocó un aumento significativo en el tiempo de amasado necesario para alcanzar la consistencia deseada; el mayor valor obtenido fue para la mezcla con 2520 ppm Ca. A igual concentración de In (12\%), un aumento en el contenido de calcio provocó una disminución de $t_{d}$, lo que sugiere que en presencia del prebiótico el Ca desarrolla antes la red de gluten (Figura 3.3.a).

En las mezclas con $\mathrm{Ca}_{3} \mathrm{Cl}_{2}$, un incremento en esta sal provocó un aumento en el $\mathrm{t}_{\mathrm{d}}$, principalmente en ausencia o a baja concentración de inulina. $A \quad I n \geq 12 \%$, el $t_{d}$ resultó independiente del contenido de sal. Cuando la concentración de inulina fue de 6,5\%, se obtuvieron los mayores $t_{d}$ a concentración intermedia de calcio (1800 ppm Ca) (Figura 3.3 b).

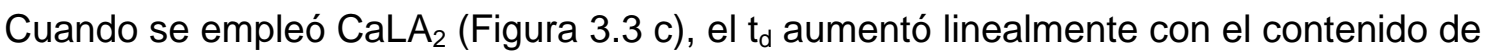
prebiótico, sin embargo no se observaron diferencias significativas de este parámetro en ausencia de inulina con el agregado de la sal de calcio.

Los $t_{d}$ obtenidos a $I n \geq 12 \%$ en las masas con sal de calcio orgánica dependieron únicamente de la presencia de inulina; ésta podría estar afectando la formación de la red de gluten, ya que se necesita más tiempo para formar la masa. Este fenómeno podría deberse a la interacción del prebiótico con el agua a través de la gran cantidad de grupos hidroxilo que posee, compitiendo de esta forma con los componentes presentes en la harina como proteínas y almidón, por el agua. A 6,5\% In, la 
concentración intermedia de calcio (1800 ppm Ca) presentó el mayor $t_{d}$. Este comportamiento observado con el agregado de las sales orgánicas es opuesto al obtenido al emplear una sal inorgánica como $\mathrm{CaCO}_{3}$, lo que sugiere una interacción diferente entre los aniones orgánicos y los inorgánicos con proteínas y agua.

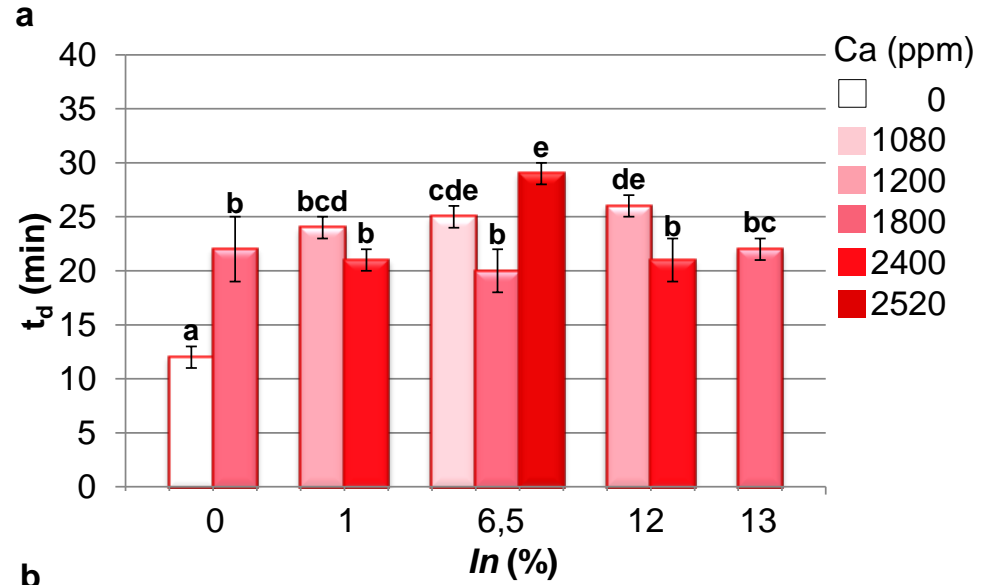

b

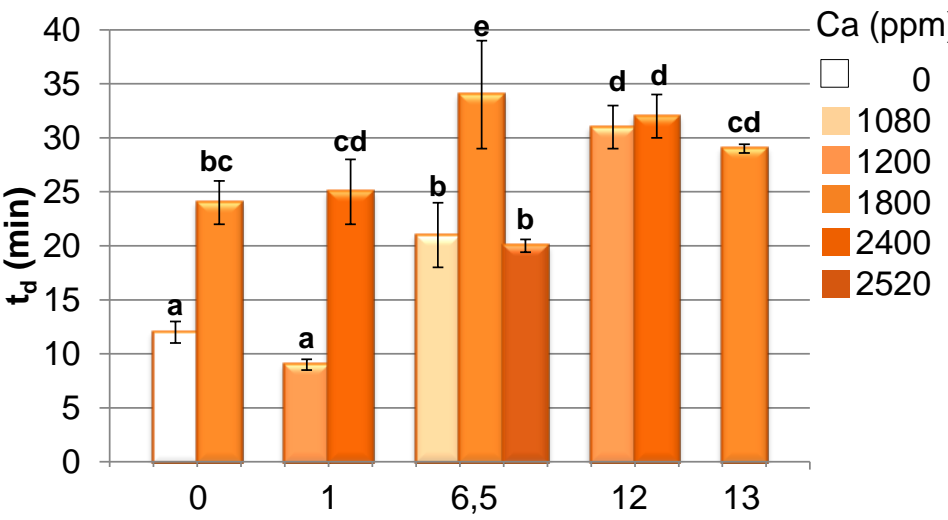

c

$\ln (\%)$

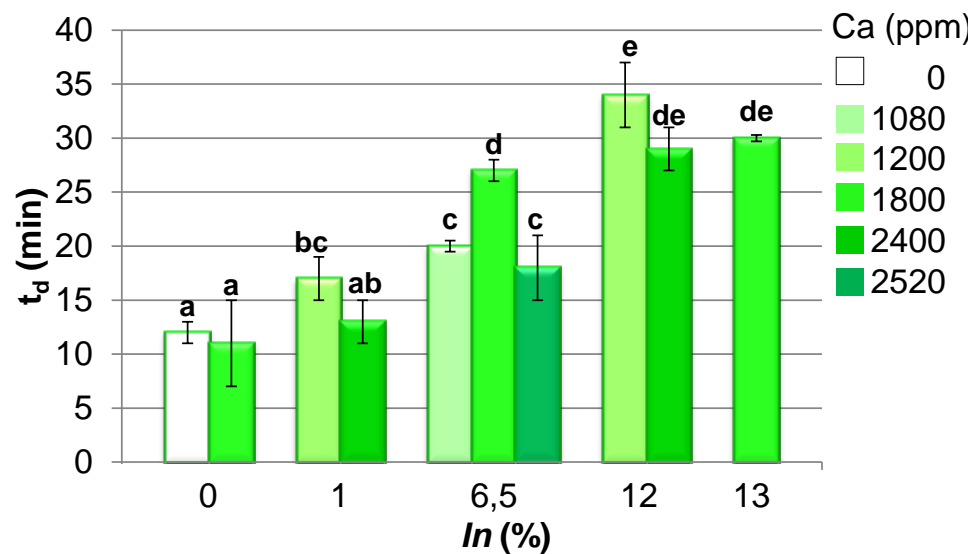

Figura 3.3.Tiempo de desarrollo de las mezclas harina de trigo - sal- sales de calcio - inulina: a) $\mathrm{CaCO}_{3}$, b) $\mathrm{Ca}_{3} \mathrm{Cl}_{2}$, c) $\mathrm{CaLA}_{2}$. Las barras de error corresponden a las desviaciones estándar. Letras diferentes indican diferencias significativas con $p<0,05$. 
La estabilidad y el grado de aflojamiento de las mezclas se vieron afectados por los niveles de prebiótico y según la sal de calcio utilizada (Tabla 3.4).

Tabla 3.4. Estabilidad y aflojamiento de mezclas de harina de trigo, sal de calcio e inulina.

\begin{tabular}{|c|c|c|c|c|c|c|c|c|}
\hline & \multirow{2}{*}{$\begin{array}{c}\mathrm{Ca} \\
(\mathrm{ppm})\end{array}$} & \multirow{2}{*}{$\begin{array}{l}\text { In } \\
(\%)\end{array}$} & \multicolumn{2}{|c|}{$\mathrm{CaCO}_{3}$} & \multicolumn{2}{|c|}{$\mathrm{Ca}_{3} \mathrm{Cl}_{2}$} & \multicolumn{2}{|c|}{$\mathrm{CaLA}_{2}$} \\
\hline & & & $\begin{array}{c}\text { Es } \\
\text { (min) }\end{array}$ & $\begin{array}{c}\text { Af } \\
\text { (UB) }\end{array}$ & $\begin{array}{c}\text { Es } \\
(\mathrm{min})\end{array}$ & $\begin{array}{c}\text { Af } \\
\text { (UB) }\end{array}$ & $\begin{array}{c}\text { Es } \\
\text { (min) }\end{array}$ & $\begin{array}{c}\text { Af } \\
\text { (UB) }\end{array}$ \\
\hline 1 & 1200 & 1 & $42 \mathrm{c}$ & $16 \mathbf{b}$ & $46 \mathrm{c}$ & $10 b$ & $32 \mathrm{c}$ & $25 f$ \\
\hline 2 & 2400 & 1 & $42 \mathrm{c}$ & 17 b & $>46$ & nd & $40 \mathrm{e}$ & 14 cde \\
\hline 3 & 1200 & 12 & $20 a$ & $15 a b$ & $31 a b$ & $15 c$ & 29 bc & $18 \mathrm{e}$ \\
\hline 4 & 2400 & 12 & $22 \mathrm{a}$ & 22 bc & $27 a$ & $37 d$ & $32 \mathrm{~cd}$ & 12 abc \\
\hline PC & 1800 & 6,5 & $>46$ & $<6$ & $45 c$ & $5 a$ & $45 f$ & $13 \mathrm{abcd}$ \\
\hline 8 & 1080 & 6,5 & $>46$ & $<6$ & $>46$ & nd & $46 f$ & $8 a$ \\
\hline 9 & 1800 & 13 & $23 a$ & 22 bc & $26 a$ & $19 c$ & $22 \mathrm{a}$ & $24 f$ \\
\hline 10 & 2520 & 6,5 & $>46$ & $13 \mathbf{b}$ & $>46$ & nd & $33 \mathrm{~cd}$ & $16 \mathrm{de}$ \\
\hline 11 & 1800 & 0 & $35 \mathrm{~b}$ & $28 \mathrm{c}$ & $>46$ & nd & $25 a b$ & $32 \mathbf{g}$ \\
\hline C & 0 & 0 & 36 bc & $10 a$ & 36 bc & $10 \mathrm{~b}$ & $36 \mathrm{de}$ & $10 a b$ \\
\hline
\end{tabular}

PC: Punto central (3 replicados). C: control. Diferentes letras en una misma columna indican diferencia significativa $(p<0,05)$. nd: no determinado.

En las mezclas del DCC con $\mathrm{CaCO}_{3}$, las muestras que presentaron mayor estabilidad y menor aflojamiento fueron las que contenían un 6,5\% In (PC, 8, 10). A niveles altos de In (> 12\%) las mezclas presentaron baja estabilidad (Tabla 3.4). Cuando se emplearon sales orgánicas, la Es y el Af de las masas se vieron afectadas tanto por los niveles de inulina como por el tipo de sal de calcio utilizada.

En ausencia de inulina ( 0 y 1800 ppm $\mathrm{Ca}$ ), el agregado de $\mathrm{Ca}_{3} \mathrm{Cl}_{2}$ produjo un aumento en la estabilidad y una disminución significativa en el aflojamiento, no pudiéndose detectar este último parámetro en el farinograma (nd) (Tabla 3.4). Según la Serie de Hofmeister, el aumento de la estabilidad de la masa sería la consecuencia del efecto estabilizante del ión citrato en la estructura de las proteínas. Cuando se empleó el nivel máximo de inulina (> 12\%), la estabilidad fue mínima y el grado de aflojamiento fue máximo (Tabla 3.4), teniendo el prebiótico un efecto negativo sobre la estructura de la red de gluten.

En cambio, si comparamos las mezclas de $\mathrm{CaLA}_{2}$ con las de $\mathrm{Ca}_{3} \mathrm{Cl}_{2}$, las masas presentaron un comportamiento opuesto en ausencia de inulina, la estabilidad disminuyó con el aumento del lactato y el aflojamiento aumentó significativamente 
(mezclas C y 11, Tabla 3.4). No se reportaron previamente datos de estabilidad de masas preparadas con sales de lactato, pero Wehrle y col. (1997) estudiaron la influencia del ácido láctico en masa de harina de trigo preparada con cloruro de sodio. Estos autores encontraron, al igual que en el caso del lactato, que el ácido láctico decreció el $t_{d}$ y la Es de las mezclas, incrementando el ablandamiento de la masa. En presencia de inulina, el mayor valor de estabilidad obtenido fue al agregar $6,5 \%$ In con 1080 y 1800 ppm Ca como $\mathrm{CaLA}_{2}$. A 13\% de inulina, el comportamiento en la estabilidad y aflojamiento fue similar al observado con las mezclas de $\mathrm{Ca}_{3} \mathrm{Cl}_{2}$, sugiriendo que niveles altos de prebiótico enmascaran la influencia del tipo de sal de calcio.

Las muestras correspondientes a igual nivel de calcio en los diferentes diseños estudiados contienen diferentes cantidades de sal. Debido a que la fórmula química de cada sal utilizada es diferente, una misma formulación en los distintos diseños contiene los mismos moles de calcio pero diferente proporción, tipo y carga de aniones. En cuanto a la proporción de aniones, una igual cantidad de calcio (por ejemplo, 3 moles de $\mathrm{Ca}$ ) implica un mayor número de moles de aniones lactato (6 moles) comparado con carbonato (3 moles) y citrato (2 moles), siendo la relación de aniones 6: 3: 2 (lactato: carbonato: citrato). En cuanto al tipo de anión, el carbonato proviene de una sal inorgánica, en cambio los aniones citrato y lactato provienen de sales orgánicas. Para estimar la carga de los diferentes aniones en la matriz se midió el $\mathrm{pH}$ de todas las masas y se buscaron en bibliografía las constantes de equilibrio $\left(\mathrm{pK}_{\mathrm{a}}\right)$ de los ácidos débiles de los aniones utilizados. La masa control presentó un pH ácido de 5,8 debido al tipo de aminoácidos que componen las proteínas del gluten (Tabla 3.5). Alrededor del $8 \%$ de los residuos de aminoácidos totales de gluten son ionizables (Kasarda y col., 1971). Estos residuos iónicos estás distribuidos entre aminoácidos ácidos $(3,2 \%)$ y básicos $(4,8 \%)$. Los residuos ácidos son principalmente ácido glutámico $\left(\mathrm{pK}_{\mathrm{a}} 4,6\right)$ y con una menor contribución de ácido aspártico $\left(\mathrm{pK}_{\mathrm{a}} 3,9\right)$.

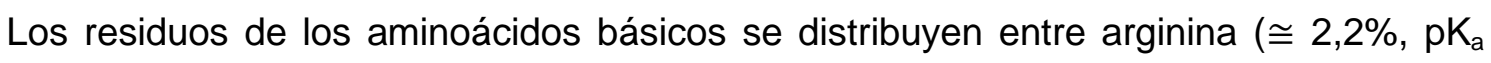
$12,5)$, histidina ( $\left.\cong 1,5 \%, \mathrm{pK}_{\mathrm{a}} 6,3\right)$ y lisina $\left(\cong 1,1 \%, \mathrm{pK}_{\mathrm{a}} 10\right)$. Los aminoácidos polares y no polares representan alrededor del $40 \%$ y $38 \%$, respectivamente, de los residuos de aminoácidos totales (Kasarda y col., 1971). A pH 5,8 los residuos de los grupos ácidos están desprotonados (cargados negativamente) mientras que los residuos de los grupos básicos están protonados. Los aminoácidos básicos están presentes en mayor proporción, por lo tanto las proteínas de trigo en masa exhiben carga neta positiva. El agregado de $\mathrm{CaCO}_{3}$ provocó una disminución de la acidez de la masa. Los valores varían entre 6,28 y 6,36 (Tabla 3.5) debido a las propiedades alcalinas del ión $\mathrm{CO}_{3}{ }^{=}$, la carga neta del gluten es menos positiva en presencia de este anión, debido a que los 
residuos de los aminoácidos ácidos están cargados negativamente y los básicos, como la arginina y lisina se encuentran protonados a diferencia de la histidina. El calcio agregado, podría estar estabilizando a través de interacciones iónicas las proteínas que constituyen la red de gluten.

En cambio, el pH de las masas elaboradas con $\mathrm{CaLA}_{2}$ resultó entre 5,57 y 5,68 y con $\mathrm{Ca}_{3} \mathrm{Cl}_{2}$ entre 5,66 a 5,72 (Tabla 3.5). Todas las masas presentaron $\mathrm{pH}$ similar; pero fueron más ácidas que la masa control. Si comparamos la carga proporcionada por los aniones provenientes de ácidos orgánicos, debido al diferente grado de protonación, la carga negativa proporcionada por cada tres moles de calcio no es -6 para ambos aniones, sino que es - 6 para el lactato y -4 para el citrato. La explicación a esta suposición se basa en que el $\mathrm{pK}_{\mathrm{a}}$ del grupo $-\mathrm{COOH}$ del ácido láctico es 3,08 y los $\mathrm{pK}_{\mathrm{a}}$ de los tres grupos - $\mathrm{COOH}$ del ácido cítrico son: 3,14; 4,77 y 6,39 (Weast, 1976). A estos valores de $\mathrm{pH}$, el anión lactato se encuentra desprotonado debido a que $\mathrm{pK}_{\mathrm{a}}<\mathrm{pH}$ de las masas, en cambio el citrato todavía tiene un grupo carboxilo protonado $\left(\mathrm{pK}_{\mathrm{a} 3}>\mathrm{pH}\right)$. Esta diferente proporción de carga negativa podría influir en la estructuración de las moléculas de agua y/o en la interacción de estos iones con la carga positiva neta de las proteínas del gluten, generando estructuras con diferente consistencia y estabilidad observada durante el amasado. La variación del $\mathrm{pH}$ de las masas en general resultó independiente del agregado de inulina a las mismas.

Tabla 3.5. Valores medios de $\mathrm{pH}$ de las masas.

\begin{tabular}{c|cc|l|l|l}
\hline & $\begin{array}{c}\mathbf{C a} \\
(\mathbf{p p m})\end{array}$ & $\begin{array}{c}\text { In } \\
(\%)\end{array}$ & \multicolumn{1}{|c}{$\mathbf{\mathrm { pH }}$} \\
\cline { 5 - 6 } & & $\mathrm{CaCO}_{3}$ & $\mathbf{C a}_{3} \mathbf{C l}_{2}$ & $\mathbf{C a L A}_{2}$ \\
\hline $\mathbf{1}$ & 1200 & 1 & $6,35 \mathbf{d e}$ & $5,71 \mathbf{a b}$ & $5,67 \mathbf{b c}$ \\
$\mathbf{2}$ & 2400 & 1 & $6,36 \mathbf{e}$ & $5,72 \mathbf{a b}$ & $5,62 \mathbf{a b}$ \\
$\mathbf{3}$ & 1200 & 12 & $6,23 \mathbf{b c}$ & $5,68 \mathbf{a}$ & $5,67 \mathbf{b c}$ \\
$\mathbf{4}$ & 2400 & 12 & $6,28 \mathbf{c d}$ & $5,68 \mathbf{a}$ & $5,64 \mathbf{b c}$ \\
$\mathbf{P C}$ & 1800 & 6,5 & $6,31 \mathbf{d e}$ & $5,71 \mathbf{a b}$ & $5,68 \mathbf{c}$ \\
$\mathbf{8}$ & 1080 & 6,5 & $6,20 \mathbf{b}$ & $5,76 \mathbf{b c}$ & $5,67 \mathbf{b c}$ \\
$\mathbf{9}$ & 1800 & 13 & $6,29 \mathbf{c d e}$ & $5,72 \mathbf{a b}$ & $5,63 \mathbf{a b c}$ \\
$\mathbf{1 0}$ & 2520 & 6,5 & $6,29 \mathbf{c d e}$ & $5,66 \mathbf{a}$ & $5,57 \mathbf{a}$ \\
$\mathbf{1 1}$ & 1800 & 0 & $6,28 \mathbf{c d}$ & $5,68 \mathbf{a}$ & $5,67 \mathbf{b c}$ \\
\hline $\mathbf{C}$ & 0 & 0 & $5,80 \mathbf{a}$ & $5,80 \mathbf{c}$ & $5,80 \mathbf{d}$ \\
\hline
\end{tabular}

PC: Punto central (3 replicados). C: control. Diferentes letras en una misma columna indican diferencia significativa $(p<0,05)$. 
Al tener, en las masas elaboradas con $\mathrm{CaCO}_{3}$, una red de gluten con menor carga neta positiva, habría menor repulsión entre las proteínas, por lo que esta sal podría estar estabilizando dicha red a través de interacciones electrostáticas e hidrofóbicas y por otro lado un mayor $\mathrm{pH}$ favorece la formación de enlaces disulfuro a través del intercambio SH/S-S, reforzando la red de gluten.

En cambio, en las masas con sales de calcio orgánicas, la presencia de los aniones tiene efecto sobre la estructura del agua e indirectamente en las interacciones hidrofóbicas entre las moléculas de proteína que forman el gluten, especialmente el ión lactato. El ión citrato a pesar de ser un anión de naturaleza orgánica y tener pH semejante al lactato, en ausencia de inulina estabilizó más la estructura del gluten que el anión lactato. Estos resultados sugieren que no sólo la carga y el pH influyen en la red de gluten, también la naturaleza química (fórmula) del anión.

Debido al inusual farinograma obtenido en presencia de altos niveles de Ca e In (2400 ppm Ca y $12 \%$ In), se decidió estudiar la estructura de la masa por SEM en las diferentes etapas de amasado según se describió en la sección 2.2.3.1. Se seleccionó la mezcla LA4 para este fin (Figura 3.4). La harina de trigo generalmente presenta dos poblaciones de gránulos de almidón, una de mayor y otra de menor tamaño. Se mezclaron los ingredientes sólidos con el agua y se comenzó a amasar y registrar el tiempo. El análisis de la estructura de la masa en diferentes periodos de amasado permite una mejor comprensión de la naturaleza de las interacciones entre los componentes de la mezcla entre sí y con el agua. A los 8 y 16 min de amasado pueden observarse los gránulos de almidón mezclados con las proteínas que formarán la red de gluten, pero aún no se observa una estructura definida (Figura 3.4). En esta etapa la mezcla posee una consistencia viscosa. Se continúa amasando y la mezcla comienza a adquirir consistencia, alcanzando la masa óptima ( $\left.t_{d}=29 \mathrm{~min}\right)$. En este momento pueden observarse los gránulos de almidón inmersos en una red proteica laminar poco homogénea correspondiente a la red de gluten ya formada, sobre la cual se apoya una cadena blanca y fina de estructura filamentosa, posiblemente formada por la inulina. A los 45 min se observa una red más desgarrada y a mayor tiempo de amasado la red adquiere un aspecto filamentoso como consecuencia del sobreamasado. 


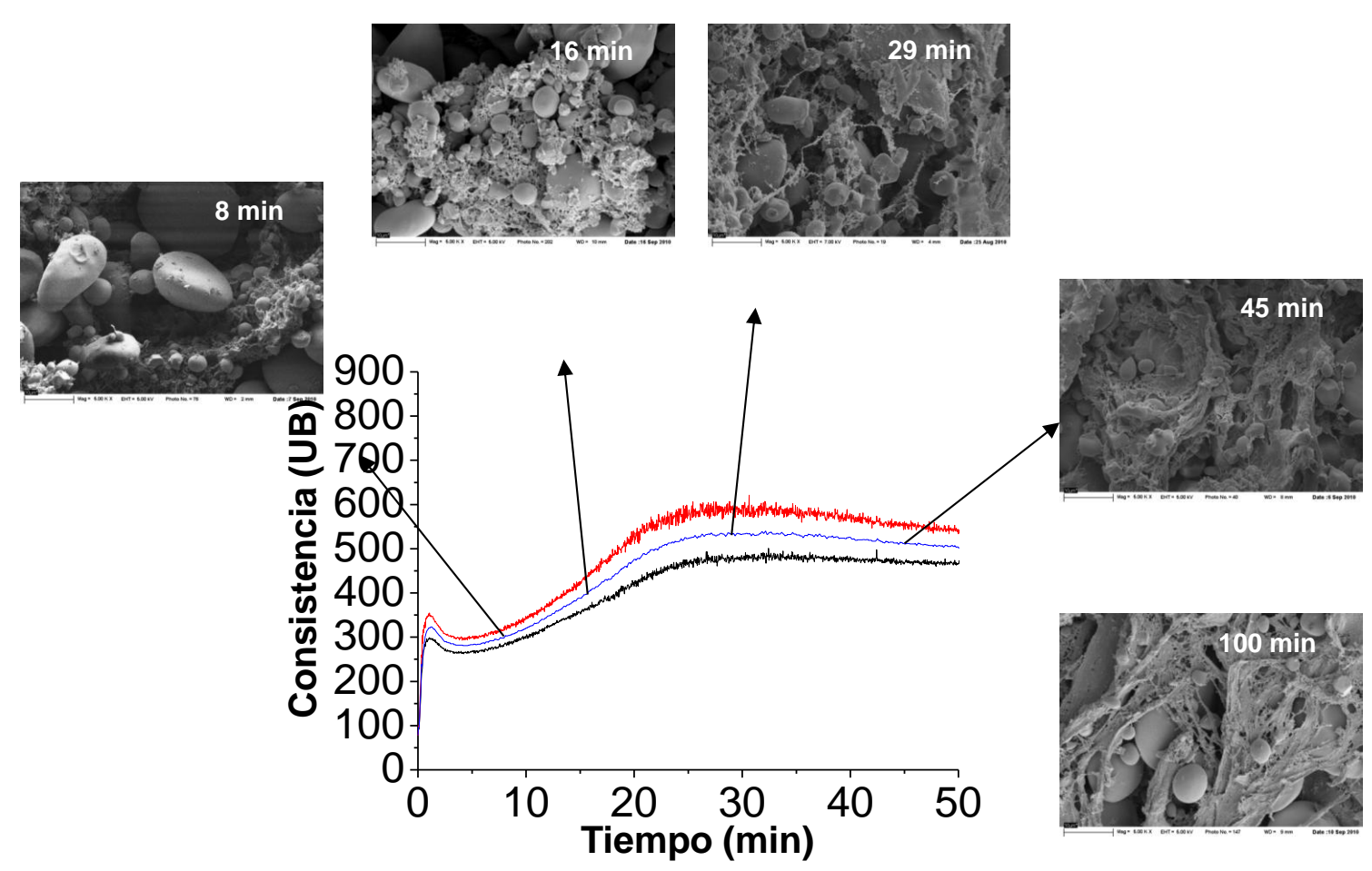

Figura 3.4. Microscopia electrónica de barrido de muestra LA4 obtenida a partir de masas obtenidas con diferentes tiempos de amasado: 8, 16, 29, 45 y 100 min. Aumento 5000X.

En el farinograma anterior puede visualizarse un segundo pico muy exagerado respecto al primero, comportamiento que podría deberse a la disposición de la inulina sobre/en la red de gluten formando una masa más consistente (29 min). Algunos autores sostienen que hay interacción del prebiótico con las proteínas de gluten (Wang y col., 2002).

El agregado de $12 \%$ In provocó un aumento en el tiempo de desarrollo respecto al control, esto podría deberse a que se necesita más tiempo para integrar todos los componentes de la masa, debido a que hay una fuerte competencia por el agua utilizada. Diversos autores encontraron la misma tendencia (Wang y col., 2002; Karolini-Skaradzinska y col., 2007; Peressini y Sensidoni, 2009).

\subsubsection{Tenacidad y extensibilidad de la masa}

Los parámetros alveográficos, a cantidad de agua constante, no permiten predecir la calidad panadera como en el caso de harinas, pero sí analizar la influencia de la inulina y las diferentes sales de calcio sobre la tenacidad $(P)$, la extensibilidad $(L)$ y el trabajo de deformación (W) de las masas; parámetros que en estas condiciones tienen relación con la absorción de agua.

La Figura 3.5 muestra los valores medios de los parámetros alveográficos obtenidos a 
partir de las mezclas con $\mathrm{CaCO}_{3}$ e In. El agregado de $\mathrm{CaCO}_{3}$ no modificó en general los valores de $\mathrm{P}, \mathrm{L}$ ni $\mathrm{W}$ de las mezclas a igual concentración de In (Figura 3.5), excepto a $6,5 \%$ In para el cual los valores de $L$ y $W$ presentaron un mínimo a 1800 ppm Ca (PC).
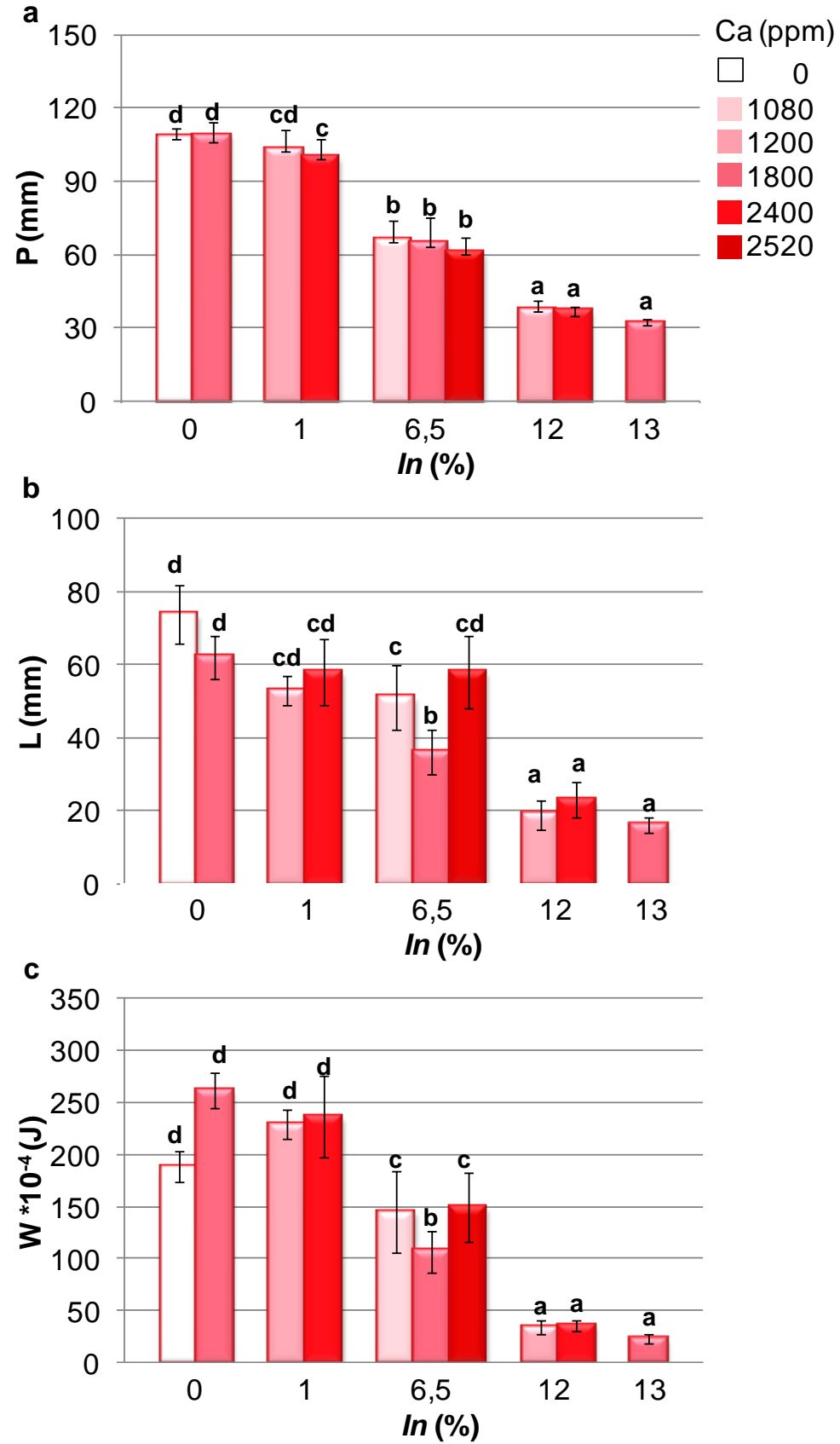

Figura 3.5. Parámetros alveográficos de las mezclas de harina de trigo con $\mathrm{CaCO}_{3}$ e In:a) Tenacidad $(P)$, b) extensibilidad $(L)$, c) trabajo de deformación $(W)$. Las barras de error corresponden a las desviaciones estándar. Diferentes letras en una misma variable indican diferencias significativas entre las medias $(p<0,05)$. 
En la Figura 3.6 se muestran los valores medios de los parámetros alveográficos de las masas formadas en presencia de sales de calcio orgánicas.

En el caso de masas con $\mathrm{Ca}_{3} \mathrm{Cl}_{2}$ los valores de $\mathrm{P}$ y $\mathrm{L}$ fueron modificados por el incremento de $\mathrm{Ca}_{3} \mathrm{Cl}_{2}$ a igual contenido de inulina. A $1 \%$ In $\mathrm{P}$ se incrementó, mientras que a $12 \%$ disminuyó $P$ al incrementar el nivel de calcio (Figura 3.6.a). En cambio, a In $\leq 6,5 \%$ un incremento en $\mathrm{Ca}_{3} \mathrm{Cl}_{2}$ disminuyó $\mathrm{L}$, a igual porcentaje de In (Figura 3.6.b). En contraste, al utilizar $\mathrm{CaLA}_{2}$ no se modificó $\mathrm{P}$ (Figura 3.6.d) ni L (Figura 3.6.e) a igual contenido de prebiótico, excepto el parámetro $\mathrm{P}$ a $6,5 \% \ln$. A 6,5\% In, P decreció significativamente con el aumento de calcio (2520 ppm Ca).

Sudha y Leelavathi (2008) estudiaron el efecto de diferentes sales de calcio (carbonato, lactato, citrato y fosfato) a diferentes niveles (800, 1200, $1600 \mathrm{mg} \mathrm{Ca} / \mathrm{kg}$ harina de trigo) sobre los parámetros alveográficos, pero sin agregado de inulina. Estos autores, como en nuestro caso, no encontraron diferencias significativas en $\mathrm{P}$ de masas con $\mathrm{Ca}_{3} \mathrm{Cl}_{2}$ respecto al control en los niveles que estudiaron; sin embargo, con $\mathrm{CaLA}_{2}$ reportaron menor valor de $\mathrm{P}$ respecto al control.

En ausencia de In, el trabajo de deformación de las masas (W) con calcio agregado (mezcla 11) fue significativamente mayor que el $W$ de la masa control (C), especialmente para $\mathrm{Ca}_{3} \mathrm{Cl}_{2}$ (Figuras 3.6.c y 3.6.f). En masas con 6,5\% In, el empleo de1800 ppm Ca proveniente de sales orgánicas presentó mayor W, contrario a lo que sucedió cuando se empleó una sal inorgánica $\left(\mathrm{CaCO}_{3}\right)$, sin embargo numéricamente los valores de $\mathrm{W}$ de la formulación con 6,5\% In y 1800 ppm Ca obtenidos fue de 107 cuando se utilizó $\mathrm{CaCO}_{3}$ y de 115 y 56, para $\mathrm{Ca}_{3} \mathrm{Cl}_{2}$ y $\mathrm{CaLA}_{2}$, respectivamente (Figuras 3.5.c, 3.6.c y 3.6.f). Estos valores están en concordancia con la naturaleza del anión.

Todos los parámetros fueron afectados negativamente por la presencia de In. La dependencia con $I n^{2}$ de la absorción farinográfica de las mezclas (Figura 3.2) se vio reflejada en los parámetros alveográficos (Figuras 3.5 y 3.6). Las mezclas con más de $6,5 \%$ In fueron expuestas a un exceso de agua, dando lugar a valores bajos de P, L y W. Como se explicó previamente, para igual cantidad de moles de calcio, el anión lactato contribuye con carga -1, en cambio el citrato posee carga neta -2, además se incorporan más moles de lactato que citrato (Salinas y Puppo, 2013b). Esta distinta carga aportada por ambos aniones orgánicos y diferente relación catión:anión podría ser la responsable de las diferencias encontradas en $\mathrm{P}$ y $\mathrm{L}$. 

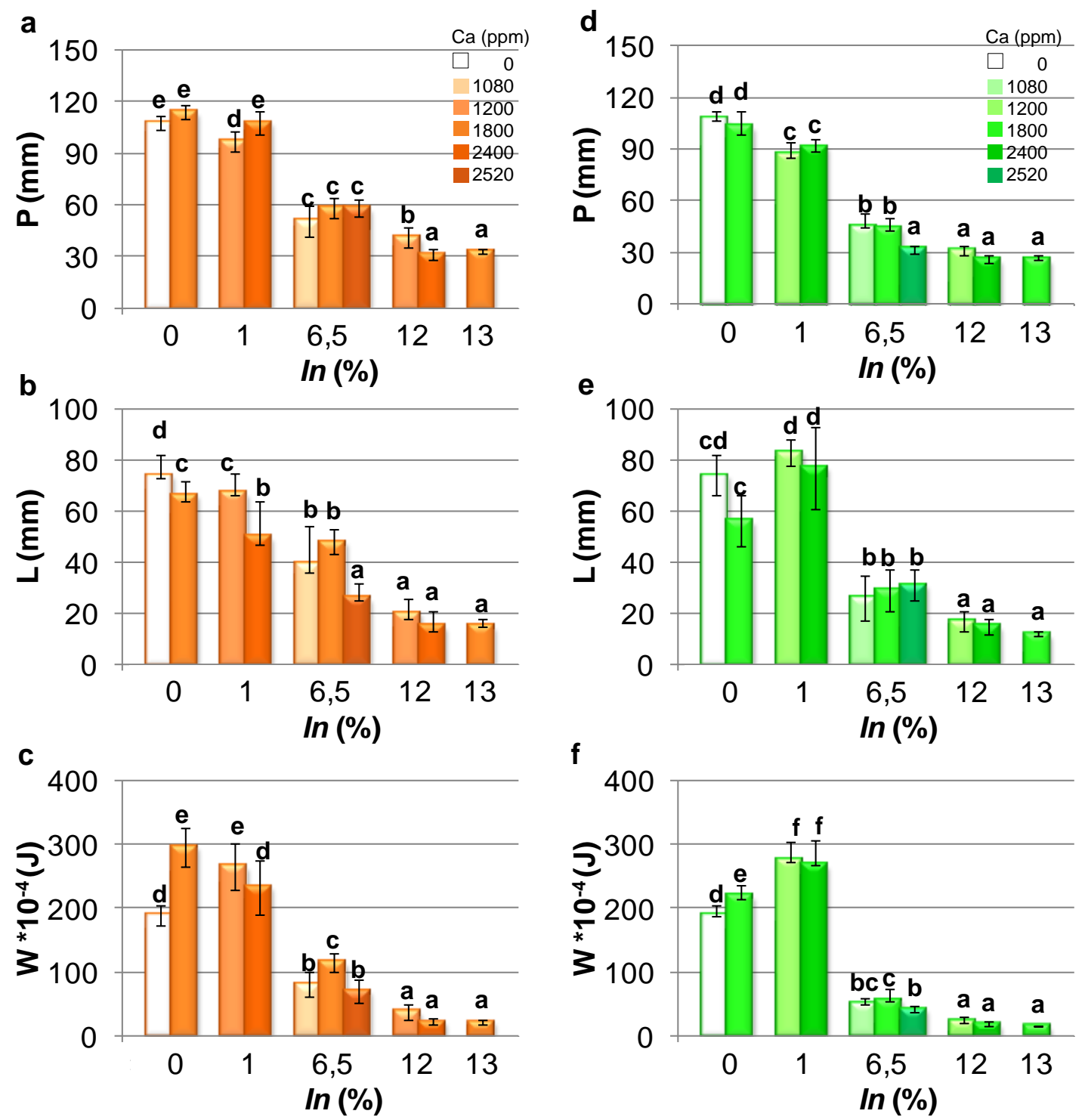

Figura 3.6. Parámetros alveográficos de las mezclas de harina de trigo con sales de calcio orgánicas e In. Tenacidad (P) (a, d), extensibilidad $(L)(b, e)$ y trabajo de deformación $(W)(\mathbf{c}, \mathbf{f})$. Mezclas con $\mathrm{Ca}_{3} \mathrm{Cl}_{2}(\mathbf{a}, \mathbf{b}, \mathbf{c})$ y con $\mathrm{CaLA}_{2}(\mathbf{d}, \mathbf{e}, \mathbf{f})$. Las barras de error corresponden a las desviaciones estándar. Diferentes letras indican diferencias significativas entre las medias con $p<0,05$.

Los parámetros farinográficos y alveográficos estudiados en esta sección, además de variar con la sal de calcio, lo hicieron con el contenido de FOS enriquecido con inulina. Por esta razón se consideró necesario hacer un estudio sobre las propiedades de hidratación de las mezclas y la movilidad molecular de las masas, que se describe en la sección siguiente. 


\subsection{Efecto de las diferentes sales de calcio y prebiótico sobre las propiedades de hidratación de masas}

\subsubsection{Humedad de masas}

En la Figura 3.7 se muestran los gráficos de superficie de respuesta obtenidos a partir de los valores de humedad $(\mathrm{H})$ de las masas estudiadas correspondientes a los tres DCC y en la Tabla 3.6 se expresan los coeficientes de regresión obtenidos a partir del polinomio aplicado a esa variable que generan las diferentes superficies de respuesta. La humedad de la masa control fue la mayor (43,4\%). El contenido de humedad varió con $I n^{2}$ y resultó inversamente proporcional con In en todos los casos, aunque en diferente proporción resultando superficies de respuesta diferentes. Cuando se empleó $\mathrm{CaCO}_{3}$ y $\mathrm{CaLA}_{2}$ el término lineal presentó mayor contribución que el cuadrático, esto significa que las masas elaboradas con alto contenido de In (12 y 13\%) presentaron menor porcentaje de humedad; independiente del nivel de sal de calcio agregada (Figuras 3.7.a y 3.7.c Tabla 3.6). Los valores de humedad obtenidos están en relación directa con la absorción de agua farinográfica. En cambio en las masas elaboradas con $\mathrm{Ca}_{3} \mathrm{Cl}_{2}$, el término con mayor significancia fue $\mathrm{In}^{2}$, que se reflejó en la diferente forma de la superficie.

La inulina ha sido el principal factor responsable de modificar la absorción de agua en las mezclas. En presencia del prebiótico se alcanzó la consistencia óptima de la masa con menor cantidad de agua. Este comportamiento se puede atribuir a la capacidad de la inulina de incorporar el agua a su estructura molecular y adquirir cierto orden conduciendo a la formación de masas más estructuradas. 

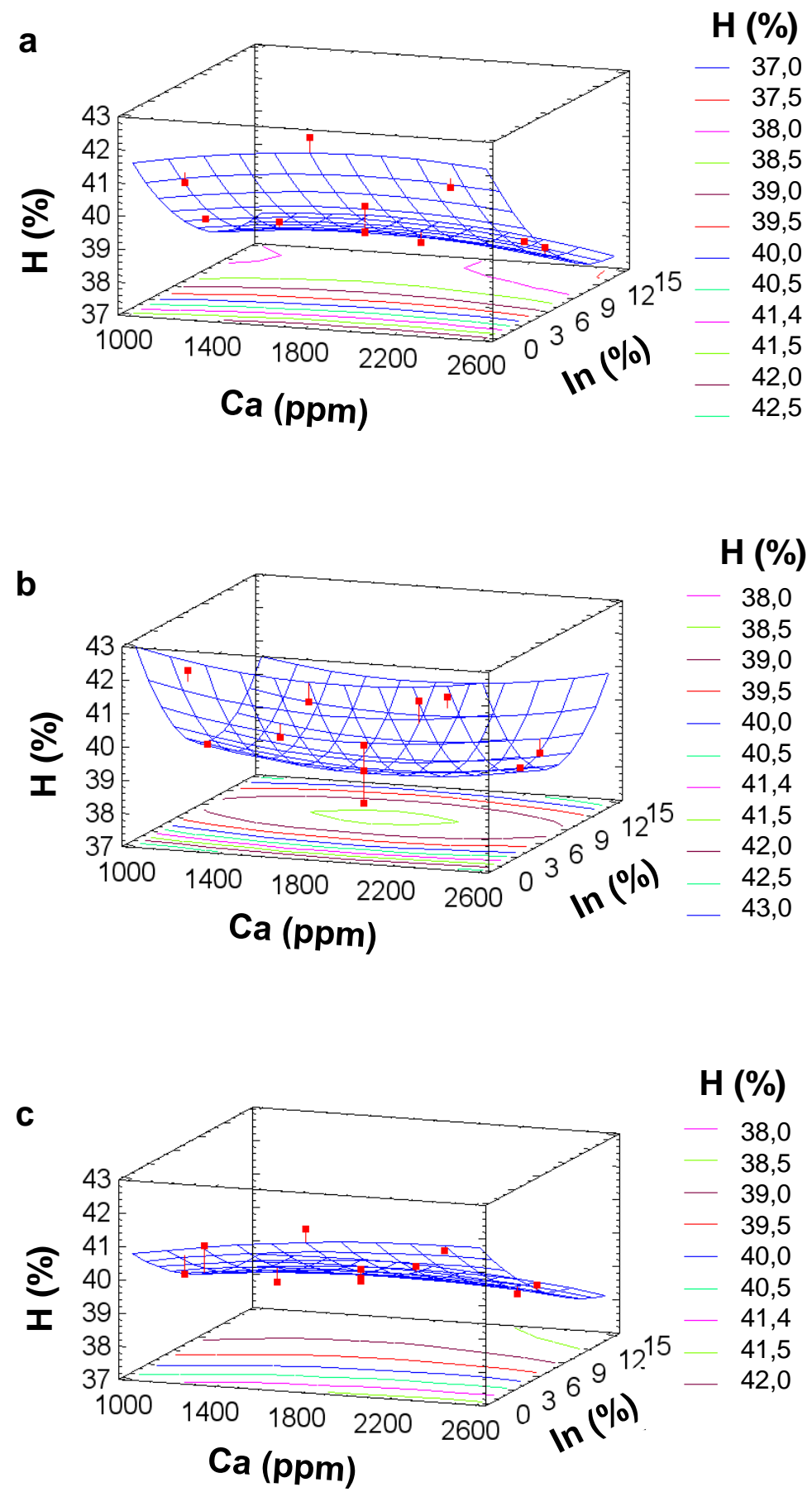

Figura 3.7. Gráfico de superficie de respuesta (SR) de la humedad de las masas: a) $\mathrm{CaCO}_{3}$, b) $\mathrm{Ca}_{3} \mathrm{Cl}_{2}$, c) $\mathrm{CaLA}_{2}$. Los puntos sobre la $\mathrm{SR}$ representan las medias de los valores experimentales obtenidos. Debajo de la SR se visualiza la superficie de contorno. 
Tabla 3.6. Análisis de varianza y coeficientes de regresión del modelo polinomio de segundo orden para la variable humedad $(\mathrm{H})$.

\begin{tabular}{|c|c|c|c|c|c|c|}
\hline \multirow{3}{*}{$\begin{array}{l}\text { Términos } \\
\text { de } \\
\text { regresión }\end{array}$} & \multicolumn{6}{|c|}{ H (\%) } \\
\hline & \multicolumn{2}{|c|}{$\mathrm{CaCO}_{3}$} & \multicolumn{2}{|c|}{$\mathrm{Ca}_{3} \mathrm{Cl}_{2}$} & \multicolumn{2}{|c|}{$\mathrm{CaLA}_{2}$} \\
\hline & b & $p$-valor & b & $p$-valor & B & $p$-valor \\
\hline Constante $\left(b_{0}\right)$ & 39,21 & & 38,92 & & 39,65 & \\
\hline $\mathrm{Ca}$ & 0,026 & 0,64 & $-0,03$ & 0,7 & 0,12 & 0,22 \\
\hline In & $-1,663$ & 0,00 & $-1,28$ & 0,00 & $-1,13$ & 0,00 \\
\hline $\mathrm{Ca}^{2}$ & 0,097 & 0,17 & 0,18 & 0,15 & $-0,14$ & 0,29 \\
\hline $\ln ^{2}$ & 0,512 & 0,00 & 1,31 & 0,00 & 0,32 & 0,02 \\
\hline $\mathrm{Ca}^{*} \ln$ & 0,154 & 0,07 & 0,08 & 0,47 & $-0,19$ & 0,13 \\
\hline $\mathrm{R}^{2}$ & & 0,969 & & 0,867 & & 0,852 \\
\hline $\mathrm{S}_{\text {Cal }}$ & & 0,283 & & 0,388 & & 0,428 \\
\hline
\end{tabular}

Diferencias significativas cuando $p$-valor $<0,05$.

\subsubsection{Actividad acuosa}

El agua en los alimentos se puede encontrar libre, ligada o interaccionando con los macrocomponentes, cuanto mayor sea el valor de disponibilidad de agua, mayor va a ser el agua libre y menor va a ser la interacción de esta con los componentes de la masa. La actividad de agua $\left(\mathrm{a}_{\mathrm{w}}\right)$ está relacionada con la disponibilidad de agua en el sistema. Se determinó la actividad acuosa según se describió en la sección 2.2.6.2.

La $a_{w}$ de la masa control fue 0,971 y los valores de $a_{w}$ de las masas obtenidas de los diferentes diseños fue alta (> 0,963), indicando que la masa es un sistema que contiene elevada disponibilidad de agua.

A niveles de $I n<6,5 \%$, el $\mathrm{CaCO}_{3}$ provocó un aumento de $\mathrm{a}_{\mathrm{w}}$, lo que sugiere que esta sal contribuye a aumentar la cantidad de agua en estado libre (Tabla 3.7). En cambio, las masas elaboradas con sales de calcio orgánicas en ausencia de In presentaron igual disponibilidad de agua que la masa control. Los valores de $a_{w}$ para masas con $\mathrm{CaLA}_{2}$ mostraron valores entre 0,966 y 0,971 , mientras que para $\mathrm{Ca}_{3} \mathrm{Cl}_{2}$ estos valores estuvieron entre 0,963 y 0,975 .

Los menores valores de $a_{w}$ pertenecen a las masas preparadas con altas concentraciones de Ca (2400 ppm) e In (12\%).

Estos resultados sugieren que hay un efecto de la sal de calcio inorgánica en ausencia y baja concentración de prebiótico sobre la disponibilidad de agua en la masa, el agregado de calcio podría favorecer las interacciones entre las proteínas provocando 
que mayor cantidad de moléculas de agua pasen a estar de un estado mas restringido a uno más libre.

\subsubsection{Movilidad molecular}

La movilidad molecular ha sido estudiada en sistemas de cereales por diferentes autores mediante técnicas de relajación usando resonancia magnética nuclear (RMN) (Leung y col., 1979; Chen y col., 1997; Ruan y col., 1997). El decaimiento exponencial de la señal puede modelarse utilizando una regresión con ecuaciones con uno, dos o más términos exponenciales. Cada término representa un tiempo de relajación $(\lambda 1, \lambda 2$, $\lambda 3 \ldots \lambda i)$, que puede estar asociado a diferentes poblaciones de moléculas que poseen diferentes movilidades. Las especies con menores tiempos de relajación presentan menor movilidad (como especies en estado sólido) que las que poseen mayores tiempos de relajación (como las que están en estado líquido). La señal del espín a tiempo cero es proporcional al número de núcleos de hidrógenos de cada especie. Empleando esta técnica, Leung y col. (1976) estudiaron diferentes sistemas basados en almidón de maíz, pectina, caseína y alginato de sodio. El almidón de maíz exhibe dos poblaciones diferentes con distinta movilidad, mientras que los otros sistemas presentan un decaimiento mono-exponencial. El comportamiento mono-exponencial es detectado cuando: (a) el intercambio de agua entre las fases (menos móviles o más móviles) es mayor en comparación con la velocidad de relajación, (b) una fase se encuentra presente en pequeña cantidad, (c) uno de los tiempos de relajación es muy corto, o (d) ambos tiempos de relajación son muy similares.

La movilidad molecular $(\lambda)$ es un parámetro relacionado con la movilidad del agua en el sistema. Valores altos de $\lambda$ denotan mayor movilidad molecular, el agua en la masa pareciera estar débilmente vinculada a otras moléculas y por consiguiente en un estado móvil de alta energía dando lugar a una estructura de la masa más lábil (Salinas y col., 2012). Este fenómeno depende de la estructura molecular de los componentes presentes en la masa. Estudios previos demostraron que la movilidad molecular fue afectada por la presencia de hidrocoloides (Linlaud y col., 2011). Leung y col. (1979) reportaron para masas un decaimiento exponencial de segundo orden asignando dos fracciones de agua de diferente movilidad, aunque otros autores (Lopes-da-Silva y col., 2007) han aplicado en el modelado de curvas de relajación obtenidas por RMN de masas, una ecuación de decaimiento exponencial de orden uno.

En la Tabla 3.7 se muestran los valores de movilidad molecular $(\lambda)$ de las masas. En ausencia de In, el agregado de $\mathrm{CaCO}_{3}$ no modificó $\lambda$. La formulación CA10 elaborada 
con el máximo nivel de calcio (2520 ppm Ca) presentó el menor valor de $\lambda$, el cual se asocia a una mayor inmovilidad de la estructura. En cambio, las masas con sales de calcio orgánicas presentaron menor $\lambda$ que la masa control, asociado a una restricción del movimiento de la matriz. En presencia de $1 \%$ In, un aumento de calcio, provocó en todos los casos mayores valores de $\lambda$ (Tabla 3.7).

Tabla 3.7. Actividad acuosa y movilidad molecular de las masas obtenidas a partir de harina de trigo - sal- calcio e inulina.

\begin{tabular}{|c|c|c|c|c|c|c|c|c|}
\hline & \multirow{2}{*}{$\begin{array}{c}\mathrm{Ca} \\
(\mathrm{ppm})\end{array}$} & \multirow{2}{*}{$\begin{array}{l}\text { In } \\
(\%)\end{array}$} & \multicolumn{2}{|c|}{$\mathrm{CaCO}_{3}$} & \multicolumn{2}{|c|}{$\mathrm{Ca}_{3} \mathrm{Cl}_{2}$} & \multicolumn{2}{|c|}{$\mathrm{CaLA}_{2}$} \\
\hline & & & $\begin{array}{l}a_{w} \\
(-)\end{array}$ & $\begin{array}{c}\lambda \\
\text { (ms) }\end{array}$ & $\begin{array}{l}a_{w} \\
(-)\end{array}$ & $\begin{array}{c}\lambda \\
(\mathrm{ms})\end{array}$ & $\begin{array}{l}a_{w} \\
(-)\end{array}$ & $\begin{array}{c}\lambda \\
\text { (ms) }\end{array}$ \\
\hline 1 & 1200 & 1 & $0,971 \mathbf{b}$ & $11,3 \mathbf{d}$ & 0,970 bcd & $9,7 \mathbf{b}$ & $0,971 \mathbf{c d}$ & $10,7 \mathbf{c d}$ \\
\hline 2 & 2400 & 1 & $0,975 \mathrm{c}$ & $12,1 \mathbf{e}$ & 0,973 cde & $10,8 \mathbf{e}$ & $0,967 \mathbf{a b}$ & 11,7 ef \\
\hline 3 & 1200 & 12 & $0,969 \mathbf{a b}$ & $10,2 \mathbf{b}$ & 0,968 abc & $9,7 \mathbf{b}$ & $0,967 \mathbf{a b}$ & 10,7 bc \\
\hline 4 & 2400 & 12 & $0,967 \mathbf{a}$ & $10,1 \mathbf{b}$ & $0,963 \mathbf{a}$ & $8,1 \mathbf{a}$ & $0,966 \mathbf{a}$ & $10,3 \mathbf{b}$ \\
\hline PC & 1800 & 6,5 & $0,974 \mathbf{b}$ & 10,8 c & $0,973 \mathbf{e}$ & $10,3 \mathbf{c}$ & 0,969 bc & 10,7 bc \\
\hline 8 & 1080 & 6,5 & $0,970 \mathbf{a b}$ & 10,9 c & $0,974 \mathrm{de}$ & $10,1 \mathrm{c}$ & $0,971 \mathbf{d}$ & 10,9 bcd \\
\hline 9 & 1800 & 13 & $0,970 \mathbf{a b}$ & 10,9 c & $0,965 \mathbf{a b}$ & $10,3 \mathbf{c d}$ & $0,967 \mathbf{a b}$ & $9,7 \mathbf{a}$ \\
\hline 10 & 2520 & 6,5 & $0,975 \mathbf{e}$ & $9,7 \mathbf{a}$ & $0,964 \mathbf{a}$ & $10,3 \mathbf{c d}$ & $0,967 \mathrm{ab}$ & 10,5 bc \\
\hline 11 & 1800 & 0 & $0,984 \mathbf{d}$ & $12,3 \mathbf{e}$ & $0,975 \mathrm{de}$ & $10,5 d$ & $0,971 \mathbf{c d}$ & $11,5 \mathrm{de}$ \\
\hline C & 0 & 0 & 0,971 bc & $12,2 \mathbf{e}$ & $0,971 \mathrm{de}$ & $12,2 \mathbf{f}$ & $0,971 \mathbf{c d}$ & $12,2 \mathbf{f}$ \\
\hline
\end{tabular}

PC: Punto central (3 replicados). C: control. Diferentes letras en una misma columna indican diferencia significativa $(p<0,05)$.

Para evaluar un comportamiento integrado de la movilidad molecular se analizaron las superficies de respuesta (SR) para los tres sistemas estudiados (Figura 3.8). Las SR resultaron diferentes para las tres sales.

En el caso de masas con $\mathrm{CaCO}_{3}$, se observó una variación inversamente con el incremento de In (Figura 3.8.a, Tabla 3.8). La inulina es un polímero de fructosa que retiene el agua a través de enlaces de hidrógeno con los grupos $\mathrm{OH}$ de las moléculas de fructosa, bajos niveles de esta molécula son suficientes para restringir la movilidad molecular. En presencia de $\mathrm{CaCO}_{3}$, la estructura está inmovilizada a pesar de que el 
agua está en un estado de alta energía (libre). Este comportamiento podría atribuirse a la influencia de la sal de calcio inorgánica en la reestructuración de la red de gluten, lo que conduce a la formación de una masa más rígida. Friedli y Howell (1996) estudiaron las propiedades de gelación de proteínas soluble de trigo desamidada y sus interacciones con diversas sales, entre ellas calcio, y proteínas básicas encontrando que las proteínas desamidadas, o sea con alta densidad de carga negativa como consecuencia de los residuos glutámicos y aspárticos, en presencia de calcio potencian la formación de una red tridimensional por puentes con las proteínas cargadas negativamente conduciendo a la formación de geles particulados, relativamente agregados, pero fuertes.

La movilidad molecular de las masas con las sales de calcio orgánicas (Figuras 3.8.b y 3.8.c, Tabla 3.8) variaron inversamente con In y $\mathrm{Ca}^{*} I n$, especialmente para $\mathrm{Ca}_{3} \mathrm{Cl}_{2}$. Este comportamiento implica que a bajos niveles de inulina, un aumento del contenido de $\mathrm{Ca}$ incrementa $\lambda$; sin embargo, a elevados niveles de prebiótico, se observó una disminución de $\lambda$ con el incremento de $\mathrm{Ca}$ (Tabla 3.7). Para las masas con citrato de calcio, también se observó una dependencia con $\mathrm{Ca}^{2}$ (Tabla 3.8). Las diferencias en la SR para las sales orgánicas, sugieren una mayor influencia del citrato con respecto al lactato de calcio, resultando la movilidad molecular de estas últimas masas más influenciadas por la inulina.

Tabla 3.8. Análisis de varianza y coeficientes de regresión para el modelo polinomio de segundo orden.

\begin{tabular}{|c|c|c|c|c|c|c|}
\hline \multirow{3}{*}{$\begin{array}{l}\text { Términos } \\
\text { de } \\
\text { regresión }\end{array}$} & \multicolumn{6}{|c|}{$\lambda(\mathrm{ms})$} \\
\hline & \multicolumn{2}{|c|}{$\mathrm{CaCO}_{3}$} & \multicolumn{2}{|c|}{$\mathrm{Ca}_{3} \mathrm{Cl}_{2}$} & \multicolumn{2}{|c|}{$\mathrm{CaLA}_{2}$} \\
\hline & B & $p$-valor & b & $p$-valor & b & $p$-valor \\
\hline $\begin{array}{c}\text { Constante } \\
\left(b_{0}\right)\end{array}$ & 10,77 & & 10,27 & & 10,71 & \\
\hline $\mathrm{Ca}$ & $-0,184$ & 0,32 & $-0,05$ & 0,73 & $-0,06$ & 0,26 \\
\hline $\ln$ & $-0,566$ & 0,00 & $-0,72$ & 0,00 & $-0,56$ & 0,00 \\
\hline $\mathrm{Ca}^{2}$ & $-0,272$ & 0,20 & $-0,42$ & 0,04 & 0,05 & 0,42 \\
\hline $\ln ^{2}$ & 0,380 & 0,08 & $-0,21$ & 0,29 & $-0,02$ & 0,80 \\
\hline $\mathrm{Ca}^{*} \mathrm{In}$ & $-0,096$ & 0,72 & $-1,35$ & 0,00 & $-0,33$ & 0,00 \\
\hline $\mathrm{R}^{2}$ & & 0,771 & & 0,600 & & 0,819 \\
\hline $\mathrm{S}_{\mathrm{Cal}}$ & & 0,362 & & 0,468 & & 0,27 \\
\hline
\end{tabular}

Diferencias significativas cuando $p$-valor $<0,05$. 
a

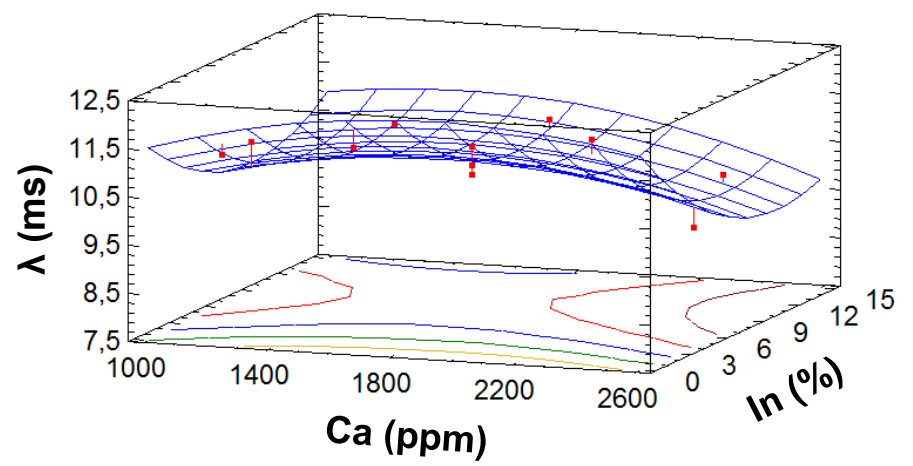

b

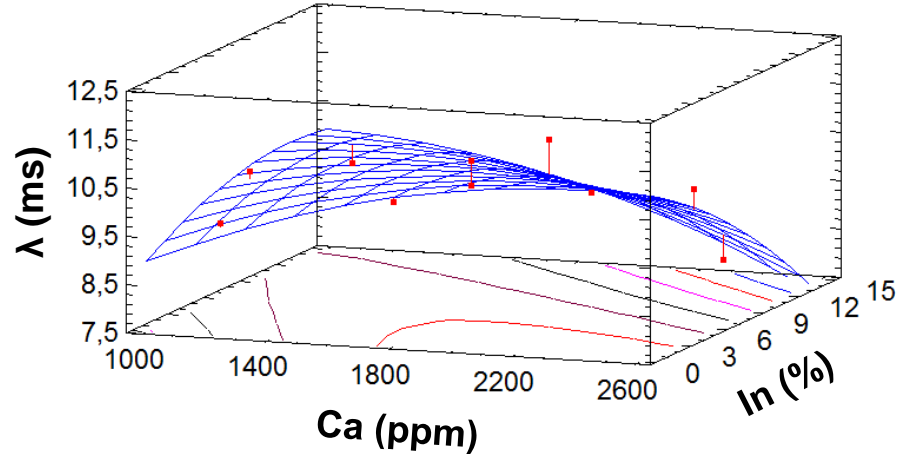

C

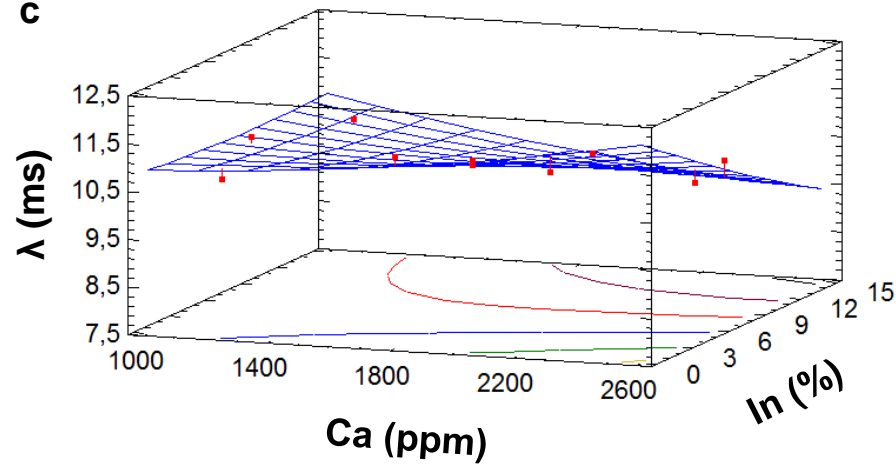

$\lambda$ (ms)

- 8,0

8,5

9,0

- 9,5

$-10,0$

- 10,5

$-11,0$

- 11,5

$-12,0$

- 12,5

$\lambda$ (ms)

- 8,0

$-8,5$

9,0

- 9,5

$-10,0$

- 10,5

$-11,0$

- 11,5

$-12,0$

- 12,5

- 13,0

$\lambda$ (ms)

$-8,0$

- 8,5

- 9,0

- 9,5

- 10,0

- 10,5

- 11,0

- 11,5

- 12,0

- 12,5

- 13,0

Figura 3.8. Gráfico de superficie de respuesta ( $\mathrm{SR}$ ) de la movilidad molecular de las masas: a) $\mathrm{CaCO}_{3}$, b) $\mathrm{Ca}_{3} \mathrm{Cl}_{2}$, c) $\mathrm{CaLA}_{2}$. Los puntos sobre la $\mathrm{SR}$ representan las medias de los valores experimentales obtenidos. Debajo de la SR se visualiza la superficie de contorno.

La movilidad molecular de las masas de los tres DCC varió fundamentalmente con la inversa de In, o sea, un incremento del prebiótico restringió la movilidad molecular de las masas independientemente de la sal de calcio utilizada.

Las diferentes propiedades de hidratación variaron como consecuencia de la formulación. Las diferencias podrían tener consecuencia en las propiedades reológicas de las masas a grandes (perfil de textura, punción, relajación) y pequeñas deformaciones (viscoelasticidad), por lo que en la siguiente sección se estudiará el 
efecto de las sales de calcio e inulina sobre la reología de la masa.

\subsection{Caracterización reológica de las masas}

\subsubsection{Perfil de textura}

La masa es un material viscoelástico muy sensible a la deformación. Cuando ésta se somete a fuerzas externas, los entrecruzamientos físicos y los enlaces químicos débiles que sostienen los constituyentes de la masa se pueden romper y reorganizar, permitiendo su relajación parcial o completa (Masi y col., 1998). El comportamiento macroestructural de la masa depende de su composición, del arreglo espacial entre sus componentes, de los tipos de enlaces existentes. Los estudios sobre la textura y la reología de la masa definen la influencia de los diversos componentes, permite el control de la calidad del producto final y orienta el diseño y la adaptación de nuevas tecnologías de proceso (Rodríguez-Sandoval y col., 2005).

En ausencia de inulina, la dureza de la masa se incrementó con el agregado de calcio (1800 ppm Ca) (Figura3.9.a). El agregado de inulina aumentó este parámetro. A 6,5\% In, mayores contenidos de $\mathrm{CaCO}_{3}$ provocaron un aumento significativo de la dureza, obteniéndose el máximo valor cuando se empleó 2520 ppm Ca. La consistencia varió en el mismo sentido que la dureza (Tabla 3.9). Estos resultados sugieren que la In confiere consistencia a la masa, probablemente debido a la capacidad de estructuración (Izydorczyk y col., 2001; Peressini y Sensidoni, 2009). Además, este efecto fue potenciado por el agregado de $\mathrm{CaCO}_{3}$, comportándose esta sal como fortalecedor de la estructura de la masa.

La adhesividad también aumentó significativamente con el incremento de inulina. En masas con un $12 \%$ In, la adhesividad de la masa decreció significativamente con la incorporación de carbonato (Figura 3.9.b). A 6,5\% In un incremento de $\mathrm{CaCO}_{3}$ provocó un aumento en la adhesividad.

La cohesividad es un parámetro relacionado con las fuerzas que vinculan entre sí los componentes de la matriz; un menor valor en la cohesividad se asocia a una menor integración de los componentes en la masa. Ambos ingredientes, Ca e In, afectaron negativamente a la cohesividad de la masa (Figura 3.9.c).

Del mismo modo, las masas con mayor consistencia fueron las que presentaron menor cohesión, lo que sugiere que un aumento en la dureza podría interferir con la unión de las partículas en la masa. 
Las masas presentaron valores de elasticidad que rondaron entre 0,86 y 0,90 (Tabla 3.9). El mayor valor se obtuvo a $6,5 \%$ In y con el mayor nivel de Ca (2520 ppm) en el caso del $\mathrm{CaCO}_{3}$. De todos modos, las variaciones, si bien fueron significativas, no fueron muy relevantes.
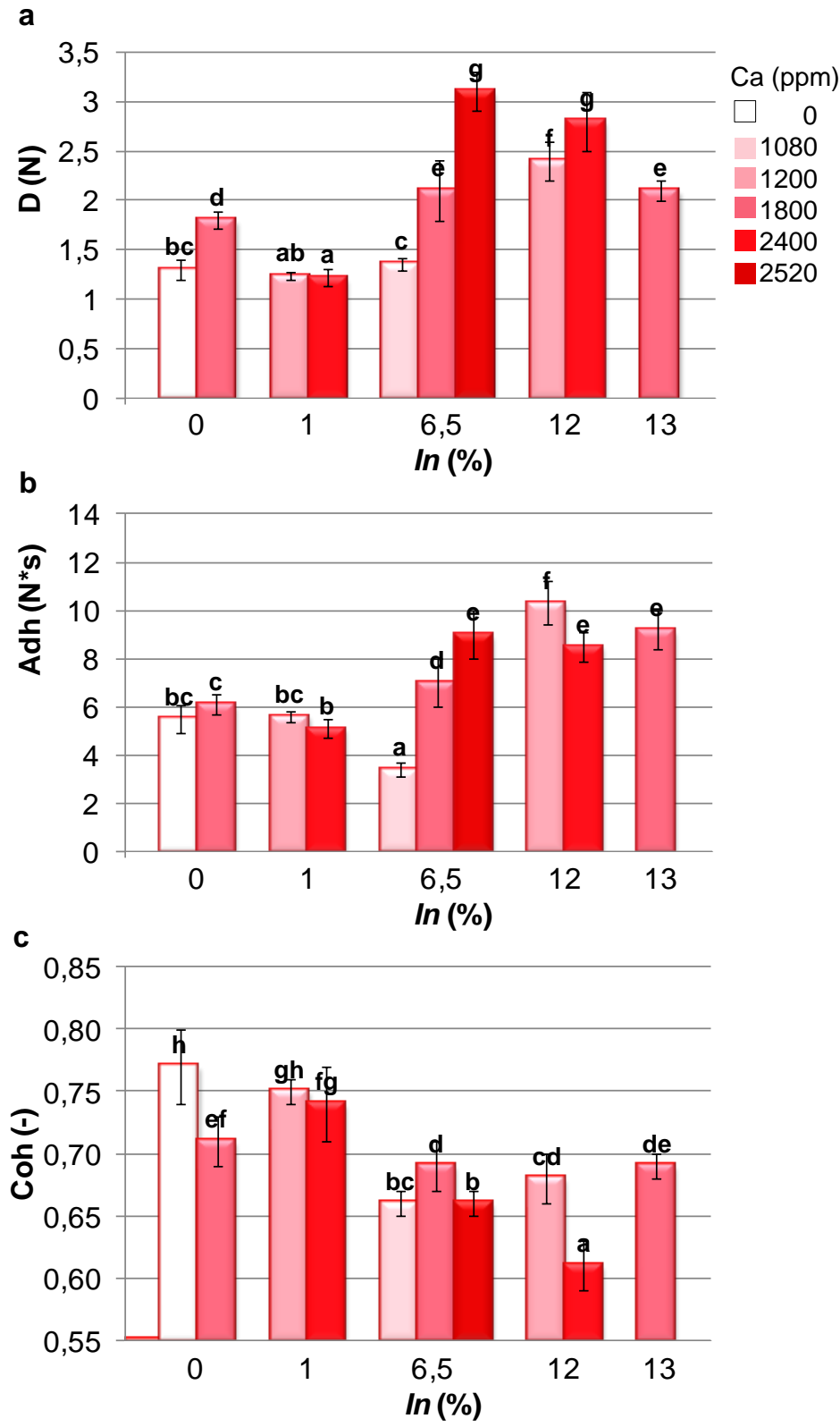

Figura 3.9. Parámetros de textura de masas con $\mathrm{CaCO}_{3}$ e In:a) Dureza (D),b) Adhesividad (Adh), c) Cohesividad (Coh). Las barras de error corresponden a las desviaciones estándar. Diferentes letras indican diferencias significativas entre las medias con $p<0,05$.

A pesar de que el contenido de agua fue similar en masas con 6,5\% In (como se mostró previamente en la Figura 3.7), la muestra con el mayor contenido de Ca (2520 ppm $\mathrm{Ca}$ ) presentó la menor movilidad molecular. Esta inmovilización de agua condujo 
a la formación de matrices de mayor dureza y consistencia. Esta masa más estructurada también es más elástica y adhesiva. Este comportamiento está de acuerdo con el estado de alta energía del agua en la masa, ésta es capaz de migrar a la superficie, contribuyendo a una mayor adhesividad.

Tabla 3.9. Consistencia y elasticidad de las masas obtenidas a partir de harina de trigo - salcalcio e inulina.

\begin{tabular}{|c|c|c|c|c|c|c|c|c|}
\hline & \multirow{2}{*}{$\begin{array}{c}\mathrm{Ca} \\
(\mathrm{ppm})\end{array}$} & \multirow{2}{*}{$\begin{array}{l}\text { In } \\
(\%)\end{array}$} & \multicolumn{2}{|c|}{$\mathrm{CaCO} 3$} & \multicolumn{2}{|c|}{ Ca3Cl2 } & \multicolumn{2}{|c|}{ CaLA2 } \\
\hline & & & $\begin{array}{l}\text { Cons } \\
\left(N^{*} S\right)\end{array}$ & $\begin{array}{c}\text { Elast } \\
(-)\end{array}$ & $\begin{array}{l}\text { Cons } \\
\left(\mathrm{N}^{\star} \mathrm{s}\right)\end{array}$ & $\begin{array}{c}\text { Elast } \\
(-)\end{array}$ & $\begin{array}{l}\text { Cons } \\
\left(N^{*} s\right)\end{array}$ & $\begin{array}{c}\text { Elast } \\
(-)\end{array}$ \\
\hline 1 & 1200 & 1 & $10 a$ & $0,86 \mathbf{a}$ & 12 bc & $0,87 \mathbf{b}$ & $12 \mathbf{b}$ & $0,86 \mathbf{a}$ \\
\hline 2 & 2400 & 1 & $10 a$ & $0,86 \mathbf{a}$ & $12 \mathbf{b}$ & $0,87 \mathbf{b}$ & $16 \mathrm{c}$ & $0,89 \mathbf{c}$ \\
\hline 3 & 1200 & 12 & $21 d$ & $0,88 \mathbf{c}$ & 18 ef & $0,88 \mathrm{c}$ & $27 \mathrm{~g}$ & $0,90 \mathrm{c}$ \\
\hline 4 & 2400 & 12 & $23 e$ & $0,88 \mathrm{c}$ & $13 c$ & $0,86 \mathbf{a}$ & $21 \mathrm{f}$ & $0,89 \mathbf{c}$ \\
\hline PC & 1800 & 6,5 & $17 \mathrm{c}$ & $0,89 \mathbf{c}$ & $17 \mathrm{e}$ & $0,89 \mathrm{c}$ & $20 \mathrm{e}$ & $0,90 \mathbf{c}$ \\
\hline 8 & 1080 & 6,5 & $9 a$ & $0,87 \mathbf{b}$ & $18 \mathrm{f}$ & $0,89 \mathbf{c d}$ & $18 d$ & $0,90 \mathbf{c}$ \\
\hline 9 & 1800 & 13 & $18 \mathrm{c}$ & $0,89 \mathbf{c}$ & 13 bc & $0,87 \mathbf{b}$ & $19 \mathrm{e}$ & $0,89 \mathbf{c}$ \\
\hline 10 & 2520 & 6,5 & $25 \mathrm{f}$ & $0,90 \mathbf{d}$ & $27 \mathrm{~g}$ & 0,89 cd & $16 c$ & $0,90 \mathrm{c}$ \\
\hline 11 & 1800 & 0 & $14 \mathbf{b}$ & $0,87 \mathbf{b}$ & $15 d$ & $0,89 \mathbf{d}$ & $12 \mathbf{b}$ & $0,88 \mathbf{b}$ \\
\hline $\mathrm{C}$ & 0 & 0 & $10 a$ & $0,87 \mathbf{b}$ & $10 a$ & $0,87 \mathbf{b}$ & $10 a$ & $0,87 \mathbf{a}$ \\
\hline
\end{tabular}

PC: Punto central (3 replicados). C: control. Diferentes letras en una misma columna indican diferencia significativa $(p<0,05)$.

Los parámetros de textura de las masas con sales orgánicas presentaron algunas diferencias con respecto a los descriptos previamente para masas con $\mathrm{CaCO}_{3}$. En ausencia de In, las sales de calcio orgánicas, al igual que ocurrió con la sal inorgánica, produjeron un aumento en la dureza de las masas con citrato y lactato (Figuras 3.10.a y 3.10.b, respectivamente), principalmente con $\mathrm{Ca}_{3} \mathrm{Cl}_{2}$. 

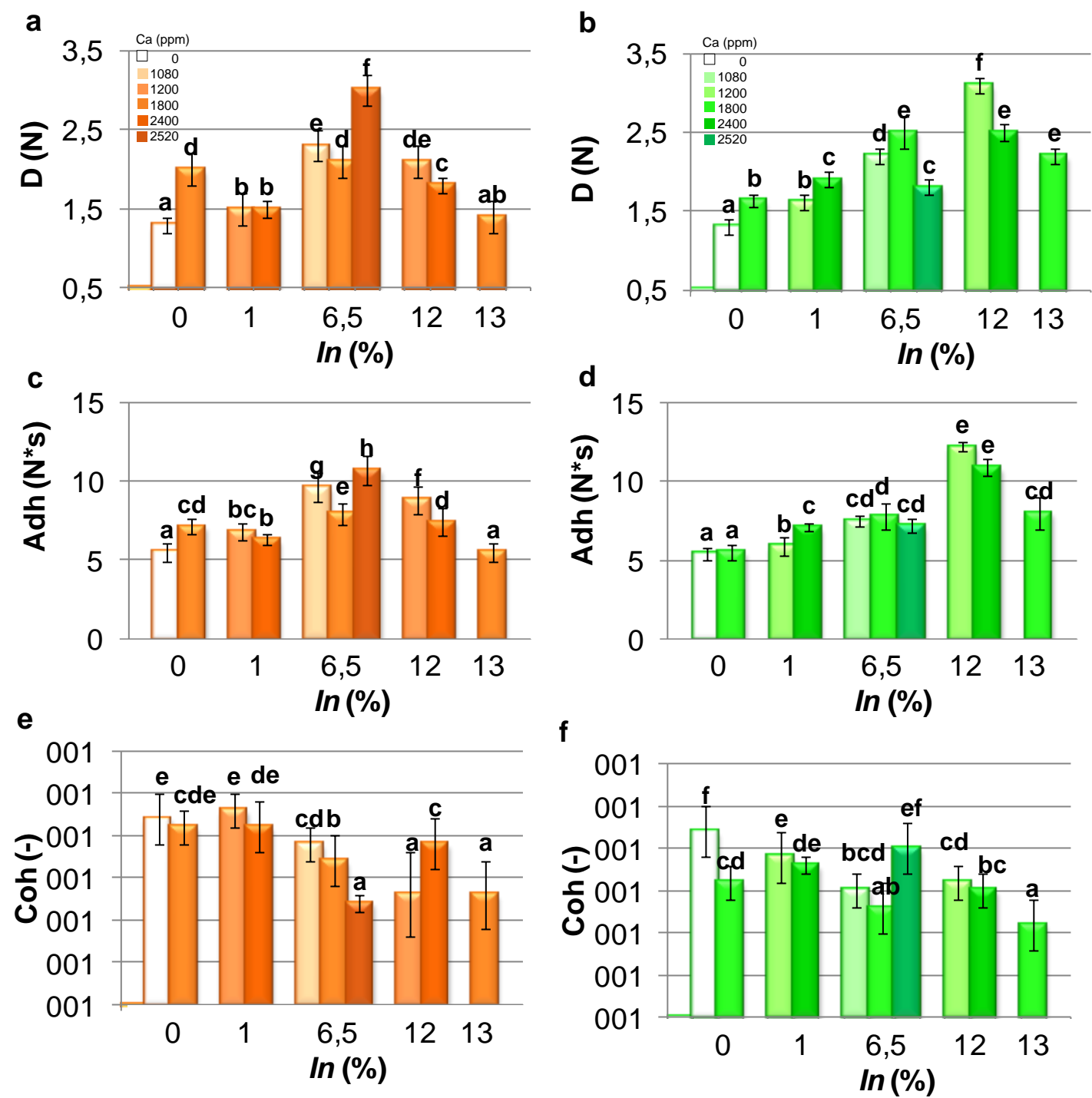

Figura 3.10. Parámetros texturales de las masas elaboradas a partir de harina de trigo con sales de calcio orgánicas e In: Dureza (D) (a, b), Adhesividad (Adh) (c, d), Cohesividad (Coh) $(\mathbf{e}, \mathbf{f})$. Las barras de error corresponden a las desviaciones estándar. Diferentes letras indican diferencias significativas entre las medias con $\mathrm{p}<0,05$. Mezclas con $\mathrm{Ca}_{3} \mathrm{Cl}_{2}(\mathbf{a}, \mathbf{c}, \mathbf{e})$ y con $\mathrm{CaLA}_{2}(\mathbf{b}, \mathbf{d}, \mathbf{f})$.

Las masas con $\mathrm{Ca}_{3} \mathrm{Cl}_{2}$, a alto nivel de calcio (2520 ppm Ca), presentan la mayor dureza, esta diferencia sugiere la formación de una red más firme como consecuencia del efecto estabilizante del anión citrato (Figura 3.10.a). A $12 \%$ In, la dureza de las masas fue alta, pero un aumento de calcio provocó una disminución de la misma, sugiriendo un efecto depresor de la sal en presencia del prebiótico, efecto opuesto al observado con $\mathrm{CaCO}_{3}$. En las masas con un 13\% In este efecto resultó disminuido.

A $1 \%$ In aumentó la dureza de la masa con el aumento de $\mathrm{CaLA}_{2}$, pero a valores $\geq$ $6,5 \%$ In el aumento de los niveles de $\mathrm{CaLA}_{2}$ disminuyó este parámetro en oposición a lo que ocurrió con las otras dos sales. Esta diferencia sugiere la formación de una red 
menos firme como consecuencia del efecto desestabilizante del anión lactato (Figura 3.10.b). Sin embargo, un incremento en el contenido de In (Figura 3.10.b) produjo un aumento en la dureza, siendo la masa control la más blanda. La consistencia de masas elaboradas con sales de calcio orgánicas siguió la misma tendencia que la dureza, similar a lo ocurrido al emplear la sal inorgánica (Tabla 3.9).

La adhesividad resultó dependiente principalmente de In (Figuras 3.10.c y 3.10.d), aunque existen diferencias en este parámetro según la sal de calcio orgánica utilizada. A 6,5\% In la adhesividad de las masas con $\mathrm{Ca}_{3} \mathrm{Cl}_{2}$ aumentó al incrementar la sal (Figura 3.10.c), a diferencia de las masas elaboradas con $\mathrm{CaLA}_{2}$ donde un aumento en la sal no modificó este parámetro (Figura 3.10.d). Las masas más adhesivas fueron las masas elaboradas con $\mathrm{CaLA}_{2}$ y altos niveles de In (12 y 13\%).

En ausencia de inulina, la cohesividad de la masa con $\mathrm{Ca}_{3} \mathrm{Cl}_{2}$ fue similar a la de la masa control (Figura 3.10.e). En cambio, un incremento en CaLA $\mathrm{A}_{2}$ provocó una disminución de este parámetro (Figura 3.10.f), asociado a una menor integración de los componentes dentro de la masa. A 6,5\% In, un aumento de $\mathrm{Ca}_{3} \mathrm{Cl}_{2}$ provocó una disminución en la cohesividad, comportamiento opuesto al observado cuando se empleó CaLA2.

En ausencia de In la elasticidad de las masas con lactato y citrato de calcio fueron mayores al control (Tabla 3.9). A cantidades $\leq 6,5 \%$ In el agregado de $\mathrm{Ca}_{3} \mathrm{Cl}_{2}$ no provocó cambios en la elasticidad de las masas. En cambio a 12\% In esta sal formó masas menos elásticas. Por otro lado, a $I n<6,5 \%$ In el $\mathrm{CaLA}_{2}$ generó masas más elásticas, aunque a altas concentraciones de In la elasticidad no se modificó con el incremento del contenido de calcio.

La mayor influencia sobre los parámetros de textura se observaron a 6,5\% In. Los aniones lactato y citrato poseen diferente capacidad de hidratación, modificando en distinta manera las interacciones entre las proteínas (Salinas y Puppo, 2013b). Por un lado, el lactato es un anión caotrópico que altera la estructura normal del agua modificando en forma negativa interacciones entre proteínas del gluten, conduciendo a una red menos rígida y por lo tanto masas más blandas. La masa es más cohesiva como consecuencia de una mayor integración entre los diferentes componentes. Por el contrario, el citrato es un anión no-caotrópico, su interacción con el agua fortalece las interacciones hidrofóbicas entre las moléculas de proteína que llevan a una red más estructurada, y por lo tanto presenta mayor dureza y menor cohesividad. Los FOS junto con inulina son componentes solubles que estarían menos involucrados en la matriz de gluten. Estos componentes solubles, debido a su efecto lubricante, son capaces de migrar a la superficie de la masa, siendo responsables de su elevada 
adhesividad.

\subsubsection{Ensayo de punción}

En la Figura 2.5 mostrada en la sección 2.2.7.1.2 se ejemplificó una curva obtenida en los ensayos de punción de masa, en la que pueden distinguirse diferentes regiones. Al comenzar el ensayo ocurre un aumento rápido de la fuerza debido a la deformación de la masa por la sonda, cuando la sonda penetra la masa ocurre una rotura irreversible de la misma que se evidencia por un cambio de pendiente. La siguiente zona de la curva registra la magnitud de la fuerza necesaria para que la sonda continúe penetrando en la matriz; en el caso de la masa, la fuerza continúa aumentando luego de la penetración. En esta zona se determinó la firmeza $(F)$ de la masa como la máxima fuerza registrada durante la penetración. Luego de este punto, la sonda se retira de la masa produciéndose una disminución de la fuerza y evidenciándose un área negativa correspondiente a un índice de viscosidad (IV) de la masa. Cuanto mayor sea el área, mayor trabajo de cohesión, más difícil es el despegue de la muestra de la sonda, lo cual da idea de cohesión y viscosidad de la masa al mismo tiempo.

En la Tabla 3.10 se muestran los valores de fuerza de penetración $\left(F_{p}\right)$ de las masas estudiadas.

En masas elaboradas con $\mathrm{CaCO}_{3}$ un aumento de In produjo un incremento en la $\mathrm{F}_{\mathrm{p}}$. Sin embargo, a igual concentración de In (1 y 12\%), un incremento de carbonato disminuyó dicho parámetro (Tabla 3.10).

Cuando se utilizó $\mathrm{Ca}_{3} \mathrm{Cl}_{2}$, se observó un comportamiento particular, sin diferencias significativas en las $F_{p}$ de las diferentes masas, resultando la masa con 1200 ppm Ca y $12 \%$ In la de mayor valor de $F_{p}$.

En masas con $\mathrm{CaLA}_{2}$ e In $1 \%$ un incremento de sal aumentó significativamente la $\mathrm{F}_{\mathrm{p}}, \mathrm{y}$ dicho aumento fue mayor aún con 12\% In (Tabla 3.10). En ausencia del prebiótico, sólo las masas con $\mathrm{CaLA}_{2}$ aumentaron significativamente la $\mathrm{F}_{\mathrm{p}}$ respecto al control, a pesar de no haberse observado un aumento sustancial en la dureza. Este comportamiento sugiere que la masa se comporta diferente frente a la compresión que a la penetración donde hay ruptura de estructura.

La F e IV siguieron la misma tendencia que la dureza y adhesividad del TPA, por lo que se decidió no analizar dichos parámetros. 
Tabla 3.10. Fuerza de penetración de las masas.

\begin{tabular}{c|cc|lll}
\hline & \multirow{2}{*}{$\begin{array}{c}\mathbf{C a} \\
(\mathbf{p p m})\end{array}$} & $\begin{array}{c}\text { In } \\
(\%)\end{array}$ & \multicolumn{3}{|c}{$\begin{array}{c}\mathbf{F}_{\mathbf{p}} \\
(\mathbf{m N})\end{array}$} \\
\cline { 4 - 6 } & & & $\mathrm{CaCO}_{3}$ & $\mathbf{C a}_{3} \mathbf{C l}_{2}$ & $\mathbf{C a L A}_{2}$ \\
\hline $\mathbf{1}$ & 1200 & 1 & $39 \mathbf{b}$ & $32 \mathbf{a}$ & $34 \mathbf{a}$ \\
$\mathbf{2}$ & 2400 & 1 & $35 \mathbf{a}$ & $34 \mathbf{a b}$ & $63 \mathbf{c d}$ \\
$\mathbf{3}$ & 1200 & 12 & $46 \mathbf{d}$ & $44 \mathbf{c}$ & $81 \mathbf{e}$ \\
$\mathbf{4}$ & 2400 & 12 & $42 \mathbf{b c}$ & $33 \mathbf{a b}$ & $77 \mathbf{e}$ \\
$\mathbf{P C}$ & 1800 & 6,5 & $40 \mathbf{b}$ & $35 \mathbf{a b}$ & $57 \mathbf{b}$ \\
$\mathbf{8}$ & 1080 & 6,5 & $46 \mathbf{c d}$ & $38 \mathbf{b c}$ & $65 \mathbf{c d}$ \\
$\mathbf{9}$ & 1800 & 13 & $42 \mathbf{b c}$ & $33 \mathbf{a b}$ & $68 \mathbf{d}$ \\
$\mathbf{1 0}$ & 2520 & 6,5 & $45 \mathbf{c d}$ & $35 \mathbf{a b}$ & $60 \mathbf{b c}$ \\
$\mathbf{1 1}$ & 1800 & 0 & $35 \mathbf{a}$ & $34 \mathbf{a b}$ & $63 \mathbf{c d}$ \\
\hline $\mathbf{C}$ & 0 & 0 & $32 \mathbf{a}$ & $32 \mathbf{a}$ & $32 \mathbf{a}$ \\
\hline
\end{tabular}

Letras diferentes dentro de una misma columna indican diferencias significativas $(p<0,05)$.

Por lo tanto, por medio de este ensayo rápido podríamos relacionar la firmeza de la masa e índice de viscosidad con los parámetros obtenidos del perfil de textura dureza y adhesividad, respectivamente.

\subsubsection{Relajación de las masas}

Para masas obtenidas a partir de diferentes harinas, Lopes-da-Silva y col. (2007) asignaron diferencias en la movilidad molecular de las matrices de proteína/agua a diferencias en la rigidez de la red. Los ensayos de relajación han sido utilizados anteriormente para el estudio de las propiedades reológicas de las masas (RodriguezSandoval y col. 2009; Correa y col., 2010). En los sólidos viscoelásticos como las masas el esfuerzo decae hacia un valor de equilibrio. De acuerdo a Yadav y col. (2006), las curvas de relajación exhiben tres zonas: una primera zona de gran pendiente, una zona de decaimiento intermedio, y una tercera con una pendiente insignificante que alcanza un valor de esfuerzo de equilibrio. La relajación es un fenómeno relacionado con la reorientación molecular y estructural del sistema. Los parámetros obtenidos luego de aplicar el modelo de Maxwell generalizado son el módulo elástico $\mathrm{E}$ y el módulo de relajación $\mathrm{T}$, los cuales nos permiten estudiar esta orientación estructural de los componentes en la masa.

En la Figura 3.11 puede observarse un gráfico típico de esfuerzo en función del tiempo 
para algunas de las formulaciones estudiadas. El comportamiento de relajación de la masa puede ser descripto a través de dos procesos: una relajación rápida (de 0,1 a 10 s), la cual se asocia a moléculas pequeñas que relajan más rápido, y un proceso lento (de 10 a $10.000 \mathrm{~s}$ ) relacionada con la relajación de los polímeros de alto peso molecular que comprenden el gluten (Dobraszczyk y Morgenstern, 2003; Li y col., 2003).

La masa control fue la que más se relajó. Con el agregado de sales, y principalmente con el prebiótico, las curvas presentaron mayor esfuerzo inicial, siendo la masa con $\mathrm{CaCO}_{3}$ la que evidenció menor relajación con 12\% In (CA4). La curva de relajación de la masa con $\mathrm{CaLA}_{2}$ (LA4) presentó similar comportamiento que la masa elaborada con $\mathrm{CaCO}_{3}(\mathrm{CA} 4)$, por lo tanto sólo se muestra esta última (Figura 3.11). La masa Cl4 se relajó más que las masas con $\mathrm{CaCO}_{3}$ y $\mathrm{CaLA}_{2}$ en presencia de $12 \%$ In. Las masas con las diferentes sales calcio sin In presentaron similares curvas de relajación; para una mejor visualización sólo se muestra en la Figura 3.11 la curva de relajación de la masa Cl11.

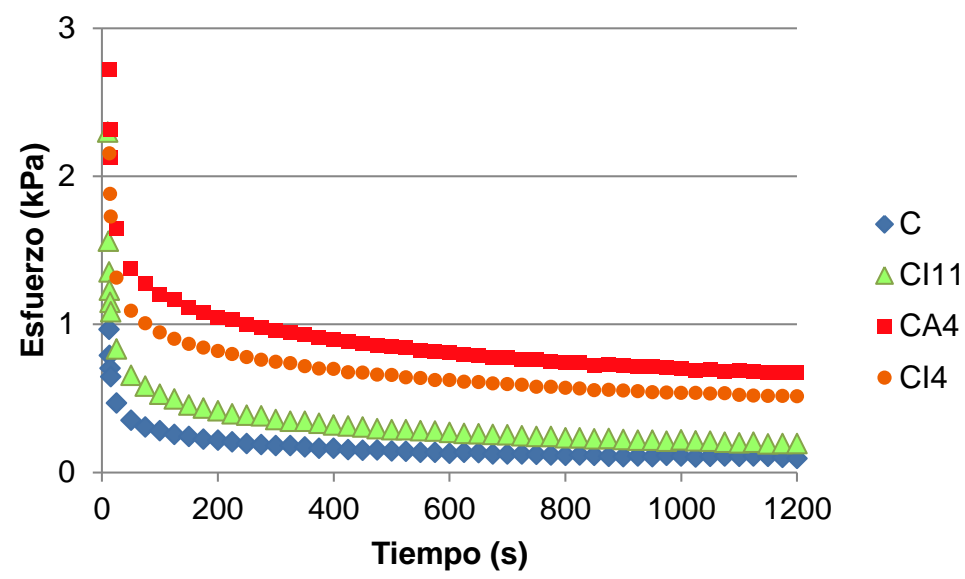

Figura 3.11. Curvas de relajación obtenidas con el texturómetro de algunas de las masas. C: control; Cl11: 1800 ppm Ca-0\% In; Cl4 y CA4: 2400 ppm Ca-12\% In.

El tiempo de relajación (T) es inverso al módulo elástico $\mathrm{E}$ y está relacionado con el grado de relajación, a mayor $\mathrm{T}$, mayor es el componente viscoso con respecto al elástico y más se relaja la masa. $E_{1}$ y $T_{1}$ gobiernan la relajación al comienzo de la deformación, que se atribuye a la orientación de las moléculas de bajo tamaño, mientras que $E_{2}$ y $T_{2}$ (zona intermedia) representan la relajación de las moléculas poliméricas. Como al comienzo la masa se relaja en mayor proporción, $\mathrm{T}_{1}$ es en general mayor que $\mathrm{T}_{2}$. Si el esfuerzo no cambia con la deformación alcanzando el equilibrio, predomina el término $\mathrm{E}_{3}$ el cual representa la energía almacenada. 
Las masas presentaron en todos los casos valores un orden mayor de $E_{2}$ comparados con los modulo $E_{1}$ y $E_{3}$. Estos resultados sugieren que las proteínas poliméricas del gluten que se relajan en la zona 2 , representada por $\mathrm{E}_{2}$, están contribuyendo en gran medida a la elasticidad de la masa. Para una mejor comprensión del fenómeno de relajación, sólo analizaremos los parámetros de $E_{3}, T_{1} y T_{2}$. Los valores promedios de los módulos elásticos en el equilibrio $\left(\mathrm{E}_{3}\right)$ se muestran en la Tabla 3.11.

En las masas elaboradas con $\mathrm{CaCO}_{3}$, los valores de $\mathrm{E}_{3}$ aumentaron significativamente sólo cuando estaba presente el prebiótico, las masas con mayores niveles de In presentaron los mayores valores de $\mathrm{E}_{3}$ (Tabla 3.11).

En las masas elaboradas con $\mathrm{Ca}_{3} \mathrm{Cl}_{2}$ puede observarse que a niveles bajos de prebiótico $(\leq 6,5 \%)$ el aumento del contenido de calcio provoca un aumento de $E_{3}$ (Tabla 3.11) asociado a una mayor energía almacenada. Estos resultados serían los esperados debido al efecto estabilizador del anión de esta sal sobre la red de gluten; mayores valores de módulo elástico en el equilibrio estarían asociados a un mayor predominio del comportamiento elástico sobre el viscoso. Las masas con $12 \%$ In ( $\mathrm{Cl} 3$ y $\mathrm{Cl} 4)$ presentaron altos valores de $E_{3}$, sin embargo el módulo elástico de la formulación CI9 fue bajo, estos resultados están relacionados con bajo valor de dureza obtenido por TPA, sugiriendo que en presencia de un $13 \%$ In la masa se ablanda y pierde elasticidad.

En la Tabla 3.11 también se muestran los valores de $E_{3}$ de las masas elaboradas con $\mathrm{CaLA}_{2}$. En ausencia de inulina, $E_{3}$ de la masa con $\mathrm{CaLA}_{2}(0,20 \mathrm{kPa})$ fue significativamente mayor que el valor obtenido para la masa de control $(0,11 \mathrm{kPa})$, en concordancia con el mayor valor de dureza. En presencia del prebiótico se observa la misma tendencia que para el $\mathrm{CaCO}_{3}, a \geq 12 \%$ In los valores de $\mathrm{E}_{3}$ son mayores, o sea hay una fuerte dependencia del prebiótico encubriendo el efecto del anión. 
Tabla 3.11. Módulo elástico en el equilibrio de las masas

\begin{tabular}{c|cc|ccc}
\hline & $\mathbf{C a}$ & $\mathbf{I n}$ & \multicolumn{3}{|c}{$\mathbf{E}_{3}(\mathbf{k P a})$} \\
\cline { 4 - 6 } & $(\mathbf{p p m})$ & $\mathbf{( \% )}$ & $\mathrm{CaCO}_{3}$ & $\mathrm{Ca}_{3} \mathbf{C l}_{2}$ & $\mathbf{C a L A}_{2}$ \\
\hline $\mathbf{1}$ & 1200 & 1 & $0,15 \mathbf{a}$ & $0,12 \mathbf{a}$ & $0,19 \mathbf{b}$ \\
$\mathbf{2}$ & 2400 & 1 & $0,13 \mathbf{a}$ & $0,40 \mathbf{d e}$ & $0,26 \mathbf{b c}$ \\
$\mathbf{3}$ & 1200 & 12 & $0,69 \mathbf{d}$ & $0,50 \mathbf{e f}$ & $0,87 \mathbf{g}$ \\
$\mathbf{4}$ & 2400 & 12 & $0,65 \mathbf{d}$ & $0,58 \mathbf{f}$ & $0,72 \mathbf{f g}$ \\
$\mathbf{P C}$ & 1800 & 6,5 & $0,35 \mathbf{b}$ & $0,33 \mathbf{c d}$ & $0,43 \mathbf{d e}$ \\
$\mathbf{8}$ & 1080 & 6,5 & $0,46 \mathbf{c}$ & $0,28 \mathbf{b c}$ & $0,33 \mathbf{c d}$ \\
$\mathbf{9}$ & 1800 & 13 & $0,66 \mathbf{d}$ & $0,22 \mathbf{a b}$ & $0,56 \mathbf{~ e f}$ \\
$\mathbf{1 0}$ & 2520 & 6,5 & $0,51 \mathbf{c}$ & $0,50 \mathbf{e f}$ & $0,32 \mathbf{c d}$ \\
$\mathbf{1 1}$ & 1800 & 0 & $0,16 \mathbf{a}$ & $0,18 \mathbf{a b}$ & $0,20 \mathbf{b}$ \\
\hline $\mathbf{C}$ & 0 & 0 & $0,11 \mathbf{a}$ & $0,11 \mathbf{a}$ & $0,11 \mathbf{a}$ \\
\hline
\end{tabular}

Diferentes letras en igual columna indican diferencias significativas entre las medias $(p<0,05)$.

La superficie de respuesta generada (Figura 3.12) y los coeficientes de regresión obtenidos a partir del modelo cuadrático para $E_{3}$ se muestran en la Tabla 3.12. El módulo elástico $\mathrm{E}_{3}$ de masas con $\mathrm{CaCO}_{3}$ y $\mathrm{CaLA}_{2}$ (Figuras 3.12.a y 3.12.b, Tabla 3.12) aumentaron proporcionalmente con In. El modelo de regresión para la SR de $\mathrm{E}_{3}$ de masas con $\mathrm{Ca}_{3} \mathrm{Cl}_{2}$ no presentó términos estadísticamente significativos.

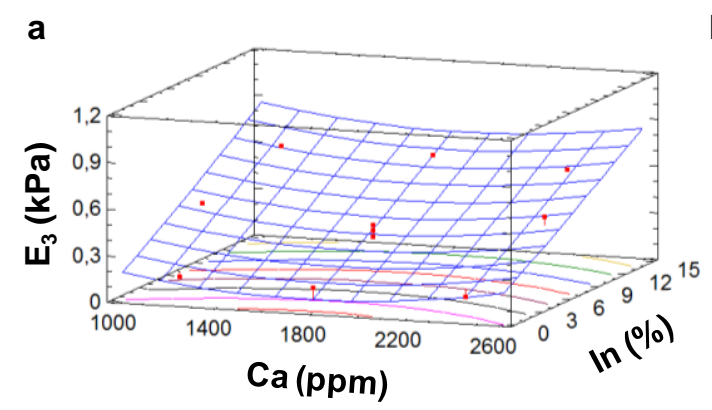

b

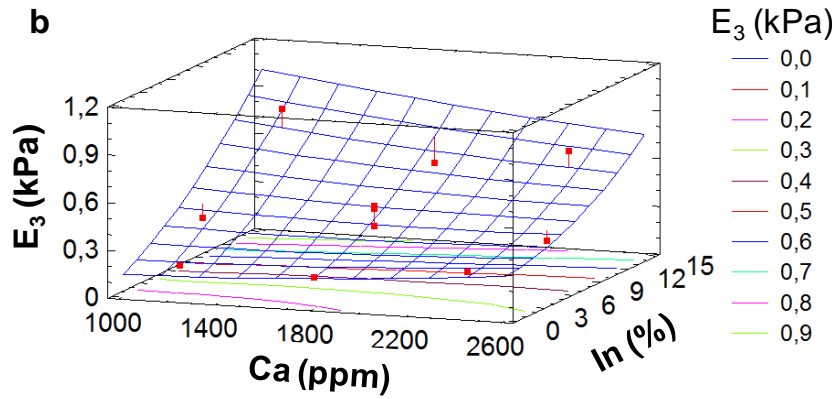

$\mathrm{E}_{3}(\mathrm{kPa})$

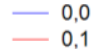

0,1
$-0,2$

0,3

$-0,4$

0,5

0,7

$-0,9$

Figura 3.12. Gráfico de superficie de respuesta (SR) del módulo elástico de equilibrio $E_{3}$ de las masas: a) $\mathrm{CaCO}_{3}$, b) $\mathrm{CaLA}_{2}$. Los puntos sobre la RSM representan las medias de los valores experimentales obtenidos. Debajo de la misma se visualiza la superficie de contorno. 
Tabla 3.12. Análisis de varianza y coeficientes de regresión para el modelo polinomio de segundo orden

\begin{tabular}{c|cc|cc}
\hline \multirow{2}{*}{ Términos de } & \multicolumn{4}{c}{$\mathrm{E}_{3}(\mathrm{kPa})$} \\
\cline { 2 - 5 } Regresión & \multicolumn{2}{|c}{$\mathrm{CaCO}_{3}$} & \multicolumn{2}{c}{$\mathrm{CaLA}_{2}$} \\
\cline { 2 - 5 } & $\mathbf{b}$ & $\boldsymbol{p}$-valor & $\mathbf{b}$ & $\boldsymbol{p}$-valor \\
\hline Constante $\left(\mathrm{b}_{0}\right)$ & 0,664 & & 0,389 \\
$\mathrm{Ca}$ & $-0,001$ & 0,94 & $-0,013$ & 0,79 \\
In & 0,088 & 0,00 & 0,228 & 0,01 \\
$\mathrm{Ca}^{2}$ & 0,000 & 0,86 & 0,012 & 0,82 \\
In $^{2}$ & 0,0004 & 0,00 & 0,05 & 0,48 \\
$\mathrm{Ca}^{*} \ln$ & 0,000 & 0,43 & $-0,055$ & 0,43 \\
$\mathrm{R}^{2}$ & & 0,957 & & 0,825 \\
$\mathrm{~S}_{\text {Cal }}$ & & 0,061 & & 0,129 \\
\hline
\end{tabular}

Diferencias significativas $(p$-valor $<0,05)$

Los tiempos de relajación $\left(T_{1} y T_{2}\right)$ se muestran en la Tabla 3.13. En las masas elaboradas con $\mathrm{CaCO}_{3}, \mathrm{~T}_{1}$ aumentó con el aumento de In, independientemente de la cantidad de calcio utilizada. Los resultados sugieren que el prebiótico favorece un mayor grado de relajación de la masa a tiempos cortos asociado con el orden de moléculas pequeñas. Comparando las masas con 6,5\% In como 8, PC y CA10, esta última (2520 ppm Ca) presentó el menor grado de relajación ( $T_{1}$ más bajo), lo que indica que el $\mathrm{CaCO}_{3}$ ejerce un efecto de refuerzo sobre la masa; en el mismo sentido previamente describimos en el TPA que esta masa fue la más dura y presentó menor movilidad molecular en ensayos de RMN.

En la segunda fase, el grado de relajación resultó menor, probablemente debido a la dificultad en el reordenamiento de las moléculas más grandes (gluten) (Tabla 3.13). Los valores más altos de $T_{1}$ y $T_{2}$ se observaron en las muestras con el más alto contenido de inulina (CA3, CA4, y CA9).

Los valores de $T_{1}$ de las masas elaboradas con $\mathrm{Ca}_{3} \mathrm{Cl}_{2}$ e inulina fueron significativamente mayores que los de la masa C y Cl11 (1800 ppm Ca- 0\% In). No se observaron diferencias significativas en los tiempos de relajación $T_{1} \mathrm{yT}_{2}$ obtenidos de las masas con $\mathrm{Ca}_{3} \mathrm{Cl}_{2}$ respecto a la masa $\mathrm{C}$ (Tabla 3.13).

La masa con CaLA $\mathrm{A}_{2}$ tuvo un comportamiento de relajación semejante al de $\mathrm{CaCO}_{3}$, con los valores más altos de $T_{1}$ y $T_{2}$ a alto contenido de inulina y con mayor grado de relajación de ambas poblaciones de moléculas al aumentar el contenido de sal (Tabla 3.13). Los resultados sugieren que con $\mathrm{CaLA}_{2}$ y alta In, hay mayor grado de relajación 
de polímeros, coincidente con la menor elasticidad de la masa encontrada en el perfil de textura.

Tabla 3.13. Tiempos de relajación de las masas.

\begin{tabular}{|c|c|c|c|c|c|c|c|c|}
\hline & \multirow{2}{*}{$\begin{array}{c}\mathrm{Ca} \\
(\mathrm{ppm})\end{array}$} & \multirow{2}{*}{$\begin{array}{l}\text { In } \\
(\%)\end{array}$} & \multicolumn{2}{|c|}{$\mathrm{CaCO}_{3}$} & \multicolumn{2}{|c|}{$\mathrm{Ca}_{3} \mathrm{Cl}_{2}$} & \multicolumn{2}{|c|}{$\mathrm{CaLA}_{2}$} \\
\hline & & & $T_{1}(s)$ & $T_{2}(s)$ & $T_{1}(s)$ & $T_{2}(s)$ & $T_{1}(s)$ & $T_{2}(s)$ \\
\hline 1 & 1200 & 1 & 294 bcd & $7,1 \mathrm{ab}$ & 316 bc & $9,0 \mathbf{a b}$ & 311 bc & 8,6 bcd \\
\hline 2 & 2400 & 1 & $315 d$ & 7,6 abc & $336 \mathrm{c}$ & $10,3 \mathbf{b}$ & $277 a b$ & $7,4 \mathbf{a b}$ \\
\hline 3 & 1200 & 12 & $337 \mathrm{de}$ & 9,0 cd & $319 c$ & $8,3 a b$ & 312 bc & 9,0 cde \\
\hline 4 & 2400 & 12 & 371 e & $9,7 \mathbf{d}$ & 297 bc & $8,0 \mathrm{ab}$ & 357 c & $10,3 \mathbf{e}$ \\
\hline PC & 1800 & 6,5 & $316 d$ & 7,9 bc & $317 c$ & $8,5 a b$ & $275 a b$ & $7,0 \mathbf{a}$ \\
\hline 8 & 1080 & 6,5 & 304 bcd & 7,6 abc & 322 c & $8,4 a b$ & 308 bc & $8,4 \mathrm{bcd}$ \\
\hline 9 & 1800 & 13 & 335 de & $8,9 \mathbf{d}$ & $340 \mathrm{c}$ & $8,5 a b$ & 331 bc & 9,5 de \\
\hline 10 & 2520 & 6,5 & $266 a b$ & $7,1 \mathrm{ab}$ & $327 \mathrm{c}$ & $8,6 \mathrm{ab}$ & $278 \mathrm{abc}$ & $7,0 \mathbf{a b}$ \\
\hline 11 & 1800 & 0 & $275 \mathrm{abc}$ & $7,3 \mathrm{ab}$ & $256 a b$ & $6,8 \mathrm{ab}$ & $282 \mathrm{abc}$ & 7,9 abc \\
\hline C & 0 & 0 & $227 \mathbf{a}$ & $6,1 \mathbf{a}$ & $227 \mathbf{a}$ & $6,1 \mathbf{a}$ & $227 \mathbf{a}$ & $6,1 \mathbf{a}$ \\
\hline
\end{tabular}

Diferentes letras en igual columna indican diferencias significativas entre las medias $(p<0,05)$.

\subsubsection{Viscoelasticidad}

Las masas presentaron valores de G' mayor que G" en todo el rango de frecuencia estudiado, lo que sugiere que son sistemas viscoelásticos en los cuales predomina el comportamiento elástico sobre el viscoso. El valor de G' de la masa control fue de 12,4 $\mathrm{kPa}$.

La Figura 3.13 muestra las superficie de respuesta (SR) de G' de las diferentes masas. Las elaboradas con $\mathrm{CaCO}_{3}$ y $\mathrm{Ca}_{3} \mathrm{Cl}_{2}$ presentaron una dependencia directamente proporcional con In, independientemente de la cantidad de sal agregada (Figuras 3.13.a y 3.13.b, Tabla 3.14). El modulo elástico dinámico ( $\left.G^{\prime}\right)$ siguió el mismo comportamiento que $\mathrm{E}_{3}$.

Las masas con CaLA $\mathrm{A}_{2}$ mostraron, para los valores de G', una SR muy diferente a las anteriores con una dependencia con $\mathrm{Ca}, \mathrm{Ca}^{2}$ y principalmente con la interacción $(\mathrm{Ca} * I n)$ (Figura 3.13.c, Tabla 3.14). Esta interacción entre ambos factores significa que a niveles bajos de $\mathrm{CaLA}_{2}$ (1200 ppm Ca) un aumento de In produjo un incremento de este parámetro. En cambio, a 2400 ppm Ca, el incremento de la inulina, produjo la disminución de G'.

Si bien una primera aproximación al análisis del comportamiento elástico lo brinda el 
parámetro G', el que mejor representa en forma completa la viscoelasticidad de la masa es la tan $\delta$, ya que es la relación entre ambos módulos (G'/G'). La masa más viscosa fue la control, la cual presentó el mayor valor de $\tan \delta(\tan \delta=0,350)$. Las SR obtenidas de éste parámetro resultaron muy diferentes dependiendo de la sal de calcio incorporada a las mezclas (Figura 3.13).
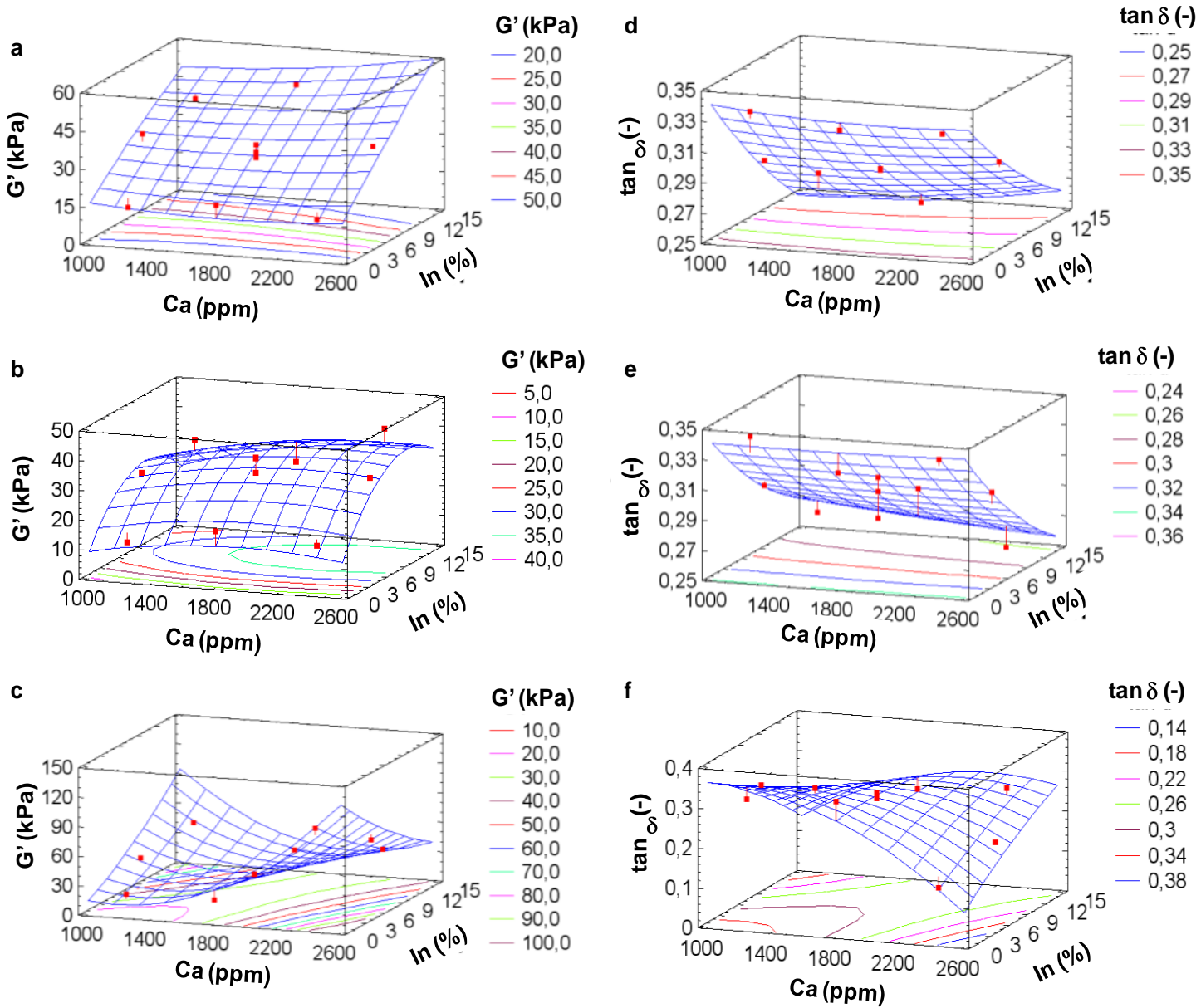

Figura 3.13. Gráfico de superficie de los parámetros del espectro mecánico dinámico de masas: Módulo elástico (G') (a, b, c), tangente del ángulo de desfasaje (tan $\delta)(\mathbf{d}, \mathbf{e}, \mathbf{f})$. Los puntos sobre la $S R$ representan las medias de los valores experimentales obtenidos. Debajo de la misma se visualiza la superficie de contorno. Masas con $\mathrm{CaCO}_{3}(\mathbf{a}, \mathbf{d}) \mathrm{Ca}_{3} \mathrm{Cl}_{2}$ (b, e) $\mathrm{CaLA}_{2}$ $(\mathbf{c}, \mathbf{f})$.

En masas elaboradas con $\mathrm{CaCO}_{3}$ se observa una dependencia lineal inversa con el agregado de In, lo cual significa que un aumento del prebiótico conduce a menores tan $\delta$ y por lo tanto una mayor elasticidad obtenida a baja deformación, independientemente del agregado de $\mathrm{CaCO}_{3}$ (Figura 3.13.d, Tabla 3.14). Similar comportamiento se observó en masas con $\mathrm{Ca}_{3} \mathrm{Cl}_{2}$ (Figura 3.13.e, Tabla 3.14).

En masas elaboradas con $\mathrm{CaLA}_{2}$ los factores de mayor influencia en tan $\delta$ fueron $\mathrm{Ca} y$ la interacción Ca*In, comportamiento concordante con la tenencia obtenida para G'. 
Tabla 3.14. . Análisis de varianza y coeficientes de regresión para el modelo polinomio de segundo orden

\begin{tabular}{|c|c|c|c|c|c|c|c|c|c|c|c|c|}
\hline \multirow{3}{*}{$\begin{array}{l}\text { Términos } \\
\quad \text { de } \\
\text { regresión }\end{array}$} & \multicolumn{4}{|c|}{$\mathrm{CaCO}_{3}$} & \multicolumn{4}{|c|}{$\mathrm{Ca}_{3} \mathrm{Cl}_{2}$} & \multicolumn{4}{|c|}{$\mathrm{CaLA}_{2}$} \\
\hline & \multicolumn{2}{|c|}{ G' (kPa) } & \multicolumn{2}{|c|}{$\tan \delta(-)$} & \multicolumn{2}{|c|}{ G' (kPa) } & \multicolumn{2}{|c|}{$\tan \delta(-)$} & \multicolumn{2}{|c|}{ G' (kPa) } & \multicolumn{2}{|c|}{$\tan \delta(-)$} \\
\hline & b & p-valor & b & p-valor & b & p-valor & b & p-valor & b & p-valor & b & p-valor \\
\hline Constante $\left(b_{0}\right)$ & 29,5 & & 0,295 & & 34,38 & & 0,298 & & 26,48 & & 0,296 & \\
\hline $\mathrm{Ca}$ & $-6,86$ & 0,28 & $-0,0004$ & 0,90 & 2,43 & 0,29 & $-0,002$ & 0,80 & 16,05 & 0,001 & $-0,039$ & 0,03 \\
\hline In & 27,5 & 0,00 & $-0,033$ & 0,00 & 8,61 & 0,01 & $-0,030$ & 0,005 & $-2,41$ & 0,39 & $-0,004$ & 0,75 \\
\hline $\mathrm{Ca}^{2}$ & $-8,25$ & 0,33 & 0,0023 & 0,64 & $-2,11$ & 0,48 & $8,10^{-4}$ & 0,93 & 21,68 & 0,001 & $-0,038$ & 0,08 \\
\hline $\ln ^{2}$ & 1,4 & 0,86 & $-0,001$ & 0,79 & $-7,12$ & 0,05 & 0,0046 & 0,61 & 42,15 & 0,38 & $-0,007$ & 0,71 \\
\hline $\mathrm{Ca}^{*} \ln$ & 7,12 & 0,39 & $-0,0002$ & 0,97 & 1,27 & 0,66 & $-0,02$ & 0,82 & $-23,61$ & 0,001 & 0,055 & 0,02 \\
\hline $\mathrm{R}^{2}$ & & 0,843 & & 0,951 & & 0,840 & & 0,818 & & 0,963 & & 0,832 \\
\hline $\mathrm{S}_{\text {Cal }}$ & & 7,493 & & 0,009 & & 5,39 & & 0,014 & & 6,73 & & 0,003 \\
\hline
\end{tabular}

Las diferencias resultan significativas con un valor de $p<0,05$. 
Peressini y Sensidoni (2009) encontraron que contenidos crecientes de inulina $(2,5 \%$, $5 \%$ y $7,5 \%$ ) de diferente grado de polimerización resultaron en un incremento de G' y una disminución de tan $\delta$, lo que indica una mayor elasticidad de la masa, el efecto fue menos pronunciado para inulina de cadena corta. Otros autores (Wang y col., 2002) reportaron un comportamiento opuesto, es decir, un decrecimiento en la elasticidad al adicionar a harina de trigo un $3 \%$ de inulina proveniente de achicoria.

No se habían reportado, previo a este trabajo de tesis, resultados sobre el efecto combinado inulina-calcio en propiedades reológicas de masas de harina de trigo.

Las propiedades reológicas descriptas en esta sección podrían ser consecuencia no sólo del contenido de gluten en la masa sino de su estructura. Por lo que resulta necesario estudiar la estructura de la masa; ya sea por técnicas de microscopía, como también mediante el análisis de los cambios en el perfil proteico y en su secundaria por efecto del calcio y de los FOS-inulina.

\subsection{Estructura de la masa}

\subsubsection{Contenido de gluten}

En la Tabla 3.15 se muestra el contenido de gluten húmedo $(\mathrm{GH})$ y la relación gluten húmedo/gluten seco (GH/GS) para las mezclas de los tres DCC. El contenido de GH de la muestra control fue $29,3 \%$. Los valores de $\mathrm{GH}$ estuvieron entre 25 y $33 \%$ para todas las masas.

En ausencia de In, con el agregado de $\mathrm{CaCO}_{3}$ el valor de $\mathrm{GH}$ resultó igual al de la muestra control y la relación GH/GS disminuyó. Con inulina y diferentes contenidos de calcio, el GH y GH/GS no variaron significativamente.

Los valores de $\mathrm{GH}$ obtenidos a partir de masas elaboradas con $\mathrm{Ca}_{3} \mathrm{Cl}_{2}$ fueron mayores al de la masa control. A 6,5\% In se obtuvo más GH a partir de masas con citrato y carbonato que con lactato. Estos resultados apoyan el efecto estabilizante de estos aniones en proteínas de gluten. Altas concentraciones de prebiótico incrementaron los valores de $\mathrm{GH} / \mathrm{GS}$ en masas con $\mathrm{Ca}_{3} \mathrm{Cl}_{2}$.

En el caso de $\mathrm{CaLA}_{2}$, el menor valor de GH se observó para la masa con 1\% In-2400 ppm Ca y 6,5\% In-2520 ppm Ca. A $\leq 6,5 \%$ In, el CaLA $\mathrm{C}_{2}$ desfavoreció la formación de gluten, confirmando el efecto de desestabilizante de este anión sobre la interacción de proteínas en la red de gluten. A $12 \%$ In, un incremento de $\mathrm{CaLA}_{2}$ no modificó el 
contenido de $\mathrm{GH}$, esto sugiere un efecto protector del prebiótico contra el efecto negativo del lactato sobre la estructura de las proteínas, favoreciendo la matriz de gluten. La misma tendencia se observó para la relación $\mathrm{GH} / \mathrm{GS}$, obteniendo el valor más bajo la masa con 2400 ppm Ca y $1 \%$ In. Al igual que para el citrato, para lactato, altos contenidos de In condujeron a los mayores valores de GH/GS (Tabla 3.15).

Ya que el gluten es la base de la estructura de la masa, no sólo la cantidad sino también su calidad es importante, y está estrechamente relacionada con la naturaleza de las proteínas y su capacidad de hidratación, por lo que el valor GH/GS es un parámetro importante a evaluar. Para todas las muestras se obtuvieron valores de GH/GS alrededor de 3, que es un valor óptimo para masas a emplear en panificación.

Tabla 3.15. Gluten húmedo y relación gluten húmedo/gluten seco de los diferentes sistemas sales de calcio - inulina-harina de trigo estudiados

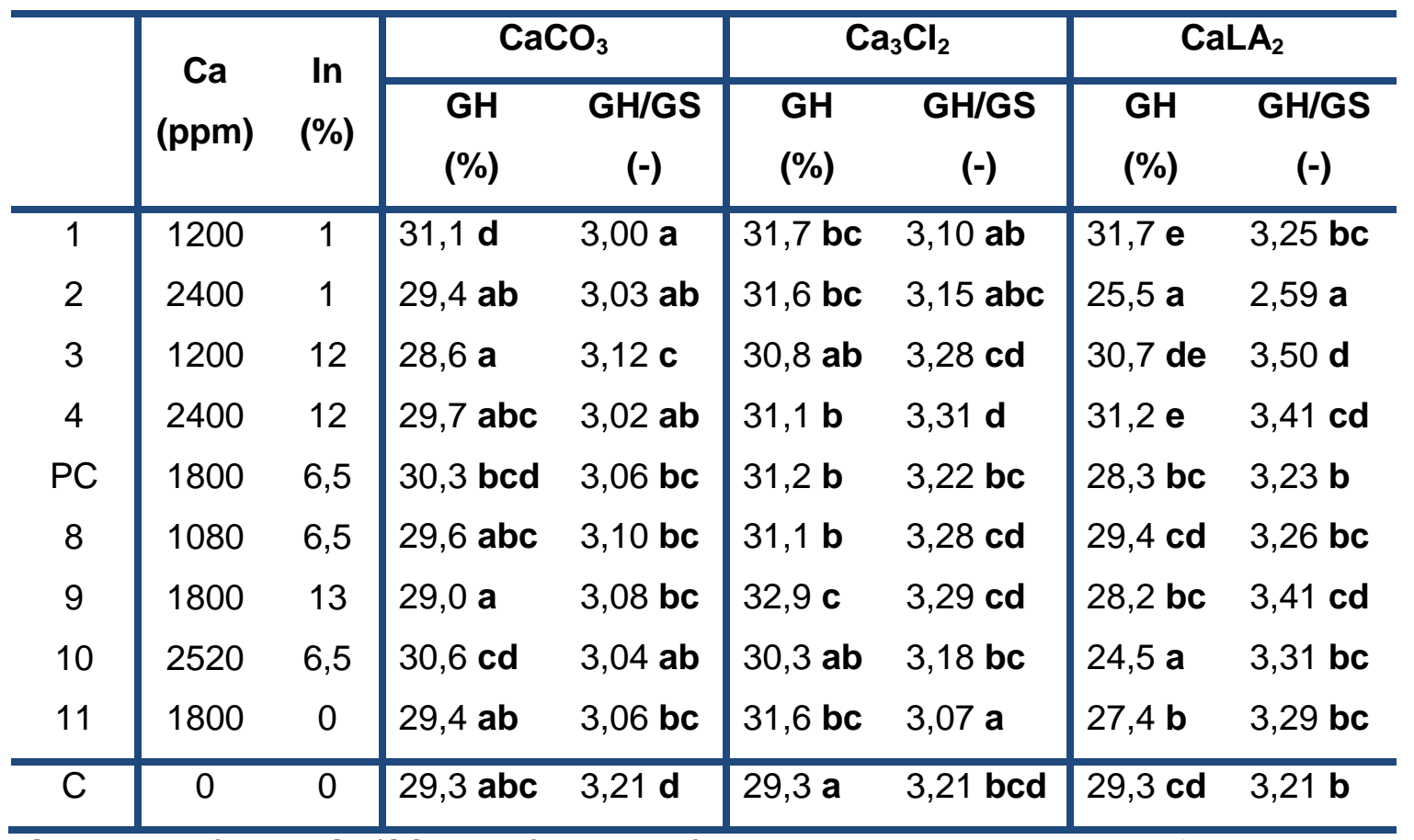

GH: gluten húmedo. GH/GS: relación gluten húmedo respecto al gluten seco. Diferentes letras en una misma columna indican diferencias significativas entre las medias $(p<0,05)$.

\subsubsection{Microestructura de la masa}

La microestructura de algunas de las masas se estudió por microscopia electrónica de barrido (Figuras 3.14 y 3.15). Puppo y col. (2005) han empleado esta técnica para evaluar cómo se encuentran los diferentes componentes de la harina en la masa. En 
las mismas se puede observar la red de gluten envolviendo a los gránulos de almidón. En la Figura 3.14 se muestra las SEM de la masa control $(\mathrm{C})$ y de las masas con $1 \%$ In. La masa $\mathrm{C}$ presentó una estructura proteica abierta. La red de gluten en presencia de $\mathrm{CaCO}_{3}$ fue más homogénea que la de la masa control (Figura 3.14, CA1) y resultó más laminar con 2400 ppm de Ca. La red de gluten de las masas de citrato y lactato con igual nivel de calcio ( $\mathrm{Cl} 2$ y LA2) presentaron una estructura más filamentosa. La calidad del gluten es un factor importante ya que este polímero es un componente fundamental en la estructura de la masa. Hemos observado que hay una correlación entre los valores de GH y la estructura observada por SEM. Masas con similar contenido de $\mathrm{GH}(\cong 32 \%)$ formaron una estructura de gluten homogénea (Figura 3.14, LA1, Cl1, Cl2). Una red de gluten menos laminar fue observada para la masa $\mathrm{C}$, pero también para la masa LA2, masas con valores de GH menor a 30\%.

La microestructura de masas con $12 \%$ In se muestran en la Figura 3.15. Todas las masas presentaron similar estructura en la que puede observarse una fina cadena entrelazada y ramificada correspondiente posiblemente a la inulina, la cual se apoya sobre la matriz de gluten; todas las masas presentaron igual cantidad $\mathrm{GH}$, aproximadamente el 31\% (Tabla 3.15). La matriz de gluten detrás de la red de inulina de la masa CA4 pareciera ser más homogénea que la masa CA3. La misma tendencia se observa en la red de gluten perteneciente a las masas con $\mathrm{Ca}_{3} \mathrm{Cl}_{2}$.

Las masas con citrato y lactato observadas presentan el mismo contenido de gluten, sin embargo, la masa LA4 parece exhibir una estructura proteica más abierta confirmando el efecto desestabilizador del anión lactato.

Peressini y Sensidoni (2009) observaron por microscopía confocal láser de barrido la presencia de una mayor concentración de proteína en las masas preparadas con inulina, atribuyendo este fenómeno a una menor absorción de agua para la formación de las mismas. En nuestro caso, las masas CA3 y CA4, presentaron menor absorción de agua (Tabla 3.3), también exhibieron una matriz proteica más concentrada y uniforme (Figura 3.15). Pero en mezclas de inulina-sales de calcio, la correlación de una red proteica más concentrada con la menor absorción de agua no siempre correlacionó en nuestro caso, probablemente debido no sólo al efecto del prebiótico, sino también al de las sales de calcio utilizadas, principalmente al anión que acompaña al calcio. 

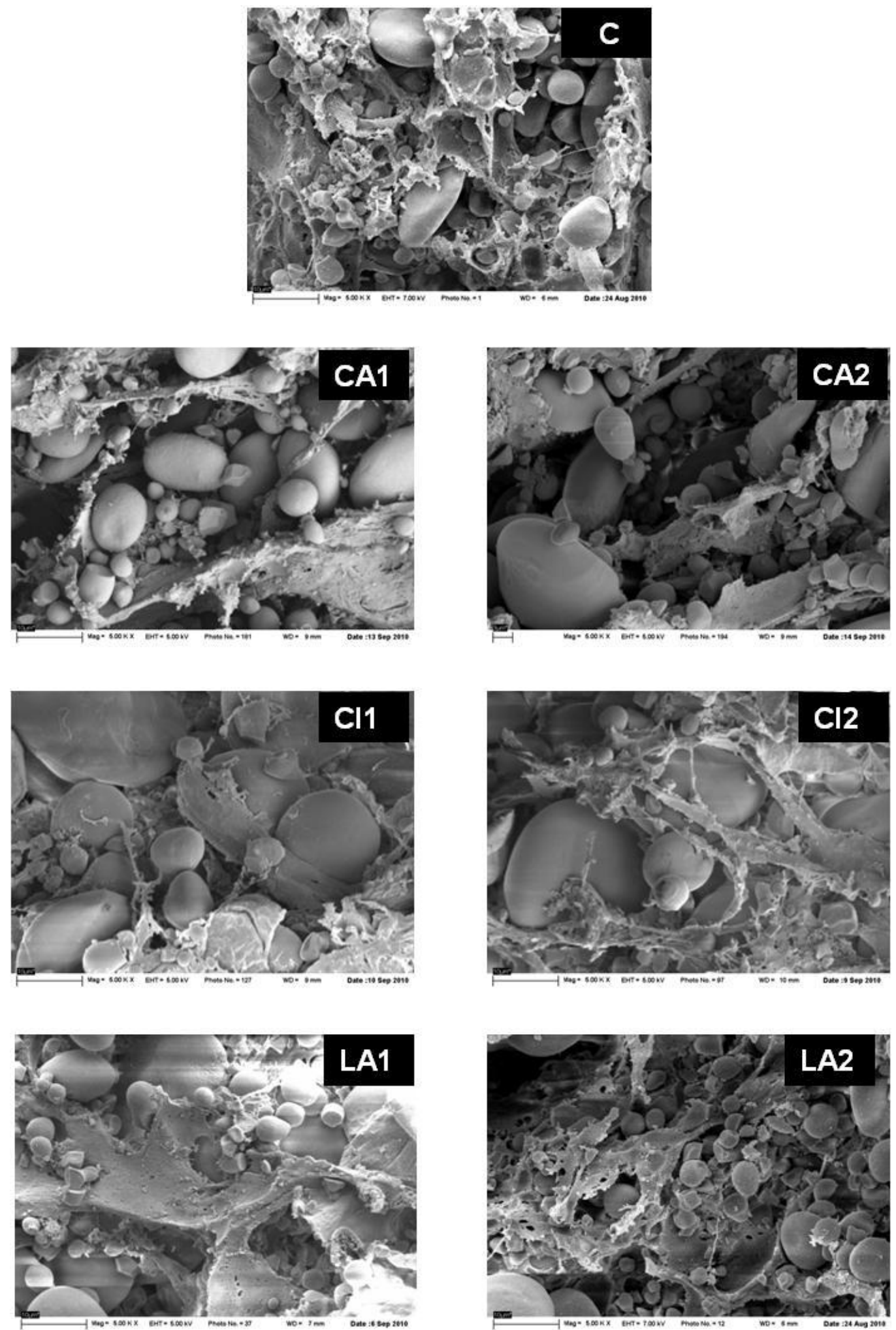

Figura 3.14. Microscopia electrónica de barrido de masas. C: control; CA1, Cl1 y LA1 (1200 ppm Ca $-1 \%$ In); CA2, Cl2 y LA2 (2400 ppm Ca - 1\% In). 

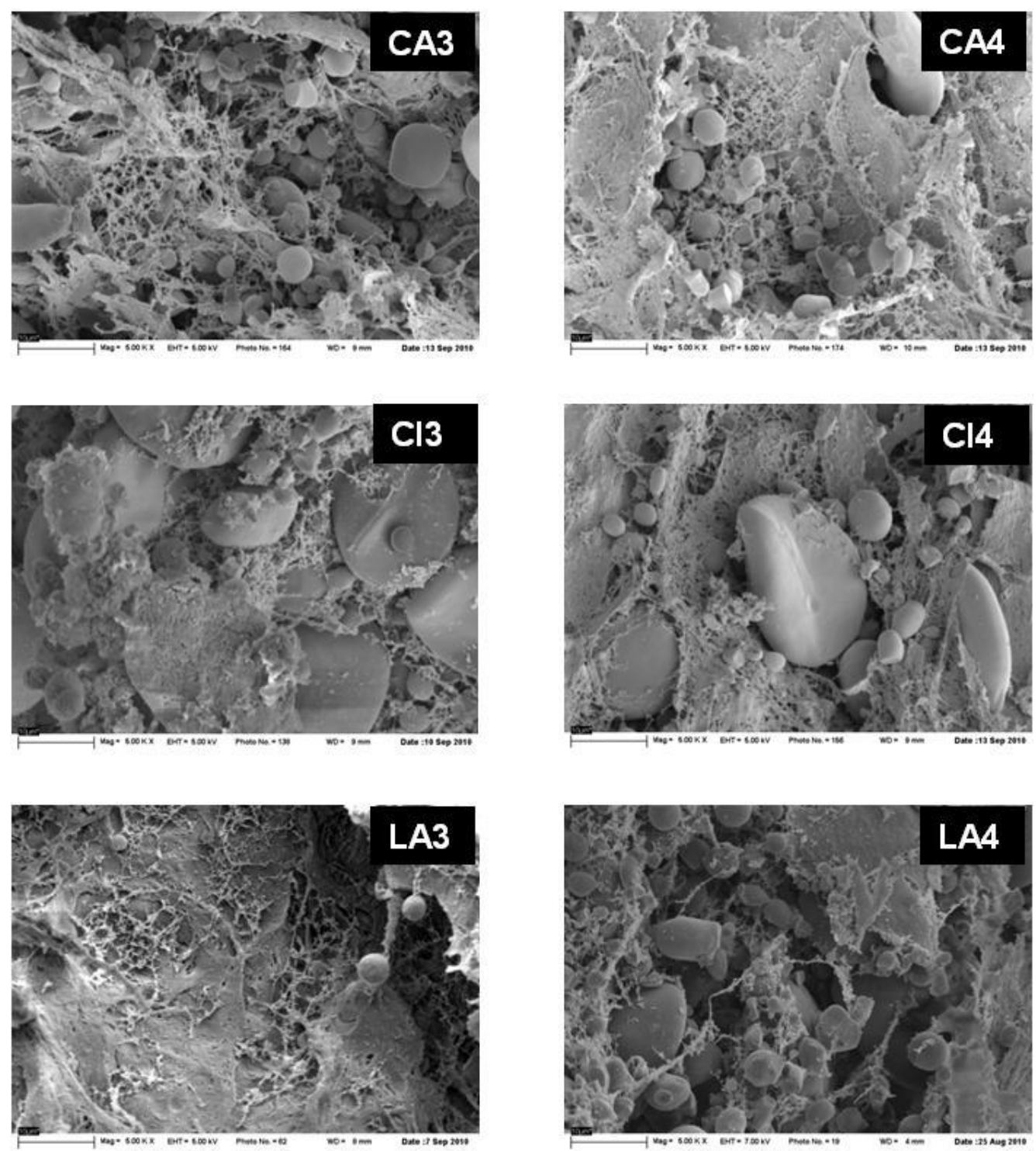

Figura 3.15. Microscopia electrónica de barrido de masas. C: control; CA3, Cl3 y LA3 (1200 ppm Ca $-12 \%$ In); CA4, Cl4 y LA4 (2400 ppm Ca - 12\% In). 


\subsubsection{Perfil electroforético}

La calidad del grano de trigo y por ende de la harina y sus derivados depende, como se mencionó anteriormente, no sólo de la cantidad sino también de la calidad de las proteínas de gluten: gliadinas y gluteninas. En una separación mediante SDS-PAGE, las gliadinas (GD) siguen el mismo patrón que en una A-PAGE, separándose en cuatro grupos. La Figura 3.16.a muestra el perfil electroforético de las gliadinas, en el que se pudieron distinguir las $\omega$-GD $(\cong 66 \mathrm{kDa})$ en muy baja proporción, las $\gamma$-GD (30$50 \mathrm{kDa}$ ) y las $\alpha / \beta-G D(20-30 \mathrm{kDa})$. Se extrajo baja cantidad de gliadinas, tanto de la harina $(H)$ como de la masa $(C)$, aunque en mayor proporción se observaron las $\alpha / \beta$ GD de aproximadamente $25 \mathrm{kDa}$. En ausencia de In, se extrajo mayormente gliadinas de masas con la siguiente tendencia: $\mathrm{CaCO}_{3}(\mathrm{CA} 11)>\mathrm{Ca}_{3} \mathrm{Cl}_{2}(\mathrm{Cl11})>\mathrm{CaLa}_{2}(\mathrm{LA} 11)$, conteniendo el extracto mayormente $\alpha / \beta-y-G D$. En masas con In se extrajo menos cantidad aún, especialmente en el caso de LA4. Esto sugiere que no se extrajeron proteínas por estar unidas al polímero base de gluteninas o porque la matriz está más estructurada en presencia del prebiótico y no permitió el contacto del solvente de extracción con las proteínas. Aunque la estructura observada en la SEM (sección 3.5.2) fue más abierta en esta última masa, la presencia del prebiótico sobre la red proteica podría haber minimizado el contacto del solvente con las proteínas disminuyendo la extracción. Este comportamiento se condice con una mayor dureza y elasticidad $\left(\mathrm{E}_{3}\right)$ de la masa LA4 en comparación con Cl4 y CA4. Las masas con lactato de calcio, tanto en presencia como en ausencia de prebiótico, presentaron los mayores valores de fuerza de punción (sección 3.4.2), pudiendo explicar éste parámetro la menor extracción de proteínas a partir de estas masas.

En el caso de las gluteninas, a partir de todas las masas se extrajo mayor proporción de LMW-GS (43-30 kDa), especialmente de C y CA11. De estas dos masas también se extrajo una proteína de $25 \mathrm{kDa}$. La inulina favoreció la extracción proteica de masas con carbonato y citrato y produjo el efecto contrario en las masas con lactato.

Los resultados de las electroforesis sugieren que en masas con $\mathrm{CaLA}_{2}$, especialmente en presencia del prebiótico, la matriz formada es más estable a la disociación proteica. 
a) gliadinas

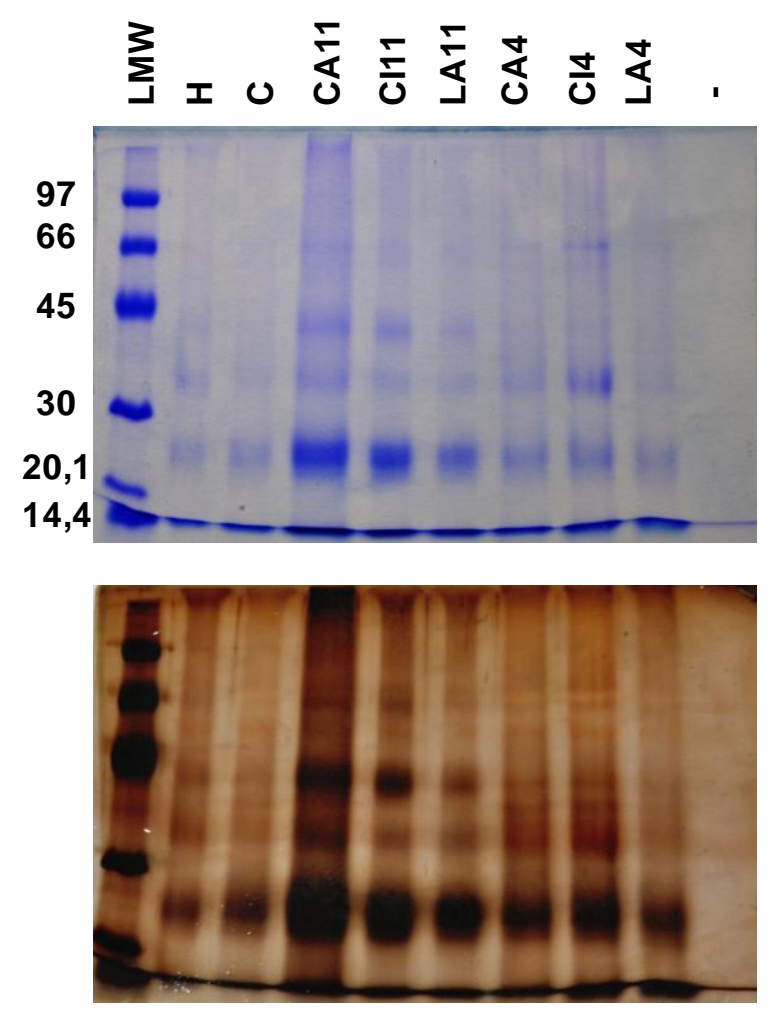

b) gluteninas
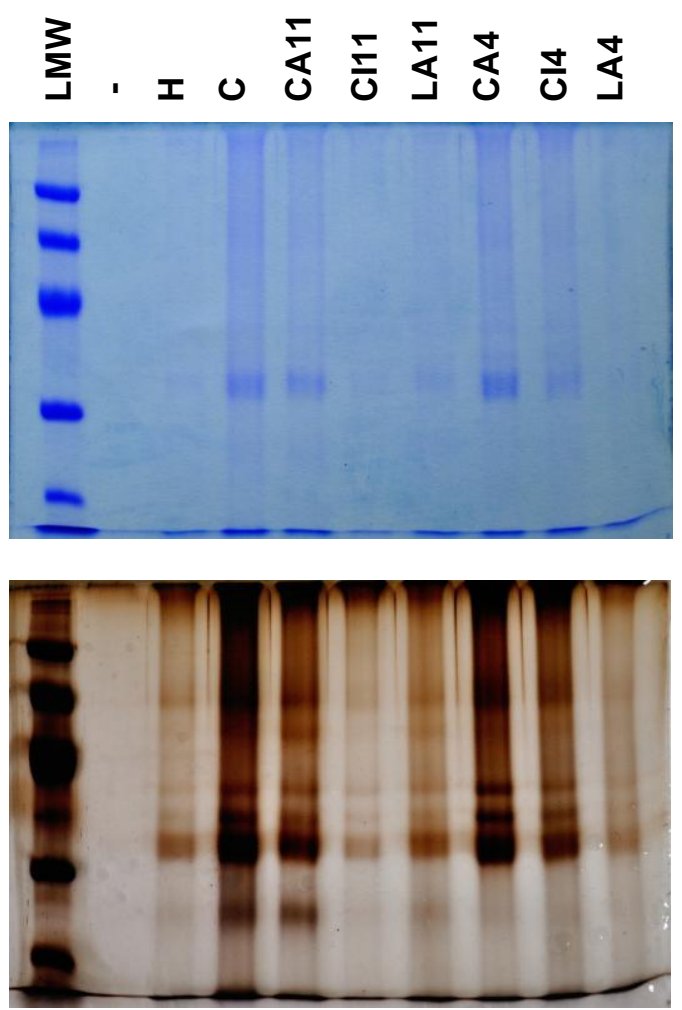

Figura 3.16. Electroforesis en gel de poliacrilamida: a) gliadinas extraídas a partir de masas liofilizadas con propanol al 50\%, b) gluteninas extraídas con ácido acético 0,1 M. Arriba: tinción Coomasie Blue y debajo: tinción con plata. H: harina, C: masa control, CA11, Cl11, LA11: 1800 ppm Ca-0\% In, CA4, Cl4, LA4: 2400 ppm Ca-12\% In.

\subsubsection{Estructura secundaria de proteínas}

El objetivo del estudio estructural en proteínas es tener mayor conocimiento sobre la estructura tridimensional de las mismas. Las proteínas in vivo actúan de forma interfacial por medio de la formación de complejos dinámicos con membranas biológicas, ácidos nucleicos, polisacáridos y otras proteínas. Los estudios por espectroscopia infrarroja por transformada de Fourier-FTIR pueden dar una idea global de la estructura secundaria de la proteína y de los cambios en dicha estructura por la interacción con otros componentes, en nuestro caso, las sales de calcio e inulina.

Las proteínas y polipéptidos exhiben bandas características en los espectros FTIR. Uno de los modos más utilizados es la banda de la Amida I. Este modo vibracional se origina en el estiramiento $\mathrm{v} \mathrm{C}=\mathrm{O}$ perteneciente al grupo amida acoplado con el modo de flexión del grupo $\mathrm{N}-\mathrm{H}$ y el estiramiento $v \mathrm{C}-\mathrm{N}$ dando bandas en la región 1600-1700 $\mathrm{cm}^{-1}$. Esta banda consiste en una superposición de elementos estructurales diferentes 
como: $\alpha$-hélice $\left(1650-1658 \mathrm{~cm}^{-1}\right)$, hoja plegada $\beta$ paralela $\left(1613-1625 \mathrm{~cm}^{-1}\right) \mathrm{y}$ antiparalela $\left(1675-1695 \mathrm{~cm}^{-1}\right)$, estructura $\alpha$-hélice solvatada $\left(1625-1637 \mathrm{~cm}^{-1}\right)$, giros$\beta\left(1666-1673 \mathrm{~cm}^{-1}\right)$ y estructura al azar $\left(1637-1645 \mathrm{~cm}^{-1}\right)$. El procedimiento matemático de fiteo y deconvolución permite la identificación y asignación de las mismas.

La banda Amida I del espectro FTIR fue diferente en todas las muestras; se muestra a modo de ejemplo las correspondientes a la de la masa control y con citrato de calcio (2400 ppm Ca - 12\% In) (Figura 3.17). La Tabla 3.16 muestra los porcentajes calculados para los diferentes componentes de la estructura secundaria de las proteínas presentes en las masas.

Un aumento del contenido de $\alpha$-hélice es indicativo de una mayor estructuración o plegamiento proteico (Tu, 1982); suele ir acompañado de un incremento de la estructura hélice solvatada, asociada a cadenas de segmento corto interconectadas con segmentos de $\alpha$-hélice (Murayama y Tomida, 2004) y giros- $\beta$; y de una disminución de la estructura de hoja- $\beta$ plegada paralela y antiparalela.

En todas las muestras se presentó una disminución de la conformación de a-hélice lo que se corresponde con un desplegamiento de la estructura proteica asociada a la interacción con el calcio y la inulina. Este efecto resultó mucho más marcado para las masas con lactato de calcio (LA11) y citrato de calcio + inulina (Cl4).

De las tres sales, el $\mathrm{CaLA}_{2}$ (LA11) fue la que favoreció en mayor proporción la formación de una estructura proteica más desplegada, como puede deducirse de los menores valores, con respecto al control, de $\alpha$-hélice y hélice solvatada junto con el aumento de las hojas y los giros- $\beta$. Este resultado fue acompañado de una menor proporción de gluten formado.

En presencia de inulina, el CaLA ${ }_{2}$ (LA4) favoreció la formación de una estructura con un muy elevado porcentaje de giros- $\beta$ y muy baja proporción de hoja $\beta$ antiparalela y hélice solvatada; pero con un mayor contenido de $\alpha$-hélice, sugiriendo un plegamiento de la proteína por efecto del prebiótico. Este resultado fue concordante con la formación de masas más duras y consistentes. Los giros- $\beta$ están definidos como regiones del polipéptido donde la cadena cambia de dirección, favoreciendo el plegamiento de la proteína (Marcelino y Gierasch, 2008). Para el $\mathrm{Ca}_{3} \mathrm{Cl}_{2}$ se observó el efecto opuesto, una desestructuración de la estructura secundaria de la proteína debido a la inulina. Los cambios de estructura proteica provocados por el $\mathrm{CaCO}_{3}$ no resultaron influenciados por la presencia del prebiótico.

Estos resultados, sugieren una vez más, una interacción Ca-proteína dependiente del tipo de sal y de su interacción con la inulina. 

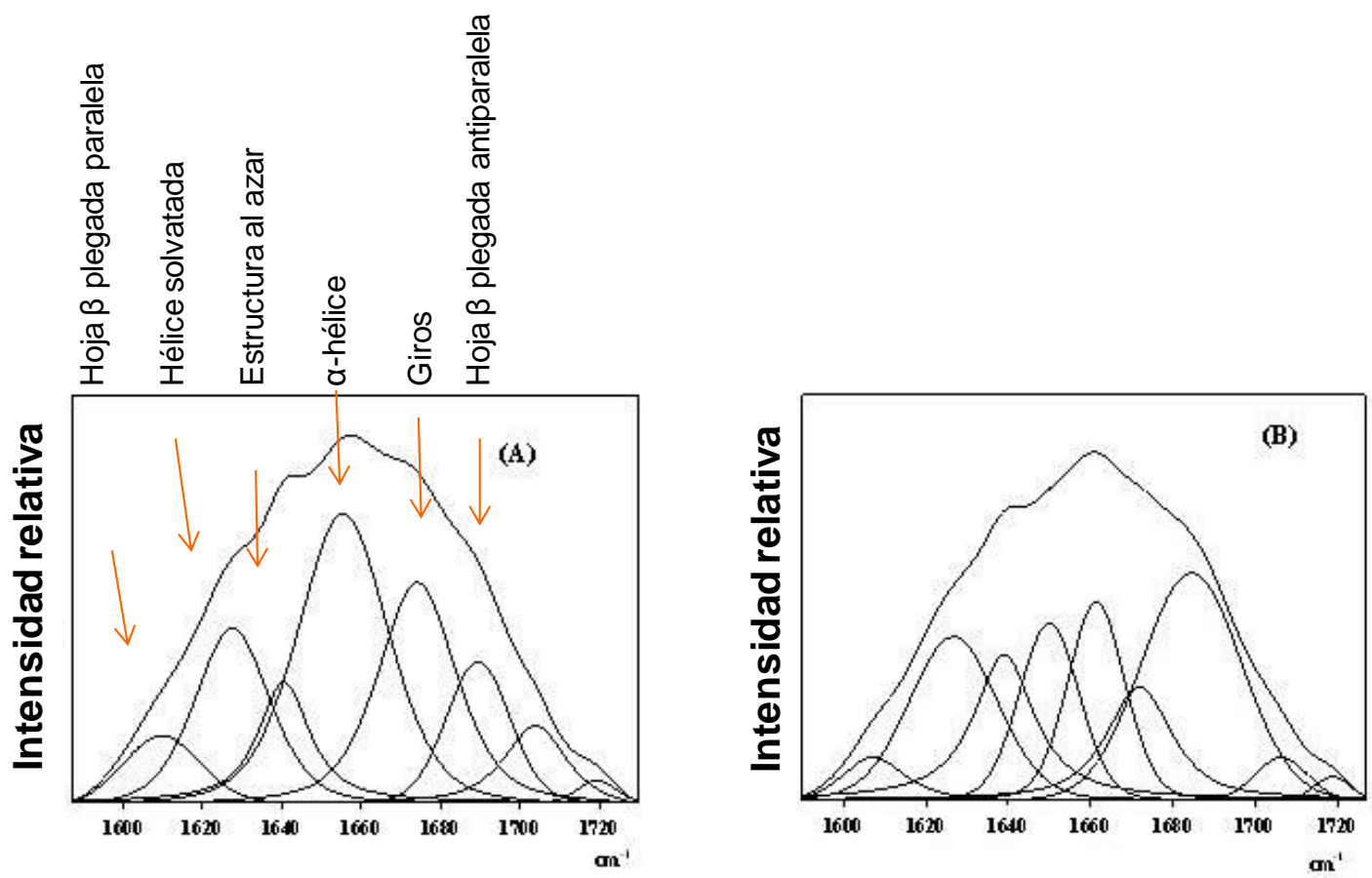

Figura 3.17.Espectro FTIR. Banda Amida I. Componentes de la estructura Secundaria de la proteína. a) masa control (C). b) masa con citrato de calcio+inulina ( $\mathrm{Cl} 4)$.

Tabla 3.16. Porcentaje para las diferentes componentes de la estructura secundaria de las proteínas.

\begin{tabular}{|c|c|c|c|c|c|c|}
\hline & 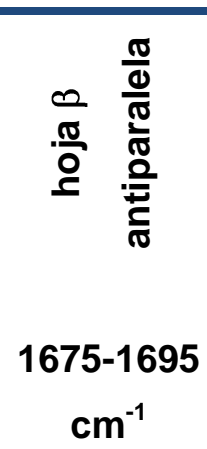 & $\begin{array}{c}\text { 옿 } \curvearrowleft \\
\text { o } \\
1666-1673 \\
\mathrm{~cm}^{-1}\end{array}$ & 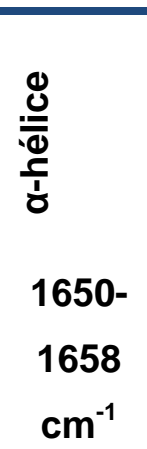 & $\begin{array}{c}\frac{\sqrt{N}}{\pi} \\
\frac{\pi}{\pi} \\
1637-1645 \\
\mathrm{~cm}^{-1}\end{array}$ & 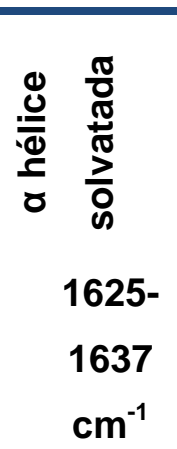 & $\begin{array}{c}\frac{\pi}{0} \\
\frac{\pi}{\pi} \\
\frac{0}{\pi} \\
\frac{0}{0} \\
\frac{\pi}{0} \\
1613-1625 \\
\mathrm{~cm}^{-1}\end{array}$ \\
\hline C & 16,71 & 21,11 & 30,93 & 8,50 & 16,46 & 6,24 \\
\hline CA11 & 20,04 & 22,59 & 26,65 & 10,23 & 8,31 & 12,17 \\
\hline Cl11 & 20,98 & 20,92 & 21,41 & 11,52 & 14,91 & 10,81 \\
\hline LA11 & 29,53 & 26,30 & 11,20 & 11,94 & 11,73 & 9,32 \\
\hline CA4 & 27,05 & 13,60 & 27,48 & 15,79 & 6,36 & 9,70 \\
\hline $\mathrm{Cl} 4$ & 28,84 & 10,41 & 13,36 & 12,16 & 13,28 & 21,86 \\
\hline LA4 & 9,57 & 41,77 & 20,60 & 11,10 & 6,10 & 10,95 \\
\hline
\end{tabular}




\section{Conclusiones parciales}

El farinograma fue modificado por la presencia de sales de calcio orgánicas, el CaLA $\mathrm{A}_{2}$ presentó un primer pico más pronunciado que $\mathrm{Ca}_{3} \mathrm{Cl}_{2}$ debido a la diferente interacción del anión con el agua. Altas concentraciones de prebiótico modificaron sustancialmente el segundo pico farinográfico como consecuencia de la estructuración de la inulina sobre la red de gluten. La mezcla control fue la de mayor absorción de agua y menor tiempo de desarrollo.

En ausencia de prebiótico, el agregado de calcio $\left(\mathrm{CaCO}_{3}\right.$ y $\left.\mathrm{Ca}_{3} \mathrm{Cl}_{2}\right)$ aumentó el tiempo de desarrollo; en cambio a alto prebiótico las mezclas con $\mathrm{Ca}_{3} \mathrm{Cl}_{2}$ y $\mathrm{CaLA}_{2}$ tardaron más tiempo en desarrollar la masa, independientemente del contenido de la sal. Alto prebiótico provocó masas menos estables y con mayor aflojamiento en todos los casos.

La inulina limitó la absorción de agua en la masa, debido a su alta capacidad de ligar agua. En exceso de agua, la presencia de prebiótico provocó una disminución considerable de la tenacidad y extensibilidad de la masa. Cuando se empleó $\mathrm{CaCO}_{3}$ y $\mathrm{CaLA}_{2}$ estos parámetros cambiaron principalmente con el prebiótico, enmascarando el efecto de los respectivos aniones; mientras que con $\mathrm{Ca}_{3} \mathrm{Cl}_{2}$, estos parámetros fueron también afectados por la sal.

La humedad de las masas varió con el prebiótico, en el mismo sentido que la absorción de agua. Un incremento del prebiótico restringió la movilidad molecular. La movilidad de las masas con $\mathrm{CaLA}_{2}$ y $\mathrm{Ca}_{3} \mathrm{Cl}_{2}$ fue afectada además por las sales de calcio, incrementándola con el incremento de la sal (con bajo prebiótico).

El $\mathrm{CaCO}_{3}$ en presencia de inulina actuó como agente reforzador de la masa, con menor movilidad molecular, sugiriendo que la inulina atrapa e inmoviliza agua dentro de la matriz de gluten. Este comportamiento se potenció con altos contenidos de $\mathrm{Ca}$ (2520 ppm) debido a la reestructuración del gluten por efecto del catión divalente y las interacciones disulfuro favorecidas a $\mathrm{pH}$ ligeramente alcalino, conduciendo a matrices más homogéneas, duras y elásticas.

En general, cuando se usó $\mathrm{CaLA}_{2}$, la masa se formó en menor tiempo y fue más estable que la masa con $\mathrm{Ca}_{3} \mathrm{Cl}_{2}$, resultando en una mayor movilidad molecular. $\mathrm{A}$ mayor nivel de $\mathrm{Ca}_{3} \mathrm{Cl}_{2}$ (2520 ppm Ca) se obtuvo la masa más dura y adhesiva y de menor cohesividad, al igual que con $\mathrm{CaCO}_{3}$ pero exhibió comportamiento opuesto al 
$\mathrm{CaLA}_{2}$. Este comportamiento pudo atribuirse al efecto desestabilizador del anión lactato en la estructura de las proteínas de gluten.

La viscoelasticidad de la masa resultó para $\mathrm{CaCO}_{3}$ y $\mathrm{Ca}_{3} \mathrm{Cl}_{2}$ independiente del nivel de Ca a diferencia de $\mathrm{CaLA}_{2}$ que varió con la interacción $\mathrm{Ca}^{*} / n$. Un incremento de prebiótico en las sales que estabilizan la red de gluten $\left(\mathrm{CaCO}_{3}\right.$ y $\left.\mathrm{Ca}_{3} \mathrm{Cl}_{2}\right)$ provocó menores valores de tan $\delta$, asociado a un predominio del comportamiento elástico. $A$ grandes deformaciones la energía almacenada $\left(E_{3}\right)$ resultó mayor con el incremento de prebiótico en masas con $\mathrm{CaCO}_{3}$ y $\mathrm{CaLA}_{2}$ encubriendo el efecto de las sales, a diferencia de $\mathrm{Ca}_{3} \mathrm{Cl}_{2}$.

En general, las masas que formaron mayor cantidad de gluten $\left(\mathrm{CaCO}_{3}\right.$ y $\left.\mathrm{Ca}_{3} \mathrm{Cl}_{2}\right)$, presentaron una matriz más homogénea; en cambio con $\mathrm{CaLA}_{2}$ y control se obtuvieron masas menos laminares y mas fibrosas. A pesar de ello, las masas con $\mathrm{CaLA}_{2} \mathrm{e}$ inulina, quizá por efecto del prebiótico, presentaron mayor plegamiento proteico coincidente con masas más duras y elásticas que conllevaron a una menor extracción de gliadinas y gluteninas solubles.

La estructura del gluten y las propiedades de hidratación y reológicas de la masa, para el mismo contenido de calcio, resultaron dependientes del tipo de anión (carbonato, citrato o lactato) que acompaña al calcio en la sal. Estas propiedades también variaron con el contenido de inulina y con la interacción entre el prebiótico y las sales de calcio.

Los cambios observados en las propiedades de hidratación y reológicas de las masas se verán reflejados en la calidad del pan obtenido luego del horneado, por lo que su estudio resulta importante para predecir la calidad de una determinada formulación. 


\section{CAPÍTULO 4}




\subsection{Composición química de la harina empleada en panificación}

En la Tabla 4.1 se muestra la composición porcentual de la harina de trigo utilizada en la preparación de los panes frescos y de los destinados a los ensayos nutricionales. También se empleó en la elaboración de las masas congeladas y de los panes obtenidos a partir de estas masas una vez descongeladas.

Tabla 4.1. Composición porcentual de la harina.

\begin{tabular}{cc}
\hline Harina & $\begin{array}{c}\text { Composición porcentual } \\
\text { (\%) }\end{array}$ \\
\hline Proteínas & $9,92 \pm 0,02$ \\
Lípidos & $0,86 \pm 0,02$ \\
Humedad & $11,85 \pm 0,03$ \\
Fibra dietaria total & $3,08 \pm 0,13$ \\
Cenizas & $0,382 \pm 0,009$ \\
Hidratos de carbono & 73,91 \\
\hline
\end{tabular}

Media \pm desviación estándar.

El contenido de hidratos de carbono fue calculado por diferencia como se explicó en la sección 3.1. Esta harina 0000 (CAA, 2013) procedente de una nueva partida, presentó parámetros de calidad similares a los de la harina usada en la elaboración de masas del Capítulo 3.

En la Tabla 4.2 se presentan los parámetros farinográficos, alveográficos y el contenido porcentual de gluten húmedo $(\mathrm{GH})$, gluten seco $(\mathrm{GS})$ y la relación gluten GH/GS de la harina.

Esta es una harina de calidad óptima, presenta un valor del trabajo de deformación (W) mayor a 200, por lo cual es considerada una harina fuerte apta para la elaboración de productos fermentados (panificados, en nuestro caso). 
Tabla 4.2. Parámetros farinográficos, alveográficos y contenido de gluten de la harina.

\begin{tabular}{|c|c|c|c|}
\hline \multicolumn{4}{|c|}{ Parámetros farinográficos } \\
\hline $\mathrm{Ab}(\%)$ & $t_{d}(\min )$ & Es (min) & Af (UB) \\
\hline 57,9 & 18 & 38,0 & 12 \\
\hline \multicolumn{4}{|c|}{ Parámetros alveográficos } \\
\hline$P(\mathbf{m m})$ & $\mathrm{L}(\mathrm{mm})$ & P/L (-) & $W^{*} 10^{-4} \mathrm{~J}$ \\
\hline 132 & 47 & 2,81 & 264 \\
\hline \multicolumn{4}{|c|}{ Contenido de gluten } \\
\hline GH (\%) & $\overline{G S}$ & & GH/GS (-) \\
\hline 24,4 & & & 2,80 \\
\hline
\end{tabular}

Debido a que esta harina es la que se utilizó en la elaboración de los panes, es que se decidió estudiar la influencia de los ingredientes nutricionales (calcio e inulina) en el comportamiento térmico de la misma en condiciones de exceso y restricción de agua a fin de poder predecir su comportamiento durante el proceso de panificación.

\subsection{Propiedades térmicas de las mezclas}

\subsubsection{Gelatinización de almidón}

En la calorimetría diferencial de barrido (DSC) se mide la diferencia de temperatura entre la muestra y un material de referencia durante ciclos de calentamiento y/o enfriamiento programados y se compara el flujo de calor de la muestra con respecto a una referencia (Choi y col., 2010). Esta última debe ser un material inerte que no sufra ningún cambio físico ni químico en el rango de temperatura ensayado (Añon y Jovanovich, 2000). Cuando la muestra sufre algún cambio de fase o alguna transición, la energía absorbida o liberada se refleja en un cambio de temperatura entre la muestra y el material de referencia, el cual es proporcional al flujo de calor. Las transiciones térmicas pueden observarse al graficar el flujo de calor en función de la temperatura o el tiempo, obteniéndose picos cuya área es proporcional a la variación de entalpía y la dirección hacia abajo o hacia arriba indica si se trata de un proceso endotérmico o exotérmico, respectivamente.

Se estudió el proceso de gelatinización de algunas de las formulaciones en las masas por medio de DSC. Las masas se elaboraron según se explicó en la sección 2.2.4. 
En la Figura 4.1 se muestran los termogramas obtenidos a partir de las masas de algunas de las formulaciones del diseño elaboradas con $\mathrm{CaCO}_{3}$ e In junto con el de la masa control (C).Los valores de los parámetros de gelatinización, temperaturas y variación de entalpía se presentan en la Tabla 4.3.

En el termograma de la masa $(\mathrm{C})$ se pueden observar dos picos endotérmicos asociados al proceso de gelatinización del almidón de $72{ }^{\circ} \mathrm{C}\left(\mathrm{T}_{\mathrm{pl}}\right)$ y $90^{\circ} \mathrm{C}\left(\mathrm{T}_{\text {pll }}\right)$ (Figura 4.1). La presencia de dos picos asociados al proceso de gelatinización se debe a que en la masa hay una restricción de agua. La masa con $\mathrm{CaCO}_{3}$ en ausencia de In (CA11) presentó un termograma similar a la masa C. A $12 \%$ In hubo un desplazamiento hacia mayores temperaturas de ambos picos de $10 \stackrel{\circ}{ }$, independiente del contenido de sal.

Las entalpías de gelatinización $\left(\Delta \mathrm{H}_{\mathrm{g}}\right)$ de las masas $\mathrm{C}$ y CA11 ( $\sin I n$ ) fueron las mayores. $\mathrm{A} 1 \%$ In, el aumento de $\mathrm{CaCO}_{3}$ provocó una disminución significativa de la entalpía (Tabla 4.3), asociada a una menor gelatinización en presencia del calcio. Hubo un efecto del prebiótico (12\%) en la disminución de la gelatinización, evidenciado por los valores significativamente menores en aproximadamente un $50 \%$ respecto al control cuando se expresó este parámetro en $\mathrm{J} / \mathrm{g}$ masa seca. Estos resultados podrían ser debidos a que se necesitó una menor cantidad de agua en presencia de inulina para elaborar la masa, como vimos en la sección 3.2, por lo tanto habría menos agua disponible necesaria para producir la gelatinización.

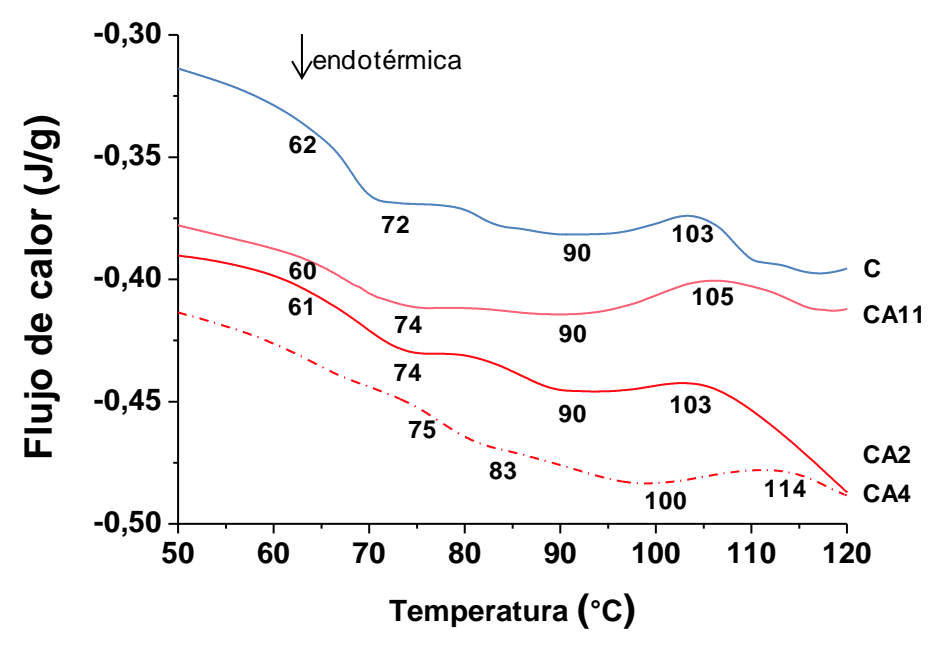

Figura 4.1. Termograma de masas con carbonato de calcio. C: control, CA11: 1800 ppm Ca0\% In, CA2: 2400 ppm - Ca-1\% In, CA4: 2400 ppm Ca-12\% In. 
Tabla 4.3. Parámetros de gelatinización de masas con carbonato de calcio.

\begin{tabular}{c|cc|llll|l}
\hline & $\begin{array}{c}\mathbf{C a} \\
(\mathbf{p p m})\end{array}$ & $\begin{array}{c}\text { In } \\
(\%)\end{array}$ & $\mathbf{T}_{\text {Ons }}\left({ }^{\circ} \mathbf{C}\right)$ & $\mathbf{T}_{\mathrm{pl}}\left({ }^{\circ} \mathbf{C}\right)$ & $\mathbf{T}_{\mathrm{pll}}\left({ }^{\circ} \mathbf{C}\right)$ & $\mathbf{T}_{\text {off }}\left({ }^{\circ} \mathbf{C}\right)$ & $\Delta \mathbf{H}_{\mathrm{g}}(\mathbf{J} / \mathbf{g})$ \\
\hline $\mathbf{C}$ & 0 & 0 & $62 \mathbf{a}$ & $72 \mathbf{a}$ & $90 \mathbf{a b}$ & $103 \mathbf{a}$ & $7,12 \mathbf{c}$ \\
\hline CA11 & 1800 & 0 & $60 \mathbf{a}$ & $74 \mathbf{b}$ & $90 \mathbf{a b}$ & $106 \mathbf{b}$ & $6,78 \mathbf{b c}$ \\
CA1 & 1200 & 1 & $60 \mathbf{a}$ & $75 \mathbf{b}$ & $92 \mathbf{b}$ & $105 \mathbf{a b}$ & $6,10 \mathbf{b}$ \\
$\mathbf{C A 2}$ & 2400 & 1 & $61 \mathbf{a}$ & $74 \mathbf{b}$ & $90 \mathbf{a}$ & $103 \mathbf{a b}$ & $4,48 \mathbf{a}$ \\
CA3 & 1200 & 12 & $74 \mathbf{b}$ & $82 \mathbf{c}$ & $99 \mathbf{c}$ & $110 \mathbf{c}$ & $3,70 \mathbf{a}$ \\
CA4 & 2400 & 12 & $75 \mathbf{b}$ & $83 \mathbf{c}$ & $100 \mathbf{c}$ & $114 \mathbf{d}$ & $3,88 \mathbf{a}$ \\
\hline
\end{tabular}

Letras distintas en una misma columna indican diferencias significativas $(p<0,05)$.

Los termogramas de las masas con sales de calcio orgánicas fueron semejantes a los de masas con $\mathrm{CaCO}_{3}$ (Figura 4.2). La diferencia radicó en que con estas sales se observó tanto en ausencia como presencia de $1 \%$ del prebiótico, mayores temperaturas de pico $T_{\text {pll}}$.

El $\Delta \mathrm{H}_{\mathrm{g}}$ de las masas con $\mathrm{Ca}_{3} \mathrm{Cl}_{2}$ e In también fue menor que la de la masa C. A $1 \% \ln$, el aumento de citrato presentó la misma tendencia en el $\Delta \mathrm{H}_{\mathrm{g}}$ que el carbonato (Figura 4.2.a, Tabla 4.4). Se puede comprobar que estas masas que presentaron mayor humedad (sección 3.3.1) también exhibieron mayor entalpia de gelatinización.

Las masas elaboradas con $\mathrm{CaLA}_{2}$ presentaron un comportamiento particular, muy diferente a lo esperado. Cuando se utilizó 1200 ppm Ca, se encontraron valores sumamente pequeños de $\Delta \mathrm{H}_{\mathrm{g}}(2,13$ y $2,99 \mathrm{~J} / \mathrm{g})$. Tanto a $1 \%$ como a $12 \% \mathrm{In}$, el aumento de calcio desde 1200 a 2400 ppm aumentó significativamente este parámetro, sugiriendo que el ión lactato favorece el proceso de gelatinización (Figura 4.2.b, Tabla 4.5). A igual cantidad de $\mathrm{CaLA}_{2}$, el aumento de inulina no afectó la gelatinización. 

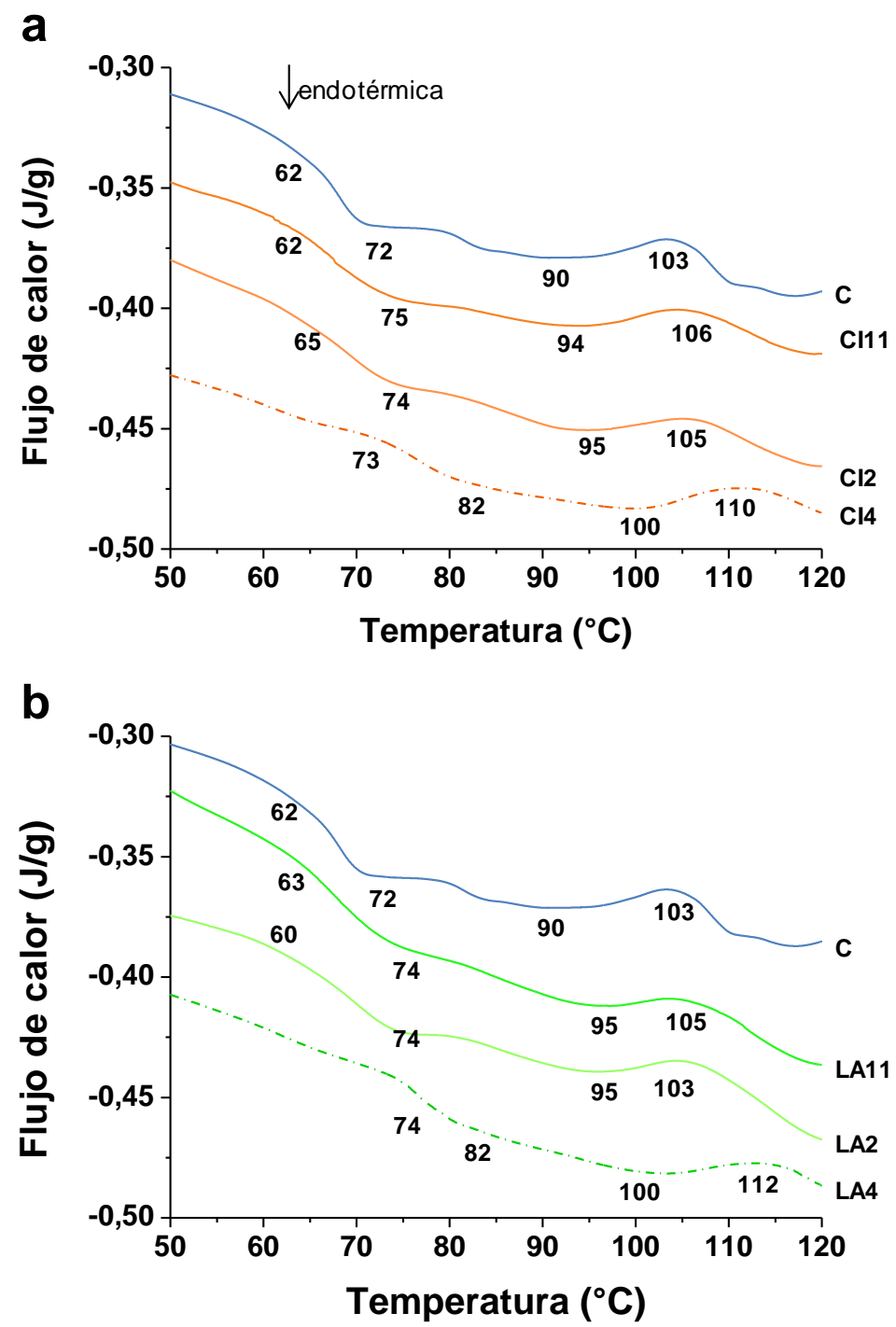

Figura 4.2. Termograma de masas obtenido por $\mathrm{DSC}$ : a) $\mathrm{Ca}_{3} \mathrm{Cl}_{2}$, b) $\mathrm{CaLA}_{2}$. C: control, Cl11/LA11: 1800 ppm Ca-0\% In, Cl2/LA2: 2400 ppm Ca-1\% In, Cl4/LA4: 2400 ppm Ca-12\% In.

Tabla 4.4. Parámetros de gelatinización de masas con citrato de calcio.

\begin{tabular}{|c|c|c|c|c|c|c|c|}
\hline & $\begin{array}{c}\mathrm{Ca} \\
(\mathrm{ppm})\end{array}$ & $\begin{array}{c}\text { In } \\
(\%)\end{array}$ & $\mathrm{T}_{\text {Ons }}\left({ }^{\circ} \mathrm{C}\right)$ & $\mathrm{T}_{\mathrm{pl}}\left({ }^{\circ} \mathrm{C}\right)$ & $\mathrm{T}_{\mathrm{pll}}\left({ }^{\circ} \mathrm{C}\right)$ & $\mathrm{T}_{\text {off }}\left({ }^{\circ} \mathrm{C}\right)$ & $\Delta H_{g}(J / g)$ \\
\hline C & 0 & 0 & $62 b$ & $72 \mathbf{a}$ & $90 \mathbf{a}$ & $103 \mathbf{a}$ & $7,12 \mathbf{b}$ \\
\hline Cl11 & 1800 & 0 & $62 \mathrm{~b}$ & 75 b & 94 b & $106 \mathbf{a}$ & $5,80 \mathrm{ab}$ \\
\hline Cl1 & 1200 & 1 & $59 a$ & 74 b & $91 \mathbf{a}$ & $105 \mathbf{a}$ & $6,66 \mathbf{b}$ \\
\hline $\mathrm{Cl} 2$ & 2400 & 1 & $65 c$ & 74 b & $95 \mathbf{b}$ & $105 \mathbf{a}$ & $5,27 a b$ \\
\hline $\mathrm{Cl} 3$ & 1200 & 12 & $74 d$ & $82 \mathrm{c}$ & $102 d$ & $111 b$ & $4,40 \mathbf{a}$ \\
\hline $\mathrm{Cl} 4$ & 2400 & 12 & $73 d$ & $82 \mathrm{c}$ & $100 \mathrm{c}$ & $110 \mathbf{b}$ & $4,14 \mathbf{a}$ \\
\hline
\end{tabular}

Letras distintas en una misma columna indican diferencias significativas $(p<0,05)$ 
Tabla 4.5. Parámetros de gelatinización de masas con lactato de calcio.

\begin{tabular}{c|cc|llll|l}
\hline & $\begin{array}{c}\mathbf{C a} \\
(\mathbf{p p m})\end{array}$ & $\begin{array}{c}\text { In } \\
(\%)\end{array}$ & $\mathbf{T}_{\text {Ons }}\left({ }^{\circ} \mathbf{C}\right)$ & $\mathbf{T}_{\mathrm{pl}}\left({ }^{\circ} \mathbf{C}\right)$ & $\mathbf{T}_{\mathrm{pll}}\left({ }^{\circ} \mathbf{C}\right)$ & $\mathbf{T}_{\text {off }}\left({ }^{\circ} \mathbf{C}\right)$ & $\Delta \mathbf{H}_{\mathrm{g}}(\mathbf{J} / \mathbf{g})$ \\
\hline $\mathbf{C}$ & 0 & 0 & $62 \mathbf{a}$ & $72 \mathbf{a}$ & $90 \mathbf{a}$ & $103 \mathbf{a}$ & $7,12 \mathbf{d}$ \\
\hline LA11 & 1800 & 0 & $63 \mathbf{a}$ & $74 \mathbf{b}$ & $95 \mathbf{b}$ & $105 \mathbf{a b}$ & $5,64 \mathbf{c d}$ \\
LA1 & 1200 & 1 & $63 \mathbf{a}$ & $74 \mathbf{b}$ & $95 \mathbf{b}$ & $103 \mathbf{a}$ & $2,13 \mathbf{a}$ \\
LA2 & 2400 & 1 & $60 \mathbf{a}$ & $74 \mathbf{b}$ & $95 \mathbf{b}$ & $104 \mathbf{a}$ & $5,14 \mathbf{b c d}$ \\
LA3 & 1200 & 12 & $74 \mathbf{b}$ & $82 \mathbf{c}$ & $101 \mathbf{c}$ & $108 \mathbf{b}$ & $2,99 \mathbf{a b}$ \\
LA4 & 2400 & 12 & $74 \mathbf{b}$ & $82 \mathbf{c}$ & $100 \mathbf{c}$ & $114 \mathbf{c}$ & $4,28 \mathbf{b c}$ \\
\hline
\end{tabular}

Letras distintas en una misma columna indican diferencias significativas $(p<0,05)$.

\subsubsection{Viscosidad de pastas de mezclas}

La viscoamilografía es una técnica utilizada para obtener un registro de la viscosidad de una suspensión de almidón de una concentración determinada durante ciclos de calentamiento y enfriamiento a velocidad constante de cizallamiento. Se pueden evaluar los procesos de gelatinización y retrogradación a corto plazo de las suspensiones acuosas a base de almidón durante dichos ciclos (Chantaro y Pongsawatmanit, 2010). Cuando los gránulos de almidón se calientan en exceso de agua, éstos se hinchan irreversiblemente, lixivia la amilosa de los gránulos y éstos pierden su birrefringencia formando una suspensión viscosa denominada pasta. Finalmente, se produce durante el enfriamiento y el almacenamiento una re-asociación de las moléculas de almidón gelatinizado para formar una estructura ordenada que se define como retrogradación del almidón o asentamiento (Arjona-Roman y col., 2011).

En nuestro caso, todas las mezclas estudiadas mostraron un perfil RVA similar (Figura 4.3). A modo de ejemplo se muestra la viscosidad de la muestra control, $\mathrm{Cl} 2$ y $\mathrm{Cl} 4$. También se muestra la rampa de temperatura utilizada en el ensayo. 


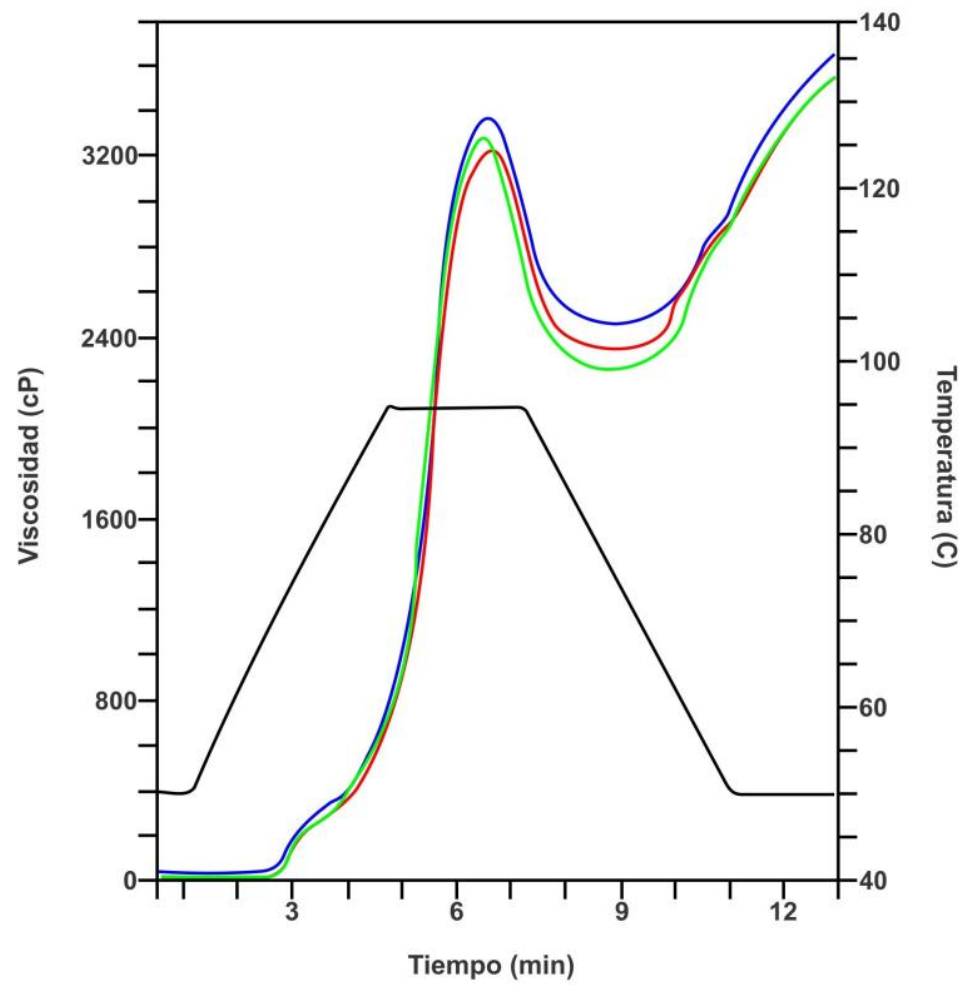

Figura 4.3. Viscoamilograma obtenido a partir de mezcla control y con citrato de calcio e inulina. Control, C (azul); 2400 ppm Ca, 1\% In (verde) y 2400 ppm Ca, 12\% In (rojo).

Los parámetros obtenidos a partir de los viscoamilogramas se muestran en la Figura 4.4 .

La viscosidad de pico (VP) (Figura 4.4.a) de las mezclas con $\mathrm{CaCO}_{3}$ y $12 \%$ In resultaron igual a $\mathrm{C}$, pero se obtuvieron mayores valores en presencia de $1 \% \ln$. A $1 \%$ In el $\mathrm{CaCO}_{3}$ favorecería la interacción agua-almidón en el proceso de gelatinización, haciendo que los gránulos se hinchen más generando mayor viscosidad. Al emplear $\mathrm{Ca}_{3} \mathrm{Cl}_{2}$ no hubo diferencias significativas entre los VP obtenidos a partir de las mezclas estudiadas con respecto al control. Con $\mathrm{CaLA}_{2}$, un incremento de sal aumenta levemente la viscosidad de pico, coincidente con un incremento en el valor de $\Delta \mathrm{H}_{\mathrm{g}}$ mostrado en la Tabla 4.5.

En general, todas las suspensiones mostraron a igual contenido de $\mathrm{Ca}$, una disminución de VP con el aumento del prebiótico $(12 \%$ In). La variación de éste parámetro se correlaciona con el $\Delta \mathrm{H}_{\mathrm{g}}$ obtenida por DSC. El descenso de VP en presencia del prebiótico puede ser debido a la competencia de la inulina con los componentes de los gránulos de almidón por la captación de agua; los gránulos de almidón se hidratan menos, se hinchan menos alcanzando menor viscosidad. Brennan y Samyue (2004) estudiaron las propiedades de pasta de suspensiones de almidón de trigo con diferentes niveles de inulina (2,5\%, 5\% y 10\%) encontrando disminución de VP con el incremento de la misma, atribuyendo este comportamiento a la inhibición de 
la gelatinización del almidón por parte del prebiótico. Similares resultados fueron observados con harina de maíz (hi-maiz) e inulina (Brennan y col., 2008). Los valores de viscosidad de pico obtenidos por medio de RVA resultaron coincidentes con la tendencia obtenida en los parámetros calorimétricos por DSC para las diferentes masas (Tablas 4.3, 4.4 y 4.5); un atraso en el inicio de la gelatinización, mayores temperaturas de pico y menor entalpía con niveles altos de inulina.

La estabilidad (BD) de todas las muestras disminuyó con un aumento de $12 \%$ In (Figura 4.4.b). Las suspensiones con $\mathrm{CaCO}_{3}$ presentaron los menores valores de BD. Cuando se utilizaron sales de calcio orgánicas se encontró que las muestras con 12\% In fueron similares a la mezcla control, mientras que a inulina $1 \%$ los valores obtenidos de $\mathrm{BD}$ fueron altos. Estos resultados sugieren que a $1 \%$ In las sales de calcio disminuyen la estabilidad (aumento de BD), pero un alta inulina contribuye a la estabilidad del gel durante el calentamiento.

La viscosidad final (VF) alcanzada luego de la etapa de enfriamiento en mezclas con $\mathrm{CaCO}_{3}$ resultó mayor en presencia de $1 \%$ In, comparadas con la pasta control y las pastas con $12 \%$ In (Figura 4.4.c). Las suspensiones con $\mathrm{CaCO}_{3}$ presentaron mayor VP, como consecuencia de una mayor interacción entre el agua y el almidón, por lo tanto se favorece el proceso de gelatinización. En cambio, en las mezclas con sales de calcio orgánicas no se encontraron diferencias significativas en los valores de VF, se observaron valores significativamente menores que los obtenidos con $\mathrm{CaCO}_{3}$. Estos resultados sugieren que el $\mathrm{CaCO}_{3}$ favorece la formación de pastas más viscosas, mientras que el $\mathrm{Ca}_{3} \mathrm{Cl}_{2}$ y el $\mathrm{CaLA}_{2}$ no contribuyen en la viscosidad de pasta aunque haya exceso de agua.

El SB-2, relacionado con la tendencia a la retrogradación de las pastas, resultó influenciado por el prebiótico (Figura 4.4.d). A mayor inulina las mezclas presentaron mayor SB-2, independientemente del aumento de $\mathrm{CaCO}_{3}$ y $\mathrm{Ca}_{3} \mathrm{Cl}_{2}$; sin embargo contrario a lo que se esperaba, el aumento de $\mathrm{CaLA}_{2}$ (a igual nivel de inulina) disminuyó significativamente el este parámetro, sugiriendo una menor habilidad para retrogradar. Gupta y col. (2012) relacionaron los valores de SB-2 con la facilidad de cocción y la tendencia de la amilosa a retrogradar. Estos autores también encontraron que los ácidos orgánicos, entre ellos cítrico y láctico, decrecen los valores de asentamiento, y es afectado más por la naturaleza del ácido que por su concentración. Similares observaciones fueron reportadas por Wu y col. (2010) en harina de arroz de diferentes variedades. Arjona-Roman y col. (2011) también encontraron que los valores de VP y SB fueron influenciados más por la acción del ácido cítrico que por efecto de otros factores. 
Por otro lado, el incremento del contenido de inulina de $1 \%$ a $12 \%$ en la harina de trigo conteniendo la misma cantidad de $\mathrm{Ca}_{3} \mathrm{Cl}_{2}$ produjo un aumento en SB-2. El $\mathrm{CaCO}_{3}$ se comportó similar al $\mathrm{Ca}_{3} \mathrm{Cl}_{2}$, formándose una pasta más viscosa y estable luego del enfriamiento. Este comportamiento podría ser causado no sólo por la retrogradación del almidón, sino también por la capacidad de la inulina de estructurarse. El SB-2, además de ser influenciado por la estructura ramificada de la amilopectina, la relación amilosa/amilopectina y el contenido de agua, lo fue por el tipo de sal de calcio y el contenido de calcio empleado.
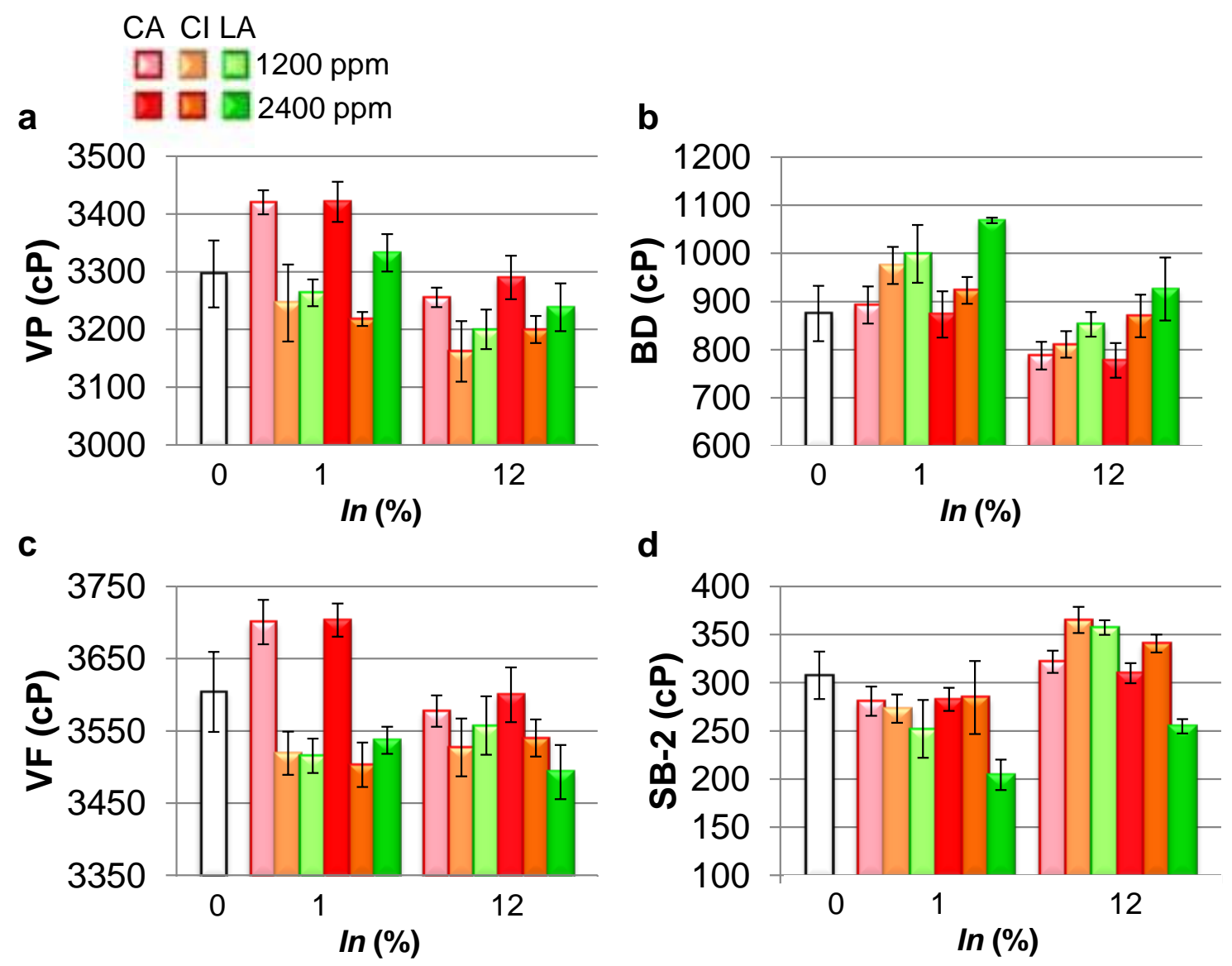

Figura 4.4. Parámetros viscoamilográficos: a) Viscosidad de pico (VP), b) Estabilidad (BD), c) Viscosidad final (VF), d) Asentamiento-2 (SB-2). Media \pm desviación estándar.

El comportamiento de las mezclas estudiadas en esta sección frente al tratamiento térmico, tanto en sistemas con restricción de agua (masa) como en exceso de agua (suspensiones) se comportan diferentes. Dependieron principalmente del prebiótico, aunque también fueron modificadas según la sal de calcio. El carbonato de calcio presentó similar tendencia que el citrato de calcio en las variables estudiadas, pero diferentes al emplear lactato de calcio. Todos estos cambios durante el calentamiento 
y posterior enfriamiento podrían tener consecuencias sobre la calidad final de los panes.

\subsection{Capacidad de expansión de la masa durante el proceso de fermentación}

Se realizaron las curvas de fermentación de todas las masas para evaluar el comportamiento frente al leudado de las mismas y determinar el tiempo óptimo de fermentación según se describió en la sección 2.2.10.1.

Las curvas de fermentación obtenidas experimentalmente (incremento de volumen en función del tiempo) de la masa control (C) y de las masas con 12\% In y 2400 ppm Ca, empleando como fuente de calcio $\mathrm{CaCO}_{3}$ (CA4), $\mathrm{CaLA}_{2}$ (LA4) y $\mathrm{Ca}_{3} \mathrm{Cl}_{2}$ (Cl4), se muestran en la Figura 4.5.

Se puede observar que el agregado de altas concentraciones de los ingredientes nutricionales origina curvas con diferente variación en $\Delta \mathrm{V}$ respecto del control. La masa $C$ aumentó en mayor proporción el volumen que las masas elaboradas con agregado de calcio e inulina, alcanzando estas últimas el plateau a menores tiempos de fermentación.

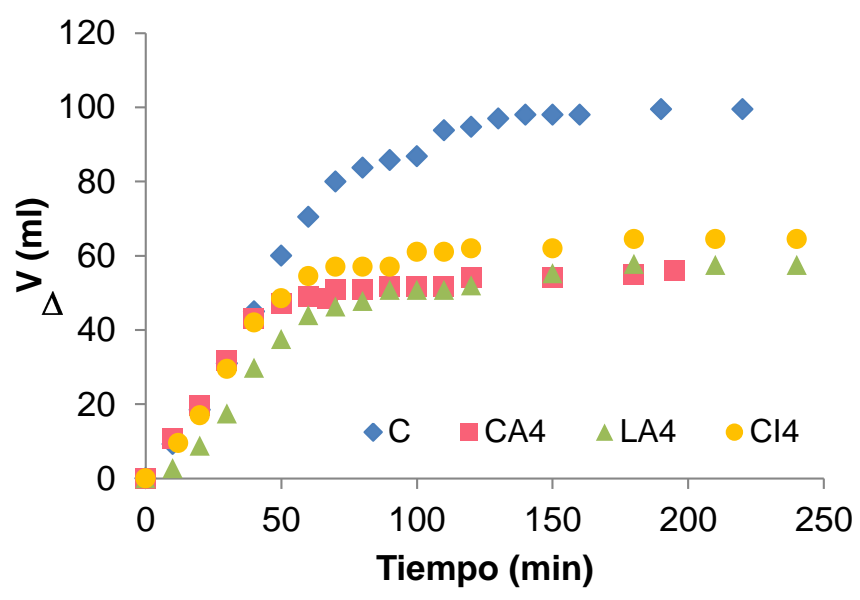

Figura 4.5. Curvas de fermentación típicas obtenidas a partir de masa control (C) y de las masas con 2400 ppm Ca y 12\% In (CA4, Cl4 Y LA 4). 
En la Tabla 4.6 se muestra uno de los tres coeficientes de regresión $\left(\mathrm{V}_{\max }\right)$ obtenido luego de aplicar la regresión sigmoidea de Chapman según se describió en la sección 2.2.10.1 y el tiempo de fermentación $\left(\mathrm{t}_{\mathrm{f}}\right.$ ) optimizado a partir de este modelo, definido como el tiempo requerido por la masa para alcanzar tres cuartos del volumen máximo. El $V_{\max }$ representa el máximo incremento de volumen alcanzado por la masa durante el proceso de fermentación.

La masa $\mathrm{C}$ presentó el mayor valor de $\mathrm{V}_{\max }$. En ausencia de In el agregado de las sales de calcio disminuyó el valor de $\mathrm{V}_{\max }$. $\mathrm{A}$ valores $\geq 6,5 \% \ln$, también disminuyeron aún más los valores de $\mathrm{V}_{\max }$, sugiriendo un mayor efecto a alto nivel de In. A $12 \%$ In, un incremento de $\mathrm{CaCO}_{3}$ provocó una disminución de $\mathrm{V}_{\max }$ a diferencia de $\mathrm{Ca}_{3} \mathrm{Cl}_{2}$, que aumentó en forma significativa este parámetro, lo que sugirió que se obtendría un mayor volumen de pan con el empleo de esta sal orgánica. En cambio, el incremento de $\mathrm{CaLA}_{2}$ no modificó el $\mathrm{V}_{\max }$.

Los mayores tiempos de fermentación, salvo alguna excepción, se observaron en masas con concentraciones 0 ó $1 \%$ In. En ausencia de In, el agregado de calcio no modificó el $t_{f}$ de las masas comparado con el control C. En cambio a $1 \%$ In, un aumento de calcio (como carbonato y lactato) incrementó $t_{f}$. Por otro lado, cuando se utilizó citrato disminuyó el $\mathrm{t}_{\mathrm{f}}$ (47 min), alcanzando más rápidamente los tres cuartos de volumen máximo en presencia de esta última sal. Los $t_{f}$ resultaron bajos cuando se empleó alta inulina, indicando que en presencia del prebiótico se necesita un menor tiempo de fermentación; esto último es deseado para el proceso de panificación debido a que acorta los tiempos en la elaboración de los panes siendo deseable para la industria y/o los panaderos.

Peressini y Sensidoni (2009) estudiaron el efecto del agregado de Raftiline ${ }^{\circledR}$ ST, la cual está enriquecida con FOS, al igual que la utilizada en esta tesis Synergy $1^{\circledR}$. Estos autores no encontraron diferencias significativas en el volumen máximo alcanzado durante el ensayo de fermentación al utilizar 2,5\%, $5 \%$ y $7,5 \%$ de inulina en una harina fuerte. De todos modos, más allá del efecto del prebiótico, a nivel de inulina elevado y constante (12\%) se observaron diferentes comportamientos en $V_{\max } y t_{f}$, dependiendo del tipo y cantidad de sal: estos parámetros no se modificaron con el $\mathrm{CaLA}_{2}$, aumentaron con $\mathrm{Ca}_{3} \mathrm{Cl}_{2}$ y disminuyeron con $\mathrm{CaCO}_{3}$. 
Tabla 4.6. Volumen máximo $\left(\mathrm{V}_{\max }\right)$ y tiempos de fermentación $\left(\mathrm{t}_{\mathrm{f}}\right)$ de las masas.

\begin{tabular}{|c|c|c|c|c|c|c|c|c|}
\hline & \multirow{2}{*}{$\begin{array}{c}\mathrm{Ca} \\
(\mathrm{ppm})\end{array}$} & \multirow{2}{*}{$\begin{array}{l}\text { In } \\
(\%)\end{array}$} & \multicolumn{2}{|c|}{$\mathrm{CaCO}_{3}$} & \multicolumn{2}{|c|}{$\mathrm{Ca}_{3} \mathrm{Cl}_{2}$} & \multicolumn{2}{|c|}{$\mathrm{CaLA}_{2}$} \\
\hline & & & $\begin{array}{l}V_{\max } \\
(\mathrm{ml})\end{array}$ & $\begin{array}{c}t_{f} \\
(\min )\end{array}$ & $\begin{array}{l}V_{\max } \\
\text { (ml) }\end{array}$ & $\begin{array}{c}t_{f} \\
(\min )\end{array}$ & $\begin{array}{l}V_{\text {max }} \\
(\mathrm{ml})\end{array}$ & $\begin{array}{c}\mathbf{t}_{\mathbf{f}} \\
(\min )\end{array}$ \\
\hline 1 & 1200 & 1 & 90 ef & $57 \mathrm{c}$ & $95 \mathrm{fg}$ & $75 \mathrm{~g}$ & $86 \mathrm{~cd}$ & 66 bc \\
\hline 2 & 2400 & 1 & $86 \mathbf{f g}$ & $66 \mathbf{d}$ & $90 \mathbf{f}$ & $47 \mathrm{~b}$ & $90 \mathrm{~d}$ & $81 \mathrm{~d}$ \\
\hline 3 & 1200 & 12 & $63 \mathrm{bc}$ & $48 \mathrm{~b}$ & $46 \mathbf{a}$ & $32 \mathbf{a}$ & $56 a$ & $49 a$ \\
\hline 4 & 2400 & 12 & $54 \mathbf{a}$ & $39 \mathbf{a}$ & $63 \mathrm{~cd}$ & 49 bc & $56 \mathbf{a}$ & $67 \mathbf{a b}$ \\
\hline PC & 1800 & 6,5 & $71 \mathrm{~d}$ & $63 \mathrm{~cd}$ & 79 e & $56 \mathrm{~cd}$ & 67 b & $70 \mathrm{bcd}$ \\
\hline 8 & 1080 & 6,5 & $65 c$ & $46 a b$ & $68 d$ & $65 \mathrm{de}$ & $80 \mathrm{c}$ & 94 cd \\
\hline 9 & 1800 & 13 & $58 a b$ & $47 a b$ & 55 b & $39 \mathbf{a}$ & $54 \mathbf{a}$ & $63 \mathbf{a b}$ \\
\hline 10 & 2520 & 6,5 & $67 c$ & $47 a b$ & $63 \mathrm{c}$ & $62 \mathrm{de}$ & 69 b & $48 \mathbf{a}$ \\
\hline 11 & 1800 & 0 & $88 \mathrm{e}$ & $68 d$ & $83 \mathbf{e}$ & 65 ef & $92 d$ & 79 cd \\
\hline C & 0 & 0 & $100 \mathbf{g}$ & $67 d$ & $100 \mathrm{~g}$ & $67 \mathrm{f}$ & $100 \mathbf{e}$ & 67 bc \\
\hline
\end{tabular}

Letras diferentes en una misma columna indican diferencias significativas $(p<0,05)$.

Es probable que un menor volumen máximo y menores tiempos de fermentación tengan consecuencias directas en la calidad de los panes.

\subsection{Evaluación de la calidad panadera}

La calidad de los panes obtenidos se evaluó mediante la determinación del volumen específico de la hogaza, el color de la corteza; la firmeza, humedad y alveolado de la miga según se describió en la sección 2.2.10.3.

\subsubsection{Volumen especifico}

El volumen específico $\left(\mathrm{V}_{\mathrm{E}}\right)$ de los panes se muestra en la Figura 4.6. En panes elaborados con $\mathrm{CaCO}_{3}$ (Figura 4.6.a) un incremento en la sal de calcio no provocó cambios significativos del $\mathrm{V}_{\mathrm{E}}$ a $I n \leq 12 \%$. Al agregar un $13 \%$ In se obtuvo el mayor volumen específico, indicando una alta capacidad de la matriz de gluten para retener el gas producido durante la fermentación debido a un desarrollo adecuado de la red durante el amasado en presencia del prebiótico. Si comparamos el valor de $\mathrm{V}_{\max }$ obtenido para ésta ultima formulación (CA9) hubiésemos esperado valores bajo de $V_{E}$, 
sin embargo eso no ocurrió, este comportamiento podría deberse a que la masa fue más blanda y cohesiva (TPA) lo que le permitió expandirse más durante el horneado sugiriendo además que la inulina influye en la expansión de la masa y retención del $\mathrm{CO}_{2}$ durante la cocción, quizá por la formación de una matriz gelificada interpenetrada con la red de gluten provocando panes de mayor volumen específico.

Los resultados sugieren que un elevado volumen de masa fermentada no necesariamente se traduce en un mayor volumen de pan.

Meyer y Peters (2009) obtuvieron panes de mayor volumen en presencia de la enzima invertasa presente en Saccharomyces cerevisiae; sugiriendo que esta enzima podría hidrolizar fácilmente las fracciones de inulina de cadena más corta y emplearlas como sustrato conduciendo a una mayor fermentación.

En panes con sales de calcio orgánicas, se observó un comportamiento diferente que en el caso anterior, un incremento de inulina provocó una disminución del $V_{E}$, especialmente en el caso del lactato (Figuras 4.6.b y 4.6.c). Los mayores $V_{E}$ se obtuvieron en ausencia o con $1 \%$ de inulina. Con un nivel de $6,5 \%$ In se logró mantener el volumen más con citrato que con lactato de calcio; un incremento de $\mathrm{CaLA}_{2}$ (Figura 4.6.c) provocó una disminución significativa del $V_{E}$, a diferencia del $\mathrm{Ca}_{3} \mathrm{Cl}_{2}$ que no tuvo influencia en $\mathrm{V}_{\mathrm{E}}$. O sea, en presencia de $\mathrm{CaLA}_{2}$ la red no es lo suficientemente fuerte como para soportar la expansión durante la cocción.

En el Capítulo 3, se analizó la influencia de la inulina y las sales de calcio en las características de las masas, se planteó el efecto desestabilizante del anión lactato sobre las proteínas de la red de gluten. Con esta sal se forma una red de gluten poco estable que podría colapsar durante la expansión, dando lugar a un bajo volumen especifico de pan, especialmente a niveles de 12 y $13 \%$ In. Una alta concentración de prebiótico en presencia de $\mathrm{CaLA}_{2}$ podría interferir durante el amasado en la formación de la red proteica estable, conduciendo a una matriz que retiene menos gas y que favorecería la formación de una miga con alvéolos más pequeños que se traducen en un menor $\mathrm{V}_{\mathrm{E}}$.

La superficie de respuesta (SR) que explica el comportamiento de $V_{E}$ a diferentes concentraciones de sales de calcio e inulina se muestra en la Figura 4.7. Estas SR resultaron diferentes según la sal de calcio utilizada. En el caso de panes con $\mathrm{CaCO}_{3}$, el modelo no ajustó. 

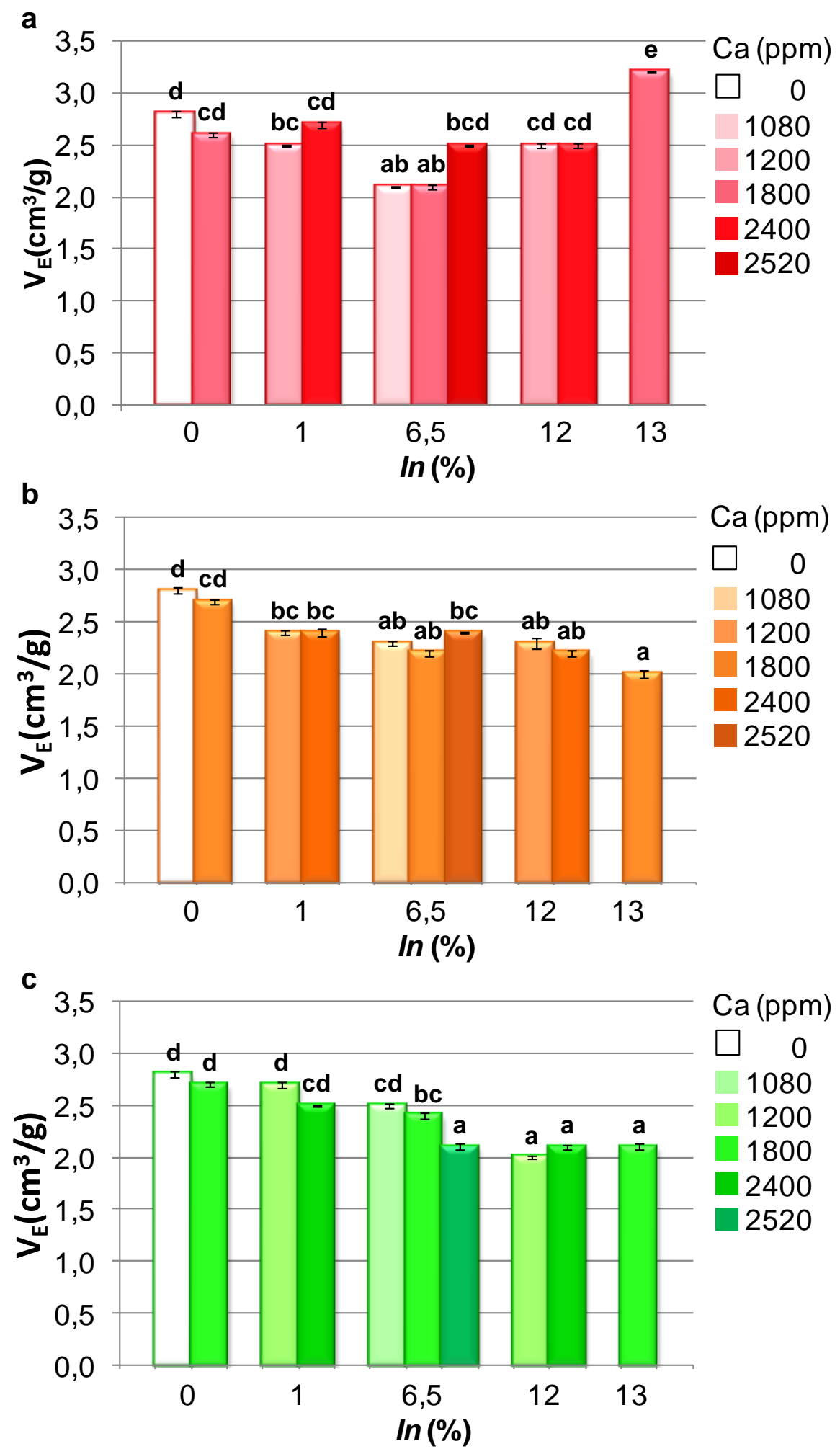

Figura 4.6. Volumen específico de los panes: a) $\mathrm{CaCO}_{3}$, b) $\mathrm{Ca}_{3} \mathrm{Cl}_{2}$, c) $\mathrm{CaLA}_{2}$. Letras diferentes en un mismo gráfico indican diferencias significativas con $\mathrm{p}<0,05$. Media \pm desviación estándar. 
El volumen específico de los panes con las sales de calcio orgánicas (Figuras 4.7.a y 4.7.b, Tabla 4.7) variaron en forma inversa lineal con In.

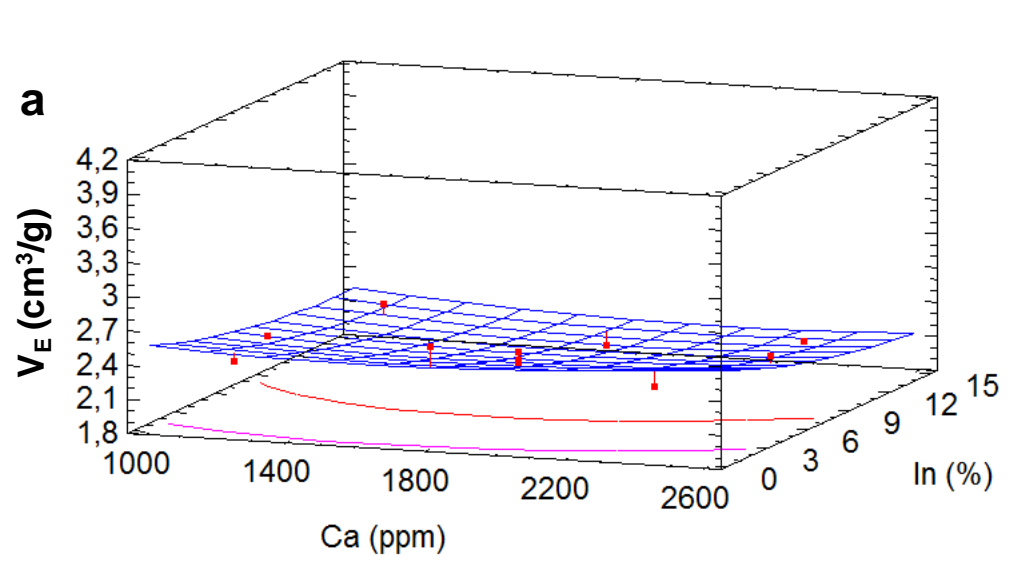

$\mathrm{V}_{\mathrm{E}}\left(\mathrm{cm}^{3} / \mathrm{g}\right)$

$-2,1$

2,3

$-2,5$

$-2,7$

$-2,9$

$-3,1$

$-3,3$

$-3,5$

$\begin{array}{r}3,5 \\ -\quad 37 \\ \hline\end{array}$

$-3,9$

- 4,1

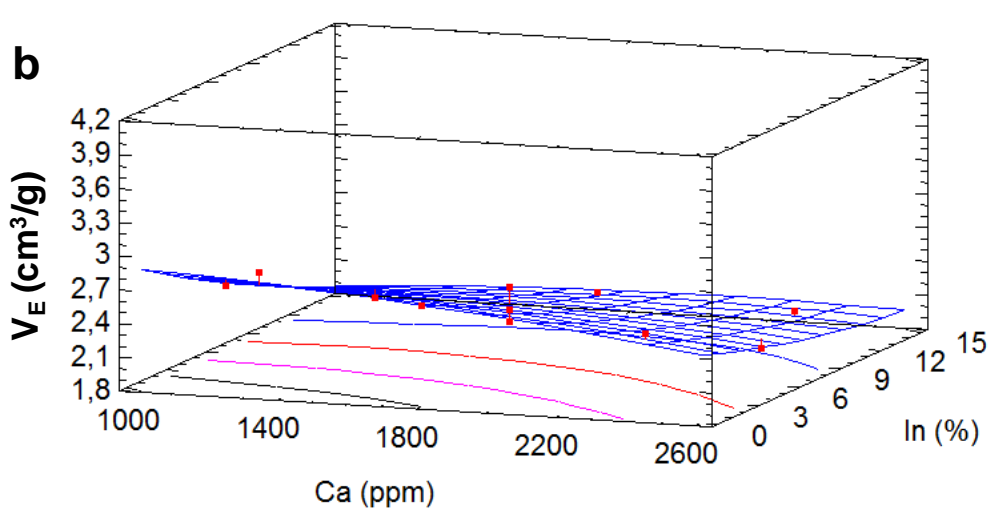

$\mathrm{V}_{\mathrm{E}}\left(\mathrm{cm}^{3} / \mathrm{g}\right)$

- 2,1

- 2,3

- 25

- 2,7

- 2,9

- 3,1

- 3,3

- 3,5

- 3,7

$-3,9$

Figura 4.7. Gráfico de superficie de respuesta (SR) del volumen especifico de los panes: a) $\mathrm{Ca}_{3} \mathrm{Cl}_{2}$, b) $\mathrm{CaLA}_{2}$. Los puntos sobre la $\mathrm{SR}$ representan las medias de los valores experimentales obtenidos. Debajo de la SR se visualiza la superficie de contorno. 
Tabla 4.7. Análisis de varianza y coeficientes de regresión para el modelo polinomio de segundo orden.

\begin{tabular}{c|cc|cc}
\hline \multirow{2}{*}{$\begin{array}{c}\text { Términos } \\
\text { de }\end{array}$} & \multicolumn{4}{c}{$\mathrm{V}_{\mathrm{E}}\left(\mathrm{cm}^{3} / \mathbf{g}\right)$} \\
\cline { 2 - 5 } regresión & \multicolumn{2}{|c|}{$\mathrm{Ca}_{3} \mathrm{Cl}_{2}$} & \multicolumn{2}{c}{$\mathrm{CaLA}_{2}$} \\
\cline { 2 - 5 } & $\mathbf{b}$ & $\mathbf{p}$-valor & $\mathbf{b}$ & $\mathbf{p}$-valor \\
\hline Constante $\left(\mathrm{b}_{0}\right)$ & 2,245 & & 2,339 \\
$\mathrm{Ca}$ & $2,91^{*} 10^{-3}$ & 0,96 & $-0,084$ & 0,15 \\
In & $-0,166$ & 0,03 & $-0,264$ & 0,00 \\
$\mathrm{Ca}^{2}$ & $5,1^{*} 10^{-3}$ & 0,51 & $-0,036$ & 0,60 \\
In $^{2}$ & 0,051 & 0,51 & 0,033 & 0,64 \\
$\mathrm{Ca}^{*} \ln$ & $-0,025$ & 0,74 & 0,075 & 0,29 \\
$\mathrm{R}^{2}$ & & 0,679 & & 0,872 \\
$\mathrm{~S}_{\text {Cal }}$ & & 0,141 & & 0,128 \\
\hline
\end{tabular}

Diferencias significativas cuando $p$-valor $<0,05$.

\subsubsection{Color de la corteza}

El color de la corteza de los panes es un parámetro importante al momento de la elección del pan por parte del consumidor, colores muy claros o muy oscuros no son deseables. El índice de pardeamiento (IP) es un parámetro que se calcula teniendo en cuenta los tres valores $L^{*}, a^{*}$ y $b^{*}$ obtenidos por medio del colorímetro, el cual se encuentra relacionado con la coloración marrón de la corteza como se describió en la sección 2.2.10.3.2. Este color es característico de la corteza que aparece como consecuencia de la reacción de pardeamiento no enzimático entre los hidratos de carbono reductores y los grupos aminos pertenecientes a residuos aminoacídicos de las proteínas (Reacción de Maillard).

En la Tabla 4.8 se presentan los diferentes índices de pardeamiento (IP) de la corteza de los panes estudiados. Debido a que el tiempo y la temperatura de horneado fue la misma para todas las formulaciones, podemos inferir que el cambio en la formulación por el agregado de las diferentes sales de calcio e inulina provoca cambios visibles a simple vista en el color de los panes nutricionalmente mejorados, comparados con el pan control.

En los panes elaborados con $\mathrm{CaCO}_{3}$, un aumento de la sal de calcio incrementó el IP ( 0 y $1 \%$ In). Este efecto puede deberse a que el anión carbonato alcaliniza la masa y la reacción de Maillard se favorece a $\mathrm{pH}$ alcalino y a baja actividad acuosa, como 
también al menor contenido de agua (condiciones de deshidratación) de la corteza. A cantidad de In $\geq 6,5 \%$, el color de la corteza resultó independiente del contenido de carbonato de calcio.

Los panes con $\mathrm{Ca}_{3} \mathrm{Cl}_{2}$ y $\mathrm{CaLA}_{2}$ en ausencia de prebiótico presentaron menor y mayor IP que el pan control, respectivamente. Ambas sales, a $1 \%$ In no modificaron el IP, mientras que a $12 \%$ lo disminuyeron. A $6,5 \%$ In, el citrato favoreció el pardeamiento, mientras que el lactato produjo el efecto contrario.

Tabla 4.8. Índice de pardeamiento de la corteza de los panes.

\begin{tabular}{|c|c|c|c|c|c|}
\hline & \multirow{2}{*}{$\begin{array}{c}\mathrm{Ca} \\
(\mathrm{ppm})\end{array}$} & \multirow{2}{*}{$\begin{array}{l}\text { In } \\
(\%)\end{array}$} & \multicolumn{3}{|c|}{ IP (-) } \\
\hline & & & $\mathrm{CaCO}_{3}$ & $\mathrm{Ca}_{3} \mathrm{Cl}_{2}$ & $\mathrm{CaLA}_{2}$ \\
\hline 1 & 1200 & 1 & $62 \mathrm{c}$ & $45 \mathrm{~b}$ & $53 \mathrm{c}$ \\
\hline 2 & 2400 & 1 & $75 d$ & $44 \mathrm{~b}$ & 52 bc \\
\hline 3 & 1200 & 12 & $97 \mathrm{f}$ & $80 \mathrm{f}$ & 86 e \\
\hline 4 & 2400 & 12 & $97 \mathrm{f}$ & $71 \mathbf{e}$ & $76 \mathbf{d}$ \\
\hline PC & 1800 & 6,5 & 84 e & $56 \mathrm{c}$ & $73 d$ \\
\hline 8 & 1080 & 6,5 & 84 e & $55 \mathrm{c}$ & 85 e \\
\hline 9 & 1800 & 13 & $102 \mathbf{f}$ & $80 \mathrm{f}$ & $93 \mathrm{f}$ \\
\hline 10 & 2520 & 6,5 & $86 \mathrm{e}$ & $61 \mathrm{~d}$ & $74 \mathrm{~d}$ \\
\hline 11 & 1800 & 0 & 55 b & $35 a$ & $48 \mathrm{~b}$ \\
\hline C & 0 & 0 & $41 \mathbf{a}$ & $41 \mathrm{~b}$ & $41 \mathbf{a}$ \\
\hline
\end{tabular}

Letras diferentes en una misma columna indican diferencias significativas con un $p<0,05$.

Las cortezas de todos los panes con agregado de alta In presentaron una disminución de la luminosidad y un aumento de los parámetros $a^{*}$ y $b^{*}$ respecto al control (datos no mostrados), que trae como consecuencia un mayor IP, sugiriendo una coloración más rojiza con el incremento del prebiótico. Peressini y Sensidoni (2009) reportaron un incremento de la coloración de la corteza empleando dos harinas, una débil y otra más fuerte, adicionando inulina $(2.5 \%, 5 \%$ y $7.5 \%)$ de diferente grado de polimerización. Estos autores atribuyeron el aumento de coloración en la corteza al incremento en el contenido de azucares reductores, los cuales están involucrados en las reacciones de Maillard durante el horneado. En ese mismo sentido, panes elaborados con fibra de achicoria ( $3 \%, 6 \%, 9 \%$ y $12 \%$ base harina) presentaron mayor coloración de corteza con el aumento de fibra (Frutos y col., 2008). 


\subsubsection{Textura de las migas}

Los parámetros obtenidos a partir del análisis de perfil de textura (TPA) de la miga son importantes al momento de analizar el efecto de la formulación sobre la calidad del pan, debido a que están relacionados con la percepción del consumidor. Los consumidores prefieren panes con miga tierna y aireada, asociado a bajos valores de firmeza. La integración de los componentes es un tributo importante, de manera que una cohesividad alta es deseada. Además un pan fresco debe tener una miga con una elasticidad que no se oponga al proceso de masticación. La masticabilidad es un parámetro asociado al esfuerzo que hay que realizar durante la masticación que depende de la elasticidad, la firmeza y la cohesividad de la miga y se pretende que sea baja. La textura de la miga se encuentra relacionada directamente con otras características del producto como son la humedad, la densidad y la porosidad. En general, la firmeza presentada por un producto panificado será menor a mayores valores de humedad y volumen del mismo. Además, el tamaño y distribución de los alvéolos también influyen en la textura de la miga (Cauvain, 2004).

En la Figura 4.8 se muestran los valores de firmeza, masticabilidad (Mast) y cohesividad (Coh) obtenidos a partir de TPA de migas frescas de los panes elaborados con $\mathrm{CaCO}_{3}$ e In. Los valores de firmeza de los panes sin inulina resultaron similares a los de la miga C (Figura 4.8.a). Sin embargo con igual contenido de In, un incremento en $\mathrm{CaCO}_{3}$ provocó una disminución de la firmeza, asociado a una miga más blanda, esto podría corresponderse con mayor área alveolar, parámetro que analizaremos más adelante; es decir, hay más aire formando parte de la rodaja entonces el sensor registra menos fuerza durante la compresión. La masticabilidad varía en el mismo sentido que la firmeza (Figura 4.8.b) o sea las migas más blandas presentan menor masticabilidad, asociado a una menor fuerza de masticación.

A valores $\leq 6,5 \% \operatorname{In}$, un aumento de $\mathrm{CaCO}_{3}$ incrementó la cohesividad de la miga (Figura 4.8.c), asociado a una miga con estructura más fuerte que se desgrana menos durante la compresión. 
a
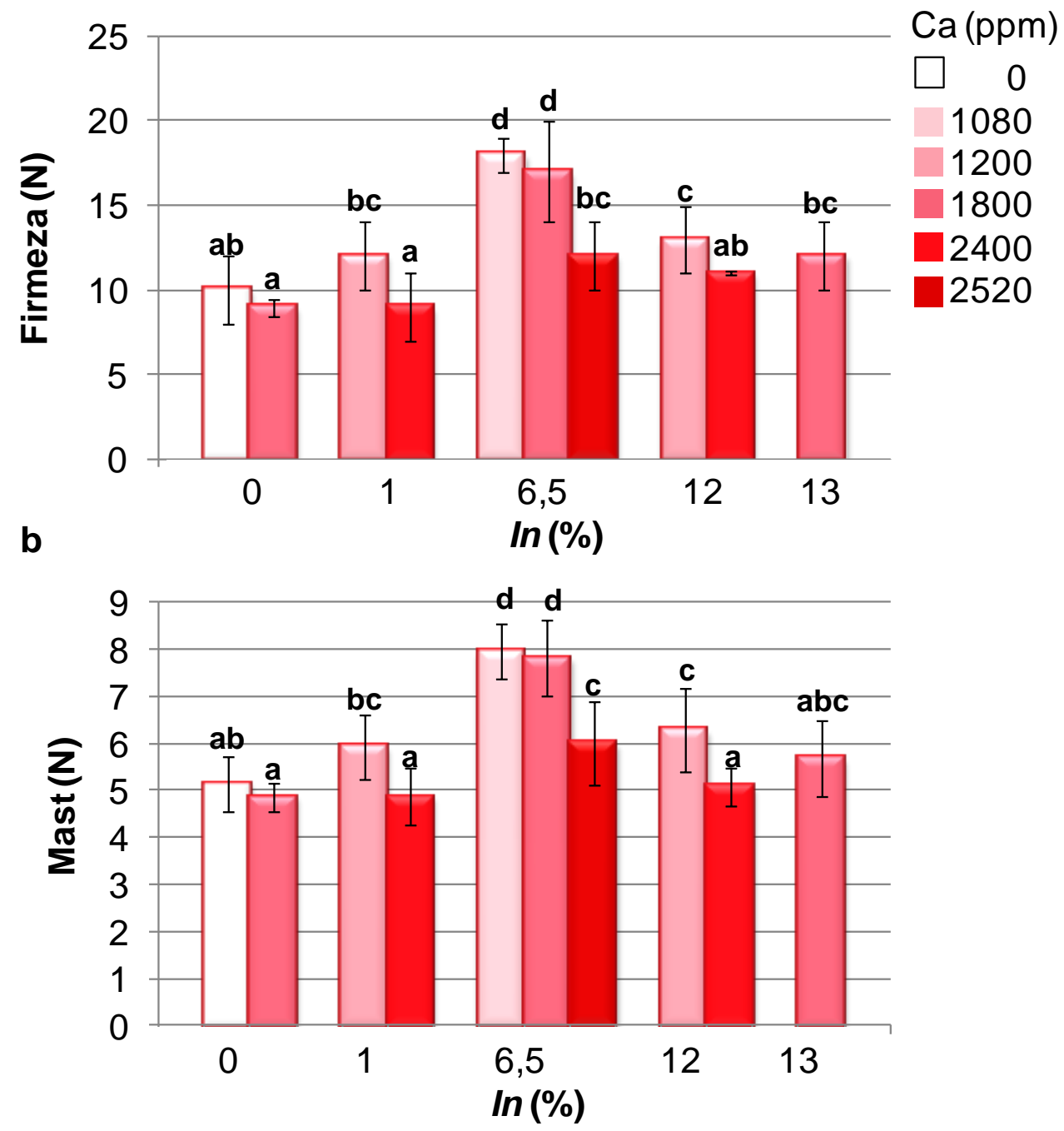

C

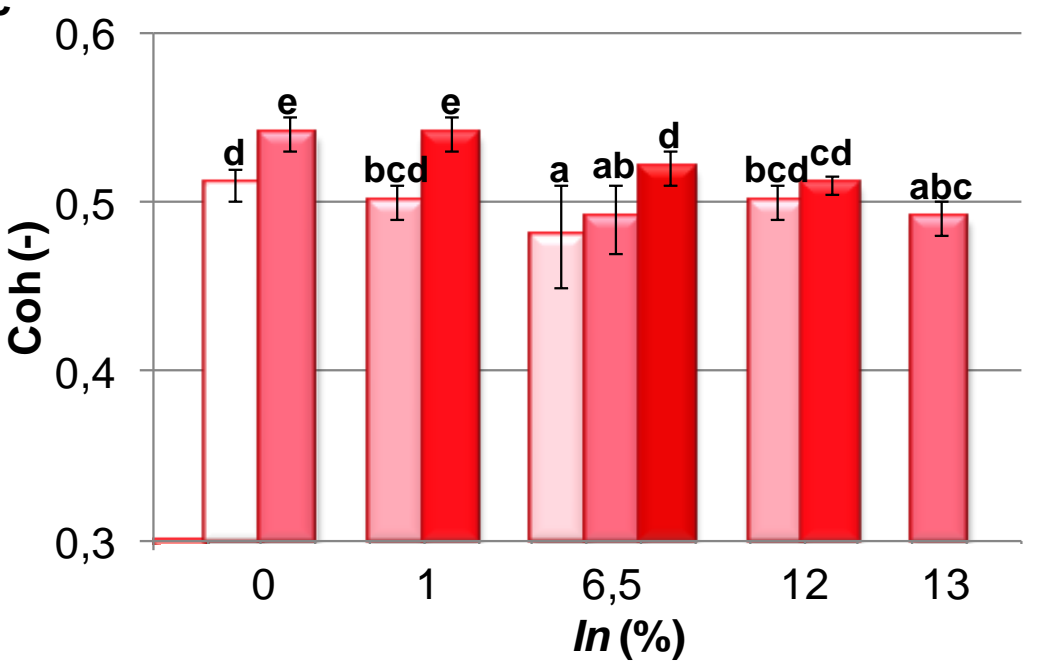

Figura 4.8. Firmeza, masticabilidad y cohesividad de migas de panes frescos con $\mathrm{CaCO}_{3}$. Letras diferentes en un mismo gráfico indican diferencias significativas con $p<0,05$. Media \pm desviación estándar. 
En la Figura 4.9 se observan algunos de los parámetros texturales de miga fresca obtenida como el resultado de la fortificación de los panes con sales de calcio orgánicas.

A diferencia de la firmeza obtenida en las migas con $\mathrm{CaCO}_{3}$, en general se observó para ambas sales orgánicas que un aumento de In provocó un incremento de la firmeza (Figuras 4.9.a y 4.9.d). Un incremento de $\mathrm{Ca}_{3} \mathrm{Cl}_{2}$ provocó una disminución de la firmeza a igual concentración de prebiótico utilizado $(\leq 12 \%$ In) (Figura 4.9.a) similar al emplear $\mathrm{CaCO}_{3}$. En cambio a $\geq 6,5 \%$ In las migas con $\mathrm{CaLA}_{2}$ resultaron más firmes por efecto del prebiótico, independiente del nivel de calcio agregado.
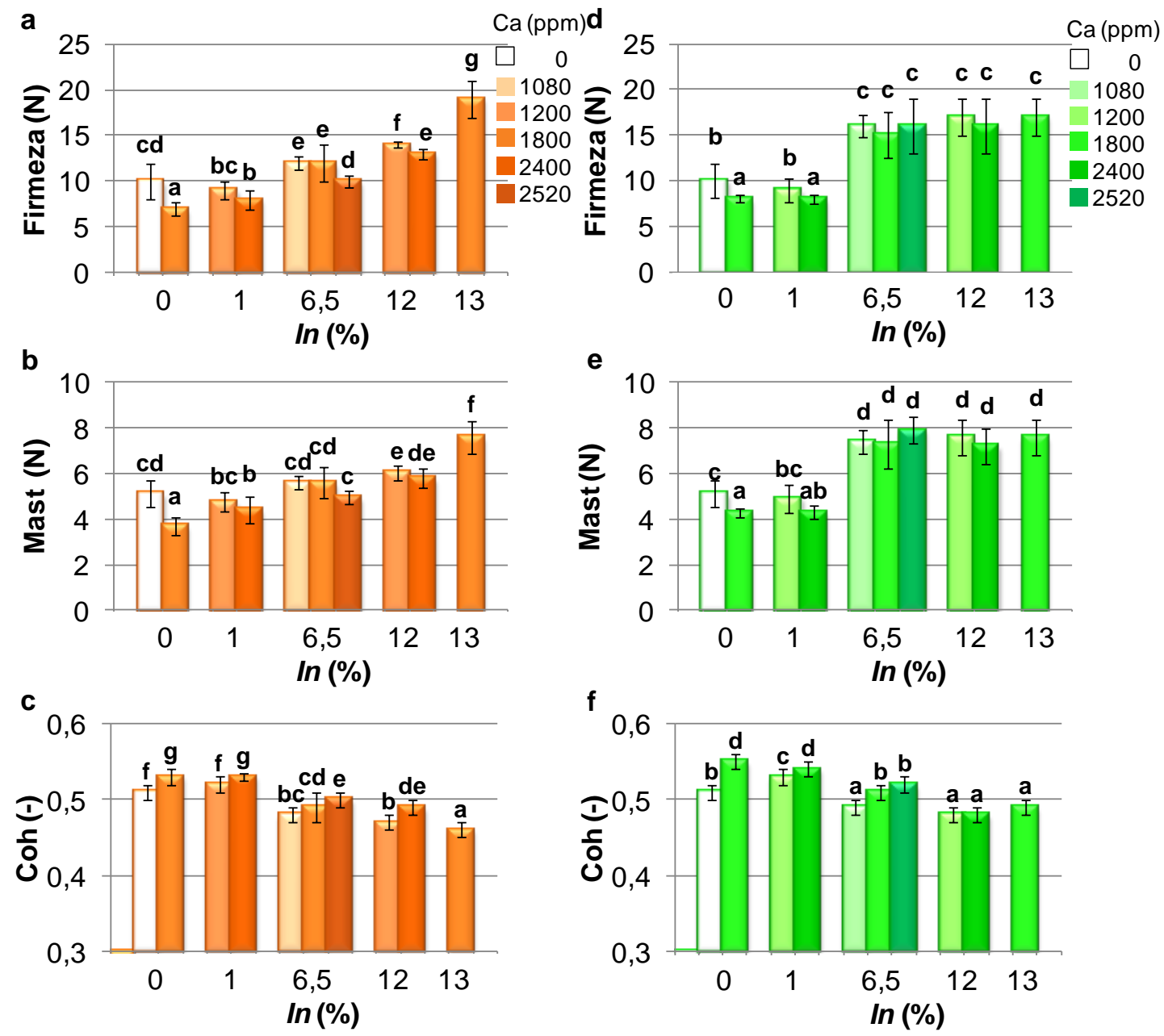

Figura 4.9. Firmeza, masticabilidad y cohesividad de migas de panes frescos con $\mathrm{Ca}_{3} \mathrm{Cl}_{2}$ y $\mathrm{CaLA}_{2}$. Letras diferentes en un mismo gráfico indican diferencias significativas con $p<0,05$. Barras: medias \pm desviación estándar.

Diversos autores reportaron un incremento en la firmeza de la miga de pan con la adición de inulina (Morris y Morris, 2012). Kim y col (2001) encontraron evaluando diferentes suspensiones de inulina la capacidad de este hidrato de carbono de gelificar 
luego del calentamiento, este fenómeno podría ser el responsable de la mayor firmeza de las migas.

En general, una disminución en la firmeza está relacionada con un incremento del volumen específico de los panes.

En la Tabla 4.9 y 4.10 se muestra el resto de los parámetros obtenidos del análisis de perfil de textura de las migas de los panes. En todos los casos, la consistencia varió en el mismo sentido que la firmeza según la sal de calcio empleada. Si bien se obtuvieron diferencias significativas, la elasticidad de todas las migas fue elevada, la mayoría superior a 0,90. La elasticidad y resiliencia aumentaron con el agregado de $\mathrm{CaCO}_{3}$ a $\leq$ $1 \%$ In, provocando migas más elásticas y de mayor recuperación instantánea. $A \geq$ 6,5\% In ambos parámetros fueron mínimos (Tabla 4.9).

Tabla 4.9. Consistencia, elasticidad y resiliencia de migas frescas con $\mathrm{CaCO}_{3}$.

\begin{tabular}{|c|c|c|c|c|c|}
\hline & \multirow{2}{*}{$\begin{array}{c}\mathrm{Ca} \\
(\mathrm{ppm})\end{array}$} & \multirow{2}{*}{$\begin{array}{l}\text { In } \\
(\%)\end{array}$} & \multicolumn{3}{|c|}{$\mathrm{CaCO}_{3}$} \\
\hline & & & $\begin{array}{l}\text { Cons } \\
\left(N^{*} s\right)\end{array}$ & $\begin{array}{c}\text { Elast } \\
(-)\end{array}$ & $\begin{array}{c}\text { Resi } \\
(-)\end{array}$ \\
\hline 1 & 1200 & 1 & 219 bc & $0,97 \mathbf{b}$ & $0,38 a b$ \\
\hline 2 & 2400 & 1 & $159 \mathbf{a}$ & $0,99 \mathrm{c}$ & $0,46 \mathrm{c}$ \\
\hline 3 & 1200 & 12 & $230 \mathrm{c}$ & $0,93 \mathbf{a}$ & $0,36 \mathbf{a}$ \\
\hline 4 & 2400 & 12 & $180 \mathbf{a b}$ & $0,93 \mathbf{a}$ & $0,38 \mathbf{a b}$ \\
\hline PC & 1800 & 6,5 & $306 d$ & $0,94 \mathbf{a}$ & $0,37 a b$ \\
\hline 8 & 1080 & 6,5 & $311 d$ & $0,93 \mathbf{a}$ & $0,35 \mathbf{a}$ \\
\hline 9 & 1800 & 13 & 206 bc & $0,93 \mathbf{a}$ & $0,35 \mathbf{a}$ \\
\hline 10 & 2520 & 6,5 & 213 bc & $0,95 a b$ & $0,42 \mathbf{b}$ \\
\hline 11 & 1800 & 0 & $162 \mathbf{a}$ & $1,00 \mathrm{c}$ & $0,51 \mathbf{d}$ \\
\hline C & 0 & 0 & $189 \mathrm{ab}$ & $0,96 \mathbf{b}$ & $0,41 \mathbf{b}$ \\
\hline
\end{tabular}

Letras diferentes en una misma columna indican diferencias significativas con un $p<0,05$.

En general, la elasticidad y resiliencia de migas con $\mathrm{Ca}_{3} \mathrm{Cl}_{2}$ y $\mathrm{CaLA} \mathrm{A}_{2}$ siguió la misma tendencia que con $\mathrm{CaCO}_{3}$, tanto a baja como a alta In (Tabla 4.10). Sin embargo, a $\geq$ $12 \%$ In la resiliencia no se modificó con el nivel de Ca para $\mathrm{CaCO}_{3}$ y $\mathrm{CaLA}_{2}$, pero aumentó con el incremento de $\mathrm{Ca}_{3} \mathrm{Cl}_{2}$. 
Tabla 4.10. Consistencia, elasticidad y resiliencia de migas frescas empleando sales de calcio orgánicas.

\begin{tabular}{|c|c|c|c|c|c|c|c|c|}
\hline & \multirow{2}{*}{$\begin{array}{c}\mathrm{Ca} \\
(\mathrm{ppm})\end{array}$} & \multirow{2}{*}{$\begin{array}{l}\text { In } \\
(\%)\end{array}$} & \multicolumn{3}{|c|}{$\mathrm{Ca}_{3} \mathrm{Cl}_{2}$} & \multicolumn{3}{|c|}{$\mathrm{CaLA}_{2}$} \\
\hline & & & $\begin{array}{l}\text { Cons } \\
\left(N^{*} s\right)\end{array}$ & $\begin{array}{c}\text { Elast } \\
(-)\end{array}$ & $\begin{array}{c}\text { Resil } \\
(-)\end{array}$ & $\begin{array}{l}\text { Cons } \\
\left(N^{*} s\right)\end{array}$ & $\begin{array}{c}\text { Elast } \\
(-)\end{array}$ & $\begin{array}{c}\text { Resil } \\
(-)\end{array}$ \\
\hline 1 & 1200 & 1 & $182 \mathbf{b}$ & $0,99 \mathbf{e}$ & $0,44 \mathbf{f}$ & $177 \mathrm{c}$ & $0,99 \mathbf{d}$ & $0,47 \mathbf{d}$ \\
\hline 2 & 2400 & 1 & $155 \mathbf{a}$ & $0,99 \mathbf{e}$ & $0,48 \mathbf{g}$ & 145 b & $1,00 \mathbf{d}$ & $0,51 \mathbf{e}$ \\
\hline 3 & 1200 & 12 & $248 d$ & $0,92 \mathbf{b}$ & $0,33 \mathbf{b}$ & 241 ef & $0,91 \mathbf{a}$ & $0,37 \mathbf{a}$ \\
\hline 4 & 2400 & 12 & $237 \mathrm{~cd}$ & $0,92 \mathbf{b}$ & $0,47 \mathbf{g}$ & $290 \mathrm{f}$ & $0,91 \mathbf{a}$ & $0,36 \mathbf{a}$ \\
\hline PC & 1800 & 6,5 & $224 \mathrm{c}$ & 0,93 bc & $0,36 \mathrm{c}$ & $241 \mathrm{e}$ & $0,94 \mathbf{b}$ & 0,41 bc \\
\hline 8 & 1080 & 6,5 & 222 c & $0,94 \mathbf{c}$ & 0,35 bc & $291 \mathrm{f}$ & 0,94 bc & $0,38 \mathrm{ab}$ \\
\hline 9 & 1800 & 13 & 330 e & $0,88 \mathbf{a}$ & $0,30 \mathbf{a}$ & 244 ef & $0,90 \mathbf{a}$ & $0,37 \mathbf{a}$ \\
\hline 10 & 2520 & 6,5 & $193 \mathbf{b}$ & 0,93 bc & $0,38 \mathbf{e}$ & 216 de & $0,96 \mathbf{c}$ & 0,42 c \\
\hline 11 & 1800 & 0 & $133 a$ & $0,99 \mathbf{e}$ & $0,47 \mathbf{g}$ & $106 \mathbf{a}$ & $0,99 \mathbf{d}$ & $0,47 \mathbf{d}$ \\
\hline C & 0 & 0 & 189 b & $0,96 \mathbf{d}$ & $0,41 \mathbf{e}$ & 189 cd & 0,96 bc & $0,41 \mathbf{b c}$ \\
\hline
\end{tabular}

Letras diferentes en una misma columna indican diferencias significativas con un $p<0,05$.

En la Figura 4.10 se muestran las superficies de respuesta de la Elast y Mast de las migas de panes elaborados con $\mathrm{CaCO}_{3}$. La Elast varía en forma inversa con el incremento de In y directa con $I n^{2}$ (Tabla 4.11). La Mast, en cambio, varió en forma inversa con Ca e $1 n^{2}$; un incremento de calcio facilitaría el trabajo de masticación como consecuencia de la obtención de migas mas blandas. No se muestra la SR generada a partir de la Coh debido a que no se obtuvieron con el modelo coeficientes de regresión significativos.

La Elast, Coh y Mast de las migas de los panes elaborados con sales de calcio orgánicas se muestran en la Figura 4.11. En ambos casos la Elast y Coh disminuyen (Tablas 4.12 y 4.13), en cambio la Mast se incrementa con el agregado de In; en este último caso además varia con $I n^{2}$.

Las superficies generadas a partir de los diferentes diseños presentaron similar forma en los parámetros elasticidad y cohesividad; sin embargo, la forma de la SR de la variable Mast de migas con $\mathrm{CaCO}_{3}$ resultó similar a la SR de migas con $\mathrm{CaLA}_{2}$. 

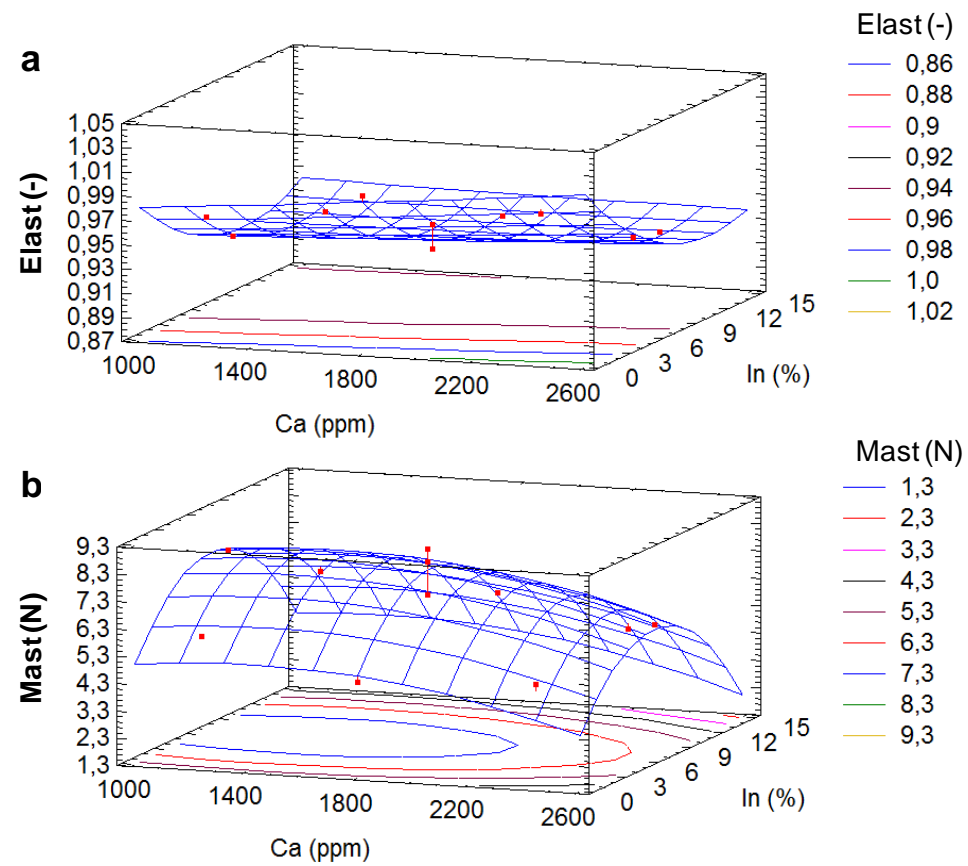

Mast (N)

- 1,3

- 2,3

- 3,3

$-4,3$

$-5,3$

- 6,3

$-7,3$

$-8,3$

8,3
-

Figura 4.10. SR de los parámetros de perfil de textura: a) Elasticidad (Elast), b) Masticabilidad (Mast) de migas con $\mathrm{CaCO}_{3}$.Los puntos sobre la $\mathrm{SR}$ representan las medias de los valores experimentales obtenidos. Debajo de la misma se visualiza la superficie de contorno.

Tabla 4.11. Análisis de varianza y coeficientes de regresión para el modelo polinomio de segundo orden.

\begin{tabular}{|c|c|c|c|c|}
\hline \multirow{3}{*}{$\begin{array}{l}\text { Términos } \\
\text { de } \\
\text { regresión }\end{array}$} & \multicolumn{4}{|c|}{$\mathrm{CaCO}_{3}$} \\
\hline & \multicolumn{2}{|c|}{ Elast (-) } & \multicolumn{2}{|c|}{ Mast (N) } \\
\hline & b & $p$-valor & b & $p$-valor \\
\hline Constante $\left(b_{0}\right)$ & 0,937 & & 7,756 & \\
\hline $\mathrm{Ca}$ & $6,4^{*} 10^{-4}$ & 0,09 & $-0,669$ & 0,03 \\
\hline $\ln$ & $-0,027$ & 0,00 & 0,244 & 0,33 \\
\hline $\mathrm{Ca}^{2}$ & $7,7^{\star} 10^{-4}$ & 0,86 & $-0,506$ & 0,15 \\
\hline $\ln ^{2}$ & 0,018 & 0,01 & $-1,72$ & 0,00 \\
\hline $\mathrm{Ca}^{*} \ln$ & $-0,005$ & 0,27 & $-0,05$ & 0,87 \\
\hline $\mathrm{R}^{2}$ & & 0,950 & & 0,897 \\
\hline $\mathrm{S}_{\text {Cal }}$ & & 0,008 & & 0,592 \\
\hline
\end{tabular}

Diferencias significativas cuando $\mathrm{p}$-valor $<0,05$. 

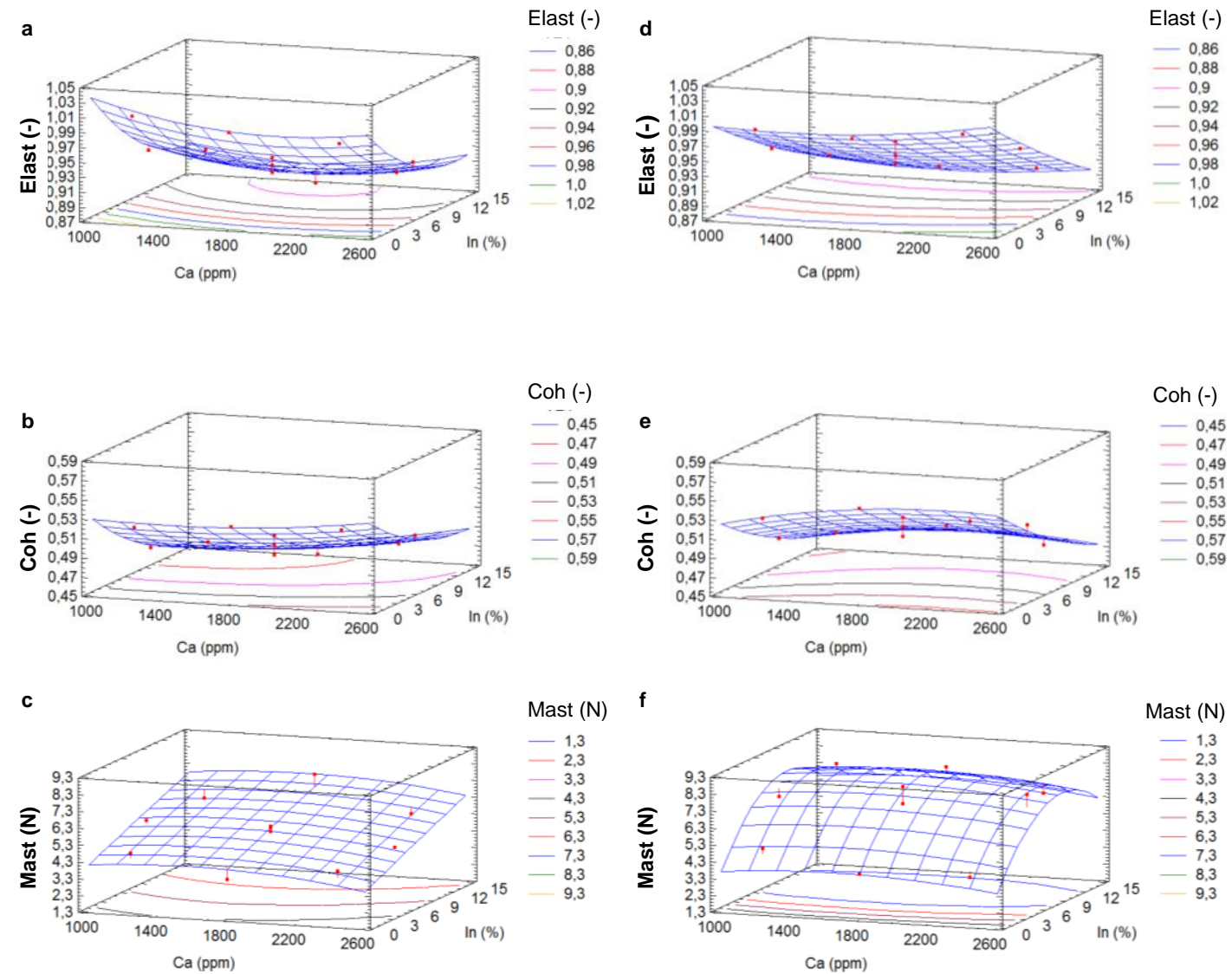

Figura 4.11. SR de los parámetros de perfil de textura: Elasticidad (Elast) (a, d), Cohesividad (Coh) (b, e), Masticabilidad (Mast) (c, f) de migas con $\mathrm{Ca}_{3} \mathrm{Cl}_{2}(\mathbf{a}, \mathbf{b}, \mathbf{c})$ y $\mathrm{CaLA}_{2}(\mathbf{d}, \mathbf{e}, \mathbf{f})$. Los puntos sobre la SR representan las medias de los valores experimentales obtenidos. Debajo de la misma se visualiza la superficie de contorno.

Tabla 4.12. Análisis de varianza y coeficientes de regresión para el modelo polinomio de segundo orden.

\begin{tabular}{|c|c|c|c|c|c|c|}
\hline \multirow{3}{*}{$\begin{array}{l}\text { Términos } \\
\text { de } \\
\text { regresión }\end{array}$} & \multicolumn{6}{|c|}{$\mathrm{Ca}_{3} \mathrm{Cl}_{2}$} \\
\hline & \multicolumn{2}{|c|}{ Elast (-) } & \multicolumn{2}{|c|}{ Coh (-) } & \multicolumn{2}{|c|}{ Mast (N) } \\
\hline & b & $p$-valor & b & $p$-valor & b & $p$-valor \\
\hline Constante $\left(b_{0}\right)$ & 1,140 & & 0,488 & & 5,596 & \\
\hline $\mathrm{Ca}$ & $-1,3^{*} 10^{-4}$ & 0,39 & 0,008 & 0,06 & $-0,195$ & 0,41 \\
\hline $\ln$ & $-0,017$ & 0,00 & $-0,025$ & 0,00 & 1,073 & 0,00 \\
\hline $\mathrm{Ca}^{2}$ & $3,2^{*} 10^{-8}$ & 0,14 & $3,8 * 10^{-3}$ & 0,43 & $-0,296$ & 0,36 \\
\hline $\ln ^{2}$ & $5,2 * 10^{-4}$ & 0,07 & $7,3^{*} 10^{-3}$ & 0,16 & $-0,018$ & 0,95 \\
\hline $\mathrm{Ca}^{*} \ln$ & $1,5^{\star} 10^{-6}$ & 0,48 & $2,5^{*} 10^{-3}$ & 0,59 & 0,025 & 0,93 \\
\hline $\mathrm{R}^{2}$ & & 0,946 & & 0,931 & & 0,838 \\
\hline $\mathrm{S}_{\text {Cal }}$ & & 0,013 & & 0,009 & & 0,574 \\
\hline
\end{tabular}

Diferencias significativas con $\mathrm{p}$-valor $<0,05$. 
Tabla 4.13. Análisis de varianza y coeficientes de regresión para el modelo polinomio de segundo orden.

\begin{tabular}{c|cc|cc|cc}
\hline \multirow{2}{*}{$\begin{array}{c}\text { Términos } \\
\text { de }\end{array}$} & \multicolumn{5}{c}{ CaLA $_{2}$} \\
\cline { 2 - 7 } regresión & \multicolumn{2}{|c|}{ Elast (-) } & \multicolumn{2}{c}{ Coh (-) } & \multicolumn{2}{c}{ Mast (N) } \\
\cline { 2 - 7 } & $\mathbf{b}$ & $\boldsymbol{p}$-valor & $\mathbf{b}$ & $\boldsymbol{p}$-valor & $\mathbf{b}$ & $\boldsymbol{p}$-valor \\
\hline Constante $\left(\mathrm{b}_{0}\right)$ & 0,943 & & 0,511 & & 7,731 \\
$\mathrm{Ca}$ & $4,9^{*} 10^{-3}$ & 0,28 & $6,7^{*} 10^{-3}$ & 0,11 & $-0,116$ & 0,67 \\
In & $-0,040$ & 0,00 & $-0,026$ & 0,00 & 1,570 & 0,00 \\
$\mathrm{Ca}^{2}$ & $6,0^{*} 10^{-3}$ & 0,32 & $-6^{*} 10^{-3}$ & 0,26 & $-0,282$ & 0,45 \\
In $^{2}$ & $2,6^{*} 10^{-3}$ & 0,66 & $4,4^{*} 10^{-3}$ & 0,39 & 1,324 & 0,01 \\
$\mathrm{Ca}^{*} \ln$ & $-2,5^{*} 10^{-3}$ & 0,66 & $-0,003$ & 0,61 & 0 & 1 \\
$\mathrm{R}^{2}$ & & 0,950 & & 0,927 & & 0,911 \\
$\mathrm{~S}_{\text {Cal }}$ & & 0,011 & & 0,009 & & 0,681 \\
\hline
\end{tabular}

Diferencias significativas con $\mathrm{p}$-valor $<0,05$.

\subsubsection{Humedad de la miga}

En la Figura 4.12 se observan las humedades de las migas frescas de las diferentes formulaciones estudiadas. La miga control fue la más húmeda.

En ausencia de $I n$, un incremento de $\mathrm{CaCO}_{3}$ provocó una disminución en la humedad. En cambio, en presencia de In (1 y 6,5\%) se obtuvieron migas más húmedas con el aumento de nivel de calcio (Figura 4.12.a); pero a niveles elevados de In se obtuvieron las migas menos húmedas sin efecto de la sal. Este fenómeno estaría relacionado con la cantidad de agua agregada y/o la humedad de la masa, que fueron menores a mayor contenido de prebiótico (sección 3.2).

$\mathrm{La} \mathrm{H}$ de las migas obtenidas a partir de panes con sales de calcio orgánicas fueron también menores a la $\mathrm{H}$ de la miga control, pero se observó un comportamiento diferente en presencia de inulina y con el nivel de sal. A In $\leq 6,5 \%$, un aumento de $\mathrm{Ca}_{3} \mathrm{Cl}_{2}$ provocó migas menos húmedas (Figura 4.12.b), a mayores valores de In la humedad disminuyó independientemente del calcio. En el caso de migas con $\mathrm{CaLA}_{2}, \mathrm{H}$ disminuyó solamente con el incremento del prebiótico (Figura 4.12.c).

Esta disminución en la humedad podría ser la responsable de la mayor firmeza de la miga de pan con alto nivel de prebiótico, como se describió en la sección 4.4.3. 

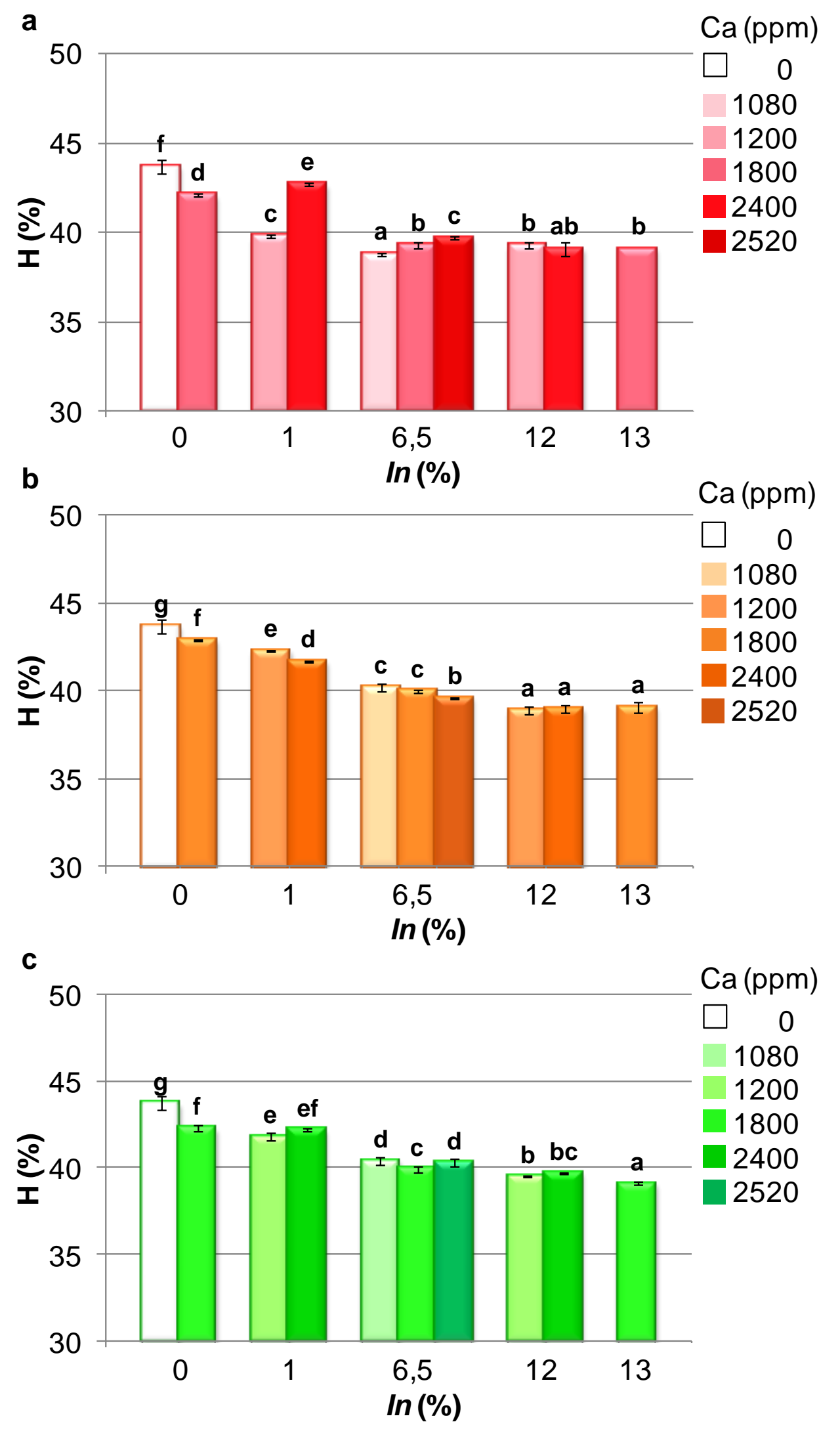

Figura 4.12. Humedad de migas de panes frescos: a) $\mathrm{CaCO}_{3}$, b) $\mathrm{Ca}_{3} \mathrm{Cl}_{2}$, c) $\mathrm{CaLA}_{2}$. Letras diferentes en un mismo gráfico indican diferencias significativas con $p<0,05$. Media \pm desviación estándar. 
En la Figura 4.13 se muestra los gráficos de SR obtenidos para la humedad de las migas. La SR de los panes con $\mathrm{CaCO}_{3}$ fue diferente a las obtenidas con las otras sales de calcio. La $\mathrm{H}$ de las migas con $\mathrm{CaCO}_{3}$ dependió de $\mathrm{Ca}, \mathrm{In}, \mathrm{In}^{2}$ y de la interacción $\mathrm{Ca}^{*}$ In (Figura 4.13.a, Tabla 4.14). En cambio, cuando se empleó CaLA $\mathrm{A}_{2}$ varió en forma inversa con In y directa con $\operatorname{In}^{2}$ (Figura 4.13.b, Tabla 4.14). La SR de la humedad de las migas con $\mathrm{Ca}_{3} \mathrm{Cl}_{2}$ no ajustó con el modelo propuesto.
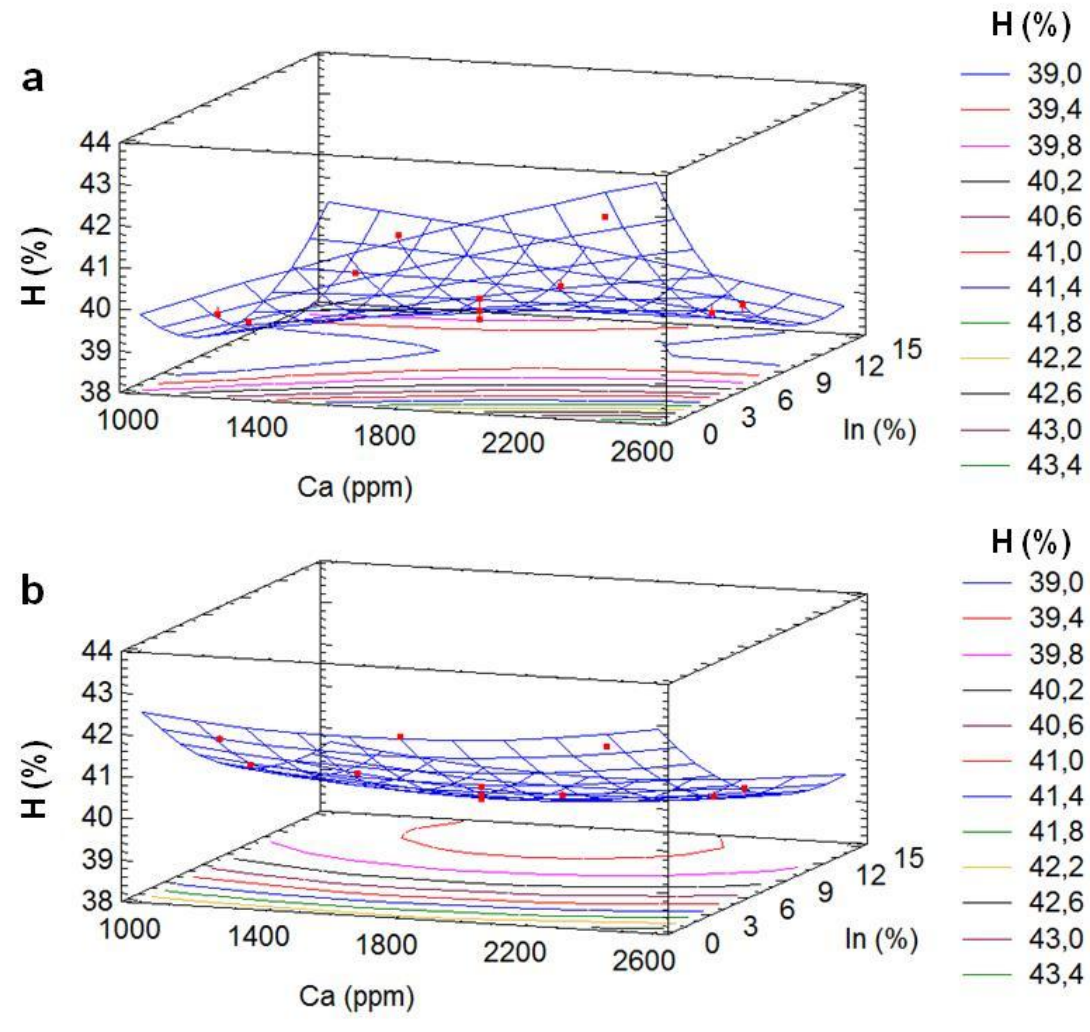

Figura 4.13. $\mathrm{SR}$ de la humedad de las migas de los panes: a) $\mathrm{CaCO}_{3}$, b) $\mathrm{CaLA}_{2}$. Los puntos sobre la SR representan las medias de los valores experimentales obtenidos. Debajo de la SR se visualiza la superficie de contorno. 
Tabla 4.14. Análisis de varianza y coeficientes de regresión para el modelo polinomio de segundo orden.

\begin{tabular}{c|cc|cc}
\hline \multirow{2}{*}{$\begin{array}{c}\text { Términos } \\
\text { de }\end{array}$} & \multicolumn{4}{c}{$\mathbf{H}(\%)$} \\
\cline { 2 - 5 } regresión & \multicolumn{2}{|c|}{$\mathrm{CaCO}_{3}$} & \multicolumn{2}{c}{$\mathrm{CaLA}_{2}$} \\
\cline { 2 - 5 } & $\mathbf{b}$ & $\boldsymbol{p}$-valor & $\mathbf{b}$ & $\boldsymbol{p}$-valor \\
\hline Constante $\left(\mathrm{b}_{0}\right)$ & 39,29 & & 40,02 \\
$\mathrm{Ca}$ & 0,549 & 0,00 & 0,070 & 0,33 \\
In & $-1,119$ & 0,00 & $-1,256$ & 0,00 \\
$\mathrm{Ca}^{2}$ & $-0,011$ & 0,93 & 0,255 & 0,03 \\
In $^{2}$ & 0,927 & 0,00 & 0,498 & 0,00 \\
$\mathrm{Ca}^{*} \ln$ & $-0,775$ & 0,00 & $-0,050$ & 0,58 \\
$\mathrm{R}^{2}$ & & 0,984 & & 0,988 \\
$\mathrm{~S}_{\text {Cal }}$ & & 0,228 & & 0,171 \\
\hline
\end{tabular}

Diferencias significativas cuando $\mathrm{p}$-valor $<0,05$.

\subsubsection{Alveolado de la miga}

La miga es la parte blanda y esponjosa interna del pan. Las características de ésta dependen en gran medida del número de alvéolos y su tamaño. En un pan de buena calidad se espera obtener gran cantidad de alvéolos, de tamaño y distribución homogénea.

En la Tabla 4.15 se muestran las propiedades estructurales de las migas de pan obtenidas por análisis de imagen, evaluadas a través del número de alvéolos $(\mathrm{N})$, área media de los alvéolos (AM) y porcentaje de área ocupada por alvéolos (AT) o fracción de aire. En general los valores AM de las migas resultaron semejantes, por lo que un mayor número de alveolos $(\mathrm{N})$ provocará un mayor porcentaje de aire retenido en la miga.

En ausencia de inulina la miga con $\mathrm{CaCO}_{3}$ presentó menor $\mathrm{N}$ y menor AT que la miga control. A $1 \%$ In, un aumento de calcio disminuyó AM, sin aumentar su número, obteniéndose menor \% aire. A $12 \%$ In, N aumentó con el $\mathrm{Ca}$ y como AM resultó relativamente constante, resultó en un mayor AT; esto es coincidente con una menor firmeza en la miga. 
En los panes elaborados con $\mathrm{Ca}_{3} \mathrm{Cl}_{2}$, el agregado de 1800 ppm Ca en ausencia de In, aumentó el porcentaje de aire retenido (AT), esto podría provocar migas más blandas y esponjosas que la miga control. Con $1 \%$ In, N aumentó y AM disminuyó significativa y considerablemente, es decir se formaron más alvéolos más pequeños. Los panes con $12 \%$ In presentaron menor $\mathrm{N}$ y mayor $\mathrm{AM}$ que los panes con $1 \% \mathrm{In}$, independientemente del calcio agregado; obteniéndose menores valores de $\%$ aire retenido en presencia de alta $I n$; esto podría provocar migas más duras y menos esponjosas.

Todos los panes elaborados con $\mathrm{CaLA}_{2}$ e In presentaron menos porcentaje de aire retenido que la miga control. A $1 \%$ In, un aumento de calcio provocó la formación de menor número de alvéolos $(<\mathrm{N})$ de mayor área $(>\mathrm{AM})$. Aunque el $\mathrm{AT}$ retenido en la miga fue el mismo en ambos casos; el $\mathrm{CaLA}_{2}$ al favorecer menor proporción de alvéolos y más grandes, redundó en una estructura de migas más abierta y por ende menos firme (Figura 4.9).

Tabla 4.15. Parámetros obtenidos del análisis de imagen de las migas.

\begin{tabular}{|c|c|c|c|c|c|c|c|c|c|c|c|}
\hline & & n & & $\mathrm{CaCO}_{3}$ & & & $\mathrm{Ca}_{3} \mathrm{Cl}_{2}$ & & & $\mathrm{CaLA}_{2}$ & \\
\hline & (ppm) & (\%) & $\begin{array}{c}\mathrm{N} \\
\left(\mathrm{cm}^{-2}\right)\end{array}$ & $\begin{array}{c}\mathrm{AM}^{*} 10^{3} \\
\left(\mathrm{~cm}^{2}\right)\end{array}$ & $\begin{array}{l}\text { AT } \\
(\%)\end{array}$ & $\begin{array}{c}\mathrm{N} \\
\left(\mathrm{cm}^{-2}\right)\end{array}$ & $\begin{array}{c}A M^{\star} 10^{3} \\
\left(\mathrm{~cm}^{2}\right)\end{array}$ & $\begin{array}{l}\text { AT } \\
(\%)\end{array}$ & $\begin{array}{c}\mathrm{N} \\
\left(\mathrm{cm}^{-2}\right)\end{array}$ & $\begin{array}{c}\mathrm{AM}^{*} 10^{3} \\
\left(\mathrm{~cm}^{2}\right)\end{array}$ & $\begin{array}{l}\text { AT } \\
(\%)\end{array}$ \\
\hline 1 & 1200 & 1 & $156 d$ & $25 \mathrm{~b}$ & $17 \mathrm{f}$ & $246 d$ & $14 \mathbf{a}$ & $15 \mathbf{c d}$ & $203 e$ & $11 \mathbf{a}$ & 10 bcd \\
\hline 2 & 2400 & 1 & $160 d$ & $19 a$ & $13 \mathrm{de}$ & $226 d$ & $14 \mathbf{a}$ & 14 bcd & $145 d$ & $19 \mathbf{b}$ & $11 \mathrm{bcd}$ \\
\hline 3 & 1200 & 12 & $79 \mathbf{a b}$ & $21 a b$ & $8 \mathrm{abc}$ & $114 \mathbf{a b}$ & $22 \mathbf{b}$ & $11 a$ & 126 bcd & $19 \mathbf{b}$ & 10 bcd \\
\hline 4 & 2400 & 12 & $111 \mathrm{c}$ & $21 a b$ & $11 \mathrm{~cd}$ & $115 a b$ & $23 \mathbf{b}$ & $11 a$ & $130 \mathrm{~cd}$ & $19 \mathbf{b}$ & 10 bcd \\
\hline PC & 1800 & 6,5 & $72 \mathbf{a}$ & $19 a$ & $6 \mathrm{abc}$ & $144 \mathrm{c}$ & $21 \mathrm{~b}$ & $13 a b$ & $104 \mathbf{b}$ & $19 \mathbf{b}$ & $9 a b$ \\
\hline 8 & 1080 & 6,5 & $73 a b$ & $21 a b$ & $7 \mathrm{abc}$ & $104 \mathbf{a}$ & $29 \mathrm{c}$ & 13 abc & $76 \mathbf{a}$ & $21 \mathrm{bc}$ & $7 \mathbf{a}$ \\
\hline 9 & 1800 & 13 & $140 d$ & $22 a b$ & $13 \mathrm{de}$ & $145 c$ & 26 bc & $16 d$ & 116 bcd & $24 \mathrm{c}$ & $13 d$ \\
\hline 10 & 2520 & 6,5 & 101 bc & $21 a b$ & 9 bc & $145 \mathrm{c}$ & $25 \mathrm{bc}$ & $16 \mathbf{c d}$ & $98 a b$ & $25 \mathrm{c}$ & $11 \mathrm{bcd}$ \\
\hline 11 & 1800 & 0 & $112 \mathrm{c}$ & $21 a b$ & $10 \mathrm{~cd}$ & 143 bc & $29 \mathrm{c}$ & 19 e & $123 \mathrm{bcd}$ & 22 bc & 12 cd \\
\hline C & 0 & 0 & $138 d$ & $25 \mathrm{~b}$ & 15 ef & 138 bc & $25 \mathrm{bc}$ & 15 cd & $138 d$ & $25 \mathrm{c}$ & $15 \mathrm{e}$ \\
\hline
\end{tabular}

Letras diferentes en una misma columna indican diferencias significativas con $p<0,05$.

El pan no solamente debe tener buena calidad cuando está recién elaborado o fresco, sino también debería mantener esa calidad en el tiempo, por lo que resulta importante evaluar la influencia de las sales de calcio y del prebiótico en la perdurabilidad de dicha calidad cuando el pan es almacenado algunos días a temperatura ambiente. 


\subsection{Estabilidad de los panes frente al almacenamiento}

Se estudiaron los cambios en la calidad panadera luego del almacenamiento a 1 y 3 días. Se evaluó, como se describió anteriormente, la firmeza de la miga de los panes a través de un análisis de perfil de textura de la miga (sección 2.2.11.1) y la humedad (sección 2.2.11.3). Para comprender el efecto de los ingredientes nutricionales (calcio e inulina) en el proceso de envejecimiento del pan, algunas de las formulaciones (C, 1 , 2, 3 y 4) se almacenaron hasta 7 días. De las curvas de firmeza en función del tiempo de almacenamiento, aplicando el modelo de Avrami (Armero y Collar, 1998) se estudió el efecto de la sal de calcio e inulina sobre la recristalización del almidón, uno de los principales procesos responsables del envejecimiento del pan. Por otro lado se determinó la cristalinidad de la miga del pan fresco (día 0) y al quinto día (día 5) empleando difractometría de rayos $X$ (DRX). Por medio de calorimetría diferencial de barrido (DSC), se simuló la cocción de la masa en una capsula de DSC y se almacenó en cámara de $20^{\circ} \mathrm{C}$ durante 3,5 y 7 días como se describió anteriormente (sección 2.2.11.4).

\subsubsection{Firmeza de la miga durante el almacenamiento}

La pérdida de frescura del pan durante el almacenamiento disminuye la aceptabilidad por parte de los consumidores. Este fenómeno se conoce como envejecimiento del pan e incluye los siguientes procesos: endurecimiento de la miga, pérdida de crujibilidad de la corteza y deterioro de las propiedades organolépticas (Cauvain, 1998). En la Figura 4.14 se observan los diferentes perfiles de textura obtenidos a partir de miga de pan fresco y de panes almacenados. En todos los gráficos se destaca la ausencia del área negativa correspondiente a la adhesividad. 


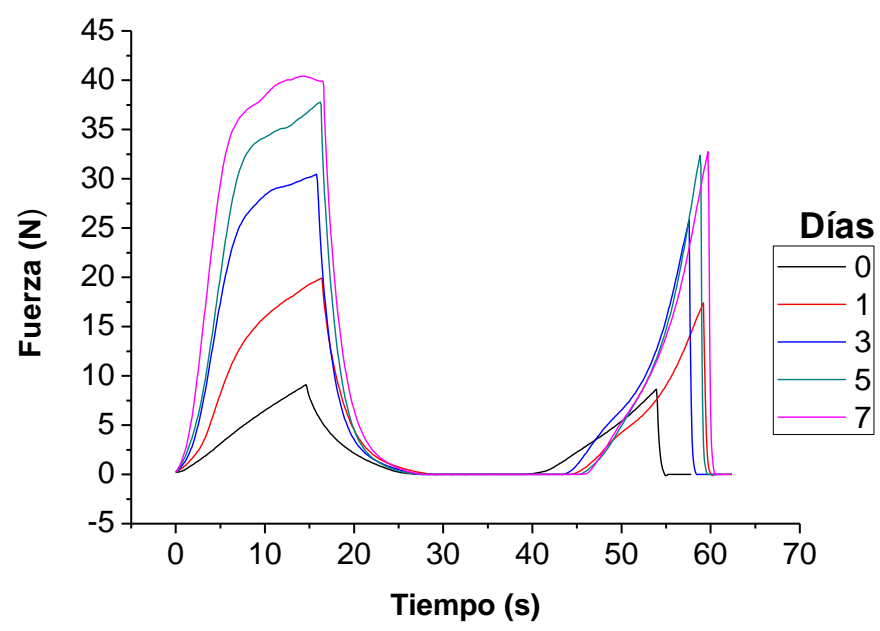

Figura 4.14. Perfiles de texturas de rodajas de panes frescos (0) y almacenados durante 1, 3, 5 y 7 días.

La firmeza (fuerza máxima del primer pico) es un descriptor usado para determinar los cambios en la dureza de la miga a través del tiempo. Como puede observarse en la Figura 4.14, con el almacenamiento se incrementa este parámetro como consecuencia de la pérdida de humedad y la retrogradación del almidón (Pateras, 1998).

En la Figura 4.15 se graficaron los valores de firmeza de las migas de los panes frescos con $\mathrm{CaCO}_{3}$ (Día 0) y luego de almacenarlos durante 1 (Día 1) y 3 (Día 3) días a $20^{\circ} \mathrm{C}$. Para una mejor comprensión del gráfico, vale destacar que se mantuvo la misma convención de color e intensidad de color que la de los gráficos de los capítulos anteriores, es decir, un aumento en la intensidad, con el incremento del nivel de calcio. En todas las formulaciones, la firmeza aumentó significativamente con el periodo de almacenamiento. En ausencia de In, el agregado de $\mathrm{CaCO}_{3}$ no provocó cambios en la firmeza de la miga, sin embargo luego de 3 días de almacenamiento, la miga con mayor cantidad de calcio resultó más blanda que la miga control, por lo que el agregado de calcio parecería retardar algunos de los procesos de envejecimiento del pan. 


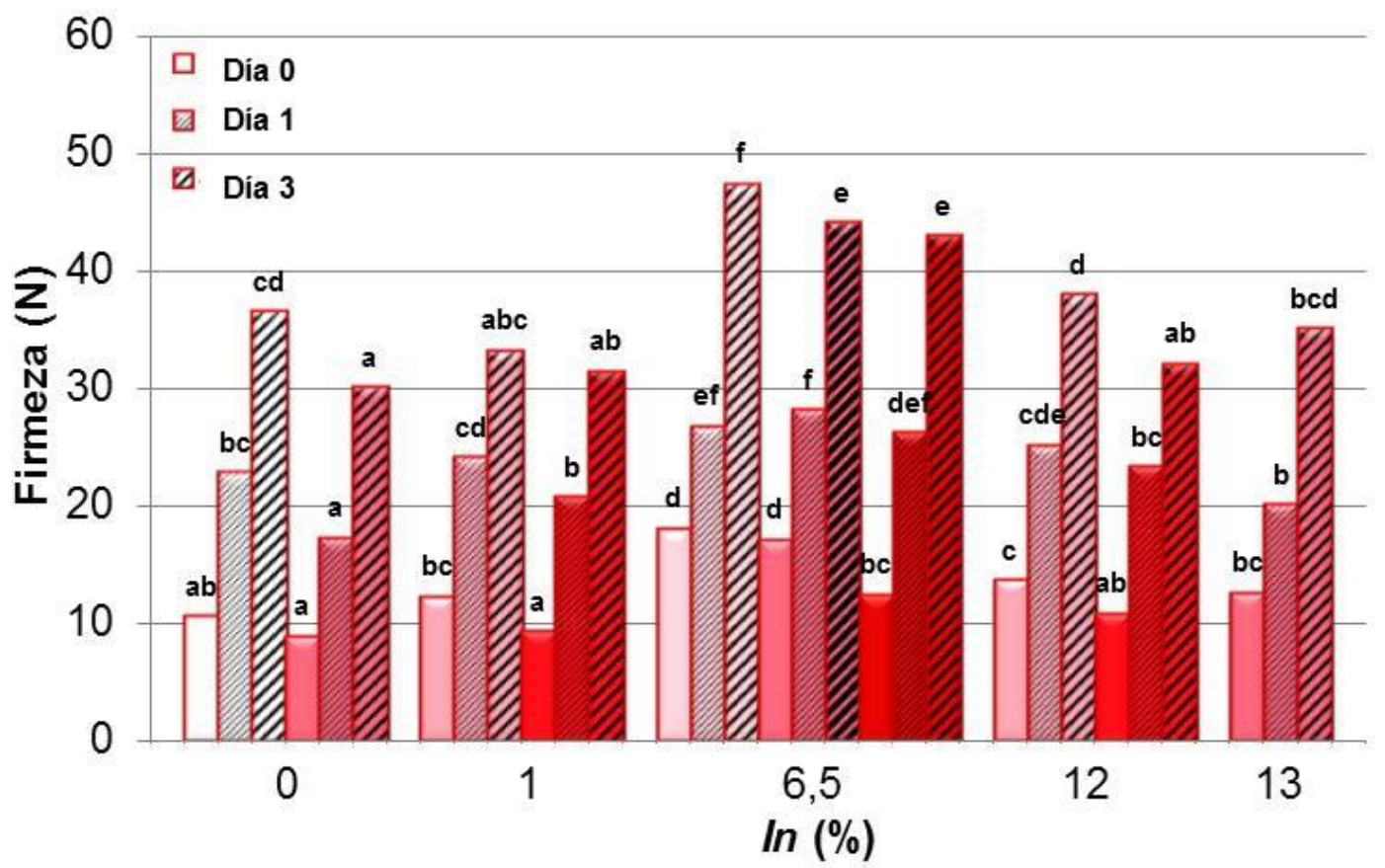

Figura 4.15. Firmeza de la miga de los panes con $\mathrm{CaCO}_{3}$ frescos y almacenados. Letras diferentes indican diferencias significativas para igual día de almacenamiento $(p<0,05)$.

La firmeza de la miga de los panes con sales de calcio orgánicas se muestra en la Figura 4.16. La dureza de las migas, como era esperable, aumentó significativamente con los días de almacenamiento. En la Figura 4.16.a, la principal diferencia observada es a $12 \%$ In, a pesar de que un aumento de $\mathrm{Ca}_{3} \mathrm{Cl}_{2}$ ablanda la miga fresca, no modificó el valor de firmeza al tercer día, siendo este considerablemente superior al del resto de las formulaciones. En general, las migas frescas más blandas fueron también las menos duras al tercer día de almacenamiento; y las formulaciones que más resistieron el aumento de dureza fueron las que contenían 1\% de inulina.

La firmeza de la miga de los panes con $\mathrm{CaLA}_{2}$ (Figura 4.16.b) almacenados resultó muy superior a la de los panes con $\mathrm{Ca}_{3} \mathrm{Cl}_{2}$. A 6,5\% de In no hubo diferencias significativas en la firmeza con el nivel de $\mathrm{CaLA}_{2}$ (día 0 y 1 ), sin embargo al tercer día de almacenamiento aumentó significativamente con 2520 ppm de Ca. 


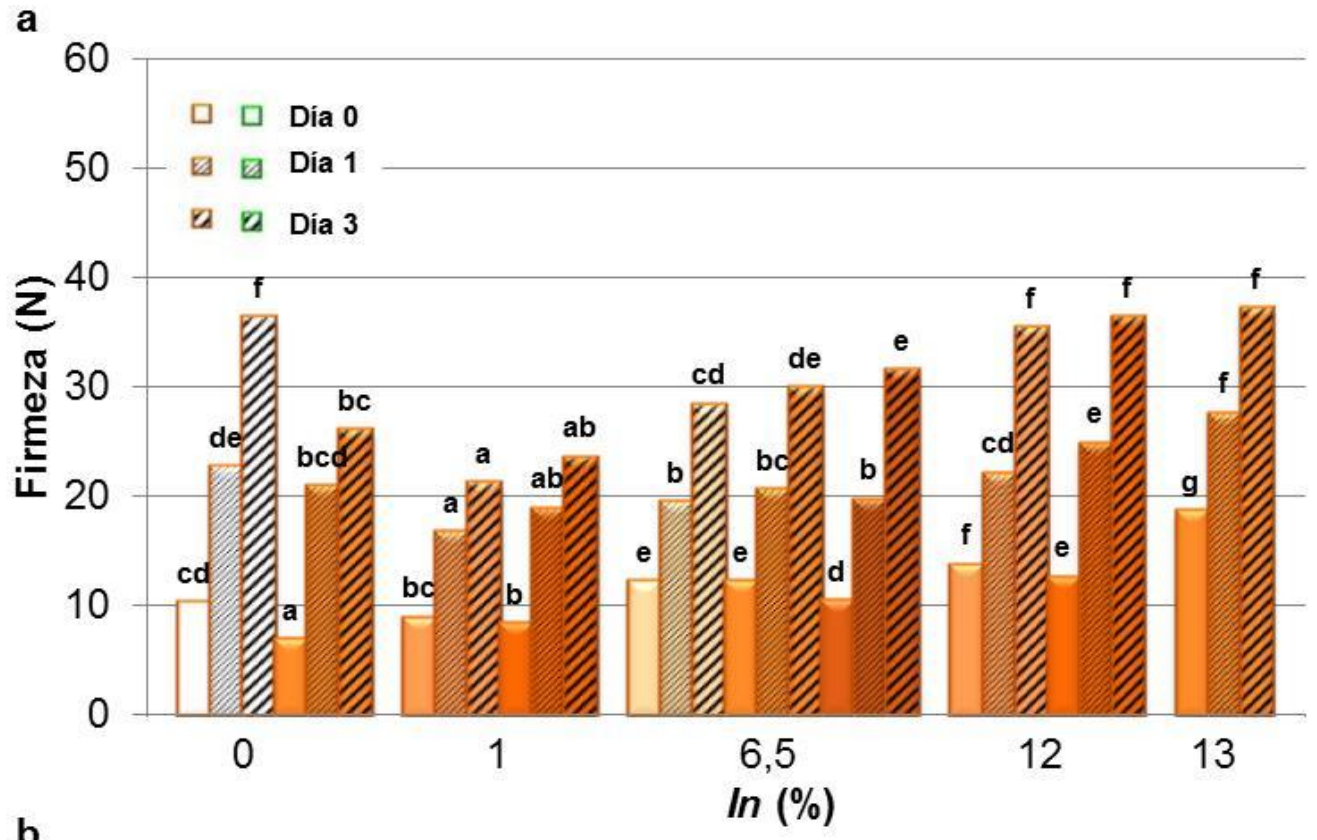

b

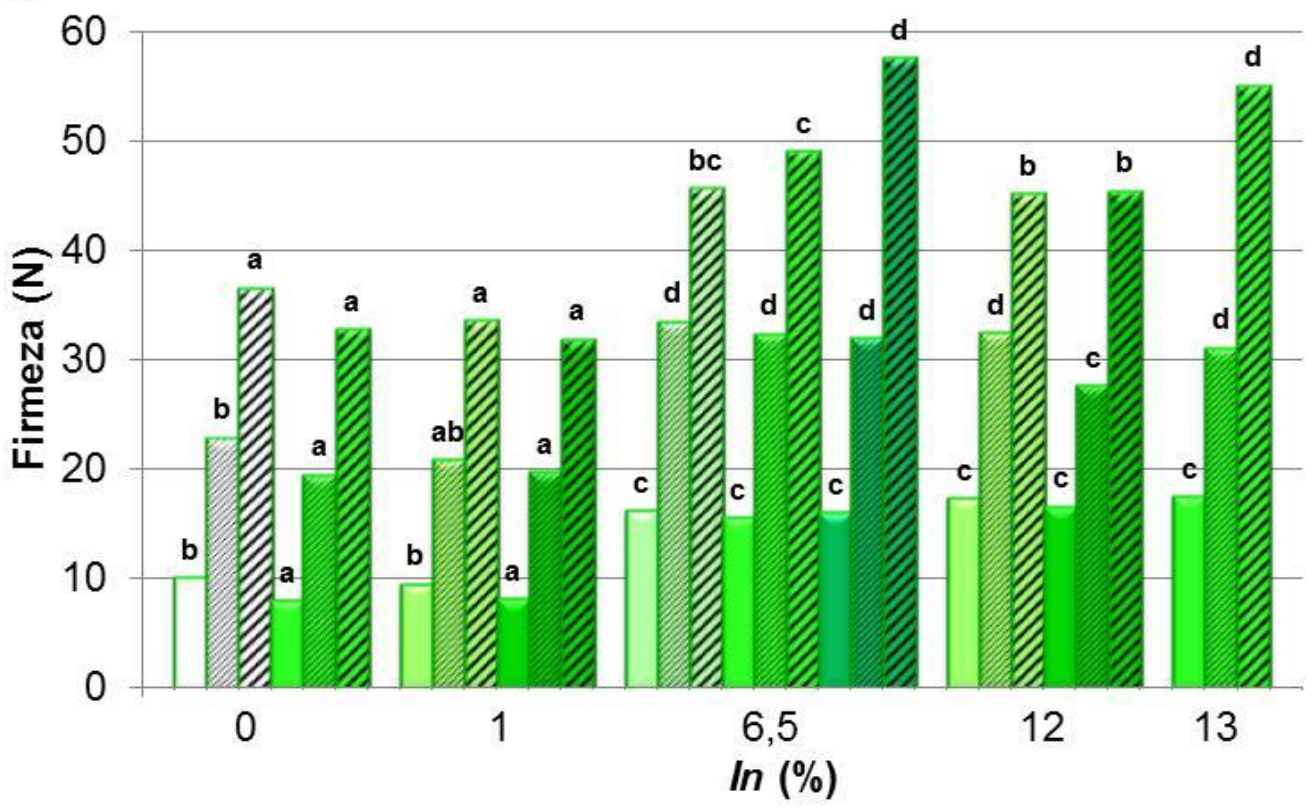

Figura 4.16. Firmeza de la miga de los panes frescos y almacenados. a) $\mathrm{Ca}_{3} \mathrm{Cl}_{2}$, b) $\mathrm{CaLA}_{2}$. Letras diferentes indican diferencias significativas para igual día de almacenamiento en un mismo gráfico $(p<0,05)$.

Para poder visualizar más claramente el efecto combinado de ambos aditivos, se calculó utilizando los valores promedios, el incremento de firmeza durante el almacenamiento respecto a la firmeza original y se expresó en porcentaje (Tabla 4.16). También se calculó la pérdida de elasticidad y cohesividad y el incremento de masticabilidad. 
Si comparamos la formulación $\mathrm{C}$ con CA11, confirmamos que la presencia de calcio en ausencia de In incrementa menos la firmeza luego de almacenar durante 3 días el pan. En presencia de $I n$, el agregado de $\mathrm{CaCO}_{3}$ provocó los mayores incrementos de firmeza (a igual inulina) y masticabilidad. El pan con menor aumento de firmeza al cabo de 3 días fue el del punto central (1800 ppm Ca, 6,5\% In). También resultó el de menor variación de elasticidad y cohesividad. La miga control fue la que menos elasticidad perdió. La pérdida de cohesividad fue similar en todas las formulaciones.

Cuando analizamos los cambios ocurridos en los parámetros texturales de las migas con sales de calcio orgánicas durante el almacenamiento se pueden distinguir varias tendencias. Se observó un incremento de la dureza con el agregado de $\mathrm{Ca}_{3} \mathrm{Cl}_{2}$, tanto en ausencia como en presencia de In (Tabla 4.16). Todas las migas disminuyeron su cohesividad en porcentaje similar al tercer día de almacenamiento, excepto la miga con el máximo contenido de calcio ( $\mathrm{Cl} 10)$ que fue la miga que presentó menos integración entre partículas, o sea, se desgranó más. Las migas con mayor incremento de la masticabilidad fueron las que no contenían In, en cambio, la miga con $13 \%$ In fue la que mejor mitigó los cambios en firmeza y masticabilidad durante el almacenamiento.

El incremento de la firmeza de la miga en ausencia de In resultó mayor con el agregado de $\mathrm{CaLA}_{2}$ (Tabla 4.16). En presencia de In también el aumento de esta sal provocó un mayor incremento de la firmeza (a igual concentración de In). Comparando las migas con 1800 ppm Ca, se puede observar que un mayor nivel de In amortiguó más el incremento de firmeza y masticabilidad, parámetros que presentaron la misma tendencia.

El $\mathrm{Ca}_{3} \mathrm{Cl}_{2}$ fue la sal que más soslayó los incrementos en la firmeza y masticabilidad de las migas. 
Tabla 4.16. Cambios en algunos de los parámetros de textura de la miga de pan durante el almacenamiento.

\begin{tabular}{|c|c|c|c|c|c|c|c|c|c|c|}
\hline & \multirow{2}{*}{\multicolumn{2}{|c|}{$\begin{array}{cc}\mathrm{Ca} & \mathrm{In} \\
(\mathrm{ppm}) & (\%)\end{array}$}} & \multicolumn{2}{|c|}{$\Delta$ Firm (\%) } & \multicolumn{2}{|c|}{$\Delta$ Mastic (\%) } & \multicolumn{2}{|c|}{$\Delta$ Elast (\%) } & \multicolumn{2}{|c|}{$\Delta$ Cohes $(\%)$} \\
\hline & & & Dĺa 1 & Día 3 & Dĺa 1 & Día 3 & Día 1 & Día 3 & Día 1 & Día 3 \\
\hline CA1 & 1200 & 1 & 98 & 173 & 44 & 52 & -6 & -11 & -23 & -38 \\
\hline CA2 & 2400 & 1 & 126 & 244 & 63 & 88 & -7 & -12 & -23 & -38 \\
\hline CA3 & 1200 & 12 & 86 & 181 & 18 & 53 & -10 & -12 & -29 & -38 \\
\hline CA4 & 2400 & 12 & 117 & 199 & 56 & 57 & -8 & -15 & -21 & -38 \\
\hline PC & 1800 & 6,5 & 65 & 159 & 34 & 60 & -2 & -9 & -16 & -33 \\
\hline CA8 & 1080 & 6,5 & 49 & 164 & 6 & 54 & -5 & -10 & -25 & -35 \\
\hline CA9 & 1800 & 13 & 60 & 181 & 1 & 51 & -12 & -15 & -28 & -37 \\
\hline CA10 & 2520 & 6,5 & 112 & 248 & 45 & 91 & -6 & -12 & -27 & -38 \\
\hline CA11 & 1800 & 0 & 95 & 241 & 66 & 92 & -4 & -13 & -12 & -36 \\
\hline Cl1 & 1200 & 1 & 87 & 137 & 35 & 39 & -8 & -12 & -22 & -34 \\
\hline $\mathrm{Cl} 2$ & 2400 & 1 & 108 & 181 & 49 & 69 & -7 & -10 & -22 & -33 \\
\hline $\mathrm{Cl} 3$ & 1200 & 12 & 60 & 157 & 25 & 34 & -2 & -17 & -20 & -37 \\
\hline $\mathrm{Cl} 4$ & 2400 & 12 & 97 & 188 & 39 & 41 & -9 & -17 & -22 & -41 \\
\hline PC & 1800 & 6,5 & 68 & 144 & 19 & 30 & -9 & -12 & -23 & -39 \\
\hline $\mathrm{Cl} 8$ & 1080 & 6,5 & 59 & 132 & 15 & 27 & -8 & -11 & -21 & -38 \\
\hline Cl9 & 1800 & 13 & 48 & 99 & 4 & 24 & -10 & -9 & -22 & -31 \\
\hline Cl10 & 2520 & 6,5 & 88 & 200 & 31 & 53 & -8 & -11 & -24 & -43 \\
\hline Cl11 & 1800 & 0 & 190 & 273 & 110 & 114 & -8 & -12 & -21 & -35 \\
\hline LA1 & 1200 & 1 & 121 & 257 & 72 & 103 & -5 & -12 & -18 & -35 \\
\hline LA2 & 2400 & 1 & 145 & 299 & 92 & 133 & -5 & -10 & -17 & -35 \\
\hline LA3 & 1200 & 12 & 87 & 161 & 39 & 45 & -7 & -15 & -20 & -35 \\
\hline LA4 & 2400 & 12 & 67 & 175 & 10 & 72 & -12 & -6 & -26 & -34 \\
\hline PC & 1800 & 6,5 & 110 & 243 & 49 & 99 & -7 & -11 & -25 & -36 \\
\hline LA8 & 1080 & 6,5 & 107 & 183 & 46 & 63 & -7 & -10 & -24 & -36 \\
\hline LA9 & 1800 & 13 & 78 & 216 & 27 & 85 & -10 & -9 & -21 & -36 \\
\hline LA10 & 2520 & 6,5 & 100 & 262 & 38 & 111 & -10 & -10 & -24 & -35 \\
\hline LA11 & 1800 & 0 & 148 & 317 & 91 & 161 & -5 & -5 & -19 & -34 \\
\hline C & 0 & 0 & 119 & 250 & 72 & 113 & -2 & -7 & -23 & -37 \\
\hline
\end{tabular}




\subsubsection{Envejecimiento del pan. Modelo de Avrami}

Las primeras investigaciones sobre la aplicación del modelo de Avrami en la cinética de endurecimiento de migas, mostró que el exponente de Avrami $n$ era cercano a uno (Ec. 2.34). Zobel y Kulp (1996) encontraron exponentes de Avrami diferentes de uno, llegaron a la conclusión que el aumento de firmeza durante el envejecimiento del pan no sólo es el resultado de la retrogradación de la amilopectina sino también de varios factores al mismo tiempo, como la difusión de la humedad entre la miga y la corteza, y las interacciones almidón-gluten.

En una matriz alimentaria tan compleja como el pan, el modelo de Avrami pierde la mayor parte de su significado físico, sin embargo sigue siendo un modelo matemático útil para describir la cinética de envejecimiento debido a que se ajusta a los datos observados. Para poder aplicar este modelo, se regresionó la firmeza en función del tiempo de almacenamiento con la ecuación exponencial de primer orden (Capítulo 2). Se puede observar en la Figura 4.17 que la firmeza aumentó en forma sostenida con 7 días de almacenamiento, a excepción de la miga $\mathrm{C}$ que alcanzó un plateau a los 5 días. La Firmeza de las migas con $\mathrm{CaCO}_{3}$ de todas las formulaciones estudiadas aumentó en forma similar (Figura 4.17.a). La Firmeza de las migas con sales de calcio orgánica en presencia de alto prebiótico aumentó más que a bajo prebiótico, alcanzando mayor Firmeza al final de la experiencia en presencia de $\mathrm{CaLA}_{2}$ (Figuras 4.17.b y $4.17 . c)$.

Del modelo se evaluó la fracción de recristalinización $(\theta)$ en función del tiempo (Figura 4.18) y se calcularon la constante de velocidad $(k)$ y la relación nucleación/crecimiento de los cristales $(n)$ que se muestran en la Tabla 4.17.

La retrogradación del almidón es un proceso de cristalización que se inicia con núcleos formados espontáneamente y a partir de los cuales los cristales crecen a lo largo de estos núcleos; en estas condiciones el exponente $n$ de Avrami es igual a uno. En nuestro caso, en general los coeficientes $n$ obtenidos fueron diferentes de 1 (Tabla 4.17), sugiriendo que la recristalización del almidón no es la única causa responsable del envejecimiento del pan. 

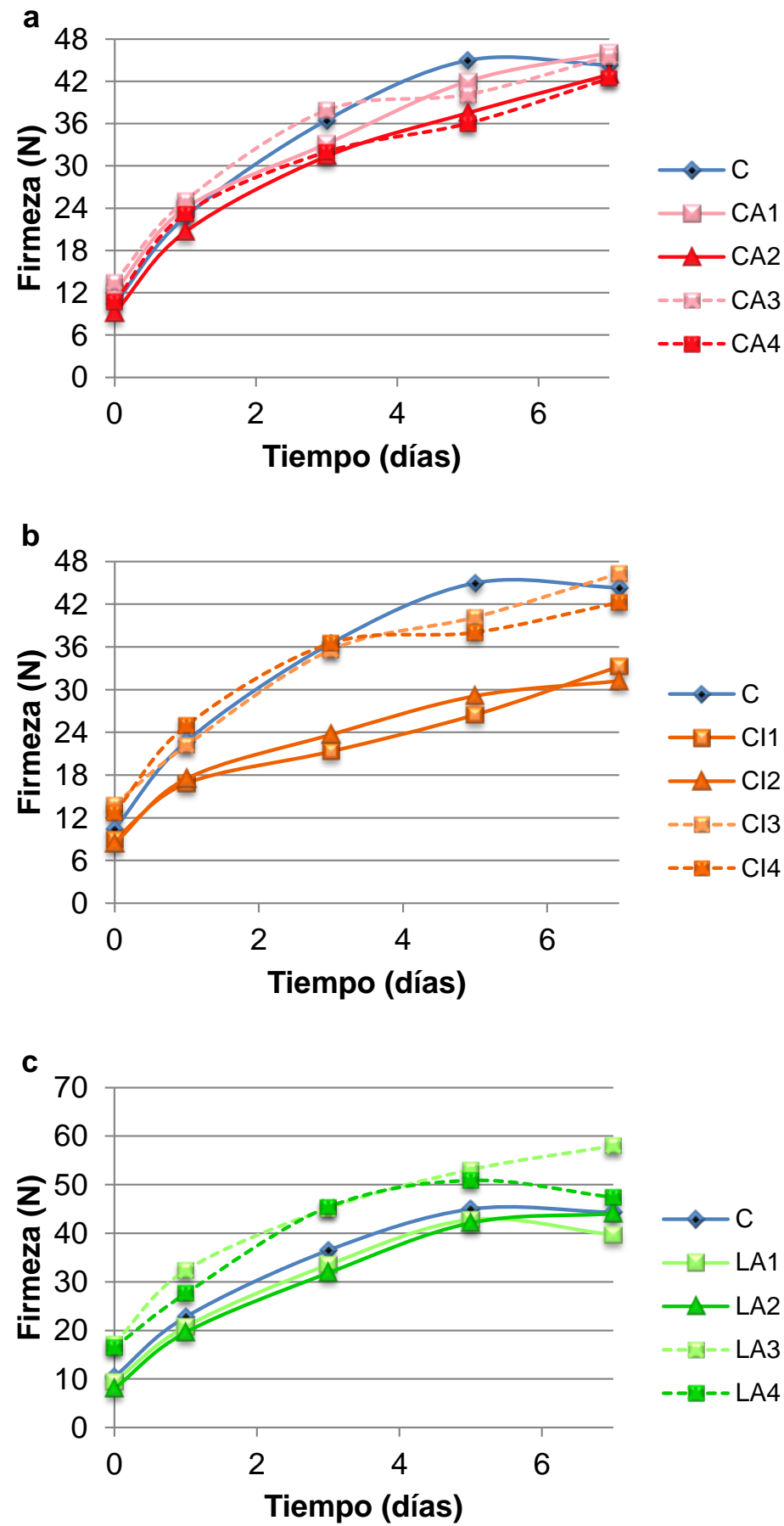

Figura 4.17. Firmeza de la miga de los panes frescos y almacenados. a) $\mathrm{CaCO}_{3}$, b) $\mathrm{Ca}_{3} \mathrm{Cl}_{2}, \mathbf{c}$ ) $\mathrm{CaLA}_{2}$. 

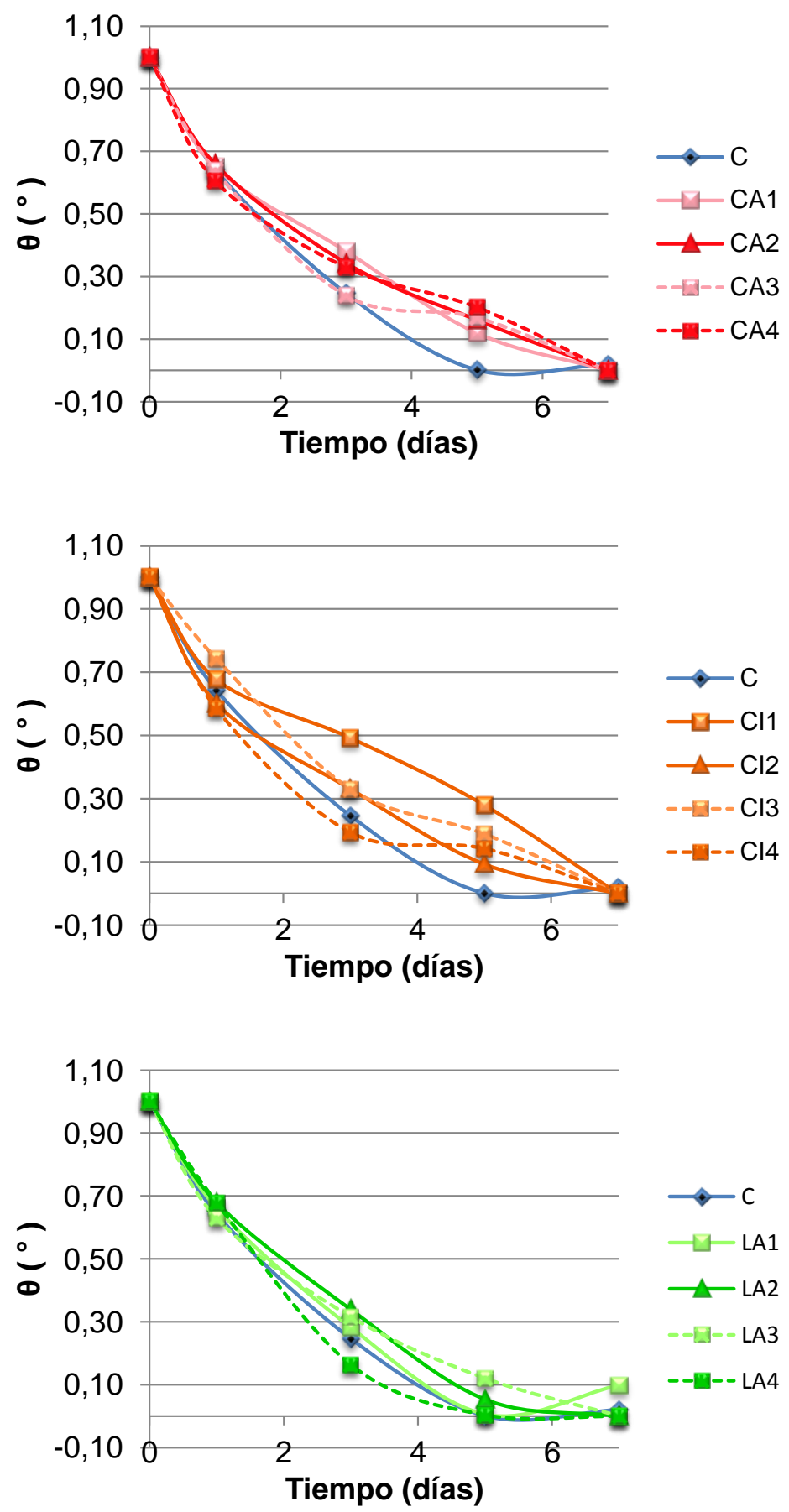

Figura 4.18. Theta en función del tiempo de almacenamiento: a) $\mathrm{CaCO}_{3}$, b) $\mathrm{Ca}_{3} \mathrm{Cl}_{2}$, c) $\mathrm{CaLA}_{2}$.

La constante de velocidad, $k$, a alto calcio y alta inulina resultó baja para carbonato y citrato y mayor en el caso del lactato, siendo para esta última formulación mayor la velocidad de crecimiento de los cristales (Tabla 4.17) y por lo tanto, envejece más rápido que los panes con la misma formulación pero diferente tipo de sal de calcio $\left(\mathrm{CaCO}_{3}\right.$ y $\left.\mathrm{Ca}_{3} \mathrm{Cl}_{2}\right)$. 
Tabla 4.17. Coeficientes de regresión de Avrami.

\begin{tabular}{c|cc|ccc}
\hline & $\begin{array}{c}\text { Ca } \\
(\mathbf{p p m})\end{array}$ & $\begin{array}{c}\mathbf{I n} \\
(\%)\end{array}$ & $\begin{array}{c}\boldsymbol{n} \\
\mathbf{( - )}\end{array}$ & $\begin{array}{c}\mathbf{k} \\
\left(\mathbf{d i ́}^{-1} \mathbf{)}\right)\end{array}$ & $\mathbf{r}^{\mathbf{2}}$ \\
\hline CA1 & 1200 & 1 & 0,3943 & 0,9463 & 0,987 \\
CA2 & 2400 & 1 & 0,4073 & 0,9104 & 0,999 \\
CA3 & 1200 & 12 & 0,4726 & 0,9047 & 0,993 \\
CA4 & 2400 & 12 & 0,5015 & 0,7221 & 0,999 \\
\hline Cl1 & 1200 & 1 & 0,4787 & 0,8849 & 0,990 \\
CI2 & 2400 & 1 & 0,3160 & 1,0766 & 0,997 \\
Cl3 & 1200 & 12 & 0,5606 & 0,8690 & 0,993 \\
Cl4 & 2400 & 12 & 0,5015 & 0,7221 & 0,999 \\
\hline LA1 & 1200 & 1 & 0,3833 & 1,2124 & 0,989 \\
LA2 & 2400 & 1 & 0,3545 & 1,1456 & 0,988 \\
LA3 & 1200 & 12 & 0,4479 & 0,9166 & 0,999 \\
LA4 & 2400 & 12 & 0,3851 & 1,4322 & 0,999 \\
\hline C & 0 & 0 & 0,4197 & 1,2018 & 0,992 \\
\hline
\end{tabular}

\subsubsection{Humedad de la miga durante el almacenamiento}

La humedad de las migas tanto de los panes frescos como almacenados se muestra en la Figura 4.19. Hubo una pérdida sustancial y significativa de humedad en todas las migas al cabo de 3 días de almacenamiento. El comportamiento de los panes con $\mathrm{CaCO}_{3}$ (Figura 4.19.a) y $\mathrm{CaLA}_{2}$ (Figura 4.19.c) fue, al cabo de ese período, significativamente diferente al obtenido con $\mathrm{Ca}_{3} \mathrm{Cl}_{2}$ (Figura 4.19.b).

En el caso de las dos primeras sales, no se observaron prácticamente diferencias significativas con el nivel de calcio, pero sí con el de inulina, presentando las migas con prebiótico menor humedad durante el almacenamiento. En ausencia de In, la miga fresca con $\mathrm{CaCO}_{3}$ fue menos húmeda que la control (Figura 4.19.a), como ya habíamos descripto en la sección 4.4.4, sin embargo al día 3 de almacenamiento, si bien las $\mathrm{H}$ fueron menores, no se registraron diferencias significativas. Este comportamiento sugiere que la muestra con esta sal pierde menos agua (Tabla 4.18); hecho que concuerda con los menores valores de masticabilidad en presencia de carbonato de calcio. 

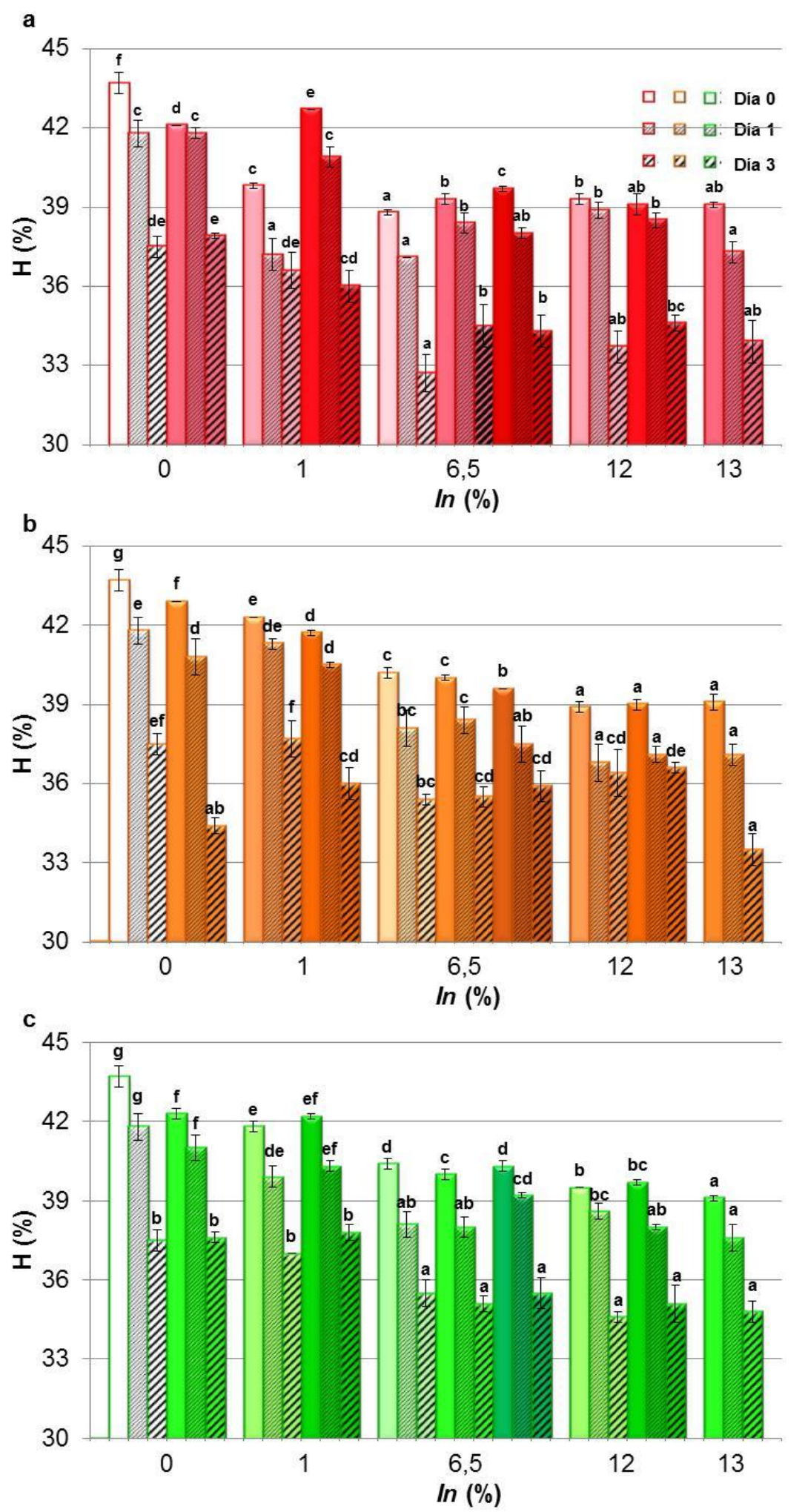

Figura 4.19. Humedad de la miga de los panes frescos y almacenados: a) $\mathrm{CaCO}_{3}$, b) $\mathrm{Ca}_{3} \mathrm{Cl}_{2}$, c) $\mathrm{CaLA}_{2}$. Letras diferentes indican diferencias significativas para igual día de almacenamiento en un mismo gráfico $(p<0,05)$. 
En cambio, en las migas frescas con $1 \%$ In, un aumento de calcio provocó migas más húmedas, cuya pérdida de agua fue mayor luego de 3 días de almacenamiento (Tabla 4.18). En el caso de los panes con $\mathrm{CaLA}_{2}$ el contenido de humedad resultó dependiente de la inulina. Los panes con alta In fueron los menos húmedos (a igual día de almacenamiento) e independiente del calcio agregado. El porcentaje de pérdida de agua fue similar en todos los casos.

Sin inulina las migas con $\mathrm{Ca}_{3} \mathrm{Cl}_{2}$ perdieron mucha mayor cantidad de agua luego de 3 días, comportamiento ligado al mayor incremento en la firmeza. Esta sal de calcio estaría ejerciendo alguna modificación en los componentes de la miga que provoca que el agua se pierda más fácilmente disminuyendo la vida útil. $\mathrm{A}$ 6,5\% In, el $\mathrm{Ca}_{3} \mathrm{Cl}_{2}$ logró mitigar la pérdida de humedad a niveles altos (2520 ppm Ca). A $12 \%$ In, el $\mathrm{Ca}_{3} \mathrm{Cl}_{2}$ ya no tuvo efecto en la humedad, sugiriendo que la inulina controla la pérdida de humedad más que la sal de calcio. En este mismo sentido, a igual contenido de $\mathrm{Ca}_{3} \mathrm{Cl}_{2}$, una mayor inulina derivó en menor pérdida de humedad de la miga.

Tabla 4.18. Cambios en la humedad de la miga durante el almacenamiento de los panes.

\begin{tabular}{|c|c|c|c|c|c|c|c|c|}
\hline & \multirow{3}{*}{$\begin{array}{c}\mathrm{Ca} \\
(\mathrm{ppm})\end{array}$} & \multirow{3}{*}{$\begin{array}{l}\text { In } \\
(\%)\end{array}$} & \multicolumn{6}{|c|}{$\Delta \mathrm{H}(\%)$} \\
\hline & & & \multicolumn{2}{|c|}{$\mathrm{CaCO}_{3}$} & \multicolumn{2}{|c|}{$\mathrm{Ca}_{3} \mathrm{Cl}_{2}$} & \multicolumn{2}{|c|}{$\mathrm{CaLA}_{2}$} \\
\hline & & & Día 1 & Día 3 & Día 1 & Día 3 & Día 1 & Día 3 \\
\hline 1 & 1200 & 1 & -6 & -8 & -2 & -11 & -5 & -11 \\
\hline 2 & 2400 & 1 & -4 & -16 & -3 & -14 & -5 & -10 \\
\hline 3 & 1200 & 12 & -1 & -14 & -5 & -6 & -2 & -12 \\
\hline 4 & 2400 & 12 & -1 & -11 & -5 & -6 & -4 & -12 \\
\hline PC & 1800 & 6,5 & -2 & -12 & -4 & -11 & -5 & -12 \\
\hline 8 & 1080 & 6,5 & -4 & -16 & -5 & -12 & -6 & -12 \\
\hline 9 & 1800 & 13 & -5 & -13 & -5 & -14 & -4 & -11 \\
\hline 10 & 2520 & 6,5 & -4 & -14 & -5 & -9 & -3 & -12 \\
\hline 11 & 1800 & 0 & -1 & -10 & -5 & -20 & -3 & -11 \\
\hline C & 0 & 0 & -4 & -14 & -4 & -14 & -4 & -14 \\
\hline
\end{tabular}

Los cambios en las propiedades físicas de los panes debido al almacenamiento están estrechamente relacionados con los cambios estructurales de sus componentes, principalmente del almidón. Por esta razón se decidió evaluar la influencia de las sales de calcio e inulina en el fenómeno de retrogradación del almidón.

\subsubsection{Retrogradación del almidón}




\section{Calorimetría diferencial de barrido. DSC}

El almidón gelatinizado no se encuentra en equilibrio termodinámico, por lo tanto, con el tiempo se produce una progresiva reasociación de las moléculas de almidón (Eliasson y Gudmundsson, 1996). A esta recristalización se la conoce con el nombre de retrogradación y puede disminuir la digestibilidad del almidón. La retrogradación de la amilopectina es un fenómeno a largo plazo que se produce en forma gradual con el almacenamiento de los productos amiláceos y está directamente relacionada con el envejecimiento del pan. Sin embargo, la amilosa se reasocia más rápidamente que la amilopectina. Con el objetivo de analizar el proceso de retrogradación del almidón, las muestras horneadas en el DSC fueron sometidas a un segundo ensayo calorimétrico luego del almacenamiento. La estructura cristalina de la amilopectina retrogradada se pierde después del recalentamiento a aproximadamente $70^{\circ} \mathrm{C}$, en cambio para fundir la amilosa retrogradada se requieren mayores temperaturas, por lo que por medio de esta técnica evaluamos el efecto de los ingredientes nutricionales sobre la retrogradación de la amilopectina (Miles y col., 1985).

En la Figura 4.20 se observa a modo de ejemplo los termogramas de las masas gelatinizadas y almacenadas durante 3,5 y 7 días. En el rango de temperatura seleccionado se observa un único pico de gelatinización, además a medida que aumenta el tiempo de almacenamiento el área de pico es cada vez más grande.

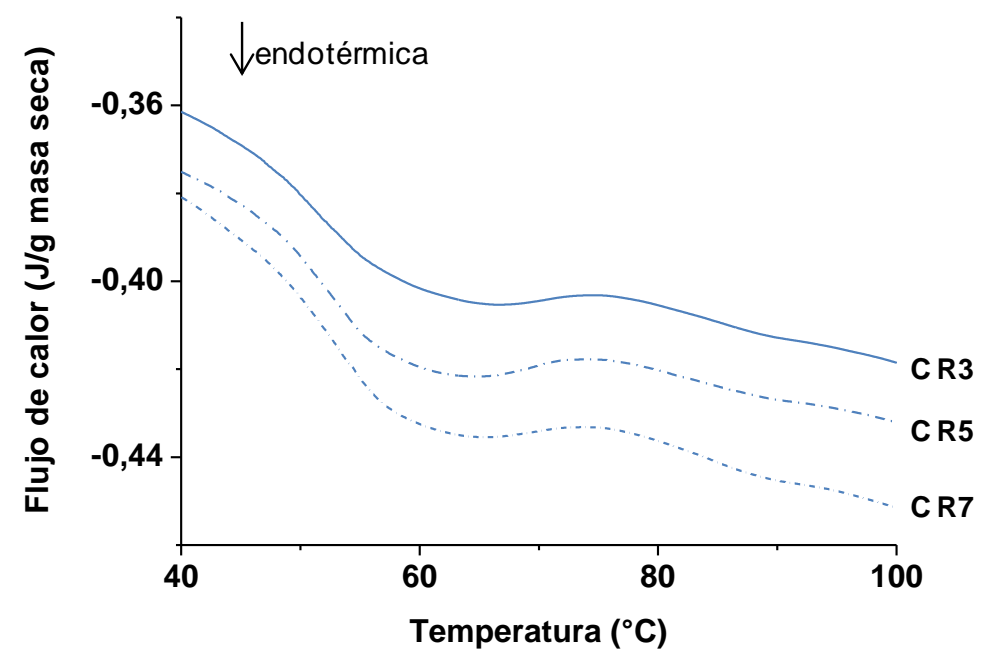

Figura. 4.20. Termograma de la masa control previamente gelatinizada y luego de almacenarla durante 3,5 y 7 días a $20^{\circ} \mathrm{C}$. 
El análisis de las temperaturas de gelatinización permite establecer el efecto de las diferentes sales y la inulina durante el almacenamiento. En la Tabla 4.19 se muestran los valores de temperatura de inicio $\left(T_{0}\right)$, promedio o de pico $\left(T_{p}\right)$, final $\left(T_{f}\right)$ y la variación de entalpia de la masa que fuera previamente gelatinizada (Día 0), evaluada luego de su almacenamiento (Días 3, 5 y 7). Una masa recién gelatinizada, a la que se le hace inmediatamente una nueva corrida de DSC no presenta termograma con picos detectables.

Las temperaturas de inicio $\left(\mathrm{T}_{0}\right)$ de la retrogradación de las masas cocidas almacenadas se corrieron hacia menores valores, comparadas con las obtenidas durante la gelatinización de la masa fresca (sección 4.2.1). Este parámetro no se modificó sustancialmente con los días de almacenamiento ni con el tipo de sal. La endoterma de retrogradación presentó temperaturas de pico $T_{p}$ de alrededor de $65 \stackrel{\circ}{ } \mathrm{C}$ con sal y alta inulina (12\%), siguiendo el mismo comportamiento que $T_{0}$ con los días y el tipo de sal (Tabla 4.19).

El grado de retrogradación se evalúa mediante los cambios en la variación de entalpía $(\Delta \mathrm{H})$, parámetro relacionado con la cantidad de calor necesario para fundir los cristales de amilopectina retrogradada. Los valores de $\Delta \mathrm{H}$ se muestran en la Tabla 4.19. Al realizar el ensayo inmediatamente luego de la gelatinización las variaciones de entalpias resultaron prácticamente despreciables, esto es esperado ya que recién en esa instancia comienza a retrogradar la amilosa, y para poder fundirla es necesario altas temperaturas debido a su estabilidad térmica. Luego de tres días de almacenamiento, el mayor aumento de entalpía se observó en C, asociado a una mayor recristalización del almidón en ausencia de las sales de calcio e In, fenómeno que podría explicar también el gran aumento de firmeza obtenido luego de ese periodo, como se explicó en la sección 4.5.1. El $\Delta \mathrm{H}$ no aumentó con mayores tiempos, sugiriendo que en ausencia de calcio e inulina, la amilopectina retrograda rápidamente. Las muestras con $12 \%$ In presentaron al Día 3 menor $\Delta \mathrm{H}$, asociado a una menor retrogradación; parámetro que aumentó al Día 7. Aunque las diferencias no fueron significativas, el $\mathrm{CaCO}_{3}$ fue la sal que mejor logró junto con la inulina, retrasar el envejecimiento. 
Tabla 4.19. Temperaturas de gelatinización obtenidas a partir de masas cocidas retrogradadas.

\begin{tabular}{|c|c|c|c|c|c|c|}
\hline & & & \multicolumn{4}{|c|}{ Día 3} \\
\hline & $\begin{array}{c}\mathrm{Ca} \\
(\mathrm{ppm})\end{array}$ & $\begin{array}{l}\text { In } \\
(\%)\end{array}$ & $\begin{array}{c}\mathrm{T}_{0} \\
\left({ }^{\circ} \mathrm{C}\right)\end{array}$ & $\begin{array}{c}\mathrm{T}_{\mathrm{p}} \\
\left({ }^{\circ} \mathrm{C}\right)\end{array}$ & $\begin{array}{c}\mathrm{T}_{\mathrm{f}} \\
\left({ }^{\circ} \mathrm{C}\right)\end{array}$ & $\begin{array}{c}\Delta H \\
(J / g)\end{array}$ \\
\hline C & 0 & 0 & $46 a$ & $64 a b$ & $78 a b$ & $4,04 \mathbf{d}$ \\
\hline CA11 & 1800 & 0 & $47 a$ & $59 a$ & $76 a$ & 2,99 cd \\
\hline Cl11 & 1800 & 0 & $47 a$ & $62 a b$ & $77 a b$ & 2,82 bc \\
\hline LA11 & 1800 & 0 & $46 a$ & $62 a b$ & $77 \mathrm{ab}$ & 2,72 bc \\
\hline CA4 & 2400 & 12 & $51 \mathrm{c}$ & $66 \mathrm{~b}$ & $77 \mathrm{ab}$ & $1,46 \mathbf{a}$ \\
\hline $\mathrm{Cl} 4$ & 2400 & 12 & $50 \mathrm{~b}$ & $65 \mathbf{b}$ & $103 \mathrm{c}$ & $2,42 \mathrm{abc}$ \\
\hline \multirow[t]{3}{*}{ LA4 } & 2400 & 12 & $44 a$ & $64 a b$ & $80 \mathrm{~b}$ & $1,91 \mathbf{a b}$ \\
\hline & & & \multicolumn{4}{|c|}{ Día 5} \\
\hline & (ppm) & (\%) & $\begin{array}{c}\mathrm{T}_{0} \\
\left({ }^{\circ} \mathrm{C}\right)\end{array}$ & $\begin{array}{c}T_{p} \\
\left({ }^{\circ} \mathrm{C}\right)\end{array}$ & $\begin{array}{c}T_{f} \\
\left({ }^{\circ} \mathrm{C}\right)\end{array}$ & $\begin{array}{c}\Delta H \\
(\mathrm{~J} / \mathrm{g})\end{array}$ \\
\hline C & 0 & 0 & $41 a$ & $63 c$ & $76 a$ & $4,03 \mathbf{c}$ \\
\hline CA11 & 1800 & 0 & 47 bc & $61 \mathbf{a}$ & $76 a$ & $3,19 \mathbf{b}$ \\
\hline Cl11 & 1800 & 0 & $46 \mathrm{~b}$ & 62 bc & $76 \mathbf{a}$ & $3,09 \mathbf{b}$ \\
\hline LA11 & 1800 & 0 & $46 \mathrm{~b}$ & $61 a b$ & $75 a$ & $2,92 \mathbf{b}$ \\
\hline CA4 & 2400 & 12 & $50 d$ & $66 \mathrm{~d}$ & $77 \mathbf{a}$ & $1,89 \mathbf{a}$ \\
\hline $\mathrm{Cl} 4$ & 2400 & 12 & $51 \mathrm{~d}$ & $65 d$ & $103 \mathrm{c}$ & $2,83 \mathbf{b}$ \\
\hline \multirow[t]{3}{*}{ LA4 } & 2400 & 12 & 49 cd & $65 d$ & $82 \mathrm{~b}$ & $2,04 \mathbf{a}$ \\
\hline & & & \multicolumn{4}{|c|}{ Día 7} \\
\hline & $(\mathrm{ppm})$ & (\%) & $\begin{array}{c}\mathrm{T}_{0} \\
\left({ }^{\circ} \mathrm{C}\right)\end{array}$ & $\begin{array}{c}\mathrm{T}_{\mathrm{p}} \\
\left({ }^{\circ} \mathrm{C}\right)\end{array}$ & $\begin{array}{c}T_{f} \\
\left({ }^{\circ} \mathrm{C}\right)\end{array}$ & $\begin{array}{c}\Delta H \\
(\mathrm{~J} / \mathrm{g})\end{array}$ \\
\hline C & 0 & 0 & $45 a$ & $62 \mathbf{a b}$ & $76 \mathbf{a}$ & 3,85 abc \\
\hline CA11 & 1800 & 0 & 50 bc & $63 \mathbf{b}$ & $76 \mathbf{a}$ & $3,03 \mathrm{ab}$ \\
\hline Cl11 & 1800 & 0 & $46 a$ & $61 \mathbf{a}$ & $78 a$ & $3,29 a b$ \\
\hline LA11 & 1800 & 0 & $47 a b$ & $62 \mathbf{b}$ & $77 \mathbf{a}$ & $3,02 \mathbf{a b}$ \\
\hline CA4 & 2400 & 12 & $47 a b$ & $63 \mathrm{~b}$ & $78 \mathbf{a}$ & $2,21 \mathbf{a}$ \\
\hline $\mathrm{Cl} 4$ & 2400 & 12 & 50 bc & $64 \mathrm{~b}$ & $103 \mathbf{b}$ & 3,55 bc \\
\hline LA4 & 2400 & 12 & $51 \mathrm{c}$ & $66 c$ & 104 b & $4,22 \mathrm{c}$ \\
\hline
\end{tabular}

Letras distintas en una misma columna un mismo día indican diferencias significativas $(p<$ 0,05). 
Los valores de IR (Tabla 4.20) de las diferentes muestras estudiadas en diferentes días de almacenamientos confirmó el análisis de los resultados de la Tabla 4.19. La sal que favoreció una menor retrogradación (IR) fue el $\mathrm{CaCO}_{3}$, tanto en ausencia como en presencia del prebiótico.

Tabla 4.20. Índice de retrogradación.

\begin{tabular}{|c|c|c|c|c|c|}
\hline & \multirow{2}{*}{$\begin{array}{c}\mathrm{Ca} \\
(\mathrm{ppm})\end{array}$} & \multirow{2}{*}{$\begin{array}{l}\text { In } \\
(\%)\end{array}$} & \multicolumn{3}{|c|}{ IR (\%) } \\
\hline & & & Día 3 & Día 5 & Día 7 \\
\hline C & 0 & 0 & 57 & 57 & 54 \\
\hline CA11 & 1800 & 0 & 44 & 47 & 45 \\
\hline $\mathrm{Cl} 11$ & 1800 & 0 & 49 & 53 & 57 \\
\hline LA11 & 1800 & 0 & 48 & 52 & 53 \\
\hline CA4 & 2400 & 12 & 38 & 49 & 57 \\
\hline $\mathrm{Cl} 4$ & 2400 & 12 & 59 & 68 & 86 \\
\hline LA4 & 2400 & 12 & 45 & 48 & 98 \\
\hline
\end{tabular}

\section{Difracción de Rayos X. DRX}

Durante el almacenamiento del pan, el almidón va recuperando lentamente la estructura cristalina. Esta recristalización se debe principalmente a la auto-asociación de las moléculas ramificadas de la amilopectina (Primo-Martin y col., 2007). En la sección anterior evaluamos el aumento en la cristalización de este polímero durante el almacenamiento del pan mediante DSC; también puede ser evaluado mediante difractometría de rayos X (Ottenhof y Farhat, 2004; Primo-Martin y col., 2007).

Diversos autores han identificado cuatro picos en la diagrama de difracción de rayos $\mathrm{X}$ de almidón nativo de trigo a ángulos $2 \theta$ de $15^{\circ}, 17^{\circ}, 18^{\circ}$ y $23^{\circ}$, correspondientes a una distancia interplanar de 58.0, 51.0, 49.0 y 38.0 nm respectivamente (Jovanovich, 1997; Primo-Martín y col., 2007), concordante con el patrón de difracción de rayos $X$ tipo $A$ descripto por otros autores para almidones de cereales (Zobel y col., 1988). Los picos $15^{\circ}$ y $17^{\circ}$ que se observan en los espectros de difracción de rayos $X$ fueron similares al patrón normal tipo $B$ del almidón proveniente de tubérculos.

La Figura 4.21 muestra diferencias en el diagrama de difracción de rayos $\mathrm{X}$ obtenido para las muestras de miga de pan control el día de la panificación y al quinto día de 
almacenamiento. La muestra de pan fresco C0 presentó principalmente 2 picos de $2 \theta$ de $17^{\circ}$ y $20^{\circ}$. El pico detectado a $20^{\circ}$ se encuentra en todas las muestras que contienen almidón y corresponde a la presencia del complejo amilosa-lípido tipo $\mathrm{V}$ formado durante el proceso de gelatinización (Zobel y Kulp, 1996; Primo-Martin y col., 2007). Se puede observar que CR5 presentó el pico de $17^{\circ}$ más pronunciado que en $\mathrm{C} 0$, además de picos a $15^{\circ}$ y $23^{\circ}$, sugiriendo una mayor cristalinidad.

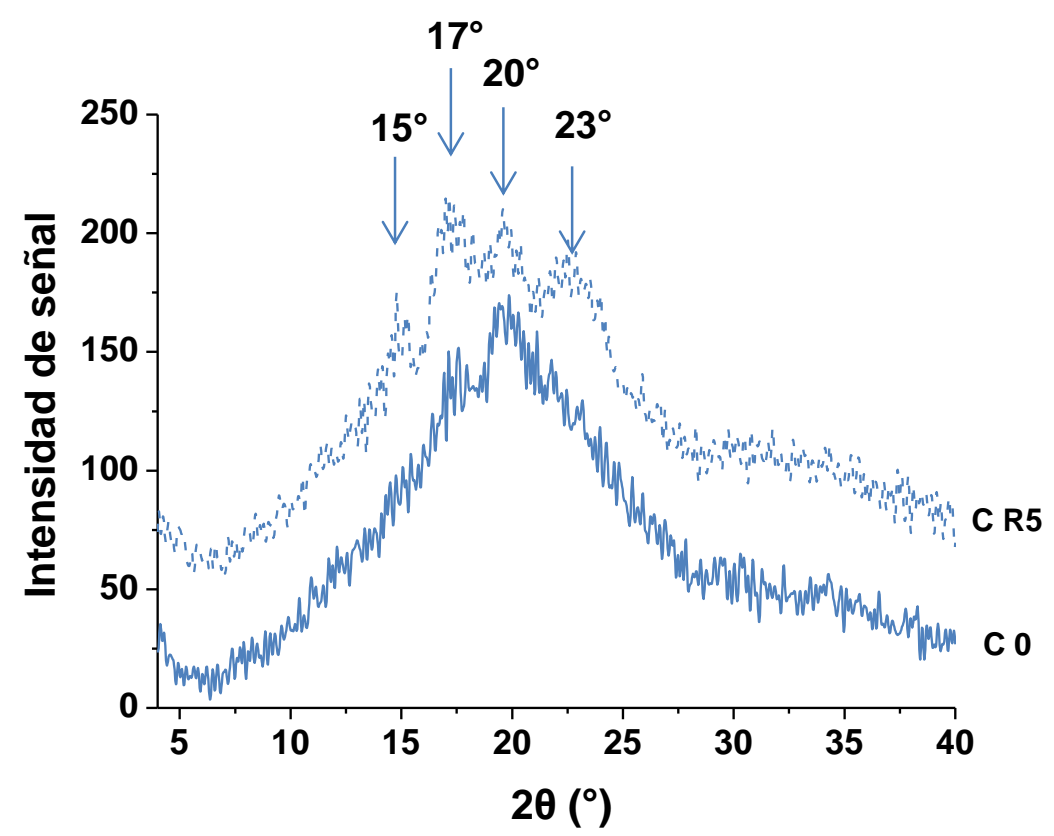

Figura 4.21. Diagrama de difracción de rayos $X$ de miga de pan control: Co: pan fresco y CR5:pan almacenado 5 días a $20 \pm 0,1 \stackrel{\circ}{ } \mathrm{C}$.

Las migas con In presentaron un pico a $18^{\circ}$ más predominante que el de $20^{\circ}$ y un pico nuevo a $12^{\circ}$ (Figura 4.22.a). Ronkart y col. (2006) estudiaron la temperatura de transición vítrea y el desarrollo de la cristalinidad por DRX, de la inulina a diferentes actividades acuosas, detectando en el difractograma el pico de $12^{\circ}$ muy pronunciado. Aravind y col. (2012) también observaron nuevos picos de difracción a $2 \theta 8^{\circ}, 12^{\circ}$, $16.2^{\circ}, 17.7^{\circ}$ y $21.8^{\circ}$ en muestras de pastas fortificadas con inulina, el pico de $12^{\circ}$ fue más evidente cuando la sustitución de semolina por inulina fue mayor al 10\%.

Con el almacenamiento (Figura 4.22.b) se observó que las muestras además del pico de $20^{\circ}$, presentaron picos en valores alrededor de 15,17 y $23^{\circ}$, cuya área se fue incrementando con el transcurso de los días, a causa de una mayor recristalización de la amilopectina. 

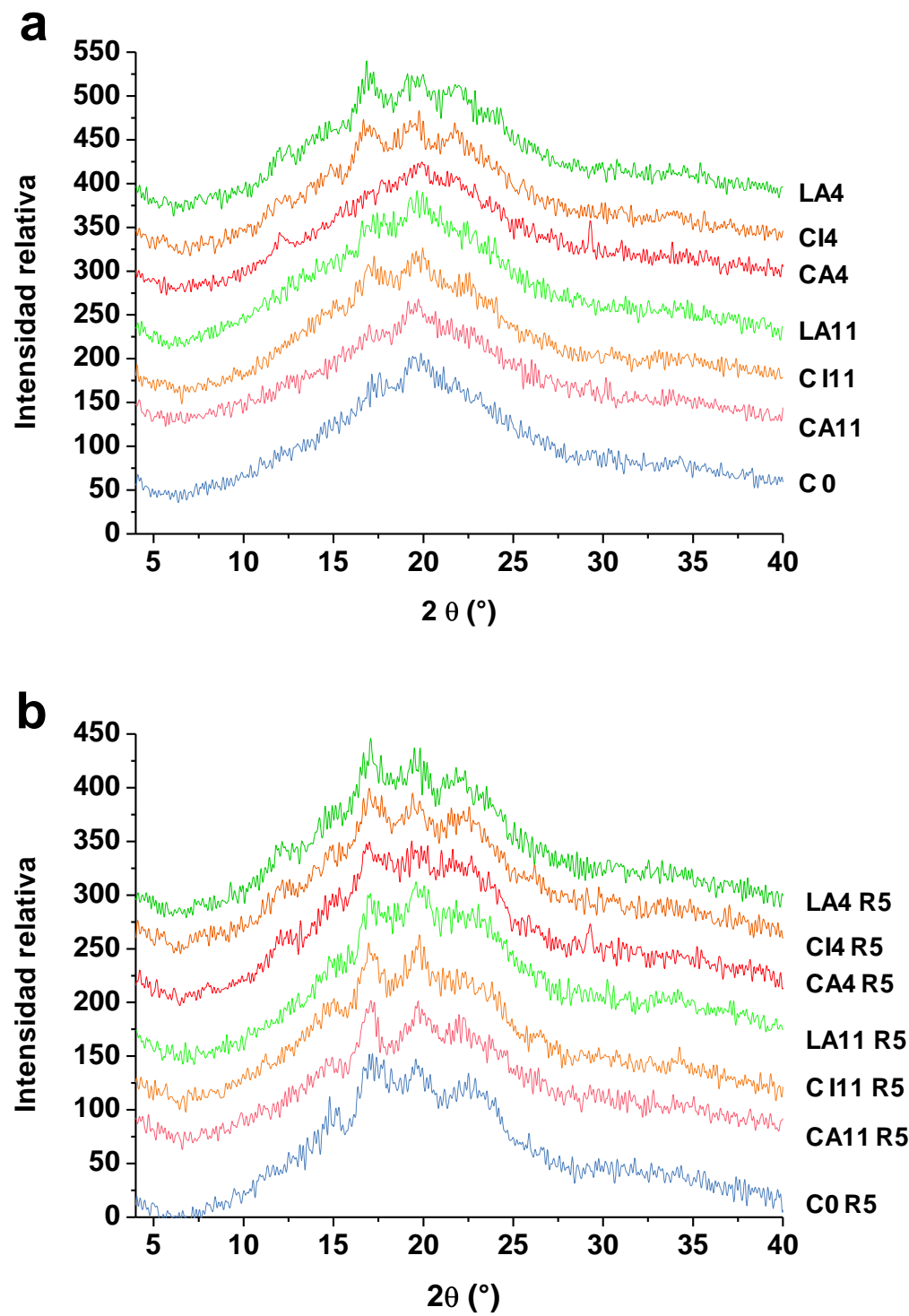

Figura 4.22. Difractograma de migas: a) frescas (Día 0), b) migas de panes almacenados (Día $5)$.

El porcentaje de cristalinidad de las migas de pan fresco se muestra en la Tabla 4.21. Durante el proceso de gelatinización la mayor parte del almidón gelatiniza; sin embargo, al ser la masa un sistema con una cantidad de agua limitada, una pequeña fracción de gránulos queda en estado cristalino. Es por ello que el valor de 6,0\% (Tabla 4.21) detectado puede deberse a este fenómeno como también a la recristalización de la amilosa. $\mathrm{El} \mathrm{CaCO}_{3}$ disminuyó significativamente la cristalinidad de la miga. Las migas con sales de calcio orgánicas y alto prebiótico presentaron mayor porcentaje de cristalinidad total debido a la recristalización de la inulina (pico $12^{\circ}$ ) junto 
con el almidón (picos $15^{\circ}$ y $17^{\circ}$ ), coincidente con un menor grado de gelatinización (sección 4.2.1). La Calm de las migas frescas con sales de calcio orgánicas fue mayor, especialmente en presencia de prebiótico.

Tabla 4.21. Porcentaje de cristalinidad obtenido por DRX de migas de panes frescos.

\begin{tabular}{c|cc|ccccccc}
\hline & $\mathbf{C a}$ & $\mathbf{I n}$ & \multicolumn{7}{c}{$\%$ CRISTALINIDAD DIA 0 } \\
& $(\mathbf{p p m})$ & $\mathbf{( \% )}$ & $\mathbf{1 2}$ & $\mathbf{1 5}$ & $\mathbf{1 7}$ & $\mathbf{2 0}$ & $\mathbf{2 3}$ & $\mathbf{C T}$ & $\mathbf{C a l m}$ \\
\hline $\mathbf{C}$ & 0 & 0 & - & $0,58 \mathbf{a b}$ & $1,31 \mathbf{b}$ & $3,72 \mathbf{d}$ & $0,44 \mathbf{a}$ & $6,0 \mathbf{b c}$ & 2,33 \\
\hline CA11 & 1800 & 0 & - & $0,68 \mathbf{a b}$ & $0,79 \mathbf{a}$ & $2,79 \mathbf{b c}$ & $0,80 \mathbf{b}$ & $5,1 \mathbf{a}$ & 2,31 \\
$\mathbf{C l 1 1}$ & 1800 & 0 & - & $0,86 \mathbf{b c}$ & $1,93 \mathbf{c}$ & $2,80 \mathbf{c}$ & $0,81 \mathbf{b}$ & $6,4 \mathbf{c}$ & 3,60 \\
LA11 & 1800 & 0 & - & $0,47 \mathbf{a}$ & $1,87 \mathbf{c}$ & $2,34 \mathbf{b}$ & $0,84 \mathbf{b}$ & $5,5 \mathbf{a b}$ & 3,16 \\
\hline CA4 & 2400 & 12 & $1,20 \mathbf{a}$ & $0,67 \mathbf{a b}$ & $1,03 \mathbf{a b}$ & $1,41 \mathbf{a}$ & $1,31 \mathbf{c}$ & $5,6 \mathbf{a b c}$ & 2,99 \\
C14 & 2400 & 12 & $1,35 \mathbf{a}$ & $1,17 \mathbf{c d}$ & $2,48 \mathbf{d}$ & $1,63 \mathbf{a}$ & $1,42 \mathbf{c}$ & $8,0 \mathbf{d}$ & 5,02 \\
LA4 & 2400 & 12 & $1,65 \mathbf{a}$ & $1,18 \mathbf{d}$ & $2,76 \mathbf{d}$ & $1,52 \mathbf{a}$ & $1,22 \mathbf{c}$ & $8,3 \mathbf{d}$ & 5,13 \\
\hline
\end{tabular}

Letras distintas en una misma columna indican diferencias significativas $(p<0,05)$. CT: cristalinidad total, Calm: cristalinidad debida al almidón correspondiente a los picos de $15^{\circ}, 17^{\circ}$ y $23^{\circ}$.

Luego de cinco días de almacenamiento, período durante el cual recristaliza la amilopectina (envejecimiento del pan), el porcentaje de cristalinidad total (CT) resultó incrementado (Tabla 4.22). A pesar de ello, comparado con la miga $C$ las sales sin inulina disminuyeron el CT, coincidente con el menor \%IR obtenido en el ensayo calorimétrico, sugiriendo un efecto protector contra el envejecimiento del pan. Ribotta y col. (2004) encontraron para miga de pan de trigo almacenado, una correlación de la retrogradación de la amilopectina medida por DSC y la estructura cristalina tipo B medida por $\mathrm{DRX}$, obteniendo mayores valores de $\Delta \mathrm{H}$ y porcentaje de cristalinidad (Tipo B), respectivamente.

En presencia de inulina se encontró un CT semejante a la miga control, sin embargo el Calm de las migas con prebiótico fue mayor; sugiriendo que la inulina promueve la retrogradación del almidón en presencia de sales. 
Tabla 4.22. Porcentaje de cristalinidad obtenido por DRX de migas de panes almacenados 5 días.

\begin{tabular}{c|cc|ccccccc}
\hline & $\mathbf{C a}$ & $\mathbf{I n}$ & \multicolumn{7}{c}{$\% \mathbf{C R I S T A L I N I D A D}$ DIA $\mathbf{5}$} \\
& $(\mathbf{p p m})$ & $\mathbf{( \% )}$ & $\mathbf{1 2}$ & $\mathbf{1 5}$ & $\mathbf{1 7}$ & $\mathbf{2 0}$ & $\mathbf{2 3}$ & $\mathbf{C T}$ & $\mathbf{C a l m}$ \\
\hline $\mathbf{C}$ & $\mathbf{0}$ & $\mathbf{0}$ & - & $1,78 \mathbf{b}$ & $3,10 \mathbf{b}$ & $2,60 \mathbf{b}$ & $5,00 \mathbf{b c}$ & $12,5 \mathbf{c}$ & 9,90 \\
\hline CA11 & 1800 & 0 & - & $1,26 \mathbf{a b}$ & $3,25 \mathbf{b}$ & $1,81 \mathbf{a b}$ & $2,79 \mathbf{a}$ & $9,1 \mathbf{a}$ & 7,29 \\
$\mathbf{C l 1 1}$ & 1800 & 0 & - & $0,90 \mathbf{a}$ & $2,97 \mathbf{a b}$ & $1,96 \mathbf{a b}$ & $3,18 \mathbf{a b}$ & $9,0 \mathbf{a}$ & 7,04 \\
LA11 & 1800 & 0 & - & $1,04 \mathbf{a b}$ & $3,00 \mathbf{b}$ & $2,22 \mathbf{a b}$ & $3,75 \mathbf{a b}$ & $10,0 \mathbf{b}$ & 7,78 \\
\hline CA4 & 2400 & 12 & $1,53 \mathbf{a}$ & $1,14 \mathbf{a b}$ & $2,62 \mathbf{a b}$ & $2,01 \mathbf{a b}$ & $4,93 \mathbf{b c}$ & $12,2 \mathbf{c}$ & 8,66 \\
$\mathbf{C l 4}$ & 2400 & 12 & $1,37 \mathbf{a}$ & $1,32 \mathbf{a b}$ & $2,28 \mathbf{a b}$ & $1,49 \mathbf{a}$ & $2,61 \mathbf{a}$ & $9,1 \mathbf{a}$ & 7,73 \\
LA4 & 2400 & 12 & $1,61 \mathbf{a}$ & $0,97 \mathbf{a b}$ & $1,90 \mathbf{a}$ & $1,90 \mathbf{a b}$ & $6,13 \mathbf{b}$ & $12,5 \mathbf{c}$ & 8,99 \\
\hline
\end{tabular}

Letras distintas en una misma columna indican diferencias significativas $(p<0,05)$. CT: cristalinidad total, Calm: cristalinidad debida al almidón correspondiente a los picos de $15^{\circ}, 17^{\circ}$ y $23^{\circ}$.

\subsection{Optimización de producto}

Se optimizó con algunos parámetros experimentales del diseño, el mejor pan para cada tipo de sal. La optimización consistió en la superposición de gráficos de contorno de las SR de las diferentes variables seleccionadas obteniendo un gráfico como se muestra en la Figura 4.23. Se eligieron las siguientes variables en un intervalo deseado: humedad (40,2 a 42,0\%), volumen especifico $\left(2,5\right.$ a $\left.3,0 \mathrm{~cm}^{3} / \mathrm{g}\right)$, cohesividad $(0,4$ a 0,5$)$ y masticabilidad $(5,5$ a $6,4 \mathrm{~N})$. Los gráficos de contorno se superpusieron (Capanzana y Buckle, 1997) (Figura 4.23), obteniéndose un área que satisface todas las condiciones de contorno (área amarilla). El área amarilla es la región que satisface todos los límites y dentro de ella fue seleccionado el punto óptimo para cada formulación. 

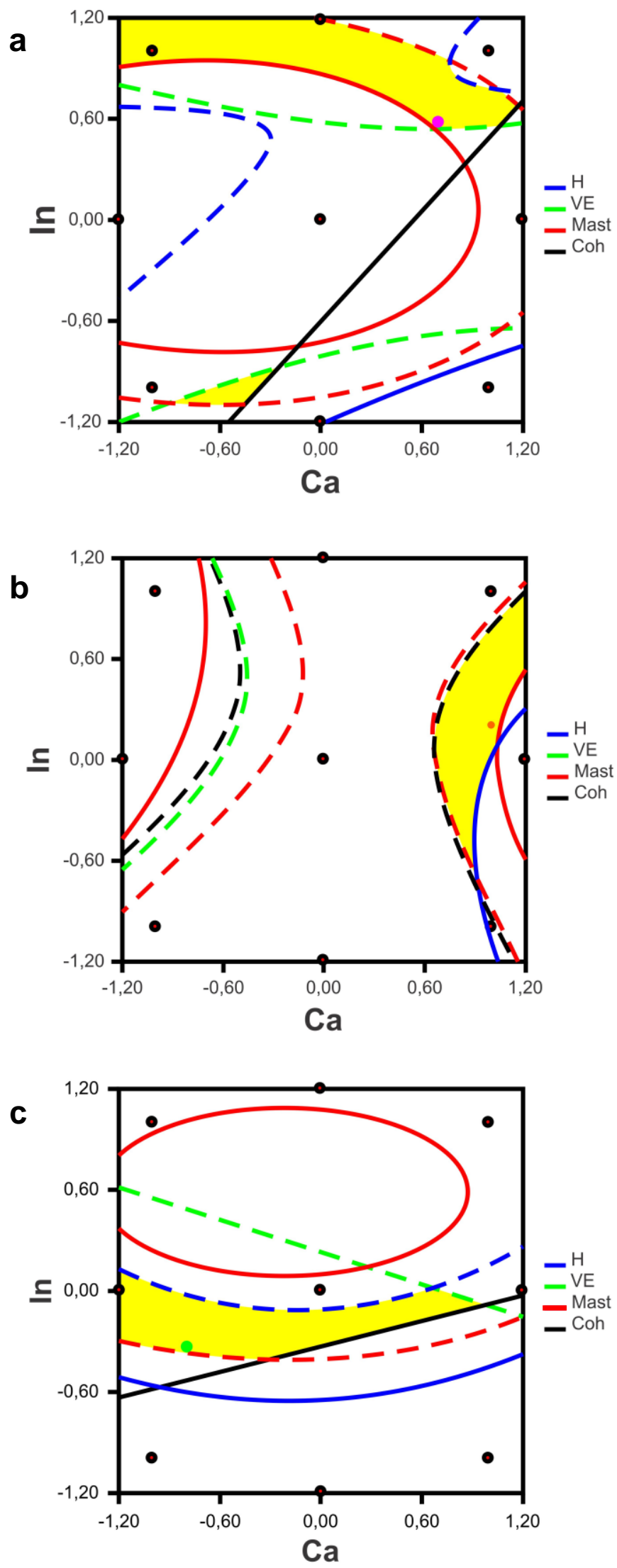

Figura 4.23. Superposición de superficies de contorno: a) $\mathrm{CaCO}_{3}$, b) $\mathrm{Ca}_{3} \mathrm{Cl}_{2}$, c) $\mathrm{CaLA}_{2}$. Líneas punteadas: límite inferior y líneas enteras: límite superior del rango. 
La función deseabilidad da idea de cuan cerca está la optimización de las metas propuestas. Si la función deseabilidad tiene un valor de 0 indica que no hay conformidad con la meta deseada, en cambio cuando alcanza el valor de 1 indica que la meta propuesta se alcanzó completamente. La deseabilidad fue mayor a 0,96 en panes con carbonato de calcio y 0,994 en panes elaborados con sales de calcio orgánicas.

En base a la función deseabilidad, se seleccionó la formulación óptima de cada uno de los panes, que se muestra en la Tabla 4.23.

Tabla 4.23. Niveles de calcio e inulina (codificados y decodificados) de las formulaciones óptimas para pan.

\begin{tabular}{c|cc|cc|cc}
\hline \multirow{2}{*}{} & \multicolumn{2}{|c|}{$\mathrm{CaCO}_{3}$} & \multicolumn{2}{c|}{$\mathrm{Ca}_{3} \mathrm{Cl}_{2}$} & \multicolumn{2}{c}{$\mathrm{CaLA}_{2}$} \\
\cline { 2 - 7 } & Cod & Decod & Cod & Decod & Cod & Decod $^{*}$ \\
\hline Ca & 0,66 & 2196 & 1,00 & 2400 & $-0,79$ & 1326 \\
In & 0,57 & 9,635 & 0,18 & 7,490 & $-0,33$ & 4,685 \\
\hline
\end{tabular}

${ }^{*} \mathrm{Ca}: \mathrm{ppm}, \operatorname{In:} \%$

Una vez que se determinó la formulación óptima, se reemplazó el valor óptimo de cada factor en el modelo de regresión obtenido para las variables: absorción farinográfica, tiempo de desarrollo y tiempo de fermentación y se calculó a partir de ellos la cantidad de agua a agregar, el tiempo de amasado y el tiempo de fermentación, respectivamente. Definido estos parámetros, se panificaron las formulaciones óptimas y se analizaron todas las variables de respuesta de los productos finales.

Los valores experimentales de cada una de las respuestas se compararon con los predichos por las ecuaciones del modelo; dichos valores se presentan en la Tabla 4.24. Puede observarse que los valores experimentales se encontraron dentro del intervalo de confianza, siendo además estadísticamente semejantes a los valores predichos dentro de un nivel de significación del 95\%. Por lo tanto, el modelo propuesto se puede utilizar para optimizar la formulación de los panes. 
Tabla 4.24. Valores experimentales y predichos de las variables respuestas de las formulaciones optimas.

\begin{tabular}{|c|c|c|c|c|c|}
\hline & & $\begin{array}{c}H \\
(\%)\end{array}$ & $\begin{array}{l}\text { Coh } \\
(-)\end{array}$ & $\begin{array}{l}\text { Mast } \\
(\mathrm{N})\end{array}$ & $\begin{array}{c}V_{E} \\
\left(\mathrm{~cm}^{3} / \mathrm{g}\right)\end{array}$ \\
\hline $\mathrm{CaCO}_{3}$ & $\begin{array}{c}\text { Experimental } \\
\text { Predicho } \\
\text { Rango }\end{array}$ & $\begin{array}{c}39,09 \pm 0,04 \\
39,02 \\
38,92-39,33\end{array}$ & $\begin{array}{c}0,52 \pm 0,01 \\
0,51 \\
0,48-0,53\end{array}$ & $\begin{array}{c}4,3 \pm 0,3 \\
6,6 \\
5,8-7,4\end{array}$ & $\begin{array}{c}3,0 \pm 0,2 \\
2,5 \\
2,1-2,9\end{array}$ \\
\hline $\mathrm{Ca}_{3} \mathrm{Cl}_{2}$ & $\begin{array}{c}\text { Experimental } \\
\text { Predicho } \\
\text { Rango }\end{array}$ & $\begin{array}{c}40,20 \pm 0,46 \\
39,15 \\
37,35-40,94\end{array}$ & $\begin{array}{c}0,52 \pm 0,01 \\
0,48 \\
0,44-0,55\end{array}$ & $\begin{array}{c}4,8 \pm 0,5 \\
6,0 \\
5,1-7,0\end{array}$ & $\begin{array}{c}2,5 \pm 0,04 \\
2,2 \\
2,0-2,3\end{array}$ \\
\hline $\mathrm{CaLA}_{2}$ & $\begin{array}{c}\text { Experimental } \\
\text { Predicho } \\
\text { Rango }\end{array}$ & $\begin{array}{c}40,60 \pm 0,07 \\
40,6 \\
40,33-40,80\end{array}$ & $\begin{array}{c}0,50 \pm 0,01 \\
0,51 \\
0,50-0,52\end{array}$ & $\begin{array}{c}5,3 \pm 0,6 \\
7,0 \\
6,07-7,93\end{array}$ & $\begin{array}{c}2,3 \pm 0,9 \\
2,5 \\
2,37-2,61\end{array}$ \\
\hline
\end{tabular}

Media \pm desviación estándar. Rango: intervalo de confianza (95\%)

Los panes no solamente deben tener propiedades físicas y texturales acorde a la naturaleza del producto, sino que deben también ser aceptados por los consumidores; por lo que a continuación se describe el grado de aceptabilidad de un panel no entrenado de consumidores habituales de pan.

\subsection{Análisis sensorial}

Los panes óptimos elaborados con sales de calcio orgánicas en promedio presentaron mejores puntuaciones en los atributos evaluados que el pan óptimo elaborado con carbonato de calcio (Tabla 4.25). El pan óptimo elaborado con lactato de calcio presentó mejor puntuación en apariencia y textura, aunque el pan elaborado con citrato de calcio presentó mejor sabor. Los tres panes óptimos tuvieron una buena aceptación global, siendo los elaborados con sales de calcio orgánicas los que mejor aceptación tuvieron. 
Tabla 4.25. Promedio de los atributos evaluados en los panes óptimos.

\begin{tabular}{c|cccc}
\hline $\begin{array}{c}\text { Panes } \\
\text { óptimos }\end{array}$ & Apariencia & Textura & Sabor & $\begin{array}{c}\text { Aceptabilidad } \\
\text { global }\end{array}$ \\
\hline $\mathrm{CaCO}_{3}$ & 6,8 & 6,0 & 6,4 & 6,5 \\
$\mathrm{Ca}_{3} \mathrm{Cl}_{2}$ & 7,0 & 5,8 & 7,1 & 6,8 \\
$\mathrm{CaLA}_{2}$ & 7,4 & 6,3 & 6,9 & 6,9 \\
\hline
\end{tabular}

Para tener una mejor comprensión de la elección de los atributos por parte de los panelistas, se graficó el ranking como porcentaje de respuestas en función del puntaje de la escala hedónica.

La mayoría de los evaluadores puntuaron al atributo apariencia en el tercio superior (7, 8, 9) (Figura 4.24.a), siendo el de mejor apariencia el pan con agregado de lactato de calcio. En el atributo sabor, la mayoría de las respuestas estuvieron concentradas en los puntajes 7 y 8 , siendo los panes elaborados con sales de calcio orgánicas los mejores puntuados (Figura 4.24.b). Para el atributo textura, las definiciones no fueron tan taxativas (Figura 4.24.c), mientras que la aceptabilidad global presentó un máximo de respuestas entre los puntajes 6 y 8 .

a) Apariencia

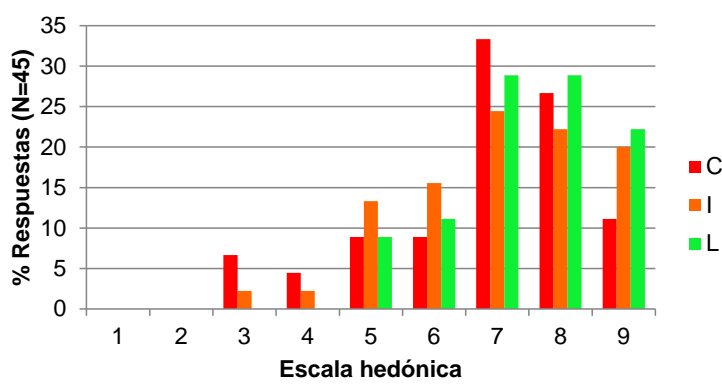

c) Textura

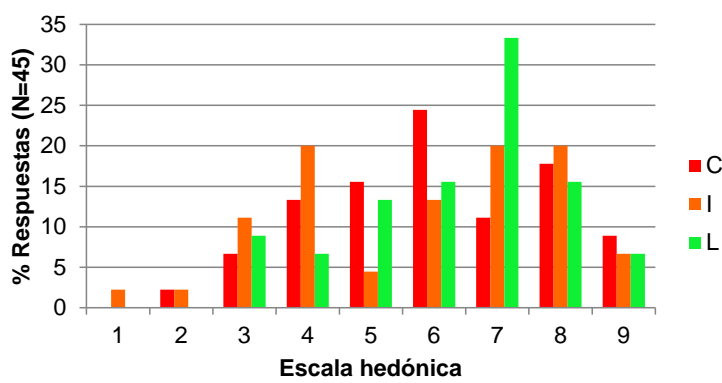

b) Sabor

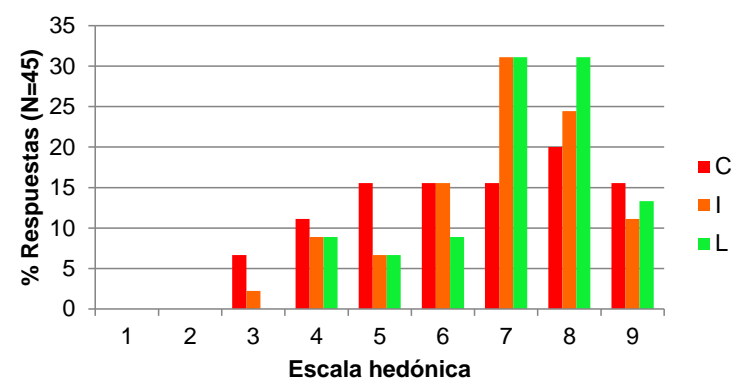

d) Aceptabilidad global

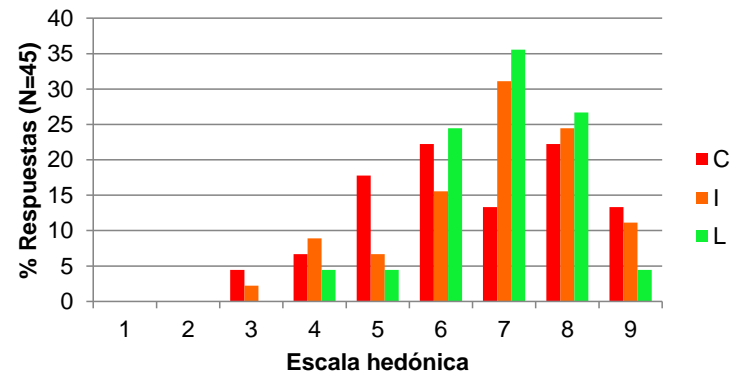

Figura 4.24. Porcentaje de respuestas de los panes óptimos. a) Apariencia, b)Sabor, c)Textura y d) Aceptabilidad global. CA (rojo), $\mathrm{Cl}$ (naranja), LA (verde).

Los resultados sugieren que los panes con diferentes sales de calcio, especialmente con sales orgánicas, tienen muy buena aceptación por parte de los consumidores. 


\section{Conclusiones parciales}

La gelatinización se vio influenciada por el prebiótico, éste retrasó e inhibió en parte el proceso de gelatinización, como puede deducirse del corrimiento de las temperaturas hacia mayores valores y de la disminución de la entalpia, llegando esta última a valores hasta $50 \%$ menores al de la masa control debido a la menor cantidad de agua que se necesitó para preparar la masa en presencia de inulina independientemente de la sal de calcio. Las masas con $\mathrm{CaCO}_{3}$ presentaron a baja inulina (1\%) una disminución en el $\Delta \mathrm{H}_{\mathrm{g}}$ al aumentar el nivel de Ca; a diferencia de las masas con CaLA $\mathrm{A}_{2}$ en las que la sal incrementó este parámetro, favoreciendo la gelatinización. No provocó cambios el agregado de $\mathrm{Ca}_{3} \mathrm{Cl}_{2}$.

En el viscoamilograma, el prebiótico generó pastas menos viscosas durante el calentamiento y cuya viscosidad final resultó también dependiente del tipo de sal. Las dispersiones con mayor viscosidad final fueron las que contenían $\mathrm{CaCO}_{3}$, especialmente a baja inulina. Este parámetro no cambió con el nivel de calcio para ninguna de las sales, ni con el de prebiótico para las sales orgánicas. Las pastas con $\mathrm{CaLA}_{2}$ formaron luego del enfriamiento un gel menos estructurado y con mayor tendencia a la ruptura por cizallamiento.

La presencia de prebiótico disminuyó el tiempo de fermentación, independientemente del nivel de calcio, y conllevó un menor incremento de volumen máximo. En ausencia de prebiótico, la presencia de sales de calcio no modificó significativamente los tiempos de fermentación comparado con el control. En cambio, a $12 \%$ In, el agregado de $\mathrm{CaCO}_{3}$ disminuyó $\mathrm{t}_{\mathrm{f}}$ a diferencia de $\mathrm{Ca}_{3} \mathrm{Cl}_{2}$ que incrementó éste parámetro.

El volumen específico de todos los panes con las diferentes sales de calcio y sin inulina fue aproximadamente el mismo $\left(2,5 \mathrm{~cm}^{3} / \mathrm{g}\right)$. En panes elaborados con sales de calcio orgánicas, en presencia de alto prebiótico, se obtuvieron panes de menor volumen específico, de miga más firme y masticable y de menor humedad. Los panes con $13 \%$ In y $\mathrm{CaCO}_{3}$ presentaron menor firmeza que los panes con $\mathrm{Ca}_{3} \mathrm{Cl}_{2}$ y $\mathrm{CaLA}_{2}$, esto podría deberse al mayor volumen específico obtenido en panes con la sal inorgánica. En general, el prebiótico incrementó la firmeza de las migas con sales orgánicas; pero en el caso del $\mathrm{CaCO}_{3}$ y el $\mathrm{Ca}_{3} \mathrm{Cl}_{2}$ un incremento en el nivel de calcio disminuyó la firmeza. 
Durante el almacenamiento, los panes con $\mathrm{CaLA}_{2}$ presentaron menor $n$ que los panes con $\mathrm{CaCO}_{3}$ y $\mathrm{Ca}_{3} \mathrm{Cl}_{2}$. Este coeficiente está asociado a la fracción de almidón recristalizado; bajos valores de $n$ sugieren una mayor nucleación durante la recristalización. Asimismo, los panes con $\mathrm{CaLA}_{2}$, principalmente la formulación LA4, presentaron una cinética de recristalización más rápida (menor tiempo, mayor k) que los panes con $\mathrm{CaCO}_{3}$ y $\mathrm{Ca}_{3} \mathrm{Cl}_{2}$, tardando menos en endurecer la miga. Sin embargo, estos dos últimos en ausencia de prebiótico mitigaron mejor el incremento de firmeza y masticabilidad durante el almacenamiento, incluso mucho más que el control.

Los panes óptimos obtenidos experimentalmente presentaron parámetros de calidad panadera dentro del intervalo esperado; sensorialmente los mejores puntuados en los parámetros sabor y aceptabilidad fueron los panes con sales de calcio orgánicas.

Resulta muy importante para una formulación determinada la obtención de un pan de calidad tecnológica óptima y constante en el tiempo. Sin embargo, las nuevas tecnologías de panificación han incorporado la producción en base a masas congeladas. Esta tecnología permite ofrecer un producto recién elaborado a cualquier hora del día, de calidad similar al producto fresco, evitando las pérdidas económicas por envejecimiento. Por esta razón es que se decidió en este trabajo estudiar las características de panes con sales de calcio e inulina elaborados a partir de masas congeladas a diferentes tiempos de almacenamiento. 
CAPÍTULO 5 
La corta vida útil de los productos panificados representa pérdidas económicas por rechazo del producto por parte del consumidor. Una estrategia para mitigar estos inconvenientes podría ser la utilización de masas congeladas para hornear antes del consumo, ofreciendo un producto similar al fresco.

Las formulaciones de las masas congeladas fueron: control (C) (sin prebiótico ni calcio), con $12 \%$ In y 2400 ppm Ca con $\mathrm{CaCO}_{3}$ (CA4), $\mathrm{Ca}_{3} \mathrm{Cl}_{2}$ (Cl4) y $\mathrm{CaLA}_{2}$ (LA4) y masas sin In pero con 1800 ppm Ca bajo la forma de $\mathrm{CaCO}_{3}(\mathrm{CA} 11), \mathrm{Ca}_{3} \mathrm{Cl}_{2}(\mathrm{Cl11})$ y $\mathrm{CaLA}_{2}$ (LA11). Las masas fueron preparadas según se describió en la sección 2.2.4 en ausencia de levadura y almacenadas a $-18^{\circ} \mathrm{C}$ durante 1, 7, 30 y 60 días para el estudio de las masas; y en presencia de levadura para optimizar los tiempos de fermentación para la panificación y evaluar la calidad de los panes.

\subsection{Evaluación de la calidad de las masas}

A las masas descongeladas, previamente almacenadas a diferentes tiempos, se les determinó humedad, actividad acuosa, y propiedades reológicas como parámetros dinámicos de viscoelasticidad y de textura.

\subsubsection{Humedad y actividad acuosa}

En la Figura 5.1 se muestra la humedad de las masas de las diferentes formulaciones antes del almacenamiento a $-18^{\circ} \mathrm{C}$ (tiempo 0 ) y de la masa descongelada luego de 60 días de almacenamiento.

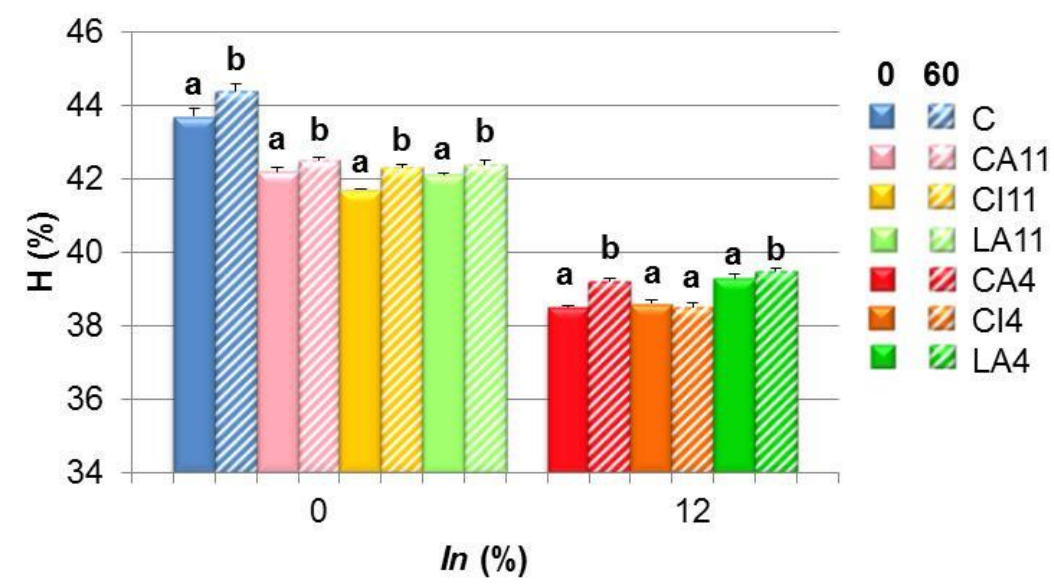

Figura 5.1. Humedad de la masa fresca y almacenada $-18 \stackrel{\circ}{\circ} \mathrm{C}$ durante 60 días. Letras diferentes indican diferencias significativas para la misma formulación entre 0 y 60 días. 
Los valores medios de humedad para una misma formulación antes y después de la congelación, a excepción del $\mathrm{Cl} 4$, aunque fueron estadísticamente diferentes por la baja variabilidad de los replicados, los valores resultaron similares, por lo que la congelación no resultó un factor de variabilidad en este parámetro. La humedad de la masa control siguió siendo mayor que la humedad de las masas con 1800 ppm Ca (CA11, Cl11, LA11); obteniendo los menores valores en masas con 2400 ppm Ca y $12 \%$ In (CA4, Cl4, LA4).

La actividad acuosa $\left(\mathrm{a}_{\mathrm{w}}\right)$ de las masas presentó un comportamiento diferente con la congelación (Figura 5.2). Para las masas sin congelar $a_{w}$ varió entre 0,947 y 0,974. Las sales aumentaron $a_{w}$, pero la inulina la disminuyó. Durante el almacenamiento en estado congelado la $a_{w}$ de las masas control, y con prebiótico se incrementó, este fenómeno estaría asociado a un cambio estructural de la matriz por efecto de la congelación conduciendo a una mayor disponibilidad de agua. Para las masas sin prebiótico no se observaron diferencias significativas en $a_{w}$, a excepción de LA11 que aumentó.

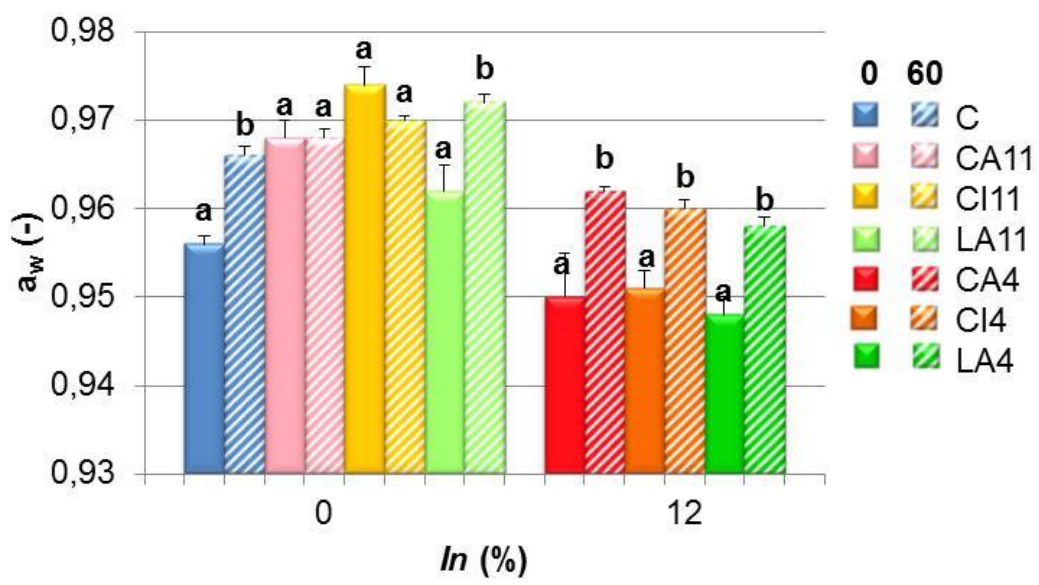

Figura 5.2. Actividad acuosa de la masa fresca y almacenada - $18{ }^{\circ} \mathrm{C}$ durante 60 días. Barras: desviación estándar. Letras diferentes indican diferencias significativas para la misma formulación entre 0 y 60 días.

Los resultados sugieren entonces que durante el almacenamiento no hubo deshidratación de las masas pero si cambios en la movilidad y disponibilidad de agua. Estos cambios afectan posiblemente la textura de las masas. 


\subsubsection{Perfil de textura}

Se analizaron a partir del perfil de textura la dureza, adhesividad y elasticidad de las masas descongeladas.

A un mismo tiempo la masa control fue la más blanda; el agregado de sales de calcio aumentó la dureza (Figura 5.3.a). Las masas con Ca e In fueron las más duras, especialmente con $\mathrm{CaCO}_{3}$ y $\mathrm{Ca}_{3} \mathrm{Cl}_{2}$ (Figura 5.3.b).

La dureza de todas las masas disminuyó significativamente al cabo de 60 días de almacenamiento, a excepción de la masa con $\mathrm{Ca}_{3} \mathrm{Cl}_{2}$ sin inulina ( $\mathrm{Cl11}$ ). Una menor dureza estaría relacionada con un debilitamiento de la masa debido a una redistribución del agua causada por la formación de hielo y la recristalización durante la congelación y el almacenamiento congelado (Ribotta y col., 2009).
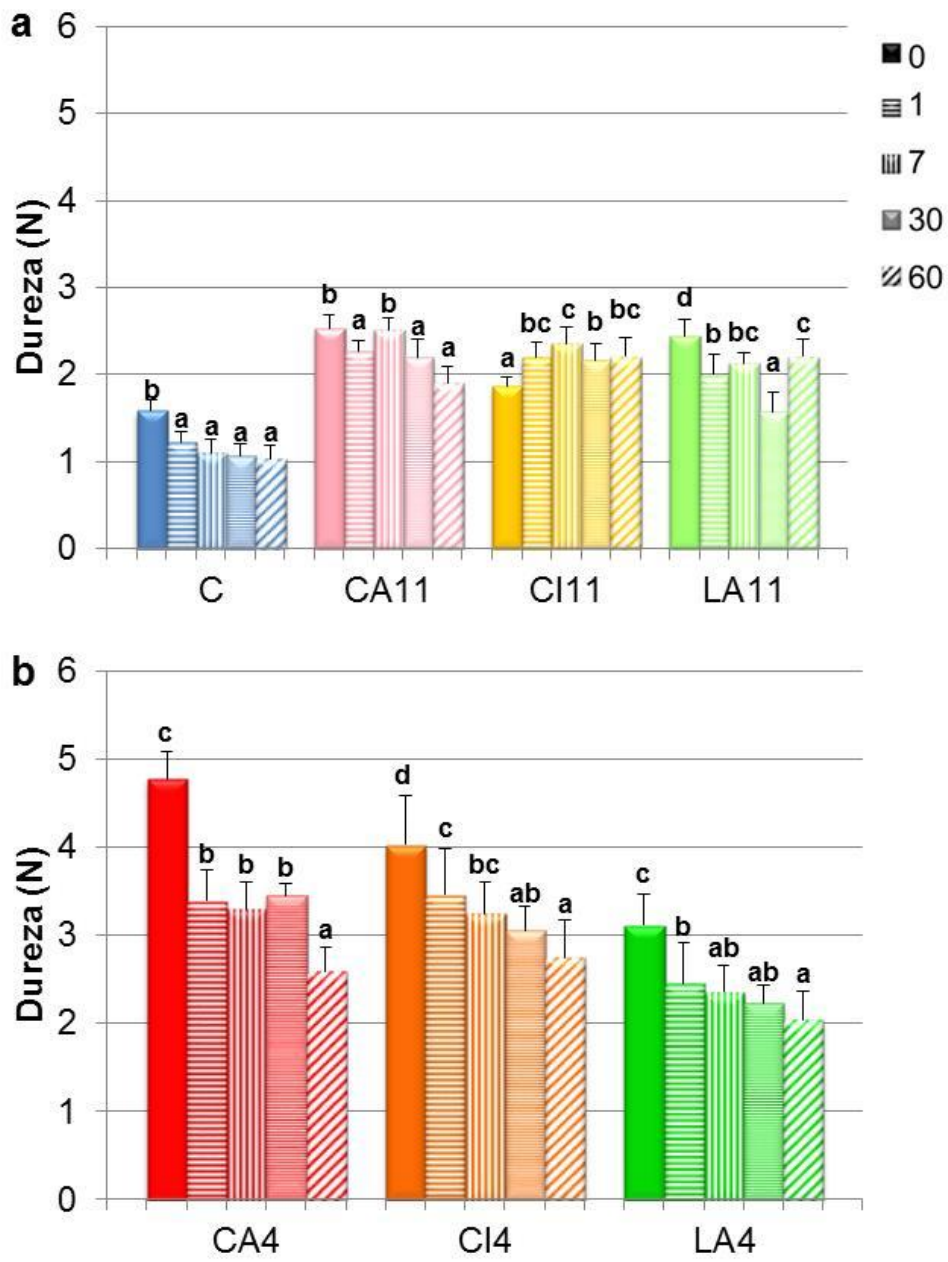

Figura 5.3. Dureza de la masa fresca y almacenada $-18^{\circ} \mathrm{C}$ durante $1,7,30$ y 60 días: a) Masas sin prebiótico, b) Masas con prebiótico. Barras: desviación estándar. Letras diferentes indican diferencias significativas para la misma formulación entre 0 y 60 días. 
La adhesividad de las masas se muestra en la Figura 5.4. Los valores de adhesividad de las masas frescas son levemente diferentes a los valores presentados en la sección 3 debido a que se ha utilizado otra partida de harina. Se encontró que la masa control fue la menos adhesiva, y el agregado de sales no aumentó sustancialmente la adhesividad (Figura 5.4.a), pero sí la incorporación de $I n$; las masas con calcio e inulina presentaron la mayor adhesividad (Figura 5.4.b). Este comportamiento se observó a todos los tiempos.

La adhesividad de la masa control luego de 60 días de congelación fue significativamente menor. Las masas con carbonato y citrato no cambiaron su adhesividad con el almacenamiento, mientras que en el caso del lactato de calcio disminuyó significativamente (Figura 5.4.a). En presencia del prebiótico, el $\mathrm{CaCO}_{3}$ y $\mathrm{Ca}_{3} \mathrm{Cl}_{2}$ disminuyeron la adhesividad de la masa, mientras que esta propiedad no varió con el $\mathrm{CaLA}_{2}$ (Figura 5.4.b). Este comportamiento sugiere que el prebiótico protege a la masa del efecto desestabilizante del ión lactato.
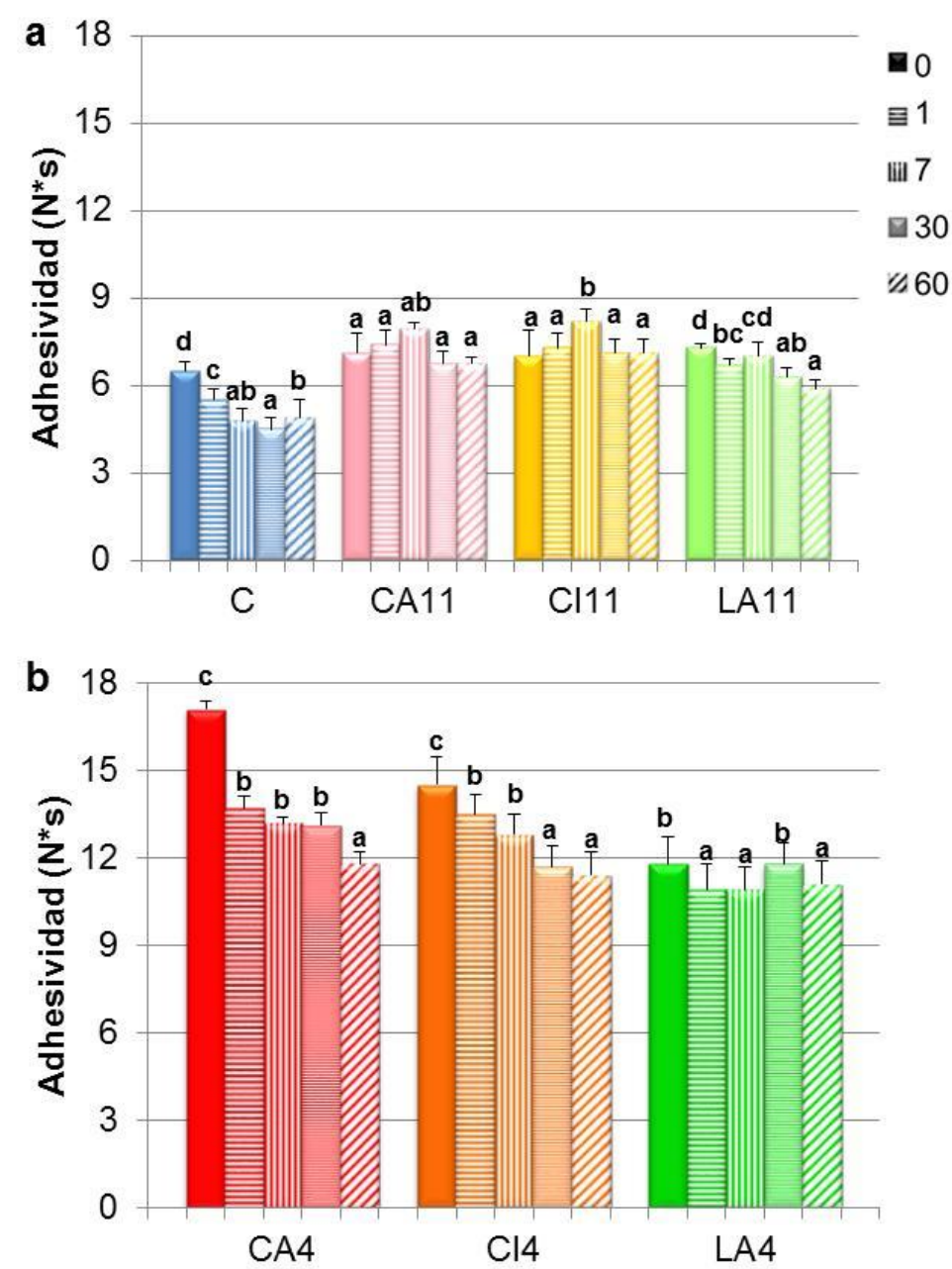

Figura 5.4. Adhesividad de la masa fresca masa fresca y almacenada $-18{ }^{\circ} \mathrm{C}$ durante $1,7,30$ y 60 días: a) Masas sin prebiótico, b) Masas con prebiótico. Barras: desviación estándar. Letras diferentes indican diferencias significativas para la misma formulación entre 0 y 60 días. 
La elasticidad, a igual tiempo de almacenamiento, cambió con la formulación (Figura 5.5). Tanto en ausencia como en presencia del prebiótico, masas con $\mathrm{CaLA}_{2}$ presentaron una disminución significativa en la elasticidad luego de 60 días de almacenamiento congelado.
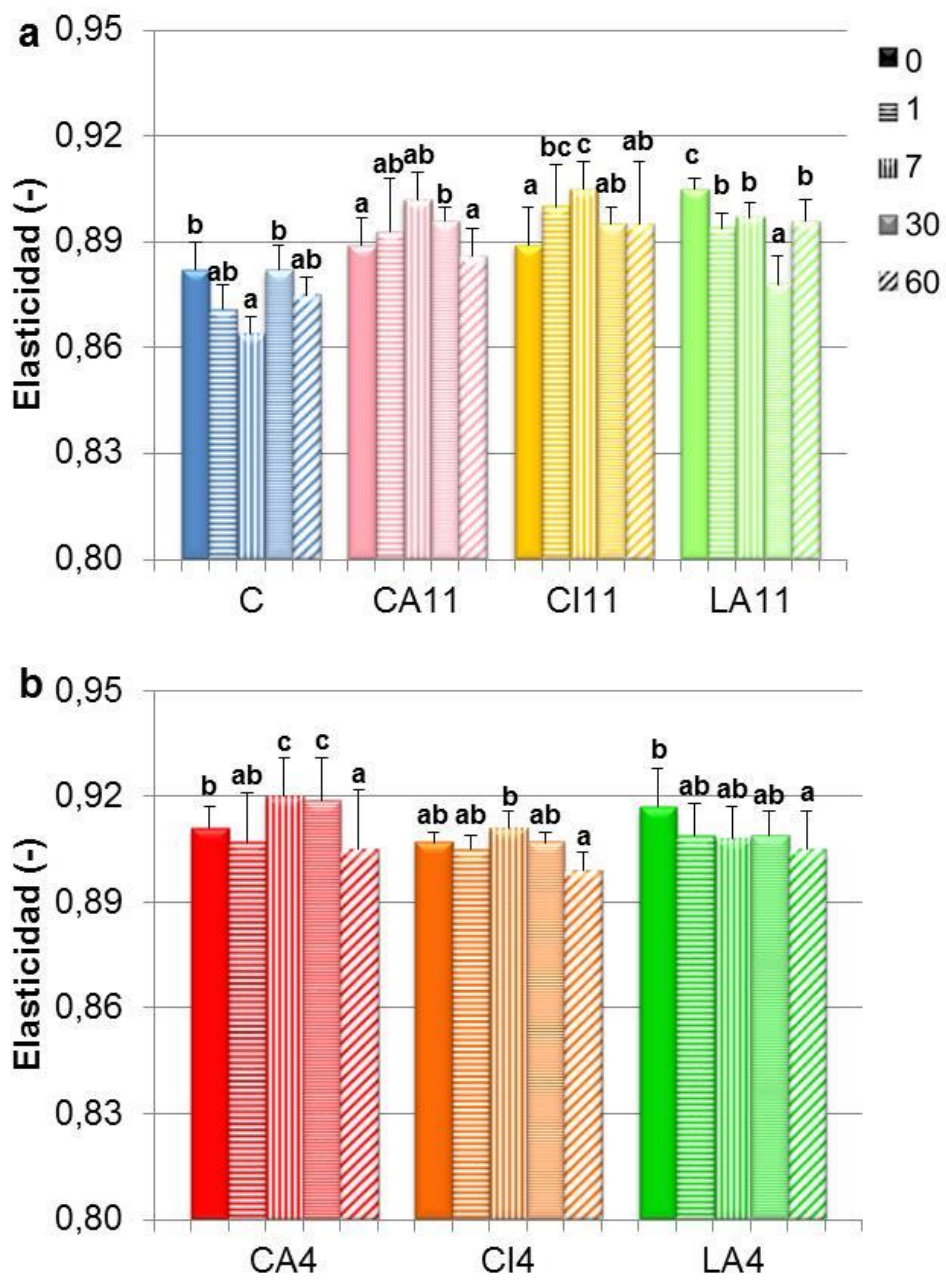

Figura 5.5. Elasticidad de las masa fresca y almacenada - $18{ }^{\circ} \mathrm{C}$ durante $1,7,30$ y 60 días: a) Masas sin prebiótico, b) Masas con prebiótico. Barras: desviación estándar. Letras diferentes indican diferencias significativas para la misma formulación entre 0 y 60 días.

\subsubsection{Ensayo reológico dinámico}

En este ensayo se determinaron en condiciones de viscoelasticidad lineal, el módulo elástico $\left(G^{\prime}\right)$ a $1 \mathrm{~Hz}$ de frecuencia y la tan $\delta$ que relaciona los módulos elástico y viscoso (tan $\delta=G^{\prime \prime} / G^{\prime}$ ); con éste último parámetro se tiene una idea más global del comportamiento viscoelástico de las diferentes masas. 
En la Figura 5.6 se muestra el parámetro G' de las masas frescas y descongeladas al final del periodo de almacenamiento (60 días). La masa control presentó el menor modulo elástico. Las masas tratadas a tiempos intermedios dieron resultados semejantes a los obtenidos con 60 días de congelación (datos no mostrados). Las masas con $\mathrm{Ca}$ e In presentaron mayor G' que las elaboradas en ausencia de prebiótico.

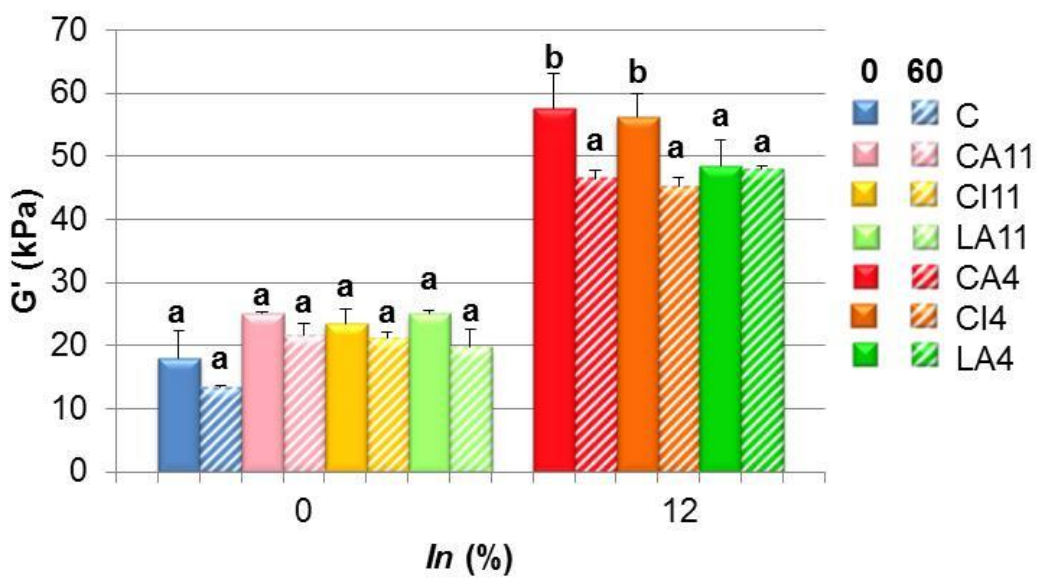

Figura 5.6. Módulo elástico de las masas frescas y almacenada $-18{ }^{\circ} \mathrm{C}$ durante 60 días. Barras: desviación estándar. Letras diferentes indican diferencias significativas para la misma formulación.

Las masas con $\mathrm{CaCO}_{3}$ y $\mathrm{Ca}_{3} \mathrm{Cl}_{2}$ disminuyeron significativamente el $\mathrm{G}$ ' con el almacenamiento en presencia de $I n$, mientras que las masas con $\mathrm{CaLA}_{2}$ no lo modificaron, ejerciendo la In un efecto protector frente a la desestructuración de la matriz por parte del ión lactato.

Los valores de la tangente del ángulo de desfasaje se presentan en la Figura 5.7. No se encontraron diferencias significativas en este parámetro al finalizar el almacenamiento para ninguna de las masas estudiadas, indicando que la congelación no produce cambios en la viscoelasticidad de cada masa luego de almacenada 60 días a $-18 \stackrel{\circ}{ } \mathrm{C}$. 


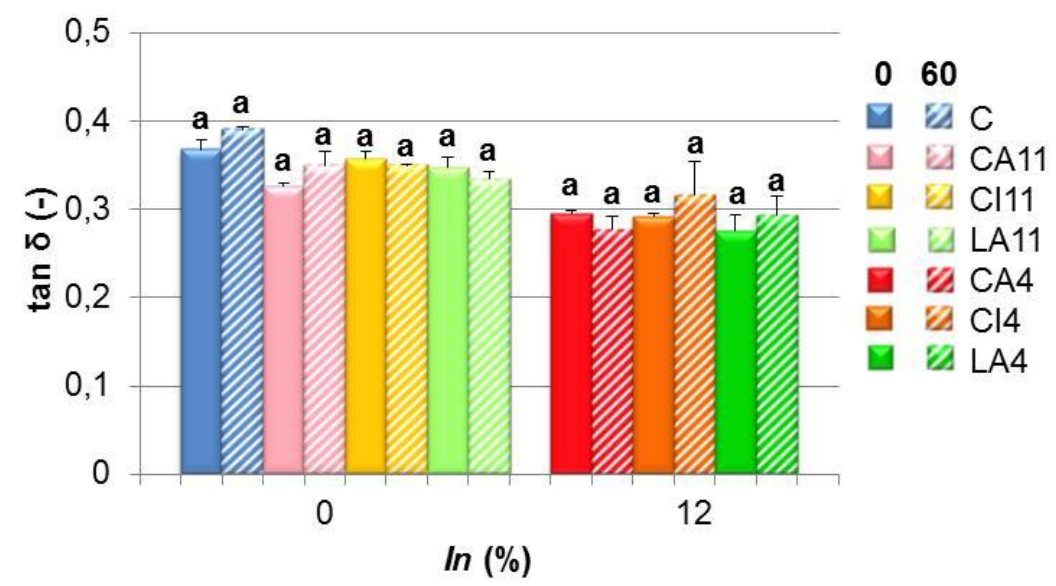

Figura 5.7. Tangente del ángulo de desfasaje de masas fresca y almacenada $-18 \stackrel{\circ}{\circ} \mathrm{C}$ durante 60 días. Barras: desviación estándar. Letras diferentes indican diferencias significativas para la misma formulación.

El comportamiento reológico de las masas no resultó modificado en forma apreciable durante el periodo de congelación estudiado. Sin embargo, uno de los desafíos tecnológicos es elaborar panes frescos a partir de masas congeladas de modo de obtener productos listos para consumir en distintos puntos de venta, por lo que resulta necesario evaluar si hay diferencias en los procesos de fermentación de la masa luego de haber sido sometida a congelación.

\subsection{Optimización de los tiempos de fermentación}

En la Figura 5.8 se muestran algunas de las curvas experimentales de expansión de masas en las que se mide el cambio de volumen $(\Delta V)$ en función del tiempo. A modo ilustrativo se muestran solamente las curvas de las masas C, LA11 y LA4. El aumento de volumen de masa durante la fermentación fue bajo con el calcio (LA11) y más aún con la inulina (LA4), a diferencia del $\Delta \mathrm{V}$ de la masa control (C). Todas las curvas de masas congeladas estuvieron por debajo de las respectivas masas frescas; presentando además de menor volumen y una cinética más lenta de fermentación. Este comportamiento resultó intensificado con mayores tiempos (60 días) de congelación a -18 ํ․ Esta importante disminución del volumen de masa fermentada ejercería una influencia negativa en el volumen de pan. 


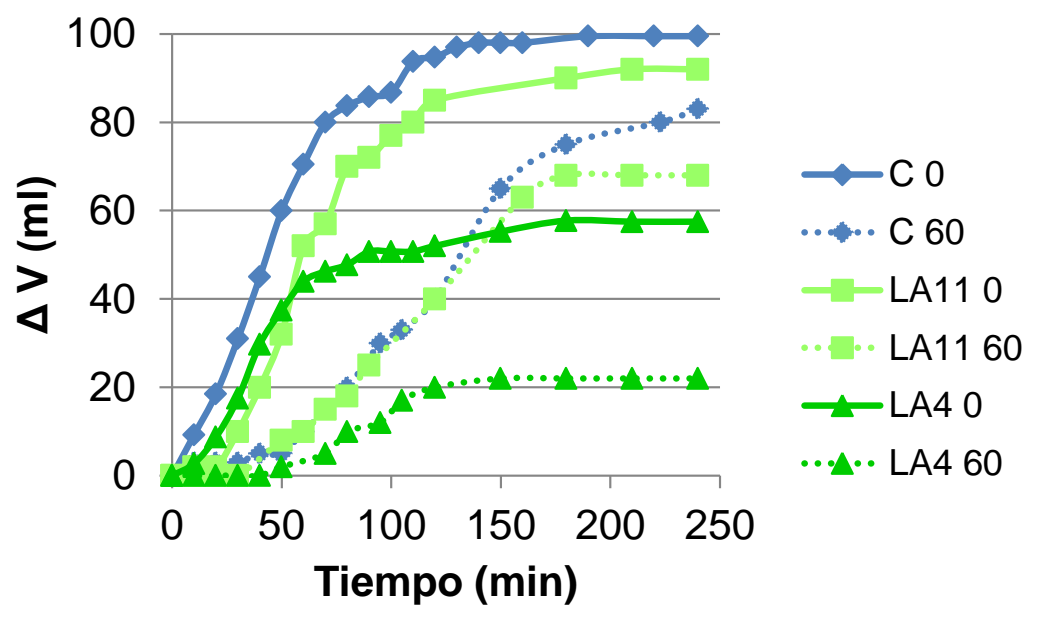

Figura 5.8. Curvas de fermentación obtenida a partir de masas frescas y luego de congelarla durante 60 días.

En la Figura 5.9 se muestran los tiempos de fermentación óptimos $\left(\mathrm{t}_{\mathrm{f}}\right)$ obtenidos a partir de las masas previamente congeladas a distintos días $\left(t_{c}\right)$. Estos $t_{f}$ fueron utilizados para fermentar la masa previo al proceso de horneado. Puede observarse que en todas las formulaciones el $t_{f}$ aumentó significativamente por efecto del almacenamiento a $-18 \stackrel{\circ}{ } \mathrm{C}$. Este mayor $t_{f}$ podría atribuirse a una menor producción de $\mathrm{CO}_{2}$ como consecuencia de un menor número de levaduras activas y/o a la disminución de la habilidad del gluten para retenerlo (Perron y col., 1999; Ribotta y col., 2001). Los metabolitos de la fermentación de las levaduras pueden alterar la estabilidad de los productos congelados. Las levaduras en masas congeladas pueden sufrir pérdida parcial en su capacidad de fermentación ya sea por los efectos fisiológicos sobre las células del agua congelada o por la concentración de ciertos metabolitos de la fermentación (Hsu y col., 1979). 


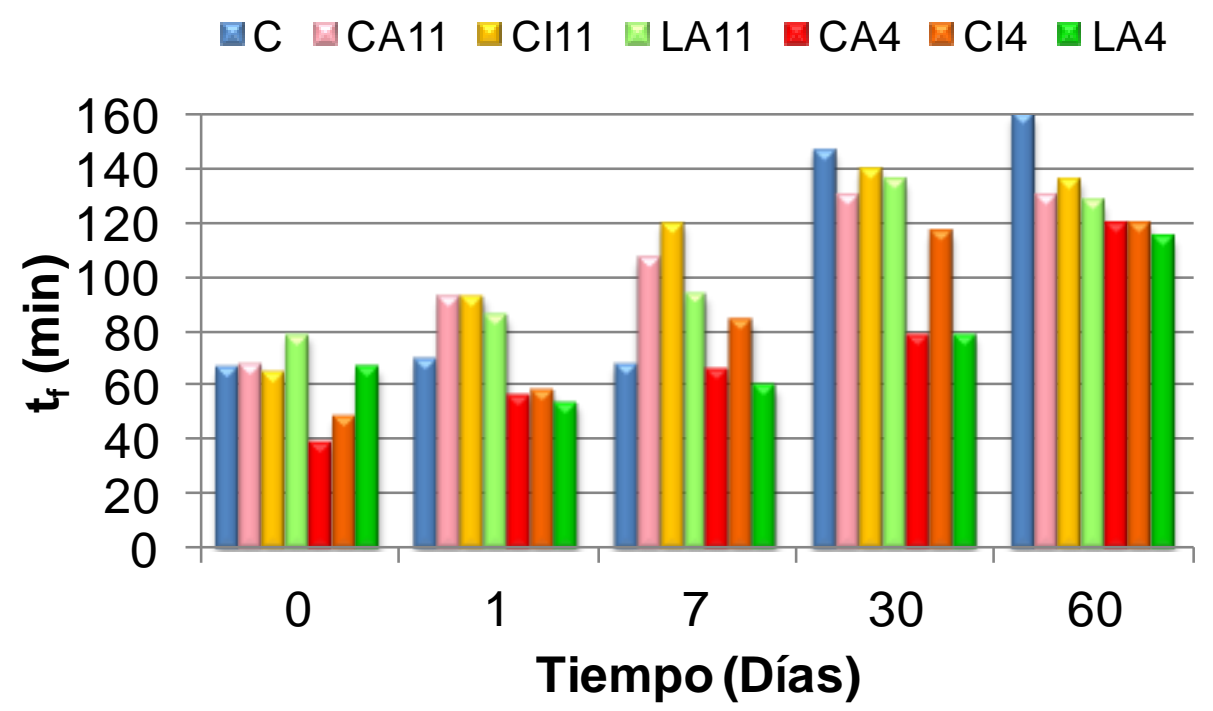

Figura 5.9. Tiempo de fermentación obtenido a partir de las curvas de fermentación. de masa fresca y almacenada $-18 \stackrel{\circ}{\circ}$ durante $1,7,30$ y 60 días.

\subsection{Evaluación de la calidad panadera}

La calidad panadera de piezas elaboradas con masas previamente congeladas se evaluó a través de medidas de volumen específico de pan, color de corteza, firmeza, masticabilidad, humedad y alveolado de la miga.

\subsubsection{Volumen específico}

Los valores de volumen específico $\left(\mathrm{V}_{\mathrm{E}}\right)$ de los panes obtenido a partir de masas frescas y congeladas a $-18^{\circ} \mathrm{C}$ se muestran en la Figura 5.10 .

Si comparamos las diferentes formulaciones en un mismo día, encontramos que los valores de $\mathrm{V}_{\mathrm{E}}$ de los panes con In y $\mathrm{Ca}$ resultaron menores que en ausencia de In, siendo más marcado para los panes con $\mathrm{CaLA}_{2}$. Si comparamos el $\mathrm{V}_{E}$ durante el tiempo de almacenamiento, encontramos que hasta el séptimo día de congelamiento no se observaron diferencias significativas en este parámetro. Pasada una semana de almacenamiento $V_{E}$ disminuyó aunque no significativamente. Finalizada la etapa de almacenamiento, se encontraron menores valores de $V_{E}$ en los panes elaborados con $\mathrm{CaCO}_{3}$ y $\mathrm{Ca}_{3} \mathrm{Cl}_{2}$ en presencia de prebiótico, lo que podría deberse como mencionamos anteriormente, a una menor expansión previa de la masa durante la fermentación (menor $\Delta \mathrm{V}$ ). Al día 60 de almacenamiento el $\mathrm{V}_{\mathrm{E}}$ de LA4 se mantuvo 
significativamente similar al $V_{E}$ de las piezas obtenidas a partir de masas frescas, debido al efecto protector de la inulina del efecto desestabilizador del anión lactato sobre la red de gluten.

Filipović y col. (2010) estudiaron el efecto de diferentes fibras comerciales (5\%) sobre masas congeladas (-18 ํㅡ durante 60 días) para posteriormente utilizarlas en la elaboración de panes. Encontraron un efecto protector de inulina obteniendo una mejora de la calidad del producto final. En cambio, cuando emplearon fructooligosacáridos de menor peso molecular, éstos se incorporaron en la estructura del gluten contribuyendo a un deterioro de la misma, resultando no sólo en una disminución de las propiedades reológicas evaluadas durante la fermentación, sino también en un efecto adverso en el volumen del pan y la calidad de la miga.
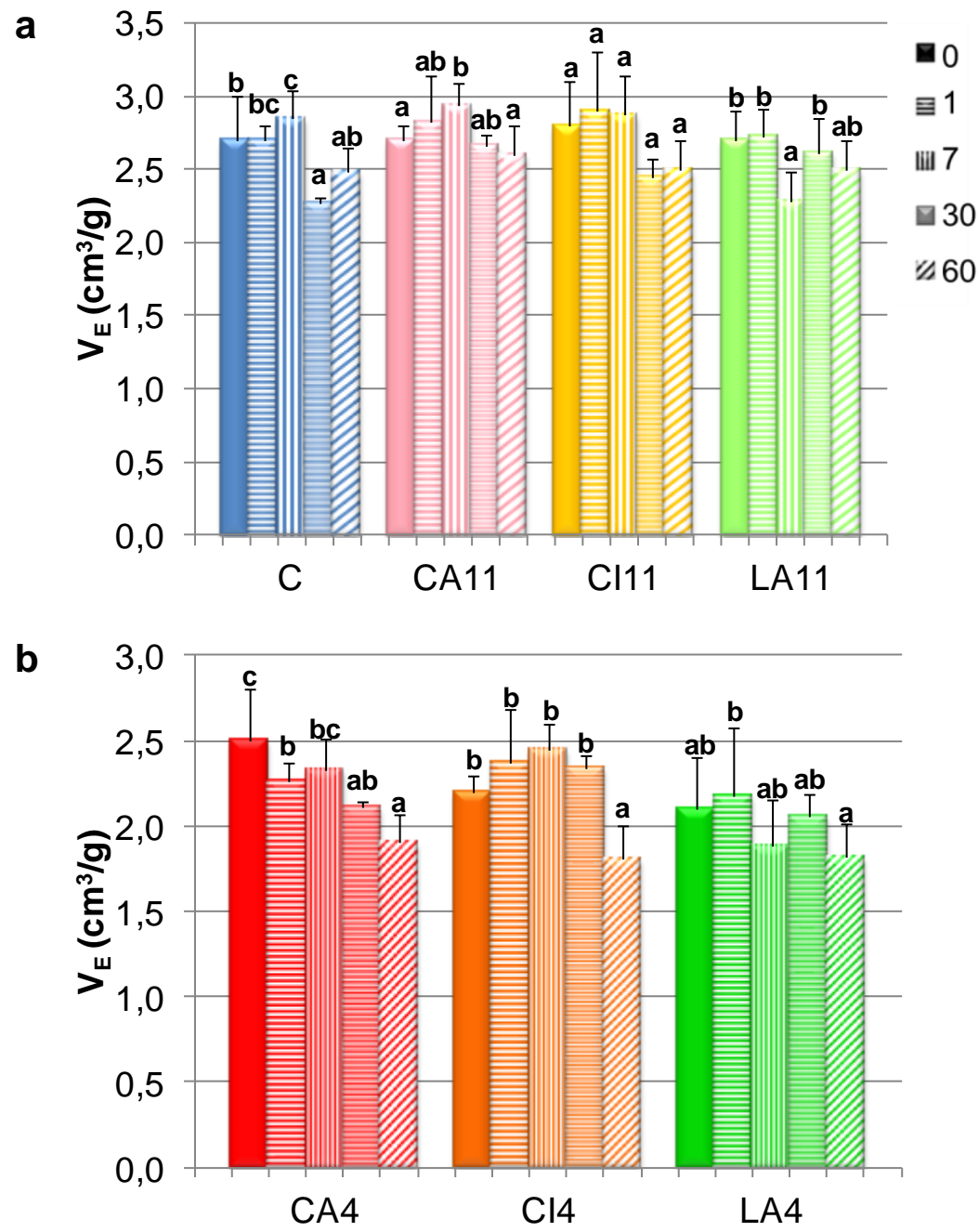

Figura 5.10. Volumen especifico de los panes frescos y congelados a $-18^{\circ} \mathrm{C}$ durante $1,7,30$ y 60 días: a) Masas sin prebiótico, b) Masas con prebiótico. Barras: desviación estándar. Letras diferentes indican diferencias significativas para la misma formulación entre 0 y 60 días. 


\subsubsection{Color de la corteza}

En la Figura 5.11 se muestran los valores del índice de pardeamiento (IP) de la corteza de los panes según lo descripto en la sección 2.2.10.3.2. Las cortezas de los panes elaborados con calcio e In presentaron coloración amarillo-rojiza, y de mayor intensidad que la de los panes conteniendo solamente calcio o el pan control. Las masas congeladas dieron panes con altos valores de IP para todas las formulaciones. Los panes con $\mathrm{CaCO}_{3}$ y $\mathrm{Ca}_{3} \mathrm{Cl}_{2}$ incrementaron significativamente el IP por la congelación de la masa durante 60 días a $-18^{\circ} \mathrm{C}$; mientras que este aumento se observó en todas las cortezas de los panes con In, especialmente para el caso del $\mathrm{CaLA}_{2}$. Estos mayores valores de IP, asociados a cortezas más coloreadas, se corresponden con una mayor formación de compuestos coloreados productos de la reacción de Maillard.

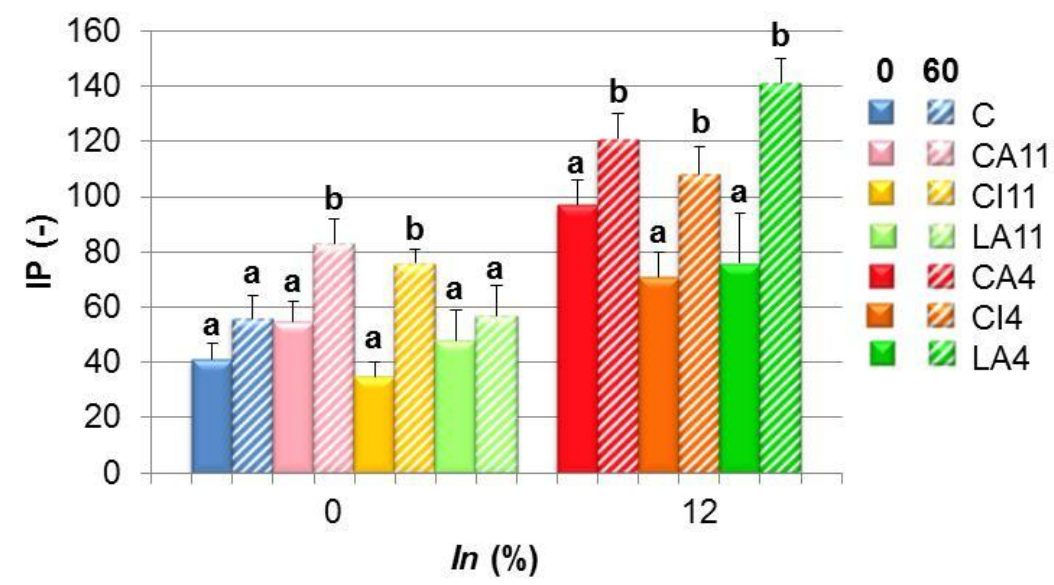

Figura 5.11. Índice de pardeamiento de los panes frescos y congelados a - 18ำ durante 60 días. Barras: desviación estándar. Letras diferentes indican diferencias significativas para la misma formulación.

\subsubsection{Perfil de textura de la miga}

De todos los parámetros obtenidos a partir del análisis de perfil de textura de la miga de pan, se analizaron en éste capítulo sólo la firmeza y masticabilidad de la miga. Faridi y Faubion (1990) encontraron que ambos parámetros correlacionan fuertemente con la percepción de la frescura del pan por parte de los consumidores. 
La firmeza de la miga de pan obtenido a partir de la formulación control aumentó con el tiempo de almacenamiento de la masa en estado congelado (Tabla 5.1). Diversos autores encontraron resultados en este mismo sentido atribuyendo a que el aumento de la firmeza podría ser debido a la pérdida de agua durante el almacenamiento de la masa a $-18^{\circ} \mathrm{C}$ (Wang y col., 2006; Giannou y Tzia, 2007; Phimolsiripol y col., 2008, Yi y Kerr, 2009). En nuestro caso las piezas de masa previamente moldeadas fueron almacenadas en forma individual envueltas en film, de manera que no perdieron humedad; aunque no se pudo mitigar la migración de agua dentro del sistema, cambiando su disponibilidad.

En general, los panes elaborados con las diferentes sales de calcio tanto con como sin el prebiótico aumentaron también la firmeza de la miga de pan con 60 días de almacenamiento de las masas en estado congelado (Tabla 5.1). En presencia de In se observó una relación inversa con el volumen específico del pan. Por lo tanto el incremento en la firmeza de la miga de pan está probablemente relacionado con la disminución del volumen (Inoue y Bushuk, 1992, Berglund y Shelton, 1993). A 60 días, la firmeza de las migas obtenidas a partir de panes con calcio no difirió significativamente de la del pan control. En presencia del prebiótico y con $\mathrm{CaCO}_{3}$ y $\mathrm{CaLA}_{2}$ este comportamiento resultó acentuado. La inulina refuerza la red de gluten, provoca masas más elásticas aunque se forman panes de menor volumen con migas más firmes.

Tabla 5.1. Efecto de los factores empleados sobre la firmeza y masticabilidad de miga de pan.

\begin{tabular}{|c|c|c|c|c|c|c|}
\hline & \multirow{2}{*}{$\begin{array}{c}\mathrm{Ca} \\
(\mathrm{ppm})\end{array}$} & \multirow{2}{*}{$\begin{array}{l}\text { In } \\
(\%)\end{array}$} & \multicolumn{2}{|c|}{$\begin{array}{l}\text { Firmeza miga } \\
\text { (N) }\end{array}$} & \multicolumn{2}{|c|}{$\begin{array}{l}\text { Masticabilidad miga } \\
\qquad(\mathrm{N})\end{array}$} \\
\hline & & & $\begin{array}{l}\text { Miga pan * } \\
(\text { tc }=0 \text { d) }\end{array}$ & $\begin{array}{l}\text { Miga pan ** } \\
(\mathrm{tc}=60 \mathrm{~d})\end{array}$ & $\begin{array}{c}\text { Miga pan * } \\
(\mathrm{tc}=0 \mathrm{~d})\end{array}$ & $\begin{array}{l}\text { Miga pan ** } \\
(\mathrm{tc}=60 \mathrm{~d})\end{array}$ \\
\hline C & 0 & 0 & $10,4 \mathbf{b}$ & $14,6 \mathbf{a}$ & $5,1 \mathrm{c}$ & $7,1 \mathbf{b}$ \\
\hline CA11 & 1800 & 0 & $7,8 \mathbf{a}$ & $12,6 \mathbf{a}$ & 4,9 bc & $6,0 \mathbf{a}$ \\
\hline Cl11 & 1800 & 0 & $7,0 \mathbf{a}$ & $12,6 \mathbf{a}$ & $3,7 \mathbf{a}$ & $6,0 \mathbf{a}$ \\
\hline LA11 & 1800 & 0 & $8,8 \mathbf{a}$ & $12,6 \mathbf{a}$ & $4,3 \mathbf{a b}$ & $6,0 \mathbf{a}$ \\
\hline CA4 & 2400 & 12 & $10,7 \mathbf{b}$ & $28,5 \mathrm{c}$ & $9,4 \mathbf{e}$ & $11,4 \mathrm{c}$ \\
\hline $\mathrm{Cl} 4$ & 2400 & 12 & 12,7 c & $17,1 \mathbf{b}$ & $8,5 \mathbf{d}$ & $7,1 \mathbf{b}$ \\
\hline LA4 & 2400 & 12 & $13,4 \mathrm{c}$ & $27,5 \mathrm{c}$ & $8,8 \mathrm{de}$ & $10,8 \mathrm{c}$ \\
\hline
\end{tabular}

En una misma columna letras distintas indican diferencias significativas con $p<0,05$.

* Panes obtenidos a partir de masas sin congelar, ${ }^{* *}$ Panes obtenidos de masas congeladas a $-18 \stackrel{\circ}{\circ}$ durante 60 días. 
El efecto del almacenamiento en estado congelado sobre la masticabilidad de la miga de pan fue similar al observado con la firmeza (Tabla 5.1).

\subsubsection{Humedad de la miga}

Se encontró que la humedad de la miga del pan $C$ fue la mayor (Figura 5.12) y se retuvo más agua en la miga de este pan cuando se elaboró a partir de masa congelada. Los panes con sales de calcio, debido al tratamiento, retuvieron menos agua. A diferencia de lo observado en masas (Figura 5.1), las sales por sí solas no logran retener la humedad de la miga durante el horneado, quizá porque interfieren en la interacción agua-proteína de gluten. Esta menor humedad de la miga obtenida a partir de masas congeladas podría ser la responsable de una mayor firmeza, ya que no hubo cambios en el $V_{E}$.

Las migas con sales de calcio orgánicas en presencia de prebiótico ( $\mathrm{Cl} 4$ y LA4) presentaron mayor humedad luego del almacenamiento de la masa.

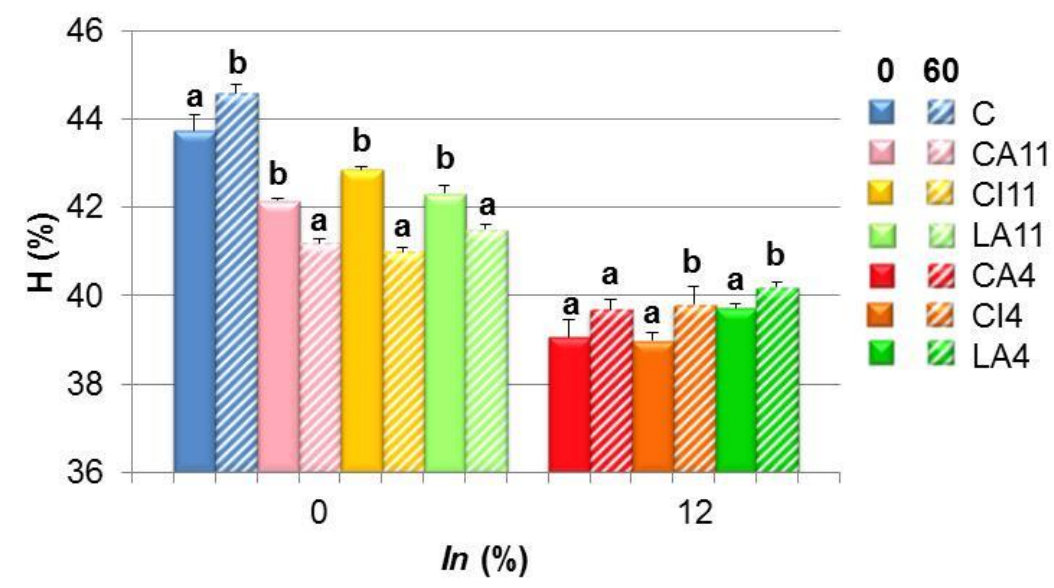

Figura 5.12. Humedad de las migas de los panes obtenidos a partir de masa fresca y congelada a $-18{ }^{\circ} \mathrm{C}$ durante 60 días. Barras: desviación estándar. Letras diferentes indican diferencias significativas para la misma formulación.

\subsubsection{Alveolado de la miga}

El efecto del almacenamiento congelado de la masa en el alveolado de la miga se estudió por medio de análisis de imagen, analizando el número de alvéolos $(\mathrm{N})$, el área media alveolar (AM) y el porcentaje de aire o de área ocupada por alvéolos (AT). 
El efecto de la congelación de la masa influyó en el número de alvéolos $/ \mathrm{cm}^{2}$ de las migas de panes C y LA4 (Figura 5.13). Con el tratamiento, las migas control y con $\mathrm{CaLA}_{2}$ e In presentaron un menor número de alveolos, $48 \%$ menos que las migas obtenidas de masas frescas (LA4).

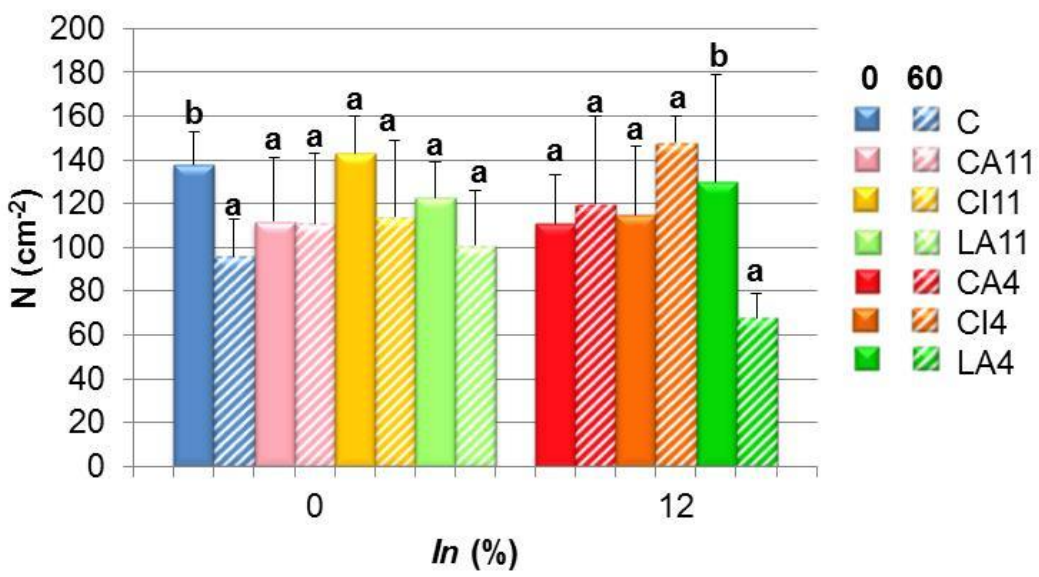

Figura 5.13. Numero de alveolo por unidad de área de las migas de los panes obtenidos a partir de masa fresca y congelada a $-18 \stackrel{\circ}{ } \mathrm{C}$ durante 60 días. Barras: desviación estándar. Letras diferentes indican diferencias significativas para la misma formulación.

Luego de almacenar las masas 60 días, la miga control presentó un aumento significativo del área media (AM) (Figura 5.14); junto con una disminución de $\mathrm{N}$ podemos dilucidar que la miga control obtenida luego del almacenamiento de la masa presentó menos alvéolos pero de mayor tamaño, por lo que la estructura de la miga se encuentra más abierta, debido posiblemente a la rotura mecánica de la red de gluten como consecuencia de los cristales de hielo en la masa durante su congelación. Mediante SEM se pudo confirmar el efecto nocivo de la formación de los cristales de hielo en masas no fermentadas y almacenadas en estado congelado (Ribotta y col., 2009). 


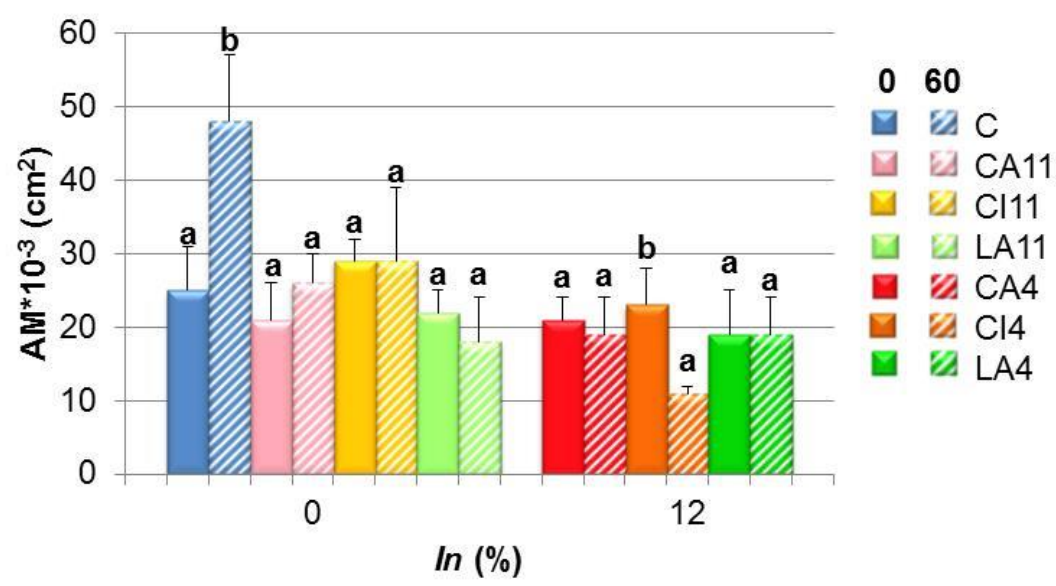

Figura 5.14. Área media del alveolo de las migas de los panes obtenidos a partir de masa fresca y congelada a $-18{ }^{\circ} \mathrm{C}$ durante 60 días. Barras: desviación estándar. Letras diferentes indican diferencias significativas para la misma formulación.

La miga control presentó un mayor porcentaje de aire (Figura 5.15) y resultó más húmeda, por lo que se esperaría que fuera más blanda; hecho que no fue evidenciado. La estructura de la miga es más abierta, pero como presenta menor diámetro la rodaja la firmeza es mayor. Las migas provenientes de masas congeladas con $\mathrm{CaCO}_{3}$ presentaron mayor AT; las de $\mathrm{CaLA}_{2}$ con In presentaron la menor AT y la mayor dureza.

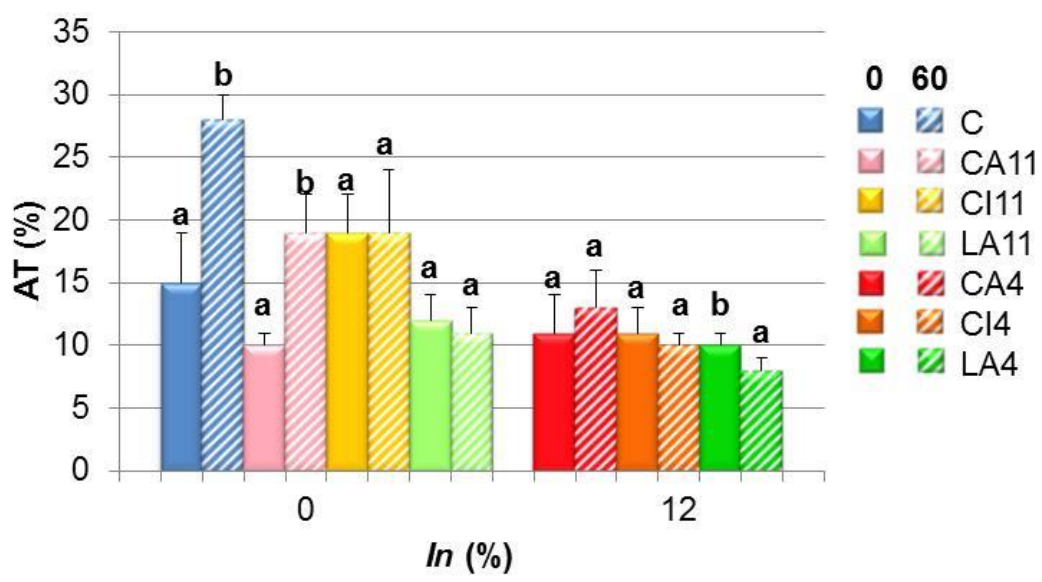

Figura 5.15. Área total de aire ocupado por los alveolo se las migas de los panes obtenidos a partir de masa fresca y congelada a $-18 \stackrel{\circ}{ } \mathrm{C}$ durante 60 días. Barras: desviación estándar. Letras diferentes indican diferencias significativas para la misma formulación. 


\section{Conclusiones parciales}

Los valores de humedad y $a_{w}$ de las masas descongeladas, sugieren que durante el almacenamiento no hubo deshidratación de las masas pero sí cambios en la movilidad y disponibilidad de agua en presencia del prebiótico.

La dureza y adhesividad de la masa control disminuyeron luego de finalizado el periodo de almacenamiento. El agregado de $\mathrm{CaCO}_{3}$ y $\mathrm{CaLA}_{2}$ ablandó la masa a diferencia de $\mathrm{Ca}_{3} \mathrm{Cl}_{2}$ que la endureció. En presencia del prebiótico las masas se ablandaron aunque presentaron menor adhesividad. No se vio afectado el comportamiento viscoelástico de todas las masas durante el almacenamiento en el periodo de congelación estudiado.

Los tiempos de fermentación aumentaron durante el almacenamiento, como consecuencia de la muerte/inactivación de las levaduras; por lo que quedaría a futuro estudiar el efecto de la congelación de panes pre-cocidos en lugar de la de masas, para evitar este inconveniente tecnológico.

En ausencia de prebiótico $\left(\mathrm{CaCO}_{3}\right.$ y $\left.\mathrm{Ca}_{3} \mathrm{Cl}_{2}\right)$, no se modificó el volumen específico pero la miga fue menos húmeda y por lo tanto más dura en presencia de todas las sales de calcio usadas. Los panes con prebióticos, presentaron migas más húmedas aunque mucho más firmes luego del almacenar la masa en estado congelado; este efecto se corresponde con el menor volumen específico obtenido. El excesivo aumento de la firmeza de la miga LA4 podría deberse a una disminución en la proporción de aire retenido en los alveolos ya que no resultó afectado el volumen especifico.

De todas las formulaciones estudiadas, los panes con sales de calcio que estabilizan la red de gluten $\left(\mathrm{Ca}_{3} \mathrm{Cl}_{2}\right.$ y $\left.\mathrm{CaCO}_{3}\right)$ en presencia de prebiótico presentaron menor $\mathrm{V}_{\mathrm{E}}$, mayor firmeza y similitud en el alveolado; a diferencia de los panes con CaLA $\mathrm{A}_{2}$ en los que no se modificó el $V_{E}$ pero las migas fueron muy firmes y con poco aire retenido en la miga. Por lo tanto esta tecnología sería útil aplicarla a masas con $\mathrm{CaCO}_{3}$ y fundamentalmente con $\mathrm{Ca}_{3} \mathrm{Cl}_{2}$, ya que esta última sal produce un menor incremento en la firmeza comparada con la sal inorgánica. 
Se debe corroborar que el calcio incorporado al producto, además de que forme panes de buena calidad y permita aplicar tecnología de congelación, sea efectivamente absorbido y aprovechado por el organismo por lo que es necesaria la realización de ensayos nutricionales de algunas de las formulaciones. 
CAPÍTULO 6 


\subsection{Estudios nutricionales in vitro realizados sobre los panes}

\subsubsection{Determinación de la composición porcentual de los panes}

La composición centesimal de los panes óptimos frescos se determinó según se describió en la sección 2.2.15.1.1 y se muestra en la Tabla 6.1. Los panes resultaron semejantes en composición, a excepción del contenido de FOS/In, resultado esperable teniendo en cuenta las formulaciones óptimas.

Tabla 6.1. Composición porcentual del pan óptimo.

\begin{tabular}{c|ccc}
\hline \multirow{2}{*}{ Componente } & \multicolumn{3}{|c}{ Composición porcentual (\%) } \\
\cline { 2 - 4 } & CA op & Cl op & LA op \\
\hline Humedad & $39,07 \pm 0,04$ & $40,20 \pm 0,38$ & $40,60 \pm 0,05$ \\
Proteínas & $6,382 \pm 0,015$ & $6,465 \pm 0,005$ & $6,582 \pm 0,003$ \\
Lípidos & $2,96 \pm 0,34$ & $2,89 \pm 0,43$ & $3,13 \pm 0,40$ \\
Cenizas & $1,431 \pm 0,070$ & $1,729 \pm 0,069$ & $1,546 \pm 0,050$ \\
FOS/In & $8,14 \pm 0,08$ & $7,12 \pm 0,08$ & $5,80 \pm 0,27$ \\
Hidratos de carbono* & 42,02 & 41.60 & 42.34 \\
\hline
\end{tabular}

${ }^{*}$ Los hidratos de carbono provenientes de la harina se calcularon por diferencia.

\subsubsection{Digestibilidad in vitro de almidón y estimación del índice glicémico}

En los alimentos la digestibilidad y la absorción del almidón varían tanto in vitro como in vivo, dependiendo del contenido de amilosa y amilopectina, del grado de gelatinización, de la cantidad y tipo de fibra presente en el alimento, además del pH y de las interacciones entre proteínas.

Durante la cocción, el almidón es gelatinizado y se va a digerir más rápidamente debido a los cambios estructurales que favorecen un mejor acceso de las enzimas hidrolíticas a este polímero.

Es importante conocer la velocidad de digestión del almidón, porque aquellos que se absorben rápidamente producen en la sangre un aumento rápido y alto de la glucemia seguida de una caída abrupta; en cambio aquellos que tienen digestión lenta producen curvas aplanadas y sostenidas. El procesamiento incrementa la disponibilidad enzimática del almidón a diferentes grados, no obstante, la fibra dietética y el almidón 
resistente tienen un efecto opuesto, restringiendo o evitando la digestión (Schmiedl y col., 2000).

En este trabajo de tesis se estudió la cinética de hidrolisis de almidón de los panes óptimos y del pan control, el cual se utilizó como referencia. En este ensayo cinético se evaluaron los miligramos de azucares reductores (principalmente maltosa) formados en el tiempo como consecuencia de la hidrólisis enzimática del almidón (Figura 6.1). El pan control presentó a los $60 \mathrm{~min}$ un valor de $65 \mathrm{mg}$ maltosa/g almidón, en cambio los panes óptimos elaborados con $\mathrm{CaCO}_{3}, \mathrm{CaLA}_{2}$ y $\mathrm{Ca}_{3} \mathrm{Cl}_{2}$ presentaron 32,0, 31,5 y 34,0 mg maltosa/g almidón, respectivamente. Estos resultados sugieren que en los panes con agregado de calcio e inulina, la presencia de estos componentes, principalmente del prebiótico disminuyeron el contenido de almidón disponible, haciéndolo poco accesible a la hidrólisis enzimática.

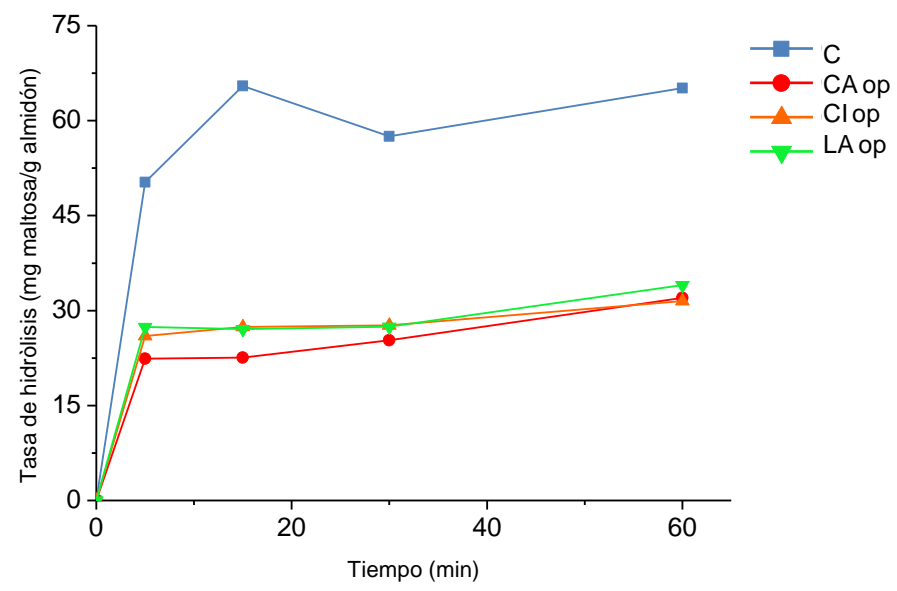

Figura 6.1. Cinética de hidrólisis de almidón de los panes: pan control (C), pan con $\mathrm{CaCO}_{3}(\mathrm{CA}$ op), pan con $\mathrm{Ca}_{3} \mathrm{Cl}_{2}$ (Cl op) y pan con $\mathrm{CaLA}_{2}$ (LA op).

El índice glicémico (IG) es un biomarcador que cuantifica en forma estandarizada la respuesta glicémica. Permite la clasificación de los hidratos de carbono $(\mathrm{CHO})$ de los alimentos en dos grupos: aquellos cuyo consumo provoca un efecto glicémico alto y los que producen un efecto glicémico bajo. Este indicador, propuesto por Jenkins y col. (1981) obedece a la necesidad de distinguir el efecto fisiológico de los CHO independientemente de la complejidad de su estructura (simple o compleja), en tanto son capaces de elevar la glicemia y la insulinemia, así como también de producir saciedad. Por lo tanto, es un indicador de la calidad saludable de los alimentos respecto a sus $\mathrm{CHO}$. La literatura refiere valores de IG iguales o superiores a 70 como poco saludables y menores a 40-45 como saludables y por lo tanto, recomendables (Levitan y col., 2007, Hare-Bruun y col., 2006). EI IG se determina midiendo el 
contenido de glucosa en sangre en función del tiempo que produce el consumo de 50 $\mathrm{g}$ de $\mathrm{CHO}$ de un alimento estándar en relación con la que produce el consumo de $50 \mathrm{~g}$ de $\mathrm{CHO}$ del alimento ensayo. Se expresa como porcentaje de la relación entre el área bajo la curva del alimento y la del patrón. Como patrón de referencia se emplean la glucosa y el pan blanco, ya que ambos producen curvas glicémicas altas y amplias. En consecuencia, el pan blanco es el alimento patrón y presenta un IG de 100 (Mathers y Wolever, 2002).

Teniendo en cuenta los costos y la complejidad de este tipo de determinaciones, se han desarrollado métodos in vitro a fin de estimar las respuestas de diversos alimentos (Granfeldt y col., 1992, Goñi y col., 1997, Englyst y col., 1999, Araya y col., 2002).

En este trabajo, dada la similitud en la forma de la curva, se predijo el índice glicémico (IG) in vitro como la relación de áreas debajo de la curva de la cinetica de hidrólisis de almidón entre cada pan óptimo y el pan control, considerando $100 \%$ el area para este último. Los valores de IG de los panes óptimos fueron 45, 50, y 47\% para CA, Cl y LA, respectivamente. Los valores de IG de estos panes los hace atractivos para el diseño de dietas, no sólo para las personas con deficiencia de calcio sino también para personas diabéticas, ya que el incremento de glucosa en sangre sería menor si la persona consumiera estos panes elaborados con calcio y prebiótico. De todos modos, este comportamiento debería ser corroborado con ensayos in vivo.

\subsubsection{Disponibilidad de minerales}

La fortificación de alimentos para el consumo masivo es una importante estrategia para mejorar la situación nutricional de las poblaciones. Revisten particular importancia las deficiencias de minerales como hierro $(\mathrm{Fe})$, cinc $(\mathrm{Zn})$ y calcio $(\mathrm{Ca})$. La principal causa de deficiencia para estos minerales puede ser una menor ingesta y/o menor biodisponibilidad de los mismos en los alimentos consumidos por la población.

La biodisponibilidad depende tanto de factores exógenos como endógenos (secreciones digestivas, estado de los depósitos y velocidad de eritropoyesis, entre otros). Entre los factores exógenos encontramos a distintos componentes de los alimentos: los inhibidores como fitatos, fosfatos, polifenoles u otros minerales y los promotores como ácido ascórbico, citrato y proteínas cárnicas (Pita Martín de Portela, 2003).

Para que la fortificación con minerales sea efectiva debe seleccionarse una combinación de un compuesto de fortificación con un alimento-vehículo que sea segura y aceptable por la población a la que está dirigida. No debe afectar 
adversamente la calidad organoléptica y la vida útil del alimento y debe proveer Fe y/o Ca en una forma estable y de alta biodisponibilidad (Martinez-Navarrete y col., 2002).

El pan es un excelente vehículo para la fortificación con minerales.

La dializabilidad de los minerales $\left(D_{M}\right)$ como un indicador de la biodisponibilidad potencial fue determinada por medio del método in vitro según se describió en la sección 2.2.15.1.3.

En la Tabla 6.2 se muestra los valores de dializabilidad de los diferentes minerales de los panes óptimos. La dializabilidad del hierro $\left(\mathrm{D}_{\mathrm{Fe}}\right)$ fue estadísticamente diferente en los tres panes, presentando mayor valor el pan óptimo elaborado con $\mathrm{Ca}_{3} \mathrm{Cl}_{2}$. Este último pan presentó también mayor dializabilidad de $\mathrm{Zn}$ y de $\mathrm{Ca}$, lo que hace a este pan un vehículo importante, no sólo para favorecer la disponibilidad del calcio sino también para la del hierro y zinc, ambos minerales también importantes en la nutrición.

Tabla 6.2. Dializabilidad mineral en panes óptimos.

\begin{tabular}{l|ccc}
\hline & $\mathbf{C A}$ & $\mathbf{C l}$ & $\mathbf{L A}$ \\
\hline $\mathbf{D}_{\mathrm{Fe}}$ & $16,5 \pm 1,2 \mathbf{a}$ & $26,9 \pm 0,9 \mathbf{c}$ & $18,5 \pm 1,1 \mathbf{b}$ \\
$\mathbf{D}_{\mathrm{Zn}}$ & $20,7 \pm 2,1 \mathbf{a}$ & $39,7 \pm 1,0 \mathbf{b}$ & $22,6 \pm 2,2 \mathbf{a}$ \\
$\mathbf{D}_{\mathrm{Ca}}$ & $24,8 \pm 2,1 \mathbf{a}$ & $28,7 \pm 1,9 \mathbf{b}$ & $23,6 \pm 0,5 \mathbf{a}$ \\
\hline
\end{tabular}

Letras diferentes en una misma fila indican diferencias significativas.

Los ácidos orgánicos actúan como promotores de la absorción mineral. En esta matriz alimentaria el citrato resultó más eficiente que el lactato para aumentar la disponibilidad potencial de los tres minerales estudiados.

\subsection{Ensayo de experimentación sobre modelo animal}

\subsubsection{Elaboración de las dietas}

Para los ensayos in vivo se utilizó pan elaborado con carbonato de calcio, formulación CA4, el cual fue secado, molido y almacenado en bolsas cerradas en cámara de $4^{\circ} \mathrm{C}$ durante toda la experiencia. Para poder elaborar dietas isocalóricas, se determinó previamente la composición y el contenido de calcio del pan CA4 (Tabla 6.3) según se describió en la sección 2.2.15.1.1. 
Tabla 6.3. Composición porcentual del pan CA4.

\begin{tabular}{c|c}
\hline \multirow{2}{*}{ Componente } & $\begin{array}{c}\text { Composición } \\
\text { porcentual (\%) }\end{array}$ \\
\cline { 2 - 2 } & CA4 seco \\
\hline Humedad & $9,93 \pm 0,50$ \\
Proteínas & $9,35 \pm 0,41$ \\
FOS/In & $9,15 \pm 0,1$ \\
FDT & $3,95 \pm 0,06$ \\
Lípidos & $3,64 \pm 0,45$ \\
Cenizas & $2,457 \pm 0,055$ \\
\hline
\end{tabular}

El método enzimo-gravimetrico utilizado para la determinación de FDT no cuantifica los oligosacáridos debido a que éstos no precipitan en etanol 78\% (Elleuch y col., 2011), por lo que debió ser cuantificado por HPLC (sección 2.2.15.1.1). La FDT cuantificada es la proveniente de la harina de trigo.

La dieta DP que contiene el pan CA4, se formuló como se mostró en la sección 2.2.15.2.3. Esta dieta presentó, al igual que la dieta con prebiótico DS, un $10 \%$ de fibra. A este porcentaje contribuyen no sólo el FOS enriquecido con inulina sino también la fibra presente en la harina de trigo.

El contenido de calcio en las dietas fue: $5,00 \mathrm{mg} \mathrm{Ca} / \mathrm{g}$ dieta control (DC), 5,74 mg Ca/g dieta Synergy1 (DS) y 4,91 mg Ca/g dieta pan (DP); y el contenido de fósforo fue de 3 $\mathrm{mg} / \mathrm{g}$.

\subsubsection{Ingesta de nutrientes}

En la Tabla 6.4 se muestra la cantidad de dieta expresada en gramos/día y la ingesta total de dieta consumida durante toda la experiencia por cada lote de animales estudiado. Se observa que las ratas a las que se le ha administrado la dieta control (DC) consumieron significativamente más cantidad de dieta por día que las ratas alimentadas con dietas con Synergy1 (DS) y con pan con calcio + Synergy1 (DP). Los 
animales consumieron significativamente mayor cantidad de dieta DC durante toda la experiencia que los lotes a los que se le proporcionó DS y DP.

Tabla 6.4. Consumo de dieta de los diferentes lotes.

\begin{tabular}{ccccc}
\hline & \multicolumn{4}{c}{ Consumo } \\
\cline { 2 - 5 } Lote & g dieta/día & mg Ca/día & $\mathbf{g}$ In/día & $\begin{array}{c}\text { Total } \\
(\mathbf{g})\end{array}$ \\
\hline DC & $19 \mathbf{b}$ & $94 \mathbf{b}$ & 0,00 & $1108 \mathbf{b}$ \\
DS & $15 \mathbf{a}$ & $76 \mathbf{a}$ & 1,50 & $899 \mathbf{a}$ \\
DP & $16 \mathbf{a}$ & $80 \mathbf{a}$ & 1,12 & $940 \mathbf{a}$ \\
\hline
\end{tabular}

Letras diferentes en una misma columna indican diferencias significativas $(p<0,05)$.

Las diferentes dietas fueron administradas a libre demanda, por lo que las dietas con In como fuente de fibra provocaron mayor saciedad que la dieta con celulosa (DC). Levrat y col. (1991) estudiaron el efecto de la dieta con inulina $(5-10 \%$ In) sobre los ácidos grasos generados durante la fermentación junto a la acumulación de calcio en el ciego. Estos autores señalaron una reducción en el consumo de las dietas con valores de $I n>10 \%$, atribuyendo esa disminución a la acumulación de fluidos en el intestino.

\subsubsection{Peso corporal}

Se pesaron los animales al iniciar el experimento, durante la experiencia y al final del ensayo. Los lotes de ratas empleados tuvieron pesos iniciales significativamente diferentes entre sí (Tabla 6.5). Esto se debe a que la experiencia del lote control se hizo en una primera etapa y las experiencias en ratas a las que se les administraron las dietas DS y DP fueron en simultáneo, en una etapa posterior. Si bien el destete se realiza alrededor de los 21 días de edad, cuando los animales alcanzan un peso de 40 $\pm 5 \mathrm{~g}, \mathrm{y}$ así se hizo en todos los casos, debido a algunos problemas inherentes al uso del bioterio, fue necesario adelantar las experiencias de los lotes DS y DP y partir de ratas de peso inicial algo menor al control.

Si bien DC y DS presentaron mayor aumento de peso absoluto, para independizarnos del diferente peso inicial de las ratas de cada lote, se calculó el aumento de peso relativo a $100 \mathrm{~g}$ de peso de rata como se muestra en la Tabla 6.5. No se observaron diferencias significativas en el aumento porcentual de peso entre las ratas de los 
diferentes lotes.

Tabla 6.5. Peso de los animales al inicio y final de la experiencia.

\begin{tabular}{c|cccc}
\hline \multirow{2}{*}{ Lote } & \multicolumn{4}{|c}{ Peso animal (g) } \\
\cline { 2 - 5 } & 0 día & 60 días & $\Delta$ Peso & $\Delta$ Peso/100 g rata \\
& & & $(\mathbf{g})$ & $(\mathbf{g} \%)$ \\
\hline DC & $42,9 \mathbf{b}$ & $327 \mathbf{b}$ & $284,1 \mathbf{b}$ & $87 \mathbf{a}$ \\
DS & $35,7 \mathbf{a}$ & $269 \mathbf{a b}$ & $233,3 \mathbf{a b}$ & $86 \mathbf{a}$ \\
DP & $35,7 \mathbf{a}$ & $228 \mathbf{a}$ & $192,3 \mathbf{a}$ & $84 \mathbf{a}$
\end{tabular}

Letras diferentes en una misma columna indican diferencias significativas $(p<0,05)$.

En la Figura 6.2 se muestra cómo se va modificando el porcentaje de incremento de peso de los animales de los diferentes lotes en el tiempo. Este parámetro fue calculado según la ecuación 6.1:

$$
\Delta \text { Peso }(\%)=\frac{m_{f}-m_{0}}{m_{0}} * 100
$$

Donde $m_{f} y m_{0}$ son los pesos finales e iniciales promedio de las ratas. Podemos observar que los animales alimentados con DP experimentaron, a partir de los 30 días de experiencia, una menor velocidad de ganancia de peso que los animales que consumieron DS y DC.

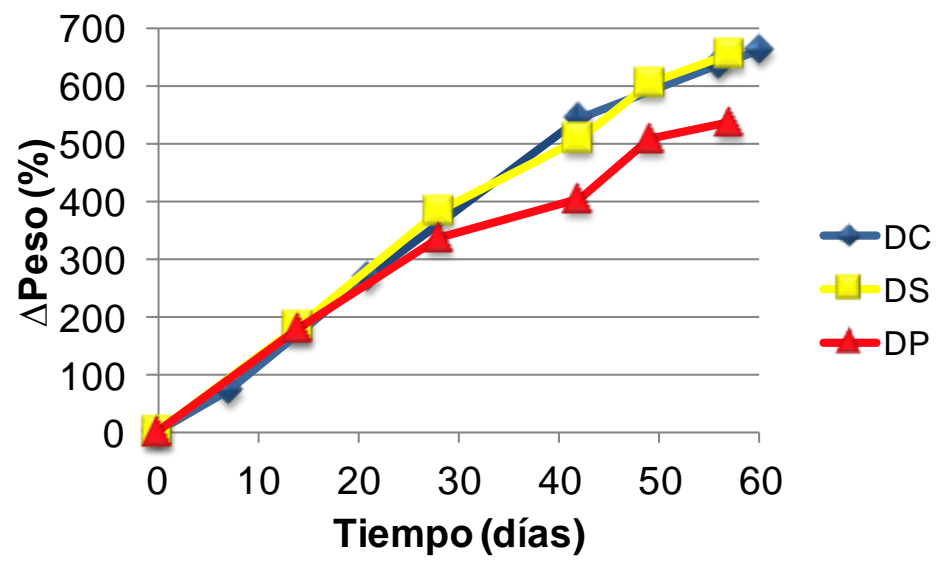

Figura 6.2. Aumento de peso porcentual de los animales durante el tiempo de la experiencia. 


\subsubsection{Determinación de la densidad mineral ósea}

La densidad mineral ósea (DMO) obtenida por densitometría de cuerpo entero (Total), y por densitometrías de áreas (Fémur, Columna y Tibia Proximal) de las ratas de los diferentes lotes estudiados se muestran en la Figura 6.3. La DMO total fue significativamente menor en el grupo alimentado con DP (Figura 6.3.a) comparado con el control. En el caso de la DMO de fémur (Figura 6.3.b) no se encontraron diferencias significativas entre los diferentes lotes estudiados durante la experiencia. La DMO de la columna vertebral obtenida a partir de los animales alimentados con DP fue levemente mayor, aunque no significativa, que la de los animales que consumieron DC. La mayor DMO de columna resultó la de los animales que consumieron DS (Figura 6.3.c). La DMO de tibia del lote DC fue la menor (Figura 6.3.d), parámetro que aumentó significativamente en los animales que consumieron dietas con $10 \%$ de Synergy1, el caso del lote DS.
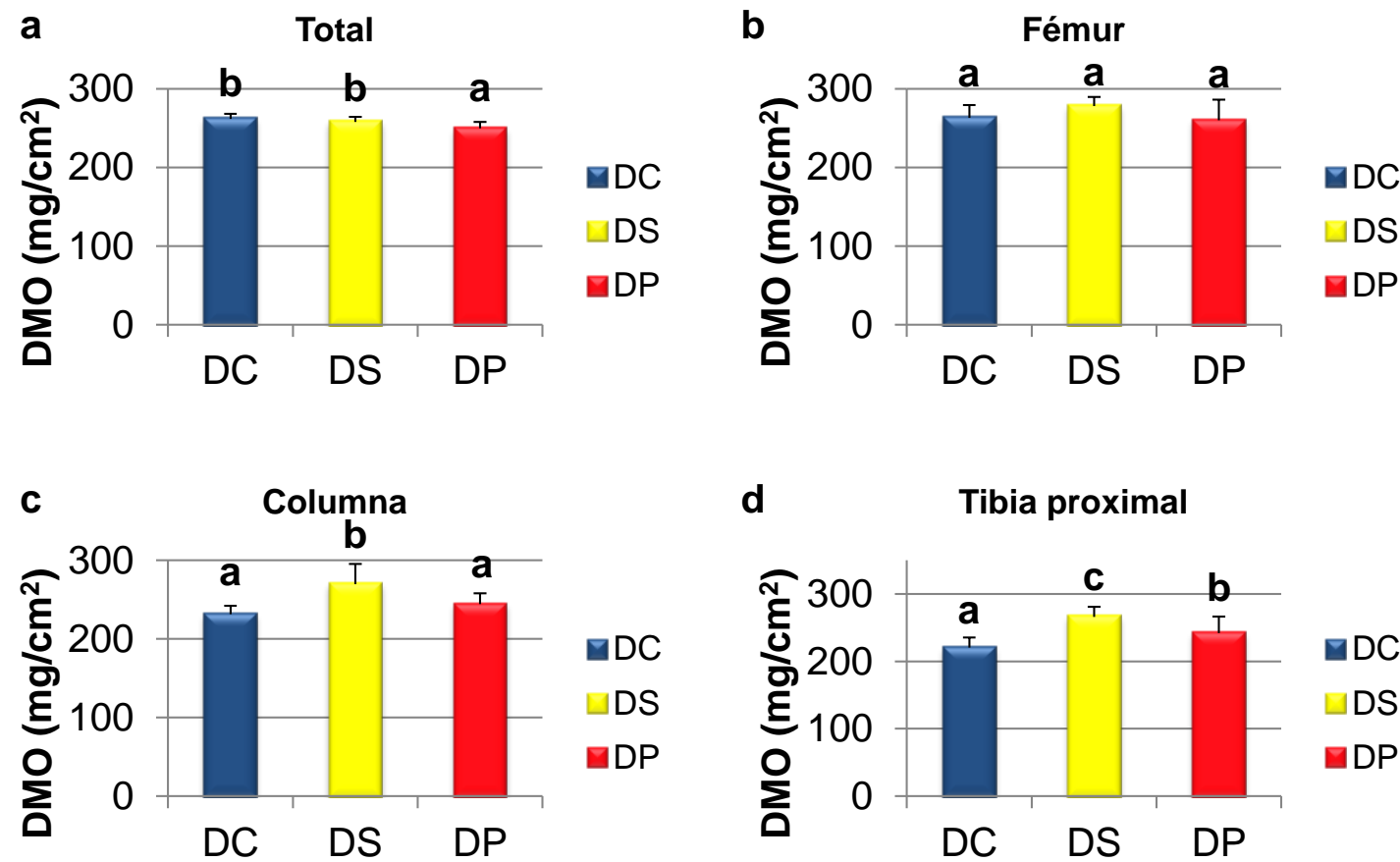

d Tibia proximal

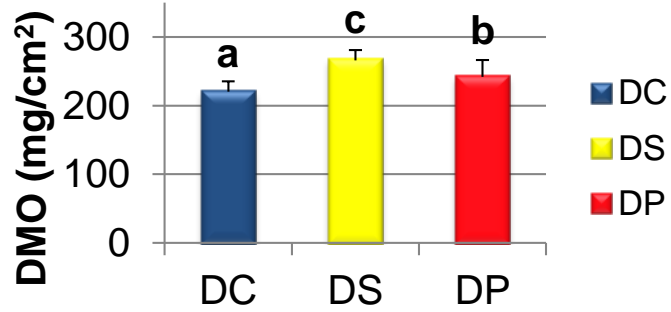

Figura 6.3. Densidad mineral ósea obtenida a partir de los animales pertenecientes a los diferentes lotes. a) DMO total, b) DMO fémur, c) DMO Columna y d) DMO Tibia proximal.Letras diferentes en un mismo gráfico indican diferencias significativas $(p<0,05)$. Media \pm desviación estándar. 
Kruger y col. (2003) estudiaron el efecto de fructo-oligosacaridos con distintos grados de polimerización (GP) sobre la biodisponibilidad de calcio en un modelo de ratas en crecimiento. Compararon tres tipos de prebiótico (5\% p/p en dieta): FOS (GP 2-8), Inulina (GP > 23) e Inulina enriquecida con FOS (GP 2-8) (92\% In con 8\% FOS). Estos autores encontraron que la $\mathrm{DMO}$ en el fémur y en la columna aumentó significativamente en las ratas alimentadas con In (GP > 23) con respecto al control (5 $\%$ sacarosa en la dieta). Scholtz-Ahrens y col. (2001) observaron que el incremento de la absorción del calcio y la mineralización ósea expresados como el contenido de calcio en el hueso dependen de la dosis administrada de FOS, del tiempo de administración, del contenido de calcio en la dieta, de qué parte del esqueleto se estudia y de la edad del animal.

\subsubsection{Absorción aparente de calcio}

Las heces de las ratas alimentadas con DS presentaron menor consistencia (diarrea) que las heces de las ratas pertenecientes al lote DP, aunque el contenido de In en la dieta fue el mismo. Por lo que fue difícil la recolección de las mismas.

En la Figura 6.4 se muestra la absorción aparente de calcio $\left(A A_{C a}\right)$ de los diferentes lotes de ratas alimentados con las distintas dietas, calculados según se explicó en la sección 2.2.15.2.6. Si bien el contenido de calcio en las dietas no era significativamente diferente, las ratas a las que se las alimentó con prebiótico directamente (DS) presentaron una $\mathrm{AA}_{\mathrm{Ca}}$ significativamente mayor comparados con los lotes DC y DP. Las ratas que se alimentaron con la dieta a base de pan (DP) presentaron una menor $\mathrm{AA}_{\mathrm{Ca}}$ que aquellas a las que se les proporcionó la dieta a base del prebiótico (DS), lo que indicaría que en el pan el procesamiento (amasado y horneado) o la presencia de componentes antinutricionales como fitatos podrían tener consecuencia en la absorción del mineral. Si bien los fitatos normalmente se degradan durante la fermentación, se ha observado un efecto inhibitorio del calcio sobre la misma; se formaría un fitato de calcio de baja solubilidad, menos sensible a la acción de las fitasas (Hallberg y col., 1987). Asimismo, como el pan tiene 9,15\% de FOS/In, en $100 \mathrm{~g}$ de dieta DP (76,3 g pan) habría 6,9 g versus $10 \mathrm{~g}$ en la DS y esto podría explicar el mayor $\mathrm{AA}_{\mathrm{Ca}}$ de la DS para concentración similar de calcio; demostrando la influencia del prebiótico en la absorción de $\mathrm{Ca}$. 


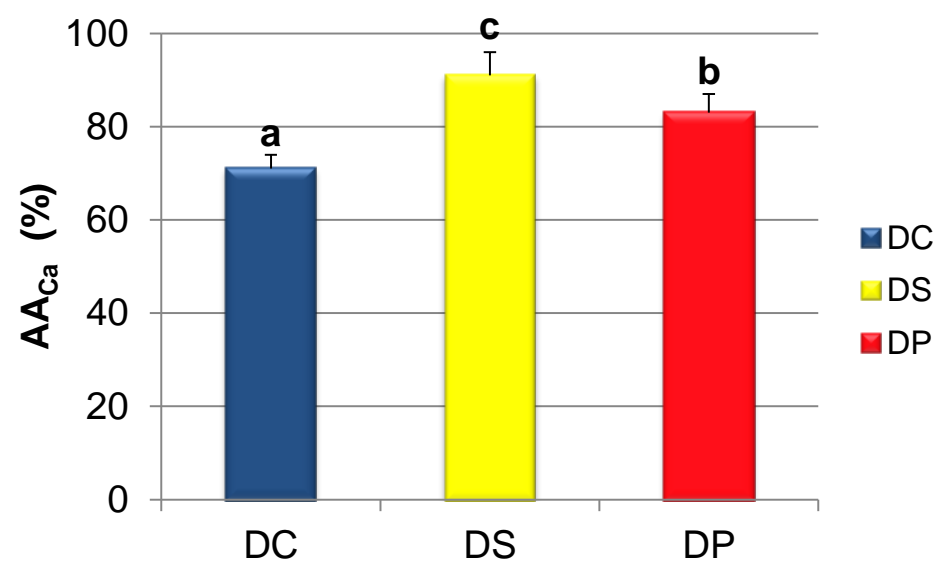

Figura 6.4. Absorción aparente de calcio. Letras diferentes indican diferencias significativas $(p<0,05)$. Media \pm desviación estándar.

\subsubsection{Resultados obtenidos posterior al sacrificio de los animales}

Una vez finalizado el experimento se sacrificaron los animales, se les extirpó el ciego, el fémur y la tibia proximal.

\subsubsection{Peso y pH de la fermentación}

En la Figura 6.5 se muestran el peso promedio del ciego y $\mathrm{pH}$ del contenido cecal obtenido a partir de los animales de los diferentes lotes estudiados. El contenido cecal de las ratas pertenecientes al lote DS fue significativamente mayor que el de los otros lotes y en el caso de DP el peso del ciego fue similar al de las ratas pertenecientes al lote DC.
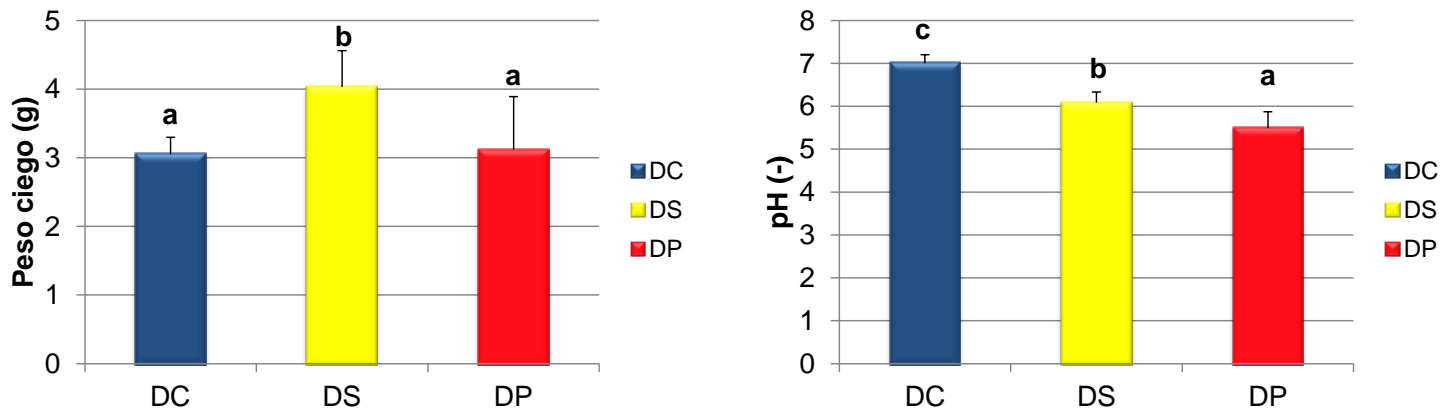

Figura 6.5. Peso del ciego y pH del contenido cecal. 
El $\mathrm{pH}$ del contenido cecal del lote DC fue el mayor. El lote de ratas que consumió la dieta DP presentó el menor pH (Figura 6.5).

Tanto el aumento de peso del ciego como el $\mathrm{pH}$ del contenido cecal indicarían actividad prebiótica de la dieta. Los oligosacáridos no son absorbidos en la parte superior del tracto gastrointestinal, entran al intestino grueso donde son fermentados por la microbiota intestinal. Por efecto de la fermentación, se produce una disminución del $\mathrm{pH}$ como resultado de la producción de ácido láctico y ácidos grasos de cadena corta, principalmente de propionato, acetato y butirato (Levrat y col., 1991).

\subsubsection{Determinación histológica y estimación del volumen óseo}

El hueso es un tejido dinámico en constante formación y reabsorción, que permite el mantenimiento del volumen óseo, la reparación del daño tisular y la homeostasis del metabolismo fosfocálcico. Este fenómeno equilibrado denominado proceso de remodelado permite la renovación de un $5 \%$ del hueso cortical y un $20 \%$ del trabecular al año. Aunque el hueso cortical constituye un $75 \%$ del total, la actividad metabólica es 10 veces mayor en el trabecular, ya que la relación entre superficie y volumen es mayor (la superficie del hueso trabecular representa un $60 \%$ del total). Por esto la renovación es de un 5-10\% del hueso total al año. El remodelado óseo existe toda la vida, pero en una primera etapa (en crecimiento) el balance es positivo.

En la Figura 6.6 se muestra la fotografía de los cortes histológicos de la porción proximal de la tibia derecha luego de colorearse como se describió en la sección 2.2.15.3.2. Puede verse que el número de trabéculas en el hueso de DC es menor que en los huesos de las ratas alimentadas con Synergy1 (DS) y pan con Synergy1 (DP). Estos resultados indican que hubo una mayor formación de hueso, sugiriendo un incremento en la absorción de calcio por efecto del prebiótico.

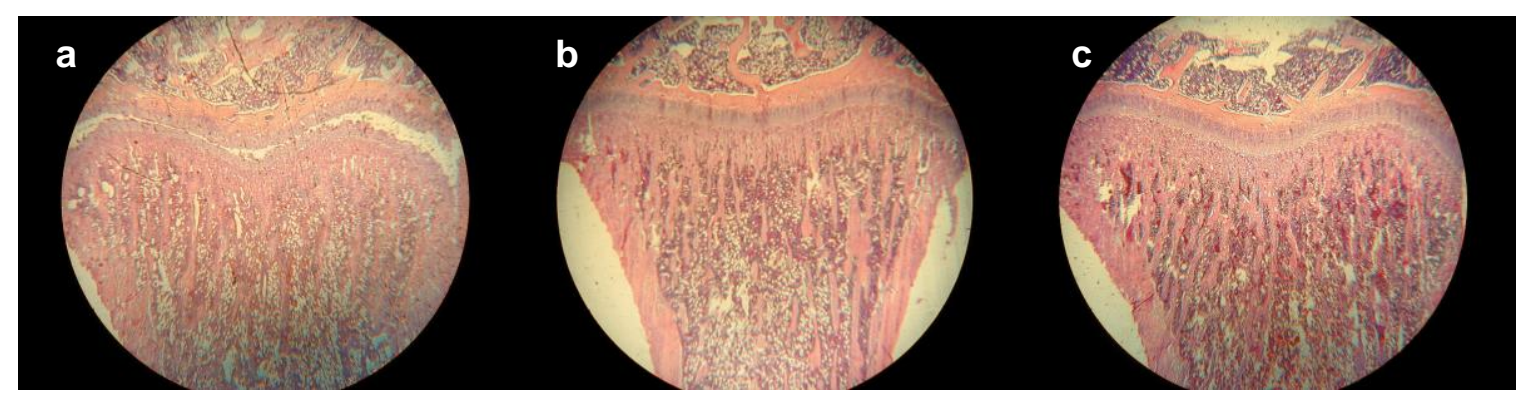

Figura 6.6. Corte histológico de tibia derecha. a) Lote DC, b) Lote DS, c) Lote DP. 
Se determinó por medio de análisis de imágenes el porcentaje de área que estaba ocupada por las trabéculas óseas y se lo expresó como porcentaje de volumen óseo (Figura 6.7). El volumen óseo porcentual fue significativamente mayor en las ratas pertenecientes a los lotes DS y DP en comparación con el lote control.

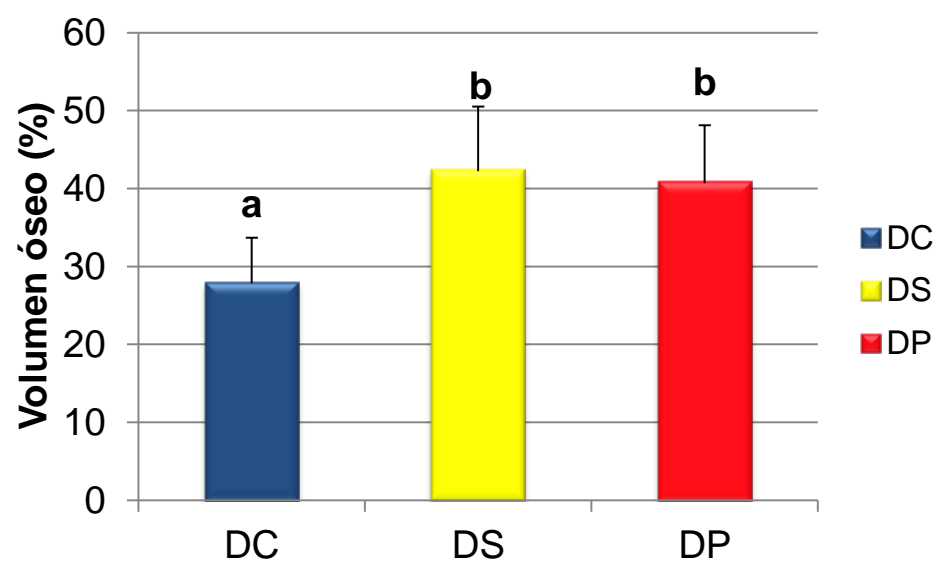

Figura 6.7. Volumen Óseo (\%) en tibia derecha proximal.

Diversos autores han estudiado el efecto de los prebióticos, como la inulina y la oligofructosa, sobre el aumento de la absorción de minerales de la dieta, especialmente de calcio (Scholz-Ahrens y Schrezenmeir, 2002; Weaver, 2005), el contenido mineral óseo $(\mathrm{CMO})$ y su efecto positivo sobre la estructura del hueso (Harrington y col., 2001; Scholz-Ahrens y Schrezenmeir, 2007).

Se han descripto distintos mecanismos responsables del incremento de la absorción de minerales mediados por FOS. La microflora intestinal es modificada como consecuencia de la presencia de Synergy1, ésta genera ácidos grasos de cadena corta como consecuencia de la fermentación colónica disminuyendo el pH del contenido cecal (Coudray y col., 2005). Como ya se mencionó, uno de los mecanismos planteados es que al descender el pH luminal, el mineral es más soluble en el lumen del intestino y de esta forma es más fácilmente absorbido por la célula de la mucosa intestinal (Ohta y col., 1995).

Otro mecanismo, además del anterior, es la modificación en la arquitectura de la mucosa intestinal de rata que surge como consecuencia del aumento de la celularidad (aumento del número de células) y el número de las criptas. Ambos mecanismos podrían contribuir a un aumento en la superficie de absorción del mineral (Kleessen y col., 2003).

Younes y col. (2001) estudiaron el efecto de la inulina y almidón resistente en la fermentación del intestino de ratas reportando un incremento en la absorción y balance de $\mathrm{Ca}$ y $\mathrm{Mg}$, sin alterar la concentración en plasma de ambos minerales. La inulina 
agregada a la dieta aumenta la retención de calcio en el cuerpo entero (Raschka y Daniel, 2005) y afecta positivamente la mineralización de los huesos (Zafar y col., 2004; Bosscher y col., 2006).

Se han descripto ya mecanismos mediante los cuales la inulina y la oligofructosa influyen en la absorción del calcio pero no en productos panificados.

\subsubsection{Medidas y composición ósea}

Se obtuvo como medida ósea la longitud y el peso del fémur derecho libre de tejido muscular y desgrasado. La longitud y peso del fémur resultó mayor en el lote DC. Se determinó el porcentaje de ceniza (C) y de sustancia orgánica (SO), y a partir de estos valores se calculó la relación $\mathrm{C} / \mathrm{SO}$; una mayor relación da una idea de una mayor cantidad de minerales en el hueso. Si bien el fémur del lote control fue más largo que los lotes con Synergy1, no se encontraron diferencias significativas en el contenido porcentual de cenizas entre los lotes estudiados. Tampoco se observaron diferencias significativas en la relación C/SO entre los lotes (Tabla 6.6).

Tabla 6.6. Longitud y peso del hueso. Relación cantidad de ceniza/sustancia orgánica y Ca/P.

\begin{tabular}{cccccccccc}
\hline & $\begin{array}{c}\text { Longitud } \\
\text { hueso } \\
(\mathbf{c m})\end{array}$ & $\begin{array}{c}\text { Peso } \\
\text { hueso } \\
(\mathbf{m g})\end{array}$ & $\begin{array}{c}\mathbf{C} \\
(\mathbf{m g} \%)\end{array}$ & $\begin{array}{c}\text { Ca } \\
\text { hueso } \\
(\mathbf{m g})\end{array}$ & $\begin{array}{c}\mathbf{P} \\
\text { hueso } \\
(\mathbf{m g})\end{array}$ & $\begin{array}{c}\text { Ca } \\
(\mathbf{m g} \%)\end{array}$ & $\begin{array}{c}\mathbf{P} \\
(\mathbf{m g} \%)\end{array}$ & $\begin{array}{c}\mathbf{C} / \mathrm{SO} \\
(-)\end{array}$ & $\begin{array}{c}\mathbf{C a} / \mathbf{P} \\
(-)\end{array}$ \\
\hline DC & $1,84 \mathbf{b}$ & $504 \mathbf{b}$ & $59,5 \mathbf{a}$ & $115,9 \mathbf{c}$ & $60,2 \mathbf{b}$ & $23,0 \mathbf{b}$ & $11,9 \mathbf{a}$ & $1,47 \mathbf{a}$ & $1,94 \mathbf{b}$ \\
DS & $1,64 \mathbf{a}$ & $470 \mathbf{b}$ & $59,2 \mathbf{a}$ & $92,4 \mathbf{b}$ & $58,1 \mathbf{b}$ & $19,7 \mathbf{a}$ & $12,4 \mathbf{a}$ & $1,48 \mathbf{a}$ & $1,59 \mathbf{a}$ \\
DP & $1,53 \mathbf{a}$ & $407 \mathbf{a}$ & $59,7 \mathbf{a}$ & $79,9 \mathbf{a}$ & $50,6 \mathbf{a}$ & $19,8 \mathbf{a}$ & $12,5 \mathbf{a}$ & $1,45 \mathbf{a}$ & $1,58 \mathbf{a}$ \\
\hline
\end{tabular}

Letras diferentes indican diferencias significativas en una misma columna $(p<0,05)$. C: cenizas; SO: sustancia orgánica, Ca: calcio, P: fósforo.

El calcio y el fósforo representan el principal componente mineral del hueso. Ambos deben estar disponibles simultáneamente y en cantidades suficientes, para que la mineralización ósea sea adecuada. La carencia de uno de ellos, de ambos o de la vitamina $D$ da lugar a complicaciones, especialmente osteopenia, raquitismo y fracturas (Steichen y col., 1980; Senterre, 1991).

La relación $\mathrm{Ca} / \mathrm{P}$ de un hueso ideal es igual a 2 . Esta relación fue mayor en los fémures de las ratas pertenecientes al lote $\mathrm{DC}$. Los valores bajos de $\mathrm{Ca} / \mathrm{P}$ en los lotes DS y DP podrían deberse a que el hueso no terminó de madurar debido a que las 
ratas perteneciente a estos lotes crecieron menos que las ratas pertenecientes al lote DC.

\subsubsection{Modificación de la microbiota en heces durante la experiencia}

\subsubsection{Recuento de anaerobios viables}

Se realizó un recuento total de bifidobacterias y lactobacilos en la materia fecal de las ratas los días $0,2,23$ y 50 del ensayo.

En la Figura 6.8 se muestra el resultado expresado en ufc/g de materia fecal (MF). Se puede observar que el número de lactobacilos y bifidobacterias encontrados en materia fecal de ratas que recibieron una dieta control (DC) va disminuyendo durante la experiencia, observándose una disminución de 2 órdenes de magnitud entre el día 0 y el día 50 del ensayo. En cuanto al número de microorganismos encontrados en la materia fecal de las ratas que recibieron la dieta DS podemos decir que se mantiene constante durante el ensayo, observándose un leve incremento al final de la experiencia. Finalmente, en la materia fecal de las ratas a las que se les administró una dieta con prebiótico proveniente del pan (DP) se observó un aumento hasta el día 23 de la experiencia y una disminución significativa el día 50 del ensayo.

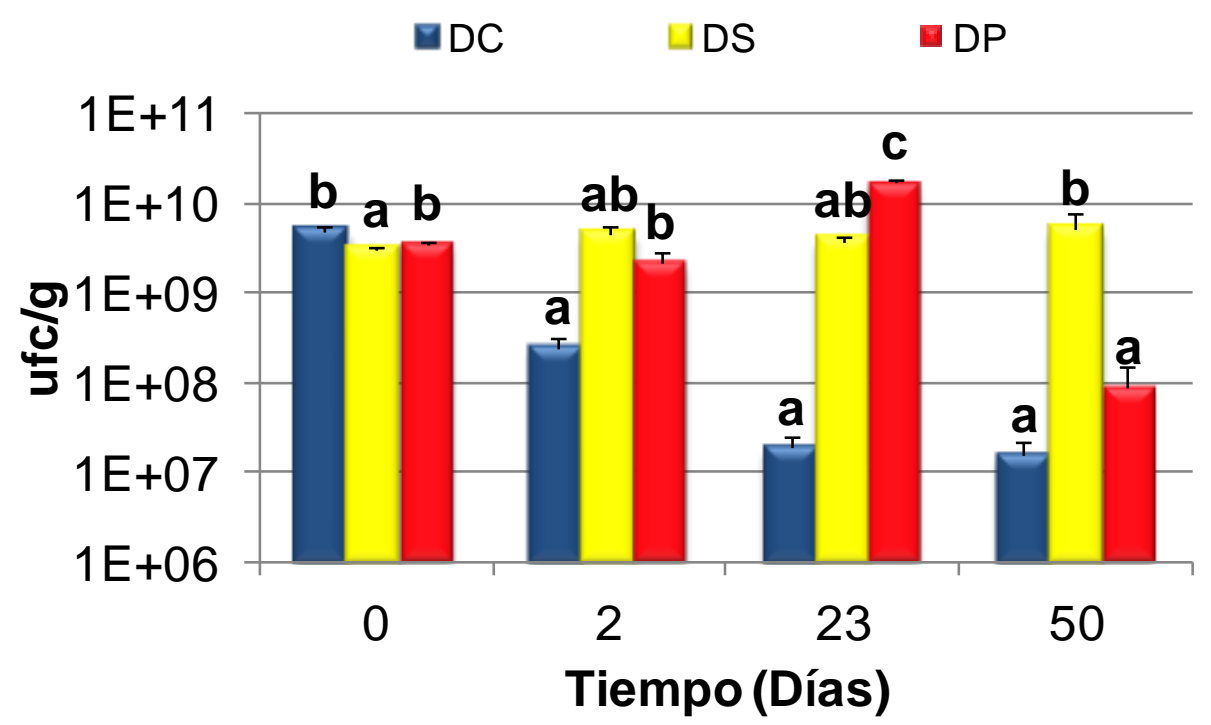

Figura 6.8. Recuento de anaerobios en MRS con cys. Letras diferentes en un mismo lote indican diferencias significativas $(p<0,05)$. Media \pm desviación estándar. 
Estos resultados nos permiten observar que, a diferencia de lo observado en la DC, tanto la dieta DS como la DP son capaces de mantener constante la cantidad de bifidobacterias y lactobacilos presentes en la materia fecal de las ratas que las consumieron.

\subsubsection{Características de las colonias obtenidas en agar MRS}

En la Figura 6.9 se muestran, a modo de ejemplo, microfotografías representativas de los tres tipos de colonias encontradas en el medio de cultivo de todos los contenidos fecales de las ratas de los tres lotes estudiados.

Se observó: A) una colonia blanca puntual de tamaño pequeño, con bordes definidos; B) una colonia estrellada de tamaño grande, con bordes irregulares; C) una colonia color crema de tamaño grande, con bordes difusos.
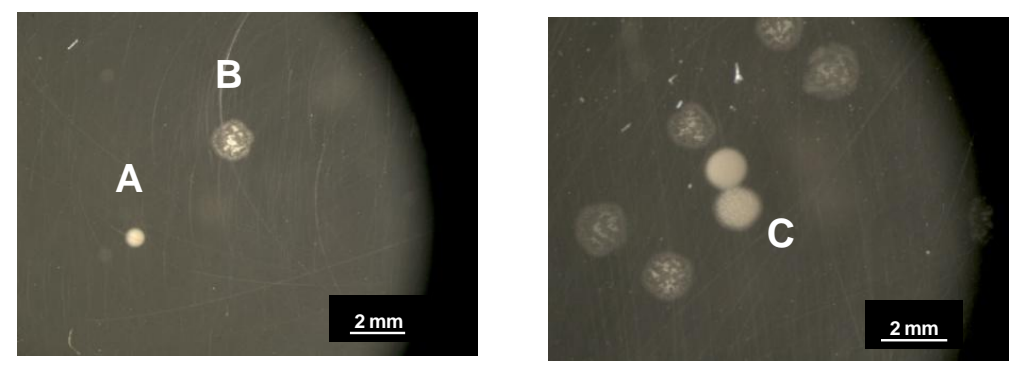

Figura 6.9. Fotografía de la morfología de colonias obtenidas empleando una lupa.

En la Figura 6.10 se muestran, a modo de ejemplo, las diferentes colonias con su respectivo microorganismo luego de ser teñidos con la coloración de Gram.

En el extendido de la colonia $A$ se pueden observar pequeños cocos, en cambio en los extendidos de las colonias $\mathrm{B}$ y $\mathrm{C}$ se distinguen bacilos, presentando disposición en cadena cuando la colonia fue la $\mathrm{B}$.

Si bien la identificación particular de las colonias no es un objetivo de este trabajo, se aclara que como consecuencia del medio de cultivo altamente selectivo, estos microorganismos son principalmente Lactobacillus y Bifidobacterium. 

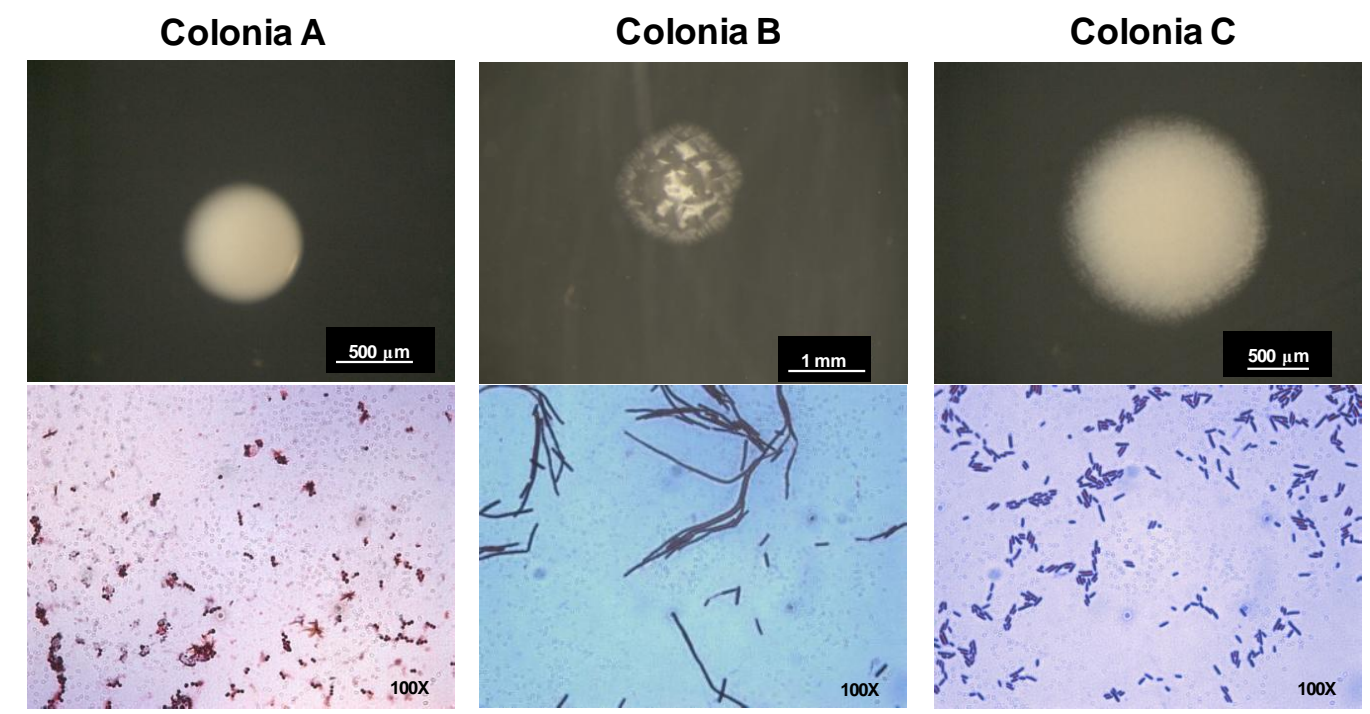

Figura 6.10. Imagen de las diferentes colonias con su respectiva coloración de gram.

\subsubsection{Análisis de diversidad microbiológica}

Con la finalidad de investigar la modificación de la microbiota presente en materia fecal como consecuencia de las diferentes dietas en el modelo de rata en crecimiento, se utilizó una técnica independiente del cultivo comúnmente empleada para el estudio de comunidades microbianas complejas. La metodología utilizada fue la electroforesis en gel con gradiente desnaturalizante químico (DGGE) que consiste en la amplificación de ADN con oligonucleótidos específicos, separación electroforética en gel con gradiente desnaturalizante químico y análisis de los perfiles resultantes.

Para ello se extrajo el ADN de las heces, se amplificó con oligonucleótidos específicos para Eubacterias (518R y 341F-GC) que codifican para la región V3 del ARNr 16S (Muyzer y col., 1993).y los amplicones resultantes se separaron mediante DGGE.

Se estudiaron muestras de heces de ratas tomadas los días 0, 23 y 50 de los tres lotes y además del día 36 del lote DS. Los perfiles electroforéticos obtenidos a partir de la amplificación del ADN de las heces estudiadas se muestran en la Figura 6.11.

El número de bandas encontrado en los diferentes perfiles varió entre 21 y 48 . Si comparamos los perfiles de las muestras pertenecientes a las ratas de los grupos DC, DP y DS para el día 0 podemos observar que, aunque algunas bandas son comunes, los perfiles obtenidos resultaron diferentes entre sí. Esto es de esperar, ya que la microbiota de cada rata es única. Esta variabilidad de la microbiota entre individuos está ampliamente descripta en ratones (Snart y col., 2006; Montesi y col., 2005) y microbiota intestinal humana (Zoetendal y col., 1998; Vanhoutte y col., 2006). 
Sin embargo, no sólo se observaron diferencias entre las ratas de los distintos grupos, sino que también hubo diferencias en la microbiota de una misma rata a lo largo del tiempo, y este fenómeno es debido a la dieta. Por ejemplo, el número de bandas del perfil obtenido para DS 50 presentó un mayor número de bandas que el perfil obtenido para DS 0 . El número de bandas de los perfiles no es indicativo de la cantidad de especies que están presentes en cada comunidad debido a que una especie puede presentar más de una banda en su perfil electroforético (Cocolin y col., 2001; Salles y col., 2002), pero el análisis de los perfiles electroforéticos permite comparar las variaciones que se producen en las comunidades microbianas.

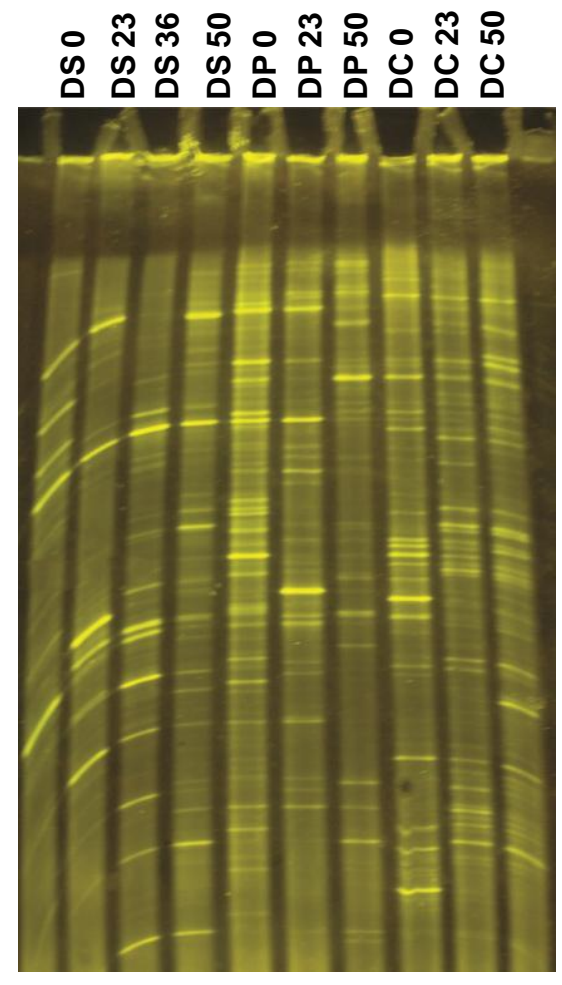

Figura 6.11. Perfiles electroforéticos obtenidos por DGGE de amplicones del gen que codifica para la región V3 del ARNr $16 \mathrm{~S}$ obtenidos a partir de ADN aislado de las diferentes heces. DS: dieta Synergy1, DP: dieta pan, DC: dieta control. El número que acompaña a la sigla corresponde al dia de toma de muestra de la materia fecal.

Para analizar la similitud existente entre los perfiles electroforéticos obtenidos por DGGE de las distintas heces se utilizó el coeficiente de Jaccard y se realizó un análisis de cluster mediante el método de agrupamiento de ligamiento promedio no ponderado (UPGMA). En la Figura 6.12.a se muestra el dendograma acompañado por las calles del gel para una mejor comprensión de lo descripto previamente. En la Figura 6.12.b se muestra el dendograma amplificado para una mejor visualización de los resultados. 


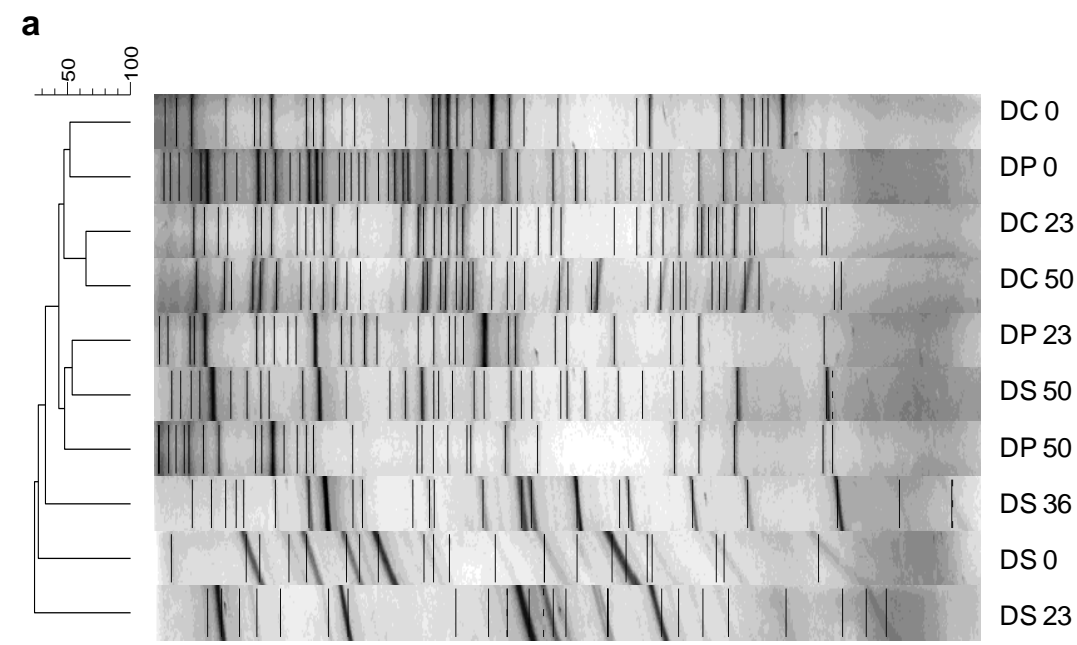

b

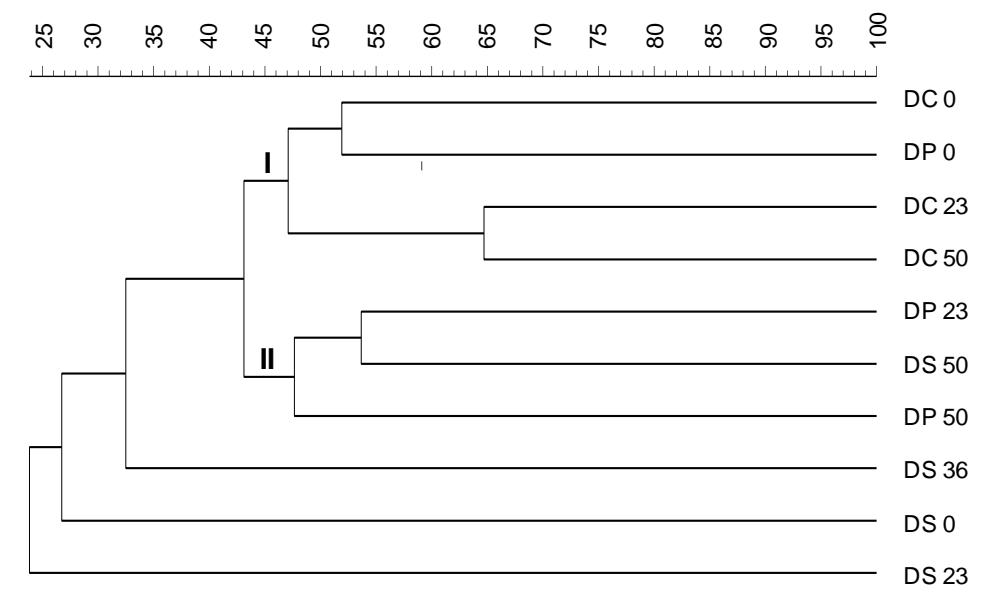

Figura 6.12. a) Dendrograma junto a la correspondiente calle del gel, b) Dendograma amplificado.

Del análisis del cluster puede establecerse que entre todos los perfiles existen un $24 \%$ de similitud. Es de destacar que los amplicones obtenidos luego de la amplificación de las muestras de ADN pertenecientes a las ratas que consumieron la dieta DS los días 0, 23 y 36 mostraron perfiles electroforéticos con bajos porcentajes de similitud con el resto de los perfiles estudiados. DS 0 y DS 36 presentaron un 27 y un $33 \%$ de similitud con el resto de las dietas, respectivamente.

Por otro lado, se observaron dos subcluster bien definidos (I y II) que presentaron un $43 \%$ de similitud entre sí. El subcluster I) formado por los perfiles de las muestras DC0, DC23, DC50 y DP0 y el subcluster II) formado por los perfiles de DP 23, DP 50 y DS 50 . 
De este análisis se puede inferir que hubo una similitud en la microbiota en ausencia del prebiótico (subcluster I, 47\% similitud), mientras que a los 50 días de la experiencia las dietas con FOS/In, DS y DP presentaron una similitud de $48 \%$ (subcluster II).

Luego de 50 días de consumo de las dietas, los lotes DS y DP presentaron en materia fecal una microbiota diferente a la del DC. 


\section{Conclusiones parciales}

Los panes óptimos presentaron un menor porcentaje de hidrólisis del almidón, por lo cual se presume que tendrían un bajo índice glicémico, lo que resultaría favorable especialmente en pacientes con diabetes. Además, serían una importante fuente de calcio. La dializabilidad de hierro y cinc resultó mayor en los panes elaborados con $\mathrm{Ca}_{3} \mathrm{Cl}_{2}$, por lo que el citrato mejoró la disponibilidad de estos minerales. Por lo tanto, en la fortificación con calcio no sólo es importante la cantidad sino también el tipo de sal empleada debido a que, aunque resulten productos de calidad semejantes, las distintas sales de calcio afectan la disponibilidad de otros minerales.

En el ensayo in vivo se encontró que las ratas del lote control consumieron más dieta que las alimentadas con prebiótico (DS y DP), indicando que esto dos últimos lotes se saciaban consumiendo menos dieta; a pesar de ello el porcentaje de aumento de peso de los animales fue semejante en todos los lotes.

El ciego del lote DP resultó significativamente más ácido como consecuencia de la fermentación rápida de oligo y polisacáridos por parte de la microflora colónica (Bifidobacterias y Lactobacillus) resistente a este medio.

La presencia de prebiótico aumentó la absorción aparente de calcio, especialmente en la dieta DS, debido a que si bien ambas dietas tuvieron un $10 \%$ de fibra, parte de la fibra del pan proveniente de la harina de trigo no favorece la absorción de calcio.

La densidad mineral ósea total (DMO) fue significativamente menor en los animales que consumieron dieta con pan, sin embargo no hubo diferencias significativas en la DMO de fémur. La DMO de tibia proximal fue mayor en las ratas alimentadas con DS, con una tendencia similar a la de absorción aparente de $\mathrm{Ca}$. Aunque las ratas pertenecientes al lote DP presentaron menor absorción de calcio, los lotes que consumieron prebiótico (DS y DP) presentaron un mayor número de trabéculas y mayor volumen óseo, lo que se asocia a una mayor fijación de calcio en el hueso.

Se realizó durante los días $0,2,23$ y 50 un recuento de anaerobios viables en materia fecal en medio MRS, selectivo para lactobacilos y bifidobacterias, encontrando que en las ratas que consumieron dieta control (DC) disminuyó durante la experiencia, en cambio en las ratas que consumieron In aumentó dicho recuento hasta el día 23 con DP y luego disminuyó mientras que con la dieta DS se mantuvo constante. Estas 
diferencias estuvieron acompañadas por cambios en el perfil de bandas de ADN entre las distintas muestras y durante los días de ensayo. Se encontró una similitud en la microbiota en ausencia del prebiótico, mientras que a los 50 días de la experiencia las dietas con FOS/In, DS y DP, presentaron una similitud de $48 \%$ entre sí y diferente al la del lote DC.

Quedaría a futuro evaluar mediante ensayos in vivo, el efecto prebiótico y la fortificación de las diferentes sales de calcio en los panes óptimos, además de un lote al que se le proporcione una dieta con pan control, para ver si se correlacionan con los ensayos in vitro.

Los panes resultaron ser un vehículo interesante para la fortificación con calcio, los cuales no sólo aportaron calcio, sino también favorecieron la disponibilidad de otros minerales como hierro y cinc, principalmente cuando se utilizó $\mathrm{Ca}_{3} \mathrm{Cl}_{2}$. Los ensayos in vivo, además de reafirmar el efecto del prebiótico sobre la absorción de calcio, nos permitieron inferir que el proceso de panificación (amasado, fermentación, horneado) no afectó a la mayoría de los parámetros de absorción de calcio y biodisponibilidad, favoreciendo además una biota microbiana benéfica.

Por lo tanto, los panes fortificados en presencia de prebiótico son potenciales alimentos funcionales, que además de cubrir deficiencias nutricionales en la población mejorarían la salud de la población. 


\section{CONCLUSIONES}

$>$ El agregado de FOS-inulina (Synergy1) provocó diferencias en las propiedades de hidratación, disminuyendo la absorción de agua. También hubo efecto de las diferentes sales de calcio, no sólo debido a la naturaleza del anión sino a la diferente carga que cada uno de ellos aporta. Las propiedades de hidratación en presencia de sales orgánicas presentaron similar comportamiento.

> Las propiedades reológicas de las masas dependen fundamentalmente de la estructura de la red de gluten; además de ser modificadas por el prebiótico variaron según la sal de calcio utilizada. La presencia de $\mathrm{CaCO}_{3}$ presentó similar tendencia que el $\mathrm{Ca}_{3} \mathrm{Cl}_{2}$, con un efecto estabilizador de la matriz de gluten. Con $\mathrm{CaLA}_{2}$ se observó una tendencia diferente. La naturaleza y la carga del anión provocaron cambios en la estabilización de las proteínas debido a la modificación de la estructura y disponibilidad del agua.

La inulina fue el ingrediente que más modificó los parámetros térmicos, produjo corrimientos hacia mayores temperaturas y disminución de la entalpia de gelatinización, provocando que una menor proporción del almidón de la masa gelatinice en presencia de In.

La calidad panadera varió según el tipo y cantidad de sal de calcio utilizada para la fortificación, además de hacerlo con el prebiótico. Los panes con $\mathrm{CaLA}_{2}$ envejecieron más rápido y en mayor medida comparado con las otras sales de calcio, resultando en panes de menor calidad.

> Se lograron obtener tres panes óptimos, uno con cada sal de calcio, de calidad panadera esperada. Estos panes fueron aceptados satisfactoriamente por los consumidores. 
> Aunque hubo modificaciones reológicas de la masa durante la congelación, luego de descongelar, fermentar y hornear, los panes fueron similares a los obtenidos a partir de masas frescas. En consecuencia, se podría aplicar la tecnología de congelación de masa en la obtención de panes esencialmente en aquellos fortificados con sales de calcio que estabilizan la red de gluten.

> El pan con calcio y prebiótico usado en el ensayo in vivo, no solamente aumentó la absorción aparente de calcio sino que también ejerció efecto sobre la microbiota intestinal favoreciendo el desarrollo de los microorganismos saludables debido a la presencia del prebiótico. Además, la combinación de ambos ingredientes resultó en panes de bajo índice glicémico, esto podría deberse a la restricción de accesibilidad a las enzimas como consecuencia de gelificación de la inulina, haciendo al almidón menos digerible.

El consumo promedio de pan en nuestro país es cercano a los 200 g/día. Teniendo en cuenta una ingesta adecuada (IA) de $1000 \mathrm{mg} \mathrm{Ca} /$ día para mujeres en edad adulta, si se fortificara la harina con 2400 ppm Ca, el pan aportaría alrededor del $24 \%$ de la IA. 


\section{BIBLIOGRAFIA}

\section{A}

American Association of Cereal Chemists (AACC International). (2000), 10 Ed. St. Paul, MN: The American Association of Cereal Chemists, Inc.

Añon M.C., Jovanovich G. (2000). Calorimetría diferencial de barrido (Capítulo 5) en Caracterización funcional y estructural de proteínas. Pilosof, A. Editorial Universitaria de Buenos Aires.

Aravind N., Sissons M. J., Fellows C. M., Blazek J., Gilbert E. P. (2012). Effect of inulin soluble dietary fibre addition on technological, sensory, and structural properties of durum wheat spaghetti. Food Chemistry, 132(2), 993-1002.

Araya H., Contreras P., Alvina M., Vera G., Pak N. (2002). A comparison between an in vitro method to determine carbohydrate digestion rate and the glycemic response in young men. European journal of clinical nutrition,56(8), 735-739.

Arjona-Roman J.L., Melendez-Perez R., Vazquez-Duran A., Del Rio-Garcia J.C., MendezAlbores A., Moreno-Martinez E. (2011). Thermal and Pasting Properties of Citric Acid Supplemented Poultry Diets. Journal of Animal and Veterinary Advances, 10(12): 15731579.

Armero E., Collar C. (1998). Crumb Firming Kinetics of Wheat Breads with Anti-staling Additives. Journal of Cereal Science, 28: 165-174.

Association of Official Analytical Chemists (AOAC). (2000). Government Printing Office, editors. Official methods of analysis of the A.O.A.C., $17^{\circ}$ ed. Washington, DC. Estados Unidos.

Atwell W.A. (1998). Method for reducing syruping in refrigerated doughs. Patent Application WO 97/26794.

Autio K., Sinda E. (1992). Frozen doughs: Rheological changes and yeast viability. Cereal Chemistry, 69: 409 - 413. 
B

Bárcenas M.E., Rosell C.M. (2005).Effect of HPMC addition on the microstructure, quality and aging of wheat bread. Food Hydrocolloids, 19: 1037-1043.

Belitz H., Kieffer R., Seilmeier W., Wieser H. (1986). Structure and function of gluten protein. Cereal Chemistry, 63: 336-341.

Belitz H., Grosch W. (1999). Polysaccharides. En: Food Chemistry, Segunda edición. Editado por Belitz H, Grosch W. Springer, Alemania. pp 237-318.

Belton P.S. (1999). On the elasticity of wheat gluten. Journal of Cereal Science, 29: 103107.

Belton P.S. (2003).The molecular basis of dough rheology. Capítulo 13 en Bread making Improving Quality. Editado por Stanley P. Cauvain. Publicado por Woodhead Publishing Limited, Cambridge-Inglaterra

Berdanier C.D. (1998). Microminerals. En: Advanced Nutrition Micronutrients. Ed Berdanier C.D. Cap. 7. CRC Press LLC.

Berglund P.T., Shelton D.R. (1993). Effect of frozen storage duration on firming properties of breads baked from frozen doughs. Cereal Foods World, 38: 89-90, 92-93.

Bettge A.D., Morris C.F. (2000). Relationships among grain hardness, pentosan fractions and end-use quality of wheat. Cereal Chemistry, 77 (2): 241-247.

Biedrzycka E., Bielecka M. (2004). Prebiotic effectiveness of fructans of different degrees of polymerization. Trends in Food Science and Technology, 15: 170-175.

Biliaderis C.G., Izydorczyk M.S., Rattan O. (1995). Effect of arabinoxylans on breadmaking quality of wheat flours. Food Chemistry, 5: 165-171.

Bosscher D., Van Loo J., Franck A. (2006). Inulin and oligofructose as functional ingredients to improve bone mineralization. International Dairy Journal, 16(9):10921097.

Bourne M.C. (1978).Texture profile analysis. Food Technology, 32(7):62-66, 72.

Bourne M.C. (2002). Food Texture and Viscosity: Concept and Measurement. Segunda edición. Academic Press, California, Estados Unidos. 
Box G.E.P., Wilson K.B. (1951). On the Experimental Attainment of Optimum Conditions. Journal of the Royal Statistical Society, Series B, 13, 1-45.

Bray D. (2000).Critical point drying of biological specimens for scanning electron microscopy. En: J R Williams y A A Clifford (Ed.), Methods in biotechnology, vol 13. Supercritical fluid methods and protocols. Capítulo. 31. Totowa: Humana Press Inc.

Brennan C.S., Samyue E. (2004). Evaluation of Starch Degradation and Textural Characteristics of Dietary Fiber Enriched Biscuits. International Journal of Food Properties, 7(3): 347-657.

Brennan M.A., Monro J.A., Brennan C.S. (2008). Effect of inclusion of soluble and insoluble fibres into extruded breakfast cereal products made with reverse screw configuration. International Journal of Food Science and Technology, 43, 2278-2288.

Bronner F., Pansu D. (1999). Nutritional aspects of calcium absorption. The Journal of nutrition, 129(1): 9-12.

Buera M.P., Retriella C., Lozano R.D. (1985). Definition of colour in the non-enzymatic browning. Die Farbe, 33: 316-326.

Byler D. M., Susi H. (1986). Examination of the secondary structure of proteins by deconvolved FTIR spectra.Biopolymers, 25(3), 469-487.

\section{C}

Calaveras J. (2004). Nuevo tratado de panificación y bollería. $2^{\circ}$ Edición. Editan AMV y Mundi-prensa, Madrid. España.

Calligaris S., Nicoli M.C. (2006). Effect of selected ions from lyotropic series on lipid oxidation rate. Food Chemistry, 94: 130-134.

Campbell G.M. (2003). Bread aeration. Capítulo 17 en Breadmaking Improving Quality. Editado por Stanley P. Cauvain. Woodhead Publishing Limited. Cambridge - Inglaterra.

Campbell G.M., Fang C., Muhamad I.I. (2007). On predicting roller milling performance VI Effect of kernel hardness and shape on the particle size distribution from first break milling of wheat. Food and Bioproducts Processing, 85 (C1):7-23.

Capanzana M.V., Buckle K.A. (1997). Optimization of germination conditions by response surface methodology of a high amylose rice (Oryza sativa) cultivar. LebensmittelWissenschaft und-Technologie, 30: 155-163. 
Carr N.O., Daniels N.W.R., Frazier P.J. (1992). Lipid interactions in breadmaking. Critical Reviews en Food Science and Nutrition, 31: 237-258.

Catterall P. (1998). La molienda - Capítulo 12- en Fabricación de pan. Editado por Cauvain, S.P; Young, L.S. Editorial Acribia, S.A. Zaragosa, España.

Cauvain S.P. (1998). Improving the control of staling in frozen bakery products. Trends in Food Science and Technology, 9(2): 56-61.

Cauvain S.P. (2002). Pan: el producto (Capítulo1); Procesos de panificación (Capítulo 2). En: Fabricación de pan editado por Cauvain, S.P. y Young, L.S. Editorial Acribia S.A, Zaragoza, España.

Cauvain S.P. (2004). Improving the texture of bread (Capítulo 18) en Food Texture Vol 2: Solid foods. Editado por David Kilcast. Woodhead Publishing Limited, Cambridge, Inglaterra.

Chang C., Zhang H.P., Xu J., Li W.H., Liu G.T., You M.S., Li B.Y. (2006). Identification of allelic variations of puroindoline genes controlling grain hardness in wheat using a modified denaturing PAGE. Euphytica 152:225-234.

Chantaro P., Pongsawatmanit R. (2010). Influence of sucrose on thermal and pasting properties of tapioca starch and xanthan gum mixtures. Journal of Food Engineering, 98, 44-50.

Chen P.L., Long Z., Ruan R., Labuza T.P. (1997). Nuclear magnetic resonance studies of water mobility in bread during storage. Lebensmittel-Wissenschaft und-Technologie, 30: 178-183.

Choi Y.J., Kim B.Y, Baik M.Y. (2010). Analytical methodology for bread staling. Journal of the Korean Society for Applied Biological Chemistry, 53 (4): 389-400.

Chung O.K., Pomeranz Y., Finney K.F. (1978). Wheat flour lipids in breadmaking. Cereal Chemistry, 55 (5): 598-618.

Cocolin L., Manzano M.,Cantoni C., Comi G. (2001). Denaturing Gradient Gel Electrophoresis Analysis of the 16S rRNA Gene V1 Region To Monitor Dynamic Changes in the Bacterial Population during Fermentation of Italian Sausages. Applied and Environmental Microbiology, 67(11): 5113-5121. 
Código Alimentario Argentino CAA (2013). Tomo I-a. Capítulos IX (Art. 661-Res. 167) y XVII. http://www.anmat.gov.ar/alimentos/normativas alimentos caa.asp. Accedido $\underline{25 / 03 / 2013 .}$

Cook J.D., Reddy M.B. (2001). Effect of ascorbic acid intake on nonheme-iron absorption from a complete diet. The American journal of clinical nutrition; 73(1): 93-98.

Cornish G.B., Bekes F., Allen H.M., Martin D.J. (2001). Flour proteins linked to quality traits in an Australian doubled haploid wheat population. Australian Journal of Agricultural Research, 52: 1339-1348.

Correa M.J., Añón M.C., Pérez G.T., Ferrero C. (2010). Effect of modified celluloses on dough rheology and microstructure. Food Research International, 43, 780-787.

Coudray C., Bellanger J., Castiglia-Delavaud C., Rémésy C., Vermorel M., Rayssiguier Y. (1997). Effect of soluble or partly soluble dietary fibres supplementation on absorption and balance of calcium, magnesium, iron and zinc in healthy young men. European Journal of Clinical Nutrition, 51: 375-380.

Coudray C., Demigné C., Rayssiguier Y. (2003). Effects of dietary fibers on magnesium absorption in animals and humans. Journal of Nutrition, 133:1-4.

Coudray C., Feillet-Coudray C., Tressol J. C., Gueux E., Thien S., Jaffrelo, L., Mazur A., Rayssiguier Y. (2005). Stimulatory effect of inulin on intestinal absorption of calcium and magnesium in rats is modulated by dietary calcium intakes. European journal of nutrition, 44(5): 293-302.

Courtin C.M., Roelants A., Delcour J.A. (1999). Fractionation reconstitution experiments provide insight into the role of endoxylanases in bread-making. Journal of Agricultural and Food Chemistry, 47: 1870-1877.

Courtin C.M., Delcour J.A. (2002). Arabinoxylans and endoxylanases in wheat flour breadmaking. Journal of Cereal Science, 35: 225-243.

Cuniberti M. (2004). Propuesta de clasificación del Trigo Argentino. IDIA INTA, 6: 21-25.

Czerniejewski C.P., Shank C.W., Bechtel W.G., Bradley W.B. (1964). The mineral of wheat flour and bread. Cereal Chemistry, 41: 65-72. 


\section{D}

De Gennaro S., Birch G.G., Parke S.A., Stancher B. (2000). Studies on the physicochemical properties of inulin oligomers. Food Chemistry, 68 (2): 179-183.

De la Vega M.C.G. (2009). Proteínas de la harina de trigo: clasificación y propiedades funcionales. Temas de Ciencia y Tecnología, 13 (38): 27-32.

De Man J.C., Rogosa M., Sharpe M. (1960). A medium for cultivation of lactobacilli. Journal of Applied Bacteriology, 23: 130-135.

Dengate H.N. (1984). Swelling, pasting and gelling of wheat starch. Advances en Cereal Science and Technology, 6: 49-82.

Dewettinck K., Van Bockstaele F., Kühne B., Van de Walle D., Courtens T.M., Gellynck X. (2008). Nutritional value of bread: Influence of processing, food interaction and consumer perception. Journal of Cereal Science, 48: 243-257.

Dobraszczyk B.J., Morgenstern M.P. (2003). Rheology and the breadmaking process. Journal of Cereal Science, 38: 229-245.

Drago S.R., Valencia M.E. (2008) Biodisponibilidad y métodos de determinación. En "Minerales en Alimentos y Dietas Iberoamericanas", CYTED, Editora SBAN, San Pablo, Brasil; 111-142.

\section{$\mathbf{E}$}

Eitenmiller R.R., Landen W.O. (1999). Vitamin D. En: Vitamin analysis for the health and food sciences. Ed. Eitenmiller R.R., Landen W.O. Cap. 2. CRC Press LLC.

Eliasson A., Larsson K. (1993). Bread. En: Cereals in Breadmaking. Editado por Eliasson A, Larsson K. Marcel Dekker, Estados Unidos. 325-363.

Eliasson A.C., Gudmundsson M. (1996). Starch: Physicochemical and functional properties, Capítulo 10. En: Carbohydrates in food. A-C. Eliasson, ed. Marcel Dekker In., 431-503.

Eliasson A.C. (2003). Starch structure and bread quality. Capítulo 7 en Breadmaking Improving Quality. Editado por Stanley P. Cauvain. Woodhead Publishing Limited. Cambridge, Inglaterra. 
Elleuch M., Bedigian D., Roiseux O., Besbes S., Blecker C., Attia H. (2011). Dietary fibre and fibre-rich by-products of food processing: Characterization, technological functionality and commercial applications: A review. Food Chemistry, 124(2), 411-421.

Encuesta Nacional de Nutrición y Salud (2007). Ministerio de Salud. Buenos Aires, Argentina. Disponible en: www.msal.gov.ar Consultado Julio 2013.

Englyst H., Hudson G. (1996). The classification and measurement of dietary carbohydrates. Food Chemistry, 57: 15-21.

Englyst K.N., Englyst H.N., Hudson G.J., Cole T.J., Cummings J.H. (1999). Rapidly available glucose in foods: an in vitro measurement that reflects the glycemic response. The American journal of clinical nutrition, 69(3): 448-454.

Ewart J.A.D. (1977). Re-examination of the linear gluten hypothesis. Journal of Science of Food and Agriculture, 28(2): 191-199.

Ewart J.A.D. (1989). Hypothesis for how linear glutenin holds gas in dough. Food Chemistry, 32: 135-150.

\section{$\mathbf{F}$}

Food and Agriculture Organization (FAO). (2009). Hojas de Balance de Alimentos, Colección FAO Roma, Italia. En: www.fao.org/waicent/fao Consultado julio 2013.

FAO. (1996). Hojas de Balance de Alimentos, Colección FAO (1996). Estadística número 131, FAO, Roma, Italia.

FAOMHO Expert Consultation Bangkok, Thailand (2001). Human Vitamin and Mineral Requirements. 1ํo edición. FAO. Food and Nutrition Division. Roma. 151-180; 195-222; 257-270; 300-301.

Faridi H., Faubion J.M. (1990). Dough rheology and baked product texture. Nueva York City, NY: Avi Books. 1-3, 356-358.

Farináceos.

Alimentos

Argentinos

(2013).

http://www.alimentosargentinos.gov.ar/contenido/sectores/farinaceos/informes/Farinace os anuario 2012.pdf 12/06/2013.

Fausch H., Kündig W., Neukom H. (1963). Ferulic acid as a component of a glycoprotein from wheat flour. Nature, 199-287. 
Figueroa-Espinoza M.C., Rouau X. (1998). Oxidative crosslinking of pentosans by a fungal laccase and horseradish peroxidase: Mechanism of linkage between feruloylated arabinoxylans. Cereal Chemistry, 75: 259-265.

Filipović J., Filipović N., Filipović V. (2010). The effects of commercial fibres on frozen bread dough. Journal of the Serbian Chemical Society, 75(2): 195-207.

Flamm G., Glinsmann W., Kritchevsky D., Prosky L., Roberfroid M. (2001). Inulin and oligofructose as dietary fiber: A review. Critical Reviews in Food Science and Nutrition, 41: 353-362.

Flickinger E., Van Loo J., Fahey G. (2003). Nutritional responses to the presence of inulin and oligofructose in the diet of domesticated animals: A review. Critical Reviews in Food Science and Nutrition, 43: 19-60.

Food and Agriculture Organization of the Unites Nations (FAOSTAT). (2013) http://faostat.fao.org/. Consultado el 12/06/2013.

Friedli G.L., Howell N. (1996). Gelation properties of deamidated soluble wheat proteins.Food hydrocolloids, 10: 255-261.

Frutos M.J., Guilabert-Antón L., Tomás-Bellido A., Hernández-Herrero J.A. (2008). Effect of artichoke (Cynara scolymus L.) fiber on textural and sensory qualities of wheat bread. Food Science and Technology International, 14 (5 suppl): 49-55.

\section{G}

Gan Z., Ellis P.R., Schofield J.D. (1995). Mini review: Gas cell stabilization and gas retention in wheat bread dough. Journal of Cereal Science, 21: 215-230.

García M.O. (2004). Comercio de trigo pan. Características de la oferta y la demanda mundial. Programa Nacional de Calidad de Trigo.

Geneser F. (2004). Histología. Cuarta Edición. Ed. Panamericana. Madrid. España.

Ghiasi K., Hoseney R.C., Varriano-Marston E. (1982). Effects of Flour Components and Dough Ingredients on Starch Gelatinization. Cereal Chemistry, 60 (1): 58-61.

Gianibelli M.C., Acciaresi H.A., Arango M.C. (1994). Gluteninas de alto peso molecular: Efecto de su presencia en la calidad industrial de variedades de trigo argentinas. III Congreso Nacional de Trigo. Bahía Blanca, Buenos Aires Argentina. pp. 250. 
Gianibelli M.C., Larroque O.R., Macritchie F., Wrigley C.W. (2001). Biochemical, genetic, and molecular characterization of wheat endosperm proteins. American Association Cereal Chemistry, 1: 158-236.

Giannou V., Kessoglou V., Tzia C. (2003). Quality and safety characteristics of bread made from frozen dough. Trends en Food Science and Technology, 14(3): 99-108.

Giannou V., Tzia C. (2007). Frozen dough bread: quality and textural behavior during prolonged storage - prediction of final product characteristics. Journal of Food Engineering, 79 (3): 929-934.

Gibson G.R., Beatty E.R., Wang X., Cummings J.H. (1995). Selective stimulation of bifidobacteria in the human colon by oligofructose and inulin. Gastroenterology, 108: 975-982.

Gibson G.R., Roberfroid M.B. (1995). Dietary modulation of the human colonic microbiota: introducing the concept of prebiotics. Journal of Nutrition, 125: 1401-1412.

Gomori G.A. (1942). A modification of the colorimeter phosphorus determination for use with the photoelectric colorimeter. Journal of Laboratory and Clinical Medicine, 27: 955960.

Goñi I., Garcia-Alonso A., Saura-Calixto F. (1997). A starch hydrolysis procedure to estimate glycemic index. Nutrition Research, 17(3): 427-437.

Gordon DT, Peilett L. (1992). Physical and Chemistry properties of nutrients affecting their absorption and utilization. Chap 10. En: Physical Chemistry of Sahwartrberg HG and Hartel RW. Ed. Marcel Decker Inc. NY. Basel. H Kong

Granfeldt Y, Bjorck I, Drews A, Tovar J. (1992). An in vitro procedure based on chewing to predict metabolic response to starch in cereal and legume products. European journal of clinical nutrition, 46: 649-660.

Grosch W., Wieser H. (1999). Redox reactions in wheat dough as affected by ascorbic acid. Journal of Cereal Science, 29: 1-16.

Gruppen H., Komelink F.J.M., Voragen A.G.J. (1993). Water unextractable cell wall material from wheat flour. III. A structural model for arabinoxylans. Journal of Cereal Science, 19: 111-128. 
Gudmundsson M., Eliasson A.C., Bengston S., Aman P. (1991). The effects of water soluble arabinoxylan on gelatinization and retrogradation of starch. Starch / Stärke, 43: 5-10.

Gueimonde M., Tölkkö S., Korpimäki T., Salminen S. (2004). New Real-Time Quantitative PCR Procedure for Quantification of Bifidobacteria in Human Fecal Samples. Applied and Environmental Microbiology, 70: 4165-4169.

Gupta S., Shimray C.A., Rao V. (2012). Influence of organic acids on rheological and bread-making characteristics of fortified wheat flour. International Journal of Food Sciences and Nutrition, 63(4): 411-420.

\section{H}

Hajšelová M. Analysing wheat and flour. Capítulo 9 en Bread making Improving Quality Editado por Stanley P. Cauvain. Publicado por Woodhead Publishing Limited, Cambridge, Inglaterra.

Hallberg L., Hulthén L. (2000) Prediction of dietary iron absorption: an algorithm for calculating absorption and bioavailability of dietary iron. The American journal of clinical nutrition, 71(5): 1147-1160.

Hallberg L., Rossander L., Skånberg A. B. (1987). Phytates and the inhibitory effect of bran on iron absorption in man. The American journal of clinical nutrition, 45(5): 988-996.

Hamet, M.F. (2012). Polisacáridos de bacterias lácticas de fermentos artesanales para el desarrollo de alimentos funcionales. Estudio del efecto prebiótico. Tesis Doctoral. Facultad de Ciencias Exactas. Universidad Nacional de La Plata. Argentina.

Hare-Bruun H., Flint A., Heitmann B.L.(2006).Glycemic index and glycemic load in relation to changes in body weight, body fat distribution, and body composition in adult Danes. The American Journal of Clinical Nutrition, 84: 871-979.

Harrington M.E., Flynn A., Cashman K.D. (2001). Effects of dietary fibre extracts on calcium absorption in the rat. Food Chemistry, 73(3): 263-269.

Hassan B.H., Alhamdan A.M., Elansari A.M. 2005. Stress relaxation of dates at khalal and rutab stages of maturity. Journal of Food Engineering, 66: 439-445.

Haytowitz D.B, Pehrsson P.R, Holden J.M. (2002). The Identification of Key Foods for Food Composition Research. Journal of Food Composition and Analysis, 15(2):183-194 
Heaney R.P., Recker R.R. (1985). Estimation of true calcium absorption. Annals of internal medicine, 103(4): 516-521.

Heaney R.P., Weaver C.M. (1989). Oxalate: effect on calcium absorbability. The American journal of clinical nutrition, 50(4): 830-832.

Holm J., Björck I., Asp N.G., Sjöberg L.B, Lundquist I. (1985).Starch availability in vitro after flaking, steam-cooking and popping of wheat. Journal of Cereal Science, 3: 193-206.

Hoseney R.C. (1984). Functional properties of pentosans in baked foods. Food Technology, 38: 114-117.

Hoseney R.C., Rogers D.E. (1990). The formation and properties of wheat flour doughs. Food Science and Nutrition, 29 (2): 73-93.

Hoseney RC. 1994a. Structure of Cereal. En: Principles of Cereal Science and Technology, $2^{\circ}$ edición. Editado por Hoseney RC. American Association of Cereal Chemists, Estados Unidos.1-27.

Hoseney R.C. (1994b). Gluten proteins. En: Principles of Cereal Science and Technology. $2^{\circ}$ edición. Editado por Hoseney RC. American Association of Cereal Chemists, Estados Unidos. pp. 197-211.

Hotz C., Gibson R.S. (2007). Traditional Food-Processing and Preparation Practices to Enhance the Bioavailability of Micronutrients in Plant-Based Diets. The Journal of nutrition, 137(4): 1097-1100.

Howitt C:A., Tamás L., Solomon R. G., Gras P.W., Morell M.K., Békés F., Appels R. (2003). Modifying flour to improve functionality. Capítulo 11 en Breadmaking Improving Quality Editado por Stanley P. Cauvain. Publicado por Woodhead Publishing Limited, Cambridge, Inglaterra.

Hsu K., Hoseney R., Seib P. (1979). Frozen Dough. I. Factors affecting stability of yeasted doughs. Cereal Chemistry, 56: 419-424.

\section{I}

Inoue Y., Bushuk W. (1991). Studies on frozen doughs. I. Effects of frozen storage and freeze-thaw cycles on baking and rheological properties. Cereal Chemistry, 68: 627-631.

Inoue Y., Bushuk W. (1992). Studies on frozen doughs. II. Flour quality requirements for bread production from frozen dough. Cereal Chemistry, 69: 423-428. 
Inoue Y., Sapirstein H., Takayanagi S., Bushuk W. (1994). Studies on frozen doughs. III. Some factors involved in dough weakening during frozen storage and thaw freeze cycles. Cereal Chemistry, 71: 118-121.

Izydorczyk M.S., Hussain A., MacGregor A.W. (2001). Effect of barley and barley components on rheological properties of wheat dough. Journal of Cereal Science, 34: $251-260$.

\section{J}

Jackson E.A., Holt L.M., Payne P.I. (1983).Characterization of high molecular weight gliadin and low-molecular-weight glutenin subunits of wheat endosperm by two dimensional electrophoresis and the chromosomal localization of their controlling genes. Theoretical and Applied Genetics, 66: 29-37.

Jane J. (2004). Starch: Structure and Properties. Capítulo 7 en Chemical and functional properties of food saccharides. Editado por Piotr Tomasik.CRC PRESS LLC. Boca Raton -Washington, D.C. Estados Unidos.

Jeffrey G.A., Saenger W. (1994). Hydrogen Bonding en Biological Structures, SpringerVerlag, Berlin.

Jenkins D., Wolever T., Taylor R., Barrer H., Fielden H., Baldwing A., Newman H., Jenkins A., Goff D. (1981). Glycemic index of food a physiological basis for carbohydrate exchange. The American Journal of Clinical Nutrition, 34: 362-366.

Jones R, Taylor N, Senti F. (1959). Electrophoresis and fractionation of wheat gluten. Archives of Biochemistry and Biophysics, 84: 353-376.

Jovanovich, G. (1997). Estudio de las interacciones entre almidón y lípidos en harina de trigo. Tesis Doctoral. Facultad de Ciencias Exactas. Universidad Nacional de La Plata. Argentina.

\section{K}

Karlsson R., Olered R., Eliasson A.C. (1983). Changes in starch granule size distribution and starch gelatinization properties during development and maturation of wheat, barley and rye. Starch/Stärke, 35: 335-340. 
Karolini-Skaradzińska Z., Bihuniak P., Piotrowska E., Wdowik L. (2007). Properties of dough and qualitative characteristics of wheat bread with addition of inulin. Polish of Journal and Nutrition Sciences, 57(4(B)): 267-270.

Kasarda D.D., Nimmo C.C., Kohler G.O. (1971). Proteins and the amino acids composition of wheat fractions. En Y. Pomeranz (Ed.), Wheat chemistry and technolology, Cap 6. St Paul: American Association of Cereals Chemists.

Kasarda D.D., King G., Kumosinski T.F. (1994). Comparison of spiral structures in wheat high molecular weight glutenin subunits and elastin by molecular modeling. En: Molecular Modeling: From Visual Tools to Reality. Editado por Kumosinski TF y Liebman MN. ACS Symp. Ser. No.576. Am. Chem. Soc.: Washington, DC. pp. 209-220.

Khan K., Zhu J., Huang D.Y., Borneo R. (2002). Glutenin size distribution, determinated by multi-stacking SDS-PAGE: Relationship to Breadmaking Quality. Capítulo 5 en Cereal Chemists, Minnesota, Estados Unidos.

Khuri A.I., Cornell, J.A. (1996). Response surfaces: designs and analyses, $2^{\circ}$ Edición. Marcel Dekker, Nueva York, Estados Unidos.

Kim S.K., D’ Appolonia B.L. (1977a). Effect of pentosans on retrogradation of wheat starch gels. Cereal Chemistry, 54: 150-160.

Kim S.K., D’ Appolonia B.L. (1977b) .Bread staling studies III. Effect of pentosans on dough bread and brad staling rate. Cereal Chemistry, 54: 225- 229.

Kim S.K., D’Appolonia B.L. (1977c). Bread staling studies I. Effect of protein content on staling rate and bread crumb pasting properties. Cereal Chemistry 54 207-215.

Kim Y., Faqih M.N., Wang S.S. (2001). Factors affecting gel formation of inulin. Carbohydrate Polymers, 46: 135-145.

Kinsella J.E., Lee Hale M. (1984). Hydrophobic Associations and Gluten Consistency: Effects of Specific Anions. Journal of Agricultural and Food Chemistry, 32: 1054-1056.

Kleessen B., Hartmann L., Blaut M. (2003). Fructans in the diet cause alterations of intestinal mucosal architecture, released mucins and mucosa-associated bifidobacteria in gnotobiotic rats.British Journal of Nutrition, 89 (5): 597-606

Komlenić D.K, Ugarčić-Hardi Ž., Jukić M., Planinić M., Bucić-Kojić A., Strelec I. (2010). Wheat dough rheology and bread quality effected by Lactobacillus brevis preferment, dry 
sourdough and lactic acid addition. International Journal of Food Science and Technology, 45 (7): 1417-1425.

Kruger M.C., Brown K.E., Collett G., Layton L., Schollum L.M. (2003). The Effect of Fructooligosaccharides with Various Degrees of Polymerization on Calcium Bioavailability in the Growing Rat. Experimental Biology and Medicine, 228(6): 683-688.

Lee M.R., Swanson B.G., Baik B.K. (2001). Influence of amylose content on properties of wheat starch and breadmaking quality of starch and gluten blends. Cereal Chemistry, 78 (6): 701-706.

León A., Durán E., de Barber C.B. (1997). A new approach to study starch changes occurring in the dough-baking process and during bread storage. Zeitschrift für Lebensmittel Untersuchung und Forschung 204: 116-120.

León A.E., Rosell C.M. (2007). De tales harinas, tales panes. Granos, harinas y productos de panificación en lberoamérica. Baez impresiones, primera edición, Argentina pp. 1771.

Leung H.K., Steinberg M.P., Wei L.S., Nelson A.I. (1976). Water binding of macromolecules determined by NMR. Journal of Food Science, 41: 297-300.

Leung H.K., Magnuson J.A., Bruinsma B.L. (1979). Pulsed NMR study of water mobility in flour dough. Journal of Food Science, 44: 1408-1411.

Levitan E., Mittleman M., Hakansson N., Wolk A. (2007). Dietary glycemic index, dietary glycemic load, and cardiovascular disease in middle-aged and older Swedish men. The American Journal of Clinical Nutrition, 85: 1521-1526.

Levrat M.A., Rémésy C., Demigné C. (1991). High propionic acid fermentations and mineral accumulation in the cecum of rats adapted to different levels of inulin. The Journal of Nutrition, 121(11): 1730-1737

Li W., Dobraszczyk B.J., Schofield J.D. (2003). Stress relaxation behavior of wheat dough, gluten, and gluten protein fractions. Cereal Chemistry, 80(3), 333-338.

Lima I., Singh R.P. (2001). Viscoelastic behaviour of fried potato crust. Journal of Texture Studies, 32: 131-141. 
Linalud N., Ferrer E., Puppo M.C., Ferrero M.C. (2011). Hydrocolloids: interaction with water, starch and protein on wheat dough. Journal of Agricultural and Food Chemistry, 59(2): 713-719.

Lindsay M.P., Skerritt J.H. (1999). The glutenin macropolymer of wheat flour doughs: structure-function perspectives. Trend in Food Science and Technology, 10: 247-253.

Lopes-da-Silva J.A., Santos D.M.J., Freitas A., Brites C., Gil A.M. (2007). Rheological and nuclear magnetic resonance (NMR) study of hydration and heating of undeveloped wheat doughs. Journal of Agricultural and Food Chemistry, 55: 5636-5644.

\section{M}

Maloney D.H., Foy J.J. (2003). Yeast Fermentations. Capítulo 3 en Handbook of Dough Fermentations editado por Kulp, K. y Lorenz, K. Marcel dekker, inc. Nueva York, Estados Unidos.

Marcelino A.M., Gierasch L.M. (2008). Roles of $\beta$-turns in protein folding: from peptide models to protein engineering. Biopolymers, 89 (5): 380-391.

Martin M.L., Hoseney R.C. (1991). A mechanism of bread firming I. Role of starch swelling. Cereal Chemistry, 68: 498-503.

-Monzó J., Fito P. (2002). Iron deficiency and iron fortified foods-a review. Food Research International, 35(2), 225-231.

Masi P., Cavella S., Sepe M. (1998).Characterization of dynamic viscoelastic behavior of wheat flour dough at different moisture content. Cereal Chemistry, 75 (5): 428-432.

Mathers J., Wolever T. (2002). Digestion and metabolism of carbohydrates. En: Gibney M, Vorster H, Kok F, editores. Introduction to Human Nutrition. Blackwell Science, pag 6980.

Matuda T.G., Parra D.F., Lugão A.B., Tadini C.C. (2005). Influence of vegetable shortening and emulsifiers on the unfrozen water content and textural properties of frozen French bread dough. LWT - Food Science and Technology, 38: 275-280.

Matz S. (1999). Ingredients from wheat. En: Bakery Technology and Engineering, 3o Edición. Editado por Matz S. Pan-Tech International, Estados Unidos. 1-21. 
Metakovskii E.V., Wrigley C.W., Bekes F., Gupta R.B. (1990). Gluten polypeptides as useful genetic markers of dough quality in Australian wheats. Australian Journal of Agricultural Research, 41: 289-306.

Meuser F., Suckow P. (1986). Chemistry and physics of baking. Ed. Blanshard Frazier PJ, Galliard T. The Royal Society of Chemistry, Londres 42-61.

Meyer D., Peters B. (2009). Enhancing the nutritional value of bread with inulin. Bakery. AgroFood industry hi-tech, 20 (3): $48-50$.

Miles M. J., Morris V. J., Orford P. D., Ring S. G. (1985). The roles of amylose and amylopectin in the gelation and retrogradation of starch. Carbohydrate Research, 135(2): 271-281.

Miller D, Schrinken B, Rassmussen R. (1981). An in vitro method for estimation of iron availability from meals. The American Journal of Clinical Nutrition, 34: 248-256

Miller R.A., Graf E., Hoseney C. (1994). Leavened Dough pH Determination by an Improved Method. Journal of Food Science, 58 (5): 1086-1087.

Miller D.D. (2000). Minerales. En: Química de los alimentos. Fennema OR, Ed. Acribia, Zaragoza; 633-734.

Ministerio de Agricultura, ganadería y pesca (MPGyA). (2013). Informe diario del mercado de granos. http://www.minagri.gob.ar/new/00/programas/dma/informe diario/01 infogra.pdf. 12/06/2013.

Montesi A., García-Albiach R., Pozuelo M. J., Pintado C., Goñi, I., Rotger R. (2005). Molecular and microbiological analysis of caecal microbiota in rats fed with diets supplemented either with prebiotics or probiotics. International Journal of food microbiology, 98(3), 281-289.

Montgomery D.C. (1997). Design and Analysis of Experiments.4 Edición. John Wiley y Sons. Nueva York. Estados Unidos.

Moon M., Giddings J. (1993). Rapid separation and measurements of particle size distribution of starch granules by sedimentation /steric field-flow fractionation. Journal of Food Science, 58: 1166-1171.

Morris C., Morris G.A. (2012). The effect of inulin and fructo-oligosaccharide supplementation on the textural, rheological and sensory properties of bread and their role in weight management: A review. Food Chemistry, 133: 237-248. 
Murayama K., Tomida M. (2004). Heat-induced secondary structure and conformation change of bovine serum albumin investigated by Furier Transform Infrared Spectroscopy. Biochemistry, 43: 11526-11532.

Muyzer G., De Waal E., Uitierlinden A. (1993). Profiling of complex microbial populations by denaturing gradient gel electrophoresis analysis of polymerase chain reaction-amplified genes coding for 16S rRNA. Applied and Environmental Microbiology, 59: 695-700.

\section{$\mathbf{N}$}

Ng P., Bushuk W. (1988). Statistical relationships between high molecular weight subunits of glutenin and breadmaking quality of Canadian-grown wheats. Cereal Chemistry, 65: 408-412.

Ng P., Xu C., Bushuk W. (1991). Model of glutenin structure based on farinograph and electrophoretic results. Cereal Chemistry, 68: 231-235.

Nicolas Y., Paques M., Ende van den D., Dhont J.K.G., Polanen van R.C., Knaebel A., Steyer A., Munch J.P., Blijdestein T.B.J., Aken van G.A. (2003). Microrheology: new methods to approach the functional properties of food. Food Hydrocolloids, 17(6): 907913.

Niness K.R. (1999). Inulin and oligofructose: what are they? The Journal of Nutrition. 129:1402S-1406S.

O' Brien C.M., Mueller A., Scannell A.G.M., Arendt E.K. (2003). Evaluation of the effects of fat replacers on the quality of wheat bread. Journal of Food Engineering, 56: 265-267.

Ohta A., Ohtsuki M., Baba S., Adachi T., Sakata T., Sakaguchi E.I. (1995). Calcium and magnesium absorption from the colon and rectum are increased in rats fed fructooligosaccharides. The Journal of Nutritional, 125(9): 2417-2424.

Osborne T.B. (1924). The Vegetable Proteins. Logmans, Green and Co. Londres.

Ottenhof M.A., Farhat I.A. (2004). The effect of gluten on retrogradation of wheat starch. Journal of Cereal Science, 40: 269-274. 
$\mathbf{P}$

Parfitt A.M., Drezner M.K., Glorieux F.H., Kanis J.A., Malluche H., Meunier P.J., Ott S.M., Recker R.R. (1987). Bone Histomorphometry: Standarization of Nomenclature, symbols, and units. Journal of Bone and Mineral Research. 2(6): 595-610.

Pateras I. (1998). Bread Spoilage and Staling. En: Technology of Breadmaking. Eds S P Cauvain and L S Young, London, Blackie Academic \& Professional, 240-261.

Payne P., Corfield K. (1979). Subunit composition of wheat glutenin proteins, isolated by gel filtration in dissociating medium. Planta, 145: 83-88.

Peressini D., Sensidoni A. (2009). Effect of soluble dietary fibre addition on rheological and breadmaking properties of wheat doughs. Journal of Cereal Science, 49(2): 190-201.

Perlin A.S. (1951a). Isolation and composition of the soluble pentosans of wheat flour. Cereal Chemistry, 28: 370-381.

Perlin A.S. (1951b). Structure of the soluble pentosans of wheat flours. Cereal Chemistry, 28: 282-393.

Perron C.E., Lukow O.M., Bushuk W., Townley-Smith F. (1999). The blending potential of diverse wheat cultivars in a frozen dough system. Cereal Foods World, 44(9): 667-672.

Phimolsiripol Y., Siripatrawan U., Tulyathan V., Cleland J.D. (2008). Effects of freezing and temperature fluctuations during frozen storage on frozen dough and bread quality. Journal of Food Engineering, 84: 48-56.

Pita Martín de Portela M. L. (2003). Vitaminas y Minerales en Nutrición. º Edición, Editorial La Prensa Médica Argentina, Buenos Aires, Argentina.

Pita Martín de Portela ML. (2006). Ingestas recomendadas de nutrientes: evolución histórica. En: Energía y macronutrientes en la Nutrición del siglo XXI. Pita Martín de Portela ML. La Prensa Médica Argentina, Buenos Aires (Argentina); 23-37.

Pogna N., Redaelli R., Dachkevitch A., Dal Belin Peruffo A. (1994). Genetics of wheat quality and its improvement by conventional and biotechnological breeding. En: Wheat Production, Properties and Quality. Editado por Bushuk W, Rasper V. Chapman Hall. Estados Unidos. pp. 205-224. 
Pool-Zobel, B., van Loo, J., Rowlands, I., Roberfroid, M.B. 2002. Experimental evidences on the potential of prebiotic fructans to reduce the risk of colon cancer. Br. J. Nutr. 87, S273-S281.

Praznik W., Cieślik E., Filipiak-Florkiewicz A. (2002). Soluble dietary fibres in Jerusalem artichoke powders: Composition and application in bread. Food/Nahrung, 46(3), 151157.

Primo-Martin C., van Nieuwenhuijzen N.H., Hamer R.J., van Vliet T. (2007). Cristallinity changes in wheat starch during the bread making process: Starch cristallinity in the bread crust. Journal of Cereal Science, 45: 219-226.

Programa SARA (Sistema de Análisis y Registro de Alimentos). Programa informático para Análisis de Encuestas Alimentarias. (2005). Dirección Nacional de Salud Materno Infantil. Ministerio de Salud. Disponible en: http://www.msal.gov.ar/htm/site/ennys/site/sara.asp. Consultado julio 2013.

Prosky L., Hoebregs H. (1999). Methods to determine food inulin and oligofructose. Journal of Nutrition, 129: 1418-1423.

Puppo M.C., Calvelo A., Añón M.C. (2005). Physicochemical and rheological characterization of wheat flour dough. Cereal Chemistry, 82(2): 173-181.

\section{$\mathbf{R}$}

Ranhotra G.S., Gelrot J.A., Leinen S.D., Schneller F.E. (1997). Bioavailability of calcium in breads fortified with different calcium sources. Cereal chemistry, 77(3): 293-296.

Ranhotra G.S., Gelroth J.A., Leinen S.D. (2000). Utilization of calcium in breads highly fortified with calcium as carbonate or as dairy calcium. Cereal chemistry, 74(4): 361363.

Raschka L., Daniel H. (2005). Diet composition and age determine the effects of inulin-type fructans on intestinal calcium absorption in rat. European Journal of Nutrition, 44(6): 360-364.

Rastall R.A., Fuller R., Gaskins H.R., Gibson G.R. (2000). Colonic functional foods.en: Functional foods. Concept to product. Ed.G R Gibson y C M Williams. Cap. 4. CRC Press LLC. Boca Raton, FL, Estados Unidos. 
Reddy M.B., Cook J.D. (1997) Effect of calcium intake on non heme-iron absorption from a complete diet. The American journal of clinical nutrition, 65(6): 1820-1825.

Reves P.G., Nielsen F.H., Fahey G.C Jr. (1993) AIN-93 purified diets for laboratory rodents: final report of the American Institute of Nutrition Ad Hoc Writing Committee on the reformulation of the AIN-76A rodent diet. The Journal of Nutrition, 123(11): 1939-1951.

Ribotta P. D., Tadini C. C., Gularte, M. A., Collar, C., Galotto, M. J., Gómez Pallarés, M., ... \& Añón, M. C. (2009). Alternativas tecnológicas para la elaboración y la conservación de productos panificados. Ed. Ribotta y Tadinni. 1ª Edición, pp. 30-35.

Ribotta P.D., Cuffini S., León A.E., Añón M.C. (2004). The staling of bread: an X-ray diffraction study. European Food Research and Technology, 218:219-223.

Ribotta P.D., León A.E., Añon M.C. (2001). Effect of freezing and frozen storage of doughs on bread quality. Journal of Agricultural and Food Chemistry, 49(2): 913-918.

Ribotta P.D., León A.E., Añon M.C. (2003). Effect of yeast frezzing in frozen dough. Cereal Chemistry, 80: 454-458.

Roberfroid M. (1993). Dietary fibre, inulin and oligofructose: a review comparing their physiological effects. Critical Reviews en Food Science and Nutrition, 33(2): 103-148.

Roberfroid M. (1999). Concepts in functional foods: the case of inulin and oligofructose. Journal of Nutrition, 129: 1398-1401.

Roberfroid M. (2000). Non digestible oligosaccharides. Critical Reviews in Food Science and Nutrition, 40: 461-480.

Roberfroid M. (2005a). Introducing inulin-type fructans. British Journal of Nutrition, 93 (Supp. 1), S13-S25.

Roberfroid M. (2005b). Inulin-type fructans: functional food ingredients (p. 370). Boca Raton: CRC Press.

Rodríguez-Sandoval E., Fernández-Quintero A., Alaya-Aponte A. (2005). Reología y textura de masas: aplicaciones en trigo y maíz. Ingeniería e Investigación, 57: 72-78.

Rodriguez-Sandoval E., Fernandez-Quintero A., Cuvelier, G. (2009). Stress relaxation of reconstituted cassava dough. LWT - Food Science and Technology, 42, 202-206.

Ronkart S., Blecker C., Fougnies C., Van Herck J. C., Wouters J., Paquot M. (2006). Determination of physical changes of inulin related to sorption isotherms: An X-ray 
diffraction modulated differential scanning calorimetry and environmental scanning electron microscopy study. Carbohydrate polymers, 63(2), 210-217.

Rosell C.M. (2003). The nutritional enhancement of wheat flour. En Bread Making Improving Quality. Ed. Cauvain S.P. CRC Press, Woodhead Publishing Ltd, Cambridge, Inglaterra.

Ross M.H., Pawlina W. (2007). Histology. A text and Atlas. Sexta edición. Editorial Médica Panamericana. Madrid. España. Capítulo 8.

Ross C., Taylor C.L., Yaktine A.L., Del Valle HB. (Editores). (2010). Dietary Reference Intakes for Calcium and Vitamin D. A. Committee to Review. Food and Nutrition Board \& Institute of Medicine, National Academy of Sciences, Washington, D.C.

Ruan R.R., Zou C., Wadhawan C., Martinez B., Chen P.L., Addis P. (1997). Studies of hardness and water mobility of cooked wild rice using nuclear magnetic resonance. Journal of Food Process Preservation, 21: 91-104.

Rudloff S., Lönnerdal B. (1992). Solubility and digestibility of milk proteins in infant formulas exposed to different heat treatments. Journal of Pediatric Gastroenterology and Nutrition, 15(1): 25-33.

Russell P.L. (1983). A kinetic study of bread staling by differential scanning colorimetry and compressibility measurements. The effects of added monoglyceride. Journal of Cereal Science, 1(4) 297-303.

\section{S}

Salinas M.V., Zuleta A., Ronayne P., Puppo M.C. (2012). Wheat flour enriched with calcium and inulin: A study of hydration and rheological properties of dough. Food Bioprocess and Technology, 5: 3129 - 3141.

Salinas M.V., Puppo M.C. (2013a). Effect of organic calcium salts-inulin systems on hydration and thermal properties of wheat flour. Food Research International, 50: 298 306.

Salinas M.V., Puppo M.C. (2013b). Rheological Properties of Bread Dough Formulated with Wheat Flour-Organic Calcium Salts-FOS-Enriched Inulin Systems. Food Bioprocess and Technology. DOI 10.1007/s11947-013-1180-y. 
Salles J.F., De Souza A., van Elsas J (2002). Molecular method to assess the diversity of burkholderia species in environmental samples. Applied and Environmental Microbiology, 68(4): 1595-1603.

Schmiedl D., Bauerlein M., Bengs H., Jacobasch G. (2000). Production of heat-stable, butyrogenic resistant starch. Carbohydrate Polymers, 43: 183-193.

Scholz-Ahrens K.E., Schaafsma G., Van der Heuvel E.G.H.M., Schrezenmeir J. (2001). Effects of prebiotics on mineral metabolism. The American Journal of Clinical Nutrition, 73(2):459S-464S

Scholz-Ahrens K.E., Schrezenmeir J. (2002). Inulin, oligofructose and mineral metabolismexperimental data and mechanism. British Journal of Nutrition, 87(2): 179-186.

Scholz-Ahrens K.E., Schrezenmeir J. (2007). Inulin and oligofructose and mineral metabolism: the evidence from animal trials. The Journal of Nutrition, 137(11): 25132523.

Schwierz N., Horinek D., Netz R.R. (2010) Reversed anionic Hofmeister series: The interplay of surface charge and surface polarity. Langmuir, 26 (10): 7370-7379.

Senterre J.(1991). Osteopenia versus rickets in premature. Nestlé Nutrition Workshop Series 21: 145-154.

Shewry P.R., Popineau Y., Lafiandra D., Belton P. (2001). Wheat glutenin subunits and dough elasticity: findings of the EUROWHEAT project. Trend en Food Science and Technology, 11: 433-441.

Shittu T.A., Raji A.O., Sanni L.O. (2007). Bread from composite cassava-wheat flour. I. Effect of baking time and temperature in some physical properties of bread loaf. Food Research International, 40: 280-290.

Shittu T.A., Raji A.O., Sanni L.O. (2008). Bread from composite cassava- heat flour. II: Effect of cassava genotype and nitrogen fertilizer on bread quality. Food Research International, 41: 569-578.

Singh H., MacRitchie F. (2001). Application of Polymer Science to Properties of Gluten. Journal of Cereal Science, 33: 231-243.

Slavin J. (2003). Impact of the proposed definition of dietary fiber on nutrients data bases. Journal of Food Composition and Analysis, 16: 287-291. 
Snart J., Bibiloni R., Grayson T., Lay C., Zhang H., Allison G. E., Laverdiere J.K., Temelli F., Vasanthan T., Bell R., Tannock G. W. (2006). Supplementation of the Diet with Highviscosity Beta-Glucan Results in Enrichment for Lactobacilli in the Rat Cecum. Applied and Environmental Microbiology, 72:1925-1931.

Šramková Z., Gregová E., Šturdík E. (2009). Chemical composition quality of wheat grain. Acta Chimica Slovaca, 2 (1): 115 - 138.

Sroan B.S, Bean S.R., MacRitchie F. (2009). Mechanism of gas cell stabilization in bread making. I. The primary gluten-starch matrix. Journal of Cereal Science, 49: 32-40.

Stauffer C. (1998). Fundamentos de formación de la masa. Fabricación de pan editado por Cauvain, S. y Young, L. Acribia, Zaragoza.

Stauffer C.E. (2007). Principles of Dough Formation. En: Technology of Breadmaking, $2^{\circ}$ ed. Springer Estados Unidos, 309-310.

Steffe J.F. (1996). Rheological methods in food process engineering. Segunda edición. East Lansing: Freeman Press.

Steichen J.J., Gratton T.L., Tsang R.C. (1980). Osteopenia of prematurity: The cause and possible treatment. Journal of Pediatrics, 95: 528-534.

Sudha M.L., Leelavathi K. (2008). Influence of micronutrients on rheological characteristics and bread-making quality of flour. International Journal of Food Sciences and Nutrition, 59(2): 105-115.

Szczesniak A.S. (2002). Texture is a sensory property. Food quality and preference, 13(4): 215-225.

$\mathbf{T}$

Tatham A.S., Miflin B.J., Shewry P.R. (1985). The beta-turn conformation in wheat gluten proteins: Relationship to gluten elasticity. Cereal Chemistry, 62: 405-412.

Tatham A. (1995). The structures of wheat protein. En: Wheat Structure. Biochemistry and Functionality. Editado por Schofield, J. Royal society of Chemistry, Inglaterra. pp. 53-63.

Tolstoguzov V. (1997). Thermodinamic aspects of dough formation and functionality. Food Hydrocolloids, 11(2): 193-197. 
Trumbo P., Yates A.A., Schlicker S., Poos M. (2001). Dietary reference intakes: vitamin A, vitamin $\mathrm{K}$, arsenic, boron, chromium, copper, iodine, iron, manganese, molybdenum, nickel, silicon, vanadium, and zinc. Journal of the American Dietetic Association, 101(3), 294-301.

Tu A.T. (1982). Proteins. En: Raman Spectroscopy en Biology; Principles and Applications. Ed. Tu A.T. John Wiley and Sons Eds. Inc. (Nueva York, Estados Unidos), pp. 65-116.

\section{U}

USDA (2008).United States Department of Agriculture Commodity Requeriments. WFBF6. Washington DC, Ustados Avidos. at: www.apfo.usda.gov/Internet/FSA File/wfbf6.pdf.

\section{V}

Valencia M.E., Ronayne de Ferrer P.A., Pita Martín de Portela M.L. (2013). Biodisponibilidad de nutrientes minerales. Revista Farmacéutica (En prensa).

van Oort M, van Straaten F, Laane C. (1995). Pentosans and bread-making. International Food Ingredients, 2:23-27

Vanhoutte T., De Preter V., De Brandt E., Verbeke K., Swings J., Huys, G. (2006). Molecular monitoring of the fecal microbiota of healthy human subjects during administration of lactulose and Saccharomyces boulardii. Applied and Environmental Microbiology, 72(9): 5990-5997.

Varriano-Marston E., Hsu K.H., Mahdi J. (1980). Rheological and structural changes in frozen dough. Baker's Digest, 54: 32-34.

Vatsala C.N., Dharmesh Saxena C., Haridas Rao P. (2001). Optimization of ingredients and process conditions for the preparation of puri using response surface methodology. International Journal of Food Science and Technology, 36: 407-414.

Vinkx C.J.A., Van Nieuwenhove C.G., Delcour J.A. (1991). Physicochemical and functional properties of rye non-starch polysaccharides. III. Oxidative gelation of a fraction containing water-soluble pentosans and proteins. Cereal Chemistry, 68:617-622. 
$\mathbf{W}$

Wang J., Rosell C.M., de Barber C.B. (2002). Effect of the addition of different fibres on wheat dough performances and bread quality. Food chemistry, 79: 221-226.

Wang R., Zhou W., Yu H.H., Chow W.F. (2006). Effects of green tea extract on the quality of bread made from unfrozen and frozen dough processes. Journal of the Science of Food and Agriculture, 86: 857-864.

Watherhouse A., Chatterton N. (1993). Glossary of fructans terms. En: Science and Technology of Fructans. Suzuki M., Chatterton N. (Editores). Boca Raton, USA: CRC Press pp.369.

Weast R.C. (Editor) (1976). Handbook of chemistry and physics: A ready-reference book of chemical and physical data, $56^{\circ}$ edición, CRC, Ohio, Estados Unidos.

Weaver C.M. (2005) Inulin, oligofructose and bone health: experimental approaches and mechanisms. British of Journal Nutritional, 93(1): 99-103.

Webb C., Owens G.W. (2003). Milling and flour quality. Capítulo 10. En Breadmaking improving Quality. Editado por Stanley P. Cauvain. Ed. Woodhead Publishing Limited. Cambridge, Inglaterra.

Weegels P.L., de Groot A.M.G., Verhoek J.A., Hamer R.J. (1994). Effects on Gluten of Heating at Different Moisture Contents. II. Changes in Physico-Chemical Properties and Secondary Structure. Journal of Cereal Science, 19(1): 39-47.

Wehrle K., Grau H., Arendt E.K. (1997). Effects of Lactic Acid, Acetic Acid, and Table Salt on Fundamental Rheological Properties of Wheat Dough. Cereal Chemistry, 74(6): 739744.

Wheat Marketing Center. (2004). Wheat and Flour testing methods: A guide to understanding wheat and flour quality. Portland, Oregon. Estados Unidos.

Wieser H. (2000). Comparative investigations of gluten proteins from different wheat species. I. Qualitative and quantitative composition of gluten protein types. European Food Research and Technology, 211: 262-268.

Wieser H. (2003). The use of redox agent. En: Bread Making: Improving Quality. Editado por Cauvain SP. Woodhead Publishing, Cambridge, Reino Unido, 20: 213-240.

Wieser H. (2007). Chemistry of gluten proteins. Food Microbiology, 24: 115-119. 
Wolfgor R., Drago S., Rodriguez V., Pellegrino N., Valencia M. (2002). In vitro measurement of available iron in fortified foods. Food Research International, 35: 85-90.

Wolt M.J., D' Appolonia B.L. (1984a). Factors involved in the stability of frozen dough. I. The influence of yeast reducing compounds on frozen dough stability. Cereal Chemistry, 61: 209-212.

Wolt M.J., D' Appolonia B.L. (1984b). Factors involved in the stability of frozen dough. II. The effect of yeast type, flour type, and dough additives on frozen-dough stability. Cereal Chemistry, 61: 213-221.

Woychik J, Boundy J, Dimler R. (1961). Starch gel electrophoresis of wheat gluten proteins with concentrated urea. Archives of Biochemistry and Biophysics, 94: 477-482.

Wrigley C, Andrews J, Bekes F, Gras P, Gupta R, MacRitchie F, Skerritt J. (1998). Proteinprotein interactions-essential to dough rheology. En: Interactions: The Keys to Cereal Quality. Editado por Hamer R, Hoseney R. American Association of Cereal Chemists, Estados Unidos. pp. 18-20.

Wu W.S, Tsai Y.H., Wei C.I., Sun Pan B., Huang T.C. (2010). Effect of organic acids on the pasting properties of rice flour from waxy and non-waxy varieties. Journal of Food Quality, 33: 137-154.

\section{$\mathbf{Y}$}

Yadav N., Roopa B.S., Bhattacharya S. (2006). Viscoelasticity of simulated polymer and comparison with chickpea flour doughs. Journal of Food Process Engineering, 29: 234252.

Yi J., Kerr W.L. (2009). Combined effects of freezing rate, storage temperature and time on bread dough and baking properties. LWT - Food Science and Technology, 42: 14741483.

Younes H., Coudray C., Bellanger J., Demigné C., Rayssiguier Y., Rémésy C. (2001) Effects of two fermentable carbohydrates (inulin and resistant starch) and their combination on calcium and magnesium balance in rats. British Journal of Nutrition 86:479-485. 


\section{Z}

Zafar T.A., Weaver C.M., Zhao Y., Martin B.R., Wastney M.E. (2004). Nondigestible oligosaccharides increase calcium absorption and suppress bone resorption in ovariectomized rats. The Journal of Nutrition, 134(2):399-402.

Zobel H.F., Young S.N., Rocca L.A. (1988). Starch gelatinization: An X-ray diffraction study. Cereal Chemistry, 65(6): 443.446.

Zobel H.F., Kulp K. (1996). The staling mechanism. En: Baked Goods Freshness: Technology, evaluation, and inhibition of staling. Eds. Hebeda R.H., Zobel H.F. Marcel Dekker (Nueva York, Estados Unidos), pp. 1-64.

Zoetendal E.G., Akkermans A.D., De Vos W.M. (1998). Temperature gradient gel electrophoresis analysis of $16 \mathrm{~S}$ rRNA from human fecal samples reveals stable and host-specific communities of active bacteria. Applied and environmental microbiology, 64(10): 3854-3859. 